\title{
Das Buch im Buch. Untersuchungen zu einem Motiv in der gegenwärtigen literarischen Kommunikation
}

\author{
Dissertation \\ zur Erlangung des philosophischen Doktorgrades \\ an der Philosophischen Fakultät \\ der Georg-August-Universität Göttingen
}

vorgelegt von

Barbara Bayer-Schur

aus Göttingen

Göttingen, im Juli 2011

Prüfungsfach: Komparatistik

1. Gutachter: Prof. Dr. Gerhard Lauer

(Neuere deutsche Literatur, Seminar für Deutsche Philologie)

2. Gutachterin: Prof. Dr. Simone Winko

(Neuere deutsche Literatur, Seminar für Deutsche Philologie) 



\section{Inhalt}

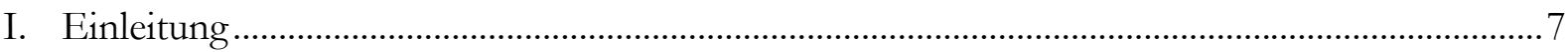

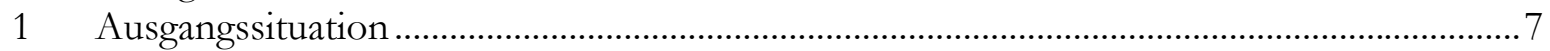

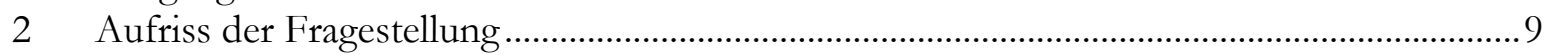

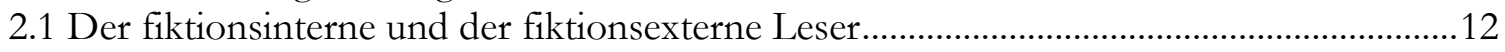

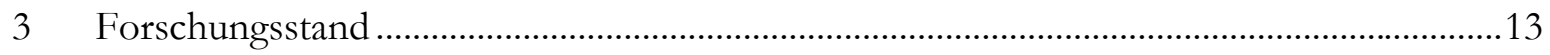

3.1 Skizze des Forschungsstands zu Buch und Lesen im Roman..........................................13

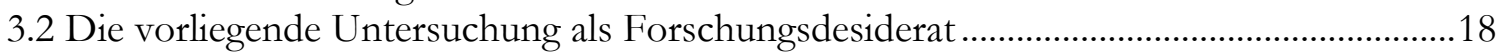

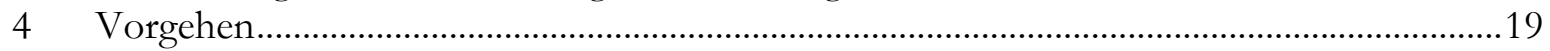

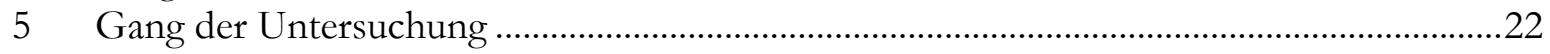

II. Fiktionale Darstellungen des ,Buchs im Buch' bis in die 1990er Jahre und

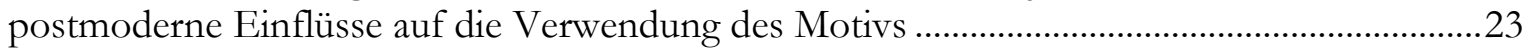

1 Der Roman etabliert sich auf dem deutschen Buchmarkt................................................23

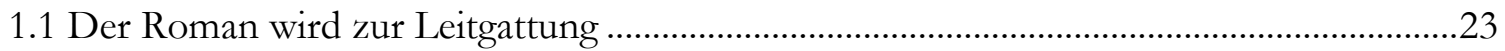

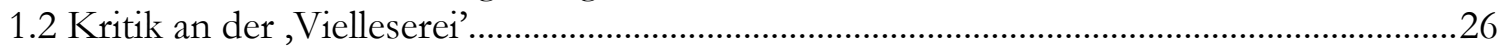

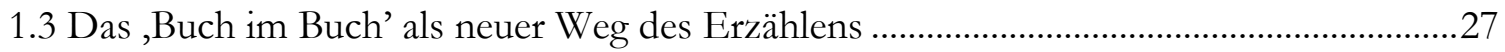

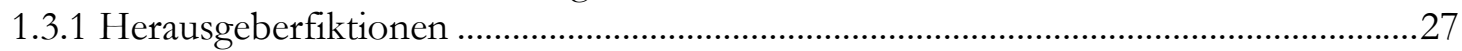

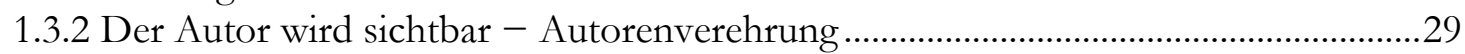

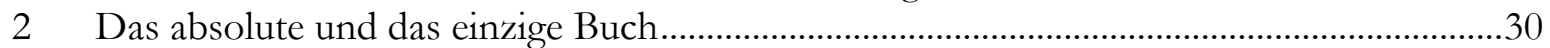

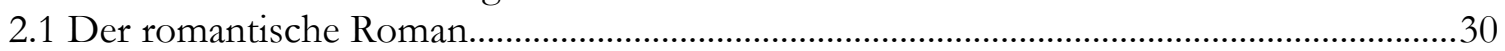

2.2 Das Buch als Lebensbuch - Novalis' Heinrich von Ofterdingen (1802, posthum) ......................32

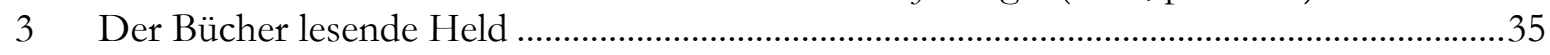

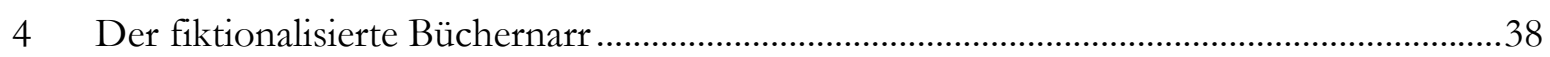

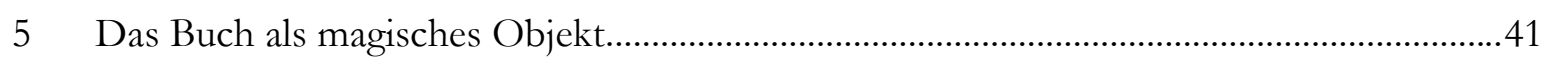

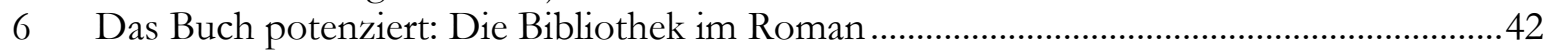

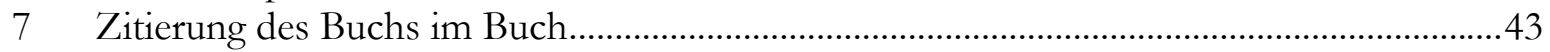

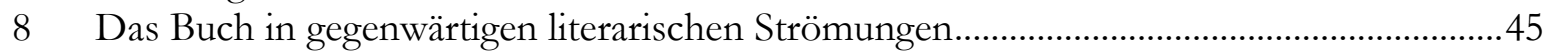

$9 \quad$,Buch im Buch' und postmoderne Einflüsse...........................................................................4

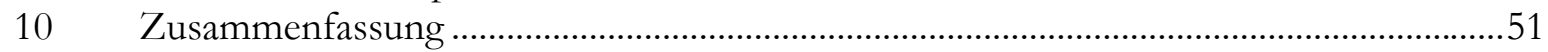

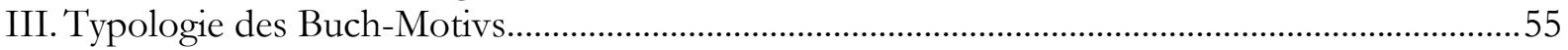

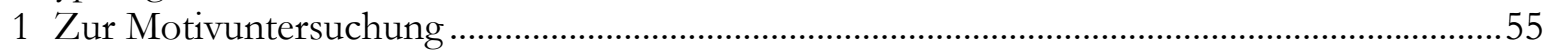

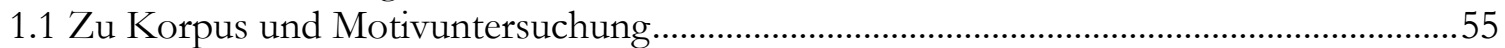

1.1.1 Korpus an untersuchten Romanen...........................................................................56

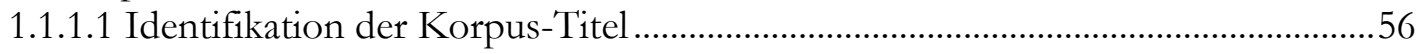

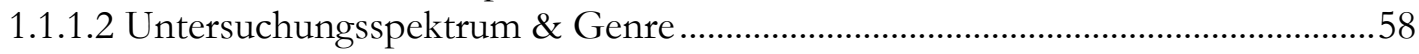

1.1.1.3 Abgrenzung zu ausgelassenen Themenbereichen....................................................59

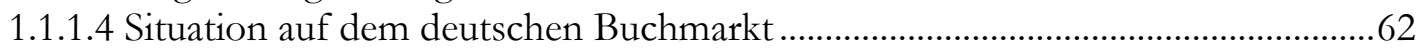

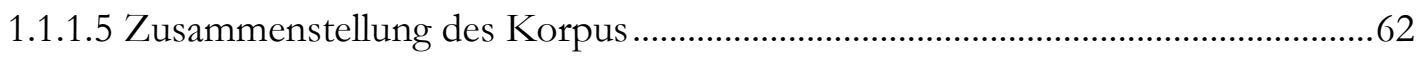

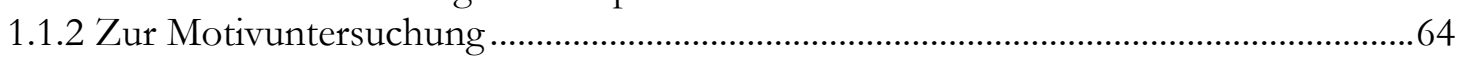

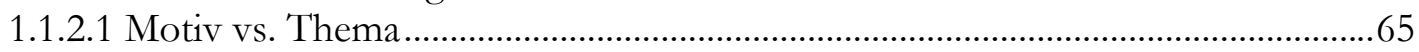

1.1.2.2 Das ,Buch im Buch': Motiv, Metapher, Kollektivsymbol.........................................69

2 Die Suche nach dem Buch - „Der Mythos vom letzten Exemplar eines Buchs“................... 70

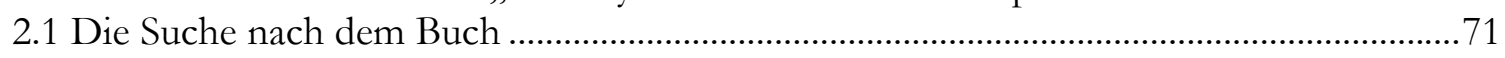

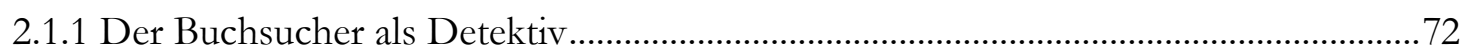

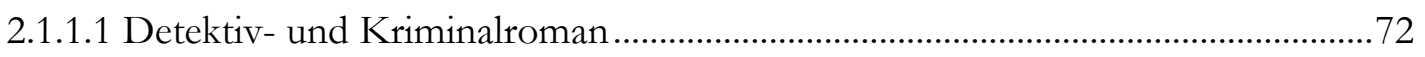

2.1.1.2 Inchbold und Corso - zwei genarrte Antihelden .................................................

2.1.1.3 Der Buchsucher - Eine typische Detektivfigur ......................................................76

2.1.1.4 Sherlock Holmes - William von Baskerville........................................................77

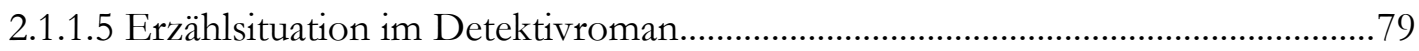

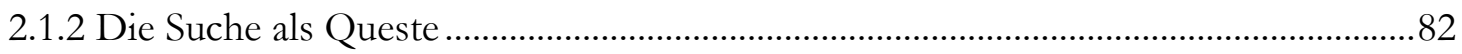

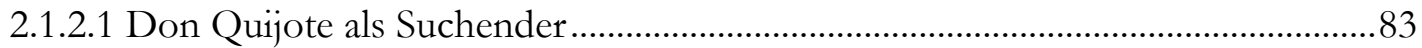




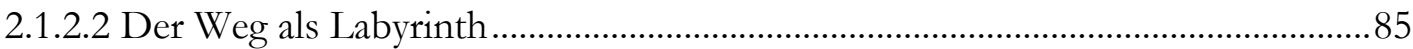

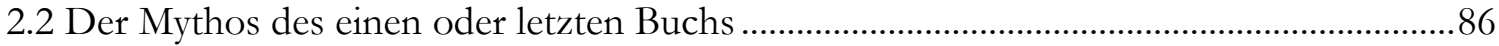

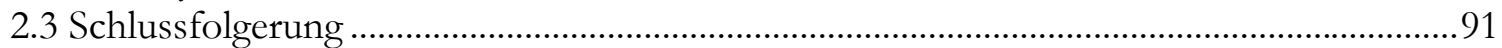

3 „Jedes einzelne Buch hat eine Seele.“ - Buch und Leben ........................................................92

3.1 Anthropomorphisierung des Buchs: Lebendige Bücher.......................................................92

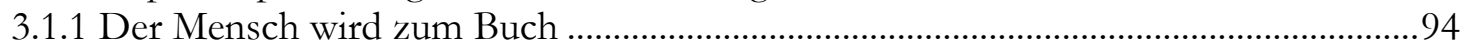

3.1.1.1 Die Verwandlung: Der Leser wird zum Buch......................................................94

3.1.1.2 Subtile, figurative Wandlung in ein Buch............................................................ 96

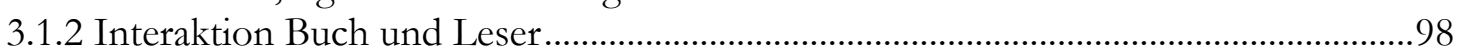

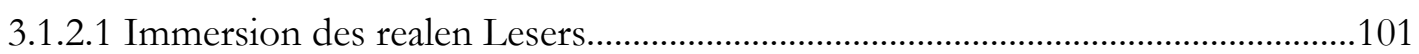

3.1.3 Das Buch als Ersatz für Essen \& Trinken, Liebe, Zuhause ........................................103

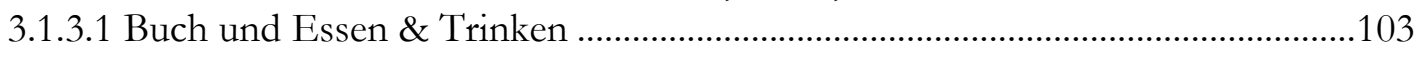

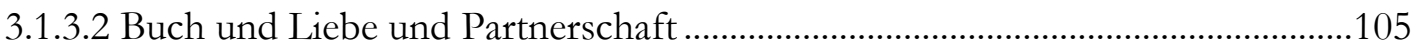

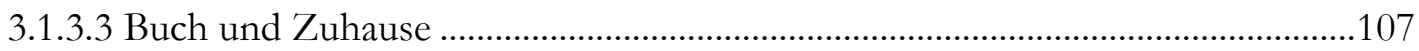

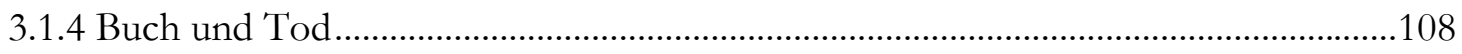

3.1.4.1 Der ,Friedhof der Vergessenen Bücher' in Der Schatten des Windes.....................108

3.1.4.2 Der Leser als Gefahr für das Buch .................................................................110

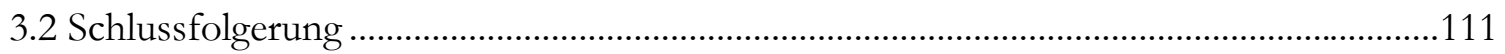

4 „Ich möchte wissen, wie es war, er zu sein.“ - Auf den Spuren des Autors...........................111

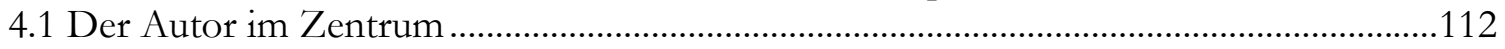

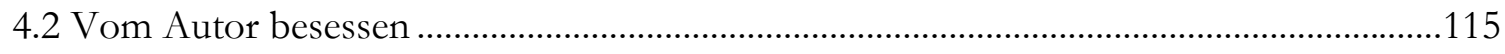

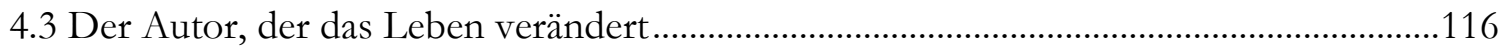

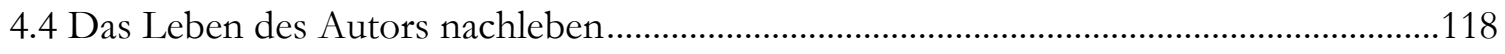

4.4.1 Figur, fiktiver Autor und realer Autor ......................................................................121

4.5 Identifikation des Protagonisten mit dem fiktiven Autor...............................................121

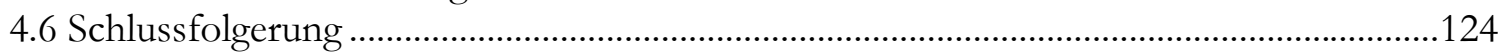

5 „Es gibt nichts Gefährlicheres als ein Buch“ - Das gefährliche Buch...................................126

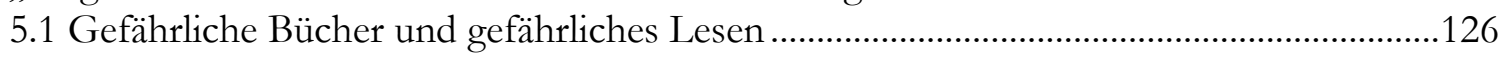

5.2 Unerwünschte Bücher in politischen Kontexten ................................................................128

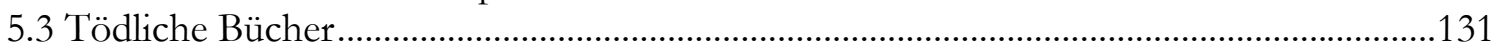

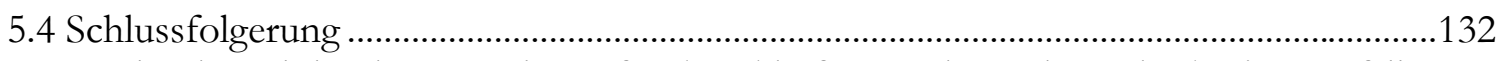

6 „Leser durch und durch“, von einer „,fast krankhaften Sucht nach Bücherbesitz“ Befallene

und „Mörder aus Bücherwut“ - Büchernarren .........................................................................133

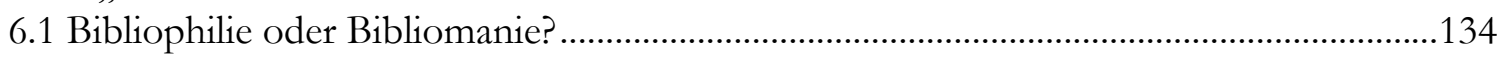

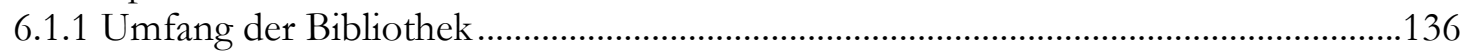

6.1.2 Bibliomanie als krankhafter Umgang mit Büchern ...................................................137

6.2 Büchernarren in den untersuchten Romanen................................................................139

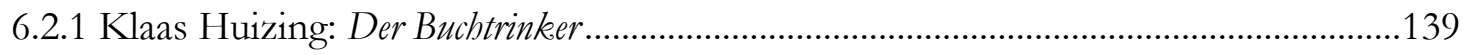

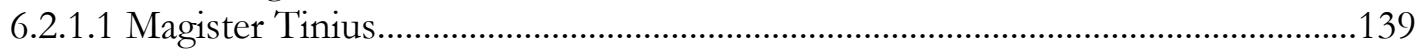

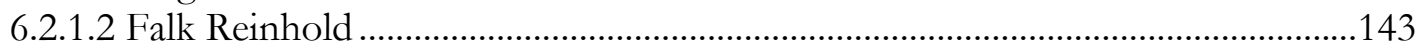

6.2.2 Carlos María Domínguez: Das Papierhaus....................................................................145

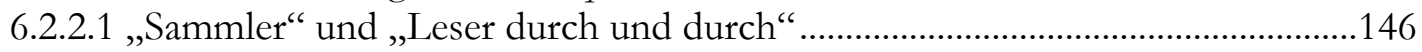

6.2.2.2 Das ,Buch im Buch' - Die Schattenlinie .................................................................147

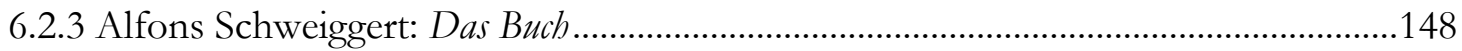

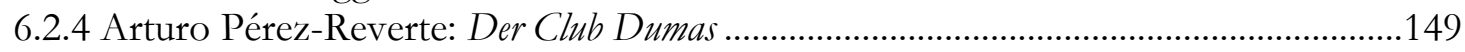

6.3 Richtiger und falscher Umgang mit Büchern .....................................................................149

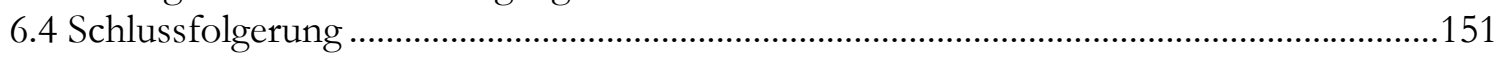

7 Von Buchlingen und LiteraturAgenten - Fantastische Buchwelten .........................................153

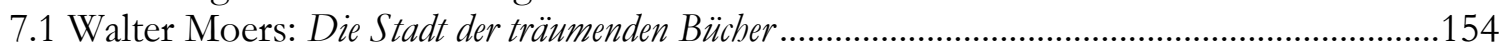

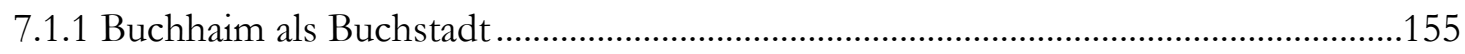

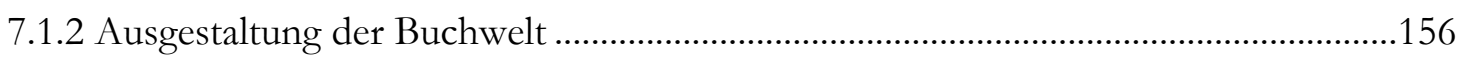

7.1.3 Die fantastische Buchwelt und Buch-Motive ...............................................................157 
7.1.4 Die Stadt der träumenden Bücher als Fantasyroman ................................................159

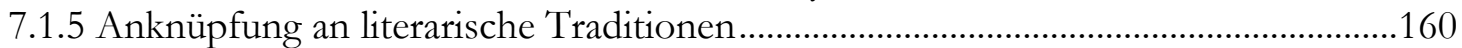

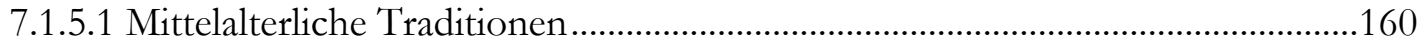

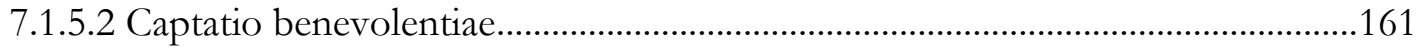

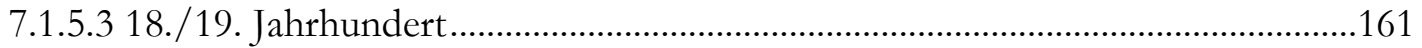

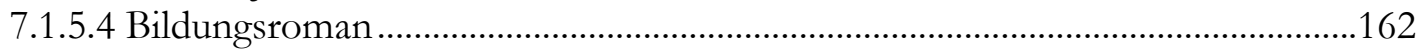

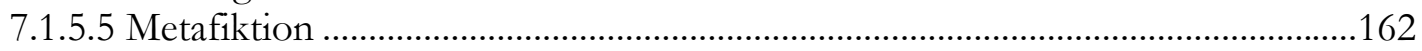

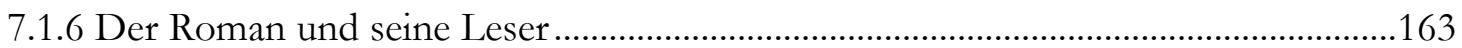

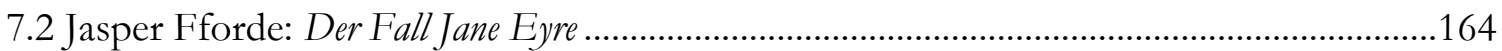

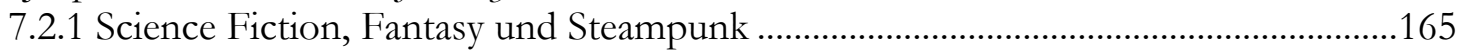

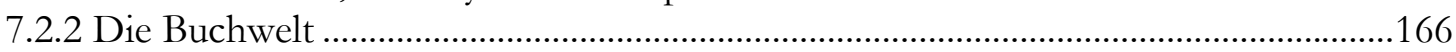

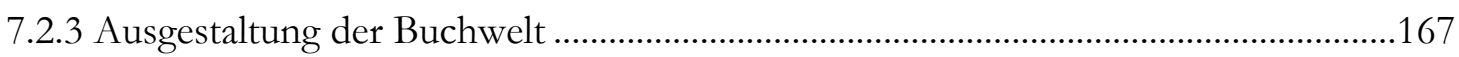

7.2.4 Literarische Figuren, Fiktion und Realität in der Anderswelt.....................................168

7.2.4.1 Eintritt in den Roman: Eindringen von der 1. fiktiven Ebene in die 2.............169

7.2.4.2 Austritt aus dem Roman: Eindringen von der 2. fiktiven Ebene in die 1.........172

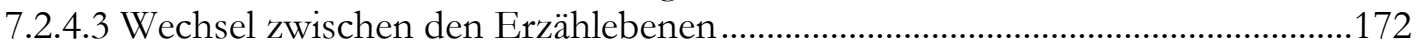

7.2.4.4 Figuren in ihrer fiktiven Wirklichkeit .............................................................174

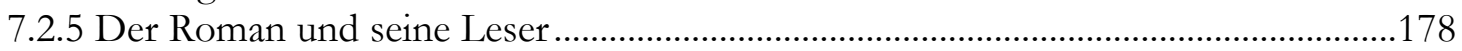

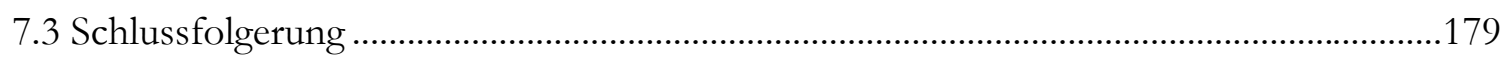

8 „Irgendwann im September 1991 ging die zivilisierte Welt unter.“ -

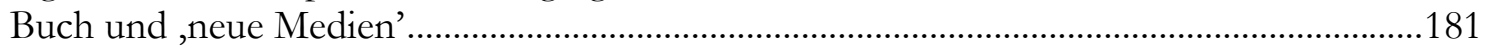

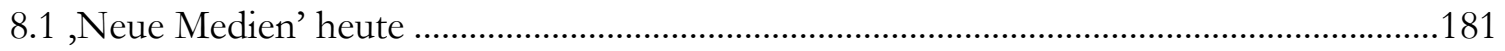

8.2 Fiktionsinterne Kritik an den ,neuen Medien’ und die „Kunst zu lesen“.........................183

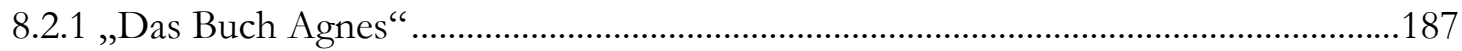

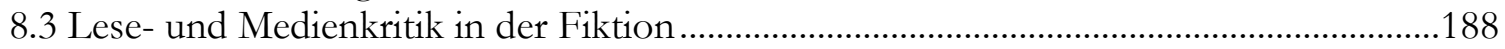

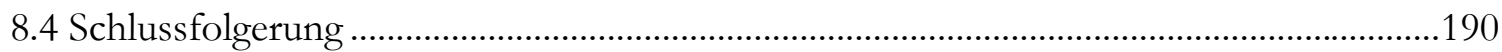

9 „Unsere Wirklichkeit ist also nur die Fiktion eines Schriftstellers?“ -

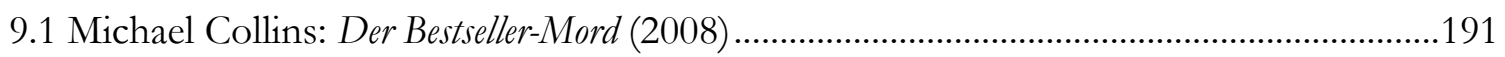

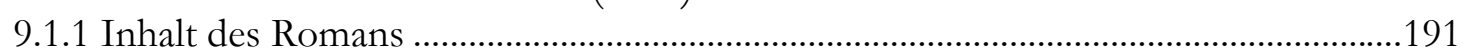

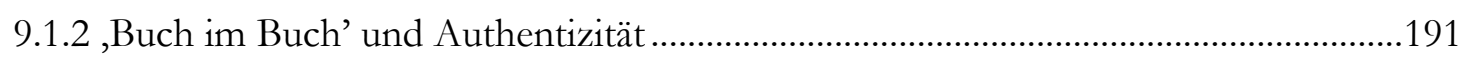

9.1.3 Buch-Motiv und Genrewechsel ............................................................................192

9.1.4 Intertextuelle Bezüge im Roman...........................................................................194

9.1.5 Der Roman im Roman als „Beichte“? Roland Barthes’ „Tod des Autors“ „.............195

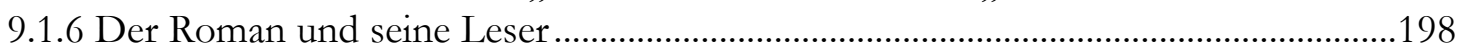

9.2 Arturo Pérez-Reverte: Der Club Dumas (1997) ....................................................................199

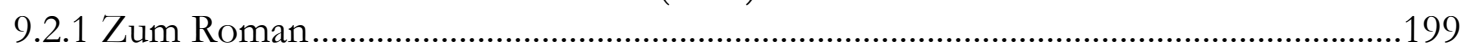

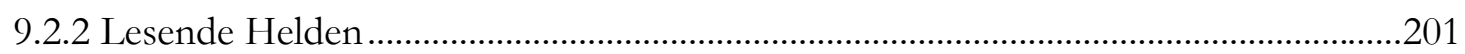

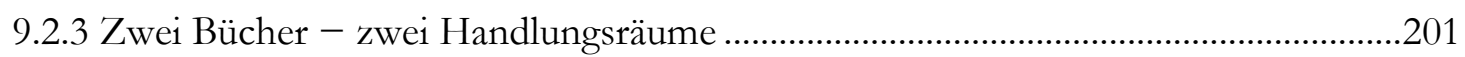

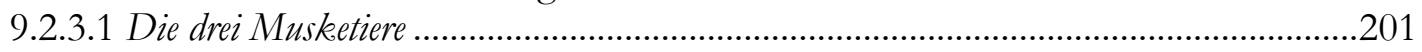

9.2.3.2 Das Buch der neun Pforten ins Reich der Schatten ......................................................202

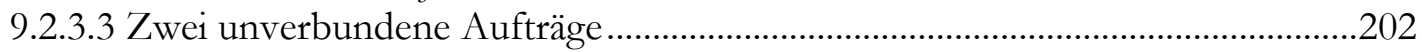

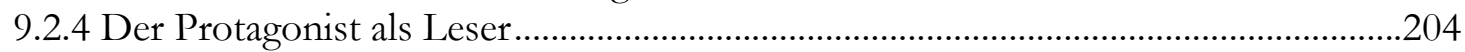

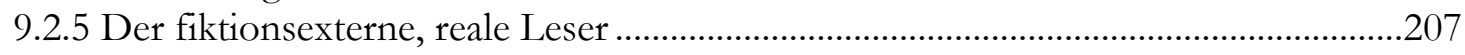

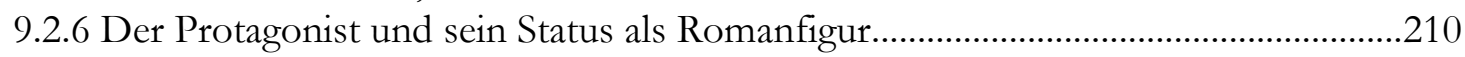

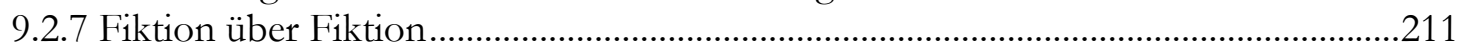

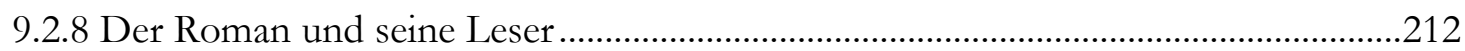

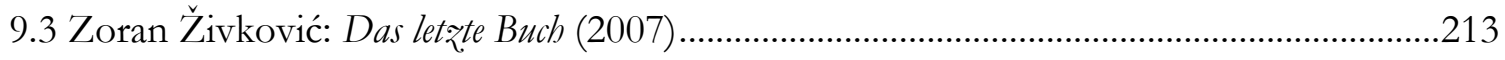

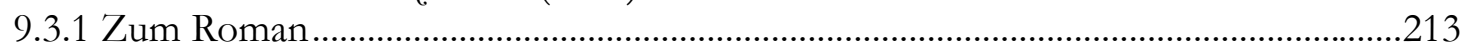

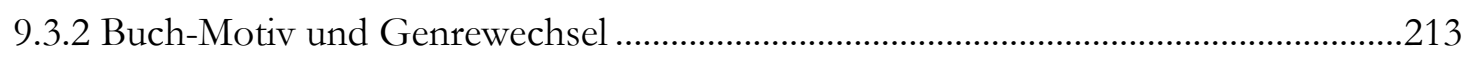

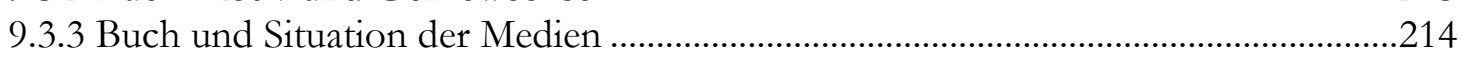


9.3.4 Buch-Motiv und Erzähltheorie: „Wirklichkeit des Autors“ und

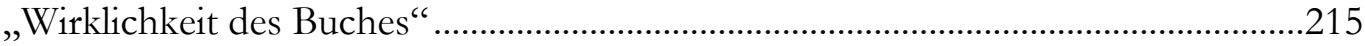

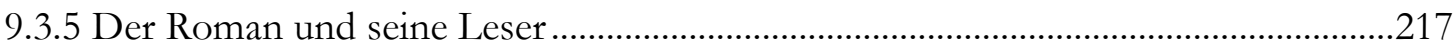

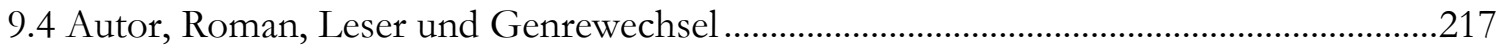

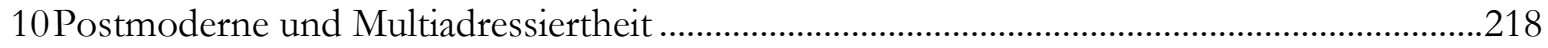

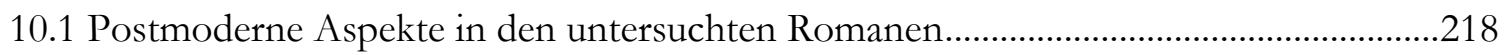

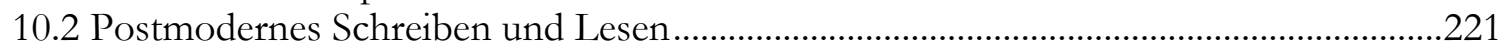

11Die Protagonisten der Buch-Bücher - Lesertypologie .........................................................222

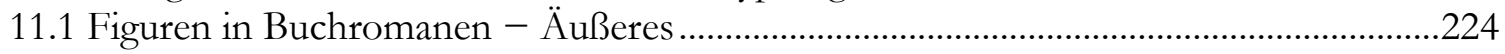

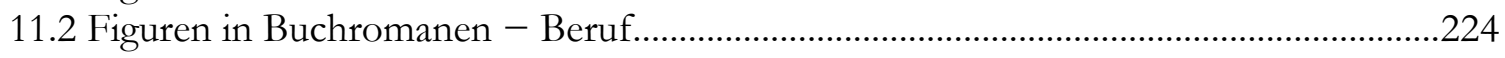

11.2.1 Das Klischee des Buchhändlers in der Fiktion......................................................225

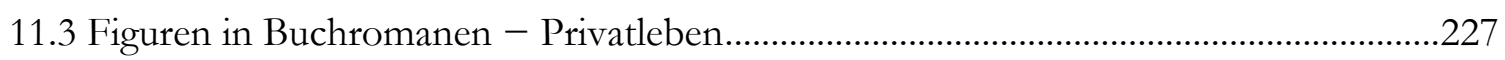

11.4 Der Buchfund - Anlass der Beschäftigung mit dem Buch............................................228

11.5 Der Protagonist als Erzähler-Ich - Anlass des Schreibens..............................................228

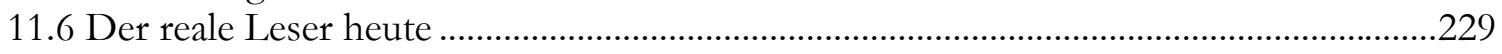

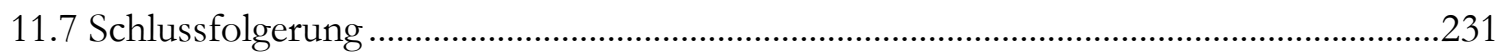

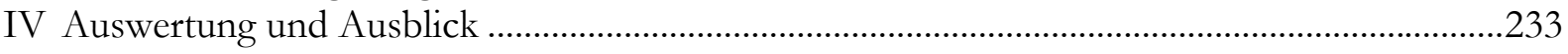

1 Das ,Buch im Buch' in den untersuchten Romanen ..........................................................23

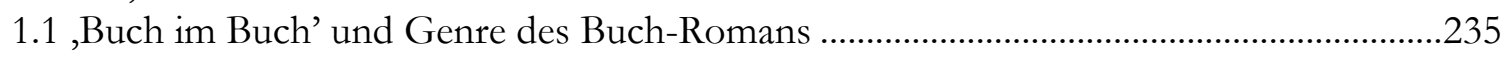

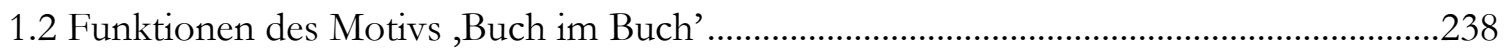

1.2.1 Interne Funktionen des Buch-Motivs: Fiktionsebene ................................................239

1.2.2 Externe Funktionen des Buch-Motivs: Außertextuelle Ebene ..................................241

2 Symptomatizität des Buch-Motivs im Roman oder Warum ,Buch im Buch'? ..................243

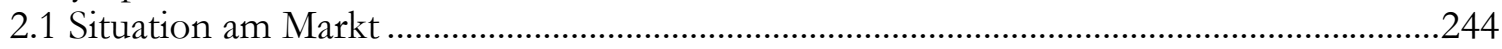

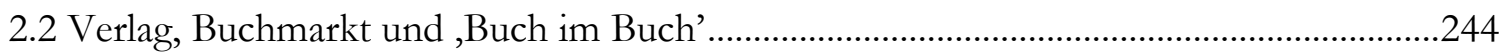

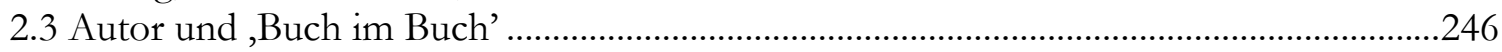

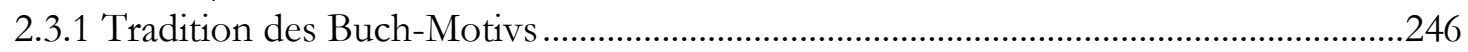

2.3.2 Reaktionen auf neue Schreibweisen .....................................................................247

2.3.3 Reaktion auf den Medienwandel............................................................................2. 249

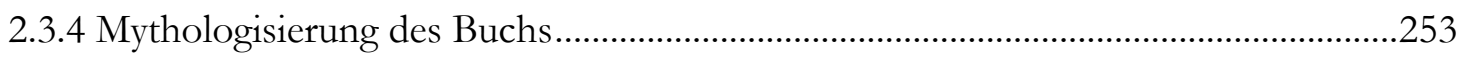

2.3.5 Autor und Publikum - Für wen schreibt der Autor?.................................................255

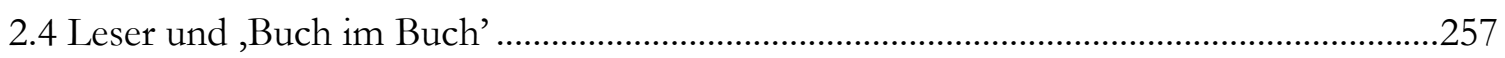

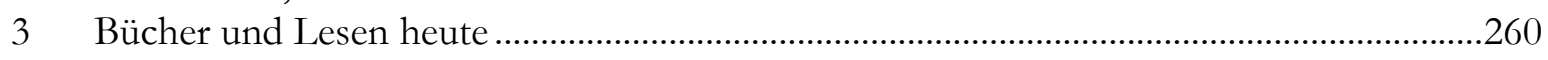

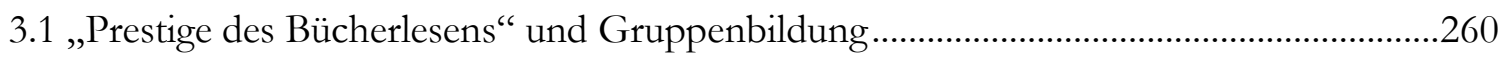

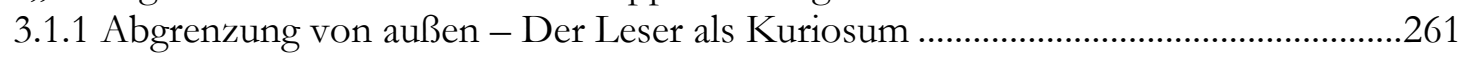

3.1.2 Abgrenzung von innen - Gruppenbildung ...............................................................2. 262

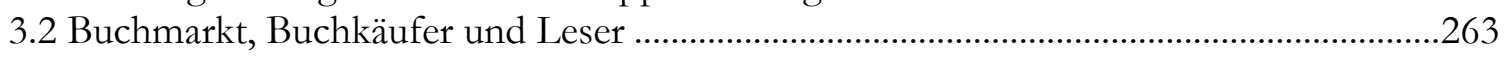

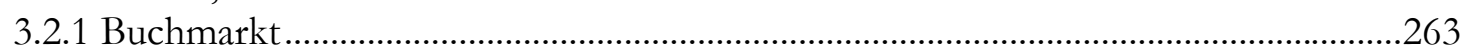

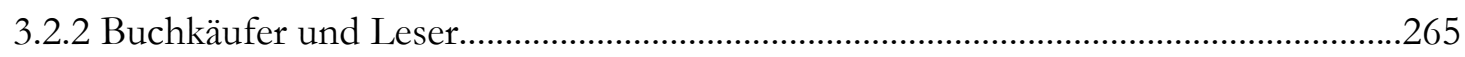

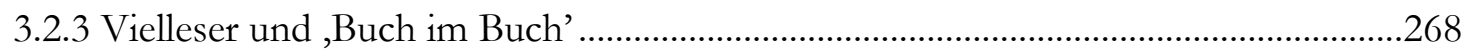

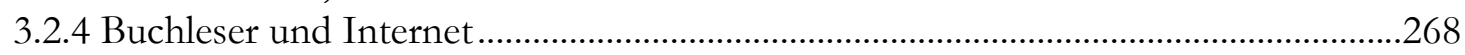

3.3 Literarische Kommunikation und Leseverhalten................................................................269

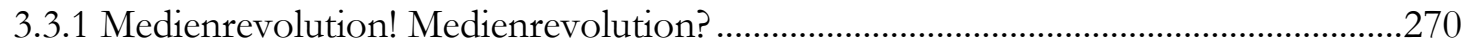

3.3.2 Auswirkungen des Medienwandels auf die Akteure der

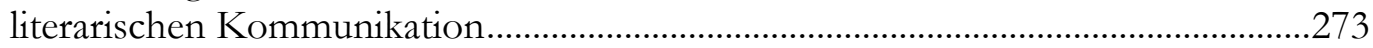

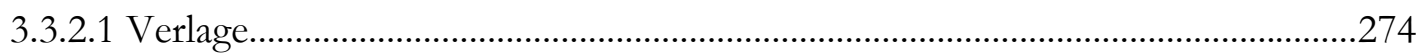

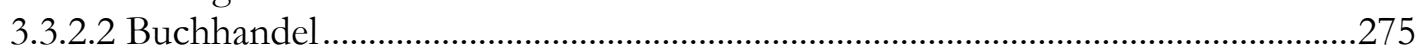

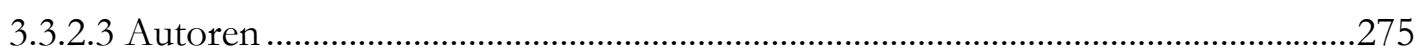

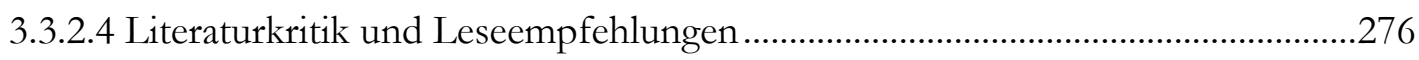

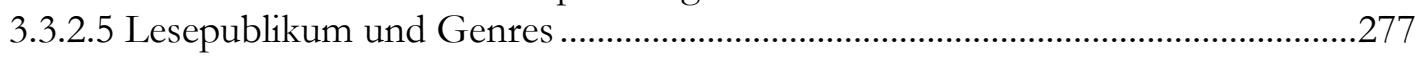

3.3.2.6 Wie gelesen wird - Umgang mit dem Text .......................................................22

3.3.2.7 Was gelesen wird - Das Beispiel All-Age-Literatur als Lesetrend ......................279 


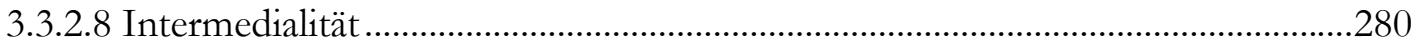

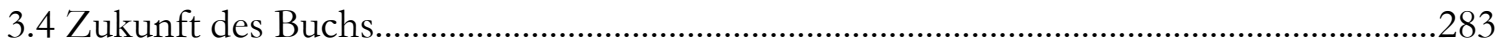

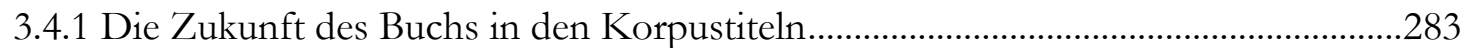

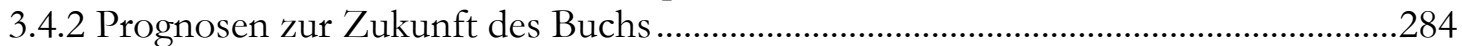

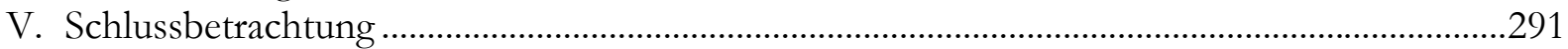

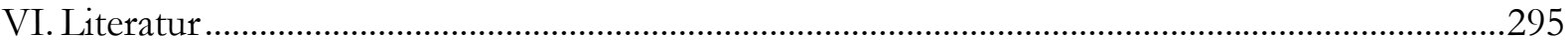

\section{Tabellen}

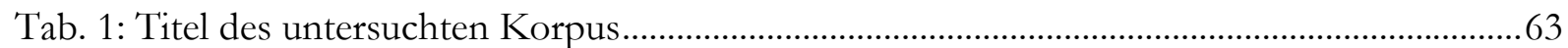

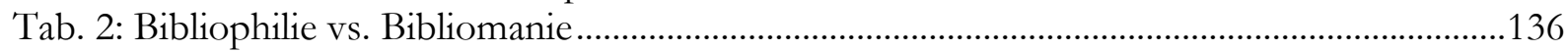

Tab. 3: Die Bücher in den untersuchten Romanen..........................................................................224

\section{Abbildungen}

Abb. 1: Umschlagabbildung des Romans Mein Leben als Buch von Peter Jacobi.

Abb. 2: Zeichnung von Nikolai W. Gogol, wiedergegeben nach

Peter Jacobi: Mein Leben als Buch.

Abb. 3: Alfons Schweiggert: Das Buch, S. 135. 



\section{Einleitung}

\section{Ausgangssituation}

In unserem sog. Wissens-, Informations- und Medienzeitalter hat das Buch seine Stellung als Leitmedium ${ }^{1}$, besonders unter den Unterhaltungsmedien, an ,neue' und digitale Medien abgegeben: Das Buch befindet sich heute nicht nur in einer Konkurrenzsituation zu visuellen, sondern auch zu elektronischen und digitalen Medien, die es als Informations- und Unterhaltungsmedien ergänzen. Die digitale Konkurrenz zum Buch führe zu einem Rückgang des Lesens, sogar zu einer Abkehr vom Buch, wie kulturpessimistische Prognosen lauten. TV, Internet und Computer (-spiele) stellen nicht nur eine enorme Konkurrenz zum Bücherlesen dar, das sich den Vorwurf gefallen lassen muss, zeitraubend, unsozial und anstrengend, da zu kopflastig, zu sein, sondern bieten sogar Möglichkeiten, das gedruckte Buch vollkommen zu ersetzen. Das Buch scheint bedroht von den neuen digitalen Medien, die dazu in der Lage sind, Aufgaben und Funktionen des Buchs zu übernehmen, nämlich Texte verfügbar zu machen und gelesen zu werden. Darüber hinaus fühlen sich die Akteure des Buchmarkts, besonders der herstellende und verbreitende Handel, herausgefordert, da digitale Optionen zudem ihre Aufgaben, wie Publikation und Vertrieb von Büchern übernehmen könnten. Hinzu kommt die elektronische Konkurrenz auch für das Lesen von Texten: E-Books und ihre Lesegeräte, die E-Book-Reader. Gerade aus dieser prekären Situation des Buchs heraus wird dem Buch und auch dem Bücherlesen eine neue Begeisterung entgegengebracht. Es gibt heute einen neuen Trend, spätestens seit dem leserschichten- und generationenübergreifenden Massenmedien-Phänomen Harry Potter, der Bücher und Lesen neu belebt und in den Vordergrund rückt, was sich wiederum in einer an diesen Diskurs angelehnten Romanliteratur ausdrückt.

Nicht erst seit der durch den Literaturkritiker Marcel Reich-Ranicki im Oktober 2008 ausgelösten Diskussion um die Qualität des deutschen Fernsehens ${ }^{2}$ erfährt das Buch ein starkes Interesse als Gegenstand einer Debatte über den Status von Buch und Lesen sowie die Zukunft des

1 Jürgen Nelles versteht als Leitmedium jenes Medium, das ,innerhalb eines bestimmten Zeitraums die gegenüber anderen Medien umfassendste Verbreitung erfährt" und die größte Wirkung auf Gesellschaft, Weltanschauung und Kunst ausübt, vgl. Jürgen Nelles: Bücher über Bücher. Das Medium Buch in Romanen des 18. und 19. Jahrbunderts. Würzburg: Königshausen \& Neumann, 2002, S. 25.

2 Aus Ärger über die mangelnde Qualität des deutschen Fernsehens lehnte Reich-Ranicki die Annahme des ihm zugedachten Deutschen Fernsehpreises für sein Lebenswerk am 12.10.2008 ab. Ironischerweise handelte es sich bei der TV-Sendung, für die er ausgezeichnet werden sollte, um das Literarische Quartett, in dem er in den 1990ern mit einer Kritikerrunde Buchnovitäten besprach. Da dieser Eklat zeitnah zur Frankfurter Buchmesse stattfand, erfuhr die Debatte um die Rolle von Büchern und Lesen einen neuen Höhepunkt. „Aus gegebenem Anlass“ diskutierte Reich-Ranicki daraufhin am 17.10.2008 in einer Spezialsendung im Fernsehen mit dem TV-Moderator Thomas Gottschalk über die Qualität des Fernsehens, wobei er recht einseitig die Buchkultur als grundlegend positiv und qualitativ hochwertig, das Fernsehen als durchweg minderwertig und niveaulos darstellte. Kritiker warfen ReichRanicki nach diesem Auftritt vor, in der Vergangenheit gefangen zu sein, und nicht mit den neuen kulturellen und gesellschaftlichen Entwicklungen Schritt zu halten. 
Buchs angesichts der digitalen Medien, die wiederum in allen Medien ausgetragen wird. Das ,Buch' hat im Zuge dessen auch als Unterhaltungsmedium eine neue Aktualität erlangt. Dabei darf nicht unerwähnt bleiben, dass man unter dem zu lesenden Buch heute - größtenteils synonymisch $^{3}$ - den Roman als unterhaltsame Lektüre für ein Massenpublikum versteht, die dem Identifikationsbedürfnis der Leserschaft nachkommt. Der Diskurs um das Buch, hervorgerufen durch die Annahme, das Buch werde mehr und mehr obsolet, führt zu einer „Wiederkehr des Buchs“. Dieser Diskurs findet nun seinen Niederschlag in der aktuellen Romanliteratur: Das Buch wird in seinem eigenen Medium, dem Buch, thematisiert. In diesen Romanen wird das Buch „nicht bloß thematisiert - es wird gefeiert und verherrlicht, (...) dramatisiert, pathetisiert, dämonisiert, heroisiert, mythisiert ${ }^{\star 4}$, wie die Publizistin und Literaturkritikerin Sigrid Löffler in ihrer Zeitschrift „Literaturen“ feststellte, der im Oktober 2005 das Themenheft „Lesen“ gewidmet war.

Der Roman hat heute die Spitzenposition auf dem Belletristik- und dem gesamten Buchmarkt inne und stellt die beim Lesepublikum populärste Gattung dar, denn das Lesen zur Unterhaltung und Entspannung hat die größte Bedeutung unter Lesern ${ }^{5}$. Ist ,Lesen’ heute im allgemeinen Verständnis zwar mit dem Lesen von Romanen verbunden, gilt dennoch: „Lesen bildet“. Die immer größere Seltenheit des Lesens als Lieblingsbeschäftigung fördert zugleich ihr Prestige, öffnet aber auch eine Schere zwischen Nichtlesern und Lesern.

Der Trend oder ,Gegentrend' hin zum Buch ist in vielfältigen Zusammenhängen zu beobachten. Zum einen finden die Veränderungen auf dem Buchmarkt Ausdruck in der wachsenden Verquickung von Hoch- und Populärliteratur und in einer zunehmenden Intermedialität. Eine Vielzahl von Drehbüchern für Kinofilme z. B. bedient sich bei der (Jugend-)Literatur, die mitunter gezielt auf eine spätere Verfilmung geschrieben zu sein scheint ${ }^{6}$, umgekehrt werden manche Romane erst nach der Verfilmung auf der Basis des Drehbuchs geschrieben, um der Zuschauerschaft eine Vertiefung in den Inhalt zu ermöglichen ${ }^{7}$. Zum anderen zeigt sich ein Trend hin zum Buch auch in dem Phänomen, das mit dieser Arbeit untersucht werden soll. Es ist zu beobachten, dass in einer wachsenden Anzahl von Romanen das Buch selbst eine (Haupt-)Rolle spielt. Es interagiert mit dem Leserprotagonisten, treibt die Handlung voran und löst sie schließlich auf. Das Buch kann dabei

3 Die Gleichsetzung von Buch und Roman galt bereits in der Blütezeit des Romans um 1800, vgl. Nelles (2002), S. 288.

4 Sigrid Löffler: „Entspanne dich. Sammle dich. Nimm und lies!“ In: Literaturen 10 (2005), S. 8-17, hier S. 8.

Löffler zitiert mit dem Titel ihres Beitrags den als Kult-Roman verehrten ,Metaroman’ von Italo Calvino Wenn ein Reisender in einer Winternacht (1979).

5 Die Bezeichung „Leser“ schließt im Folgenden stets den weiblichen Leser mit ein.

6 Man denke hier neben J. K. Rowlings Harry-Potter-Reihe u. a. auch an die erfolgreichen filmischen Umsetzungen der Romane von Stephenie Meyer. Auch Comics sind durch ihre inhärente Nähe zum Film und die filmischen Methoden, derer sie sich bedienen, bestens zur Verfilmung geeignet, die in den letzten Jahren denn auch deutlich zunehmen, z. B. Batman, Spiderman, Iron Man etc. Auffällig ist das durchgängig fantastische Genre.

7 Vgl. Volker Wehdekings Vorwort zu Nina Waldkirch: Der Trend zum Mystery-Genre in neuen Romanen und Filmadaptionen. Dan Brown, Arturo Pérez-Reverte und Wolfgang Hoblbein. Marburg: Tectum, 2007, o. Sz. 
Objekt einer Suche sein, Handlungsanweisung oder Aufklärung für den Protagonisten bieten oder Kontakt mit einem beeindruckenden Menschen herstellen, der hinter dem Buch steht.

Am deutschen Buchmarkt ist der Trend, der das Buch wieder populär und aktuell werden lässt, eindeutig abzulesen. Um die Jahrtausendwende, besonders in den letzten, etwa 20 Jahren, sind etliche Originalausgaben und Übersetzungen von Romanen auf dem deutschsprachigen Markt erschienen, in denen dem Buch oder dem Bücherfreund ein eminenter Raum zugestanden wird $^{8}$. Dies stellt sich als ein Phänomen dar, das in allen Literaturen zu Hause ist. Darüber hinaus überschreitet dieses Phänomen die ohnehin aufweichenden Genregrenzen: Es ist ebenso in hochkultureller Literatur anzutreffen wie in Unterhaltungsliteratur.

Als Folge des Diskurses um das Buch, ausgelöst durch die Konkurrenz oder gar ,Bedrohung’ des Buchs durch digitale Medien, die es, wie vermutet wird, ablösen könnten, erlebt das Buch eine veritable Renaissance auch als literarisches Motiv in der gegenwärtigen Romanliteratur, wobei an dieser Stelle auch andere Faktoren bedingend wirken.

\section{$2 \quad$ Aufriss der Fragestellung}

Die in dieser Arbeit gestellte Frage ist die nach den Gründen für das gehäufte Vorkommen des Buch-Motivs und somit der innerliterarischen Autoreflexivität in aktueller internationaler Romanliteratur, also auch nach der Funktion des Motivs ,Buch im Buch’. Der Begriff ,Funktion’ wird im Fach uneinheitlich gebraucht und ist nicht eindeutig bestimmt (vgl. Kap. IV.1.2). Als Funktion wird die „Aufgabe, Rolle Leistung oder Wirkung ${ }^{(9)}$ eines Elementes in einem größeren Ganzen angesehen, die Bestimmung kann also auch auf ein literarisches Motiv übertragen werden. Oft wird die Funktion eines Textes mit seiner Wirkung oder der Autorintention gleichgesetzt, was allerdings irreführend sein kann. In dieser Arbeit wird die Funktion des Buch-Motivs als seine Fähigkeit, Textrelationen herzustellen und Wirkungen auf den Leser hervorzurufen bestimmt und folgt damit der Definition von Harald Fricke ${ }^{10}$. Die Leserwirkungen bleiben in dieser Arbeit jedoch aus notwendigen Gründen spekulativ, da sie im Rahmen dieser Untersuchung kaum belegbar sind. Die Definition des Funktionsbegriffs legt die Untersuchung der internen und externen Funktionen des Buch-Motivs nahe (vgl. Kap. IV.1.2). Die interne Funktion umreißt die Beziehung von Textelementen zu einander auf der innerliterarischen Ebene, z. B. die Beziehung des Buch-Motivs zu anderen Motiven oder Figuren. Die externe Funktion verweist auf die Beziehun-

\footnotetext{
Vgl. dazu auch Löffler (2005), S. 8.

9 Vgl. Ansgar Nünning: Art. „Funktion“. In: Ders. (Hg.): Metəler Lexikon Literatur- und Kulturtheorie.

3. akt. u. erw. A. Stuttgart, Weimar: Metzler, 2004, S. $202 \mathrm{ff}$.

10 Vgl. Ebd., S. 203.
} 
gen von Textelementen zu Aspekten außerhalb des Textes, z. B. auf Reflexionen gegenwärtiger gesellschaftlicher Diskurse im Text.

Die Darstellung des Buchs in der neueren Literatur kann als Indikator dafür aufgefasst werden, welchen Stellenwert das Buch in der heutigen Gesellschaft denn überhaupt (noch) hat. Die Vermutung liegt nahe, den Medienwandel für dieses literarische Phänomen verantwortlich zu machen $^{11}$, also die Konkurrenzsituation, der Bücher heute unterliegen. Dies allein wäre aber zu kurz gedacht. Das Buch-Motiv ist in der Romanliteratur kein neues Phänomen ${ }^{12}$, es führen neben dem Medienwandel auch diverse andere Faktoren zu einem Auftreten des Buch-Motivs in aktueller Literatur und bedingen es. Das Buch-Motiv besitzt in der Literatur eine reiche und lange Tradition und wird daran anschließend thematisiert. Außerdem spielen selbstreflexive Schreibweisen, die Schreiben und Lesen fiktionalisieren und einem postmodernen Schreibstil zuzuordnen sind, eine Rolle. Die Häufung des Buch-Motivs in aktuellen Romanen lässt sich zudem auf eine veränderte Mediennutzung zurückführen: Angesichts der allgegenwärtigen Konkurrenz durch die elektronischen Medien werden Buch und Lesen einfach etwas Besonderes, fast Ungewöhnliches, da die Beschäftigung mit dem Buch nicht mehr selbstverständlich ist und sich seine Wahrnehmung und Wertschätzung durch ein breites Publikum wandelt.

Um Äußerungen vornehmen zu können, die sich mit der Stellung des Buchs heute befassen, muss zunächst die Darstellung des Buchs in seinem ureigenen Umfeld, nämlich der Literatur, analysiert werden. Daher wird eine hermeneutische Motivuntersuchung vorgenommen, die das Motiv in den Romanen des zusammengestellten Korpus erforscht. Ein Motiv ist durch die Literaturgeschichte vererbbar und kann in unterschiedlichen Kontexten eingesetzt werden, es folgt einer Tradition und vermittelt zugleich den Zeitgeist. Es liegt daher nahe, das ,Buch im Buch’ als Motiv zu identifizieren, denn auch das Buch in Romanen verweist sowohl auf literarische Traditionen als auch auf aktuelle Diskurse. Aus diesem Grund wird das Motiv ,Buch im Buch’ im Zentrum dieser Arbeit stehen. Die Gestaltung dieses Motivs unterliegt allerdings einer Akzentverschiebung gegenüber der Thematisierung des ,Buchs im Buch’ in der bisherigen Literatur. Wo vormals noch ein ,lesender Held' mit seinen Lektüreerfahrungen und -eindrücken im Vordergrund stand und in der Handlung des (fiktiven) Buchs Parallelen zu seiner eigenen Situation und Vorbilder für sein Handeln und seine moralische Ausbildung findet, werden dem Buch selbst nun Qualitäten und Cha-

11 Günther Stocker geht davon aus, dass die beobachtete „Aufwertung des Viellesens [...] im Zusammenhang der aktuellen Medienkonkurrenz durch Fernsehen, Computer, CD-ROM und Internet zu verstehen“ sei, vgl. Günther Stocker: Vom Bücherlesen. Zur Darstellung des Lesens in der deutschsprachigen Literatur seit 1945. Heidelberg: Universitätsverlag Winter, 2007, S. 90.

12 Stocker weist zu Recht darauf hin, dass Löffler mit ihrer Behauptung, der Buchleser als Buchheld stelle ein neuartiges Phänomen der Romanliteratur dar, gründlich falsch liege, vgl. Stocker (2007), S. 90, Anm. 53. 
rakteristika zugeschrieben, die Rückschlüsse auf Produzenten und Rezipienten von Literatur sowie auf die gesamte literarische Kommunikation zulassen.

Auch auf der Grundlage intertextueller Referenzen oder auch durch Einflüsse von Gelesenem, auf das der Autor ganz bewusst anspielt, das er zitiert oder auch unbewusst einbindet, finden sich in jedem Buch explizit oder implizit andere Bücher ${ }^{13}$. Diese Arbeit befasst sich jedoch ausschließlich mit Romanen, in denen Bücher und ihre Interaktion mit dem Protagonisten im Mittelpunkt stehen. Dabei ist das Buch im Roman kein unbedeutender Gegenstand, sondern ausschlaggebend für die Handlung des Romans. Es beeinflusst das Leben des Protagonisten entscheidend und hat im Text eine sinnkonstituierende und handlungsprogressive Funktion.

Es konnten Motivgruppen gebildet werden, die die Figur-, Motiv-, Handlungs- und Genrekombinationen vereinen, mit denen das Buch in den Romanen verknüpft wird. Daraus lassen sich Aussagen ableiten über den Status, den das Buch unter Buchmenschen einnimmt, die das Buch schreiben, es verlegen und ihm ein Publikum zutrauen - kurz: Die Gründe und die Art und Weise, wie ein Buch in der aktuellen Literatur dargestellt und beschrieben wird, können meiner Meinung nach als Indikator dafür angesehen werden, wie es um das Buch heute steht, welches Prestige, welcher Einfluss ihm zugestanden wird, welche Rolle es in der heutigen Medienlandschaft für die Akteure des Buchmarkts, für Verlage und vor allem Autoren und Leser spielt.

Aus diesem Grund ist die Untersuchung der Ausgestaltung des Motivs ,Buch im Buch’ wichtig. Das Buch wird häufig , an sich' geschätzt, als Gegenstand und Objekt der Sehnsucht wie z. B. für einen Antiquar oder einen Sammler, der den Wert des alten Buchs schätzt. An dieser Stelle muss gefragt werden, ob das Buch mittlerweile für eine, der heutigen als Kontrapunkt entgegen-

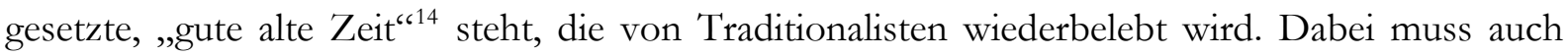
gefragt werden, wie das Buch in der heutigen Gesellschaft überhaupt konnotiert ist. Bei der Betrachtung der literarischen Buchdarstellungen sticht hervor, dass das Buch z. T stilisiert, fast schon mystifiziert und ,sakralisiert ${ }^{\text {“15 }}$ wird. Es erscheint einer Prüfung wert, ob derzeit tatsächlich von einer „,nostalgische[n] Verklärung des Lesens“"16 gesprochen werden kann, ob dem Buch eine Art Renaissance widerfährt oder ein beinahe trotziger Versuch von Autoren unternommen wird, an der Tradition des Lesens festzuhalten. Kritiker sehen im Buch und der Begeisterung für das Lesen unter Umständen ein Nicht-Schritt-halten mit aktuellen kulturellen Entwicklungen, die Zeit der ,neuen Medien' hat schließlich begonnen. Dennoch muss die Annahme der neuen nicht

13 Vgl. dazu Nelles (2002), S. 13.

14 Stocker (2007), S. 90, erwähnt die Thematisierung des Lesens in aktuellen Hollywood-Filmen, das „,eine diffuse Sehnsucht nach einer vermeintlich besseren alten Zeit" evozieren soll.

15 Günther Stocker: Schrift, Wissen und Gedächtnis. Das Motiv der Bibliothek als Spiegel des Medienwandels im 20. Jahrbundert. Würzburg: Königshausen \& Neumann, 1997, S. 288.

16 Stocker (2007), S. 90. 
die Aufgabe der alten Medien bedeuten, so dass viele Leser sich zu ,Mehrmediennutzern' gewandelt und geöffnet haben. Es wird untersucht, ob das Buch tatsächlich für einen Anachronismus, für das Alte, Vergangene steht, das seine Faszination in die Gegenwart ausstrahlt, während die elektronischen Medien - die Bezeichnung ,neue Medien’ expliziert es bereits - für Moderne und Aufgeschlossenheit, den Fortschritt, stehen. Außerdem werden Anzeichen dafür erforscht, wie die innerliterarische Thematisierung des Buchs in Romanen der Gegenwart die aktuelle Situation des kulturellen Umbruchs, den Medienwandel reflektiert.

Leitthese dieser Arbeit ist die Annahme, dass das ,Buch im Buch’ eingesetzt wird, um kulturkritische Mutmaßungen zu transportieren - befürchtete Ersetzung des Buchs durch elektronische und digitale Medien in der Medienwelt -, dass es aber dennoch nicht durch neue Medien verdrängt, sondern ersetzt wird. Es ist weiterhin anzunehmen, dass der Leser durch das Buch-Motiv zu Wertungen von Literatur und des Buchmarkts sowie einer Reflexion des Kulturbetriebes und der Mediensituation angeregt wird.

\subsection{Der fiktionsinterne und der fiktionsexterne Leser}

Zur Vervollständigung der Untersuchung des ,Buchs im Buch’ wird auch der Leser in den Blick genommen, und zwar in der Motivuntersuchung derjenige auf der Erzählebene, im zweiten, auf den heutigen Buchmarkt und die aktuelle literarische Kommunikation fokussierten Teil dieser Arbeit der reale Leser. Das „Buch im Buch’ setzt den Leser im Buch voraus, denn ohne die Interaktion zwischen dem Buch und einem Protagonisten, der auch dessen Text kennt, könnte keine (Roman-)Handlung entstehen.

Dem innerliterarischen Leser ist in der fiktionalen Literatur viel Aufmerksamkeit geschenkt worden - die Beispiele reichen von Don Quijote und Madame Bovary bis hin zu Edgar Wibeau (vgl. Kap. II.3). Dabei lag das Hauptaugenmerk auf dem Eindruck, den das Gelesene auf den lesenden Protagonisten macht und schließlich Einfluss auf seinen Charakter und sein Schicksal nimmt ${ }^{17}$. Bei der (literarischen Beschreibung von) Lektüre steht der Leser selbst im Vordergrund, seine Gedanken, Vorstellungen, Wünsche und Sehnsüchte, die er in das Gelesene projiziert.

In vielen Titeln des Korpus ist der Leserprotagonist jedoch nicht mit einem fiktionalen Inhalt konfrontiert, außerdem soll nicht der Prozess des Lesens erforscht werden. In einigen Büchern hat der Protagonist keine Gelegenheit zur Lektüre oder das Buch wird durch seine situative Brisanz wichtig. Dennoch nimmt das Buch Einfluss auf das Schicksal des Protagonisten und führt zu un-

17 Vgl. dazu auch die Untersuchungen zum Motiv „Gelebte Literatur“ in der Literatur in Theodor Wolpers (Hg.): Gelebte Literatur in der Literatur: Studien zu Erscheinungsformen und Geschichte eines literarischen Motivs: Bericht über Kolloquien der Kommission für literaturwissenschaftliche Motiv- und Themenforschung 1983-1985. Abhandlungen der Akademie der Wissenschaften in Göttingen, Phil.-Hist. Klasse, III, 152. Göttingen, 1986. 
erwarteten Ereignissen. Entscheidend ist, was hinter den Büchern in den Büchern steht. In einigen Titeln sind es deshalb auch die Autoren, die mittels ihrer Bücher in eine geistige Beziehung zu den Lesern auf der Textebene treten, so dass der Protagonist mitunter die Züge der Person annimmt, der er nachforscht, wobei sich ein Spiel mit Identitäten, Analogien und Wiederholungen entspinnt.

Der reale Leser steht besonders im Zentrum der Bemühungen um das Überleben des Buchs. In den gängigen literaturtheoretischen Ansätzen seit den 1960ern wurde der Leser und sein Rezeptionsprozess bereits entscheidend aufgewertet („Tod des Autors“, Roland Barthes; „Der implizite Leser“, Wolfgang Iser). Im Zuge dieser Theorien gilt der Leser als Schöpfer des Textes, der sich gegenüber dem Autor emanzipiert. Nicht nur der Leser wird durch das Lesen verändert, wenn das Buch den in seiner Alltagsroutine erstarrten, passiven Protagonisten zu neuer Aktivität ermutigt, auch der Leser erweckt seinerseits den unbelebten Text quasi zum Leben.

Aber natürlich auch ganz konkret als Käufer spielt der Leser eine Rolle auf dem Buchmarkt, da nur durch Kauf und Lesen das Buch als Handelsware fortbestehen kann. Es wird im Weiteren untersucht werden, wie Leser auf das fiktionalisierte Buch reagieren und versucht, Hinweisen dafür nachzugehen, weshalb Leser zu einem Buch-Roman greifen. Da die Behandlung eines Buchs im Roman Raum für literaturbezogene Betrachtungen und erzähltheoretische Fragestellungen bietet, wird auch danach gefragt, ob alle Leserschichten, auch ein nicht-professionelles Lesepublikum von ,Normallesern"18, vermag, das ,Buch im Buch’ zu goutieren.

\section{Forschungsstand}

\subsection{Skizze des Forschungsstands zu Buch und Lesen im Roman}

Die Grundlage dieser Arbeit bildet die Untersuchung des Motivs „Buch im Buch', wobei dieses Motiv in anderen Zusammenhängen bereits gut untersucht worden ist. Es wundert daher nicht, dass die literaturwissenschaftliche, besonders die komparatistische ,Buch-im-Buch'-Forschung, heute als besonders rege und produktiv gilt ${ }^{19}$, während Ralph-Rainer Wuthenow noch 1980 bedauerte, dass „dieses fesselnde Phänomen bisher so wenig Beachtung gefunden hat “20. Auch Theodor Wolpers weist darauf hin, dass der mit dem ,Buch im Buch’ verwandte Motivkomplex

18 Dies sind „Rezipienten, die literarische Texte ohne Hinblick auf professionelle Verwendungen oder Verarbeitungen lesen“, vgl. Renate von Heydebrand \& Simone Winko: Einführung in die Wertung von Literatur. Paderborn: Schöningh, 1996, S. 102.

19 Vgl. Dietmar Rieger: Imaginäre Bibliotheken. Bücherwelten in der Literatur. München: Fink, 2002, S. 13.

20 Ralph-Rainer Wuthenow: Im Buch die Bücher oder Der Held als Leser. Frankfurt/Main: Europäische Verlagsanstalt, 1980, Vorbemerkung. - Als Unterhaltungsmedium macht das Fernsehen dem Buch seinen Rang nicht nur zunehmend streitig, sondern hat es an Popularität bereits überholt. Die thematologische Studie von Claudia Schmitt: Der Held als Filmseher. Filmerleben in der Gegenwartsliteratur. Würzburg: Königshausen \& Neumann, 2007, nimmt ausdrücklich auf Wuthenows Untersuchung Bezug. 
„Gelebte Literatur“ in der Forschung wenig beachtet wurde ${ }^{21}$, verweist aber auf die zahlreichen Arbeiten zu Don Quijote, einem , lesenden Helden’.

Uwe Japp fragt in seinem bekannten Aufsatz „Das Buch im Buch“22 danach, weshalb „Bücher in Büchern in den verschiedensten Zeiten überhaupt so häufig Verwendung “23 finden und verankert den Ursprung dieses Phänomens in der sakralen Verehrung von Büchern in der Antike $^{24}$. Zudem diskutiert er den Vorwurf an die Literatur, die das Buch thematisiert, eine hermetische Literatur zu sein: Sie nehme sich nicht der Realität an, sondern kreise um sich selbst und bewege sich dabei nicht aus sich selbst heraus. Durch diese auf die Spitze getriebene innerliterarische Selbstreflexion finde die Realität für den Leser dann hauptsächlich im Kopf statt. Dadurch wirke die Literatur verschlossen und unzugänglich, rätselhaft und unverständlich. Beim Lesen bleibe trotz Verständnis des Geschriebenen ein Gefühl der Fremdheit bestehen ${ }^{25}$. Der Leser empfinde auf diese Weise Faszination für den Text, aber gleichzeitig Verunsicherung. Erwartungen von Lesern und Reaktionen auf verrätselte, selbstbezügliche Buch-Bücher werden in dieser Arbeit in Kapitel III.9 und IV.2.5.1 diskutiert. Für die in dieser Arbeit untersuchten Titel kann die von Japp beschriebene Unzugänglichkeit von Buch-Büchern nicht uneingeschränkt gelten (vgl. Kap. III.1.1.2). Vielmehr ergeben sich aus den herangezogenen Lesermeinungen Anzeichen dafür, wie sich der Leser unter dem Eindruck des Buchs öffnet und neue Perspektiven und Eindrücke gewinnt. Japp fasst den Begriff ,Buch im Buch’ sehr weit und bezieht in seiner Abhandlung auch wissenschaftliche Titel mit ein, die zur Untermauerung von Aussagen über ein wissenschaftliches Fachgebiet in Romanen dienen, ebenso unterschiedliche dichterische Umsetzungen desselben literarischen Stoffes. In dieser Arbeit wird ausschließlich das Motiv ,Buch' im Roman untersucht, und das konzentriert auf die Literatur der letzten Jahre. Ausgeklammert bleiben literarische Situationen, in denen aus bedeutsamen Büchern vorgelesen wird, sowie Darstellungen und Auffassungen von Bibliotheken - ein Themenfeld, das bereits gut untersucht ist.

Die ,Buch-im-Buch'-Forschung befasst sich mit den großen Komplexen der Motive ,Buch', ,Lesen' und ,Bibliothek', wobei letzteres bisher am intensivsten erforscht wurde, besonders unter dem Aspekt der Ordnung von Wissen. Die mit der Fiktionalisierung zusammenhängenden Schwerpunkte der literaturwissenschaftlichen Forschung, die sich mit der Bibliothek in Büchern ${ }^{26}$, sprich

21 Vgl. Theodor Wolpers: Vorwort zu Wolpers (1986), S. 7-29, hier S. 9.

22 Uwe Japp: „Das Buch im Buch. Eine Figur des literarischen Hermetismus“. In: Neue Rundschau 86 (1975), S. $651-670$.

23 Ebd., S. 653.

24 Ebd., S. 652.

25 Vgl. Stephan Jaeger: Art. „Hermetik“. In: Nünning (32004), S. 257.

26 Vgl u. a. Rieger (2002), Stocker (1997), Klaus Döhmer: Merkwürdige Leute. Bibliothek und Bibliothekar in der Schönen Literatur, 2., verb. u. erg. Aufl. Würzburg: Könighausen \& Neumann, 1984, ${ }^{1} 1982$, sowie Debra A. Castillo: The translated world. A postmodern tour of libraries in literature. Tallahassee: Florida State Univ. Press, 1984. 
Romanen, befasst, liegen im Bereich der Intertextualitäts-, Kanon- und Erinnerungsforschung ${ }^{27}$. Dargestellt wird die Bibliothek in diesen Fiktionalisierungen hauptsächlich als Wissens- und Erinnerungsspeicher, außerdem wird ihre Rolle für die Zukunft des Lesens und der Schriftkultur beleuchtet. Die Forschung kommt zu dem Ergebnis, dass sich die Bibliothek, und somit auch das Buch, trotz der Medienkonkurrenz durchsetzen werde, da die virtuelle Welt der elektronischen Medien kaum echte Alternativen zum gedruckten Wort zu bieten in der Lage sei, auch keine vergleichbaren Möglichkeiten konservatorischer Art. Dem Schlagwort der Wissensgesellschaft begegnend wird die Bibliothek auch als Ausdruck von Macht gesehen, da sie durch das Wissen, das sie vermittelt oder aber vorenthält, in Kultur und Gesellschaft eingreift. Die Bibliothek erscheint in den Fiktionalisierungen also nicht als eine dem Protagonisten gleichwertig gegenüber gestellte Figur, sondern als übergeordnete Instanz, die den Protagonisten mit Wissen versorgt, ihm Schutz bietet oder ihn ehrfurchtsvoll staunen lässt. Sie erfährt jedoch, genau wie das „Buch im Buch', eine Mythisierung und Verehrung durch die Figuren, die auch auf den realen Leser übergehen soll.

$\mathrm{Zu}$ neuen Rollen und Funktionen fiktionaler Literatur im heutigen Medienwandel hat Günther Stocker bereits 1994 geforscht. Angesichts neuerer technologischer Bedingungen bezeichnet er fiktionale Literatur im Titel seiner Arbeit treffend als ein „rebellisches Fossil““28, das jedoch, so sein Fazit, keine Tendenz zeige, in nächster Zeit auszusterben. Allerdings sei fiktionale Literatur nicht mehr allein dazu in der Lage, die immer komplexere Welt zu kodieren.

Dietmar Rieger stellt in seiner romanistischen Arbeit, die ausschließlich französische und italienische Werke berücksichtigt, fest, dass die Zahl der Bibliotheksfiktionalisierungen in den letzten Jahren stetig angestiegen ist ${ }^{29}$. Mit dieser Aussage führt er hin zu meiner Beobachtung, dass in einer großen Zahl von Romanen der letzten Zeit Bücher als Motiv auftauchen und gar von einer Renaissance des Buchs im Medienzeitalter gesprochen werden kann. Rieger hebt als kennzeichnende Merkmale der Bibliothek in den thematisierten Darstellungen das Geheimnisvolle und Rätselhafte hervor, das aus dem Nicht-Verstehen resultiert. Die Mystifizierung des Buchs sowie seine literarische Darstellung in überwiegend spannungsbetonten Handlungen werden auch in der vorliegenden Arbeit herausgestellt, u. a. durch den „Mythos des einzigen oder letzten Buch““.

\footnotetext{
27 Vgl. vor allem Stocker (1997), der besonders auf die Arbeiten von Aleida und Jan Assmann zur Schriftforschung und zum kulturellen Gedächtnis rekurriert.

28 Vgl. Günther Stocker: Ein rebellisches Fossil. Die fiktionale Literatur im Zeitalter der modernen Kommunikationstechnologien. Aachen: Alano, 1994.

29 Vgl. Rieger (2002), S. 12.
} 
Zum ,Bücherlesen' ist als Arbeit der letzten Zeit die von Günther Stocker, Vom Bücherlesen. Zur Darstellung des Lesens in der deutschsprachigen Literatur seit $1945(2007)^{30}$, hervorzuheben, die sich, wie schon der Titel verspricht, mehr dem Leseakt und der Geschichtlichkeit des Lesens zuwendet. Stocker betont die heute prekäre Situation des Lesens und zieht Titel nach 1945 hinzu, um die „Geschichte, die Gegenwart und die mögliche Zukunft dieser Kulturtechnik zu verstehen“31, ohne allerdings zu betonen, dass die Phänomene des Lesers und des Buchs ,im Buch’ in aktueller Literatur besonders häufig auftreten.

Zwar sind Buch und Lesen untrennbar miteinander verbunden, doch legt die vorliegende Arbeit einen anderen Schwerpunkt und leistet einen Beitrag zur Forschung nach dem ,Buch im Buch'. Die Forschung nach der Selbstbezüglichkeit von Literatur und fiktionalisierter Lektüre wartet bisher überwiegend mit Arbeiten zur Literatur des 18. Jahrhunderts ${ }^{32}$ auf und rückt die Vielzahl lesender Heldinnen und Helden in den Fokus. Die einschlägige Untersuchung Im Buch die Bücher oder Der Held als Leser (1980) von Ralph-Rainer Wuthenow erläutert den Einfluss ausgewählter Lektüre auf den lesenden Helden in der Literatur des 18. Jahrhunderts und der Goethezeit und formuliert eine für die literaturwissenschaftliche Untersuchung wichtige Möglichkeit, das Buch-Motiv zu erfassen: „Die klassische Erscheinungsform des Buches im Buch sieht [...] so aus, dass ein Mensch, wie uns erzählt wird, ein Buch in die Hand bekommt und darin erstaunt und betroffen eben die Geschichte liest, die erzählt werden sollte. ${ }^{\text {“33 }}$ Dies trifft voll und ganz zu auf das bekannteste und folgenreichste Beispiel der Selbstreferentialität im Roman, das mittels des „Buchs im Buch’ gezeigt wird: Novalis’ Heinrich von Ofterdingen (1802). Der lesende Held ist betroffen, dass er seine eigene Geschichte in der Geschichte findet, die er im Buch vor sich hat. In ihrer Arbeit Erlesene Welten. Der fiktive Leser in der modernen Literatur: Karl Pbilipp Moritz, Gottfried Keller, Peter Handke (2005) ${ }^{34}$ unternimmt Andrea Elisabeth Dahms Werkanalysen dreier Romane, die ,lesende Helden’ porträtieren, wobei wiederum das Interesse an Darstellungsweisen und Funktionen von Leser- und Lektüreentwürfen im Mittelpunkt steht.

In diesem Punkt bietet die vorliegende Arbeit eine wichtige Ergänzung zu den bekannten Untersuchungen zum ,lesenden Helden' und seiner Art mit Gelesenem umzugehen. Es ist weniger der Prozess der Lektüre, der Verhalten oder Entscheidungen motiviert, sondern vielmehr das Buch selbst resp. sein größtenteils non-fiktionaler Inhalt, der betroffen macht, z. B. die Lebens-

30 Vgl. Stocker (2007). - Diese Arbeit enthält auch einen umfassenden Überblick über die Forschungsliteratur zum Thema ,Lesen' in der Literatur, die sich aus naheliegenden Gründen an vielen Stellen mit der Forschung zum Motiv ,Buch im Buch' überschneidet.

31 Ebd., S. 13.

32 Vgl. u. a. Wuthenow (1980) und Nelles (2002), Edgar Bracht: Der Leser im Roman des 18. Jabrhunderts, Frankfurt/Main etc.: Peter Lang, 1987, um nur einige zu nennen.

33 Wuthenow (1980), S. 174.

34 Vgl. Andrea Elisabeth Dahms: Erlesene Welten. Der fiktive Leser in der modernen Literatur. Karl Pbilipp Moritz, Gotffried Keller, Peter Handke. Frankfurt/Main etc.: Peter Lang, 2005. 
geschichte einer Person oder die Enthüllungen um eine Person oder einen Vorgang, da dieser Text den Protagonisten beeindruckt, beeinflusst und schließlich zu neuem Denken anregt.

Um 1800 wurden Bücher in Büchern hauptsächlich zu didaktischen Zwecken und zur Verbreitung aufklärerischer und moralischer Ideen innerliterarisch funktionalisiert. Dies zeigt Jürgen Nelles in seiner Arbeit Bücher über Bücher. Das Medium Buch in Romanen des 18. und 19. Jahrbundert (2002). Obwohl Nelles ausschließlich um 1800 erschienene Titel analysiert, findet sich in seiner Untersuchung eine meiner Arbeit ähnliche Ausgangssituation, denn die Thematisierung der Selbstbezüglichkeit des Buchs wurde ebenso durch eine Medienkonkurrenzsituation angeregt, in der sich das Buch befand. Die von Nelles untersuchten Titel gewannen im Zuge einer bürgerlichen ,Leserevolution' an Bedeutung und Beliebtheit. Zu dieser Zeit stand der Roman mit anderen Printmedien wie der Zeitschrift, dem Schlüsselmedium der damaligen bürgerlichen Gesellschaft, in Konkurrenz und setzte sich allmählich aus dem Zusammenwirken der Agenten des Buchmarkts und neuen Anforderungen an das Lesen heraus als Leitmedium durch. Auf den Aufstieg des Romans gehe ich in Kap. II.1.1 näher ein, da er eine Blütezeit der Selbstreflexion des ,Buchs im Buch' bedingte. Meine Untersuchung befasst sich dagegen mit dem Medienwandel an der Schwelle zum dritten Jahrtausend. Das Buch erfährt heute eine besondere Popularität, die sich in der Thematisierung des Buchs in aktuellen Romanen ausdrückt und durch die Profilierung der elektronischen Medien als Leitmedien hervorgerufen, allerdings auch durch andere Faktoren, wie traditionelle und aktuelle Schreibweisen, bedingt wird. Die Autothematisierung von Büchern ist in diesen Kontexten also als Gegentrend zur tatsächlichen Medienwirklichkeit anzusehen.

Wie virulent das Motiv ,Buch im Buch’ ist, zeigt eine komplementäre Untersuchung unter gleichem Titel von Anne Siebeck aus dem Jahr 2009 ${ }^{35}$. Ausgehend von ähnlichen Beobachtungen der aktuellen Medien- und Buchlandschaft, die auch die vorliegende Arbeit angeregt haben - das Buch als Motiv spielt eine herausragende Rolle in aktuellen Romanen -, unternimmt Siebeck eine Motivuntersuchung anhand der Gegenwartsliteratur und diskutiert in der Einleitung auch aktuelle Spielfilme. Allerdings erforscht sie ausschließlich fantastische Literatur, auf die in dieser Arbeit mit der exemplarischen Untersuchung von zwei Titeln eher ein Schlaglicht geworfen wird. Außerdem verlegt sich Siebeck ganz auf Kinder- und Jugendliteratur, die in der vorliegenden Untersuchung ausdrücklich ausgeklammert bleibt. So bilden beide Untersuchungen zum „Buch im Buch’ eine anregende Ergänzung zu einander. 


\subsection{Die vorliegende Untersuchung als Forschungsdesiderat}

In seiner Sammelrezension Geschichte[n] von Lesern und Büchern in Büchern (2004), in der er sechs Neuerscheinungen über Bücher und Leser bespricht, stellt Gerhard Sauder fest, dass ,Bücher in Büchern' inzwischen weitgehend untersucht seien: „Neue Entdeckungen - abgesehen von sicher noch zu entdeckenden Romanen mit dem Bibliotheksmotiv - dürften kaum noch zu erwarten sein. ${ }^{\text {“36 }}$ Dieser Aussage begegnet die vorliegende Arbeit mit ihrem Ansatz, der ein in der aktuellen Romanliteratur häufig beobachtetes Phänomen untersucht und es u. a. auf die Situation des Buchs in der Medienkonkurrenz zurückführt. Gleichzeitig sucht sie mittels der Betrachtung der literarischen Buchdarstellungen auch in Unterhaltungsliteratur die populäre Sichtweise auf das Buch zu erforschen. Somit füllt die vorliegende Arbeit eine Forschungslücke aus, denn die bisherige Forschung hat sich auf kanonisierte und hochliterarische Titel beschränkt. Als genreund milieuübergreifende Untersuchung - das Korpus reicht von hochkulturellen Titeln bis zu unterhaltender Spannungsliteratur - leistet sie einen Beitrag dazu, die heutige Literatur besser zu verstehen. Die Selbstthematisierung des ,Buchs im Buch’ überschreitet nicht nur die Grenzen der Erzählebenen, vielmehr verwischen auch die Grenzen der Nationalliteraturen zusehends, so dass eine internationale Literatur entsteht, deren Gattungen und Genres ineinanderfließen.

Die vorliegende Untersuchung beschäftigt sich mit Fragen, die für die heutige philologische Forschung und auch für den Buchmarkt immer wichtiger werden, nämlich einerseits mit Fragen der Motivgeschichte des Buchs, andererseits mit denen nach der Stellung und Zukunft des gedruckten Buchs in der modernen Mediengesellschaft. Es wird geprüft, ob die Thematisierung des ,Buchs im Buch' erst durch die aktuelle problematische Stellung des Buchs in Medienkonkurrenz und -wechsel hervorgerufen wird, oder ob nicht auch andere Faktoren, wie literarische Traditionen oder gewisse aktuelle Schreibweisen, entscheidend wirken.

Die bisherige ,Buch-im-Buch'-Forschung setzt, wie im vorigen Kapitel beschrieben, andere Akzente als die vorliegende Arbeit. Damit verwandt ist außerdem eine vielgestaltige Lese- und Leserforschung, die u. a. durch wirkungsästhetische Konzepte angeregt wurde. Dieser Aspekt der Rezeptionsforschung wertet den Leser als aktiven Part und Mitschöpfer des Textes auf. Neu bei dem Ansatz der vorliegenden Arbeit ist der Fokus auf dem Buch, weniger auf der Lektüre des Textes durch den Protagonisten. Dies ist auch der Tatsache geschuldet, dass der Inhalt des Buchs dem Protagonisten zwar bekannt ist, in den untersuchten Romanen jedoch kaum eine Darstellung des Leseprozesses oder unmittelbare Reflexion des Gelesenen stattfindet. Hier zeigt sich ein

36 Gerhard Sauder: „Geschichte[n] von Lesern und Büchern in Büchern [Sammelrez.]“. In: KulturPoetik. Zeitschrift für kulturgeschichtliche Literaturwissenschaft Bd. 4, H. 2 (2004), S. 255-266, hier S. 266. 
großer Unterschied zur bisherigen Buchforschung, besonders in Hinblick auf den Einfluss von Gelesenem auf den ,lesenden Helden’.

Überdies werden die derzeitigen Umwälzungen auf dem Buchmarkt und in der literarischen Kommunikation betrachtet, und es wird eine mögliche Erklärung vorgenommen, wie die aktuelle Position des Buchs in der Medienwelt aussieht und wie eine zukünftige beschaffen sein könnte. Zwar war das Buch in seiner Geschichte schon zuvor ähnlichen Situationen der Medienkonkurrenz ausgesetzt, wie z. B. im Falle des Aufkommens von Radio und Hörspiel bzw. Fernsehen, doch noch nie zuvor wurde wie heute ernsthaft die Wichtigkeit und Notwendigkeit des Buchs als Medium auf den Prüfstand gestellt. Die Arbeit möchte zeigen, weshalb das ,Buch im Buch’ innerhalb dieses Kontextes gerade heute thematisiert wird und dass die innerliterarisch suggerierten kulturkritischen Mutmaßungen in der realen Medienwelt kaum greifen.

\section{$4 \quad$ Vorgehen}

In der vorliegenden zweigeteilten Arbeit wird zunächst anhand einer Motivtypologie gezeigt, wie das Buch als Motiv in aktuellen Romanen porträtiert und mit welchen anderen Motiven es kombiniert wird. Im Anschluss wird versucht, die Gründe für das „Buch im Buch’ zu benennen, dabei werden besonders die Gründe des Autors, so zu schreiben untersucht, und auch die Gründe der Leser, zu Buch-Büchern zu greifen. Des Weiteren wird ein kurzer Überblick darüber gegeben, welche Rolle das Buch heute für die einzelnen Instanzen des Buchmarkts spielt und wie sich die Akteure der literarischen Kommunikation mit den neuen digitalen Möglichkeiten auseinandersetzen, die ihre originären Aufgaben übernehmen können.

Der analytische Hauptteil befasst sich zunächst mit der Untersuchung des Buch-Motivs und anderer buchbezogener Motive, wie dem Büchernarren, in den Titeln des Romankorpus. Die Zusammenstellung des Korpus erfolgte aufgrund der Eignung der Titel und ihrer Erfüllung der Auswahlkriterien (vgl. Kap. III.1.1.1.1), bleibt jedoch subjektiv und nicht zwingend, da ebenso gut andere Titel hätten gewählt werden können. Bei aller Subjektivität der Auswahl kristallisieren sich doch deutliche Übereinstimmungen in der Porträtierung des Buch-Motivs in den Romanen heraus. Dabei werden die vorherrschenden Motive, mit denen das Buch kombiniert wird, in einer typologischen Aufstellung zu Motivgruppen zusammengefasst. Daraus werden wiederum Aussagen abgeleitet, wie das Buch-Motiv konnotiert ist, in welchen Genres es überwiegend auftritt und welche Implikationen mit ihm verbunden sind. Entscheidend ist hier auch die Ermittlung der Art und Weise, wie die Motive und Themen die Handlung strukturieren.

Die Befunde über die Beschaffenheit der Motivstrukturen und die Qualitäten und Charakteristika, die dem Buch im betrachteten Korpus zugebilligt werden, legen die skizzierten Aus- 
sagen zur heutigen Stellung des Buchs nahe. Nicht nur das Leseverhalten des Publikums ändert sich, sondern auch die Wahrnehmung des Buchs. Zum Teil als Relikt vergangener Tage und hochkulturelles Studienobjekt weltfremder Elfenbeinturmbewohner belächelt, bildet sich auf der anderen Seite eine Gruppe von Viellesern heraus, die auch mit anspruchsvollen Inhalten umgehen können und ein besonderes Publikum für Buch-Bücher darstellen. Außerdem werden ästhetische Konzepte wie die postmoderne Erzählweise vorgestellt, die Auswirkungen auf das Schreiben und in ihrer Mehrfachkodierung Auswirkungen auf das Lesen der Buch-Bücher in unterschiedlichen Publikumsgruppen haben.

Da zu den aktuellen Romanen des betrachteten Korpus noch wenig oder keine Sekundärliteratur existiert, erfolgt die Untersuchung, sofern verfügbar, unter Berücksichtigung einschlägiger Rezensionen zu den Büchern. Außerdem werden Leserrezensionen, sog. ,Kunden-Reviews’ von der Plattform des Online-Buchhändlers Amazon.de herangezogen, um einen Einblick in die Bewertungen der untersuchten Romane von Lesern zu erhalten. Auf diesem Weg können Leserstimmen direkt eingefangen und die Erwartungen von Lesern an einen Text und wiederum ihre Meinungen dazu bewertet werden. Diese Vorgehensweise wurde bisher wenig angewandt.

Alles in allem können allein aus der Motivuntersuchung nur bedingt Thesen abgeleitet werden, da das Korpus kaum systematisch fassbar erscheint und keine endgültige Begründung für die Auswahl der einzelnen Titel gegeben werden kann. Die Annahmen sind in jedem Fall äußerst subjektiver Natur, denn die Motivuntersuchung stellt nur eine ausgewählte Möglichkeit dar, die Charakteristika und Funktionen des Buchs in der heutigen Gesellschaft zu bestimmen und sich der Sichtweise von Autor und Leser auf das Buch zu nähern. Dennoch kann die Motivuntersuchung wichtige Hinweise darüber liefern, wie das Buch gesehen wird und welche Stellung es innehat.

In einem zweiten Schritt wird geprüft, aus welchem Grund das Buch überhaupt als Motiv in aktuellen Romanen eingesetzt wird, und dies aus dem Blickwinkel verschiedener Instanzen des Literaturbetriebs und Buchmarkts heraus. An dieser Stelle können Ableitungen darüber aufgestellt werden, wie die Selbstthematisierung des Buchs in Romanen der Gegenwart die aktuelle Situation des medialen Umbruchs reflektiert. Die innerliterarische Darstellung des Buchs fußt auf Rahmenbedingungen der literarischen Kommunikation, auf Ansichten des Autors, und den Wünschen und Erwartungen des Lesers.

Nach der Ermittlung dieser Motive lässt sich feststellen, in welche Kontexte und Genres das fiktionalisierte Buch eingebettet wird und mit welchen anderen Motiven es häufig kombiniert wird. Das Buch-Motiv selbst ist ein feststehendes, das stets mit denselben Attributen verbunden wird: Nostalgie, Historisierung, Verklärung, Idealisierung. Dies lässt wiederum Rückschlüsse zu auf die Positionierung des Autors in Bezug auf Buch und ,neue Medien' und den Status des Buchs 
in der Gesellschaft, denn der Autor beschreibt das Buch in einer Weise, der das Publikum zustimmen kann, und die sich mit der Vorstellung der Leser deckt oder weitgehend überschneidet.

Ein Element, das alle Bücher des Korpus eint, ist das Buch als das Besondere, beinahe Exotische, auf die Spitze getrieben im Mythos des einzigen oder letzten Buchs seiner Art. Somit wird aber zugleich das Buch als heutige Massen- und/oder Ramschware karikiert. Angesichts des Paradigmenwechsels hin zu elektronischer Lektüre in Form von E-Books und der Entwicklung einer Gruppe von Viellesern, die zugleich auch andere, elektronische Medien extensiv nutzt, zu Mehrmediennutzern oder einfach einer Abnahme an Lesern, wird der Buchleser als vielleicht sogar aussterbende Art vorgeführt. Ob diese Darstellung der Wirklichkeit entspricht, ist zu prüfen.

Nicht nur die Buchbranche, die gesamte literarische Kommunikation steht angesichts der Popularität und der stetigen Verbesserung der elektronischen, nun digitalen Medien vor neuen Herausforderungen. Um die neue Betrachtung des Buchs und die neuen Wege, die die einzelnen Instanzen der Branche beschreiten, zu erläutern und zu untermauern, werden neuere, statistisch gestützte Erhebungen zum Käufer- und Leserverhalten sowie zur Mediennutzung herangezogen, die u. a. im Auftrag des Börsenvereins des Deutschen Buchhandels e. V. durchgeführt wurden. Außerdem finden Studien zum Buchmarkt und der Zukunft des Buchs Eingang in die Untersuchung, ebenso wie mögliche, auf der Basis aktueller Markt- und Gesellschaftsentwicklungen entworfene Zukunftsszenarien.

In meiner Untersuchung nehme ich außerdem immer wieder Bezug auf die Forschung von Günther Stocker, der in drei Arbeiten ${ }^{37}$ ähnliche Themenkomplexe zu Buch und Lesen, doch unter anderer Zielsetzung und Perspektive untersucht. Darüber hinaus stelle ich in Kap. II einen Bezug zur bürgerlichen Leserevolution im ausgehenden 18. Jahrhundert her, die im Weiteren immer wieder als Referenz aufgenommen wird. Diese sog. ,Leserevolution' war durch eine Ausdifferenzierung der literarischen Kommunikation, von Buchmarkt und Lesepublikum, gekennzeichnet, die prägend für die folgenden Jahrhunderte wirkte. Die Aufwertung des Buchs zog eine neue Bewertung der gesamten Gattung Roman nach sich. Die Leser verlangten ständig nach neuem Lesestoff, so dass sich Titelangebot und fiktionale Genres vervielfachten - eine Situation von Buch und Lesen, die der heutigen stark ähnelt. Heute kommt hinzu, dass die Handlungsfelder einzelner Instanzen des Buchmarkts nicht mehr klar konturiert sind, denn die Aufgaben vermischen sich und werden von anderen, neuen Medien übernommen. 


\section{$5 \quad$ Gang der Untersuchung}

Im anschließenden Kapitel II wird die reiche und lange Tradition des ,Buchs im Buch' in der Romanliteratur vorgestellt und einschlägige Beispiele von Romanen angeführt, die vor dem Untersuchungszeitraum dieser Arbeit nachhaltig das „Buch im Buch’ thematisiert haben. Die Vorstellung der Buch-Bücher erfolgt ab dem ausgehenden 18. Jahrhundert, als sich das Bürgertum emanzipierte und zur tonangebenden Gesellschaftsschicht wurde. Diese Umwälzungen bedingten gepaart mit einer Ausdifferenzierung des literarischen Marktes, neuen Bedingungen für Buchdruck und -verbreitung sowie neuen Lektürevorlieben des Bürgertums den Aufstieg des bürgerlichen Romans zum Leitmedium, dessen Erfolg zu verstärkter Selbstreflexion des eigenen Mediums führte.

In Kapitel III wird der analytische Hauptteil geboten, in welchem die Typologie des BuchMotivs untersucht wird. Ein vorgeschalteter theoretischer Teil erläutert zunächst die Zusammenstellung des Korpus, gibt eine Differenzierung der Begriffe ,Motiv' und ,Thema' und identifiziert dabei das Phänomen ,Buch im Buch’ als Motiv. Die Motivkomplexe, mit denen das Buch-Motiv kombiniert wird, um tragfähig für die Handlung zu wirken, werden in jeweils einem gesonderten Abschnitt erläutert. Die untersuchten Romane werden zudem in den Kontext des postmodernen Schreibens gestellt, denn viele Charakteristika des Buch-Motivs lassen sich auf postmoderne Schreibweisen zurückführen. Außerdem werden die Leserprotagonisten der fiktionalen Ebene typologisiert und dem realen heutigen Leser gegenübergestellt.

Die aus der Motivuntersuchung gewonnenen Thesen werden in Kapitel IV aufgegriffen und in den Zusammenhang der Frage nach der heutigen Stellung des Buchs gestellt. Zunächst wird die interne Funktion des Buchs in den Romanen untersucht und damit eine Zusammenfassung der Ergebnisse der typologischen Motivuntersuchung gegeben. Anschließend wird neben der internen besonders der externen Funktion des Buch-Motivs nachgegangen, nämlich wie es in die Gesellschaft hineinwirkt. Somit wird nach den Gründen für das Phänomen ,Buch im Buch' geforscht, und dies aus Sicht der einzelnen Akteure der Buchbranche, besonders aber aus Sicht von Autoren und Lesern: Warum schreiben Autoren Bücher über Bücher und warum werden sie veröffentlicht und gelesen? Anschließend wird ein kurzer Abriss der aktuellen Situation des Buchs in der Medienlandschaft gegeben, wobei besonders das heutige Buchkäufer- und Leserverhalten berücksichtigt wird. Zudem werden die Reaktionen der Instanzen des Buchmarkts auf digitale Möglichkeiten vorgestellt, die das Potential besitzen, deren originäre Aufgaben wie Publikation und Marketing von Büchern zu übernehmen. Ein Ausblick auf eine mögliche Zukunft des Buchs angesichts massiver medialer Konkurrenz rundet die Untersuchung ab. Den Abschluss in Kapitel V bildet eine Zusammenfassung der bisher aufgestellten und diskutierten Thesen und Ergebnisse. 


\section{Fiktionale Darstellungen des ,Buchs im Buch' bis in die 1990er Jahre und postmoderne Einflüsse auf die Verwendung des Motivs}

Das literarische Phänomen des ,Buchs im Buch’ gibt es, seit es Bücher gibt, bis in die heutige Zeit. In diesem Kapitel werden literarische Darstellungen des „Buchs im Buch’ seit der Etablierung des Romans als Leitgattung auf dem deutschen Buchmarkt Ende des 18. Jahrhunderts vorgestellt. Dies liegt darin begründet, dass Buch und Literatur als Motiv (vgl. Kap. III.1.1.2.1) stets in fiktionaler Literatur, nämlich Romanen, auftreten. Schlaglichtartig werden im Folgenden fiktionale Darstellungen von Büchern, bzw. ihren Vorgängern, nämlich Pergamenten oder Handschriften, in besonderen motivischen und literaturhistorischen Kontexten gezeigt, und zwar nach thematischen Aspekten gegliedert. Zuvor wird erläutert, wie sich der Roman im späten 18. Jahrhundert zur Leitgattung auf dem deutschen Buchmarkt herausbildete, denn der Aufstieg des Romans war Auslöser für die vielfache Selbstthematisierung von Buch und Literatur. Die vorgestellten literarischen Darstellungen des Buchs bringen zum Ausdruck, dass das Buch immer auch Gegenstand im eigenen Medium war und ist - in dieser literarischen Tradition stehen auch die heutigen Buch-Bücher. Die vorgestellten Romane sind sozusagen die Vorgänger der Titel, anhand derer in Kap. III das Motiv „Buch im Buch’ geordnet nach Motivgruppen untersucht wird.

\section{Der Roman etabliert sich auf dem deutschen Buchmarkt}

\subsection{Der Roman wird zur Leitgattung}

Im späten 18. Jahrhundert erlangte das Medium Buch eine wachsende Bedeutung für sämtliche Instanzen des damaligen Buchmarkts ${ }^{38}$. Es wurde zum Leitmedium unter den Printmedien und überflügelte damit sogar noch die Gelehrten Zeitschriften und Journale, die als Rezensionsorgane zuvor über Jahrzehnte maßgebliches Medium des modernen bürgerlichen Selbstverständnisses gewesen waren. Obwohl der Roman seit jeher schlecht beleumundet war, als unmoralisch galt und keine Legitimierung in der aristotelischen Poetik fand, wurde er zur beliebtesten Buch-

38 Die Umwälzungen, die die bekannten Umstrukturierungen auf dem Buchmarkt sowie die bürgerliche Emanzipation und Veränderung der bürgerlichen Lektürepraxis um 1800 - erwähnt sei hier nur die Romanund ,Lesesucht' - nach sich gezogen haben, sind bereits an anderer Stelle hinreichend diskutiert worden, u. a. bei Rolf Engelsing: „Die Perioden der Lesergeschichte in der Neuzeit. Das statistische Ausmaß und die soziokulturelle Bedeutung der Lektüre“. In: Archiv für Geschichte des Buchwesens 10, 1969, Sp. 944-1002; Ders: Der Bürger als Leser. Lesergeschichte in Deutschland 1500-1800. Stuttgart: Metzler, 1974; Günter Erning: Das Lesen und die Lesewnt. Beiträge zu Fragen der Lesergeschichte, dargestellt am Beispiel der schwäbischen Provinz: Bad Heilbrunn: Klinkhardt, 1974; Rudolf Schenda: Volk obne Buch. Studien zur Sozialgeschichte der populären Lesestoffe 1770-1910. Frankfurt: Klostermann, 1970 oder besonders bei Erich Schön: Der Verlust der Sinnlichkeit oder Die Verwandlungen des Lesers. Mentalitätswandel um 1800. Stuttgart: Klett-Cotta, 1987. 
gattung - die er auch heute noch ist -, so dass die Begriffe „Buch“ und „Roman“ im Kontext des Lesens zur Unterhaltung damals wie heute weitgehend synonym gebraucht werden.

Die Durchsetzung des Romans zur Leitgattung verdankt sich der Entwicklung des modernen Bürgertums im ausgehenden 18. Jahrhundert ${ }^{39}$. Während der Begriff ,Bürger’ zuvor Rechtsposition und Stand im städtischen Gefüge bedeutete, ist der moderne Bürger nicht mehr in die ständische Gesellschaft integriert. Vor allem Beamte zählten in Deutschland zu diesen neuen Bürgern. Die Gründe für den Aufstieg des Romans sind in den gesellschaftlichen Umwälzungen der Zeit zu suchen. Die einsetzende Transformation der Ständegesellschaft setzte neue Möglichkeiten von Identität und Öffentlichkeit frei. Für beide spielen die (Massen-)Medien eine zentrale Rolle. Die (Druck-)Medien, vor allem Gelehrte Zeitschrift und Roman, wurden zum Ausdruck und Instrument der Emanzipation und Individualisierung des modernen Bürgertums und der Abgrenzung des Einzelnen nach oben (zum Adel) und unten (zum Volk). Das Buch, also weitgehend der Roman, wurde so zum identitätsstiftenden Kommunikationsmedium der Bürger. Mit dem modernen Bürgertum entsteht ein neues literarisches Publikum und zwar aufgrund seiner Werte, seiner Lebensweise und -bedingungen. Der Bürger instrumentalisierte Bildung und Literatur zunächst zur Erlangung seines Amtes, bevor er sie an sich wertschätzte, u. a. zur Profilierung gegenüber dem Adel. Außerdem verfügte der Bürger über die nötigen finanziellen Ressourcen, um an der literarischen Kommunikation teilzunehmen, für den Buchkauf ebenso wie für die Leihgebühr einer Bücherei oder die Mitgliedschaft in einer Lesegesellschaft. Was stattfand, war der „faszinierende Prozeß des Übergangs vom Analphabetentum zur Lektüre ${ }^{\text {“40 }}$, wobei zum einen eine mit der heutigen vergleichbare Leserschaft von Romanen entstand, zum anderen der heutige Literaturbegriff ${ }^{41}$.

Damit einhergehend veränderten sich die Lektürevorlieben und -praxis des bürgerlichen Lesepublikums: Der moderne Bürger las anders und anderes als seine Ahnen. Das bürgerliche Lesermilieu entdeckte Bücher, neben ihrer Eigenschaft als Bildungslieferanten, auch als Unterhaltungsobjekt und Zeitvertreib. Der Roman entwickelte sich speziell für bürgerliche Interessen und hier besonders für weibliche Bedürfnisse, denn damals wie heute lasen vor allem Frauen Romane zur Unterhaltung, während Männer noch mehr als Bücher Zeitung lasen, um sich zu informieren. Die „bürgerliche ,Arbeitsteilung’ von Mann und Frau““42 ermöglichte der Frau mehr Zeit für die Romanlektüre, das Lesen über fiktive Aktivitäten kompensierte jedoch auch ihre Handlungs-

39 Vgl. dazu und für das Folgende Schön (1987), S. 41. - Von der hier erläuterten Auffassung eines modernen Bürgertums unterscheidet sich der Begriff ,Bürger' heute deutlich und meint u. a. den gesellschaftlichen Status einer Zivilperson im Gegensatz zur einer Instanz des Staates.

40 Bernhard Fabian: „Der Gelehrte als Leser“. In: Herbert Göpfert (Hg.): Buch und Leser. Vorträge des ersten Jahrestreffens des Wolfenbütteler Arbeitskreises für Geschichte des Buchwesens, 13.-14. Mai 1976. Hamburg: Hauswedell, 1977, S. 48-88, hier S. 48.

41 Vgl. Schön (1987), S. 41.

42 Ebd., S. 42 
unfähigkeit. Der bürgerliche Leser des 18. Jahrhunderts war kein gelehrter Leser, auch kein professioneller, dessen Alltag vom Lesen bestimmt wurde, ihm stand nur die Freizeit zur Lektüre zur Verfügung, ein Begriff, der zu dieser Zeit zur Unterscheidung von täglichen Arbeitsphasen entsteht. Lesen muss der Bürger mit Alltag und Arbeit in Einklang bringen. Die Zeit eines kleinen, als Hausschatz gehüteten Kanons an religiöser Lektüre, die immer wieder intensiv gelesen und sogar auswendig gelernt wurde, war vorbei - der Bürger begann, nach immer neuem Lesestoff zu verlangen und extensiv zu lesen. Daraus folgte, dass sich das Romanangebot drastisch wandelte ${ }^{43}$.

Die neue Einstellung des bürgerlichen Lesepublikums zu fiktionaler Lektüre ging mit dem wachsenden, sich wandelnden Buchmarkt eine fruchtbare Wechselbeziehung ein. Romane steuerten 1770 4\% des gesamten Buchangebots bei, im Jahr 1800 hatte sich ihr Anteil bereits so gut wie verdreifacht und machte nun 11,7\% der Gesamtproduktion aus ${ }^{44}$. Hinzu kommt, dass der Anteil der in deutscher Sprache erschienenen Titel in diesem Jahr fast 97\% ausmachte. Der Buchmarkt stand nun also einer breiten Leserschaft offen, nicht nur der gelehrten kulturellen Elite. Auch die Verleger wurden sich der Ökonomie des Buchs mehr und mehr bewusst und erkannten, wie man mit Romanen gutes Geld verdienen konnte. Das Buch wurde als Ware und einträgliches Handelsobjekt wahrgenommen, als Teil einer entstehenden modernen „Kulturwarenindustrie ${ }^{\text {“45 }}$. Die Etablierung des Netto- und späteren Konditionsbuchhandels im späten 18. Jahrhundert, schlechthin der Wandel vom reinen Tauschgeschäft hin zur Geldwirtschaft im Buchhandel, läutete ein „dem buchhändlerischen Wesen völlig fremdes, kaufmännisches’ Zeitalter“446 ein.

Der private Besitz von Büchern, gerade auch von modischer Lektüre, wuchs - man versenkte sich geradezu in fiktionale Welten. Damit einher ging ein ganz neuer Begriff des Lesens und des Gelesenen. Der Protagonist war nun nicht mehr nur ideales und moralisches Beispiel für ein gelungenes Leben, sondern ein bürgerlicher Held, dessen Lebenswelt der des Lesers entsprach. Auf diese Weise konnte man sich in den Protagonisten besser hineinversetzen, sich mit ihm identifizieren und mit seinem Schicksal mitfiebern. Die immer größere Nachfrage nach immer neuem Lesestoff begünstigte auch eine Umwälzung des Buchmarkts, der wiederum die frühe Form eines Massenmarkts hervorbrachte. In einer Zeit, in der Buchmarkt, Lektüre und Lesegewohnheiten solch tiefgreifenden Entwicklungen unterzogen waren, war die (Selbst-)Thematisierung von Lesen und Büchern besonders ergiebig und literarische Lesedarstellungen, besonders solche des ,lesenden Helden', florierten.

43 Vgl. zu neuen Bedingungen des Literaturmarktes in der ,Sattelzeit' Schön (1987), S. 43-46.

44 Vgl. dazu Reinhard Wittmann: Geschichte des deutschen Buchhandels. München: Beck, 1999, S. 123.

45 Ebd., S. 121.

46 Johann Goldfriedrich: Geschichte des deutschen Buchhandels vom Beginn der klassischen Litteraturperiode bis zum Beginn der Fremdherrschaft (1740-1804). Leipzig: Verlag des Börsenvereins der Dt. Buchhändler, 1909, S. 271. 


\subsection{Kritik an der, Vielleserei'}

Lesen oder auch nur die Fähigkeit dazu waren nicht immer erwünscht. Es mehrten sich bei weltlichen und kirchlichen Autoritäten die Sorge um die Verbreitung der allgemeinen Lesefähigkeit, die aufrührerische Tendenzen nach sich ziehen konnte, in der literarischen Öffentlichkeit Unbehagen und Unverständnis angesichts der Expansion und Ausdifferenzierung des Buchmarkts und in gelehrten Eliten die Ablehnung des Romans, der die berüchtigte ,Lesesucht' oder ,Lesewut' gerade unter Frauen und jungen Männern entfachte ${ }^{47}$. Der Begriff „Lesesucht“ wurde zum ersten Mal in Rudolf Heinrich Zobels Briefe über die Erziebung der Frauenżimmer (1773) erwähnt, wobei Lesesucht und Lesewut nur Teile einer größeren Debatte zum Lesen überhaupt waren. Skepsis gegenüber dem Lesen gibt es, seitdem gelesen wird, und die Erörterung der Frage, wie viel und vor allem was gelesen werden sollte, reicht bis in unsere Zeit hinein.

Spätestens mit dem Erfolg von Goethes Werther (1774) und dem damit einsetzenden Durchbruch des Romans im deutschsprachigen Raum begann eine Debatte um ,falsche' Lektüre - die falsche Art zu lesen ist ebenso gemeint wie die falschen Texte - sowie um die Gefährlichkeit des Lesens überhaupt (vgl. Kap. III.5). Die gängigen Vorurteile gegen den Roman standen vielfach in bester aufklärerischer Tradition, die moralische Ansprüche an Texte und Leser stellte. Im Rahmen des expandierenden Buchmarkts würde der Leser jedoch nur nach immer mehr Lesematerial verlangen und das Gelesene nur unreflektiert, verschlingen'. ,Vielleserei’ wurde als intellektuelle Faulheit angesehen, da zwar sehr viel und sehr viele einzelne Texte gelesen wurden, man sich aber kaum die Mühe machte, das Gelesene ganz aufzunehmen, gar auswendig zu lernen, wie es zuvor üblich war, und gründlich durchzuarbeiten. ${ }^{48}$ So könne der Geist die Informationsmassen nicht verarbeiten und der Körper durch die passive, meist sitzende Beschäftigung während der Lektüre Schäden davontragen.

Die ,schöne Literatur' wurde aus mehreren Gründen besonders misstrauisch beäugt: Zum einen aus poetischen Gründen, denn sie stand traditionell im Verdacht des Trivialen, zum anderen aus moralischen. Ein religiös-moralischer Vorwurf gegen das Romanlesen war die Verführbarkeit des Lesers. Außerdem halte die ,Vielleserei’ den Leser von vernünftigen oder nützlichen Tätigkeiten und Gedanken ab, er verschwende nur seine Zeit, und umgekehrt: Wer Zeit für den Luxus der ,nutzlosen’ schöngeistigen Lektüre erübrigen könne, sei wohl im Alltag nicht ausgelastet. Überdies entfremde das Einfühlen in fiktionale Welten den (empfindsamen) Leser schließlich

\footnotetext{
47 Vgl. zur Lesesuchtdiskussion Schön (1987), S. 46-49 und zu den Argumenten gegen die Lesesucht Erning (1974), bsd. S. 80-89. - Eine umfassende Darstellung mit Zitaten aus einschlägigen Polemiken gegen das übermäßige Lesen bietet Dominik von König: „Lesesucht und Lesewut“. In: Göpfert (1977), S. 89-124.

48 Vgl. Paul Goetsch: „Von Bücherwürmern und Leseratten. Der Motivkomplex Lesen und Essen“. In: Literaturwissenschaftliches Jahrbuch 37 (1996), S. 381-406, hier S. 392.
} 
derart von der Realität, von seinen alltäglichen familiären, ökonomischen, politischen und religiösen Pflichten, dass er zu einem nützlichen Leben nicht mehr in der Lage sei. Als besonders von der Lesesucht betroffen galten Frauen und junge Männer, die (noch) nicht im Berufsleben verankert und in der Gesellschaft etabliert waren.

\subsection{Das ,Buch im Buch’als neuer Weg des Erzählens}

Um 1800 wird Literatur in der Literatur immer häufiger reflektiert. Die Gründe dafür liegen in der neuen Etablierung des Romans und der Lektüre überhaupt: Angesichts der Neuerungen von Lesestoffen und -gewohnheiten werden fiktionale Inhalte, die dies thematisieren, populär. Die Gattung, in der Literatur reflektiert wird, ist wiederum der Roman: „Als sich allererst etablierende Gattung hat der Roman wie keine andere Gattung des 18. Jahrhunderts Literatur zu seinem Thema gemacht. ${ }^{\text {“49 }}$ Die Lektüre von Büchern gewinnt eine immer stärkere Bedeutung nicht nur im privaten Bereich, sondern auch im gesellschaftlichen Leben, im Austausch über die Lektüre. Die Literatur des bürgerlichen Zeitalters emanzipierte sich gegenüber den überkommenen literarischen Vorbildern, wie denen aus der Antike, und entwarf ihre eigenen Themen, die die Zeitumstände, und eben die Umstürze auf dem Buchmarkt reflektierten ${ }^{50}$, von denen die Autoren unmittelbar betroffen waren und daher großen Anteil hatten.

Mit der Selbstthematisierung von Lektüre im Roman beginnt sich auch das Buch in fiktionalen Darstellungen zu etablieren. Doch kann das Buch nicht allein auftreten, da es sonst einfach ein Gegenstand wäre. Das Buch benötigt in der Fiktion wie in der Wirklichkeit die Kombination mit anderen Motiven und vor allem mit dem Leser, denn erst dieser lädt das Buch durch seine Auseinandersetzung mit dessen Inhalt mit Bedeutung auf. Deshalb wird in der Literatur das Auftreten des Buchs stets mit einer Leserfigur verknüpft, mitunter auch als Satire oder als Warnung vor einem möglichen Realitätsverlust durch ein Sich-Verlieren in den fiktionalen Welten.

\subsubsection{Herausgeberfiktionen}

Zu den Büchern, die Bücher zum Gegenstand machen, gehören auch Herausgeberfiktionen, die in der Literatur des späten 17. Jahrhunderts erfunden werden. Das Verschachteln von Büchern in Büchern, wie es in Herausgeberfiktionen üblich ist, ist laut Japp „die hermetische Geste par excellence“ ${ }^{\text {551 }}$. Die Grenzen zwischen Fiktion und Wirklichkeit lösen sich für den Leser auf, da die Wahrscheinlichkeit des Fiktionalen erhöht wird. Die Herausgeberfiktionen legitimieren sich durch angebliche Manuskriptfunde, die der Erzähler in der Handlung vorgeschalteten Kommentaren

\footnotetext{
49 Friedhelm Marx: Erlesene Helden. Don Sylvio, Werther, Wilhelm Meister und die Literatur, 1995, S. 49 , nicht eingesehen, zitiert nach Stocker (2007), S. 79.

50 Als Beispiel für einen Roman, der den Literaturbetrieb des 18. Jahrhunderts karikierend darstellt, sei hier Friedrich Nicolais Das Leben und die Meinungen des Herrn Magister Sebaldus Nothanker (1773/76) genannt.

51 Japp (1975), S. 655.
} 
erläutert. Sie stellen die Vorläufer der Bücherfunde in den Titeln aus dem hier untersuchten Korpus dar. Ein weltberühmtes Beispiel hierfür ist Robinson Crusoe (1719). In der Absicht, dem Vorwurf mangelnder Seriosität und Unglaubwürdigkeit zu entgehen, authentifiziert der Autor Daniel Defoe seine Geschichte mit dem Hinweis auf Originalaufzeichnungen des Protagonisten Robinson Crusoe, die ihm vorliegen und die er nur noch in der Funktion eines Herausgebers zur Publikation bereitstellen müsse. Ein weiteres Beispiel für eine frühe Herausgeberfiktion ist Grimmelshausens Simplicissimus (1668): Ein Kapitän habe die von Simplicissimus selbst verfasste Geschichte seines Lebens mit in seine Heimat genommen und dem Adressaten German von Schleiffheim (ein Anagramm zu Christoffel Grimmelshausen) zur Veröffentlichung übergeben.

Der Manuskriptfund kann auch in der Rahmenhandlung durch den Erzähler eingeführt werden. Dies erhöht den Wirklichkeitsbezug und die Glaubwürdigkeit der Binnenhandlung, was paradoxerweise dadurch geschieht, dass eine weitere fiktionale Ebene, nämlich die Rahmenhandlung, eingefügt wird. Die Fiktion führt vor, wie jemand, häufig auf Reisen, zu einem Buch oder Manuskript gelangt, in dem von einer wahren Begebenheit, einer „Geschichtsbeschreibung“652, berichtet wird. Dies ist der Fall in Insel Felsenburg von Johann Gottfried Schnabel (1731), der das Manuskript schließlich unter seinem Namen der Öffentlichkeit zugänglich gemacht hat.

Außer den vorgeblich wahren Berichten, die keine Romane, also nicht fiktive Geschichten sein wollten, waren auch - kaum verschlüsselte - Schlüsselromane über tatsächliche private oder Öffentliche Ereignisse populär, die leicht als Wiedergabe eines aktuellen Skandals oder brisanter Details der Innenpolitik des jeweiligen Publikationslandes entlarvt werden konnten ${ }^{53}$. Neben die vorgeblich wahren öffentlichen und privaten Historien, die tatsächlich jedoch Roman und Erfindung waren, wie La Guerre d'Espagne (1707) und Robinson Crusoe (1719), traten nun tatsächlich wahre öffentliche und private Historien, die als Fiktion zu lesen waren, wie Menantes' Satyrischer Roman (1706) und Manleys New Atalantis (1709). Wie viel des Berichteten ist wahr? Wie viel des Erdichteten ist erfunden? Affaires publiques werden als erfunden bezeichnet, während Romane, also Erdichtetes, als wahr betont und so glaubhafter gemacht werden. Fiktion und Realität werden einerseits als unabhängige Territorien aufgefasst, deren Diskrepanz ja gerade die Spannung für den geübten Leser ausmacht, andererseits verschwimmen ihre Grenzen, so dass von hermetischer Literatur an dieser Stelle nicht die Rede sein kann.

Mit den Herausgeberfiktionen werden anspruchsvolle literarische Methoden als Stilmittel genutzt, die das zeitgenössische Leseverhalten reflektieren, da auch der Leser durch seine vermehrte

\footnotetext{
Johann Gottfried Schnabel: Die Insel Felsenburg, Frankfurt/Main: Insel, 1988, S. 11.

53 Vgl. Olaf Simons: Marteaus Europa oder Der Roman, bevor er Literatur wurde. Eine Untersuchung des deutschen und englischen Buchangebots der Jahre 1710 bis 1720. Editions Rodopi: Amsterdam \& Atlanta, 2001, S. 194-198 sowie die folgenden Kapitel.
} 
Übung im Lesen von Romanen besser mit Fiktion umgehen kann und nach für ihn reizvoller und elaborierter Lektüre verlangt. Die Autonomisierung von Literatur in der Literatur bietet hier einen guten Weg, der auch heute noch beschritten wird, wenn literaturtheoretische Konzepte in Romanen reflektiert werden. Mit der Entwicklung von Theorien zur Literatur schreitet auch die Entwicklung der Art, Romane zu schreiben und zu lesen, voran.

\subsubsection{Der Autor wird sichtbar - Autorenverehrung}

Nicht immer wurde Fiktion aber auch als solche verstanden. Gerade eine empathische Art zu lesen führte dazu, dass der Leser kaum dazu in der Lage war, zwischen Autor und Erzähler zu unterscheiden. Um dies zu illustrieren, sei hier die Verehrung für Jean-Jacques Rousseau erwähnt, die gerade seit der Veröffentlichung von Julie ou la Nouvelle Héloïse (1761) einsetzte. Durch zwei Vorworte zur Nowvelle Héloïse steuerte Rousseau die Lektüre seiner Leser, denn sein Ziel war es, in das Leben seiner Leser hineinzuwirken und so die Fiktion plausibel zu machen ${ }^{54}$. Er erklärt darin erstens, wie er so etwas Gewagtes, da tendenziell Unmoralisches - einen Roman zu schreiben tun konnte und führt zweitens in den Roman ein, indem er erläutert, wie dieser zu lesen sei: Nämlich als wahre Geschichte zweier Liebender, die in (tatsächlich geschriebenen) Briefen mitgeteilt werde, welche Rousseau lediglich herausgebe. Die Leser wurden angeleitet, sich in die Figuren hineinzuversetzen und deren Gefühle, aus deren Schilderung ein Großteil des Romans besteht, förmlich nachzuempfinden, heute würden wir sagen: empathisch und identifikatorisch zu lesen. Das erklärt die Tränen, die laut zahlreichen zeitgenössischen Schilderungen während der Lektüre reichlich geflossen sein sollen, und die für die damalige Literatur völlig neue Bindung der Leser an den Autor. Die Leser wollten sich von „Freund Jean-Jacques“ ${ }^{\text {“55 }}$, der so lebensnah über Liebe, Leben und Familie schrieb, sogar Ratschläge für ihr eigenes Leben geben lassen und waren nicht nur an seinem Werk, sondern auch an seiner Person überaus interessiert. Das Unvermögen, zwischen Literatur und Realität zu differenzieren, wurde durch Rousseau provoziert, und die Leser haben mitgespielt. Auch in den Romanen um Bücher lesende Helden oder Büchernarren wird dieses Unvermögen thematisiert und karikiert, außerdem seine schädlichen Folgen aufgezeigt.

\footnotetext{
54 Vgl. Robert Darnton: „Leser reagieren auf Rousseau: Die Verfertigung der romantischen Empfindsamkeit“. In: Ders.: Das große Katzenmassaker. Streifz̈̈̈ge durch die franz̈öische Kultur vor der Revolution. München: Hanser, 1989, S. 245-285, hier S. 266.

55 Ebd., S. 252.
} 


\section{Das absolute und das einzige Buch}

\subsection{Der romantische Roman}

Jens Schreiber definiert den Beginn des „Zeitalter[s] der Bücher ${ }^{\text {‘56 }}$, „wenn das Buch, | die Bücher, die Bibliothek zu dem Raum werden, in dem der Diskurs sich aufhält, seinen Bestand sichert, sich vermehrt, gegen sein Sterben arbeitet. ${ }^{* 57}$ Bücher waren um 1800 nicht nur Trägermedien für Debatten, sondern auch selbst Gesprächsthema.

In der romantischen Fiktion bildet die Reflexion von Schrift und Schreiben, und auch des Buchs, die Reflexion des eigenen Ichs durch die romantischen Autoren ab, die ihre Wurzeln wiederum in der Autonomieästhetik des 18. Jahrhunderts und in der idealistischen Philosophie Schellings und besonders Fichtes als Idol der Romantiker hat. An dieser Stelle kann nur verkürzt der Kern von Fichtes Philosophie wiedergegeben werden, nämlich, dass das Individuum, das ,Ich', im Mittelpunkt jeglicher Wahrnehmung stehe ${ }^{58}$. Im Zuge des Reflexionsprozesses des Ichs über sich selbst werde das Subjekt zum Objekt, woraus die Auffassung der „,romantischen Selbstvermittlung“ entsteht, die darüber nachsinnt, wie der Mensch, das Ich, über sich selbst und wiederum über diesen Denkprozess reflektieren kann. Nach Fichte konstruiert sich das Ich also durch die unendliche Analyse seiner selbst. Übersetzt in die Literatur bedeutet dies: Über das Schreiben schreiben und über das Lesen lesen. Die Ideen dieser romantischen Selbstreferenz und -reflexion tauchen in der Neoromantik ebenso wieder auf wie in der Postmoderne. Die Reflexion über die künstlerische Produktion als innerliterarische Selbstreflexion des Künstler-Ichs bildet einen der Eckpfeiler des postmodernen Schreibens (vgl. dazu Kap. II.9).

„Kaum eine romantische Erzählung verzichtet darauf, Schrift oder Schreiben, das Requisit des Buches oder zumindest den Akt der Imagination zum Thema zu machen“"59, bringt es Detlef Kremer auf den Punkt. In der Romantik spielte das Buch eine ganz eigene Rolle als Reflexionsobjekt, besonders der Roman, den die Romantiker mit Friedrich Schlegel als ein „romantisches Buch“60 betrachteten. Schlegel forderte ein „Buch schlechthin, [ein] absolutes Buch, in dem ,alle Bücher nur Ein Buch sein“ sollten, wie die Bibel, die zwar aus mehreren Büchern zusammengefasst ist, doch als vollkommenes, harmonisches Ganzes erscheint. ${ }^{61}$ Als absolutes, nicht mehr

56 Friedrich Schlegel: „Brief über den Roman“. In: Ders.: Kritische Friedrich-Schlegel-Ausgabe. Hg. v. Ernst Behler. Bd. 2: Charakteristiken und Kritiken I (1796-1801). Hg. u. eingel. v. Hans Eichner. Paderborn: Schöningh, 1967, S. 329-339, hier S. 332.

57 Schreiber (1983), S. 131.

58 Vgl. zu Fichtes Philosophie den Artikel „Fichte“ in Wilhelm Weischedel: Die philosophische Hintertreppe. München: dtv, 2001, S. 188-199.

59 Detlef Kremer: Romantische Metamorphosen. E.T.A. Hoffmanns Erzählungen. Stuttgart \& Weimar: Metzler, 1993, S. $13 f$.

60 Friedrich Schlegel: „Brief über den Roman“. In: Schlegel (1967), S. 335.

61 Vgl. dazu Friedrich Schlegel: „Ideen [95]“. In: Schlegel (1967), S. 256-272, hier S. 265. - Vgl. zur Idee des absoluten Buchs auch Hans Blumenberg: Die Lesbarkeit der Welt. Frankfurt/Main: Suhrkamp, 1981, S. 267-280. 
überbietbares und vollkommenes Buch sollte der romantische Roman der von Schlegel geforderten progressiven Universalpoesie entsprechen und als fortschreitende, allumfassende Transzendentalpoesie alle Stile, Gattungen und Dichtungsarten in sich vereinigen. Goethes Wilhelm Meisters Lehrjabre (1795/96) hatte aufgrund dessen für den romantischen Roman eine besondere Vorbildfunktion inne und wurde zu einem der zentralen geistigen Ausgangspunkte der neuen romantischen Bewegung. Friedrich Schlegel sah in ihm neben Fichtes Wissenschaftslehre (1793) und der Französischen Revolution eine der „größten Tendenzen des Zeitalters“62, also neben der geistigen und der politischen Erneuerung eine ästhetisch-literarische, die eine Poesie der Poesie ins Zentrum stellte.

Nach Schlegels Überzeugung stellte der Roman die absolute romantische Poesie dar ${ }^{63}$. So konnte der Roman dazu dienen, an den Ursprung aller Poesie zurückzukehren und Individuelles mit dem Universalen zu einer neuen Mythologie zu vereinen. Der absolute Roman war für Schlegel dazu in der Lage, die verlorene Einheit mit dem Universalen und so das verlorene Goldene Zeitalter wiederherzustellen. Zwar ist der Roman vollkommen und ,absolut', doch ist er auch unbeschränkt, unendlich, ,progressiv' und kann nie vollendet werden. Was dem Roman zuvor zum Nachteil gereichte, nämlich die fehlende Verankerung in der traditionellen Poetik, wurde nun von Schlegel als Gewinn aufgefasst: Der Roman als neue Gattung der Dichtung konnte das neue, progressive Element des romantischen Dichtungsideals bestens verkörpern.

In einer als verschlüsselt wahrgenommenen Welt ist der Mensch weit entfernt vom Goldenen Zeitalter, da er sich von der Natur und dem Universum entfernt hat und entfremdet fühlt. Die Welt wird nicht mehr unmittelbar verstanden, alles ist nur über vermittelnde Instanzen auszumachen, selbst die Natur erscheint als Buch, dessen Chiffren erst entziffert werden müssen. Das Buch gewinnt in diesem Kontext für die Romantiker eine neue Bedeutung, da es die bisher selbstverständliche Tradition der kollektiven und familiären mündlichen Überlieferungen ersetzt und fortführt. Nur über das absolute Buch könne die verloren gegangene Einheit zwischen Mensch und Natur, Mensch und Universum wiederhergestellt werden. Alles Wissenswerte wird nun über das Medium Buch weitergegeben, mit dem eine Sinnhaftigkeit hergestellt werden konnte, die in der Welt verloren gegangen war $^{64}$. Für diese „Literarisierung des Daseins“665 oder ,Romantisierung der Welt' bildete die romantische Weltsicht den Ausgangspunkt. Sie führt über

62 Friedrich Schlegel: „Athenäums-Fragmente [216]“. In: Schlegel (1967), S. 165-255, hier S. 198.

63 Vgl. für das Folgende Gerhart Hoffmeister: „Der romantische Roman. 1. Theorie“. In: Helmut Schanze (Hg.): Romantik-Handbuch. 2., durchges. u. akt. A. Stuttgart: Kröner, 2003, S. 208-212.

64 Vgl. dazu Marianne Kesting: „Aspekte des absoluten Buches bei Novalis und Mallarmé“. In: Euphorion 68 (1974), S. 420-436, hier S. 431.

65 Ralph-Rainer Wuthenow: „Lesende Figuren: Die Bücher im Buch“. In: Neue Rundschau 2 (1989), S. 152-162, hier S. 157. 
Mallarmés Aussage, die ganze Welt sei da ,pour aboutir à un livre ${ }^{666}$ bis hin zu Jorge Luis Borges' Bibliotheksuniversum. Borges sieht die Bibliothek als Universum und das Universum als Bibliothek („,Das Universum, das andere die Bibliothek nennen ${ }^{667}$ ), in der alles Wissen angesammelt ist.

Die Bücher selbst stellen ein Mysterium dar, das es durch Lesen, als Interpretation von Zeichen und Chiffren, zu entziffern gilt. Die Unzugänglichkeit kann durch Lektüre aufgebrochen werden. Lesen ist also ein produktiver Prozess, die Welt auszulegen und sie sich über die Literatur anzueignen, zum hermetischen Raum des Buchs gilt es also nun, einen Zugang zu finden. Das Buch wird auch in der Fiktion mit Rätselhaftem in Verbindung gebracht oder mit der Vermittlung von geheimem Wissen. Hier liegt schon die Begründung dafür, dass das Buch heute so häufig in Romanen der Spannungs- und Mystery-Literatur ${ }^{68}$ vorkommt. Das Abenteuer des Geistes, das die Denkrätsel der Selbstthematisierung und Doppelungen in Buch-Romanen nach sich ziehen, wird in rätselhaften und abenteuerlichen Genres adäquat umgesetzt. Um 1800 tritt das Buch oft im Geheimbundroman auf und wird nach Etablierung dieses Genres einer seiner festen Bestandteile. Das Buch wird mit dem Genre gekoppelt, es wird nun in neuen Vertretern des Genres als Geheimnisträger regelrecht erwartet.

Novalis sieht die Existenz der Menschen in einem „colossale[n] Roman“, das Leben als einen „Von uns gemachte[n] Roman“699 - nicht mehr als Welttheater, denn zum Leitmedium ist um 1800 der Roman geworden. Einen ähnlichen Wechsel können wir in der heutigen, Wissensgesellschaft' ausmachen: Borges sieht die Bibliothek als Universum des Wissens, aber nicht mehr als Sammlungspunkt fiktionaler Literatur.

\subsection{Das Buch als Lebensbuch - Novalis'Heinrich von Ofterdingen (1802, posthum)}

Die Auffassung des Buchs als Unikat, als das besondere, einzige Buch, stammt aus den Anfängen der Buchherstellung, in der jeder Codex als einzigartige Handschrift erstellt wurde. Den singulären und kostbaren Charakter unterstreichen häufig verfeinerte Buchilluminationen. Um eine solche langwierige und aufwändige Arbeit zu rechtfertigen, musste der Inhalt etwas Besonderes sein, und so sind viele Manuskripte der Heiligen Schrift, als Grundlage der christlichen Buchreligion,

66 Stéphane Mallarmé: CEuvres complètes. Paris, 1945, S. 378 und 872, nicht eingesehen, zitiert nach: Japp (1975), S. 667.

67 Borges, Jorge Luis: „Die Bibliothek von Babel“. In: Ders.: Die Bibliothek von Babel. Erzählungen. Stuttgart: Reclam, 1974, S. 47-57, hier S. 47.

68 Die Bezeichnung „Mystery“ für ein Romangenre, das unheimliche, paranormale Begebenheiten in der Alltagswelt schildert und mit Spannungselementen kombiniert, ist in Deutschland erst seit einigen Jahren gebräuchlich. Zuvor wurde der Begriff von den USA ausgehend für Filme geprägt. Durch die Vermischug von Übernatürlichem und Alltagswelt ist das Genre mit dem Magischen Realismus verwandt. Das Mystery-Genre ist hybrid, da es Elemente mehrerer Genres verwendet, wie solche des Krimis, Horrors oder der Fantasy. Das Unheimliche wird hier subtiler gezeichnet als im Horror-Genre, denn es geht vorrangig um das Lösen geheimnisvoller Rätsel, vgl. Waldkirch (2007), S. 18-21.

69 Wuthenow (1989), S. 161. 
vorbehalten. Das so mühevoll hergestellte und prächtig ausgestattete Buch war nicht nur Leseobjekt, sondern erst recht Wertobjekt.

Es war die Erfindung des Buchdrucks durch Gutenberg, die das Ende des Buchs als kostbares Einzelstück markierte. Der Druck initiierte die neue Möglichkeit, einen Text vielfach in immer gleicher Form zu reproduzieren. Ein gedruckter Text war auf diese Weise gegenüber den elitären Handschriften verhältnismäßig preiswert zu bekommen, das Buch konnte so zur Ware werden und neue Käufer- und Leserschichten erschließen, das gedruckte Wort überhaupt ein größeres und neues Publikum finden, z. B. über Flugschriften.

Als Grundmuster für die Vorstellung des ,absoluten Buchs', das in der Fiktion vorkommt, dient die Bibel. Obwohl selbst ein Konglomerat ganz heterogener Texte unterschiedlicher Autoren, bildet sie dennoch als Buch, in dem sich alle anderen finden, eine Einheit, die über Jahrhunderte hinweg kulturstiftend gewirkt hat. Die romantische literarische Darstellung des ,Buchs im Buch' zeigt, dass die Identitätssuche jedoch nicht allein durch die Bibel bestimmt wird, die nicht mehr ausschließliche Instanz zur Anleitung für ein gelungenes Leben ist, noch wichtiger sind Selbstbestimmung und Selbsterkenntnis durch Erfahrungen.

Novalis sah seine Zeit als eine Zeit der Bücherflut und Lesewut ${ }^{70}$. Als Reaktion darauf kann man sich Novalis' Idealvorstellung eines absoluten, alle Bücher vereinenden Buchs denken, die er mit Schlegel teilte. Sein Heinrich von Ofterdingen war als Antwort auf Wilhelm Meister konzipiert, denn wie Meister im Archiv der Turmgesellschaft stößt auch Heinrich auf ein Buch mit den Aufzeichnungen seines Lebens. Er erkennt, dass sein Leben in diesen Schriften vorgezeichnet ist und dass er seine „Lehrjahre“ als Erfahrung benötigt, um Erkenntnis über die Welt und über sich selbst zu erlangen. Mit seinen zwei Teilen „Die Erwartung“ und „Die Erfüllung“ schließt Heinrich von Ofterdingen allerdings auch an die zwei Bibelteile an.

Der Roman schildert eine unendliche Steigerung in der romantischen Selbstvermittlung: Heinrich hat das Buch des Einsiedlers vor sich, wie der reale Leser den Roman Heinrich von Ofterdingen:

Endlich fiel ihm ein Buch in die Hände, das in einer fremden Sprache geschrieben war [...]. Es hatte keinen Titel, doch fand er noch beym Suchen einige Bilder. Sie dünkten ihm ganz wunderbar bekannt, und wie er recht zusah, entdeckte er seine Gestalt ziemlich kenntlich unter den Figuren. [...] Er sah sein Ebenbild in verschiedenen Lagen. ${ }^{71}$

Das aufgefundene Buch stellt Heinrichs „Lebensbuch“"72 dar, einen „Roman von den wunderbaren Schicksalen eines Dichters, worinn die Dichtkunst in ihren mannichfachen Verhältnissen dar-

70 Vgl. Nelles (2000), S. 242f.

71 Novalis: „Heinrich von Ofterdingen. 1. Teil: Die Erwartung““. In: Werke, Tagebücher und Briefe.

Hg. v. Richard Samuel. Bd. 1: Das dichterische Werk, Tagebücher und Briefe. München: Hanser, 1978, S. 312.

72 Der Begriff des „Lebensbuchs“ erscheint zuerst in den Nachtwachen des Bonaventura. 
gestellt und gepriesen wird.“73 Es ist an ihn adressiert, und nur er ist dazu in der Lage, die Bedeutung der Bilder für sein Leben zu erkennen, da nur er sämtliche dargestellte Figuren kennt. Die „fremde Sprache“ kann er noch nicht entziffern, da er der (Dicht-)Kunst noch fern ist. Im Buch findet Heinrich seine eigene Geschichte wieder, wobei das Buch zeitlos ist und den Fluchtpunkt für Heinrichs Leben bildet, in dem Vergangenheit und Zukunft zusammengeführt werden. Er erkennt darin vor allem seine Zukunft, die entsprechend der Bilder im weiteren Verlauf des Romans erzählt wird. Im Anschluss an die Lektüre verläuft sein Leben tatsächlich wie im Buch beschrieben.

Das ,Buch im Buch' ist als Steigerungsfigur bei Novalis anzutreffen. Das Buch ist ein Spiegel, in dem Heinrich sein Ebenbild, aber auch seinen Doppelgänger erkennt. Dies ist zugleich eine Doppelung für den Leser, die immer weiter gesteigert werden kann: Er liest von Heinrich, der sich selbst als Leser erkennt, dieser könnte seinerseits einen Leser im Buch vor sich haben usf. Das Gelesene spiegelt oder wiederholt sich in der Handlung auf der ersten Erzählebene Wuthenow spricht hier von der „Wirkung des Gelesenen als dramatische Vergegenwärtigung“674: was der Leser tut, was er denkt, geschieht auch in dem Buch, das er vor sich hat.

Zwar soll aus Heinrich ein Dichter werden, doch schreibt er zunächst nicht, vielmehr ist er ein Leser. Heinrich ist also zum einen das alter ego Novalis', des Dichters, zum anderen eins mit dem Leser. Der Leser wird so eins mit Novalis und in die Lage versetzt, den als Fragment erhaltenen Roman durch seine aktive Lesetätigkeit fortzusetzen. Durch seine Rezeption des Textes wird der Leser auf diese Weise in die Schaffung von Literatur eingebunden: „Der wahre Leser muß der erweiterte Autor sein “75. Das Buch zeigt sich nach dieser Auffassung als Medium eines unvollendeten, grenzenlosen Textes, der den Lebensweg des lesenden Protagonisten darstellt und erhellt. Es bedarf der Vermittlung durch Geschriebenes, um seine Lebensgeschichte nicht nur an den Leser, sondern auch an den Protagonisten selbst heranzutragen. Leben und Buch durchdringen einander, eine Einlösung der von Friedrich Schlegel geforderten „progressiven Universalpoesie“. In der Literaturwissenschaft seit den 1960ern finden sich verstärkt Konzepte, die den Leser und seinen Rezeptionsprozess in den Fokus rücken und aufwerten, ausgehend von Roland Barthes’ Theorie vom „Tod des Autors“. Barthes setzte die bislang vorherrschende Auffassung, der Autor sei der alleinige Schöpfer des Textes und somit die maßgebliche Deutungsinstanz, außer Kraft und betonte stattdessen den Leser als maßgebliche Instanz im Entstehungsprozess von Literatur (vgl. Kap. III.9.1.5).

\footnotetext{
Novalis (1978), S. 265.

Wuthenow (1980), S. 26.

Fragment von Novalis, zitiert nach Kesting (1974), S. 433.
} 
Wie Heinrich von Ofterdingen entdecken die Leserprotagonisten späterer Lektüreepochen ein Buch aus scheinbarem Zufall oder werden auf ein Buch gestoßen, das Einfluss auf ihr Denken und Handeln ausübt und eine Wende herbeiführt. Die Entwicklung des „Buchs im Buch’ verläuft um 1800 parallel zum Schicksal der Romane zu einer Zeit, als sie sich als Leitgattung auf einem von vorwiegend religiösen Schriften bestimmten Buchmarkt durchzusetzen beginnen.

\section{Der Bücher lesende Held}

,Gelebte Literatur' ist ein beliebtes Motiv, das unter ganz unterschiedlichen Aspekten in der Weltliteratur eingesetzt wird. Die Reflexion eines Helden über seinen Lesestoff ist vor allem in Romanen möglich, in denen die Rolle des fiktiven Lesers reflektiert und unendlich gesteigert werden kann, erst recht in solchen Büchern im Buch, die denselben Titel tragen wie der vorliegende Roman: Wir lesen im Buch vor uns über einen Leser, der wiederum davon liest, dass jemand etwas liest ... Dennoch ergibt sich hinsichtlich des ,Buchs im Buch’, das in der anschließenden Motivuntersuchung auf Verwendung und Kombination mit anderen Motiven und Genres untersucht wird, eine Akzentverschiebung gegenüber den Motiven ,gelebte Literatur' und ,lesender Held'.

Das bekannteste und häufigste Motiv, das mit einem fiktionalisierten Buch verknüpft wird, ist ein Bücher lesender Held, der in der von ihm gelesenen Literatur ,lebt', einem doppelt fiktiven Helden nacheifert oder die im gelesenen Buch gezeigten Wertmuster und Verhaltensweisen übernimmt. Aufgrund des häufigen Auftretens eines ,lesenden Romanhelden' oder einer ,lesenden Heldin' in der Literatur des 18. Jahrhunderts hat auch die literaturwissenschaftliche Forschung hier einen Schwerpunkt ${ }^{76}$.

Das Buch kann für den Leser durch das Eintauchen in fiktive Welten einen Ausgleich zum Alltag schaffen. So entsteht auf der einen Seite ein Bezug zur eigenen Gegenwart, den der Leser im Buch findet, eine Lehre, die er aus dem Buch ziehen kann, auf der anderen Seite aber auch ein Dualismus zwischen Realität und Buchwelt, der bei übermäßiger Lektüre mitunter die Unterscheidung zwischen fiktiver und wirklicher Welt erschwert. Solche Fälle einer realitätsverzerrenden oder sogar -negierenden Wahrnehmung der Welt, ausgelöst durch die Lektüre, werden in der Literatur am Bücher , lesenden Helden' illustriert, der immer auch Warnung für den realen Leser sein soll. Der ,lesende Held' begibt sich in einer Vielzahl der Fälle derart in die Lektüre hinein, dass er mitunter seine Realität nicht mehr zu meistern in der Lage ist, oftmals schließt eine Vermischung von fiktiver Romanwelt und Realität daran an. In dieser Erzählsituation erkennt der reale Leser seine eigene Tätigkeit, das Lesen, gespiegelt wieder. Mit dem literarischen Werk wird versucht, einen Ausschnitt aus der realen Welt fiktional aufbereitet und in Literatur überführt zu 
vermitteln. Der reale Leser wiederum nimmt diese medial gebrochene Welt bei der Lektüre auf und versucht, sie in seine Sicht der Realität zu integrieren.

In den Büchern werden - neben der Bibel - überwiegend (zeitgenössische) Romane gelesen, Autobiographien, Tagebücher und Briefe spielen ebenfalls eine Rolle. Das Fiktionale auf zweiter Ebene wird dadurch legitimiert, dass der reale Leser seine Rolle noch besser gespiegelt sehen kann, schließlich liest er einen Roman. Außerdem fordert die Fiktion zu Reflexion und Identifikation mit dem Protagonisten heraus. Welcher fiktive Held aber liest die Bücher in den Büchern? Seit den Veränderungen in der Lektürepraxis um 1800 werden in der Realität vorwiegend bürgerliche Leser durchs Lesen geprägt. Ihnen stellt sich die Lektüre als einschneidendes Erlebnis dar, das ihr ganzes Leben beeinflussen soll, was sich auch fiktionsintern bei Wilhelm Meisters und Anton Reisers Shakespeare-Lektüre zeigt. In Anlehnung an Novalis' Kommentar zum Wilhelm Meister handelt es sich hier um eine „Wallfahrt des Bürgers zur Bildung ${ }^{677}$, einer fiktiven Bildung vermittelt durch fiktionale Literatur, die in der Praxis kaum umsetzbar ist.

Neben mittelalterlichen Literaturschaffenden wie Gottfried von Straßburg, der in seinen Werken Kommentare über seine Dichterkollegen und Wertungen über deren Werke einbringt, ist Dante wohl der erste, der ein Buch, den mittelalterlichen Versroman, Lancelot du Lac, auftreten lässt, und zwar als ,Kuppler' zwischen den beiden lesenden Liebenden Francesca da Rimini und Paolo Malatesta. Shakespeares Prospero verkriecht sich in seinen Büchern und sieht sie sogar als Ersatz für sein Herzogtum: „Me, poor man - my library / Was dukedom large enough“ (The Tempest, I, 2). Prototypisch wird das Motiv des Bücher lesenden Helden aber erst seit Don Quichote (1605/15), ein Paradebeispiel dafür, über der extensiven Lektüre von Romanen das eigene Leben in der Realität nicht mehr meistern zu können.

In Romanen des 18. Jahrhunderts waren Lesedarstellungen in vielen Fällen auch Stellungnahmen und Beiträge zur Lesedebatte. Diese konnten ein Lob des Lesens oder Kritik an der Lesesucht ausdrücken. Zu dieser Zeit waren Don-Quichottiaden weit verbreitet: Am Beispiel eines Bücher lesenden Helden, der sich völlig in seiner Lektüre verliert und zum Leben in der Realität nicht mehr fähig ist, wurde das Leseverhalten in einer Zeit reflektiert, in der das Lesen von Romanen neu war und immer wichtiger und populärer wurde ${ }^{78}$. Richtiges oder vom Autor als falsch aufgefasstes Lesen wurde zwischen den Zeilen oder ganz explizit kommentiert und bewertet. Rousseau gab in seiner Nouvelle Héloïse offene Anleitungen dazu, wie sein Werk - kein Roman, sondern eine Sammlung echter Briefe - zu lesen und zu verstehen sei, während Wieland in

Japp (1975), S. 660.

78 Vgl. dazu auch Stocker (2007), S. 77-85. 
seinem Der Sieg der Natur über Schwärmerey, oder Die Abentheuer des Don Sylvio von Rosalva (1764) überzogenen Enthusiasmus für Texte vorführte und das falsche Lesen karikierte.

Die Mode des empfindsamen Schreibens und Lesens ebnete den Weg für das identifikatorische Lesen avant la lettre, bei dem sich der Leser unmittelbar in seinen Helden oder seine Heldin hineinversetzt, Geschehnisse miterlebt und Gefühle teilt und so eine enge Bindung an Text und Figuren entsteht. In seinem Versuch über den Roman (1774) betont Friedrich von Blankenburg diesen neuen Lesemodus und das mit ihm einhergehende emotionale Nachempfinden mit den Romanfiguren. Der Leser wurde nun förmlich dazu aufgefordert, sich quasi in den Text zu begeben und die Haltung und mehr oder weniger die Rolle des Protagonisten einzunehmen. Diese Leseweise wurde auch im moralisch-didaktischen Roman funktionalisiert: Nach dem Beispiel der Heldin oder des Helden sollten Leserin und Leser dazu angehalten werden, ihr eigenes (Fehl-) Verhalten zu reflektieren und zu verbessern und sich in Einklang mit den Idealen von Aufklärung und Empfindsamkeit in Moral, Religiosität und Humanität zu schulen.

Ein Bruch mit dieser Vorstellung erfolgt im selben Jahr: Goethes Werther will und kann nicht mehr Vorbild für den Leser sein. Goethe zeigt im Werther ein individuelles Schicksal, das zwar zur einfühlenden Identifikation mit dem Protagonisten einlädt, liefert jedoch keine moralische Wertung des Geschehens. Auch der Protagonist Werther ist ein Bücher lesender Held. Er liest Homer, Literatur aus einer antiken Vorzeit, die eine gänzlich andere Welt als seine bürgerliche Gegenwart schildert, in und an der er schließlich scheitert, sowie Emilia Galotti, die die Vorlage zu seinem Freitod bildet. Werther bietet kein moralisches Exemplum, sondern das genaue Gegenteil: Der Leser ist bei der Einschätzung von Werthers Schicksal ganz auf sein eigenes Urteil angewiesen.

Auch über den Kontext deutschsprachiger Literatur hinaus werden Leben und Literatur beim Lesen kontrastiert und in Beziehung gesetzt, die Grenze zwischen beiden wird mitunter sogar aufgelöst. Diese Vermischung von Fiktion und Realität galt als Auslöser für falsche Vorstellungen der Welt auf Seiten des Lesers, besonders aber der Leserin. Catherine Morland aus Jane Austens Northanger Abbey (1797/98) gewinnt durch die emphatische Lektüre von Gotbic Novels eine harmlose Vorliebe für alte Schlösser, aber auch eine übersteigerte romanhafte Fantasie, die sie Handlungs- und Charaktermuster aus Romanen auf die Wirklichkeit übertragen lässt und sie unfähig dazu macht, ihre Umwelt zutreffend einzuschätzen. Austen karikiert in ihrem Roman nicht nur den zeitgenössischen Schauerroman, sondern auch den empfindsamen Roman und eine unangemessen intensive Art zu lesen, sie äußert sich also implizit zur Debatte um das richtige Lesen. Romane standen im Generalverdacht, für bare Münze genommen zu werden, was gesellschaftlich bedenklich erschien und für Kontroversen sorgte, schließlich drohten die Leser am wahren Leben zu scheitern, wie das fiktive Beispiel von Gustave Flauberts Madame Bovary (1856/57) zeigte. 
Bücher können den ,lesenden Helden' derart prägen, dass er sie zur Grundlage seines Lebens deklariert, an der er sich entlang hangelt. Für den Titelhelden in Oscar Wildes The Picture of Dorian Gray (1890/91) ist es Joris-Karl Huysmans A rebours (1884), das „gelbe Buch“, das sich durch sein ganzes Leben zieht. Genau wie Dorian - und auch der Autor Wilde - ist der Protagonist und Vielleser Des Esseintes ein Ästhet, der sich mehr und mehr der dekadenten Suche nach exquisitesten Genüssen hingibt. Von Literatur und Kunst übersättigt, muss ein Buch für ihn extravagant ausgestattet und selten sein und eine Weile unberührt im Regal, reifen'. Die Ästhetisierung des Buchs als Kunstgegenstand und umfassende ultimative Sinnesempfindung wird so auf der fiktionsinternen Leseebene und sogar in der Realität befürwortet.

Auch die deutsche Literatur seit $1945^{79}$ ist nicht arm an literarischen Darstellungen eines ,lesenden Helden'. Ulrich Plenzdorf unternimmt mit Die neuen Leiden des jungen W. (1972/73) eine Aktualisierung des Werther-Stoffes, die nicht nur die ostdeutsche Kulturpolitik und den Umgang mit kulturellem Erbe sichtbar machen will. Er lässt seinen Wibeau den Werther quasi nachspielen, wobei deutlich wird, dass sich die neuen von den alten Leiden nicht allzu sehr unterscheiden. Goethes Werther scheint als Palimpsest immer wieder durch die Neuen Leiden durch. Im Kino wäre von einer Neuverfilmung oder einem Remake die Rede, in der (Pop-)Musik von einer Coverversion, die den bekannten Stoff, das bekannte Thema an die aktuellen Zeitumstände und den Publikumsgeschmack anpasst und so noch zugänglicher macht.

Für den Leser kann der , lesende Held' also als Vorbild dienen, aber auch als negatives Beispiel für eine nicht akzeptable Form von Realitätsverlust durch die Lektüre. Der ,lesende Held' steht für eine bestimmte Art der Beschäftigung mit Literatur - dabei ist nicht ausschlaggebend, was er liest, sondern wie er liest.

\section{Der fiktionalisierte Büchernarr}

„Der Bibliophile ist der Herr, der Bibliomane der Knecht seiner Bücher. “80 heißt es in Bogengs Zusammenschau von historischen Büchersammlern. Eine klare Grenze ist zwischen beiden Ausprägungen der Vernarrtheit in Bücher dennoch nicht zu ziehen. Eine leichte Unterscheidung liegt darin, dass ein Bibliomane unter einer krankhaften, fast wahllosen Besitzsucht leidet, für die er bereit ist, die Grenzen von Vernunft und Moral zu überschreiten. Zum Lesen kommen sie angesichts der Menge an Lektürematerial und der mangelnden Zeit, die sie auf der Suche nach neuen Büchern verbringen, schlechthin nicht mehr. Für den Bibliophilen hingegen sind Bücher in außergewöhnlicher, exquisiter Ausstattung und seltene, wertvoller Erst- und Einzeldrucke eine

79 Vgl. zur Forschung über Lesedarstellungen in deutschsprachiger Literatur seit 1945 Stocker (2007).

80 G.A.E. Bogeng: Die großen Bibliophilen, Geschichte der Büchersammler und ihrer Sammlungen. Bd. 1: Die Geschichte.

Leipzig: E.A. Seemann, 1922, S. 512. 
Liebhaberei, als Vielleser sieht er die Bücher als Mittel zum Zweck, um seiner Leselust nachzugeben und immer wieder in fiktionale Welten eintauchen zu können.

Der Bücher lesende kann in der Literatur zu einem den Büchern verfallenen Helden werden. Diese Büchernarren treten besonders konzentriert in der Literatur des 18. und 19. Jahrhunderts auf, aber auch schon in der Literatur des ausgehenden Mittelalters sind Beispiele zu finden, z. B. in Sebastian Brants Narrenschiff (1494 zuerst gedruckt).

Den literarischen Büchernarren erscheint die Lektüre als „Motivierung, Spiegelung, sogar als Droge ${ }^{\text {‘81 }}$, der Ich-Erzähler in Anton Reiser von Karl Philipp Moritz (1785-90) vergleicht denn auch seine Lesesucht mit der Sucht nach Opium. Wo unter Opfern gelesen wird, um dem tristen Alltag zu entfliehen, ist die Intensität der Lesesucht am größten. Anton Reiser führt ein Leben der Entbehrungen, verkauft seine Habe und verzichtet auf vieles, um lesen zu können. Ebenso büchernärrisch ist Jean Pauls Schulmeisterlein Maria Wutz. (1793). Wutz errichtet sich sein eigenes Weltbild aus der Lektüre, ironisch gesteigert führt dies dazu, dass er sich die Bücher, die er sich nicht leisten kann, nach Titeln aus dem Messkatalog selbst schreibt ${ }^{82}$.

In der Literatur späterer Zeit herrschen weniger einfühlende Darstellungen von begeisterten Buchlesern und -sammlern vor, die in Folge ihres Bücherwahns am Leben scheitern. Verbreiteter sind kritische und ironische Zeichnungen von ,Buchverrückten', deren Leben weitgehend aus der Jagd nach neuen Büchern besteht. Diese Darstellungen sind z. T. durchaus negativ konnotiert.

Gustave Flaubert schildert in seiner Erzählung Bibliomanie (1836) den Antiquar Giacomo, der als Bibliomane versucht, Interessenten davon abzuhalten, seltene oder kostbare Bücher zu erstehen, auf die er selbst ein Auge geworfen hat. Er schreckt nicht davor zurück, die Käufer der Bücher, die ihm etwas bedeuten, zu schädigen oder sogar zu töten. Dennoch wird betont, dass er kaum zu lesen vermag und die Botschaften der Bücher nicht versteht (das Buch, für das er beginnt, zu töten, ist eine seltene Bibel). Vielmehr schätzt er ihr Äußeres, ihren Wert und ihre Singularität. Sein Bücherschatz ist austauschbar, hat er ein wertvolles Buch erworben, richtet sich sein Begehren sofort auf ein weiteres. Als historische Vorlage diente Flaubert die Geschichte des bibliomanischen Don Vincente, eines ehemaligen Mönchs im Kloster Poblet bei Tarragona. Im Jahr 1830 verließ er sein Kloster, nachdem er bei einer Plünderung der Klosterbücherei wertvolle Werke beiseite geschafft hatte, um mit der Beute ein Antiquariat in Barcelona zu eröffnen. An den Inhalten zeigte er kein Interesse, sondern nur am Besitz der Bücher, vor allem, wenn sie rar und damit wertvoll waren. Bei einer Auktion bot er all seine Mittel auf, wurde aber dennoch überboten. Im Anschluss tötete er den bei der Auktion erfolgreichen Käufer, außerdem Käufer von Raritäten

81 Wuthenow (1989), S. 152.

82 Vgl. auch Alexander Košenina: Der gelehrte Narr. Gelehrtensatire seit der Auflelärung. Göttingen: Wallstein, 2003 , S. 136. 
aus seinem Laden, denen er versucht hatte, den Erwerb auszureden, aber dennoch zugestimmt hatte, weil er das Geld brauchte. Die Situation, dass dem Käufer kostbare Ware später gewaltsam wieder abgenommen wird, da der Verkäufer es nicht über sich bringt, den Kunstgegenstand an Dritte zu verlieren, erinnert an den Goldschmied Cardillac aus E.T.A. Hoffmanns Das Fräulein von Scuderi (1818). Don Vincentes Geschichte findet sich bei Bogeng ${ }^{83}$, der allerdings der Meinung ist, Flauberts Darstellung sei nicht detailgetreu. Dabei lässt er außer Acht, dass die Novelle um Giacomo zwar auf historische Tatsachen zurückgreift, aber dennoch Fiktion ist. Eine Analyse von Don Vincente als Büchernarr bietet Košenina ${ }^{84}$. Die Merkmale, die Don Vincente auszeichneten, finden sich in unterschiedlicher Konzentration bei den literarisch vorgeführten Büchernarren wieder, so dass er als Prototyp eines Bibliomanen bezeichnet werden kann (vgl. Kap. III.6).

Während dem Antiquar Moral und Vernunft abhanden kommen, entgleitet dem Gelehrten Peter Kien in Canettis Die Blendung (1935) die Wirklichkeit. Die Bücher beginnen, ihm die Menschen zu ersetzen, seine immense Bibliothek wird ihm zur Welt, bis er in einer Autodafé zusammen mit ihr untergeht.

Für die Büchernarren, oder Bücherwürmer, steht das Buch niemals im Singular. Es geht ihnen zwar um einen extensiven Buchbesitz, doch auch um das Lesen schlechthin. Für diese Leser würde es geradezu paradox anmuten, einem einzelnen, wenn auch besonderen Buch zu huldigen, denn die Masse der Bücher und das beständige Lesen neuer Inhalte machen ihren Bücherwahn aus. Damit bilden sie ein Extrem der bürgerlichen Neuorientierung in Bezug auf das Lesen seit dem Ende des 18. Jahrhunderts, die eine extensive Lektüre der intensiven, auf einige wenige kanonische Bücher ausgerichtete, vorzieht.

Einige fiktive Leser fühlen sich derart stark zu Büchern hingezogen, dass sie sich, dem Namen nach oder ganz wörtlich, in ein Buch verwandeln. Schon in Jean Pauls Leben Fibels, des Verfassers der Bienrodischen Fibel (1811) gerät das Buch der Welt zur Welt als Buch. Der Lebensinhalt des Büchermachers Fibel, der sogar den Namen seines Hauptwerks trägt, sind Lesen, Schreiben und Bücher. Sein erster Erfolg wird der Abdruck einer ABC-Fibel, die ihm selbst schon lesen und schreiben beigebracht und ihm so die Welt eröffnet hat.

Darstellungen von Bibliomanen als der extremsten Form eines der Buchleidenschaft verfallenen Lesers kamen bisher häufig in der Literatur vor und werden sicher auch in Zukunft thematisiert werden. In den meisten Fällen stehen diese Darstellungen als mahnendes Beispiel, weniger als Anregung, auf dieselbe Art Bücher zu konsumieren oder gar anzuhäufen. Hier wird eine ,fal- 
sche', eine bedenkliche Art vorgeführt, sich für Bücher zu begeistern - das reine Anhäufen von Büchern und ihre Wertschätzung als bloße gegenständliche Kostbarkeit, ohne sie zu lesen.

\section{Das Buch als magisches Objekt}

Das Buch wird in fiktionaler Literatur immer wieder als magisches Objekt dargestellt, was mit seiner Einzigartigkeit und Absolutheit, aber auch seiner scheinbaren Undurchdringlichkeit und Rätselhaftigkeit zusammenhängt. Das Buch wird in einen rätselhaften Kontext gestellt, was sich auch häufig im Genre niederschlägt. Ein magisches Objekt kann in unterschiedlichen Funktionen zugleich schützen und schaden, es ist aber auch dazu in der Lage, unsere Zukunft zu erhellen ${ }^{85}-$ all dies trifft auch auf das Buch zu. Ein besonderer Reiz des Buchs scheint in seiner Fähigkeit zu liegen, Realität und Fiktion zu vereinen. Es gibt unzählige Beispiele, in denen literarisch die Grenzen von Fiktion und Wirklichkeit ausgelotet und ihre Territorien überschritten werden, wenn z. B. eine Figur Teil der literarisch ausgestalteten Wirklichkeit wird oder der Leser aus der Erzählwelt Teil einer eingebetteten Handlung wird.

Das Buch als magisches Objekt hat als Motiv seinen festen Platz im fantastischen Genre. Hier zeigen viele Darstellungen, wie das ,Buch im Buch’ für den Leser gefährlich werden und letztlich tödlich wirken kann. Ein Meilenstein in der literarischen Darstellung des ,Buchs im Buch' ist Leo Perutz’ Der Meister des jüngsten Tages (1923), ein Roman, der jahrelang völlig zu Unrecht in Vergessenheit geraten ist und dringend verdient, wiederentdeckt zu werden. Perutz stellt eine Reihe von Todesfällen in den Mittelpunkt, für die, wie sich herausstellt, ein Buch verantwortlich zeichnet. In dem Folianten, den die Opfer kurz vor ihrem Tod gelesen haben, berichtet ein florentinischer Maler darüber, wie ein gewisses Räucherwerk, von dem behauptet wird, es belebe die Kreativität, Wahnvorstellungen und Schreckensvisionen verursacht, vor denen die Leser ihre Rettung einzig im Freitod sehen.

Ein dem Perutz'schen Vorbild in dieser Hinsicht auffallend ähnliches Beispiel findet man heute mit The book with no name (2006/2007) von dem Autoren Anonymous. In dem MysteryKriminalroman werden die Leser des namenlosen, alten Buchs eines anonymen Autors nach der Lektüre ermordet, während das Buch wieder an seinen angestammten Platz in einer Bibliothek zurückfindet. Eine Kriminalabteilung für Übernatürliches entsendet eigens einen Ermittler, was schon deutlich auf die Rolle hinweist, die das Fantastische in diesem Roman einnimmt. Auch hier wird angedeutet, dass das Buch, das der reale Leser gerade liest, jenes ist, über das er liest - eine

85 Peter Ganz, Vorwort zu Ders. (Hg.): Das Buch als magisches und Repräsentationsobjekt. Wiesbaden: Harrassowitz, 1992, S. 1. 
Mise en abyme als Vermischung und Verdopplung der Erzählebenen, die den Grad des Mysteriösen erhöht, Spannung erzeugt und den Leser gleichsam in das fiktive Geschehen bindet.

Ein drittes Beispiel für ein Stück fantastischer Literatur, in dem das Buch ein Eigenleben führt und den Leser schließlich tötet, ist Alfons Schweiggerts Das Buch (1989) (vgl. Kap. III.3.1.1.1). Der bücherliebende Protagonist verwandelt sich in diesem Roman in ein gegenständliches Buch, übernimmt in dieser Gestalt dessen ,Gedanken’ und rächt unangemessenes Verhalten Büchern gegenüber. Während bei Perutz der Leser bei der Lektüre derart erschreckenden Visionen ausgesetzt ist, dass er vor Entsetzen den Freitod wählt, tötet das Buch bei Schweiggert im ganz wörtlichen Sinn.

\section{Das Buch potenziert: Die Bibliothek im Roman}

Nicht nur das ,Buch im Buch’ steht im Mittelpunkt zahlreicher Fiktionalisierungen, sondern noch viel häufiger die Bibliothek, in der sich das einzelne Buch potenziert findet. Literarische Bibliotheksdarstellungen bilden so das Gegenstück zu den Buch-Büchern: Sie stellen gerade nicht ein einziges Buch in den Mittelpunkt der Betrachtungen, sondern Büchersammlungen. Die weite Verbreitung von Bibliotheksromanen hat vor allem der Erfolg von Umberto Ecos Der Name der Rose $(1980)^{86}$ vorangetrieben und beschleunigt. Ebenso Vorbild und Anregung war sicher Jorge Luis Borges’ Erzählung Die Bibliothek von Babel (1941), die ein Szenario der Welt als Bibliothek aller möglicher Bücher vorführt.

In den Bücherwelten der literarischen Bibliotheken ${ }^{87}$ treten die Bücher an die Stelle des Lebens, so dass hier nicht nur ein einziges Buch von Belang ist, sondern gerade die Ansammlung von Büchern. Es ist auffällig, dass die Bibliothek nicht als Sammlungspunkt von Belletristik dient, sondern stets ihr Status als Hort des Wissens hervorgehoben wird. Die Bibliothek ist damit auch ein Zentrum der Macht, sie ist überlegen, da sie Traditionen beinhaltet und überliefert, die den Menschen überleben könnten. Dennoch ist die Bibliothek in den literarischen Darstellungen auch ein Irrgarten, in dem eine Suche nach dem einen, vollkommenen Buch stattfindet, nach jenem, in dem sämtliche Wahrheiten des Universums enthalten sind, das alles Eigentliche und Wesentliche enthält und den Leser zum Wissenden macht. In solchen Szenarien ersetzen die Bücher letztlich die Welt und bilden ein neues Universum oder Refugium wie für Canettis Peter Kien.

Ein Beispiel für einen Bibliotheksroman der neueren Zeit ist Antonia S. Byatts Besessen (1990), wobei die Bibliothek lediglich der Handlungsort bleibt, in dem zwei Literaturwissenschaftler an-

86 Umberto Eco: Der Name der Rose. München: Hanser, 1982; deutschsprachige Ausgabe.

87 Vgl. zur Forschung über literarische Bibliothekswelten Rieger (2002) und Stocker (1997). 
hand von historischen Briefen versuchen, die bisher unbekannte Liebesbeziehung zwischen zwei viktorianischen Autoren zu rekonstruieren.

Gerade auch im Science-Fiction-Genre und seinen medialen Ausprägungen kommen häufig Bibliotheken vor. Neben der Vorstellung einer allumfassenden Bibliothek, die sämtliches Wissen sammelt, ist dies auf eine Fiktion zurückzuführen, die auf der Annahme basiert, dass das Ende des Zeitalters der Bibliotheken, die das Gutenbergsche Medium versammeln, in naher Zukunft liegt und die Bibliothek über kurz oder lang durch virtuelle Speichermedien ersetzt werden wird $^{88}$.

\section{$7 \quad$ Zitierung des Buchs im Buch}

In Anspielungen, Zitaten, bewussten und vor allem unbewussten Bezugnahmen verbergen sich in jedem Text andere Texte, in jedem Buch andere Bücher. Der Autor wird beim Schreiben in einem variierenden Maße von seinen bisherigen Leseerfahrungen geleitet, die in die Produktion von Literatur mit einfließen. Der Leser wiederum ist, abhängig von seiner Lektürekompetenz, dazu in der Lage, diese Anspielungen zu verstehen und die zitierten Werke zu erkennen. Im Falle einer absichtlichen Bezugnahme auf ein Werk spielt der Autor damit, dass der Leser den Originaltext kennt und seine Anspielungen somit versteht. Je nach den Voraussetzungsbedingungen ${ }^{89}$, je nachdem, wie weit der Leser dem Autor hier folgen kann, wird sein Lesegenuss ausfallen.

Die Gründe für das Zitieren von Büchern in Büchern sind vielfältig. So kann dies u. a. aus einem Gefühl der Lückenhaftigkeit heraus entstanden sein oder sich als Hommage an das Bekannte präsentieren, sich dabei ernsthaft in Form einer Pastiche mit dem Vorbild auseinandersetzen oder aber als Satire, Parodie oder Karikatur gestalten. An dieser Stelle seien drei völlig unterschiedliche Bezugnahmen auf Goethes Werther genannt ${ }^{90}$ : Thomas Manns Goethe-Roman Lotte in Weimar (1939) schildert das letzte (fiktive) Treffen zwischen Goethe und der inzwischen verwitweten Charlotte Kestner, geb Buff, die als Vorbild für Werthers Lotte gedient hat. Manns Roman ist durchaus als Verbeugung vor dem großen Vorbild zu verstehen. Ulrich Plenzdorf unternimmt mit Die neuen Leiden des jungen W. (1972) eine aktualisierende Nacherzählung der bekannten Handlung, während Friedrich Nicolai mit Die Freuden des jungen Werthers (1775) als Zeitgenosse Goethes keine eigentliche Parodie auf den Epoche machenden Briefroman verfasst hat, sondern eher einen Angriff auf das ,falsche Lesen'. Die neue, über den Werther eingeführte identifikatorische Art zu lesen, die für viele Aufklärer als Auslöser der durch Werthers Beispiel ange-

\footnotetext{
88 Vgl. Rieger (2000), S. 13.

89 Vgl. Heydebrand \& Winko (1996), S. 81. Als Faktoren des „Voraussetzungssystems“ des Lesers werden Wissen, Emotionen, Absichten, Erwartungen und Motivationen angeführt.

90 Vgl. dazu den Hinweis bei Japp (1975), S. 662.
} 
stoßenen empfindsamen Selbstmord-Welle galt, wird hier als unangebrachte Art, sich mit Literatur auseinanderzusetzen, ebenso satirisch zugespitzt angeprangert wie die gesamte Sturm-undDrang-Bewegung, die Goethe und seinen Helden bis zur Nachahmung verehrte.

Sind die Texte allgemein bekannt, sind auch literarische Transfigurationen möglich. Literarische Figuren finden über ihre Rolle in der Fiktion hinaus Eingang ins reale Leben, sie werden vom Leser „,in der Imagination angeeignet, assimiliert ${ }^{\star 91}$. Als die empfindsamen (Brief-)Romane, besonders die Samuel Richardsons, wie Pamela, or Virtue rewarded (1740) oder Clarissa, or, the History of a Young Lady (1748), die ,Lesewut' vorantrieben, konnte man davon ausgehen, dass der Großteil der lesenden Schicht diese Romane kannte. Das erklärt, dass die Angebetete mit dem Namen einer beliebten Romanheldin angesprochen werden konnte, explizit auf literarische Situationen Bezug genommen wurde ${ }^{92}$ und Friedrich Gottlieb Klopstock eine Ode an Die todte Clarissa (1751) verfasste, in Anlehnung an Clarissa Harlowe, die Titelheldin aus Richardsons Roman.

Mit einer besonderen Art von interkultureller und intermedialer Verknüpfung haben wir es im Fall von Helen Fieldings Bridget Jones's Diary (1996) zu tun. Tagebuchschreiberin Bridget Jones erlebt die Geschichte von Elizabeth Bennet und Mr. Darcy aus Jane Austens Pride \& Prejudice (1813) neu, und das mit einer Figur, die ebenfalls den Namen Darcy trägt. Ein besonderes Bonbon ist es, dass der Schauspieler Colin Firth in beiden Verfilmungen ${ }^{93}$ die Rolle des Mr. Darcy übernimmt. Original und Zitat sind eng miteinander verknüpft, was auch auf die jeweiligen Verfilmungen zutrifft. Das Verständnis der Allusion auf Jane Austens Klassiker wird vorausgesetzt, denn der Stoff und die literarische Figur des Mr. Darcy sind zu einem Teil des öffentlichen kulturellen Wissens geworden. Eine weitere Adaption des Austen-Klassikers parodiert diesen und mixt in einer typisch angelsächsischen Verbindung von Hoch- und Populärliteratur aus dem Originaltext und neuen, recht drastischen Horrorelementen einen „Mash-up-Bestseller“94. Seth GrahameSmiths Pride and Prejudice and Zombies (2009) mag befremden, aktualisiert aber den Plot auf geniale Weise und erschließt ihn einem neuen Publikum, das sich bisher vielleicht nicht an Austens Roman heranwagte.

Das Spiel mit dem Bekannten kann auch dazu führen, dass literarische Figuren nicht nur zum kulturellen Allgemeingut und Teil des kulturellen Gedächtnisses werden. Sie können vielmehr, ist die Identifikation mit dem Lesestoff groß genug, auch als Persönlichkeiten aufgefasst werden, die

91 Vgl. dazu Wuthenow (1989), S. 156.

92 Vgl. z. B. die „Klopstock!“'-Episode im Werther.

93 Fieldings Bestseller wurde 2001 (Regie: Sharon Maguire) unter dem Buchtitel verfilmt. Die populäre BBCVerfilmung von Jane Austens Roman als Mehrteiler stammt aus dem Jahr 1995.

94 Christoph Dallach: „Eheversprechen und Leichenschmaus“. Rezension zu Seth Grahame-Smith: Pride and Prejudice and Zombies (2010). In: Spiegel online, 05.07.2010,

[http://www.spiegel.de/kultur/literatur/0,1518,704341,00.html], eingesehen am 06.07.2010. 
in neue fiktive Welten eingebunden werden. In Fruttero \& Luccentinis Die Wabrheit über den Fall D. (1989) finden sich auf einem Kongress, bei dem unvollendet gebliebene literarische Werke zu Ende geschrieben werden sollen, u. a. „Das Geheimnis des Edwin Drood“ von Charles Dickens, große Detektive der Kriminalliteratur zusammen wie Sherlock Holmes, Hercule Poirot, Nero Wolfe und Archie Goodwin, Kommissar Maigret oder Philip Marlowe ${ }^{95}$. Die Comicreihe The League of Extraordinary Gentlemen (1999-2003) von Alan Moore, die 2003 verfilmt wurde, spielt im Jahr 1898 und handelt von literarischen Figuren, darunter Mina Harker, Allan Quatermain, Kapitän Nemo und Dr. Jekyll, die sich zur Rettung des britischen Empires zusammenschließen.

Mögliche Bezugnahmen auf bekannte Texte können aber auch Fortschreibungen sein, sei es als Verbeugung vor dem Original oder aus wirtschaftlichen Gründen, um aus der Neugier der Leser, die sich eine Ergänzung zum Beliebten erhoffen, Profit zu ziehen. Wohl hauptsächlich von den überaus erfolgreichen Vorbildern profitieren möchten die Parodien Bored of the Rings (1969) und die dreibändige Barry-Trotter-Reihe (2002-04). Eine Variante der Fortschreibungen stellen fiktive Vorgeschichten zu den Handlungen literarischer Klassiker dar. Auf diese Weise kann sichergestellt werden, dass ein großes Publikum den Inhalt der Romane kennt und an zusätzlichen Informationen und weiteren fiktiven Erlebnissen der Romanhelden interessiert ist. Meist steht eine Hauptfigur im Vordergrund, deren Erlebnisse in einem Prequel vor dem Einsetzen der bekannten Romanhandlung geschildert werden, wie in Sally Beaumans Rebecca's Tale (2001), die das ,Vorleben' der Titelheldin aus Daphne DuMauriers Rebecca (1938) beschreibt. Ein Sequel bildet die Fortsetzung eines bekannten Textes, wie z. B. Scarlett (1991) von Alexandra Ripley als Fortsetzung von Margaret Mitchells Gone with the Wind (1936).

Wie das vorangehende Kapitel zeigt, sind Bezugnahmen auf Literatur und Bücher nicht nur intertextuell, sondern auch intermedial möglich. Aus dem Transfer von Motiven und bekannten literarischen Figuren gewinnen die referentiellen Medien und Werke einen besonderen Reiz, der mit dem Wissen um das Bekannte spielt. Je nach Grad der Bekanntheit und des Erkennens von Anspielungen fällt der ästhetische Genuss für den Leser aus.

\section{Das Buch in gegenwärtigen literarischen Strömungen}

Gegenwärtige literarische Strömungen greifen auf literarische Überlieferungstraditionen zurück und bieten Raum für eine Vielzahl von Buch-Büchern. Vielfach ist aktuelle Literatur auch durch

95 Diese Konstellation erinnert an den Spielfilm Eine Leiche zum Dessert (Murder by Death, 1976, Regie: Robert Moore), der, hochkarätig besetzt, u. a. mit Truman Capote in seiner einzigen Filmrolle, zum Kultfilm wurde. Die Filmfiguren parodieren die literarischen Detektive Charlie Chan, Nick und Nora Charles aus der Thin-ManReihe, Sam Spade (Der Malteser-Falke), Hercule Poirot und Miss Marple. 
postmoderne Konstrukte beeinflusst und verweist so auf den Zeitgeist, und neben der Tradition, in der sie verankert ist, auf einen literarischen Trend.

Ende des letzten Jahrhunderts entstanden hochliterarische Werke im Umfeld der BuchBücher, in denen ein intellektuelles Spiel mit dem Leser um Literatur, Perspektiven und Handlungen getrieben wird. Leser, lesen und das Buch als Erzählstoff im Roman erlebten 1979 einen besonderen Höhepunkt, als sowohl ein Roman für jugendliche Leser (Michael Ende: Die unendliche Geschichte) als auch einer für Erwachsene (Italo Calvino: Wenn ein Reisender in einer Winternacht) Selbstreferenz und Metafiktionalität zum Thema der Fiktion machten ${ }^{96}$. Ein Vertreter der Postmoderne, der eine bekannte fiktive Welt als Handlungsort einsetzt, ist Christoph Ransmayrs Roman Die letate Welt (1988). Darin reist ein Bewunderer Ovids in dessen Heimat, um herauszufinden, ob Ovid tatsächlich im Exil verstorben ist. Auf seiner Reise stößt er auf eine Stadt, in der die Welt der Ovidschen Metamorphosen lebendig geworden ist.

In der fantastischen Literatur ist das ,Buch im Buch’ ein beliebtes Motiv und gerade in der Verquickung von Realität und Fiktion und dem Überschreiten von Erzählebenen in vielen literarischen Milieus vielfach eingesetzt worden. Der bekannteste Roman von Science-Fiction-Autor Philip K. Dick, Das Orakel vom Berge (1962), bezieht seine Handlung zu weiten Teilen aus einem fiktiven Buch. Die Dystopie zeigt eine Alternativwelt, in der die Kriegsgegner der Alliierten den 2. Weltkrieg gewonnen haben. In dem in der Erzählwirklichkeit verbotenen ,Buch im Buch’ „The Grasshopper lies heavy“ werden die Zustände der Erzählwelt beschrieben. Mithilfe des Heuschreckenbuchs entdecken die beiden Protagonisten letztlich, dass ihre Welt die eigentliche Fiktion ist.

Ray Bradburys inzwischen hauptsächlich als Schulbuchklassiker wahrgenommene Dystopie Fabrenheit 451 (1953) zeigt weniger das Buch als vielmehr seine Abwesenheit. Im geschilderten totalitären System haben Bücherverbrennungen im Zuge eines Buch- und Leseverbots den Zweck, das Gedächtnis der Menschheit auszulöschen. Erst angesichts ihrer Vernichtung wird den Menschen klar, wie wichtig Bücher für Menschen sein können: "There must be sometbing in books, things we can't imagine, to make a woman stay in a burning house; there must be something there. You don't stay for notbing." 97

Als ,Buch im Buch’ kann eines der größten Werke der Weltliteratur auch in einem Thriller auftreten. In The Dante Club (2003) schildert Matthew Pearl einen Serienmörder in den USA des 19. Jahrhunderts, der sich am Vorbild von Dantes Göttlicher Komödie orientiert ${ }^{98}$. Die Opfer werden den bei Dante beschriebenen infernalischen Strafen zugeführt, obgleich das Werk in den USA zur

96 Vgl. Löffler (2005), S. 12.

97 Ray Bradbury: Fahrenheit 451 [zuerst 1953]. Hg. v. Norbert Köhn. Stuttgart: Reclam, 1991, S. 67.

98 Darüber hinaus zeigt der Roman auffällige Parallelen zu dem David-Fincher-Thriller Sieben (1995), in dem ein Serienmörder die sieben Todsünden inszeniert. Auch dieser Antagonist ist außergewöhnlich belesen und zitiert kanonische klassische Literatur, wenn er der Polizei Hinweise zu seiner Person gibt, z. B. Chaucer, Shakespeare oder Milton. 
Zeit der Romanhandlung noch kaum bekannt war und somit nur der titelgebende Literaturclub die Zusammenhänge erkennt. Ein weiterer Roman von Pearl, The Last Dickens (2009), befasst sich mit dem verschwundenen letzten Kapitel zu Dickens’ angeblich unvollendetem letzten Roman.

Buch-Bücher gab es zu allen Zeiten, das Motiv „Buch im Buch’ seit es Bücher gibt. In heutigen literarischen Strömungen zeigt sich das Buch-Motiv ebenfalls, und zwar auffallend häufig. Dies mag zum einen an der literarischen Tradition liegen, in der die Romane stehen, zum anderen mögen aktuelle Entwicklungen, wie die Ausbildung neuer medialer Technologien, die besondere Beachtung des Buchs, als aussterbendes und dennoch überlebendes Medium, bedingen.

\section{$9 \quad$,Buch im Buch' und postmoderne Einflüsse}

Postmoderne Literatur ist geprägt von Intertextualität, Metafiktionalität und Kontextualität, ideale Bedingungen also, ein Buch im Buch zu reflektieren. Ein starkes Merkmal postmoderner Literatur ist es, dass sie Lesen und Schreiben als Selbstreferenzierung von Literatur ins Zentrum stellt. Hier ist es allerdings auch üblich, den Text auf unterschiedlichen Leseebenen verständlich und vergnüglich zu gestalten, so dass unterschiedliche Adressatengruppen z. B. Der Name der Rose als Mönchskrimi ebenso zu goutieren vermögen wie als hochliterarische philosophisch-theologische Erörterung. Die Krise der Objektivität, die der Radikale Konstruktivismus beschreibt, (vgl. Kap. III.4.1) drückt sich auch in der postmodernen Aneignung des Stilmittels ,Buch im Buch’ aus, denn jeder Leser besitzt eigene subjektive Assoziationen mit dem Buch, so dass unterschiedliche Leseebenen möglich werden. Die folgenden Ausführungen zur literarischen Postmoderne sind nicht als tiefergehende Auseinandersetzung mit dieser Strömung gedacht, da sie hauptsächlich versuchen, einen Überblick über postmoderne Charakteristika in Romanen zu bieten, die Buch und Lesen thematisieren.

Die Postmoderne als gesellschaftlicher, philosophischer und auch künstlerischer Diskurs zeigte ihre ersten Ausprägungen als ,Nach'-Moderne ausgehend von den USA in der zweiten Hälfte des 20. Jahrhunderts und war zunächst ein Sammelbegriff besonders für neue Entwicklungen in der Architektur. Jedoch sind sowohl Berechtigung als auch Definition dieses Terminus umstritten und uneindeutig. Die ästhetischen Konzepte der Moderne hatten sich eingeschliffen und abgenutzt, waren uninteressant geworden, man wollte etwas Neues wagen. Postmoderne bedeutet immer auch Überwindung oder, über etwas hinausgehen'. Wo die Moderne vor allem mit dem Erbe der Aufklärung identifiziert wird und rationalisiert ${ }^{99}$, führt die postmoderne Literatur die „modernistische Kritik am Rationalismus, am Hegelianismus, am Vernunft- und Subjekt-

99 Vgl. Peter V. Zima: Moderne - Postmoderne. Gesellschaft, Philosophie, Literatur. 2. A. Tübingen \& Basel: 2001, S. 23. Zima verweist hier auf Jürgen Habermas’ Aufsatz „Die Moderne - ein unvollendetes Projekt“. 
begriff “ 100 weiter und radikalisiert sie. In der Folge bezieht sich die literarische Postmoderne u. a. auf Konzepte der Romantik.

Im postmodernen Roman findet die Postmoderne ihre literarische Manifestation. Dieser geht über die literarischen Strukturen der Moderne hinaus und probiert als „Experimentierfeld““101 neue Wege des literarischen Schreibens aus. Dabei betont der postmoderne Roman den spielerischen Aspekt und lässt Sinnfindung durch Kunst eher außer Acht. Für von der Postmoderne beeinflusste Künstler ist bei der Schaffung von Kunst alles möglich, denn kein künstlerisches Produkt ist mehr wirklich neu, da jeder Künstler auf bereits Bekanntes zurückgreift und verweist.

Der postmoderne Roman hatte seine meist beachtete Zeit in der 1980er Jahren. Als typisch gelten zum einen die Schriften von Jorge Luis Borges, der die Vermischung von Realität und Konstruktion bzw. Fiktion ebenso schätzte wie die Täuschung des Lesers in einem intellektuellen Spiel. Zum anderen gilt Umberto Ecos Der Name der Rose als typischer Roman der Postmoderne $^{102}$, der das Konzept einem breiten Publikum bekannt machte. Durch alle Leserschichten hatte der Roman Erfolg, wie es dieser Art des Schreibens entspricht. An diesem Roman lassen sich beinahe alle Merkmale des postmodernen Schreibens beispielhaft zeigen, besonders Aspekte der Intertextualität und Metafiktionalität.

Das Charakteristische an der postmodernen Schreibart ist, dass sie Narrativität, Subjektivität, Identität sowie Wirklichkeit und Sinn außer Kraft setzt und dekonstruiert, bzw. abwandelt oder sogar parodiert. Obwohl es schwierig ist, den Terminus ,Postmoderne’ scharf zu umreißen, wird im Anschluss versucht, anhand dieser Faktoren einige Charakteristika des postmodernen Schreibens zu benennen, die jedoch nicht exklusiv in postmoderner Fiktion zu finden sind ${ }^{103}$.

\section{Narrativität}

- Die Erzählweise ist nicht linear, die Handlungselemente, die auch fragmentarisch sein können, folgen vielmehr einer nicht-chronologischen Abfolge. Der Leser muss das Geschehen, die Handlung erst für sich konstruieren, um sie zu verstehen.

- Das Werk ist dabei durchaus als Konstrukt erkennbar, außerdem sind die Konstruktionsmechanismen des Autors durchschaubar. Dieser Aspekt lehnt sich an den Radikalen Kon-

\footnotetext{
100 Ebd., S. 238.

101 Ruth Mayer: Art. „Postmoderne, Postmodernismus“. In: Nünning (32004), S. 543f, hier S. 544.

102 Vgl. Teresa de Lauretis: „Das Rätsel der Lösung - Umberto Ecos Der Name der Rose als postmoderner Roman“. In: Andreas Huyssen \& Klaus R. Scherpe: Postmoderne. Zeichen eines kulturellen W andels. Reinbek: Rowohlt, 1986, S. $251-269$.

103 Vgl. dazu Mayer (32004), S. 543f; Hans Ulrich Gumbrecht: Art. „Postmoderne“. In: Reallexikon der deutschen Literaturwissenschaft. 3., neubearb. A. Berlin \& New York: de Gruyter. Bd. 3 P-Z. Hg. v. Jan-Dirk Müller, 2003, S. 136-140; Andreas Huyssen: „Postmoderne - eine amerikanische Internationale?“. In: Huyssen \& Scherpe (1986), S. 13-44 sowie Magret Möckel: Erläuterungen zu Peter Stamm: Agnes, Hollfeld: Bange, 2001, S. $13 f$.
} 
struktivismus an, dem gemäß die Welt nur ein Produkt der eigenen Wahrnehmung eines Individuums ist.

- Besondere Erzählstruktur:

- Der Erzähler wendet sich an den Leser, der aktiv ins Geschehen einbezogen wird

- In einem Text werden verschiedene Erzählmodi und -stimmen eingesetzt.

- Der Text verwendet Umgangs- und Alltagssprache, unterschiedliche Sprachebenen und -register.

- Metafiktion: Als ,Fiktion über Fiktion' referenziert der Text auf andere Werke oder sich selbst und reflektiert dabei sich selbst. In einer unendlichen Steigerung liest der Leser z. B. über ein Buch, das denselben Titel trägt wie das vorliegende, wobei er sich selbst im fiktiven Leser erkennen kann. Postmoderne Metafiktion ist inspiriert von der Romantischen Ironie (vgl. Kap. III.7.2.4.4), die den Text im Text selbst reflektiert und das Spiel mit den Erwartungen des Lesers auslotet.

- Selbstreferenz, Metatextualität. Der Autor flicht Reflexionen über Schreiben und Lesen sowie über den Entstehungsprozess des Geschriebenen in den Text ein. Hierzu zählt auch die mit dem Motiv des Buchfundes verwandte Herausgeberfiktion, wenn ein fiktiver Herausgeber behauptet, den vorliegenden Text von Dritten erhalten zu haben und nun zu veröffentlichen oder die Geschichte von jemand anderem zu übersetzen (vgl. Kap. II.1.3.1).

- Kontextualität. Der Text ist begründet auf einem früheren, der als Subtext sichtbar ist. Dieses Merkmal tritt allerdings nicht originär im postmodernen Roman auf. Auch der moderne Roman der Neuzeit bringt Anspielungen auf andere Werke der Weltliteratur ein oder verwendet bekannte Stoffe als Subtext, u. a. verweist das beinahe schon klassische Beispiel von James Joyce’ Ulysses (1918/19) auf Odysseus' Abenteuer; Thomas Manns Dr. Faustus (1947) auf die Faustsage.

- Die trennenden Gattungszuordnungen werden aufgelöst, die Genregrenzen verschwimmen, so dass hybride Genres entstehen (,Mystery"). Damit einhergehend wird die Grenze zwischen Unterhaltungs- und Hochliteratur, zwischen E- und U-Kultur, aufgeweicht und überschritten.

- Techniken verschiedener Medien werden vermischt, z. B. kommen Strategien des Films in Romanen vor („It is necessary to use the same weapons as the enemy, his tricks and traps; that is to say, you have to put cinema and television into books. “ ${ }^{104}$ )

\section{Subjektivität}

104 Anne L. Walsh: Arturo Pérez-Reverte. Narrative tricks and narrative strategies. Woodbridge etc.: Tamesis, 2007, S. 123. Die Autorin gibt ein Zitat von Arturo Pérez-Reverte in Übersetzung wieder. 
- Die Möglichkeit zur Selbstbestimmung des Subjekts wird in Frage gestellt, der Protagonist fühlt sich ,fremd gesteuert'. Der Text setzt sich deshalb intensiv mit einem Protagonisten auseinander, aus dessen Perspektive erzählt wird und dessen Innensicht, z. B. durch eine interne Fokalisierung oder erlebte Rede, vorgeführt wird.

- Der postmoderne Held ist mit seinen Schwächen und Unzulänglichkeiten ein Anti-Held, der Raum zur Identifikation bietet.

- Objektivität ist kaum möglich, die Welt nicht objektiv erfahrbar, da sie in die persönlichen Empfindungen, Erfahrungen und Anschauungen des Einzelnen zersplittert ist.

\section{Identität}

- Das Individuum ist sich seiner selbst nicht mehr sicher und zweifelt an sich und seiner Rolle in der Gesellschaft.

\section{Wirklichkeit}

- Realität und Mythen oder Wunderbares verschmelzen auf der Ebene der Fiktion, fantastische Elemente werden in den Text eingebracht. Realität und Fiktion sind sowohl auf der fiktiven Ebene als auch in der Realität kaum noch unterscheidbar.

\section{Sinn}

- Intertextualität: Zitate, Anspielungen, intertextuelle Verweise, aber auch explizite Bezüge auf andere kulturelle Werke der Literatur, des Films, der Musik, der Wissenschaft oder der bildenden Kunst etc. sind Teil des Textes. Es wird auf Bekanntes rekurriert, dieses wird demontiert und neu zusammen gesetzt statt einem Innovationszwang ${ }^{105}$ nachzugeben, was mitunter als ,eklektizistische [...] Zitatkunst“ ${ }^{\star 106}$ empfunden wird.

- Es herrscht ein Nebeneinander mehrerer Lesarten des Textes. Der Text verweist auf verschiedene Bezugsebenen, so dass der Leser unterschiedliche Schlüsse aus dem Gelesenen ziehen kann, wie es bei beinahe jedem (fiktionalen) Text der Fall ist.

- Mehrfachkodierung: Der Text berücksichtigt unterschiedliche originäre Erwartungshaltungen von Lesern an den Text und eröffnet multiple Zugangsmöglichkeiten. Ein Dechiffrieren und Verstehen des „mehrfach codierte[n]“107 Textes auf verschiedenen Ebenen ist möglich und wird hervorgerufen durch die Vielfalt der intertextuellen und -kulturellen Bezüge. Der Normal-

\footnotetext{
105 Eben diesen „Innovationszwang“ sieht allerdings Gero von Wilpert in seinem Überblick über die Postmoderne als literarischem Phänomen als deren Merkmal, vgl. Gero von Wilpert: Art. „Postmoderne, Postmodernismus“. In: Ders.: Sachwörterbuch der Literatur. 8., verb. u. erw. A. Stuttgart: Kröner, 2001, S. 627f, hier S. 628. 
leser und damit ein Massenpublikum kann den Text als ,einfache', unterhaltsame Geschichte genießen. Darüber hinaus wird dem vorgebildeten Leser ein ,Erkennen’ der Verweise ermöglicht und, je mehr Chiffren er zu deuten und ,Leerstellen' zu füllen vermag, ein Mehr an intellektuellem Vergnügen beim Lesen zuteil. Der Autor wiederum kann auf diese Weise ebenfalls sein kulturelles Wissen und seine literarische Kenntnis unter Beweis stellen und in Kommunikation mit dem Leser treten, der als Deutungsinstanz an der Konstruktion des Textes beteiligt ist und somit gegenüber dem Autor aufgewertet wird: „,...] postmodern writing challenges us because it requires its reader to be an active co-creator of meaning rather than a passive consumer." ${ }^{108}$

Das postmoderne Schreiben ist heute, etwa 30 Jahre nach seiner Blütezeit, zwar nicht mehr richtungsweisend, seine Merkmale werden aber immer noch häufig angewandt. Dabei muss beachtet werden, dass Moderne und Postmoderne, auch in der Literatur, keine chronologisch aufeinander folgenden oder aufbauenden Systeme sind, sondern, neutral formuliert, „Problematiken“ ${ }^{109}$, die auch neben einander existieren.

\section{Zusammenfassung}

Es konnte gezeigt werden, dass es unabhängig von literarischen Moden und epochentpyischen Tendenzen zu jeder Zeit Darstellungen von Büchern in Büchern gab und gibt. Das ,Buch im Buch' findet sich als literarisches Motiv gerade in aktueller Romanliteratur und den für das untersuchte Korpus ausgewählten Titeln wieder. Gewandelt hat sich allerdings die Art und Weise, wie das Buch porträtiert wird und wie der Leser mit ihm interagiert.

Fiktionale Literatur ist untrennbar mit dem Medium Buch verbunden. Das Buch steht dabei im Kontext des Lesens zur Unterhaltung auch immer für die Gattung Roman, der seit seinem Aufstieg im ausgehenden 18. Jahrhundert zur erfolgreichsten Literaturgattung und damit zum Synonym für das Printmedium Buch wurde. Im Roman steht wie das ,Buch im Buch’ aber auch der Leser im Vordergrund. Seit der Aufwertung des Lesers und seines Rezeptionsprozesses in der Literaturwissenschaft seit etwa den späten 1960ern wird in der Romanliteratur ein besonderer Akzent auf den Leser gesetzt. Erst durch den Leser und seine Textrezeption wird der Gegenstand Buch lebendig und seiner Bestimmung zugeführt, ungelesen ist das Buch nutzlos. Der Leser animiert das Buch und wird gleichzeitig selbst aktiv. In den Romanen zeigt dies die Interaktion des Protagonisten mit dem Buch, figurativ ist hier der stärker in den Fokus gerückte Rezeptionsprozess des Lesers gemeint. Der Leser wird neben dem Autor aufgewertet, der nicht mehr allein für das Werk verantwortlich sein soll. Damit verbunden ist die häufigere Verwendung 
des Motivs „Buch im Buch’ und elaborierter Erzähltechniken, die explizit Lesen und Buch als Teil der Handlung thematisieren und den Leser in die Fiktion einbeziehen. Der Status des Buchs als Fiktion in der Fiktion wird nun reflektiert, es ist außerdem möglich, dass der Protagonist auf der Fiktionsebene zu ahnen beginnt, dass er nur Fiktion ist.

In der aktuellen Romanliteratur findet eine Akzentverschiebung vom ,lesenden Helden', der durch seine Lektüre erzogen werden soll, hin zum Fokus auf das Buch und seine Interaktion mit dem (Leser-)Protagonisten statt. In den neueren Darstellungen des „Buchs im Buch' als Motiv in der Romanliteratur erfährt der Protagonist durch ein Buch, das einen besonderen Eindruck auf ihn macht, eine Veränderung: Das Buch ist also neben dem Leser ebenso ein Protagonist. Hier kann es sehr wohl der Fall sein, dass das ,Buch im Buch' gar nicht gelesen wird, das bedeutet, es wird nicht der Leseprozess geschildert, sondern die Interaktion des Protagonisten mit dem gegenständlichen Buch. Das Buch wird nunmehr als Objekt wichtig. Das Buch zeigt sich hier mitunter als abgelöst von seinem Inhalt und erlangt als ,Buchschatz’ Bedeutung, was mit der Erkenntnis des Buchs als Handelsware zusammenhängt. Heute ist ein beliebtes Motiv in der Romanliteratur die abenteuerliche Suche nach dem, einen', besonderen und solitären Buch, was aus der Sicht des heutigen Buchmarkts und seiner sich immer schneller drehenden Massenproduktion fast paradox erscheint. Als Unikat wird das Buch rätselhaft, exotisch und geheimnisvoll, Charakteristika, die mit dem Buch-Motiv gekoppelt die Handlung steuern und mit dem Genre des Romans in Wechselbeziehung stehen.

In der literarischen Welt des 18. Jahrhunderts dagegen stand der Autor eindeutig im Vordergrund, nicht der Leser. Mit der empathischen Lektüre ging ein besonderes Interesse am Autor einher, was exemplarisch die zeitgenössische Verehrung Rousseaus verdeutlicht. Die Bindung an den Text beförderte eine Bindung an den Autor, die auch im heutigen Literaturbetrieb und in heutiger Literatur sichtbar wird: Der Autor erhält als Literat ein Gesicht, was zwar nicht eigentlich zu einem Starkult wie in der Musik- oder Filmbranche führt, doch er wird mehr und mehr als prominente Persönlichkeit wahrgenommen, dessen Privatleben für die Öffentlichkeit interessant wird. In den untersuchten Romanen ist es der Fall, dass Protagonisten einem Autor nachspüren, dessen Schriften sie derart beeindruckt haben, dass sie auch den Autor dahinter kennenlernen möchten. Im Laufe der Beschäftigung mit dem Autor stellt sich heraus, dass der Protagonist ihm immer ähnlicher wird oder es bereits ist - der Leser emanzipiert sich zunächst gegenüber dem Autor, bis er sich schließlich mit ihm identifiziert. Aus dem Blickwinkel der Literaturwissenschaft betrachtet trifft dies auch auf den Schaffensprozess von fiktionalen Texten zu.

Eine selbständige, aktive Lektüre selbst gewählter Inhalte (über Bibel und Predigt-Schriften hinaus) war nicht immer gewünscht und ist es heute auch nicht in allen Kontexten. Die Warnung 
vor der ,Vielleserei’ gegen Ende des 18. Jahrhunderts zeigt, für wie gefährlich Bücher gehalten wurden, und welches Potential zum selbständigen Denken und Handeln in ihnen vermutet wurde. Zwar ist das Lesen von Romanen heute generell nicht mehr schlecht beleumundet, doch zeigt sich damals wie heute eine Unterscheidung zwischen richtigem und falschem Lesen und einer richtigen und falschen Art mit Büchern umzugehen. Die Figur des Büchernarren ist eng verknüpft mit dem Buch-Motiv in fiktionaler Literatur und kommentiert den Umgang mit Buch und Lektüre. Der Büchernarr stellt einen Anreiz für Leser dar zu lesen, da sich der Leser gespiegelt in der Fiktion wiederfinden kann, er birgt aber zugleich eine Warnung, seinem unmäßigen Beispiel zu folgen.

Das ,Buch im Buch’ ist ein Stilmittel neuer ambitionierter fiktionaler Techniken. Schrift und Schreiben werden in den Buch-Büchern ebenso thematisiert und reflektiert wie Lesen und Leser. Es kommt häufig in diesen Romanen vor, dass der Leserprotagonist als homodiegetischer Erzähler seine Geschichte zum besseren Verständnis des Erlebten oder als Mitteilung an die Nachwelt verschriftlicht. Diese Phänomene sind vor allem als Merkmale postmoderner und von dieser inspirierter Literatur zu verstehen. Die Selbstthematisierung von Literatur im eigenen Medium ist allerdings nicht neu: Sie war schon Ausdruck der Romantik und der Forderung nach einer ,Romantisierung' der Welt, der Durchdringung von Realität und Fiktion, die es Leser und Autor möglich machen sollte, die Positionen zu wechseln und eins zu werden. Die, Welt als Buch' wird von den fantastischen Buchwelten, in denen Bücher eine dominante Rolle einnehmen, wörtlich genommen und gesteigert. Die Postmoderne bezieht sich ausdrücklich und erkennbar auf (neo-) romantische Vorbilder. Das zu entziffernde Buch, die mysteriöse Chiffre der Romantik, wird von postmodernen Konzepten und mit der Mehrfachkodierung von Texten wieder aufgegriffen. Allerdings wird die Dechiffrierung von Literatur und Welt von der Postmoderne gesteigert: Es soll nicht mehr nur eine einzige Bedeutung hinter einer Chiffre stehen, sondern so viele wie es Leser gibt, Texte seien also mehrfach kodiert und sprechen auf diese Weise unterschiedliche Leserkreise mit unterschiedlicher literarischer Kenntnis an.

Das Buch umgibt durch die Selbstthematisierung etwas Rätselhaftes, Mysteriöses. Wie in Gothic Novels ein Doppelgänger den Protagonisten verwirren kann, wird der Leser durch die Doppelung seiner Selbst durch einen fiktiven Leser herausgefordert, was ebenso in der Fiktion als auch in der Realität der Fall sein kann. Ein geistiges Rätsel entsteht, wenn der Entwirrung von Realität und Fiktion nachgespürt wird. Die Identitäten können sich auch bei der Identifizierung mit einem Autor verflechten, das Buch kann bei der Identitätssuche hilfreich sein, aber auch zusätzliche Verwirrung stiften. Die Suche nach der Lösung oder die abenteuerliche Suche nach einem besonderen Buch wirken ebenso geheimnisvoll. Das Buch-Motiv ist durch diese Mystifizierung auf bestimmte Roman-Genres festgelegt, auf Abenteuer-, Spannungs-, Detektiv-, Kriminal- oder Mystery-Literatur. 
Hatte das Buch, gerade der Roman, im ausgehenden 18. Jahrhundert eine Stellung als Leitmedium innerhalb der (Druck-)Medien inne, droht es heute, da sich digitale Medien in jedem Lebensbereich verstärkt als Leitmedien durchsetzen, mehr und mehr an Bedeutung zu verlieren. Der Roman reagiert auf die Position des eigenen Mediums und reflektiert sie. Dass sich das Buch in Konkurrenz zu anderen Medien befindet, ist heute keine neue Situation, man betrachte nur den Roman und seine Stellung in seinen Anfängen und seine letztliche Durchsetzung als Leitmedium gegenüber Gelehrten Zeitschriften. Auf der Basis der bisherigen werden immer neue Medien entstehen und sich unter bestimmten Bedingungen gegenüber den alten durchsetzen.

Bücher werden als Motiv in Romanen unter ganz verschiedenen Aspekten eingesetzt. Das Auftreten des Buchs als Motiv im Roman ist sowohl einer reichen literarischen Tradition zu verdanken als auch einer stärkeren Fokussierung auf den fiktiven Leser sowie der heutigen neuen Position und Situation des Buchs gegenüber anderen Medien geschuldet. Als in der Romanliteratur gut etabliertes Motiv bringt das „Buch im Buch’ dem Zeitgeist seiner Entstehung entsprechende Wünsche, Vorlieben und Überzeugungen in den Roman ein und prägt die Gedanken- und Vorstellungswelt des Lesers. Die anschließende Motivuntersuchung wird zeigen, welche Implikationen dies sind und wie das Buch-Motiv in Romanen der Gegenwart gezeigt wird. 


\section{III.Typologie des Buch-Motivs}

\section{Zur Motivuntersuchung}

\subsection{Zu Korpus und Motivuntersuchung}

Im Zuge des Diskurses über den Status des Buchs mit seinen Typisierungen und Argumentationsroutinen fällt eine häufige Erwähnung des Buchs als Motiv in der aktuellen Romanliteratur auf. Die Vermutung liegt nahe, dass das Buch heute gerade in einer großen Anzahl von Romanen reflektiert wird, weil das Druckwerk Buch einerseits als Medium auf dem Prüfstand steht, andererseits aus seiner angeblichen Entbehrlichkeit heraus doch eine Renaissance erlebt. Allerdings darf nicht vergessen werden, dass auch literarische Traditionen das Motiv bedingen, schließlich ist das ,Buch im Buch’ kein neues Phänomen, wie im vorigen Kapitel nachdrücklich belegt wurde. Die untersuchten Romane vermitteln eine wiederentdeckte Lust am Lesen und Freude an der Beschäftigung mit Büchern. Dabei greifen sie auf ,gute, alte Zeiten’ zurück, symbolisiert durch das traditionelle Buchmedium nebst einer implizierten Warnung davor, das Buch durch die ,neuen Medien' zu ersetzen. Die neue Situation setzt das Buch frei für neue Erweiterungen. Gegenüber den körperlosen, digitalen Medien scheint das Bedürfnis nach dem traditionellen Medium, das man auch haptisch erfahren kann, groß - der Status des Buchs wird diskutiert und das Buch zum Motiv der Literatur, gerade weil es nicht mehr eine feste Funktion inne hat. Nicht nur Bücher vermitteln heute Texte - eine Funktion, die Bücher bisher nur mit anderen Printmedien wie Zeitschriften teilten - sondern auch elektronische Medien.

Zwar machten Marshall McLuhan ${ }^{110}$ und Neil Postman ${ }^{111}$ mit ihren kulturpessimistischen Prognosen bereits in den 1960ern bzw. 1980ern, und dabei vor allem mit Blick auf das Fernsehen, später auch auf andere Bildschirmmedien, die technischen Entwicklungen neuer, visueller Medien für einen vermeintlichen Rückgang des Lesens und allgemein für einen Niedergang einer „Kultur des Lesens’ und damit einhergehend auch des Buchs verantwortlich. Dennoch kann man feststellen, dass der Leseranteil in der deutschen Bevölkerung zwischen den Jahren 1978 und 1999 weitestgehend konstant geblieben ist ${ }^{112}$. Gewandelt hat sich hauptsächlich der Zugang zu Medien und deren Nutzung, eine Entwicklung, die heute noch weiter fortgeschritten ist. In Kapitel 3.2 wird die Stellung von Buch und Lesen heute eingehend analysiert undas heutige Lesepublikum definiert als eines, das mehrere Medien selbstverständlich nutzt.

\footnotetext{
110 Vgl. Marshall McLuhan: The Gutenberg Galaxy. The Making of Typographic man. London: Routledge \& Paul, 1962. 111 Vgl. u. a. Neil Postman: Amusing ourselves to death. Public discourse in the age of show business, New York: Viking, 1985. 112 Vgl. Claudia Langen \& Ulrike Bentlage (Hg.): Das Lesebarometer - Lesen und Mediennutrung in Deutschland. Eine Bestandsaufnahme zum Leseverhalten 1999. Gütersloh: Verlag Bertelsmann Stiftung, 2000, S. 12. - Der Leseranteil definiert sich in dieser Untersuchung durch positive Antworten auf die Frage nach der Buchlektüre in den vorigen 12 Monaten und lag im betreffenden Zeitraum stabil bei etwa 70\%.
} 
Betrachtet man das aktuelle Romanangebotet näher, drängt sich der Eindruck auf, dass das Buch entgegen seiner allseits vermeintlich beobachteten Entbehrlichkeit allgegenwärtig scheint. Die Häufigkeit des fiktionalisierten Buchs ist nun der Ausgangspunkt, genauer nach dem Motiv ,Buch im Buch' und seiner Signifikanz innerhalb der Romanliteratur zu fragen. Aufgabenstellung meiner Untersuchung des ,Buchs im Buch’ ist ein motivgerichteter Querschnitt durch die aktuelle Prosa, der zum Ziel hat, ein weit verbreitetes literarisches Phänomen zu untersuchen und somit besser zu verstehen, wie die Literatur selbst mit ihrer gewandelten Position umgeht, wie das BuchMotiv in Romanen gezeigt und kombiniert wird und welche Implikationen es mit sich bringt.

Aufgrund der Aktualität der Korpustitel ist nicht für jeden Roman Sekundärliteratur erhältlich. Ergänzend zur Untersuchung am Primärtext werden für die Bücher, sofern verfügbar, auch Rezensionen aus dem Feuilleton einer überregionalen Tages-/Wochenzeitung sowie einige repräsentative Amazon.de-Leserrezensionen herangezogen. Bei letzteren divergieren die Meinungen zu einzelnen Werken mitunter sehr stark, u. a. auch aus dem Grund, da die Leser unterschiedliche literarische Vorkenntnisse besitzen und das Buch auf unterschiedlichen Ebenen rezipieren. Gerade diese Herangehensweise entspricht dem Kern der Ermittlung des „Themas“ eines Buchs und erscheint vielversprechend für die Ermittlung virulenter Funktionen des Buch-Motivs.

\subsubsection{Korpus an untersuchten Romanen}

\subsubsection{Identifikation der Korpus-Titel}

Die analysierten Romane sind nach umfangreichen Recherchen ausgewählt worden, da sie sich besonders originell und völlig unterschiedlich mit dem Buch beschäftigen, wobei gewisse stereotype Darstellungen des Buchs stets beibehalten werden. Nicht entscheidend für die Aufnahme eines Buch-Romans in das Korpus der zu untersuchenden Romane war der Blick auf avantgardistische Romanexperimente. Ein Kriterium, um die Buch-Bücher für das Korpus überhaupt erst zu identifizieren, ist die Art und Weise der Darstellung des Buchs: Das Buch tritt in den untersuchten Buch-Romanen als Gegenstand und Haupt-Agens auf. Das Korpus bildet dabei die Möglichkeiten ab, mit denen Bücher in Büchern eine Rolle spielen können. So unterschiedlich die Korpustitel auf den ersten Blick auch erscheinen mögen, haben sie doch zentrale Gemeinsamkeiten. In allen Romanen steht ein spezielles Buch im Vordergrund, das in besonderer Art und Weise auf den Protagonisten Eindruck macht und auf ihn einwirkt. Das Buch tritt dabei in traditionell bekannter Form als materiell und haptisch erfass- und erfahrbar in Erscheinung, überdies als überaus auratisches Medium. Als ,auratisch' wird in dieser Arbeit, an den allgemeinen Sprachgebrauch angelehnt, eine besondere, fast magische und charismatische Ausstrahlungskraft und Atmosphäre bezeichnet. 
In zwei Fällen (Der Club Dumas und Das Labyrinth der Welt) wurden als Binnenbuch auch Handschriften zugelassen, die auf Bücher verweisen. Eine Ausnahme bildet hier der Roman Agnes von Peter Stamm. Das ,Buch im Buch' ist hier eine virtuelle Textdatei, entspricht also nicht den zugrunde gelegten Kriterium. Der Roman wird aber doch zugelassen, da er wichtige Aspekte zur Positionierung des Buchs gegenüber den ,Neuen Medien’ beinhaltet. Ein vorkommendes Buch kann weitere nach sich ziehen, da die Protagonisten der Buch-Bücher in einer Bücherumwelt tätig sind oder in eine buchaffine Welt eingebunden sind - in den vorliegenden Romanen wird das Buch als Handlungselement geradezu erwartet, dass es als Motiv wichtig wird, rückt es zusätzlich in den Fokus. Dabei kann das Buch in einem Roman in mehreren Motivclustern, also Kombinationen von Motiven, vorkommen.

Ein weiteres Auswahlkriterium war, dass die Titel in Original oder Übersetzung innerhalb der letzten 20 Jahre, also seit etwa 1990, auf dem deutschen Buchmarkt erschienen sein sollten. Dieser Untersuchungszeitraum legitimiert sich durch die Tatsache, dass Tim Berners-Lee vom CERN (Conseil Européen pour la Recherche Nucléaire) im Jahr 1989 das World Wide Web ,erfunden' hat ${ }^{113}$ und es Anfang der 1990er Jahre auch für den privaten Nutzer geöffnet wurde (vgl. Kap. III.8.2). Seither sind WWW und Internet aus der privaten und beruflichen Welt nicht mehr wegzudenken. Der Beginn der 1990er Jahre markiert somit den Beginn der Konkurrenz zu diesem „Medium schlechthin“114, dem sich das Buch gegenüber sieht.

Erwähnenswert ist, dass die Gestaltung des Motivs ,Buch im Buch’ gegenüber bisherigen literarischen Darstellungen einer Akzentverschiebung unterliegt. Wo vormals noch ein ,lesender Held $^{\prime 15}$ mit seinen Lektüreerfahrungen und -eindrücken als Reflexionsfigur des Buchs im Zentrum stand und in der Handlung des (fiktiven) Buchs Parallelen zu seiner eigenen Situation und Vorbilder für sein Handeln und seine moralische Ausbildung findet, werden dem Buch selbst nun Qualitäten und Charakteristika zugeschrieben, die Rückschlüsse auf Produzenten und Rezipienten von Literatur sowie auf die gesamte literarische Kommunikation zulassen.In den untersuchten Romanen nun ist nicht unbedingt der Protagonist und seine Lektüre des Texts für die Handlung entscheidend, sondern das Buch selbst als Gegenstand wichtig, indem es den Helden von außen, oft als Objekt seiner Suche und nicht im Inneren als Gelesenes, beeinflusst. Da das Buch in den untersuchten Romanen. z. B. als Objekt einer Suche, über weite Teile der Handlung gar nicht verfügbar ist, steht weniger das Lesen des Textes im Vordergrund. In den

113 Tim Berners-Lee reichte 1989 einen ersten Vorschlag für ein World Wide Web (Www) ein, der im folgenden Jahr von ihm und Robert Cailliau weiter verbessert wurde, vgl. „How the Web began“, Webseite des CERN [http://public.web.cern.ch/public/en/About/WebStory-en.html], eingesehen am 01.02.2010.

114 Vgl. o. V.: „Am 30. April 1993 ist das Internet gestartet“, Webseite der Internetagentur symweb GmbH, 30.04.2008, [http://www.symweb.de/news/world-wide-web-www-15-jahre_231.htm], eingesehen am 14.07.08.

115 Vgl. u. a. die Forschung von Ralph-Rainer Wuthenow, vgl. Kap. II.3. 
wenigsten Korpustiteln wird so der Leseprozess geschildert, vielmehr hat das Buch selbst eine besondere Bedeutung. Daraus folgt, dass nicht mehr Gefühlswelt und Gedanken des Protagonisten und seine Beeinflussung durch Lektüre entscheidend ist, sondern seine Reaktionen auf das Buch, das ohne dieses Zusammenspiel einfach ein unbelebter Gegenstand wäre und seine mitunter subversive Kraft ungenutzt bliebe. Die Reaktionen des Protagonisten auf das Buch beeinflussen wiederum die Handlungen seiner Mitakteure.

Das einende Kriterium der Korpus-Titel ist die Einzigartigkeit des Buchs, die Wertigkeit, die ihm durch den Protagonisten zugesprochen wird, sowie die Kombination mit anderen Motiven, die das Motiv Buch eingeht. Das Buch wird so zu etwas ganz Besonderem. Auf der Basis dieser immer wieder mit dem Buch kombinierten Motive konnten Motivgruppen zusammengestellt werden, die einen Überblick über die Sichtweise auf das Buch geben und die zeigen, dass das Buch in allen Bereichen des Lebens und der Literatur verankert ist. Diese Verknüpfung hat unterschiedliche Auswirkungen auf die Darstellungen des Buch-Motivs in Romanen und ihre Implikationen, die im Rahmen der Motivuntersuchung ermittelt werden.

\subsubsection{Untersuchungsspektrum \& Genre}

Der Untersuchung liegen internationale Romane zugrunde, die seit den frühen 1990er Jahren auf dem deutschen Buchmarkt in Original oder Übersetzung erschienen sind. Dabei wird sowohl Hochliterarisches (Huizing, King, Pérez-Reverte, Mercier) und Unterhaltungsliteratur (Domínguez, Ruiz Zafón, Schmitt, Wharton) als auch Kriminal- und Spannungsliteratur (Collins, Živković) sowie Fantastisch-Groteskes (Schweiggert, Jacobi, Moers, Fforde) in den Blick genommen. Diese Art der Korpusbildung, die auch populäre Titel berücksichtigt, stellt einen neuen Forschungsaspekt dar, denn die bisherige Forschung hat sich auf kanonische Titel beschränkt.

Das Buch-Motiv tritt genreübergreifend in Romanen auf. Bei der Auswahl der Titel waren alle Genres zugelassen, es zeigte sich aber, dass die Buch-Romane neben fantastischen Titeln vor allem im Bereich des Mystery- und Kriminalromans oder im unheimlichen Genre anzutreffen sind. Genres werden generell durch die Verwendung gewisser Motive und Themen bestimmt, hier fügt das Buch-Motiv eine eigene Komponente hinzu und bereichert das übliche Genremuster. Die Buch-Romane evozieren eine geheimnisvolle Stimmung, die den Leser auf das zugrunde liegende Genre und Rätselhaftes einstimmt, aber im weiteren Handlungsverlauf mit dem Buch-Motiv überrascht. Das Buch tritt im Buch in Erscheinung, um im realen Leser eine bestimmte Stimmung und Assoziationen zu wecken, die er mit dem bekannten Motiv verknüpft. Auf der Erzählebene ist das Buch entscheidend für den Fortgang der Handlung, der Umgang mit dem Buch charakterisiert dabei die Figuren. Das Buch dient in vielen Darstellungen als ,altmodisches' Medium für die Aufklärung historischer Ereignisse oder für die Aufdeckung von Verschwö- 
rungen, da es selbst von einer Aura des Geheimnisvollen, Magischen und Traditionellen umgeben wird. Die Verortung von Buch-Büchern im Spannungsgenre dient dabei als Mittel, um das ,Abenteuer des Geistes' zum Ausdruck zu bringen: Mit einer unheimlich-mysteriösen oder einer kriminalistischen Handlung wird das Verfolgen der oft komplexen Erzählstrukturen für den Leser optimal umgesetzt.

In heutigen Romanen spielen auch utopische Bücherwelten eine Rolle, in denen Literatur eine ungemein größere Rolle als in unserer Welt zukommt - haben wir es hier mit einer Rückbesinnung, ja Verklärung der Zeit zu tun, in der Bücher für ein größeres Publikum wichtig waren und nun wieder werden, kurz: mit einer Glorifizierung des Buchs? Als Beispiele für Romane, in denen eine solche utopische Bücherwelt thematisiert wird, wurden zwei aktuelle fantastische Titel von Jasper Fforde und Walter Moers in das Korpus aufgenommen. Das Buch scheint einen derartigen Stellenwert in der Romanliteratur eingenommen zu haben, dass im fantastischen Genre auch Groteskes ausprobiert werden kann. Beispiele dafür sind Mein Leben als Buch und Das Buch, zwei Romane, in denen sich der Protagonist, einmal mit humorvoller, einmal ernsthafter Grundstimmung, in ein gegenständliches Buch verwandelt.

\subsubsection{Abgrenzung zu ausgelassenen Themenbereichen}

\subsection{Jugendliteratur}

Das Thema des lesenden Protagonisten, der in eine fiktive Welt einbezogen wird und diese verändern oder sogar erschaffen kann, bzw. eine Vermischung von Fiktion und Realität mit intertextuellen Bezügen, tritt nicht nur in Literatur, die ein erwachsenes Lesepublikum ansprechen soll, auf, sondern auch in der aktuellen Jugendliteratur, die das öffentliche Bewusstsein, spätestens seit J. K. Rowlings Harry-Potter-Reihe, verstärkt zur Kenntnis nimmt. Hier zeigt sich eine wahre Flut an Titeln, vor allem aus dem Bereich Fantasy, die einen Bezug zu Büchern und Lesen aufweisen, womöglich ein neuer Trend von Erzählungen, deren doppelt fiktive Welt in die Welt der Erzählung hineinragt.

Zu nennen wäre hier neben Jostein Gaarders Bibbi Bokkens magische Bibliothek (2001) vor allem Cornelia Funkes Tintenwelt-Trilogie, die zum Welterfolg und (natürlich) auch erfolgreich verfilmt wurde. Bereits 1979 machte Michael Endes Die unendliche Geschichte Furore. Auch hier ist der jugendliche Held dazu in der Lage, dem Gelesenen zum Leben zu verhelfen und selbst ein Teil der Erzählwelt zu werden. Dieses Buch, und sicher auch seine dreiteilige filmische Umsetzung, war so beliebt, dass sich der Jugendbuchautor Ralf Isau einer Sammlung von weiteren Geschichten aus dem fiktiven Fantasien annahm, die unter dem Titel Die geheime Bibliothek des Thaddäus Tillmann Trutz (2003) erschien. In seinem im Exil verfassten Jugendbuch Haroun and the Sea of Stories (1990) schildert Salman Rushdie anhand des Meers der Geschichten, das im Krieg zwischen zwei 
Staaten zu versiegen droht, die Macht der Literatur. Auch hier muss eine fiktive Welt der Fantasie vor einer Bedrohung geschützt werden. Die Beispiele ließen sich noch beliebig fortsetzen.

Jedoch bleibt in dieser Untersuchung die Jugendliteratur ausgeklammert. Das Motiv „Buch’ ist in dieser Art Literatur anderen Gesetzen unterworfen als in den Romanen, denen sich diese Arbeit widmet. Bei Jugendbüchern kann man davon ausgehen, dass das „Buch’ stets einen fiktionalen Inhalt bereithält, der das Leben des Protagonisten verändert und prägt, während dies in Romanen für ein vorwiegend erwachsenes Publikum nicht zwingend gegeben ist. Außerdem soll das ,Buch' in Jugendliteratur hauptsächlich, so kann man behaupten, als Mittel der Leseerziehung dienen ${ }^{116}$ : Das Buch wird als spannende Möglichkeit gestaltet, fiktive Welten zu erschaffen Löffler spricht von einem „Tummelplatz lesepädagogisch entflammter Jugendbuch-Autoren“117. In diesen Buchwelten kann der Leser derart versinken, dass er sich in seiner Position als Leser dazu in der Lage sieht, an diesem Abenteuer teilzuhaben, indem ihm der lesende jugendliche Held große Identifikationsmöglichkeiten bietet ${ }^{118}$. So wird der jugendliche Leser an das Lesen als Freizeitbeschäftigung herangeführt.

Ein erwachsener Leser soll selbst das Lesen als Vergnügen für sich entdecken, wobei ihm Buch-Bücher, die rätselhafte Selbstbezüge und Identifikationsmöglichkeiten mit einem Leserprotagonisten bieten, als Entscheidungshilfe dienen sollen.

\subsection{Romane um Bibliotheken und Buchhandlungen}

Neben den Romanen, in denen das Buch als Motiv in Erscheinung tritt, sind gerade in den letzten Jahren auf dem deutschen Buchmarkt eine beträchtliche Anzahl an Romanen erschienen, die Bibliotheken und Buchhandlungen, Bibliothekare, Antiquare und Buchhändler sowie die Macht des Lesens in den Mittelpunkt stellen ${ }^{119}$ : Essentiell für die vorliegende Untersuchung ist, dass sie nur Romane zulässt, die ein besonderes Buch in den Fokus rücken, und keine Romane untersucht, in denen Bücher vorrangig als Setting und stimmungsvolle Kulisse vorkommen, wie z. B. in Romanen, deren Protagonist oder Protagonistin in einer Buchhandlung oder Bibliothek lediglich tätig ist ${ }^{120}$.

Als Varianten des Büchermenschen tauchen Bibliothekarinnen und Bibliothekare in der Romanliteratur besonders häufig auf ${ }^{121}$, und das vor allem in Detektiv- ${ }^{122}$ oder Kriminalromanen.

116 Vgl. Siebeck (2009), S. 207.

117 Löffler (2005), S. 12.

118 Vgl. dazu Jost Schneider: Sozialgeschichte des Lesens. Zur historischen Entwicklung und sozialen Differenzierung der literarischen Kommunikation in Deutschland. Berlin \& New York: de Gruyter, 2004, S. 418.

119 Vgl. dazu auch Löffler (2005), S. 8, die den Leser im Roman als „,neuartige[n] Typus“ bezeichnet.

120 Dazu gehören u. a. Penelope Fitzgerald: Die Buchhandlung (1989/dt. 2000); Allen Kurzweil: Die Leidenschaften eines Bibliothekars (2001/dt. 2002); Regis de sa Moreira: Das geheime Leben der Bücher (2004/dt. 2005); Karen J. Fowler: Der Jane-Austen-Club (2004/dt. 2005); Sheridan Hay: Die Antiquarin (2007/dt. 2007) oder Martin Zusak: Die Bücherdiebin (2008).

121 Eine umfangreiche Zusammenschau von Bibliotheken in Literatur und Film bietet Anne-Marie Chaintreau: Drôles de bibliothèques. Le thème de la bibliothèque dans la littérature et le cinema, 2. éd., rev. et augm., Paris: Éd. du Cercle 
Detektivromane jedoch sind im Korpus zu finden, z. B. Der Club Dumas - hier ist auch der bibliophile und/oder literaturbegeisterte Detektiv anzutreffen. Die Bibliothek selbst ist ein beliebter Schauplatz für Verbrechen und damit Ausgangspunkt für Detektiv- oder Kriminalgeschichten, man denke nur an Agatha Christies typische Tote in der Bibliothek (1942). Offensichtlich werden in diesem Motiv zwei Dinge vereint, die nicht zusammenpassen: Das Erschreckende dringt in den ruhigen, wohlgeordneten Raum der Bibliothek ein, der einerseits ehrwürdig oder gemütlich und somit unverdächtig anmutet. Allerdings symbolisiert das in den Büchern angesammelte Wissen auch schon die Aufklärung des Verbrechens, Wissen ist aber auch oft dessen Grund.

Doch auch die Bibliothek wird nicht im Vordergrund meiner Untersuchungen stehen. In die Untersuchungen werden die Romane über Bibliotheken und Bibliothekare nicht einbezogen, da spätestens seit dem großen Erfolg von Der Name der Rose (1980) (historische) Bibliotheksromane bereits bestens erforscht sind ${ }^{123}$. Die Konnotationen, die der Bibliothek in fiktionalen Darstellungen zugesprochen werden, z. B. das Gemütliche, Altertümelnde und Rätselhafte, treffen auch auf die Atmosphäre zu, die die ,Bücher in den Büchern’ hervorrufen.

Außerdem nicht zu vernachlässigen ist der Trend der Sachbücher über das Bücherlesen ${ }^{124}$ (vgl. Kap. III.6.3): Das Thema Bücher und Lesen ist heute populär und wird populär dargeboten. Das Lesen werde allerdings laut Löffler ,in den Sachbüchern beschrieben und erläutert, als

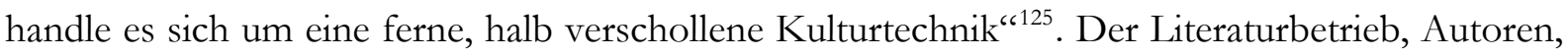
Kritiker und andere Buch- und Lesefreunde, reflektiert sich selbst und seine tägliche Lesetätigkeit, möglicherweise mit dem Ziel, diese auch anderen Menschen, ob schon Leser oder nicht, interessant zu machen - hier lässt sich ein postmoderner Trend ausmachen, über das Lesen und das Schreiben zu schreiben. Neben Sachbüchern, die das Buch thematisieren, erscheinen vermehrt Sammlungen über das Lesen und den Leser in literarischen Darstellungen, die allerdings größtenteils nur Paraphrasen literarischer Leseszenen bieten, und keiner übergreifenden For-

de la Librairie, 1993, ${ }^{11990,}$ Gottfried Rost stellt in „Die vielen Bücher! Haben Sie die alle gelesen?" Buch und Bibliothek.ar im Spiegel der Literatur betrachtet, Leipzig: Dt. Bücherei, 1981, literarische Darstellungen von Bibliothekaren vor. - Sammlungen von Romanen, Spielfilmen und TV-Serien, in denen Bibliotheken und Bibliothekare vorkommen, bieten die Websites [http://web.simmons.edu/ schwartz/bibmyst.html], [http://www.bibliomysteries.com] sowie [http://www.8ung.at/library_mistress/berufsbild/berufsbildbelletristik.html]. Interessanterweise liegt auch hier der Sammlungsschwerpunkt auf Detektivgeschichten. Letztere Website führt auch Sekundärliteratur auf.

122 Vgl. Jane Merrill Filstrup: „The Shattered Calm: Libraries in Detective Fiction“, Wilson Library Bulletin 1978, Vol. 53, Issue 4, S. 320-327 \& Issue 5, S. 392-98, hier S. 398.

123 Vgl. u. a. Stocker (1997), siehe auch Anm. 11 u. 12 zu diesem Kapitel.

124 Vgl. u. a. Daniel Pennac: Wie ein Roman (1992/dt. 1994); Alberto Manguel: Eine Geschichte des Lesens (1996/dt. 1998); Tagebuch eines Lesers (2004/dt. 2005), Die Bibliothek. bei Nacht (2007/dt. 2007); Anne Fadiman: Ex Libris. Bekenntnisse einer Bibliomanin (2000/dt. 2005); Matthew Battles: Die Welt der Bücher. Eine Geschichte der Bibliothek. (2002/dt. 2003); Nick Hornby: Mein Leben als Leser (2004/dt. 2005); Ulrich Greiner: Leseverführer. Eine Gebrauchsanweisung zum Lesen von schöner Literatur (2005); Steven Gilbar: Bibliomania. Ein listenreiches Buch über Bücher (2005/dt. 2006); Olaf Irlenkäuser \& Rainer Vollmar: Das Buch der Bücher (2006); Stefan Bollmann: Warum Lesen glücklich macht (2007) oder Alexander Pechmann: Die Bibliothek der verlorenen Bücher (2007).

125 Löffler (2005), S. 8. 
schungsfragestellung unterliegen. Die Thematisierung des Buchs wird hier lediglich als „leichte germanistische Fingerübung“ verstanden, die, von der Forschung abschätzig als „kommentierte Florilegien“126 bezeichnet, den Buchliebhaber erfreut, aber weniger als Gegenstand ernsthafter Forschungen in Betracht gezogen werden kann und soll ${ }^{127}$.

\subsubsection{Situation auf dem deutschen Buchmarkt}

Es sticht hervor, dass die Buch-Romane auf dem deutschen Buchmarkt zumeist in den gehobenen Taschenbuch-Verlagen bzw. -Reihen btb (Random House) und dtv premium (ausschließlich Erstausgaben) erschienen sind und sich das Erscheinen der ,Bücher über Bücher' insgesamt auf einige wenige Verlage konzentriert. Sein Programm aus gebundenen Büchern und Taschenbüchern, die neben der üblichen Zweitverwertung erfolgreicher Titel auch Erstausgaben bieten, beschreibt btb folgendermaßen: „Bei btb erscheinen seit Mai 1996 liebevoll ausgewählte und hochwertig ausgestattete Bücher für leidenschaftliche Leser und Bücherfreunde. Die Autoren und ihre Titel stehen für ein individuelles Programm für individuelle Leser.“128 - Ist dieser Anspruch Auftrag, Buch-Bücher ins Programm zu nehmen? Bei btb nachgefragt, lautete die Auskunft:

Es gab und gibt keinen Grund für die von Ihnen beobachtete Häufung von Titeln mit Buchbezug. Gerade die von Ihnen genannten Autoren [in meiner Anfrage nannte ich Pérez-Reverte, Huizing, King, B.B.-S.] sind mit mehreren Büchern im Programm vertreten, daß sich der ein oder andere mit dem Buch im Buch beschäftigt, ist reiner Zufall. ${ }^{129}$

Trotz dieser abschlägigen Antwort lässt sich auf dem deutschen Buchmarkt eine besondere Fokussierung eines literarischen Buchbezugs auf Verlagen mit anspruchsvollem literarischem Programm erkennen. Daraus kann man schließen, dass sich die Buch-Romane dezidiert an anspruchsvolle, kompetente Leser richten, die besondere Lektüre auf hohem Niveau schätzen.

\subsubsection{Zusammenstellung des Korpus}

In aufwändiger Recherche wurden die gängigen Bibliographien und Kataloge nach Titeln, die einen Buchbezug aufweisen, durchsucht. Dennoch ist es kaum möglich, Titel fiktionalen Inhalts zuverlässig nach ihren Themen und Inhalten, z. B. anhand eines Schlagworts, in den gängigen Katalogen zu recherchieren. Die traditionelle Art des Bibliographierens mit der modernen Internet-Buchrecherche verbindend, wie es Vorgehensweise und Thema meiner Arbeit nahe legen,

126 Stocker (2007), S. 87.

127 Vgl. dazu die Reihe „Seine Begierde, zu lesen, war unersättlich“, die im Jahr 1993 im Börsenblatt veröffentlicht wurde. Hans J. Schütz unternimmt hier eine Zusammenschau von Klassikern, die das ,Buch im Buch’ beinhalten, im Mittelpunkt steht jedoch auch hier der ,lesende Held’. Vgl. Hans J. Schütz: „Seine Begierde, zu lesen, war unersättlich“. Sechsteilige Reihe im Börsenblatt für den deutschen Buchbandel 12 (1993) 12.2.1993, S. 14-23; 13 (1993) 16.2.1993, S. 18-23; 14 (1993) 19.2.1993, S. 30-34; 15 (1993) 23.3.1993, S. 24-28; 16 (1993) 26.2.1993, S. 22-26; 17 (1993) 2.3.1993, S. 16-20.

$128 \mathrm{Vgl}$. den Internetauftritt des btb-Verlags [http://www.randomhouse.de/btb/], eingesehen am 31.03.2008. Inzwischen wurde die Programmbeschreibung verändert, vgl. Kap. IV.2.2.

129 E-Mail-Antwort einer Pressevertreterin des btb-Verlages, 07.04.2008. 
griff ich aber auch auf weitere Recherchemöglichkeiten zurück. Unschätzbare, weil einzigartige Hilfestellungen boten mir die Recherchemöglichkeiten bei Amazon.de. Der Katalog des OnlineBuchhändlers bietet als einziger mir bekannter Verweise zu thematisch ähnlichen Titeln. Natürlich zunächst auf Gewinnoptimierung angelegt („Kunden, die diesen Artikel gekauft haben, kauften auch..."), ist das Portal jedoch auch einer überaus umfassenden Recherche und Bibliographie dienlich. Darüber hinaus findet man gerade in den „Lieblingslisten“, die Kunden zusammenstellen und auf der Webseite veröffentlichen können, häufiger als man glauben mag „Bücher über Bücher“. Mit diesen Hilfsmitteln war ich dazu in der Lage, systematisch ein umfassendes, genreund milieuübergreifendes Korpus zum ,Buch im Buch’ in der neuesten Literatur zu erstellen:

- Michael Collins: Der Bestseller-Mord. Dt. EA: München: btb, 2008. Amer. OA: Death of a Writer, 2006.

- Carlos María Domínguez: Das Papierbaus. München: Diana, 2006. Argent. OA: La casa de papel, 2004. Dt. EA: Frankfurt/Main: Eichborn, 2004.

- Jasper Fforde: Der Fall Jane Eyre. Dt. EA: München: dtv premium, 2004. Engl. OA: The Eyre Affair, 2004.

- Klaas Huizing: Der Buchtrinker. München: btb, 1996. Dt. OA: München: Knaus, 1994.

- Peter Jacobi: Mein Leben als Buch. Dt. OA: Hamburg: Edition Nautilus, 1999.

- Ross King: Das Labyrinth der Welt. München: btb, 2001. Engl. OA: Ex-Libris, 1998. Dt. EA: München: Knaus, 1999.

- Pascal Mercier: Nachtzug nach Lissabon. München: btb, 2006. Dt. OA: München: Hanser, 2004.

- Walter Moers: Die Stadt der träumenden Bücher. München: Piper Tb, 2006. Dt. OA: München: Piper, 2004.

- Arturo Pérez-Reverte: Der Club Dumas. München: btb, 1997. Span. OA: El Club Dumas, 1993. Dt. EA: Stuttgart: Weitbrecht, 1995.

- Carlos Ruiz Zafón: Der Schatten des Windes. Dt. EA: Frankfurt/Main: Suhrkamp, 2003. Span. OA: La sombra del viento, 2001.

- Éric-Emmanuel Schmitt: Die Schule der Egoisten. Frankfurt/Main: Fischer Tb, 2006. Frz. OA: La secte des Égoïstes, 1994. Dt. EA: Zürich: Ammann, 2004.

- Alfons Schweiggert: Das Buch. Dt. OA: München: Ehrenwirth, 1989.

- Peter Stamm: Agnes. München: btb, 2004.Dt. OA: Zürich: Arche, 1998.

- Thomas Wharton: Salamander. Dt. EA: München: dtv premium, 2003. Kanad. OA.: Salamander, 2001.

- Zoran Živković: Das letəte Buch. Dt. EA: München: dtv, 2008. Serbische OA: Poslednja knjiga, 2007.

Tab. 1: Titel des untersuchten Korpus 


\subsubsection{Zur Motivuntersuchung}

Im Hauptteil befasse ich mich mit einer hermeneutischen Untersuchung des Motivs ,Buch im Buch $^{130}$ in den Titeln des Romankorpus, wobei die Motivgruppen in einer typologischen Aufstellung zu Kapiteln zusammengefasst werden. Das Motiv „Buch’ wird in den Romanen mit anderen Motiven kombiniert und so in neue Kontexte eingebettet, dass es eine neue Funktion entwickelt. In der neuen Funktion bringt das Motiv „Buch’ zwar kein neues Genre hervor, ist jedoch dazu in der Lage, die Handlung eines Romans zu bestimmen. Im Kriminalroman wird ein Verbrechen erwartet, das aufzuklären ist, nicht aber unbedingt ein Buch. Ein Detektiv- oder Abenteuerroman hat häufig die Suche nach einem besonderen Gegenstand zum Inhalt, dieser muss jedoch nicht zwingend das Buch sein. Ist dennoch ein Buch involviert, fügt es zum zugrunde liegenden Genre, z. B. dem Kriminalroman, ein entscheidendes Element hinzu, das mit seinen Konnotationen wie Wissen, Historie, Gelehrsamkeit, zusammenhängt.

Das ,Buch im Buch' tritt als Motiv nie isoliert auf und wird erst durch die Kombination und Interaktion mit anderen Motiven wie u. a. Suche, Leben und Tod oder fantastischer Konzeptionen neuer Buchwelten selbst handlungsrelevant und fähig, durch wiederholtes Auftreten die Handlung zu ordnen und zu strukturieren. Besonders das Zusammenspiel mit dem Protagonisten haucht dem Buch sozusagen ,Leben ein'. Es ist an dieser Stelle hervorzuheben, dass die Rahmenhandlungen besonders vieler Buch-Bücher von einem homodiegetischen Erzähler erzählt werden, so dass eine einzige Perspektive auf das Buch vorherrscht.

Nach Japp ist das „Buch im Buch’ eine „hermetische Figur““131, aber gleichzeitig auch eine „Steigerungsfigur“, die die Geschlossenheit aufhebt, denn

der thematische Bezug, in diesem Falle auf das Buch selbst, wird in einem solchen Maße gesteigert, dass er auf dem Höhepunkt Reflexionen freisetzt, die aus der Struktur der Geschlossenheit hinausführen. [...] Die thematische Verwendung von Büchern in Büchern erweist sich somit nicht nur als sehr direkt, sonders auch als besonders vielschichtig. ${ }^{132}$

Das Buch erscheint weniger als in sich geschlossen oder gar unzugänglich, es öffnet sich vielmehr in Richtung der Realität des fiktionsinternen und auch des -externen Lesers und der erfahrbaren Wirklichkeit. Ganz realitätsgetreu kann die Welt dennoch nicht wiedergegeben werden, da sie stets literarisch verfremdet und perspektivisch geschildert wird - ein Anspruch, an dem schließlich der Naturalismus gescheitert ist. Die vervielfachte, selbstreferentielle Lektüre in einem litera-

130 Die einschlägigen Handbücher zur Motivgeschichte wie Elisabeth Frenzel: Motive der Weltliteratur. 5. A. Stuttgart: Kröner, 1999 [zuerst 1976] und Dies.: Stoffe der Weltliteratur. Ein Lexikon dichtungsgeschichtlicher Längsschnitte. 9. A. Stuttgart: Kröner, 1998 [zuerst 1962] oder Horst S. Daemmrich \& Ingrid Daemmrich: Themen und Motive in der Literatur. Ein Handbuch. 2. überarb. u. erw. A. Tübingen, Basel: Francke, 1995, weisen allerdings keinen Eintrag zu einem Motivkomplex wie „Buch“, „Leser“, „Lektüre“, „Literatur“ o. ä. auf. Darauf macht auch Theodor Wolpers aufmerksam, Vorwort zu Wolpers (1986), S. 7. 
rischen Werk spielt mit der Vorstellung einer realen Welt in der Literatur, wobei das Buch jedoch nur eine bestimmte Perspektive auf die Welt zu vermitteln vermag. Hier spielen die Umstände der Produktion durch den Autor und alle ihn beeinflussenden Faktoren wie der Zeitgeist oder sein Umfeld sowie diejenigen der Rezeption durch den Leser eine Rolle.

\subsubsection{Motiv vs. Thema}

Es ist wichtig, zwischen den Begriffen ,Motiv' und 'Thema' zu unterscheiden. Diese Schlüsselbegriffe sind längst nicht eindeutig formuliert, viele Definitionen sind z. T. uneinheitlich, passen nicht zueinander oder überschneiden sich. Die Differenzierung zwischen Motiv und Thema ${ }^{133}$ ist besonders problematisch. So unterscheidbar beide auf den ersten Blick erscheinen, so schwierig wird doch eine klare Abgrenzung. Je nach Reichweite für den Text kann ein Motiv thematische Dimensionen annehmen, wenn es betont und generalisiert wird, ein Thema kann spezifiziert zum Motiv werden. Letztlich sind beide Konzepte zwei Seiten derselben Medaille und „concrete universals ${ }^{\text {“134 }}$. In dieser Arbeit werde ich den Definitionen des Reallexikon der deutschen Literaturwissenschaft ${ }^{135}$ folgen, die die aktuellen und für meine Fragestellung am besten passenden Begriffsbestimmungen bieten.

\subsection{Thema}

Das Thema ist gegenüber dem Motiv weniger konkret und bezeichnet den abstrakten Gehalt der im Text zentralen Problemstellung, der Leitidee. Wolpers fasst den Begriff Thema im Anschluss an Petriconi unter der Formel eines von einem Attribut begleiteten Abstraktums oder eines Abstraktums mit handlungsimplizierendem Zusatz ${ }^{136}$ zusammen, z. B. unerfüllte Liebe oder „virtue rewarded", wobei sich alle Elemente des Textes dem Thema als generellem Organisationsprinzip unterordnen lassen.

Ist das Thema identifiziert, ist ein deutlicher Schritt in Richtung Interpretation getan, denn das Thema trägt zur Bedeutung und zum Inhalt des Werkes bei, wenn es ihn nicht ganz ausmacht. Wie das Motiv unterliegt allerdings auch das Thema der persönlichen Interpretation des Lesers und seinen Erwartungen an den Text, die aus seiner Biographie, persönlichen Situationen und seinen Erfahrungen resultieren. Aus diesem Grund gibt es bei so gut wie jedem Buch abwei-

133 Vgl. zur Begrifflichkeit von Motiv und Thema Theodor Wolpers: „Motif and Theme as Structural Content Units and ,Concrete Universals"“. In: Werner Sollers (Hg.): The Return of Thematic Criticism. Cambridge etc.: Harvard Univ. Press, 1993, S. 80-91.

134 Ebd., S. 91.

135 Rudolf Drux: Art. „Motiv“. In: Reallexikon der deutschen Literaturwissenschaft, Bd. 2 H-O. Hg. v. Harald Fricke, 3., neubearb. A., Berlin \& New York: de Gruyter, 2000, S. 638-641 sowie Armin Schulz: Art. „Thema“, Reallexikon, Bd. 3 P-Z. Hg. v. Jan-Dirk Müller, ${ }^{32003, ~ S . ~ 634 f . ~}$

136 Wolpers (1993), S. 90 und Theodor Wolpers (Hg.): Ergebnisse und Perspektiven der literaturnissenscbaftlichen Motiv- und Themenforschung. Bericht über Kolloquien der Kommission für literaturwissenschaftlichen Motiv-und Themenforschung 1998-2000. Göttingen: Vandenhoeck \& Ruprecht, 2002, S. 101, Anm. 51 und 102. 
chende Meinungen unter Lesern darüber, „wovon der Roman handelt“, „worum es in dem Roman geht", also über das zugrunde liegende Thema.

Die Thematologie meint mit dem Thema die zugrunde liegende Idee eines Werks. „Thematics“137 dagegen befasst sich eher mit den Ableitungen und Zusammenhängen, die ein Leser beim Lesen eines Textes vornimmt, also den kognitiven Vorgängen, die bei der Rezeption eine Rolle spielen $^{138}$. Neben dem reinen Sprachmaterial des Textes und referentiellen Bezügen ist also vor allem das Erfassungsvermögen des Lesers entscheidend für die Identifikation des Themas eines Textes ${ }^{139}$. Mit diesem auf die Kognitionspsychologie abzielenden Ansatz stellt das neue Konzept der Thematics nahezu einer Überbietung der traditionellen Thematologie dar. In dieser Arbeit wird es allerdings um die kleinste inhaltliche Einheit - das Motiv - gehen, denn das ,Buch’ wird als kleinste semantische Einheit verstanden, die den Inhalt der Romane zusammenhält.

\subsection{Motiv}

Das Motiv wird hier als kleinste selbständige Einheit verstanden, die Inhalt und Bedeutung eines Werkes trägt, ein Baustein des Textes ,im Sinne eines charakteristischen, kennzeichnenden Bestandteils einer Dichtung “140, als „Sinnträger“"141, der in der übergeordneten Struktur eine eigene Bedeutung und Funktion hat. Gegenüber dem allgemeineren Thema ist das Motiv konkret. Aufgrund seiner Selbständigkeit kann es innerhalb unterschiedlicher Stoffe, fester Handlungsabläufe, die unterschiedlich ausgestaltet werden können, wie der Faust-Stoff, eingebunden werden. Dadurch wird das Motiv tradierbar, während ein Stoff immer auf den Zusammenhang mehrerer Motive angewiesen ist.

Die Strukturierung eines Textes durch Motive erfolgt durch ihre Wiederholung und Kombinationen wie „Kontrastierung, Steigerung, Parallelführung, Häufung, Überschichtung“(142. Ein Motiv tritt im Text mehrfach auf und kann neue hervorrufen: Ein ausschmückendes Detail oder eine assoziative Idee kann mitunter schon zu neuen Motiven führen. Wichtig für meine Arbeit ist die Art und Weise, wie Motive mit anderen zu komplexen Konstellationen verbunden sind. Das Buch-Motiv erscheint wiederholt im Roman, es ordnet und strukturiert Teile der Handlung, wobei es in den einzelnen Szenen als Träger von Stimmungen und Konnotationen fungiert.

\footnotetext{
137 Vgl. zum Begriff den Aufsatz von Werner Sollors: „Thematics today“. In: Max Louwerse \& Willie van Peer: Thematics. Interdisciplinary Studies. Amsterdam \& Philadelphia: John Benjamins Publishing Company, 2002, S. $217-235$.

138 Vgl. hierzu Louwerse \& van Peer, Vorwort zu Louwerse \& van Peer (2002), S. 2.

139 Vgl. Alfonsina Scarinzi: Thematics - zu einer undisziplinierten Disziplin. Aachen: Shaker, 2009, S. 37.

140 Horst S. Daemmrich \& Ingrid G. Daemmrich: Wiederholte Spiegelungen. Themen und Motive in der Literatur. Bern: Francke, 1978, S. 15.

141 Daemmrich \& Daemmrich (21995), S. XV.

142 Wolpers (2002), S. 79.
} 
Diese Entwicklung von Motivmustern oder -clustern beeinflusst die Struktur der Handlung und wirkt somit textbildend und strukturierend, wobei hier ein dynamischer, interaktiver Prozess zwischen Autor, Text und Leser unterstellt werden kann: „Motive vertiefen die Problemstellung, bestimmen oft die Richtung des Handlungsverlaufes, befestigen den textlichen Zusammenhang und regen durch die von ihnen hervorgerufenen Assoziationen die Phantasie an“"143.

Motive verweisen auf Typen, Orte, Situationen oder besondere Figurenkonstellationen und können als Kern- oder Randmotiv sichtbar sein. Das Zusammenspiel beider macht den Plot aus, die Hierarchisierung der Motive strukturiert die Handlung zusätzlich. Ein Ding- oder Gegenstandsmotiv besitzt Symbolcharakter und verweist auf damit verbundene komplexere Bedeutungszusammenhänge: Die Maske z. B. weist auf Verstellung. Worauf das Buch als Gegenstandsmotiv verweist, wird die anschließende Untersuchung zeigen. In jedem Fall wird es in den Texten mit besonderen Begebenheiten, Abstrakta und Werten, aber auch Genres, verbunden und bildet so neue Motivcluster, wie Buch und Leben, Buch und die Suche etc. Aufgrund ihres Verweischarakters rufen Motive im Leser eine bestimmte Atmosphäre, bestimmte Assoziationen hervor, die er erkennen, einordnen und in Beziehung setzen kann, so dass ihm das bekannte Motiv Orientierung gibt, und zugleich seine Erwartungen an den Text weckt. Das Buch-Motiv semantisch aufgeladen, dabei hoch assoziativ und emotional besetzt, und auf diese Weise von einer persönlichen Interpretation und Kontextualisierung durch den Leser abhängig.

Motive sind dynamisch und zeitlos. Sie können abgelöst vom Werk und vom Stoff weiter wirken und in völlig neuen Zusammenhängen wieder auftauchen. Das Buch-Motiv wirkt als literarische Tradition bis heute nach und beeinflusst die Motivgebung der aktuellen Literatur, wie an den analysierten Romanen zu sehen ist. Durch diese Verweise auf bekannte Motive treten die Autoren in „Dialog mit der literarischen Tradition“"144, drücken ihren Werken aber auch ihren eigenen Stempel auf. So besteht jedes literarische Werk aus der Kombination von alten und neuen Motiven, die wie Steine aus einem Baukasten immer wieder neu, immer wieder anders zusammengefügt werden und so ein neues Werk ergeben. Das so geschaffene Werk verweist zwar auf die Tradition, steht aber auch durch die Neu- und Rekombination der enthaltenen Motive für sich. Motive als Grundbausteine der Literatur können das Gesamtwerk eines Autors oder das Schaffen einer ganzen Epoche prägen und drücken seine Wahrnehmung aktueller Zeitumstände aus.

Die Motive eines Romans sind nicht nur im Produktionsprozess für den Autoren entscheidend, sondern in der Rezeption auch für den Leser. Durch ihren Verweischarakter evozieren Motive Erinnerungen, Stimmungen und Assoziationen. Auf diese Weise führen sie den Leser durch 
den Text - Motive zeigen an, wenn sich das Geschehen zuspitzt und koordinieren Handlungsverläufe - und erzeugen für ihn bekannte Muster, die in ihm gewisse Erwartungen an den Text wecken und ihm Orientierung durch das Werk geben. Der Leser ist so dazu in der Lage, den Text einzuordnen, und das über andere Merkmale wie die Verwendung von Sprache oder formale Traditionen hinaus. Je nach Einsatz der Motive hat es der Leser mit einem entweder gänzlich der literarischen Tradition verpflichteten, konventionellen Roman zu tun, der alle seine Erwartungen erfüllt, oder durch Neukombination der Motive mit einem neuartigen, der den Leser in seiner Erwartungshaltung nicht abholt, sondern ihn überrascht.

Darüber hinaus haben unterschiedliche Leser unterschiedliche Erwartungen an Texte, ihrer literarischen Vorbildung und Lesesozialisation entsprechende. Je nach literarischer Kenntnislage wird das Motiv wahrgenommen, erkannt und verarbeitet, so dass Texte von unterschiedlichen Lesergruppen auf ganz verschiedene Weise gelesen und entschlüsselt werden können. So ergibt sich ein Lesen und Verstehen von Texten auf unterschiedlichen Ebenen, das auch in den analysierten Romanen auftritt, wie auch die herangezogenen Leserrezensionen zeigen.

Gegenüber einem Motiv, das aus einer Figurenkonstellation besteht, wie Eifersucht, oder einer Eigenschaft, wie Geiz, kann das Buch eher als Dingmotiv betrachtet werden, das aber auch als Leitmotiv auftreten kann. Wann immer das ,Buch im Buch’ als Leitmotiv in der Handlung erscheint, ist die Situation oder die beteiligte Figur von entscheidender Bedeutung für das Voranschreiten der Handlung oder ihren Ausgang, vielleicht sogar für die Aufklärung von verwickelten Ereignissen. Dabei kann das Motiv an bereits bekannte Situationen erinnern und beim Lesen bereits empfundene Stimmungen hervorrufen.

Als literarisches Motiv steht das Buch jedoch nie isoliert. Das Buch ist hier als prototypisches Motiv zu verstehen, das grundsätzlich in Kombination und verknüpft mit anderen Motiven auftritt und dadurch Relevanz erhält. Daraus entstehen motivische Varianten, die gerade unterschiedliche Auswirkungen auf die Darstellung und Sichtweisen auf das Buch haben.

Insgesamt kann das ,Buch im Buch’ also als Motiv bestimmt werden, da es gegenüber einem eher abstrakt zu nennenden Thema konkret ist und nur einzelne Handlungsteile strukturiert, während die dem Text zugrunde liegende Fragestellung eine übergeordnete ist, z. B. in Merciers Nachtzug nach Lissabon: Das in Routine erstarrte Leben verlassen und neue Wege beschreiten. Dennoch ist das ,Buch im Buch' kein primäres Motiv, kein generelles, das zu allen Zeiten vorkommen kann, kein „menschheitstypisches “145 wie ,Konflikt zwischen Pflicht und Neigung’, ,Dreiecksbeziehung’ 
o. ä. Vielmehr ist das Buch-Motiv ein zeit- und kulturtypisches sekundäres Motiv ${ }^{146}$, denn zur vollen Einsicht setzt es ein Verständnis von Kultur, insbesondere von Literatur, voraus.

\subsubsection{Das ,Buch im Buch’: Motiv, Metapher, Kollektivsymbol}

Günther Stocker behandelt in seiner Arbeit Schrift, Wissen und Gedächtnis (1997) die Darstellung der Bibliothek in der aktuelleren Literatur und setzt in der Analyse unterschiedliche Schwerpunkte, je nachdem, ob er die Bibliothek als Motiv, als Metapher oder Kollektivsymbol ${ }^{147}$ auffasst. Diese Betrachtungsweise lässt sich auch für das Buch übernehmen ${ }^{148}$. Stocker verweist zunächst darauf, dass die Untersuchung eines Motivs hilfreich sein kann für die Erschließung synchroner (ein Motiv in Werken unterschiedlicher Nationalliteraturen) und diachroner (Entwicklung eines Motivs und seiner Verwendung im Lauf der Zeit) Fragestellungen. Außerdem helfe die Motivanalyse dabei, die Struktur eines Einzeltexts zu ergründen. All dies soll nicht allein im Mittelpunkt meiner Arbeit stehen, so dass andere Aspekte ergänzend hinzugezogen werden.

Weiterhin verweist Stocker auf den metaphorischen Charakter der Bibliothek, was auch auf das Buch übertragen werden kann. Eine Metapher ersetzt stets etwas. Das tertium comparationis, das die Metapher dann überhaupt erst sinnvoll macht, liegt begründet in den „sachlichen, gedanklichen oder bildstrukturellen Ähnlichkeiten“149 zwischen Metapher und den Dingen dahinter, die es gilt, ausfindig zu machen, wobei auch dem Buch Konnotationen und Assoziationen zugewiesen werden.

Das Buch kann darüber hinaus als Kollektivsymbol identifiziert werden ${ }^{150}$. Der Begriff wurde von Jürgen Link geprägt, der diesen folgendermaßen auslegt: „Unter Kollektivsymbolen möchte ich Sinn-Bilder (komplexe, ikonische, motivierte Zeichen) verstehen, deren kollektive Verankerung sich aus ihrer sozialhistorischen [...] Relevanz ergibt [...].“151 Weiterhin sieht Link statt einer In-

146 Vgl. Wolpers (2002), S. 88.

147 Stocker (1997), S. 102-107.

148 Hans Blumenberg diskutiert in seinem Hauptwerk Die Lesbarkeit der Welt (1981), die Chiffren in der Welt und meint damit die Lesbarkeit von Nicht-Texten, die als Symbol oder Metapher stets auch für etwas anderes stehen und einen tiefer gehenden Sinn enthalten. Bernd Scheffer dagegen sieht zehn Jahre später Blumenbergs „Lesbarkeit“ als überholt an, da die Lesbarkeit gerade von Texten dank der, neuen Medien' und eines weniger starren Kanonverständnisses nicht mehr an das Medium Buch allein gebunden ist, vgl. Bernd Scheffer: „Zur neuen Lesbarkeit der Welt: Es fängt jetzt überhaupt erst richtig an“, Webseite der Uni München, Medienobservationen, 1999, [http://www.medienobservationen.uni-muenchen.de/artikel/kunst/lesbarkeit.html], eingesehen am 14.05.2009.

149 Stocker (1997), S. 107, bezieht sich auf die Definition der Metapher im Metzler Literatur Lexikon, ${ }^{1} 1984$, S. 282.

150 Vgl. dazu auch den Artikel „Buch“ im Metəler Lexikon literarischer Symbole (2008), S. 57ff. Das Buch wird hier als Symbol der „Schöpfung und der Natur, der Geschichte, des Lebens, der Jurisdiktion, des gelehrten Wissens, der Seele sowie der Sphäre literarischer Fiktion“ gesehen - also stellvertretend für den Ursprung und den Verlauf des menschlichen Lebens und Zusammenlebens genau wie für seine wichtigsten Bereiche wie Wissen, Innenleben und soziale Regeln. Der Verweis auf die „literarische Fiktion“ steht schließlich für den häufigsten und beinahe typischen Inhalt eines Buchs, den Roman.

151 Jürgen Link: „Literaturanalyse als Interdiskursanalyse. Am Beispiel des Ursprungs literarischer Symbolik in der Kollektivsymbolik". In: Jürgen Fohrmann \& Harro Müller (Hg.): Diskurstheorien und Literaturwissenschaft.

Frankfurt/Main: Suhrkamp, 1988 (st 2091), S. 284-307, hier S. 286. 
tertextualität eine Interdiskursivität ${ }^{152}$. Das Kollektivsymbol werde eingesetzt, um eine für alle verständliche Basis zu schaffen, über die Inhalte transportiert werden. Es liegt deshalb auf der Hand, das Buch als Kollektivsymbol zu identifizieren. Niemandem ist sein typisches Aussehen, sein Zweck und seine Handhabung fremd - jeder kann sich etwas unter einem Buch vorstellen und assoziiert etwas Persönliches damit. Als Kollektivsymbol steht das Buch als Vermittler zwischen dem Spezialdiskurs Normalleser und dem Spezialdiskurs kompetenter Leser, dem Spezialdiskurs Fachleser etc., denn als Kollektivsymbol rührt das Buch an „kollektiv verankerte] literarische] Klischees ${ }^{\text {“153 }}$ und kulturelle Stereotypen. Das Buch ist in der Gesellschaft bekannt, da es, genau wie das Buch als literarisches Motiv, durch die Gesellschaft tradiert wurde. Damit sind Buch und Buch-Motiv aber auch veränderlich und kulturspezifisch: Beide sind Merkmale einer bestimmten Kultur, da sie in anderen Kulturen vielleicht ganz anders wahrgenommen werden. Es kann also festgestellt werden, dass diese Untersuchung das Buch berücksichtigt, das als Motiv in einem Buch, hier einem Roman des Korpus, vorkommt. In verschiedene Motivgruppen strukturiert wird gezeigt, wie das Buch in heutiger Literatur dargestellt und wie es mit anderen Motiven verknüpft wird.

Als Motiv wird die strukturelle Funktion des Buchs betont, die es in einer fiktionalen Handlung einnimmt. Als Metapher betrachtet wird der semantische Aspekt deutlich, da das ,Buch im Buch' für etwas außerhalb des Textes steht. Im Buch finden sich verschiedene Bedeutungsbereiche komprimiert, wobei es gilt, die zugrunde liegenden Denkmuster aufzudecken. Als Kollektivsymbol schließlich wird dem Buch seine kommunikative Funktion zugewiesen, die auf den gesellschaftlichen Gehalt des Buchs deutet. In allen diesen Funktionen werden dem Buch Konnotationen zugewiesen, die herauszufiltern den Kern der Analyse ausmacht. Ist in der folgenden Untersuchung vom Motiv „Buch’ die Rede, sind die metaphorischen und kollektivsymbolischen Aspekte stets mit eingeschlossen.

\section{Die Suche nach dem Buch - „Der Mythos vom letzten Exemplar eines Buchs“6154}

Die Suche nach einem außergewöhnlichen - besonders wertvollen, weil kostbaren, seltenen oder einzigartigen - und damit auch geheimnisumwobenen Buch ist kein neues Motiv in der Weltliteratur, man betrachte z. B. Heinrich von Ofterdingens Suche nach seinem Lebensbuch (vgl. Kap. II.2.2). Bei der Suche nach einem Buch ist dessen Singularität von großer Bedeutung, da so die Suche erst ihre Veranlassung findet. Dies drückt sich im Mythos des einzigen oder letzten

\footnotetext{
152 Vgl.Link (1988), S. 288.

153 Jürgen Link: Literaturwissenschaftliche Grundbegriffe. Eine programmatische Einführung auf strukturalistischer Basis.

3., unveränd. A. München: Wilhelm Fink, 1985, S. 192.

154 Löffler (2005), S. 12.
} 
Buchs aus. In den untersuchten Romanen stellt das Buch als Objekt der Suche und Leitmotiv das verbindende Element der Handlung dar. Das Buch als Anstoß und Anlass der Suche wirkt handlungsauslösend. Der Protagonist reagiert nun in gewisser Weise auf das Buch, auf eine seiner Aktivitäten folgt die nächste, auf die wiederum die übrigen Figuren reagieren. Das Auftreten des Buchs markiert Wendepunkte der Handlung, treibt sie voran und strukturiert sie. Auch die Personenkonstellation wird durch die Konzeption der Suche bestimmt ${ }^{155}$. Neben dem Helden, der selbst die Abenteuer und Bewährungen bestehen muss, stehen seine Helfer, aber auch seine Antagonisten. Diese Kombination von Auftreten des Buchs und Reaktion der Figuren, vor allem des Protagonisten, führt zur Lösung.

Häufig in einen historischen und abenteuerlichen Kontext eingebettet, erfreut sich dieses Motiv auch bei den Lesern großer Beliebtheit:

Die Idee, einen Protagonisten in einem vergangenen Jahrhundert auf die Suche nach einem Buch zu schicken, ist nicht neu. Dass diese Suche mit Gefahr für Leib und Leben verbunden ist, kennt man auch. Trotzdem: Wer Bücher liebt, liest nicht nur gern in ihnen, sondern auch gern über sie. [...] $]^{156}$

Bemerkenswert ist, dass hier besonders der Aspekt des Historischen betont wird, das Leser offensichtlich im Zusammenhang mit dem Buch-Motiv erwarten. Allerdings wird den Lesererwartungen, wie der Kombination des Abenteuergenres und des Buch-Motivs, die auch in der Rezension angesprochen werden, nicht immer entsprochen, sondern der Leser häufig überrascht.

\subsection{Die Suche nach dem Buch}

Die Suche nach einem Buch wird in mehreren Titeln des Korpus geschildert, in Das Labyrinth der Welt $^{157}$ (2001), Der Club Dumas ${ }^{158}(1997)$, Das letzte Buch ${ }^{159}$ (2008) und Salamander ${ }^{160}$ (2003), wobei letzterer Roman eher die Suche nach den perfekten Ingredienzien für die Herstellung eines unendlichen, perfekten Buchs illustriert. Es liegt nahe, die Buchsuche in einen Detektiv- oder Kriminalroman einzubetten, wobei in diesem Kapitel ein besonderes Augenmerk auf Das Labyrinth der Welt und Der Club Dumas liegt.

\footnotetext{
155 Vgl. dazu Daemmrich \& Daemmrich (21995), S. 338.

156 marielan: „Gefährliche Suche nach einem gefährlichen Buch“, Leserrezension zu Ross King: Das Labyrinth der Welt, Amazon.de, 06.08.2007, [http://www.amazon.de/product-reviews/3442727073/ref=cm_cr_dp_synop?ie=UTF8 \&showViewpoints=0\&sortBy=bySubmissionDateDescending\#RRDWO7XLW6RTC], eingesehen am 11.07.2010. 157 Ross King: Das Labyrinth der Welt. München: btb, 2001.

158 Arturo Pérez-Reverte: Der Club Dumas. München: btb, 1997.

159 Zoran Živković: Das letate Buch. München: dtv, 2008.

160 Thomas Wharton: Salamander. München: dtv premium, 2003.
} 


\subsubsection{Der Buchsucher als Detektiv}

\subsubsection{Detektiv- und Kriminalroman}

Die Romane, die sich um eine Buchsuche als zentrale Handlung drehen, sind in Bezug auf die Figuren und die Erzählsituation mit dem Detektiv- und dem Kriminalroman in Zusammenhang zu bringen. Ein Protagonist hat zum Ziel, einen Auftrag zu erfüllen und die Lösung für eine rätselhafte Situation zu finden: Er begibt sich auf die Suche nach einem besonderen Buch. In klassischen Detektivgeschichten ist das handlungsauslösende Moment in den meisten Fällen ein Mord, während am Anfang der Büchersuchen der Auftrag steht. Dieser Auftrag bringt die Handlung erst ins Rollen und steht ihre ganze Dauer über im Zentrum, während Peter Nusser feststellt, dass das Mordrätsel zwar das zentrale Ereignis einer Detektivgeschichte darstellt, die Handlung jedoch lediglich anstößt ${ }^{161}$.

Folgt man Nusser in seiner Darstellung des Genres, stellt man fest, dass die Buchsuche eine Kombination aus Detektiv- und Kriminalroman darstellt. Ein Detektivroman ist nach Nusser rückwärts gerichtet, wie eine analytische Erzählung ${ }^{162}$. Der Detektiv klärt ein in der Vergangenheit liegendes Ereignis auf und rekonstruiert dazu den Tathergang, entlarvt den Täter und dessen Motivation. Die Enthüllung der wahren Zusammenhänge, die zum Verbrechen geführt haben, wird dem Leser als Konklusion und Lösung erst am Ende der Erzählung chronologisch berichtet.

Die Buchsuche verläuft allerdings vorwärts gerichtet und chronologisch. Es geht hauptsächlich darum, den aktuellen Standort des geraubten oder verschollenen Buchs zu ermitteln. In ihrer chronologischen Vorgehensweise ähnelt die Buchsuche daher auch der „kriminalistische[n] Abenteuererzählung “163 und dem typischen Abenteuerroman. Der Konzeption des Kriminalromans läuft allerdings zuwider, dass im Falle eines Bücherraubs die Urheber nicht gejagt werden, sondern dass ausschließlich auf die (Wieder-)Erlangung des Buchs Wert gelegt wird. Auch die Buchsuche in Das letzte Buch, in deren Sache zwar ein Kommissar ermittelt, konzentriert sich ganz darauf, herauszufinden, welches denn überhaupt das todbringende Buch ist und wo es sich befindet. Bei der Entschlüsselung des Rätsels sind die gedanklich-analytischen Fähigkeiten eines Detektivs gefragt.

\subsubsection{Inchbold und Corso - zwei genarrte Antihelden}

Im Kontext der Suche wird das Buch als wertvoller Gegenstand vorgeführt, der die Suche überhaupt erst anstößt und plausibilisiert. Die Lesererwartung, die durch das Motiv der Suche und das zugrunde liegende Genre aufgebaut wird, wird nun sowohl in Das Labyrinth der Welt als auch in

\footnotetext{
161 Peter Nusser: Der Kriminalroman. 3., akt. u. erw. A. Stuttgart: Metzler, 2003, S. 23. - Vgl. dazu auch: Matias Martinez \& Michael Scheffel: Einführung in die Erzäbltheorie. 2., durchges. A. München: Beck, 2000, S. 36. 162 Vgl. ebd., S. 3. 
Der Club Dumas enttäuscht: Die Protagonisten Inchbold und Corso finden das Buch nicht bzw. keine Lösung für die vermuteten Zusammenhänge. So wird das Genre nicht wie gewohnt ausgestaltet und durch das Buch-Motiv variiert.

Ross King schildert in Das Labyrinth der Welt zwei Parallelhandlungen, zwischen denen immer wieder Bezugnahmen stattfinden. Die Haupthandlung in der Zeit der nach-Cromwellschen Restoration berichtet von dem Londoner Buchhändler und Anti-Helden Isaac Inchbold, der den Auftrag erhält, ein verschollenes Manuskript mit dem Titel „Das Labyrinth der Welt“ zurück an seinen Platz in einer Privatbibliothek zu bringen. Bei dieser Suche gerät der Bücherwurm in einen Wirbel aus politisch und religiös motivierten Intrigen. Der zweite Handlungsstrang führt den Leser in das Prag von 1620. Nach dem Tod Rudolfs II. vertreibt die Katholische Liga den protestantischen Winterkönig Friedrich von Böhmen vom Thron. Das Ziel des Protagonisten dieses Handlungsstrangs (der Vater von Inchbolds Auftraggeberin) ist die Rettung der okkulten Bibliothek Rudolfs II. nach England, wobei die Bücher zusammen mit Kunstschätzen in seine eigene Bibliothek überführt werden.

In beiden Erzählsträngen werden beinahe sämtliche Aspekte des Geisteslebens der Epoche behandelt und die politischen und religiösen Auseinandersetzungen der Zeit illustriert. Hinter der Schrift und nun auch hinter Inchbold sind Cromwellsche Spione ebenso her wie Agenten des Vatikans, denn der Religionskonflikt ist auch hier wirkungsmächtig. Außerdem werden der Streit zwischen England und Spanien um die Vorherrschaft in Europa und die Auseinandersetzung der Kirche mit Galilei, Kepler und anderen vermeintlichen Ketzern thematisiert.

Inchbold wird fiktionsintern suggeriert, dass das gesuchte Manuskript ein bisher verschollener Teil des antiken, alchemistischen Corpus hermeticum sei, weshalb es alle konkurrierenden Parteien an sich zu bringen suchen: Es soll entweder zu vermeintlich ketzerischen Zwecken genutzt oder aber unterdrückt werden. Erst ganz am Ende des Romans wird klar, dass das „Labyrinth der Welt" ein Palimpsest ist und einen weitaus brisanteren Text verbirgt, um den es in Wirklichkeit geht. Ein Text schimmert unter dem anderen durch und bestätigt so das Motto der Bibliothek „Littera scripta manet": Schrift ist beständig und verschwindet nie für immer. Das Corpus hermeticum, aus dem das „Labyrinth der Welt“ angeblich stammt, war ja längst als Fälschung durch alexandrinische Gelehrte aus dem 1. Jh. n. Chr. bekannt, die unterschiedliche Lehren vermischten. Die angeblichen Lehren des Hermes Trismegistos hatten also keine Bedeutung und stellten keine Gefahr für den Vatikan dar, der geheime verborgene Text dafür umso mehr.

Dieser beinhaltet eine Weltkarte aus einer seltenen Ausgabe von Ortelius' Theatrum Orbis Terrarum, die sich von allen anderen Auflagen der Kartensammlung unterscheidet. Eine dergestalte Abweichung von Textausgaben untereinander spielt auch im Club Dumas eine Rolle. Diese Karte 
zeigt als Schatzkarte die Lage der Pazifikinsel Manoa an, die als Eldorado galt. Die Kirche hat ein Interesse an der Unterdrückung dieser Schrift, da sie die Astronomie Kopernikus' und Galileis verfemen wollte, mit deren Hilfe die genaue Lage des Goldlandes zu finden sein sollte. Galileis Auffassungen galten als häretisch und gefährlich für die kirchliche Autorität, da sie ein neues, heliozentrisches Weltbild propagierte.

Der Suche nach dem Text führt zu einem veritablen Schatz und stellt somit eine doppelte Schatzsuche dar. Inchbolds Auftrag, das Manuskript vom „Labyrinth der Welt“ zu finden, war also nur ein Ablenkungsmanöver, um die Akteure der gegnerischen und konkurrierenden Parteien zu beschäftigen. In der Zwischenzeit konnte seine Auftraggeberin sich in aller Ruhe mit der Entschlüsselung des Palimpsests befassen, das ihre Bibliothek nie verlassen hat. Das Manuskript, als Buch-Vorläufer, wirkt handlungsauslösend und strukturbildend, da zu Beginn des Romans der Suchauftrag an den Protagonisten steht. Es hat insofern Einfluss auf den Suchenden, da es Inchbolds Fantasie und kulturelle Kenntnis anregt, der erst spät erkennt, dass er einer ausgelegten Fährte gefolgt ist und seine Erkenntnisse keine waren. Die Suche lief ins Leere und führte nicht zum erhofften Erfolg: Das Buch resp. Manuskript stellt auf diese Weise die Auflösung nur unter dem Aspekt dar, dass es als red herring diente, als Ablenkung von den wahren Zielen der übrigen Figuren. Das zugrunde liegende Thema des Romans ist die politische Sprengkraft von Büchern, die Gefahr, die von ihnen für bestimmte Kreise ausgehen kann, und die Macht, die ihnen zugesprochen wird. Sie stellen verbotenes Wissen dar, und es müssen Intrigen zu ihrer Unterdrückung gesponnen werden.

Ähnlich wie Inchbold wird der Protagonist in Arturo Pérez-Revertes Roman Der Club Dumas von seinem Auftraggeber vorgeführt. Der ,Bücherjäger’ Lucas Corso wird beschrieben als „,Söldner der Bibliophilie’, ein Bücherjäger auf fremde Rechnung ${ }^{\text {“164 }}$, egoistisch, skrupellos und in erster Linie auf seinen eigenen Vorteil bedacht. Sein Beruf ist es, seltene und wertvolle Bücher aufzuspüren, lukrative Nachlässe aufzukaufen und die Bücher gewinnbringend zu veräußern. Die Bücherjäger in Die Stadt der träumenden Bücher ${ }^{165}$ (2006), die in den Katakomben von Buchhaim seltene Bücher suchen, ähneln dieser Figur. Corsos Kunden gehören zu einem erlesenen Kreis von Antiquariaten in ganz Europa, die wiederum im Auftrag ihrer Kunden, der Leser (,Endkunden'), seltene, kostbare Ausgaben auffinden. Corso ist sehr belesen, obwohl er Bücher als Ware betrachtet: „Daß ich mit Büchern arbeite, soll nicht heißen, daß ich sie auch lese.“166 - „Mein Interesse ist 
nicht ästhetischer, sondern rein lukrativer Natur.“167 Titelkenntnis nutzt er als Handwerkszeug, um seiner detektivischen Tätigkeit, weniger um verfeinert-bibliophilen Interessen nachzugehen.

Corso muss sich in der Ausgangssituation des Romans mit zwei Aufträgen befassen: Zum einen wurde er beauftragt, die drei letzten Exemplare des Buchs der neun Pforten ins Reich der Schatten, „eine Art Anleitung zur Beschwörung des Teufels“168, auf ihre Echtheit zu untersuchen, wobei nur ein einziges echtes Exemplar überlebt haben soll. Dabei fällt ihm auf, dass die drei Exemplare des Buchs in den illustrierenden Holzschnitten Unterschiede aufweisen: Die Abbildung mit den jeweils abweichenden Details trägt die Signatur LCF (Lucifer) und wurde vom Buchdrucker Aristide Torchia im 17. Jh. angeblich aus dem skandalumwitterten Teufelsbuch Delomelanicon, das der Sage nach von Luzifer persönlich verfasst wurde, reproduziert. Diese Ausgangssituation für einen Schauerroman kippt jedoch im Laufe von Corsos Ermittlungen, die der Leser verfolgt. Zunehmend an Bedeutung gewinnt Corsos zweite Aufgabe. Für einen befreundeten Antiquar soll er ermitteln, ob eine gewisse Handschrift von Dumas père persönlich stammt. Es handelt sich um das Originalmanuskript des 42. Kapitels, „Der Anjou-Wein“, aus Die Drei Musketiere, das der Antiquar von einem ehemaligen Mitglied des Dumas-Clubs kurz vor dessen Selbstmord zur weiteren Veräußerung erworben hatte.

Der Bücherjäger ist im Besitz beider Texte, deren Authentizität er prüfen lassen soll, so dass eine Suche eigentlich überflüssig ist. Die physische Suche beginnt erst, nachdem ihm eines der Bücher geraubt wurde, und zwar aus rein ideellem Antrieb: Die 67 Originalkapitel des DumasRomans, die sich im Besitz des Clubs befinden, sollen komplettiert werden. Die hauptsächliche Suche dreht sich für Corso allerdings um Anzeichen für einen Zusammenhang zwischen den Büchern, der aber de facto nicht besteht. Die beiden unverbundenen Büchersuchen werden auf fatale Weise von Corso in seiner Imagination miteinander verknüpft: Aufgrund angeblicher intertextueller Verweise zwischen den beiden Werken - den Neun Pforten und den Drei Musketieren sieht er Verbindungen, die gar nicht existieren (vgl. dazu ausführlich Kap. III.9.2.4). Auch hier wirken die Bücher im Buch handlungsstrukturierend, da nach jedem Erkenntnisgewinn durch den Besuch eines weiteren Informanten ein Antagonist Corsos Pläne durchkreuzt.

Corsos Suche läuft, genau wie die Inchbolds, ins Leere. Er findet heraus, dass alle drei Kopien von Torchias Buch falsch sind, das Dumas-Manuskript kann er nicht als für echt befunden an seinen Freund zurückgeben, es wird ihm vielmehr vom Club Dumas abgenommen und in dessen Besitz zurückgeführt. Beide Protagonisten werden von ihren Auftraggebern genarrt: Inchbold dient als Lockvogel und seine Suche als Ablenkung für die Feinde seiner Auftraggeberin, wäh- 
rend Corso vom Club Dumas in einer nachgespielten, fiktiven Abenteuersituation in die Rolle des D’Artagnan gedrängt wird. Für beide Protagonisten erweist sich die Suche nach dem Buch somit als nichtig, denn beide haben red herrings verfolgt, da alles, was sie in Erfahrung gebracht haben, von ihren jeweiligen Auftraggebern für sie arrangiert worden ist. Dem Muster des Detektivromans, der am Ende eine für den Leser befriedigende und plausible Lösung bereithält, wird hier nicht entsprochen.

Im Genre der Detektivromane erwartet der Leser am Ende die Aufdeckung der Zusammenhänge, die schließlich zur Ergreifung des Täters geführt haben. Der Fall liegt bei Das Labyrinth der Welt und Der Club Dumas aber anders. Hier geht es nicht darum, bisher unbekannte Zusammenhänge aufzudecken, vielmehr ist das Gegenteil der Fall: In der Auflösung wird bewiesen, dass eben kein Zusammenhang bestand, obwohl dieser vom Protagonisten vermutet wurde. Den Erwartungen des Lesers an den Detektivroman wird somit nicht entsprochen, er wird überrascht, vielleicht fühlt er sich sogar enttäuscht. Das Buch-Motiv hat im Kontext der abenteuerlichen Suche in der Umgebung des Detektivromans eine neue Funktion angenommen: Es ist nicht nur ein gesuchtes Wertobjekt, sondern bestimmt die Handlung, indem es Anlass gibt, über erzähltheoretische Fragen zu reflektieren und das Genre variiert.

\subsubsection{Der Buchsucher - Eine typische Detektivfigur}

Der Protagonist als Buchsucher trägt deutliche Züge einer Detektivfigur. Sowohl Inchbold als auch Corso haben die Eigenschaften, die Nusser als typische Merkmale einer Detektivfigur ${ }^{169}$ ausweist: Sie sind Außenseiter, einsam und Junggesellen, besitzen körperliche Auffälligkeiten bzw. sind Trinker. Der Protagonist ist deutlich als Detektiv zu erkennen. Inchbold als Antiquar und Corso als ,Zwischenhändler' sind durch ihre buchhändlerischen und literarischen Kenntnisse prädestiniert für die Suche nach dem Buch, Inchbold zeichnet zudem eine große Liebe zu Büchern aus. Sie haben Interesse an Rätseln und versuchen, ihren Auftrag emotionslos mit Vernunft zu erfüllen, was ihnen jedoch nicht immer gelingt. Der skrupellos agierende Corso steht zunächst im Gegensatz zum weltscheuen Bücherwurm Inchbold, der im Laufe der Handlung aber eine Wandlung zum analytischen Forscher durchmacht und beharrlich seine Suche verfolgt.

In Carlos Ruiz Zafóns Der Schatten des Windes (2003) wird Fermín, der vor dem Spanischen Bürgerkrieg im Geheimdienst tätig war, von Daniels Vater als „bibliographischer Detektiv“"170 in der Buchhandlung angestellt, um Bücher aus Kundenwünschen zu beschaffen: „Es ist fast die Stelle eines literarischen Archäologen, der die Klassiker ebenso kennen muß wie die grundlegen- 
den Techniken des Schwarzhandels. “171 In dieser Tätigkeit, die literarische Kenntnisse ebenso voraussetzt wie eine gewisse kriminelle Energie, und sogar ihrer Benennung hat Fermín Ähnlichkeit mit Corso aus der Club Dumas. Auf die Parallelen zwischen Der Schatten des Windes und Titeln von Pérez-Reverte weist auch Felicitas von Lovenberg in ihrer Rezension ${ }^{172}$ des Romans hin.

In Zeiten des Internets ist ein Buchdetektiv allerdings beinahe überflüssig, da jeder, auch der Laie, gewünschte Titel durch einfache Online-Recherche über einschlägige Kataloge oder den Online-Buchhandel weltweit ausfindig machen kann. Das Motiv des Detektivs und die Verwendung des Genres Detektivroman drückt hier eine Reminiszenz an klassische Detektivromane aus.

\subsubsection{Sherlock Holmes - William von Baskerville}

Der Buchsucher wird nicht nur als Detektiv typisiert, sondern fiktionsintern explizit mit großen Detektiven der Weltliteratur wie Sherlock Holmes und William von Baskerville in Verbindung gebracht. Beide literarischen Detektive verweisen außerdem auf den ersten bibliophilen Detektivhelden der Literatur, C. Auguste Dupin aus Edgar Allan Poes The Murders in the Rue Morgue (1841/45). In Der Club Dumas wird Corso „Bruder William von Baskerville“ ${ }^{\text {(173 }}$ genannt, während er seinerseits Conan Doyle und Poe ins Spiel bringt.

Eine weitere bemerkenswerte Anspielung auf den berühmten Detektiv aus der Baker Street wird in diesem Roman in Form der Figur der Irene Adler eingebracht, die in der Fiktion Luzifer verkörpert. Ihre ,Namensvetterin' tritt in der Sherlock-Holmes-Geschichte A Scandal in Bohemia auf und ist die einzige Frau, für die Sherlock Holmes jemals so etwas wie Gefühle entwickelt, „[f]ür Sherlock Holmes bleibt sie immer die Frau“ “174. Diese Gefühle sind auf Achtung und Anerkennung begründet, denn Irene Adler ist der einzige Gegenspieler neben Prof. Moriarty, der sich Holmes intellektuell ebenbürtig erweist und es schafft, ihn zu überlisten und ihm zu entgehen. Bei PérezReverte stellt sich Irene Corso vor als: „Die Frau, lieber Watson.“ ${ }^{\text {(175 }}$, sie ist die Frau, „die Sherlock Holmes in die Knie gezwungen hat" ${ }^{\text {"176, }}$, wie explizit erwähnt wird. Außerdem liest Irene The Adventures of Sherlock. Holmes, in dieser Sammlung war die Geschichte vom Skandal in Böhmen 1892 zuerst erschienen. In Der Club Dumas überlistet Irene Adler den Detektiv Corso nicht, vielmehr hilft sie

\footnotetext{
171 Ruiz Zafón (2003), S. 97.

172 Felicitas von Lovenberg: „Labyrinth ohne Ausgang. Durch den Wind: Carlos Ruiz Zafóns Roman buhlt um Leserliebe“. In: Frankfurter Allgemeine Zeitung, 10.07.2003, S. 32. Online [http://www.faz.net/s/Rub1DA1FB848C1E44858CB87A0FE6AD1B68/Doc E02F6A269F7984A87A90FE6 584ACB5745 ATpl Ecommon Scontent.html], eingesehen am 7.09.2011.

173 Pérez-Reverte (1997), S. 387.

174 Arthur Conan Doyle: „Ein Skandal in Böhmen“. In: Werkausgabe in neun Einzelbänden. Nach den Erstausgaben neu und getreu übersetzt von Gisbert Haefs. Erzählungen Bd. 1: Die Abenteuer des Sherlock Holmes. Zürich: Haffmans, 1984, S. 7-36, hier S. 7.

175 Pérez-Reverte (1997), S. 172.

176 Ebd., S. 257.
} 
ihm, des Rätsels Lösung zu finden, denn sie scheint über das große Ganze und die Zusammenhänge der Intrige im Klaren zu sein und wirkt beinahe als Stichwortgeberin.

Das postmoderne Stilmittel der metafiktionalen Reflexion über das eigene Genre, also über Detektivromane, spielt neben der Buchsuche auch eine Rolle in Das letəte Buch. Insbesondere auf den Roman Der Name der Rose wird bei den Ermittlungen im Fall des todbringenden Buchs angespielt: Es wird vermutet, dass die Seiten des „letzten Buchs“ vergiftet worden waren und das Umblättern der Seiten so für den Leser tödlich endete (vgl. dazu Kap. III.5.3). Es wird außerdem selbstreflexiv der literarische Anspruch von Detektivromanen diskutiert, wobei das unterschwellige Ziel die Rehabilitierung des Genres ist, schließlich gehört der vorliegende Roman auch dazu. Die Figuren, ein literaturbegeisterter Kommissar und eine Buchhändlerin, sind sich darin einig, dass dieses Genre „nicht gerade wertvolle Literatur“, sogar „,minderwertige Literatur “6177 darstelle. Der Kommissar stellt fest: „Eine andere Entwicklung der Ereignisse wäre zur Trivialliteratur zu rechnen, aber das Buch, nach dem ich suche, gehört offenbar nicht dazu. “" ${ }^{178}$ Das tödliche Buch, nach dem der Kommissar sucht, trägt denselben Titel wie der vorliegende Roman, so dass wohl auch dieser vom Vorwurf der Trivialität befreit werden soll. Auch der Autor gibt, im Rahmen eines Gesprächs seiner Figuren, ein Urteil ab: Die Figuren stellen in Bezug auf ihren Autor fest, „für ihn ist ein Detektivroman keine Trivialliteratur.“179 Mit seiner konstruierten und einzig auf eine Erläuterung literaturtheoretischer Spezifika ausgerichteten Handlung ist der Roman denn auch tatsächlich nicht als trivial zu bezeichnen, wenn auch für einen nicht-literaturwissenschaftlich ausgebildeten Leser nur schwer nachvollziehbar.

Die Bezugnahme zu großen literarischen Detektiven wird auch fiktionsextern vorgenommen, wie von Lutz Krützfeldt in seiner Rezension zu Das Labyrinth der Welt.

Ross Kings Das Labyrinth der Welt erinnert unvermeidlich an Ecos Der Name der Rose. Nicht nur aus dem allgemeinen Grund, dass beide Romane von Büchern und Labyrinthen handeln, der gleichen Literaturgattung angehören und in postmodernistischer Weise erzählt sind. Die Parallelen reichen bis in die Einzelheiten: Dem Streit um Aristoteles' verloren gegangene Abhandlung über die Komödie bei Eco entspricht bei King die Suche nach einer achtzehnten Schrift des Corpus hermeticum (von dem tatsächlich siebzehn Manuskripte erhalten blieben). Die Detektivfiguren sind in beiden Fällen Büchernarren, wobei Isaac Inchbold weniger heroisch daherkommt und auch etwas von Adson von Melk an sich hat. Wie dieser erzählt er die Geschichte im Rückblick als einsamer alter Mann. Geht am Ende bei Eco die Bibliothek in einem Flammenmeer unter, so fällt sie bei King einer Sintflut zum Opfer. ${ }^{180}$

Inchbold trägt als Buchhändler büchernärrische Züge und wird wider Willen zum Detektiv. Als rückblickend berichtendes Erzähler-Ich ist Inchbold mit Adson von Melk verwandt, allerdings

177 Živković (2008), S. 10.

178 Ebd., S. 58.

179 Ebd., S. 222.

180 Lutz Krützfeldt: „Der Bücherwurm als Held. Ross Kings Roman Das Labyrinth der Welt“. In: Neue Zürcher Zeitung, 28.10.1999, S. 35. 
schildert er die Abenteuer, die er selbst erlebt hat, während Adson über seinen Lehrmeister und Gefährten berichtet und damit wiederum Dr. Watson ähnelt.

\subsubsection{Erzählsituation im Detektivroman}

Die großen Detektive der Literatur werden stets von einem Gefährten begleitet. Die Figur des Sherlock Holmes ist mit seinem deduktiv-analysierenden, streng den Gesetzen der Logik folgenden Vorgehen stark an C. Auguste Dupin angelehnt und wird von Dr. Watson begleitet. Nero Wolfe und Archie Goodwin arbeiten in Rex Stouts Nero-Wolfe-Reihe zusammen, so wie William von Baskerville den jungen Adson von Melk an seiner Seite hat.

Typisch für den modernen Detektivroman seit Murders in the Rue Morgue ist es, dass die Handlung aus dem Blickwinkel eines homo- oder autodiegetischen Erzählers wiedergegeben wird, der rückblickend das Geschehen notiert. Dieser Erzähler ist in den meisten Fällen, und so auch bei Poe, Conan Doyle und Eco, der Begleiter des Detektivs, der als Chronist über dessen große Fälle berichtet, und in der Literatur als „Watson-Figur“"181 bezeichnet wird. Die Watson-Figur hat unterschiedliche Funktionen ${ }^{182}$ : Sie dient der Vermittlung zwischen Detektivfigur und Leser, beeinflusst die Sichtweise des Lesers auf den Detektiv, verhält sich selbst inferior und dient so als Kontrastfolie der Überhöhung des Detektiv-Helden.

Der Erzähler berichtet über die Ermittlungen des Detektivs, über sein Wissen und seine Fähigkeiten, vor allem aber über seine Ermittlungserfolge. So vermittelt er mit seinen Berichten zwischen der Detektivfigur und dem Leser: Der Erzähler versucht, gedanklich mit dem Detektiv Schritt zu halten, und zieht oftmals falsche Schlussfolgerungen, die der Detektiv korrigiert. Dieser Austausch zwischen Detektiv und Assistent wird in Form eines Dialogs wiedergegeben, um dem Leser ein leichtes Nachvollziehen zu gestatten. Gegenüber dem mit übergroßem Intellekt und enormem Scharfsinn ausgestatteten Detektiv wirkt die berichtende Nebenfigur durchschnittlich und dem Detektiv treu ergeben. Durch die kontrastive Darstellung von Detektivfigur und homodiegetischem Erzähler, der seinem genialen Partner gegenüber Respekt und Bewunderung an den Tag legt, wird die Überlegenheit und Brillanz des Detektivs noch betont. Das Verhalten des Erzählers suggeriert die Leserreaktion und dient der Überhöhung des Detektivs.

Obwohl sie über die Erlebnisse des Detektivs berichtet, ist die Watson-Figur nur am Rande als Nebenfigur am Geschehen beteiligt. Stanzel nennt diesen Erzähler-Typus den „peripheren Ich-Erzähler““183, der übrigens die Merkmale trägt, die auch Nusser der Watson-Figur zuweist.

181 Nusser (32003), S. 43.

182 Vgl. ebd., S. 43f.

183 Franz Karl Stanzel: Theorie des Erzählens. Göttingen: Vandenhoeck \& Ruprecht, 1979, S. 262-266.

Vgl. auch Martinez \& Scheffel (2000), S. 82. 
Der periphere Ich-Erzähler verfügt als Nebenfigur nicht über die volle Einsicht in die wahren Zusammenhänge des Falls und berichtet nicht über die Geschehnisse als solche, wie der Detektiv sie erlebt hat, sondern gefärbt durch den Blickwinkel des nur mittelbar Beteiligten, der bewertet und kommentiert. In dieser Eigenschaft zeigen sich seine mediale Funktion und seine Bewunderung für den Detektiv. Außerdem tritt häufig eine Auktorialisierung des peripheren Ich-Erzählers ein, die den Leser vergessen lässt, dass immer noch eine Figur berichtet.

\subsection{Der Club Dumas: Boris Balkan als Watson-Figur}

In Der Club Dumas stellt die Figur des Boris Balkan eine reizvolle Variante und mit seiner Erzählperspektive eine Überbietung der Watson-Figur dar. Boris Balkan wird in der Eröffnung vom Protagonisten Corso aufgesucht, da er sich von ihm Rat in seiner Recherche nach der Authentizität des Dumas-Manuskripts erhofft. Balkan ist für Corso kein Begleiter, und dennoch erzählt er seine Geschichte mit der Stimme einer Nebenfigur. Durch seine Augen kann der Leser einen genauen, kommentierten Blick auf den Protagonisten werfen und so Insider-Wissen erhalten. Balkan gibt seinen Eindruck von Corso wieder (kann Naivität vortäuschen, Meinung über Antiquare etc.) und beschreibt ihn für den Leser, wobei er Corso gegenüber jedoch völlig neutral bleibt, wenn nicht ein klein wenig überheblich. In der Auflösung am Ende des Romans wird eine Gesprächssituation wiedergegeben, die wiederum an die Gespräche zwischen Holmes und Watson erinnert. Nur sind hier die Rollen vertauscht: Es ist der Erzähler Balkan, der als Nebenfigur gar nicht am Geschehen beteiligt war und Corso nun über die wahren Hintergründe und Zusammenhänge der Machenschaften des Clubs aufklärt, wo Corso doch im Verlauf seiner Recherchen so viele falsche Schlussfolgerungen gezogen hat, Balkan aber über die genauen Abläufe der Suche informieren kann.

Balkan bestätigt, dass es sich bei dem vorliegenden Roman um einen Detektivroman handelt, und erläutert die Stimmen, mit denen er sich als Erzähler der Geschichte äußert:

Hier nun, glaube ich, ist es an der Zeit, noch einmal eindeutig meine Funktion als Erzähler darzulegen. Treu dem Prinzip, daß der Leser in Detektivromanen über dieselben Informationen verfügen muß wie der Held der Geschichte, habe ich mich bemüht, die Ereignisse aus der Sicht Lucas Corsos zu schildern. Ausnahmen stellen das erste und fünfte Kapitel dar, wo mir nichts anderes übrigblieb, als persönlich in Erscheinung zu treten. Dies soll nun zum dritten Mal geschehen, und dabei möchte ich konsequenterweise - wie schon in den genannten Kapiteln in der ersten Person Singular erzählen. ${ }^{184}$

In Kapitel 1 und 5 sowie dem zuletzt zitierten 15. fungiert Balkan als homodiegetischer Erzähler, also als Erzähler, der selbst als Figur in der Handlung in Erscheinung tritt und ebenso viel weiß wie die Hauptfigur. Mit dem Leser tritt dieser Erzähler in direkte (Meta-)Kommunikation, wie auch Anne L. Walsh feststellt: „Revertein novels [...] are seen to be a game between author and readers.““185 
In allen übrigen Romankapiteln wechselt Balkan in den Modus der Nullfokalisierung und weiß damit mehr, als der Protagonist weiß, wenn er über Corsos Erlebnisse berichtet. Stellenweise nimmt der Erzähler auch eine interne Fokalisierung vor und tritt soweit hinter der Handlung zurück, dass er als Erzähler kaum noch sichtbar ist:

An dieser Stelle muß ich als beinahe allwissender Erzähler wieder in den Hintergrund treten und erneut den Blickwinkel Lucas Corsos einnehmen, denn Sie, lieber Leser, sollen die dramatischen Ereignisse, die im folgenden über den Bücherjäger hereinbrachen, genau so nachvollziehen können, wie er sie selbst erlebt und mir später geschildert hat. ${ }^{186}$

Corso ist für die Leser dabei ein ,guide ${ }^{\text {c187 }}$ durch die Erzählung. Der Leser verfolgt das Geschehen durch Corsos Augen, denn er verfügt über dieselben Informationen wie der Held: „Da ich mir aber vorgenommen habe, die Geschichte aus der Sicht Corsos zu erzählen, bin ich gezwungen, [...] mich innerhalb der engen Grenzen zu bewegen, die Corsos Vorstellungsvermögen gesetzt waren.“' ${ }^{\text {‘88 }}$. Dass der Leser zu keinem Zeitpunkt mehr als die Hauptfigur weiß, ist typisch für den Detektivroman. Balkan dagegen weiß über alle Ereignisse und Begebenheiten Bescheid und wirkt dadurch auf fiktionaler Ebene wie die ,Graue Eminenz', die im Hintergrund die Fäden zieht. Durch den Wechsel der Erzählstimmen und -modi bietet er dem Leser Informationen an oder enthält sie ihm vor. Allerdings verfügt er über detaillierte Kenntnisse des Geschehens, die eine nur am Rande beteiligte Nebenfigur eigentlich nicht haben kann.

Die komplexe Erzählstruktur in Der Club Dumas wird im Detail bei Waldkirch ${ }^{189}$ und Walsh $^{190}$ analysiert. Letztere untersucht auch, wie Balkan als Erzähler Corsos Gefühle und Überlegungen teilen und Einsicht in sein ,Vorstellungsvermögen' haben konnte. Genau wie Watson verfügt Balkan nur über ein eingeschränktes zuverlässiges Wissen über die Ereignisse der Hauptfigur und muss durch den Protagonisten, den Detektiv, über die Details des Falls in Kenntnis gesetzt werden („wie er mir später gestand““191). Auch Watson berichtet in der abschließenden Auflösung mehrerer Falldarstellungen darüber, wie Sherlock Holmes ihn nach der Entlarvung des Täters über die wahren Zusammenhänge aufgeklärt habe ${ }^{192}$. Balkans Legitimation für sein Wissen lautet ebenfalls, dass Corso ihn im Anschluss an seine Abenteuer über diese in Kenntnis gesetzt habe:

Einige Zeit später, als alles vorbei war, erklärte sich Corso bereit, mir den Rest der Geschichte zu erzählen. So kann ich jetzt ziemlich genau gewisse Einzelheiten rekonstruieren, obwohl ich sie nicht persönlich erlebt habe: die Verkettung von Umständen, die zu dem bitteren Ende führten, und die Auf-

\footnotetext{
186 Pérez-Reverte (1997), S. 133.

187 Walsh (2007), S. 23.

188 Pérez-Reverte (1997), S. 127.

189 Vgl. Waldkirch (2007), S. $76 f$.

190 Vgl. Walsh (2007), S. 96-99.

191 Pérez-Reverte (1997), S. 118.

192 „Das wenige, was ich über diesen Fall noch nicht wußte, erzählte mir Sherlock Holmes am nächsten Tag während unserer Rückreise.“, vgl. Arthur Conan Doyle: „Das gesprenkelte Band“. In: Werkausgabe in neun Einzelbänden. Nach den Erstausgaben neu und getreu übersetzt von Gisbert Haefs. Bd. 1: Erzählungen. Die Abenteuer des Sherlock Holmes. Zürich: Haffmans, 1984, S. 203-235, hier S. 233.
} 
lösung des Rätsels um den Club Dumas. Dank der Hinweise des Bücherjägers kann ich in dieser Geschichte den Doktor Watson spielen und Ihnen erzählen, daß die folgende Szene eine Stunde nach unserer Begegnung stattfand, und zwar in Makarovas Bar. ${ }^{193}$

Balkan bringt sich selbst nicht nur mit dem Erzähler der Holmes-Geschichten in Verbindung, sondern auch mit Dr. Sheppard, dem Assistenten von Hercule Poirot in Agatha Christies The Murder of Roger Ackroyd (1926): „Ich finde es ganz einfach amüsant, die Geschichte in der Art eines Doktor Sheppard darzustellen, wie eine Unterhaltung mit Poirot. “" ${ }^{194}$ Christie verwandte in ihrem Meisterstück eine bis dahin noch nie gewählte Erzählperspektive: Der homodiegetische Erzähler Dr. Sheppard berichtet von Poirots Vorgehen, den Mord an Roger Ackroyd aufzuklären, bis schließlich feststeht, dass Sheppard selbst der Täter war. Nach dieser Enthüllung bietet das zweite Lesen noch mehr ästhetisches Vergnügen als das erste, obwohl die Auflösung bekannt ist.

Auch eine wiederholte Lektüre von Der Club Dumas bietet dem Leser Neues. Während der ersten Lektüre ist der Leser so damit beschäftigt, mit Corsos Ereignissen und Schlussfolgerungen Schritt zu halten, dass er wichtige Details übersieht. Das erneute Lesen, bei dem mehr auf Zwischentöne geachtet werden kann, bringt die Erkenntnis, dass aus dem Text kein anderer Schluss gezogen werden kann und feststeht, dass es zwischen den beiden Büchern im Zentrum keinerlei Verbindung gibt.

\subsubsection{Die Suche als Queste}

Das Motiv einer abenteuerlichen Suche nach einem besonderen, auratischen Gegenstand, oder auch einer Person, wurde bereits in der mittelalterlichen Literatur eingesetzt. Als Beispiele können hier zum einen die Suche nach dem Heiligen Gral oder einem anderen Schatz, zum anderen die Brautfahrt oder die Suche nach dem verschollenen Vater angeführt werden. Die Queste (altfrz. Suche) stellt das Hauptmotiv der mittelalterlichen Epik, besonders der Artus-Epik ${ }^{195}$, dar und schildert als Aventiure den Aufbruch des Helden zur abenteuerlichen Suche (lat. querere suchen, besonders im Sinne von etwas zu erforschen suchen, in Erfahrung bringen wollen) sowie deren Verlauf und Ausgang.

Die Suche gilt einem Objekt (oder einer Person), das aufgefunden und nach Hause oder an einen bestimmten Ort gebracht werden muss. Mitunter benötigt der ausziehende Held das Objekt, um sich in der vorherrschenden Gesellschaftsstruktur zu bewähren und auszuzeichnen. Die Queste trägt also Merkmale einer Schatzsuche, die im Abenteuerroman und heutigen -filmen häufig vorkommt. Während der Suche, der Heldenreise, muss der Held Abenteuer bestehen und 
unter Anstrengung Hindernisse und Prüfungen überwinden. Verbunden ist die Suche mit dem Motiv der Reise, der Fahrt in ein unbekanntes Land.

Die Fahrt geschieht in der Artus-Epik, auch im Parzival, als doppelter Cursus, der eine Steigerung in den Anforderungen an den Helden als Bewährungsprobe beinhaltet:

\section{Auszug - scheinbares Gelingen oder Scheitern - Rückkehr \\ 2. Auszug - Gelingen - Rückkehr.}

In den Büchersuchgeschichten wird ein simplifiziertes Grundmuster verfolgt:

Aufbruch - Abenteuer und Bewährung: Reifung \& Erkenntnis - Rückekehr.

Die Schilderung der abenteuerlichen Reise und der Abenteuer des Helden ist zugleich ein Bericht über dessen Reifung, Entwicklung und moralische Erziehung, „[d]ie Fahrt wird zur Lebensfahrt “"196. Unabhängig vom Gelingen der Aufgabe führt die Fahrt als Suche zur Selbst- und Sinnfindung. Eigentliches Ziel der Suche waren also Reife, Charakterstärkung, Erkenntnis. Eine Queste kann daher auch Merkmale des Bildungsromans beinhalten.

\subsubsection{Don Quijote als Suchender}

Richtungsweisend für die Darstellung von Suchen und Fahrten ist Miguel de Cervantes Saavedras El ingenioso bidalgo don Quixote de la Mancha (1605/1615) geworden. Don Quijote ist ein typischer knight-errant. ein fahrender, aber auch ,irrender', sich geistig und physisch auf Irrwegen befindlicher Ritter. Derart zerrissen, verfolgt er nach dem Modell der von ihm so geliebten Ritterromane eine zweifache Fahrt. Er ist ein exzentrischer Idealist, weltfremd, realitätsfern bis zum Wahn, und das durch extensive Lektüre. Der Realitätsverlust ist einer der ältesten Vorwürfe gegen Lesen überhaupt (vgl. Kap. II.1.2). Anspielungen auf die Figur des Don Quijote kommen in Verbindung mit der Thematisierung von Lesen und Schreiben sowie dem Auftreten des BuchMotivs immer wieder vor, zum einen natürlich wegen der extremen Verwirrung von Illusion und Realität, zum anderen aber auch aufgrund der expliziten Auseinandersetzungen von Erzähler und Figuren im Text ${ }^{197}$, so dass „das Schreiben, die Bücher, das Lesen, die Literaturkritik oder überhaupt die Literatur als das, eigentliche Thema’ des Romans angesehen wurde ${ }^{\text {c198 }}$. Am Schluss des Romans bindet sich Cervantes denn auch eng bis zur Gleichsetzung an seine Hauptfigur: „Für

196 Daemmrich \& Daemmrich (21995), S. 67.

197 Vgl. ebd., S. 106.

198 Ulrich Winter: Der Roman im Zeichen seiner selbst. Typologie, Analyse und historische Studien zum Diskurs literarischer Selbstrepräsentation im spanischen Roman des 15. bis 20. Jabrhunderts. Tübingen: Narr, 1998, S. 197. 
mich allein ist Don Quijote geboren und ich für ihn; er wußte Taten zu vollbringen und ich sie zu schreiben; wie beide allein sind bestimmt, zusammen ein Ganzes zu bilden [... $]^{\text {‘199}}$.

Allerdings ist die Figur Don Quijote inzwischen enthoben von seiner hochliterarischen Provenienz auf allen Leserebenen verständlich. Auch der Normalleser hat eine Vorstellung von der Figur Don Quijote, auch wenn er den Roman vielleicht nie gelesen hat, während diejenigen, die den Roman kennen, noch intensivere Zusammenhänge herstellen können. Die Figur hat abgelöst von ihrer fiktionalen Einbettung überlebt, denn sie wurde in neue Kontexte und Funktionen übertragen und durchgeistert noch die heutige Populärkultur. Don Quijote ist nicht nur jemand, der Realität und Fiktion nicht mehr unterscheiden kann, sondern vereinfacht ein Sonderling, der jedem Leser verständlich ist. Die Autoren, die Don Quijote in dieser Art in ihren Romanen verwenden, setzen auf ein kulturelles Wissen, das sie mit dem Leser teilen, egal, wie umfangreich dieses Wissen ausfällt, und vielleicht nur den kleinsten gemeinsamen Nenner - die Figur als komischen, aber auch tragischen Sonderling - umfasst.

Einer falschen Deutung der Wirklichkeit aufgrund ihrer extensiven Literaturkenntnisse erliegen wie Don Quijote die Protagonisten aus Das Labyrinth der Welt und Der Club Dumas (vgl. Kap. III.9.2.4), die auf diese Weise und auch ganz explizit im Text mit Don Quijote in Verbindung gebracht werden. Die Ähnlichkeit von Inchbold und Don Quijote ist sogar am geschilderten Äußeren leicht erkennbar: „Kurzsichtig, asthmatisch und klumpfüßig, ist Inchbold wahrlich ein Ritter von der traurigen Gestalt.“200

Inchbold liest zu Beginn des Romans den Don Quixote und kämpft gegen politische Intrigen und Machtspiele wie gegen die sprichwörtlich gewordenen Windmühlen. Beim Aufbruch zu seiner Auftraggeberin vergleicht er sich selbst mit der Romanfigur: „,[...] während ich mich, wie Don Quijote, darauf vorbereitete, meine prallvollen Bücherregale zu verlassen und mich aufs Land hinauszuwagen, hinein in die Welt, die ich bislang so erfolgreich zu meiden gewußt hatte. “201 Don Quijote bricht in eine von seiner Fantasie verzerrte, Welt als Buch’ auf, wohingegen die „Welt“ für Inchbold die echte Welt ist, vor der er sich in seinem Bücherhaus verschanzt hatte. An anderer Stelle heißt es erneut mit Bezug auf Don Quijote, er mache sich auf: „[w]ie ein verarmter Hidalgo, der, einer Laune seiner Liebsten | folgend, mit zerbrochener Lanze und zerbeultem Schild in eine Welt voller Intrigen und Hexerei hinauszieht, um sich seiner aussichtslosen Aufgabe zu stellen.“202 Seine Auftraggeberin Alethea wird hier mit Dulcinea verglichen, die Don Quijote zu

199 Miguel de Cervantes Saavedra: Der simnreiche Junker Don Quijote von der Mancha. Aus d. Span. v. Ludwig Braunfels. 5. A. Düsseldorf: Artemis \& Winkler, 2008, S. 1160.

200 Krützfeldt (1999).

201 King (2001), S. 21.

202 Ebd., S. $225 f$. 
seinen Taten beflügelt, doch Inchbold schüttelt diese Assoziation sofort ab und setzt seine Aufgabe mit Vernunft und Verstand fort. Im Gegensatz zu dem literarischen Vorbild gelingt es Inchbold meist, der Realität den Vorrang zu geben, Vernunft walten, und sich nicht von seiner Lektüre vereinnahmen zu lassen. Zwar versucht er, den Fall des verschollenen Buchs mit Vernunft zu lösen, tappt aber dennoch in die Falle von Aletheas Andeutungen von Intrigen, die sich als Fiktion erweisen, und nimmt sie für bare Münze, muss dann aber erkennen, dass sie ihn nur benutzt hat, um ihre Verfolger auf ihn zu lenken.

Neben Inchbold wird auch eine Figur aus dem parallel geschilderten Handlungsstrang am böhmischen Hof mit Cervantes’ Ritter verglichen: „Man hat mir berichtet, daß Ihr eine hingebungsvolle Leserin seid, eine veritable Donna Quijote“6203. Die Hofdame der Winterkönigin ist eine leidenschaftliche Leserin, besonders von „romantische[n] Abenteuer[n] aus dem Sagenkreis um König Artus““204, also der art Lektüre, die auch das literarische Vorbild bevorzugt.

Wo Don Quijote seine Fantasie lebendig macht, ihm dies aber nicht bewusst ist, wird Corso, der Protagonist in Der Club Dumas, tatsächlich zum Teil einer nachgestellten fiktiven Handlung, bemerkt dies aber erst spät. Für Corso besteht die Vermischung von Illusion und Fiktion darin, dass er von einer Romanhandlung, die tatsächlich jemand mit ihm als Hauptfigur nachspielen möchte, auf die falsche Fährte und zur vermeintlichen Lösung geführt wird. Unter dem Eindruck seiner Belesenheit überinterpretiert Corso die vermeintlichen Zitate und Verweise und hat förmlich den Wunsch, wie Don Quijote, die fiktive Welt der Romane in der Realität durchzusetzen.

\subsubsection{Der Weg als Labyrinth}

Das Labyrinth ist ein Element der Queste, dass diese erschwert, da sie den Protagonisten daran hindert, sein Ziel schnell, direkt und auf dem kürzesten Wege zu erreichen. Es stellt oftmals die letzte Hürde vor dem Erreichen des Ziels dar (Theseus im Labyrinth des Minotaurus, Dornenhecke in Dornröschen, letzte Aufgabe im Trimagischen Turnier in Harry Potter und der Feuerkelch) und wirkt so als retardierendes Element vor der Lösung.

Das Labyrinth steht für Komplexität, Unübersichtlichkeit und räumliche Desorientierung. Es ist auf den ersten Blick nicht leicht zu durchschauen, ist rätselhaft und geheimnisvoll. Die Wege, oft von mehr als mannshohen Pflanzen eingefasst, sind mit Fallstricken wie überraschenden Abzweigungen der Wege oder plötzlichen Sackgassen ausgestattet, die kein Fortkommen erlauben, und werden so zu Irrwegen. Trotz des Irrwegs, den es symbolisiert, ist das Labyrinth zugleich Ausdruck größter Symmetrie und Harmonie. Ein Labyrinth wird oft als französischer, geometrisch angelegter Garten vorgeführt, dessen Wege von Buchsbaumhecken gesäumt werden. So 
komplex ein Labyrinth auf den ersten Blick erscheint, bietet es doch eine Wiederholung des Immergleichen und kann durch streng logische Vorgehensweise bezwungen werden, denn es gibt nur einen richtigen Weg zum Ziel, dem Zentrum des Irrgartens. Im übertragenen Sinne wird auch ein mentaler Irrweg mit seinen falschen Schlussfolgerungen oder gedanklichen Sackgassen als Labyrinth angesehen, wobei es der „Chiffrierung komplexer Innerlichkeit ${ }^{\text {‘205 }}$ dient. Das Meistern dieses Irrens führt zur Erkenntnis - das Labyrinth ist letztlich ein „Symbol der Erkenntnis und der Verfehlung, der Komplexität und Undurchschaubarkeit ‘206.

Auf die Literatur übertragen dient das Labyrinth als Symbol des rätselhaften Textes. Die labyrinthischen Bibliotheken in Borges’ Bibliothek von Babel und Ecos Der Name der Rose (die beiden Werke werden beinahe überall in der Literatur als fest stehender Zweiklang erwähnt) als Abbild des Universums zeigen eindrucksvoll, dass das ,Labyrinth der Welt' eines der Texte, Subtexte und Metatexte ist. Dieser Irrgarten besteht aus Intertextualität und unterschiedlichen Lesbarkeiten und ist mittels Zitaten und Anspielungen ein ständig auf sich selbst verweisendes Gebilde, wobei der Weg hindurch über das Entwirren der Querverweise verläuft. Jemand, der über eine große Textkenntnis verfügt und literarische Techniken beherrscht, wird also erfolgreicher das Labyrinth meistern - den Text auf einer anderen Ebene zu goutieren in der Lage sein - als andere. Zugleich vermittelt die Bibliothek durch ihre strenge Ordnung Übersichtlichkeit in einer zersplitterten Welt und symbolisiert wie das Labyrinth Symmetrie.

Die Protagonisten in Das Labyrinth der Welt und Der Club Dumas müssen einige Irrwege und Fehlschläge in Kauf nehmen, bevor ihre Suche abgeschlossen ist. Ihre Desorientierung ist eine figurative, die durch verrätselte oder als rätselhaft empfundene Texte und Charaktere hervorgerufen wird. Dabei verführt sie ihre Belesenheit dazu, Irrwege zu sehen, wo es keine gibt.

\subsection{Der Mythos des einen oder letzten Buchs}

Die Suche nach einem Buch besitzt erst dann Relevanz, wenn es etwas Besonderes und Einzigartiges ist und ihm ein bestimmter Wert zugeschrieben wird. Dieser Wert kann ökonomischer Art sein, wenn das Buch einen raren und damit kostbaren (Kunst-)Gegenstand darstellt, oder wenn es ideell mit einem Wert aufgeladen wird. Dabei kann es wiederum um eine persönliche Wertschätzung des Bandes als solchem gehen oder um den enthaltenen Text.

Bücher sind auch geheimnisvoll, in gewissen Kontexten beinahe magisch, wenn das Buch etwas Un- oder Außergewöhnliches, nicht Alltägliches im Protagonisten bewirkt. Ein Buch als magisch zu bezeichnen, bedeutet allerdings unter Umständen auch, es außerhalb der Grenzen von 
Vernunft und Wissenschaft zu rücken und ihm so seinen Wert gerade abzusprechen ${ }^{207}$. Das Buch erhält außerdem eine exponierte Stellung, sobald es das ,eine’ oder das letzte Buch ist, ein Unikat oder das letzte noch existente Exemplar. Aus der Kombination dieser beiden Eigenschaften Singularität und Wertigkeit - entsteht die Motivation für die Suche nach dem einzigartigen Buch in den untersuchten Romanen.

Das ,eine' Buch ist ein Buch, neben dem es kein anderes gibt, ein Buch, in dem sich alle anderen finden lassen. Als begründendes Element unserer Buchreligion wird die Bibel als ,das Buch' oder das ,Buch der Bücher’ bezeichnet. Die Auffassung vom einen besonderen Buch geht aber auch auf das absolute Buch der Romantik zurück (vgl. Kap. II.2.1). Manfred Schneider sieht mit Verweis auf die Buchreligionen und gesellschaftliche Ideologien die Autorität eines absoluten Buchs verkünden, das alle übrigen ersetzt. „Propheten des einen Buches“ ${ }^{\text {208 }}$ setzten demnach auch Bibliotheken in Brand.

In Thomas Whartons Salamander wird der Buchdrucker Nicholas Flood von einem slowakischen Grafen auf sein Schloss gerufen, um ihm ein solches unendliches Buch zu drucken: „Die Planeten, das Sternenfirmament [...], das ganze Universum ist ein riesiges, ungebundenes Buch der Rätsel. Ein Buch in der unverständlichen und unaussprechlichen Sprache Gottes. [...] Und ich will nicht mehr und nicht weniger als meine eigene, persönliche Ausgabe.“ ${ }^{209}$ Der Graf möchte Imaginäres materiell greifbar machen und ein „unendliches Buch schaffen“ ${ }^{\text {“210 }}$ lassen, zugleich aber ein Meta-Buch, ein „imaginäres Buch“‘211 ohne Anfang und Ende. Auch ein durch zwei Buchdeckel begrenztes Buch kann unendlich sein, wenn sein Inhalt seine äußere Begrenzung überschreitet und sich unter seinen Lesern verbreitet. Die Aufgabe und Motivation des Grafen ist es dabei, nicht nur ein einzigartiges Buch zu schaffen, sondern auch sein Land zu einem Gebiet auf der literarischen Landkarte Europas zu machen.

Der Buchdrucker hat den Auftrag derart verinnerlicht, das er nach dem Tod des Auftraggebers zu seiner Bestimmung wird. In diesem Roman wird eine Variante der Buchsuche geschildert, denn das Buch muss erst noch gedruckt werden. Gesucht werden in diesem Fall die idealen Bestandteile, wobei die Suche nach den Ingredienzien die Protagonisten um die ganze Welt führt. Über den Inhalt erfährt der Leser nichts. Im venezianischen Geschichtenbrunnen stoßen sie auf

207 Michael Harbsmeier: „Buch, Magie und koloniale Situation. Zur Anthropologie von Buch und Schrift““. In: Peter Ganz (Hg.): Das Bucb als magisches und Repräsentationsobjekt. Wiesbaden: Harrassowitz, 1992, S. 3-24, hier S. 3. In dem Tagungsband werden Buch und Schrift im Rahmen von Mittelalter-Studien vorwiegend unter religiösen Aspekten untersucht, z. B. das Buch als magischer Talisman.

208 Manfred Schneider: „Von keinem Auge mehr belästigt. Wissensspeicher, Machtzentralen, Boten des Überholten: Das Schicksal der Bücher in der Dämmerung der Bibliotheken“. In: Literaturen 3 (2004), S. 74-82, hier S. 76.

209 Wharton (2003), S. 47. 
einen Setzkasten mit Lettern, die sich selbst zu Druckformen finden. Mit dem Buch wird das ÄuBere angefertigt, das Medium, aber auch zugleich der Text, der ein universeller ist, da er keinen Autor besitzt, sondern sich selbst aus universellen Zeichen formt. Hier fühlt sich der Leser erinnert an das Infinite-Monkey-Theorem, das besagt, würde man einen unsterblichen Affen unendlich lange auf einer Schreibmaschine tippen lassen, würden irgendwann Shakespeares Werke ${ }^{212}$ entstehen. Das perfekte, unendliche Buch ohne Anfang und Ende ist das Ziel, das die Protagonisten vorantreibt. Im Vordergrund stehen Suchen und Sammeln, um am Ende das Objekt herstellen zu können. Die Konzeption eines unendlichen Buchs dient als Reaktion auf die heutige Massenund Überproduktion von Büchern, es ist ein Buch, das alle übrigen überflüssig macht.

In Das letəțte Buch von Zoran Živković geht es ebenfalls um ein einzigartiges, nämlich das titelgebende „letzte Buch“. Die Wirklichkeit des Lesers ist bei jedem Lesen anders, und so sieht auch das Buch bei jeder Lektüre anders aus. Es ist einzig der Titel, der schon feststeht und bleibt. Das „letzte Buch“ - „Danach gibt es kein weiteres mehr“6213 - steht im Verdacht, ein todbringendes Buch zu sein, das jeden Leser nach der Lektüre tötet, wobei die Leser keine Anzeichen einer Todesursache zeigen. Ganz banal war dieses das ,letzte' Buch, das die Opfer vor ihrem Tod gelesen haben.

Das ,Buch im Buch’ dient dazu, den Protagonisten erst auf die Spur des Autors zu bringen, und ihn auf die vielen Parallelen zwischen beiden aufmerksam zu machen. Zudem verdeutlicht es, welcher materielle oder ideelle Wert Büchern zugesprochen wird, aber auch, dass Menschen Bücher zu unterdrücken und zu vernichten suchen. Aus diesem Grund müssen Bücher geschützt und ihr Inhalt verbreitet werden, damit er nicht in Vergessenheit gerät.

In Der Schatten des Windes wird der elfjährige Daniel von seinem Vater, einem Buchhändler, auf den ,Friedhof der vergessenen Bücher’ geführt, wo er, „[q]uasi als Initiationsritus“ ${ }^{\text {214 }}$, ein Buch auswählen soll, das er an sich nimmt und ,adoptiert'. So könne er dafür sorgen, dass das Buch nicht dem Vergessen anheim fällt. Aber nicht nur der Leser adoptiert das Buch, sondern umgekehrt auch das Buch den Leser, denn es kann ihn erziehen und etwas lehren. Der Entschluss für die Auswahl und Adoption wird von beiden Seiten gefasst, das Buch erwählt sich also auch seinen Besitzer. Determinismus spielt bei der Wahl ebenfalls eine Rolle: „Der Entschluß war gefaßt. Auf beiden Seiten. [...] Jedenfalls hatte ich die Gewißheit, daß das Buch seit Jahren, wahrscheinlich seit der Zeit vor meiner Geburt, hier auf mich gewartet hatte.“‘215

\footnotetext{
212 Je nach Überlieferung des populären Mythos entstünden auf diese Weise auch sämtliche Werke der Nationalbibliothek Frankreichs oder Englands.

213 Živković (2008), S. 74.

214 Löffler (2005), S. 12.

215 Ruiz Zafón (2003), S. 11f.
} 
Die Bücher auf dem Friedhof, je ein Exemplar eines Werkes, stehen für die vielen ,Verschwundenen' während des spanischen Bürgerkrieges und der Zeit des Franco-Regimes, einer „Politik des Vergessens“6216. Der Friedhof ist ein abgeschlossener Ort für Eingeweihte und birgt ein Geheimnis, das Daniel nicht einmal mit seinem engsten Freund teilen darf. Allerdings werden die Bücher auf dem Friedhof von einem Wächter geschützt, wo sie wie in einer Bibliothek überdauern, während sie auf dem freien Markt vielleicht dem Einstampfen preisgegeben wären.

Daniel ist von der Lebensgeschichte des Autors Julián Carax, die er als Roman codiert in „Der Schatten des Windes“ vorfindet, derart fasziniert, dass er sich auf die Suche nach dem Autor macht (vgl. Kap. III.4.4). Das Buch erhält seinen Wert hier nicht nur durch die ideelle Qualität, mit der Daniel es auflädt, denn er stellt im Lauf der Handlung und mit zunehmendem Alter fest, dass der Autor und er eine Menge Gemeinsamkeiten haben. Das Buch besitzt daneben auch Wert durch seine Seltenheit: Daniels Exemplar ist das einzige noch existente Exemplar des letzten Romans von Carax, alle übrigen Exemplare wurden verbrannt, und nun ein Vermögen wert. Der materielle Wert wird auch betont, wenn der Antiquar Barceló Daniel das Buch abkaufen möchte, weil er sich ein Geschäft davon verspricht. Außerdem verleihen die Gerüchte über den verschollenen, geheimnisumwitterten Autor Carax (vermeintlicher Tod im spanischen Bürgerkrieg, tragische Liebesgeschichte etc.), die der heutigen Sensationspresse ähneln, seinen Romanen zusätzlichen Wert. Nicht nur für den Protagonisten Daniel, sondern auch für einen geheimnisvollen Unbekannten, der sich als Carax selbst herausstellt, hat das Buch einen ideellen, wenn auch negativ konnotierten Wert. Er versucht, alle Exemplare zu vernichten, auch Daniels letztes Exemplar, denn als Geschichte seiner unglücklichen Liebe und seines missglückten Lebens soll das Buch nicht mehr existieren.

Der Wert eines Buchs zeigt sich auch in der Furcht vor dem Verlust. Das ,Entwenden' des geliebten Buchs wäre für den Protagonisten Gregorius in Nachtzng nach Lissabon ${ }^{217}$ (2006) schon eine Fotokopie des Textes, da er sich den Text und den Autor ganz angeeignet hat. Gregorius ist es nicht recht, dass sein Bekannter Silveira sich eine Fotokopie des Buchs von Prado anfertigen möchte - er ist der Meinung, er habe ein Recht nicht nur am Buch selbst, sondern am ganzen Text. Silveira schließt aus Gregorius Reaktion zunächst, dass der philosophische Text und ein prosaisches Fotokopiergerät nicht zueinander passen, doch versteht er Gregorius endlich ganz, wenn er feststellt: „Und außerdem möchtest du den Text ganz bei dir behalten. Nicht nur das Buch. Den Text.“"218 Gregorius möchte nicht nur Prados gebundene Aufzeichnungen ganz behalten, sondern gerade das Immaterielle - den Text und die Gedanken dahinter. Ein Buch kann als 
Medium und Träger des Textes beliebig oft gedruckt, oder eben (foto-)kopiert werden, der Text als Inhalt bleibt einmalig. Dieser Text kann auch unterdrückt oder vorenthalten werden, wenn keine oder nicht ausreichend Druckausfertigungen verfügbar gemacht werden, wodurch bestimmte Gruppen Macht über andere ausüben.

Daniel hat dagegen kein Problem damit, den Roman mit anderen zu teilen. Er leiht Barceló das Buch zum Lesen, liest der blinden Clara, die er liebt, daraus vor und verschenkt es schließlich sogar an sie, erhält es aber im Lauf der Geschichte zurück. Die mit der Adoption des Buchs verbundene Aufgabe lautete schließlich auch, den Inhalt des Buchs zu verbreiten bzw. mit anderen zu teilen, „daß es nie verschwindet, daß es immer weiterlebt ${ }^{\text {‘219. }}$.

Das Buch wird als letztes Exemplar geheimnisvoll, da wir uns nicht vorstellen können, dass es tatsächlich einmal keine Bücher mehr geben werde. Auch im Spielfilm The Book of Eli (2010, Regie: Albert und Allen Hughes), eigentlich ein Film über eine chaotische, degenerierte Welt nach dem Untergang der Zivilisation, besitzt der Held ein ,letztes Buch', das letzte Exemplar der Bibel. In der fiktiven postapokalyptischen Welt sollen alle Exemplare vor dem Krieg, der zur Weltzerstörung führte, vernichtet worden sein, da dieses Buch eine unkontrollierbare Gefahr barg, die Menschen zu stärken. Aus diesem Grund sucht der Antagonist, die Bibel an sich zu bringen. Das letzte Buch ist hier aufgeladen als Buchschatz, etwas, das einen großen Wert besitzt und vor den falschen Besitzern verteidigt werden muss. Die Bibel wird zudem als Grundstein der Zivilisation gezeigt. Statt einer Suche hat der Held den Auftrag, die Bibel unbeschadet zu einer Gruppe von Bewahrern der Tradition zu bringen, die verlorenes Wissen sammelt und eine neue Zivilisation auf der Basis der untergegangenen zu errichten plant. Diese Buchbewahrer als Keimzelle einer neuen Zivilisation erinnern an die Gelehrten in Fahrenheit 451. In diesem Roman überdauert das Buch, da es auswendig gelernt und schließlich mündlich weitergegeben wird, dies ist auch in The Book of Eli der Fall. Der blinde Protagonist hat den Inhalt auswendig gelernt und diktiert ihn für die erneute Verbreitung. Der Antagonist, der das Buch an sich bringen konnte, kann seinen Inhalt nicht nutzen, da er den in Braille geschriebenen Text nicht entziffern kann. Als Beginn der neuen Zivilisation drucken die Buchbewahrer auf einer alten, manuell betriebenen Druckmaschine die gerettete Bibel nach, und auch weitere Grundlagentexte der menschlichen Kultur, wie der Koran oder die Thora, befinden sich in ihrer Bibliothek geretteter Bücher. Neben der Befürwortung einer Stärkung des christlichen Glaubens kann man hier ein Zitat der Gutenbergschen Medienrevolution als fundamentalem Wandel bzw. im Film als Anbeginn einer Gesellschaft sehen. Angesichts der sich heute immer stärker ausdifferenzierenden Informations- und Kommunikationswege ist dieser Plot vielleicht auch ein Plädoyer für die, wenn auch wenig wahr- 
scheinliche, Rückkehr zur oral-auditiven Übermittlung von Literatur, da diese als einzig zuverlässige Art der Bewahrung von Inhalten stilisiert wird.

\subsection{Schlussfolgerung}

Schildern sie eine Suche, sind die Buch-Bücher im Kriminal- oder Detektivgenre angesiedelt. Das Buch-Motiv bietet dabei Anlass zu Referenzen auf den klassischen Detektivroman und damit verbundenen selbstreflexiven und metafiktionalen Überlegungen, die eher der vorgebildete Leser nachvollziehen kann. Außerdem lässt sich in den untersuchten Romanen eine Aufbrechung üblicher Genreschemata erkennen. Der Buch-Roman baut zunächst das bekannte Muster eines Detektivromans auf, dessen gängige Elemente eingesetzt werden wie der Suchende, der ganz typische, aus literarischen Vorbildern bekannte Merkmale trägt. Doch findet dann eine Variation statt, nämlich wenn das Buch eben nicht gefunden wird und so mit üblichen Genremustern gebrochen wird. Das Buch bietet nun Anlass dazu, das Genre zu variieren. Vorausgesetzt wird hier allerdings ein kompetenter Leser, der die Genremuster kennt und nur so dazu in der Lage ist, auch die Variation zu durchschauen.

Der Mythos vom einzigen oder letzten Buch wird von der heutigen Massenproduktion von Büchern - hier sind Titel ebenso gemeint wie Auflagenhöhen - und der damit verbundenen Entwertung des Buchs, das nach dem Erscheinen immer schneller verramscht wird, ad absurdum geführt. Auf dem heutigen Buchmarkt erlangt ein Buch vor allem über seine Seltenheit als antiquarisches Rarum oder eine besonders aufwändige Ausstattung seinen Wert.

Allerdings ist eine Unterscheidung zwischen Text und Medium nötig: Auch wenn man „ein Buch liest“ ist damit ein Text gemeint. Der einzigartige ,Buchschatz’, der das Objekt der Suche darstellt, ist in den untersuchten Romanen stets das Medium Buch, nicht der Text. Jedoch ist nur der Text einmalig, denn das Medium ist unendlich oft reproduzierbar, was dem Erhalt des Textes $\operatorname{dient}^{220}$. Die Differenzierung zwischen „Medium“ und „Content“ wird im Zuge der wachsenden Verbreitung digitaler Publikationen zunehmend wichtig. Gerade dieses Spannungsverhältnis macht aber den Reiz der Buch-Bücher aus: Das einzigartige, besondere Buch erfährt auch aus diesem pragmatischen Grund, dass heute Bücher in einer Überzahl vorhanden sind, eine Auratisierung. Wer gern liest, liest nicht nur ein Buch und wird sich beim Lesen über schützenswerte und singuläre Bücher wiederfinden. 


\section{3 „Jedes einzelne Buch hat eine Seele. ${ }^{“ 221}$ - Buch und Leben}

In diesem Kapitel wird das anthropomorphisierte Buch im Roman vorgestellt. Sowohl fiktionsextern als auch -intern werden dem Buch immer wieder menschliche Eigenschaften zugesprochen. Es wird personifiziert und vermag dem passionierten Leser sogar Freunde oder Partnerschaft zu ersetzen. Umgekehrt verhilft gerade der Leser dem Buch zum ,Leben', eine Auffassung, die u. a. wirkungsästhetischen Konzepten wie dem Wolfgang Isers geschuldet ist. Diese Ansätze werten den Leser und seine Rezeption des Textes gegenüber dem Autor auf und relativieren die Position des Autors als alleinigem Schöpfer des Textes. Ohne gelesen zu werden, wäre ein Buch nur ein unbelebter Gegenstand, ohne den Käufer hätte das Buch auf dem Markt kaum eine Daseinsberechtigung. Die ausgewählten Romane führen anhand des Buch-Motivs vor, wie sich der Leser mit dem Buch identifiziert und schließlich sogar - in fantastischer Literatur - in ein Buch verwandeln kann oder wie der reale Leser anhand der Spiegelung seiner selbst durch den fiktionalisierten Leser in das Geschehen einbezogen wird. Als Kehrseite des Lebens wird auch das tote Buch gezeigt, das vergessene, ungelesene Buch, das seine Inhalte nicht mehr vermitteln darf.

\subsection{Anthropomorphisierung des Buchs: Lebendige Bücher}

Erzählen bedeutet Leben, das ist schon in den Erzählungen von 1001 Nacht so: Wer keine Geschichte zu erzählen vermag, dessen Leben ist bedroht. Wo Scheherazade um ihr Leben erzählt, trifft dies auch auf die fiktionsexterne Leseebene zu: Der Buchleser bereichert nicht nur sein Leben, sondern rettet auch das Leben des Buchs, denn: „Ein nicht gelesener Text existiert in gewisser Weise gar nicht, erst die Lektüre erweckt ihn zu Leben“،222. Wirkungsästhetische Modelle ${ }^{223}$ gehen davon aus, dass ein Text erst im Akt des Lesens seine volle Wirkung entfalten kann. Damit wird der Leser als dritte Instanz in die Interaktion von Autor und Text einbezogen und der Rezeptionsprozess für das Wirkungspotential eines Textes als unverzichtbar aufgewertet.

In der Kommunikation, die ein Buch zwischen Lesern herzustellen in der Lage ist, wirkt es ,lebendig'. Damit ist die Verbindung zwischen realen Lesern ebenso gemeint wie jene zwischen realem und fiktivem Leser. Das Buch weckt im Leser Gedanken, Ideen, Assoziationen und fördert aktiv den Austausch über den Buchinhalt unter Lesern. Außerdem kann es weitergereicht und sein Inhalt unzählige Male gelesen und dadurch sogar angereichert werden.

In der Romanliteratur begegnet der Leser deshalb immer wieder der Situation, dass ein Buch als Lebewesen angesehen und ihm ein beinahe menschliches Leben zugesprochen wird. Es findet 
eine regelrechte Anthropomorphisierung des Buchs statt. In den hier untersuchten Romanen ist die Sichtweise auf das Buch als ein lebendiges Wesen allerdings viel konkreter als wenn das Buch fiktionsintern als Person angesprochen wird ${ }^{224}$, also im Falle einer Allegorisierung des Buchs.

Außerdem steht das Buch als Metapher für den Verlauf des menschlichen Lebens, das man im Lauf der Zeit fortschreibt und in dem man durch Erinnern zurückblättern kann. Das „Zurückblättern im Buch meiner Jugend“،225 wird u. a. in Das Papierhaus beschworen. In diesem Roman wird

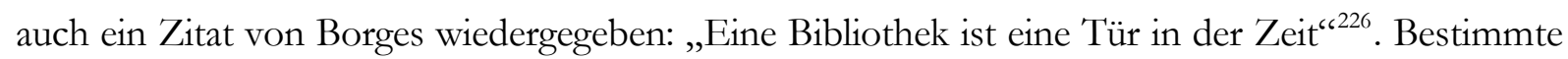
Bücher stehen in den Leserbiographien für eine bestimmte Zeit, die durch die Lektüre begleitet wurde. Beim (Wieder-)Lesen fühlt man sich an Dinge erinnert, die man erlebt hat, und ein Buchtitel ruft noch lange nach der Lektüre Emotionen und Assoziationen hervor. Dennoch ist Borges' Bibliothek aber eher ein Konzept für die Organisation von Wissen als für das einzelne Buch.

Auf das ,lebendige' Buch werden eine Reihe von menschlichen Eigenschaften übertragen und ihm auch die physischen Gegebenheiten des menschlichen Körpers zugeschrieben:

Der Einband schien in ihrer Hand zu atmen wie ein lebendiges Wesen. [...] Ein Buch, so sagen sie, besteht aus Nägeln, Zähnen, Haut, Sehnen und Knochenmark; aus Herz und Lungen, Leber, Galle und Nieren, aus Magen und Darm; aus dem Feuer des Atems und dem Wind der Blähungen; aus Schweiß, Spucke, Tränen., Schleim, Urin, Kot, Lymphe, Gelenkschmiere und Sperma. Sie verkriechen sich in dem Buch, das in ihren Händen lebendig und warm gehalten wird, schälen seine Blätter wie Schichten aus Haut, bis sie auf eine Seite aus Knochen stoßen. ${ }^{227}$

An dieser Stelle ist ein Hinweis auf das Epitaph von Benjamin Franklin erwähnenswert:

The Body of B. Franklin Printer; Like the Cover of an old Book, Its Contents torn out, And stript of its Lettering and Gilding, Lies here, Food for Worms. But the Work shall not be wholly lost: For it will, as he believ'd, appear once more, In a new \& more perfect Edition, Corrected and Amended By the Author. ${ }^{228}$

Der Grabspruch, den Franklin selbst entworfen hat, weist auf seine enge Bindung zum gedruckten Wort hin. Der Bucheinband stehe für den menschlichen Leib und die Buchstaben und Verzierungen für die Bekleidung, während der Inhalt der Seele gleiche. Die Auferstehung des Menschen am jüngsten Tag erfolge als ,Neuauflage', die vom göttlichen Autor verbessert und bereinigt werde. Nicht das Buch wird also hier personifiziert, sondern der Mensch mit buchspezifischen Termini beschrieben.

224 Vgl. dazu Winter (1998), S. 224ff.

225 Carlos María Domínguez: Das Papierhaus. München: Diana, 2006, S. 22.

226 Ebd., S. 42.

227 Wharton (2003), S. 296.

228 Vgl. „Benjamin Franklin - In His Own Words”. Webseite der Library of Congress [http://www.loc.gov/ exhibits/treasures/franklin-epitaph.html], eingesehen am 20.11.2009. 


\subsubsection{Der Mensch wird zum Buch}

Neben die Vermenschlichung des Buchs tritt die ,Verbuchlichung' eines Menschen, die als Verwandlung in zwei der untersuchten Romane geschildert wird. Die Annäherung eines Menschen an ein Buch und das beiderseitige Verschmelzen kann jedoch auch subtiler und in einem übertragenen Sinn stattfinden.

\subsubsection{Die Verwandlung: Der Leser wird zum Buch}

Die Verwandlung eines Menschen und Lesers in ein Buch wird in Peter Jacobis Mein Leben als Buch $^{229}$ (1999) sowie in Alfons Schweiggerts Das Buch ${ }^{230}$ (1989) ganz konkret, doch mit völlig unterschiedlichen Herangehensweisen dargestellt. In der humorvollen Darstellung in Mein Leben als Buch findet die Verwandlung in ein gegenständliches Buch als lustvolles Verschmelzen von Leser und Buch aus Freude an der Literatur statt. Auf die komisch-groteske Darstellung des verwandelten Menschen wird der Leser schon durch die Umschlaggestaltung des Buchs eingestimmt. Dort ist ein Mensch zu sehen, dessen Kopf von einem Buch verschlungen wird. Dieses Buch scheint in der Art der Mise en abyme eben jenes Buch darzustellen, das der reale Leser gerade in Händen hält, auf dem wiederum diese Umschlagabbildung zu sehen ist und so fort.

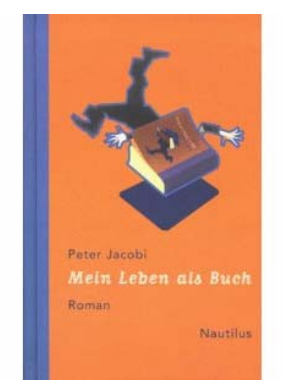

\footnotetext{
Abb. 1: Umschlagabbildung des Romans

Mein Leben als Buch von Peter Jacobi.
}

Bei Jacobi setzt die Handlung unmittelbar nach der Verwandlung des Antiquars Diogenes in ein Buch ein, die plötzlich und unbemerkt über Nacht stattfindet. Während hier die Auswirkungen der Umwandlung in ein Buch in einer heiteren Stimmung geschildert werden - der Protagonist ist neugierig auf seinen neuen Zustand, kann nur ,sehen’ und ,hören', wenn der Buchblock aufgeschlagen wird, er kann nicht eingreifen, als seine Lebensgefährtin mit seinem Konkurrenten anbändelt - geht der Kafka-Forscher Schweiggert das Thema ernsthaft an und schildert die qualvolle Verwandlung in ein rachsüchtiges Buch.

\footnotetext{
229 Peter Jacobi: Mein Leben als Buch. Hamburg: Edition Nautilus, 1999.

230 Alfons Schweiggert: Das Buch. München: Ehrenwirth, 1989. -

Der Jugendroman gleichen Titels von Wolfgang \& Heike Hohlbein (erschienen 2003 bei Ueberreuter, Wien), der sich um Bücher dreht, in denen die Schicksale von Menschen niedergeschrieben sind, wird in dieser

Untersuchung nicht berücksichtigt.
} 
Schweiggerts Herr Bibli, der sich selbst als Bibliophiler sieht, trägt wie Jean Pauls Fibel das Buch schon im Namen. Er entdeckt ein Buch, dass nur ,Das Buch’ genannt wird. Es ist einerseits ein unauffälliges, typisches Buch ohne Titel, andererseits nicht irgendein, sondern DAS Buch. Den Titel Das Buch trägt denn auch der Roman, den der reale Leser vor sich hat. Das Buch besitzt ein gewöhnliches Format und eine durchschnittliche Erscheinung, hat aber einen Einband „wie gegerbte Haut ${ }^{\star 231}$, was schon darauf hindeutet, dass sich ein Mensch darin verbirgt, aber nichts anderes als gegerbte Haut ist auch ein Ledereinband. Bibli wird ,aus der menschlichen Seinsweise in eine buchförmige umgewandelt“ ${ }^{\text {232 }}$, denn , nicht um die Menschwerdung geht es auf Erden, es geht allein um die Buchwerdung ${ }^{\text {‘233 }}$. Diese religiöse Anspielung verweist auf den Status, den Bücher unter manchen Bücherfreunden genießen.

Biblis Verwandlung vollzieht sich ohne Zustimmung des Betroffenen und unwiderruflich. Die Wahl des Buchbesitzers, der sich gar prädestiniert für dieses Schicksal fühlt, findet ebenso vorbestimmt statt wie in Der Schatten des Windes. Der Roman beginnt mit einem Todesfall auf dem Bücherflohmarkt: Eine Frau verstirbt plötzlich, nachdem sie das Buch mit dem Titel „Das Buch“ in Händen gehalten hat. Es wird suggeriert, dass Bibli ebenfalls im Buch verschwindet und stirbt, nachdem das Buch ihn abgestoßen hat. Kurz darauf greift eine neue Leserin zum Buch, der das gleiche Schicksal widerfährt, und so entsteht ein Kreislauf, der das Buch immer neuen Wirten zuführt. Dabei wird nichts über den Inhalt des Buchs gesagt, was auch unwichtig ist, denn es geht um einen abstrakten Begriff des Buchs, das Buch als Prototyp. Die Eigentumsverhältnisse sind unklar, was die Autonomie des Buchs impliziert.

Die körperliche Verwandlung vollzieht sich für Bibli schleichend, bis er schließlich unter Schmerzen seine menschliche Gestalt verliert und mit dem Buch verschmilzt. Diesen Vorgang nimmt Bibli als „Geburt eines Menschen aus einem Buch““234 wahr, als „ungeheuerlichen, schamlosen, ja als geradezu perversen Vorgang“6235. Während Diogenes seinen Zustand nicht als unangenehm empfindet und es seine einzige Sorge ist, dass er als Buch weder essen, trinken noch lesen kann, wächst in Bibli Hass auf die Schöpfer des Buchs. Seine Buchwerdung möchte er rückgängig machen und sich an den Urhebern des Buchs rächen, denn an dessen Erschaffung

[...] waren nun einmal Autoren, Verleger, Lektoren, Drucker, Buchbinder, Kritiker und weiß Gott wer noch alles beteiligt, ja, und auch die Leser. [...] Er wollte sich, das stand plötzlich für ihn fest, an all diesen in seinen Augen gedankenlosen Schöpfern - ob sie geldgierig, wissensdurstig oder vergnügungssüchtig waren, spielte für ihn keine Rolle -, er wollte sich rächen. ${ }^{236}$

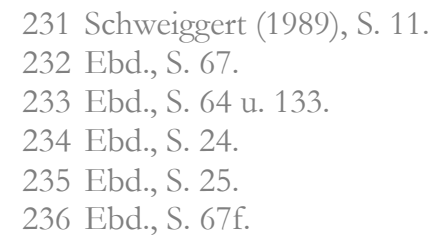


In Gestalt des Buchs übernimmt der Bücherfreund dessen ,Gedanken', möchte sich für seinen Zustand rächen, er hat sich aber auch die Anliegen des Buchs zu Eigen gemacht, da sie ihn in seiner jetzigen Gestalt selbst betreffen. Geschädigt werden im Romanverlauf jene, die einen unangemessenen Umgang mit dem Buch zeigen und den Inhalt nicht würdigen, denn „,Wer ein Buch angreift, wird durch ein Buch umkommen', dachte Bibli in Abwandlung eines Wortes der Heiligen Schrift. “237 Bemerkenswert ist, dass hier explizit auch die Leser als Urheber eines Buchs genannt werden.

Bibli rächt sich so stellvertretend für alle Bücher an der verständnislosen Lektorin, die nicht an Biblis literarische Qualität glaubt, an dem Bibliotaphen, der die Inhalte nicht zu schätzen weiß und Bücher nur aus Besitzgier anhäuft, an dem arroganten Kritiker, der als Kunstrichter, der Büchern Todesurteile auferlegt, nun durch ein Buch stirbt. Auch auf eine Parodie Marcel ReichRanickis wird auch hier nicht verzichtet; parodiert werden Name, Aussehen, Sprechweise und literarische Urteile als polemisch und überheblich. Aufgrund der breiten Bekanntheit Reich-Ranickis können diese Anspielungen auch von einem weniger hochliterarisch gebildeten Lesepublikum erkannt werden. Zum einen wird seine Tätigkeit als Literaturkritiker vorgeführt, zum anderen steht er in der öffentlichen Wahrnehmung aber beinahe schon als komische, derart häufig parodierte Figur, dass der breiten Öffentlichkeit dieses satirische Zerrbild fast geläufiger ist als die wirkliche Person. Diese Abrechnung mit zentralen Akteuren des Literaturbetriebs erschien bereits 13 Jahre vor Martin Walsers Tod eines Kritikers (2002).

Die Buchverwandlung bei Schweiggert verleiht der Idee des Leben spendenden Lesers eine besondere Qualität: Der Eigentümer erfüllt das Buch mit Leben, lässt sein Leben auf das Buch übergehen. Ebenso wird die Tatsache, dass Bücher die Gedanken und Meinungen ihrer Leser verändern können und Ideen und Ideologien weitertragen und verbreiten, auf die Spitze getrieben.

\subsubsection{Subtile, figurative Wandlung in ein Buch}

Neben den beiden genannten Beispielen, in denen die Verwandlung in ein Buch ganz explizit stattfindet, transformieren sich Menschen, vornehmlich Leser, in der Literatur auch auf figurative Art und Weise in ein Buch oder in geliebte Literatur.

„Buchmenschen“ nennen sich in Ray Bradburys Dystopie Fabrenheit 451 (1953) auf dem Lande vagabundierende Intellektuelle, die gegen das totalitäre Regime, in dem Bücher verboten sind, aufbegehren. Jeder von ihnen lernt ein verbotenes Buch auswendig, so bewahren sie deren Inhalte für bessere Zeiten: „Die Mehrzahl der Gelehrten sind keine Geister, sondern nur lebendige 
Bücher. “238 Allerdings können die Gelehrten nur eine kleine Anzahl an Büchern bewahren, da ihre Kapazitäten endlich sind und sie nur einen sehr subjektiven Kanon an Titeln erhalten. Auf diese Weise werden sie zu den Büchern, deren Texte sie nach dem Zusammenbruch des totalitären Regimes notieren wollen, bis sich die Fehler der Geschichte wiederholen, und sie die Texte für eine mündliche Wiedergabe erneut auswendig lernen müssen. So entsteht eine ewige Wiederholung von mündlicher und schriftlicher Weitergabe von Texten, die für erhaltenswert empfunden werden. Während in der Fiktion behauptet wird, dass Bücher im Gegensatz zu TVSendungen nicht real seien und deshalb nichts taugen, erklärt ein pensionierter Professor für Englische Literatur dem Protagonisten, Bücher seien sehr wohl lebendig und Menschen ähnlich: „This book has pores. It has features. This book can go under the microscope. You'd find life under the glass [...] So now do you see why books are hated and feared? They show the pores in the face of life." 239 Bücher zeigen nach dieser Auffassung die unangenehmen Wahrheiten, die zum Leben dazugehören, Menschen aber oft zu verstecken suchen, und wirken so direkt in Leben und Gesellschaft hinein.

„Die Legende von Seshat ${ }^{\text {¿240, }}$, erzählt in Salamander, führt unter dem Leitthema Unsterblichkeit die Bibliothek von Alexandria vor, die als Quelle heidnischen Wissens zerstört werden soll. Der Bibliothekar lässt die Texte aus den Büchern der Bibliothek in die Haut seiner Gehilfen tätowieren, um die Texte zu erhalten und sie von ihrer „,todbringenden Immobilität ${ }^{\star 241}$ zu befreien. Die Menschen repräsentieren jeweils das Buch, das sie in die Haut geritzt tragen. Ihr Körper dient als Medium, denn völlig medienneutral kann nicht erzählt werden, der Inhalt braucht ein Medium, um weiter getragen zu werden. Allerdings genügt es nicht, die Texte nur zu bewahren, denn Bücher müssen gelesen werden, damit sich ihre Ideen verbreiten und sie weiterleben. Die letzte Überlebende nimmt den Namen Seshat an, der „Göttin der Archive, Schwester von Thoth, oder wie die Griechen ihn nannten, Hermes Trismegistus “242. Thoth war der ägyptische Gott der Schreiber und der Wissenschaft. Seshat hat das letzte Buch der Bibliothek bei sich, das sie einer Gruppe von Lesern vorliest, es ist eine Abhandlung über die Kunst unsterblich zu werden. Auch in dem Film Die Bettlektüre (The Pillow Book, 1996, Regie: Peter Greenaway) wird ein Buch auf menschliche Haut geschrieben. Eine Kalligraphin beschreibt ihren Liebhaber mit einem Text und schickt ihn als ,lebendiges Manuskript' zu einem Verleger, nach seinem Tod wird aus seiner Haut tatsächlich ein Buch gefertigt.

Bibliophile und Büchernarren fühlen eine so große Nähe zu ihren Büchern, dass sie sich ihnen offensichtlich äußerlich annähern, das wird zumindest in den untersuchten Romanen ange- 
deutet. Die schleichende Verwandlung in ein Buch findet bei den hoffnungslosen Fällen statt, die den Büchern restlos verfallen sind: „Man kann das an der Haut erkennen; bei den Abhängigen ist sie leicht pergamentartig. [...] Gelb und dünn, in der Tat, wie Pergament.“243 Diese äußerliche Annäherung an ein Buch ist als Vorstufe zur Verwandlung anzusehen, hervorgerufen durch häufiges Verweilen in tageslichtarmen Bibliotheken.

Auch der bekannte historische Büchernarr Magister Tinius (vgl. Kap. III.6.2.1.1) wird durch das Buch ein anderer. Für den Bücherfreund findet das ,Eintauchen' ins und ,Versinken’ im Buch nicht nur im figurativen Sinne statt, vielmehr verschmilzt er förmlich mit dem Buch:

In diesen Stunden [des Lesens] hört der Körper des Johann Georg Tinius nicht auf an der hautigen Hülle. Spielerisch verwandelt er sich in ganz unterschiedliche Figuren aus seinen bunten Geschichten. In diesen Augenblicken ist er in dem Haus aus Jesus Sirach. Das ist mein Mantel, sagt er dann, und zieht ihn aus Vers 24 an. ${ }^{244}$

Klaas Huizing schildert in seinem Roman Der Buchtrinker (1994) über den Büchernarren wie der jugendliche Tinius andächtig mit seinem (noch einzigen) Buch, Sittensprüche des Buchs Jesus Sirach für Kinder, umgeht: ,Jetzt schlägt er das Buch auf. Erst ein leichter Unterdruck, dann ein frischer Luftzug, in den er hineinschlüpft. Als würde das Buch ihn aus dem leimstarren Klima seines Elternhau-

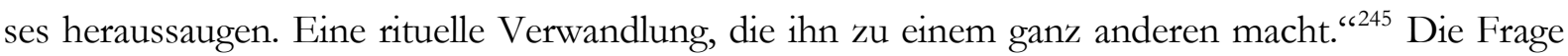
ist, wozu ein Buch einen Leser macht - zu einem Menschen, der dazu in der Lage ist, dem Alltag zu entfliehen, der besser mit den Anfeindungen des Lebens zurechtkommt, zu einem besseren Menschen? In vielen literarischen Zeugnissen markiert das Buch auch einen Wendepunkt im Leben eines Menschen oder seine Initiation in bisher nicht erschlossene Lebensbereiche. Es dient dem Wissensgewinn oder eröffnet dem Leser bisher unbekannte Welten, die in ihm den Wunsch nach einer Veränderung in ihrem Leben auslösen.

\subsubsection{Interaktion Buch und Leser}

Die Interaktion zwischen Buch und Leser kennt zwei Richtungen: Zum einen vom Buch ausgehend, das vom Leser Besitz ergreift, ihn prägt und beeindruckt, zum anderen vom Leser ausgehend, der das Buch in sich aufnimmt.

Der erste Fall wird in den untersuchten Romanen thematisiert, die die Verwandlung eines Lesers in ein Buch schildern. Hier kann sogar eine Symbiose entstehen: Es wird in den behandelten Romanen suggeriert, dass das Buch ebenso vom Leser Besitz ergreift, wie der Leser sich das Buch aneignet und es beim Lesen ,verschlingt'. Das Buch sucht sich einen Träger oder Wirt und verschlingt den Leser, der in dem Buch aufgeht. Bei Jacobi wird auch von einer Umkehrung des 
Topos „Bücherverschlingen’ berichtet, denn das Buch schaut während des Gelesenwerdens in den Leser. Die Abbildung, die in Jacobis Roman auf den Vorsatzblättern abgedruckt ist, zeigt eine Zeichnung von Nikolai W. Gogol, die das Menschen verschlingende Buch darstellt.

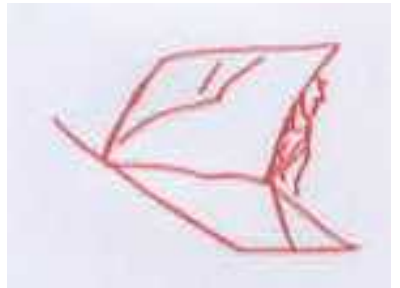

Abb. 2: Zeichnung von Nikolai W. Gogol, wiedergegeben nach Peter Jacobi: Mein Leben als Buch.

Bei Schweiggert saugt das Buch den Menschen auf, der nach wie vor seine eigenen Gedanken hat, aber durch das Buch beeinflusst wird. Besonders tritt dies bei seinen Rachegelüsten hervor, die er zwar im Namen des Buchs, jedoch zunächst aus eigenen Motiven heraus vorantreibt. Dies kann als Warnung verstanden werden, sich zu sehr in Bücher zu vertiefen und zu sehr auf sie einzulassen, da so ein selbständiges Denken und Tun nicht mehr möglich scheint - ein Vorwurf an den Realitätsverlust, der angeblich durch zu extensive Lektüre und zu große Liebe zu Büchern entsteht. Andererseits warnt der Erzähler nicht in der Tradition der Lesesucht-Kritik vor der übergroßen Nähe zu Büchern, sondern sieht die Verwandlung gleichzeitig als etwas, das sich jeder Bücherfreund wünsche: „Und welches höhere Glück kann einem Lebewesen widerfahren, als in ein Buch einzugehen und sich dabei, wenigstens für einen kurzen Zeitraum, der fleischlichen Hülle zu entäußern. “246 Diese erstrebenswerte Darstellung wird jedoch im Lauf des Romans von Biblis Erlebnissen und schließlich seinem Tod karikiert.

Mit dem Buch verbinden Bibli und die Leserin, die nach ihm im Buch versinkt, eine besonders starke wechselseitige Beziehung. Beide sind von der Lektüre im Buch völlig gefesselt und lassen sich rasch in seinen Bann ziehen. Sie empfinden einen Zwang, das Buch in der Nähe zu haben: „Je weiter sie in den Inhalt eindrang, um so mehr eignete sie sich das Buch an, um so mächtiger ergriff es auch von ihr Besitz. “247 Während die Leserin nur den Inhalt des Buchs aufnimmt, nimmt das Buch als Gegenstand von ihr Besitz.

Auch über das Vorlesen und Zuhören kann der Literaturbegeisterte eins werden mit dem Buch: „Solange [die Wörter] sich nicht veränderten - und das taten sie nicht - , konnten auch die Geschichten das Buch nicht verlassen, es sei denn durch das Vorlesen, wobei er ihnen durch sein Zuhören Einlaß in seinen Kopf gewährte, wo sie sich festsetzten und ihm nicht mehr aus 
dem Sinn gingen.“248 Die Parallele zu Cornelias Funke „Tintenwelt“-Romanen, in denen Figuren durch Vorlesen innerhalb der Fiktion zum Leben erwachen, liegt auf der Hand.

Wie das Buch den Leser prägt, so geht auch etwas vom Leser in das Buch über, und wenn es nur Randnotizen, ein vergessenes Lesezeichen oder Zigarrenasche sind: „Die zwischen den Seiten alter Bücher verbliebene Zigarrenasche ist das beste Bild für das, was vom Leben des einstigen Lesers darin geblieben ist. “249 Die Überbleibsel oder Anmerkungen des vorigen Lesers gehen auf den nächsten Leser über, so dass das Buch eine veritable Biographie, ein Schicksal erhält mit Merkmalen, die es an spätere Lesergenerationen tradiert. Bücher verändern nicht nur Menschen, „die Menschen verändern auch das Schicksal der Bücher““250. Schon in dieser Formulierung fällt die Personifizierung der Bücher auf, wenn ihnen ein eigenes Schicksal zugestanden wird. Die Veränderung findet statt, was den Verwendungszweck, oder: die Bestimmung der Bücher angeht. Nicht nur zum Lesen sind sie da, sondern auch als Geheimfach, zum Pressen von Blüten, können als Treppchen aufgestapelt oder unter einen wackligen Tisch gelegt werden, denn „,...] Papier war und blieb [...] ein organischer Abfall“ ${ }^{\star 251}$.

Wie bereits erwähnt, wird in neuerer erzähltheoretischer Forschung die Rezeption eines Textes aufgewertet und der Leser als aktiv am Entstehungsprozess beteiligt betrachtet. Die Interaktion des Lesers mit dem Buch ist ein wichtiger Punkt, den auch fiktionsintern Produzenten von Texten und Büchern beachten: „Mach etwas Schönes, aber denk daran, es geht nicht nur um den Gegenstand selbst. Erst wenn ein Leser das Buch in der Hand hält, ist das Werk vollendet.“252 Bei der Rezeption hat der Leser je nach Genre oder vorkommenden Motiven unterschiedliche Erwartungen an den Text, dabei gibt es zudem Variationen, was die literarischen Vorkenntnisse eines Lesers angeht. Je nach literarischer Vorbildung und Lesebiographie wird ein Leser dazu in der Lage sein, einen Text auf ganz unterschiedliche Weise zu entziffern und für sich zu erschließen, so dass ganz verschiedene Urteile über ein- und dasselbe Werk möglich sind.

In Anlehnung an wirkungsästhetische Modelle lautet ein gängiger Gemeinplatz, dass Lesen dem unbelebten Buch erst Leben einhaucht und Texte zum Leben erweckt. In den Verwandlungsgeschichten wird dies noch konkreter: Der Mensch wird zum Buch, und das Buch erhält somit eine menschliche Gestalt und wird lebendig. Aber auch das Buch vermag den Leser zu vitalisieren: „Als [die Leserin] Herrn Bibli [in Buchgestalt] näher ansah, spannte sich ihr Körper, kam Feuer in ihre Augen, wandelte sich die jugendliche Greisin zu einer weisen Liebhaberin voller

\footnotetext{
248 Schweiggert (1989), S. 43.

249 Ramón Gómez de la Serna, zitiert nach Schweiggert (1989), S. 54.

250 Domínguez (2006), S. 43.

251 Ebd., S. 81.

252 Wharton (2003), S. 296.
} 
Leidenschaft.“ ${ }^{253}$ Dieser wechselseitige Belebungsprozess betont noch einmal die Personifizierung des Buchs.

Eine Wechselbeziehung zwischen Buch und Leser zeigt sich auch, wenn angenommen wird, dass vom Autor ebenso etwas in den Text übergeht wie vom Leser.

Jedes einzelne Buch hat eine Seele. Die Seele dessen, der es geschrieben hat, und die Seele derer, die es gelesen und erlebt und von ihm geträumt haben. Jedesmal, wenn ein Buch in andere Hände gelangt, jedesmal, wenn jemand den Blick über die Seiten gleiten läßt, wächst sein Geist und wird stark. ${ }^{254}$

Noch mehr als beim Lesen geht der Leser beim Erzählen darüber in den Text ein. Der Leser präsentiert seinen Zuhörern den Text als subjektives persönliches Extrakt, so, wie er ihn wahrgenommen hat, und macht beim Nacherzählen oder Vortragen sicher Auslassungen oder Ergänzungen. In der Art, wie der Leser zu anderen über das Buch spricht, (kritisch, wohlwollend, vernichtend, wie über eine Person...), bleibt etwas vom Leser im Buch zurück.

\subsubsection{Immersion des realen Lesers}

Im Epilog von Schweiggerts Roman wird dem realen Leser suggeriert, dass er das Schicksal des Protagonisten teile und selbst ein Opfer des Buchs werde. Bei seiner Verschmelzung mit dem Buch verschwimmt Bibli die Schrift vor Augen:

[Bibli] sah zwar die Sätze, konnte aber deren Aussagen überhaupt nicht mehr entschlüsseln. Schließlich begannen sogar die Buchstaben zu verschwimmen, schienen übereinandergedruckt zu sein, flatterten horizontal und vertikal aus ihrer Position. Dann schien sich die Schrift zu verkleinern und nach weiterem, zunehmendem Schrumpfen gänzlich zu verblassen. [...] Aber je mehr er sich bemüht, seine inzwischen brennenden Augen auf die Zeilen und Lettern zu heften, um so weniger gelang es ihm. ${ }^{255}$

Der lesenden Studentin, dem nächsten Opfer des Buchs, widerfährt Ähnliches:

Sie kniff die Augen zusammen, denn sie erkannte die Wörter nur noch wie durch einen Nebelschleier. Soweit sie sie noch entziffern konnte, gelang es ihr jedoch nicht mehr, ihren Sinn zu begreifen. Schließlich verkleinerte sich die Typographie, und nun schien es ihr sogar, als sei überhaupt nichts mehr wahrzunehmen, als nur noch das Weiß des Papiers. ${ }^{256}$

Die Erlebnisse der lesenden Studentin werden von ihrer Person gelöst wiedergegeben - „[...] man [...] sieht die Schrift unendlich verkleinern und zuletzt ganz verblassen “257 - so dass sich der reale Leser nicht nur einbezogen, sondern auch unmittelbar betroffen fühlt. Das verallgemeinernde „man“ in den Ausführungen verstärkt diesen Eindruck. Es soll also suggeriert werden, dass sich das Schicksal des fiktionsinternen lesenden Bibliomanen ebenfalls am realen Leser vollzieht. Das Buch schreibt sich selbst fort, und der reale Leser wird, wie der Text suggeriert, soeben zu einem neuen Opfer des Buchs, denn der reale Roman trägt denselben Titel. Immer wieder 
werde das Buch „einen Buchliebhaber faszinieren, in seinen Bann ziehen, weil es ihn besitzen und verwandeln will, um sich dadurch selbst zu verwirklichen und zu erlösen.“ ‘258

Tatsächlich sind die letzten Zeilen des Buchs im Buch - ein Zitat aus den Merseburger Zaubersprüchen - in verblassender Type abgedruckt, so dass der reale Leser den Text vor sich sieht, den die fiktionsinternen Leser kurz vor ihrer Verwandlung gelesen haben.

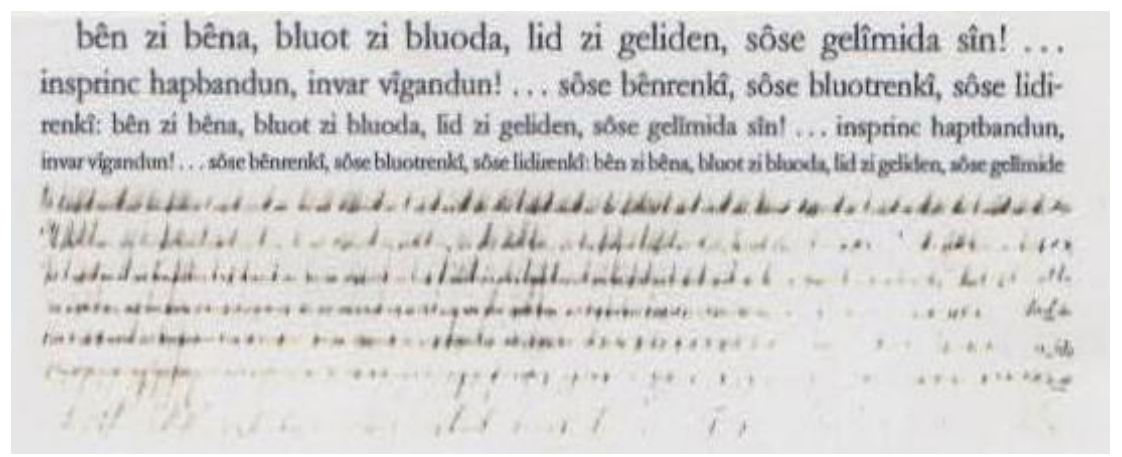

Abb. 3: Alfons Schweiggert: Das Buch, S. 135.

In Mein Leben als Buch von Jacobi wird der Leser im Text durchgehend direkt angesprochen. Da er aus der Fiktion weiß, dass das Buch mit dem Leser kommuniziert, wird so suggeriert, dass sich dies gerade - als narrative Metalepse ${ }^{259}$ - zwischen Buch und realem Leser wiederhole. Eine weitere Form der Kommunikation zwischen Buch und realem Leser findet über den Klappentext statt. Dieser verweist auf die heutige reale Situation des Buchs in der Medienkonkurrenz:

Peter Jacobi hat hier alles andere als einen Nachruf auf ein traditionelles Medium verfasst. Seine literarische Groteske plädiert begeistert für das Lesen und feiert die Unsterblichkeit des Buches. ${ }^{260}$

Dieser Paratext zeigt, dass offenbar ein gemeinsames kulturelles Wissen zwischen Verlag, Autor und Leser herrscht, da alle Instanzen anscheinend davon ausgehen, dass das Buch als traditionelles Medium beinahe ausgedient habe und seine Verdrängung durch die elektronischen Medien fürchten müsse (vgl. Kap. III.8.2). Weiterhin herrsche ein vom Verfasser des Klappentexts vermuteter Konsens, dass dies zu verhindern und Bücher zu retten seien, womit eine Aussage über den Leser getroffen und angenommen wird, dass sie dieser Meinung seien, sonst würden sie nicht zum Buch greifen. Wer gern liest und Bücher kauft, wird auch daran interessiert sein, sich für den Erhalt von Büchern einzusetzen. Allerdings sind sich die Instanzen des Literaturbetriebs sicher, dass das Buch immer existieren werde (Unsterblichkeit) und die Möglichkeit bestehe, durch Bücher über Bücher für das Lesen zu begeistern (Roman als Plädoyer für das Lesen).

Eine Online-Leserrezension zum Roman unterstützt die These, dass tatsächlich Konsens über die Mediensituation und eine befürchtete Verdrängung des Buchs durch elektronische 
Medien unter allen Akteuren des Literaturbetriebes, auch unter den Lesern, herrsche: „Die Inkarnation des Mannes passt in eine Zeit, in der Texte sich vermehrt in bits\&bytes auflösen.“261 Der Leser sieht also eine Bedrohung von Büchern durch die digitale Darstellung und Verbreitung von Texten. Der gewählte Begriff „Inkarnation“ erscheint hier jedoch problematisch - es geht ja gerade nicht um die Menschwerdung, sondern um die ,Buchwerdung’.

\subsubsection{Das Buch als Ersatz für Essen \& Trinken, Liebe, Zuhause}

Literatur vermittelt Ideen und abstrakte Vorstellungen durch Motive, Figuren und Handlungen und wirkt alltagsnah und lebendig, wenn sie Metaphern des alltäglichen Lebens verwendet. Aus diesem Grund wird das Buch in den untersuchten Romanen und darüber hinaus in Zusammenhang gebracht mit alltäglichen Dingen und Bedürfnissen wie Essen \& Trinken, Liebe und einem Zuhause. Genau wie diese Bedürfnisse gestillt werden müssen, ist für viele Leser auch das Lesen unverzichtbar. Dieser Eindruck soll durch Assoziationen auch im Leser erweckt werden, der diese Buch-Bücher liest und sich vielleicht darin wieder erkennt.

\subsubsection{Buch und Essen \& Trinken}

Bücherlesen wird in der Literatur und auch im allgemeinen Sprachgebrauch häufig mit Essen zusammengebracht ${ }^{262}$. So essentiell das Essen für den menschlichen Organismus auch sein mag, ist es doch gleichzeitig profan, wird aber in Kombination mit dem Buch-Motiv aufgewertet und in die Nähe des Geistigen und Sinnvollen gerückt ${ }^{263}$.

Ein Buch wird mit den Augen, verschlungen' wie die Nahrung mit dem Mund, als ,Bücherfresser' (Bibliophage) bezeichnet sich umgangssprachlich ein leidenschaftlicher Viel- und Schnellleser. Diese Motive werden möglicherweise in Verbindung gebracht, weil sich Leser, vor allem kurzsichtige, das Buch so nah zum Gesicht bringen, dass es aussieht, als wollten sie das Buch zum Mund führen. Lesen und Essen bieten Genuss, der als Genuss ästhetischer Art für den Leser durch verschiedene Arten von Buchnahrung und Beschaffenheit der Geschmacksknospen - literarische Vorbildung und Kenntnis - in unterschiedlichem Umfang erreicht wird.

Bücher sind aber nicht nur Genuss, sondern befriedigen darüber hinaus ein Bedürfnis, man denke hier an Verlagskampagnen wie „Lesen ist wie atmen““264. Alle Dinge des täglichen Lebens scheinen in Büchern kompensiert vorzukommen. Sie bieten nicht nur die Möglichkeit, sich in be-

\footnotetext{
261 Vgl. o. V.: „Gigantischer Lesespaß!“, Leserrezension zu Peter Jacobi: Mein Leben als Buch, Amazon.de, 10.04.2000, [http://www.amazon.de/Mein-Leben-Buch-Peter-Jacobi/dp/3894013443/ref=sr_1_1?ie=

UTF8\&s=books\&qid=1280413901\&sr=8-1], eingesehen am 12.07.2010.

262 Vgl. dazu auch Goetsch (1996).

263 Vgl. ebd., S. 381.

264 Titel einer Werbekampagne des Verlags Volk und Welt für den Bestseller des Großlesers Alberto Manguel Eine Geschichte des Lesens (1996).
} 
stimmte Situationen zu träumen und den Alltag zu vergessen, vielmehr enthalten sie alles, was der Leser braucht, sie sind profan „notwendiger Hausrat“ und zugleich das „papierne Gedächtnis der Menschheit “265. Für Schweiggerts Bibli ist Lesen Nahrung für den Geist, jedoch eine Bedürfnisbefriedigung, die erst nach Essen, Trinken und Schlafen rangiert: „[...] für seinen Geist bedeutete Lesen Speise und Trank und verschaffte ihm zudem eine Ruhe, die durchaus mit der im Schlaf zu erreichenden vergleichbar war $[\ldots]^{266 ، 6}$

Für den Buchtrinker Tinius sind Bücher ebenso notwendig wie die Flüssigkeitsaufnahme: Ein Buch auszulesen bedeutet, „leertrinken“, was aus einem Autor „herausgeflossen“ ist, und sich mit dem Text zu „sättigen“267, „Tinius trank das Papier wie ein Süchtiger.“268 Bücher sind für ihn lebenserhaltend, aber auch berauschend, worauf der Begriff ,Süchtiger' deutet. Bemerkenswert ist, dass er mitnichten den Text zu sich nimmt - bleibt man bei dieser Metapher, nimmt der Leser also das Materielle auf (Papier, Nahrung) und verarbeitet das Immaterielle (Text, Nährstoffe). Interessant ist außerdem, dass die Aufnahme von Büchern an dieser Stelle statt mit dem Essen mit dem Trinken in Verbindung gebracht wird. Das Stillen des Durstes ist dringlicher als das Stillen des Hungers, verdeutlicht aber auch das Rauschhafte, dem ein passionierter Bücherfreund verfällt.

Beim Lesen wie beim Essen \& Trinken ist das richtige Maß entscheidend. Tinius fängt eines Tages an, „,nur noch Bücher zu trinken und seine Existenz zu versaufen““269, er erkrankt an „Papierbulimie“ ${ }^{270}$ aufgrund seines straffen Lern- und Leseplans am Collegium. Dem Büchernarren Brauer in Das Papierhaus wird „kannibalische[r] Stolz und Gefräßigkeit“"271 seine Bücher betreffend vorgeworfen. Der Begriff ,Kannibalismus’ verweist hier auf den lebendigen Charakter der Bücher. Als „heißhungriger Leser“ ${ }^{\text {272 }}$ sei Brauer darauf aus gewesen „ein Buch nach dem anderen zu verschlingen““273. Mit dem Vokabular von Essen \& Trinken kann der verfeinerte Bibliophile als Gourmet, der unmäßige Bibliomane als Gourmand bezeichnet werden. Beim Lesen ist es nicht anders als beim Essen \& Trinken: Der Genuss zur Bedürfnisbefriedigung wird gesellschaftlich toleriert, da er lebensnotwendig oder zu Lernzwecken nötig ist, ein übermäßiger Genuss, das SichBetrinken, Heißhunger, Maßlosigkeit, ist verpönt. 


\subsubsection{Buch und Liebe und Partnerschaft}

Das Motiv Buch wird auch in Zusammenhang mit Liebe und Erotik verwendet. Der Bibliomane wird sogar als „Textlüstling،‘274 dargestellt. Für Bücherfreunde und besonders für Büchernarren nehmen Bücher eine Stellung ein, die man sonst nur von menschlichen Beziehungen her kennt. Wo das Buch personifiziert wird, ist aber auch eine metaphorische Liebesbeziehung zum Buch möglich, die die Beziehung zu einem geliebten Menschen ersetzt. Jens Schreiber sieht Schreiben als Schöpfungs- und Zeugungsakt von schreibender Hand, Feder und Papier und die Entwicklung von Handschrift zu Typoskript als Entwicklung hin zu neuen Möglichkeiten des Genusses ${ }^{275}$. Daraus folgt, dass Autor und Leser zu gleichen Teilen am Entstehen eines Buchs beteiligt sind: Der Autor erschafft das Buch, der Leser erweckt es in Anlehnung an Iser im Akt des Lesens zum Leben.

Die, sämtlich männlichen, Bücherfreunde, die in den untersuchten Romanen vorgeführt werden (vgl. Kap. III.11), sind alleinstehend oder in keiner funktionierenden Paarbeziehung. Ein Grund, der fiktionsintern immer wieder für die Unfähigkeit der Leser zu Liebesbeziehungen und anderen sozialen Bindungen genannt wird, ist, dass eine Beziehung zu viel Zeit und Hingabe abverlangen würde, die der Bücherfreund lieber in seine Bücher investiert. Ob dies auch für den realen Leser zutrifft, sei dahingestellt.

Bücher scheinen den ganzen Kosmos an zwischenmenschlichen Beziehungen ersetzen zu können: Sie werden betrachtet als Kinder, Geliebte, Partner, Freunde, sogar als Eltern und Erzieher. Es wird angenommen, dass Lektoren mit Büchern, verheiratet' sind. Für Bibli sind Bücher seine „heimlichen Erzeuger“ ${ }^{‘ 276}$, und er meint damit den Einfluss von Büchern auf den Leser, der einer Sozialisation gleichkommt. Bibli ist verheiratet, gibt als Familienstand aber ledig an, denn er möchte ganz für seine Bücher da sein. Er verleugnet nicht nur seine Frau, sondern muss in letzter Konsequenz vor seiner Verwandlung auch seine Bibliothek veräußern, um seine Hingabe ganz auf das Buch zu konzentrieren und in eine quasi monogame Beziehung zu ihm einzutreten:

[Des Buchs wegen] ließ er alle anderen Bücher aus dem Haus schaffen, zog sich zusehends von seinen Freunden zurück und begann, wenn zunächst auch widerstrebend, nur dem einen Buch sich hinzugeben. Er öffnete es nicht wie die anderen Bücher, um es sich einzuverleiben. Das Buch öffnete sich ihm, um eins mit ihm zu werden. ${ }^{277}$

Diese unverhohlen an eine Liebesbeziehung erinnernde Beschreibung ist in Zusammenhang mit einem unbelebten Gegenstand wie dem Buch ungewöhnlich. Der Kontakt mit dem Buch geht also über die reine Lesezeit hinaus, da das Gelesene nachschwingt und den Leser nachhaltig zu 
beeinflussen vermag. Bücher werden immer wieder als „Freunde“ beschrieben, so dass im Umfeld der Bücher eine Kompensation gegenüber fehlenden Sozialkontakten stattfindet.

Der Bibliomane Carlos Brauer in Das Papierbaus legt die Bücher so auf seinem Bett aus, dass sie die Konturen eines Menschen annehmen. So macht er die besondere Beziehung zu Büchern auch äußerlich sichtbar und lebt quasi mit einer Gestalt aus Papier und Tinte zusammen.

Falk Reinhold, der Student auf den Spuren des Büchernarren Tinius in Der Buchtrinker, hat zwar eine Partnerin, die seine Buchleidenschaft teilt, diese Beziehung beendet Reinhold allerdings, als seine Begeisterung für Tinius einen gewissen Grad der Hingabe erreicht hat. Die Buchhändlerin interessiert sich hauptsächlich für Äußerlichkeiten und unterwirft sich nicht nur Kleider-, sondern auch Büchermoden, was Reinhold ablehnt. Als vergeistigter Gelehrter beschreibt er Erotik mit Vokabeln aus dem Bereich des Lesens: in seiner Freundin „herumblättern“, er konnte sich „oft nicht sattlesen“278. Wirkt Lesen erotisch? In der öffentlichen Wahrnehmung wird ein ganz entgegengesetztes Bild von Bücherlesern entworfen (vgl. Kap. IV.3.1.1). Doch auch in Bernhard Schlinks Der Vorleser (1995) findet eine Erotisierung von Büchern in der Verbindung von Vorlesen und Erotik statt. Die des Lesens nicht mächtige Protagonistin lässt sich von ihrem Liebhaber vorlesen, was für sie bald das Essentielle ihrer Treffen wird.

Reinhold hat seine Sprache an der Literatur modelliert und macht Komplimente in einer literarisch-gehobenen Sprache, außerdem nennt er seine Freundin im Anklang an Werthers Auserwählte ,Lotte' statt bei ihrem richtigen Namen. Sein Abschiedsbrief an die Buchhändlerin fällt als philologische Edition mit Urtext, Varianten und Anmerkungen aus. Darin schreibt er, er finde den wirklichen Text seiner Freundin nicht mehr: Der Sinn, die Seele, ihre modischen Posen seien nur schöne Worte ohne Sinn dahinter. Damit wird auf den Zusammenhang von formal-äußerlichen Merkmalen eines Textes und dem Sinn, der Bedeutung dahinter angespielt. Die Freundin habe sich zu einem „Fortsetzungsroman “279 entwickelt. In diesem Kontext ist eine niedere Gattung gemeint, die wohl die Oberflächlichkeit der Freundin andeutet. Die endgültige Trennung wird als ,Kündigung des Abonnements’ vollzogen.

Während der elegante Bücherfreund Delgado in Das Papierhaus unter keinen Umständen auch nur eine Randnotiz in seinen Büchern vermerken würde, macht der Bibliomane Brauer extensive Anmerkungen in seinen Büchern, die für ihn erst den Sinn der Lektüre ausmachen, die Markierungen bezeichnet er als Liebesakt, in dem er sich das Buch ganz aneignet: „Ich vögele mit jedem Buch, keine Markierung bedeutet für mich kein Orgasmus.“ ${ }^{280}$ Delgado gönnt es sich, an 
Geburtstagen „ein unberührtes Buch aufzuschneiden“ ${ }^{“ 281}$. Aufgetrennte Papierseiten bedeuten bei antiquarischen Büchern eine Wertminderung, die er nur selten in Kauf nimmt, die aber das Lesen erst ermöglichen. Ihm geht es offensichtlich vorrangig um den äußeren Wert der Bücher.

Als Tinius sich seiner Frau nähert, gibt sie „ihm verächtlich ein Buch mit der drohenden Aufforderung, er möge sich doch dort hinein verkriechen, was Tinius künftig auch tat. “ ${ }^{\text {} 282}$ - Bücher ersetzen ihm einfach alles, sogar die Partnerin. Auch sein Chronist und Forscher Falk Reinhold entwickelt eine Art von Zärtlichkeit gegenüber Büchern. Traditionelle mit elektronischen Medien verbindend, beginnt Reinhold, die alten Texte von Tinius zu scannen. „Falk Reinhold [...] zeugte Texte um Texte. [...] Der neue Text, das war Falk Reinhold, und das war er nicht. [...] Aus sich selbst heraus unerklärbar, hatte Falk in der Wollust der Lektüre Kinder gezeugt. “" ${ }^{“ 23}$ Nach der Trennung von seiner Freundin nimmt er ein Buch ,mit ins Bett' - hier entsteht eine explizite Anspielung auf Walter Benjamins Assoziationen von Büchern und Dirnen ${ }^{284}$.

\subsubsection{Buch und Zuhause}

Der Büchernarr Brauer baut sich aus seinen Büchern am Strand vor Montevideo ein Häuschen, ein Papierhaus, das dem Roman den Titel gibt. Während Brauers Lebensumstände die rudimentärste Stufe erreichen - statt seiner Stadtvilla das Häuschen aus Büchern am Strand, kein fließendes Wasser, Strom oder Heizung -, haben die Bücher ihre erhabenste Dimension erreicht: Sie bieten ihm Schutz, ein Obdach, ein Zuhause. Die Bücher besiedeln nicht nur ideell die Innenwelt des Büchernarren, sondern auch physisch Brauers Dasein und Zuhause.

Wie bei allen Büchernarren, die eine umfangreiche Bibliothek ihr Eigen nennen, oder vielmehr in einer Bibliothek zu Hause sind, fungieren die Bücher als Refugium. Auch schon in seiner Wohnung hatte er sich „allmählich mit Büchern eingemauert, seine Wände bestanden gleichsam aus Bücherziegeln“6285. Der Bibliophile bedeckt die ganze freie Fläche seiner Wohnung und seines Lebens mit Büchern, wo er sich „mit dichtgefüllten Regalen gegen Lärm und andere Unzulänglichkeiten der Außenwelt abgeschirmt“ und einen „Schutzwall aus Büchern“286 errichtet hat. Die Bücher bieten eine wirksame Abschottung vor den Anfeindungen des Lebens.

Das Haus, erbaut aus Büchern, treibt das Leben in den Büchern auf die Spitze: Mehr braucht ein Bücherfreund nicht zum Leben als seine Bücher, sie ersetzen ihm Liebe, Partnerschaft und

281 Domínguez (2006), S. 42.

282 Huizing (1996), S. 109.

283 Ebd., S. 167.

284 Ebd., S. 119f. nach Walter Benjamin: „Einbahnstraße, Nr. 13“. In: Gesammelte Schriften. Hg. v. R. Tiedemann \& H. Schweppenhäuser. Bd. 4, Teil 1. Hg. v. T. Rexroth. Frankfurt/Main: Suhrkamp, 1972, S. 83-148, hier: S. $109 f$. 285 Domínguez (2006), S. 19.

286 Ebd., S. 46. 
ein Zuhause. In der Bibliothek ist der Büchernarr geborgen und abgeschottet gegen den Unbill der Welt, aber auch gefangen.

\subsubsection{Buch und Tod}

Das Buch wird als lebendiges Subjekt angesehen und so gehört auch der Tod mit zum Schicksal der Bücher. Das ungelesene, vergessene Buch ist tot, während der Leser das Buch im Zwiegespräch des Lesens zum Leben erweckt und mit Bedeutung auflädt. Wie oben beschrieben, geht bei der Lektüre ebenso etwas vom Leser auf das Buch über wie etwas aus dem Buch beim Leser zurückbleibt. Daher ist es auch im Interesse des Literaturbetriebs, den Leser weiterhin für das Buchlesen zu begeistern, um das Buch, auch als Konsumgut, am Leben zu erhalten.

Ohne den Leser wären Bücher nur unbelebte Objekte, die ausschließlich auf ihren äußeren Wert - prachtvoller Einband, Rarität - reduziert wären. Texte existieren genau wie Menschen, „solange sich jemand an [sie] erinnert“ “287. Daher schätzen die Weggefährten der fiktiven Autoren Prado (Nachtrug nach Lissabon) und Carax (Der Schatten des Windes) die Nachforschungen der Leserprotagonisten und geben bereitwillig Auskunft. Für das literarische Vermächtnis eines Autors sind die Leser bei Huizing die ,Testamentsvollstrecker', denn werden die Texte nicht gelesen, sind sie genauso tot wie die bereits verstorbenen Autoren.

Antiquarische Bücher sind träumende Bücher, die sich in einem „Zwischenzustand [...], der dem Schlafen ähnelte“ ${ }^{288}$ befinden, das sieht zumindest der Erzähler in Die Stadt der träumenden Bücher so. Ihre eigentliche Existenz, ihre große Zeit, nämlich diejenige als Novität, haben antiquarische Bücher bereits hinter sich und nur noch die Zeit des Zerfalls vor sich. Diese Bücher können nur zu neuem Leben erwachen, wenn sie von einem Leser gefunden und an sich genommen werden - der Traum aller Bücher -, so können sie unter den Augen des Lesers reanimiert und reaktiviert werden. In diesem Roman gibt es, analog zu Ruiz Zafóns ,Friedhof der Vergessenen Bücher' den ,Friedhof der Vergessenen Dichter', einen Platz, auf dem gescheiterte Dichter auf Zuruf Verse schmieden und sich so ihren Lebensunterhalt verdienen.

\subsubsection{Der ,Friedhof der Vergessenen Bücher' in Der Schatten des Windes}

Der ,Friedhof der Vergessenen Bücher' in dem Roman Der Schatten des Windes von Carlos Ruiz Zafón ist eine riesige Bibliothek und ein hermetischer Ort, der nur Eingeweihten zugänglich ist. Dort werden die Bücher unbekannter Autoren geschützt, doch sind sie auch gefährdet. Eingeschlossen in dieser Bibliothek und ungelesen, bis auf die geringe Möglichkeit, dass sie ein Leser adoptiert, laufen die Bücher Gefahr, ihrem ursprünglichen Zweck, der Lektüre und Verbreitung, 
entfremdet zu werden und zu sterben. Für exzessive Leser, die über dem Lesen nicht mehr aktiv am äußeren Leben teilnehmen, keinen Kontakt mehr zu den Menschen halten, sind die Bücher aber auch selbst wie Gräber.

So wie Bücher lebendig sind und durch Vernachlässigung sterben, so finden sie einen Ruheplatz auf einem Friedhof, wo sie ihrer Wiedererweckung harren. Hier wird ein Konzept entworfen, das der Leser offenbar ohne zu Zögern für sich annehmen kann. Obwohl sachlich feststeht, dass ein Buch ein unbelebter Gegenstand aus Papier, Pappe und Druckerschwärze ist, scheinen die Leser bereit, die Lebendigkeit der Bücher in den Romanen zu akzeptieren und nicht zu hinterfragen. Auch der religiöse Aspekt eines Friedhofs wird hier übernommen und auf die Bücher übertragen: Die Bücher auf dem Friedhof können zu neuem Leben auferstehen.

Ungelesene Bücher sind vergessen, um ihnen die Möglichkeit einer Reanimierung offen zu halten, werden sie auf den ,Friedhof der Vergessenen Bücher' gebracht. In der jüdischen Kultur werden, z. B. durch Schreibfehler, entweihte oder aus Altersgründen nicht mehr brauchbare Thorarollen beerdigt. Auf dem Friedhof werden aber auch von der Vernichtung bedrohte Bücher verwahrt, um sie zu schützen:

[...] wenn ein Buch dem Vergessen anheimfällt, dann versichern wir uns, die wir diesen Ort kennen, also die Aufseher, daß es hierhergelangt. Hier leben für immer die Bücher, an die sich niemand mehr erinnert, die Bücher, die sich in der Zeit verloren haben, und hoffen, eines Tages einem neuen Leser in die Hände zu fallen. In einer Buchhandlung werden Bücher verkauft und gekauft, aber eigentlich haben sie keinen Besitzer. Jedes Buch, das du hier siehst, ist jemandes bester Freund gewesen. ${ }^{289}$

Die Personifizierung der Bücher als ,gute Freunde’ wertet sie zusätzlich auf und stellt das Lesen als etwas Besonderes, Persönliches dar. Damit soll das Buch als Individuum gestärkt werden, das sich von der Massenware abhebt und ein direkter, enger Bezug zwischen Leser und Buch hergestellt werden. Im Roman muss jemand, der den Friedhof zum ersten Mal besucht, das für ihn bestimmte Buch erkennen, „und er muß es adoptieren und darum besorgt sein, daß es nie verschwindet, daß es immer weiterlebt. ““290 Der Leser, der das Buch ,adoptiert', erweckt es zu neuem Leben und bewahrt es vor Vergessen und Tod. Im Begriff ,adoptieren' wird wiederum die Vermenschlichung des Buchs deutlich. Es ist in der Vorstellung, die Autoren verbreiten und die von Lesern offensichtlich akzeptiert wird, ethisch nicht akzeptabel, dass ein Buch verschwindet. Sein Zweck und seine Bestimmung sind es, gelesen zu werden, deshalb ist auch der Leser in der Pflicht, sich um Bücher verdient zu machen, sie zu verbreiten, darüber zu sprechen. Dieses Credo erinnert beinahe an die Pflicht von Gläubigen, ihren Glauben weiterzutragen. 


\subsubsection{Der Leser als Gefahr für das Buch}

Zwar ist der Leser derjenige, der das Buch zum Leben erweckt, doch ist er auch eine Gefahr für das Buch, die durch den unpassenden Umgang mit dem Buch resultiert (vgl. Kap. III.6.3). Schweiggerts Bibli sieht seine Zukunft als Buch als eine qualvolle, schließlich tödliche vor sich:

Er sah sich in abgelegenen Bibliotheken in trostlosen Buchregalen verkümmern und verstauben. Er fühlte, wie ihn unsaubere Leserhände beschmutzen und unfein mit ihm umgingen, wenn sie gleichgültig die Ecken der Seiten umknickten, seinen Rücken durch zu weites Auseinanderbiegen beim Öffnen über die Maßen belasteten und nicht einmal davor zurückschreckten, Seiten einzureißen oder mit Stiften auf seinem Papier herumzukritzeln. Er sah sich als beschädigtes, mit allen nur erdenklichen Spuren des Gebrauchs behaftetes Exemplar auf einem Stapel liegen. Er ahnte sein Ende voraus, indem er sich ins Feuer geworfen fühlte oder unter entsetzlichen Qualen litt, als man ihn zu Brei makulierte. ${ }^{291}$

An anderer Stelle heißt es über den unachtsamen Leser:

Er reißt beim Umblättern Seiten ein, beschädigt gedankenlos beim Herausnehmen eines Buches aus dem Regal dessen Rücken, verwendet Bücher als Unterlage für schiefstehende Möbel oder benutzt sie als Wurfgeschoß. Er scheut sich nicht, Bücher mit fettigen oder in anderer Weise beschmutzten Fingern anzufassen, biegt sie beim Aufschlagen zu weit auseinander, fährt mit der Faust kräftig über die Seitenheftung, kritzelt auf dem Papier herum, legt sie rücksichtslos längere Zeit geöffnet auf das Gesicht, läßt sie im Freien liegen, jeder Witterung ausgesetzt, und verwendet sie nicht selten als Brennmaterial. ${ }^{292}$

Der Hinweis auf diesen weit verbreiteten, aber unangemessenen Umgang mit dem Buch und die Gefährdung des Buchs durch den Menschen scheint dem Autor am Herzen zu liegen, da er gleich zwei solcher Auflistungen in seinen Roman einflicht. Die Agonie des Buchs besteht laut den Romanen aus unsachgemäßem Gebrauch und aus den Endstationen des Buchs auf dem Buchmarkt ${ }^{293}$ : Lagerkeller, Makulatur, Ramsch- und Wühltische, Altpapierpresse und schließlich Vergessen und ,Tod'.

„Bibliotheken sind die wahren Friedhöfe der Ideen.“ ${ }^{294}$ - Werden die Bücher nicht genutzt und ihre Inhalt nicht denkend aufgenommen und Ideen verbreitet, findet kein Austausch und keine Vernetzung zwischen Lesern statt, werden Bibliotheken zu Friedhöfen. Bereits im 18. Jahrhundert gab es Stimmen, die die tradierte und womöglich bis zur völligen Verstaubung unbenutzte Welt des Wissens in den Bibliotheken als tot ansahen ${ }^{295}$. Diese ,tote Bibliothek' taucht als Topos in der Literatur auf und steht im völligen Gegensatz zum organischen ,Buch der Natur’.

Der Tod des Buchs geschieht durch das Vergessen seines Textes: Digitalisierung und Langzeitarchivierung elektronischer Quellen und eine beinahe unendliche Verfügbarkeit von Texten,

291 Schweiggert (1989), S. 70.

292 Ebd., S. 99.

293 Vgl. dazu auch Maike Schiller: „Endstation Altpapierpresse. Makulatur: Nach dem Ramschtisch - was aus Büchern wird, die keiner mehr lesen will.“ In: Hamburger Abendblatt, 10.05.2005, online [http://www. abendblatt.de/kultur-live/article325168/Endstation-Altpapierpresse.html], eingesehen am 14.11.2010.

294 Walter Mehring: Die verlorene Bibliothek - Autobiographie einer Kultur, 1980, S. 124, nicht eingesehen, zitiert nach: Achim Hölter: „Zum Motiv der Bibliothek in der Literatur“. In: Arcadia 28 (1993), S. 65-72, hier S. 69. 295 Vgl. dazu Japp (1975), S. 653. 
abhängig von der zukünftigen Lesbarkeit der Speichermedien, können dem entgegenwirken, aber nur, wenn die gespeicherten Texte auch tatsächlich genutzt und verbreitet werden:

Texte als Speicher - schön und gut. Sagen wir aber statt Konservieren nun Einfrieren, sagen wir zur Bibliothek nun Aufbewahrungs-Halle oder gar Aufbahrungs-Halle, polarisieren wir einen leblosen Speicher gegen eine lebendige Verkörperung, eine tote Schrift gegen eine mediale Bewegung [... $]^{296}$

\subsection{Schlussfolgerung}

Leser hauchen Büchern Leben ein. Wirkungsästhetische Ansätze, die dem Leser und dem Rezeptionsprozess eine bedeutsame Stellung gegenüber dem Verfasser eines Textes zubilligen, werden in vielen Buch-Büchern wörtlich genommen und fiktional aufbereitet. Für Leser, die sich gern mit dem Buch beschäftigen, ist es zusätzlich reizvoll, über lebendige Bücher und sich selbst als Leser zu lesen. Ein passionierter Leser sieht das Lesen als lebensnotwendiges Bedürfnis an. Nüchtern und pragmatisch betrachtet ist Lesen aber keineswegs lebensnotwendig. Für viel lesende Bücherfreunde ist es zweifellos wichtig und Gewohnheit, jeden Tag zu lesen, aber auch ohne Lesen kann man leben. An dieser Stelle wäre interessant zu untersuchen, wie Liebhaber anderer Künste, z. B. Cineasten, mit dem Konsum von Kunstwerken umgehen und ob sie ihm die gleiche Glorifizierung angedeihen lassen wie Leser den Büchern.

\section{4 „Ich möchte wissen, wie es war, er zu sein.“ ${ }^{6297}-$ Auf den Spuren des Autors}

Das Buch kann für den Protagonisten in erster Linie ein Mittel sein, den Autor dahinter besser kennen zu lernen. Dies ist der Fall in den Romanen Der Buchtrinker, Nachtzug nach Lissabon, Der Schatten des Windes und Die Schule der Egoisten ${ }^{298}$ (2004). Während das Buch bei der Buchsuche als Leitmotiv strukturbildend wirkt, ist die Handlung in den Titeln, die eine Autorensuche thematisieren, anders strukturiert. Damit auf der Ebene der Romanhandlung die Recherchen über den Autor und das Auseinandersetzen des - stets männlichen - Protagonisten mit dem - stets männlichen - fiktiven Autor vorgeführt werden können, werden in einigen untersuchten Texten die Binnen-Bücher tatsächlich als Teil der Handlung gelesen. In der Fiktion wird der Leseprozess geschildert und Passagen aus den Büchern, die auf fiktiver Ebene im Mittelpunkt stehen, wiedergegeben. Aufgrund dieses Merkmals stellen die Romane, die eine Autorensuche thematisieren, eine Besonderheit im Korpus dar, denn in den übrigen Titeln werden die Bücher im Buch nicht gelesen und spielen eher als Gegenstand eine Rolle. Zwar ist der Inhalt bekannt, doch wird nicht

\footnotetext{
296 Scheffer (1999).

297 Mercier (2006), S. 253.

298 Éric-Emmanuel Schmitt: Die Schule der Egoisten. Frankfurt/Main: Fischer, 2006.
} 
der Leseprozess, den der Protagonist durchläuft, geschildert. Die Autorensuche ist eine Variante des Motivs der Suche, wobei das Buch als Informationslieferant eingesetzt wird.

Anders ist das in Nachtzug nach Lissabon und Der Buchtrinker. Das Buch ist in diesen Romanen vorrangig ein Hilfsmittel zum Kennenlernen des Autors, wobei der Autor hinter dem Buch noch bedeutsamer ist als das Buch an sich. Das Medium Buch ebnet den Weg zum Autor. Der fortschreitende Leseprozess befördert das Vorankommen bei der Autorensuche, die fiktiven Leser steigern sich dabei aber auch weiter in die Verehrung hinein. Der Buchfund geschieht beinahe zufällig in einem Antiquariat oder einer Bibliothek, nur in Der Schatten des Windes ist die Buchwahl determiniert. Das Buch als Verschriftlichung der Gedanken, der Philosophie und des Lebens des Autors gibt schließlich den Anstoß für die Beschäftigung mit dem Autor.

Während der Lektüre dringt der Protagonist in das Leben des Autors vor, dessen Person und Maximen ihm noch wichtiger scheinen als der von ihm verfasste Text. In Die Schule der Egoisten besorgt sich der Protagonist nach dem Schneeball-Prinzip immer mehr Titel des verehrten Autors, um immer mehr über ihn zu erfahren. Nach dem ersten Bücherfund steht denn auch eher der fiktive Autor im Vordergrund der Erzählung, während die Handlung um den Protagonisten zur Rahmenhandlung gerät.

\subsection{Der Autor im Zentrum}

Nach dem Erfolg von Éric-Emmanuel Schmitts ersten Titeln auf dem deutschen Markt ${ }^{299}$ erschien sein Romanerstling Die Schule der Egoisten 2004 erstmals in deutscher Sprache. Der Roman, in dem Schmitt die Egoismus-Philosophie von Gaspard Languenhaert vorführt, einem fiktiven französischen Philosophen und Salon-Liebling des 18. Jahrhunderts, ist seiner Promotion in der Philosophie über Diderot und die Metaphysik geschuldet. Allerdings werde einer Rezension zufolge die Philosophie darin ,auf die Größe einer neckischen Anekdote zurechtgestutzt ${ }^{\text {‘300 }}$. Im Roman ist das Buch wichtig als Medium und Hilfsmittel für Hinweise, die daraus für die Forschung gezogen werden können, zunächst für wissenschaftliche Recherchen, dann für die Suche nach dem Autor. Das Thema des Romans ist somit die wissenschaftliche Forschung um der Forschung willen, und das mittels Monographien und Verweisen in einem engen Netzwerk von Buch zu Buch.

Der forschungswütige, namenlose Doktorand, der zugleich seine Geschichte erzählt, erkennt in den Episoden über den Philosophen seine eigene Situation wieder und eignet sich die Maxi-

\footnotetext{
299 Vgl. Éric-Emmanuel Schmitt: Monsieur Ibrahim und die Blumen des Koran \& Oskar und die Dame in Rosa, beide Ammann: Zürich, 2003.

300 Matthias Altenburg: „Schmitts Galanteriewaren“. In: Die Zeit, 14.10.2004, S. 53. Online

[http://www.zeit.de/2004/43/Schmitts_Galanteriewaren], eingesehen am 13.11.2010.
} 
men soweit an, dass er sich sogar mit dem Philosophen identifiziert. Zudem kann der Roman als Einführung in den Solipsismus in belletristischer Form angesehen werden. Aus diesem Grund rückt auch vornehmlich der fiktive Autor - der Philosoph Languenhaert - und sein Leben und seine Ansichten, die in verschiedenen Fragmenten dargestellt werden, in den Vordergrund der Handlung, während der Protagonist und seine Forschung beinahe zur Rahmenhandlung geraten.

Nachdem dem Ich-Erzähler der Forscher-Alltag öde geworden ist, sucht er nach Ablenkung und einem Anstoß für eine neue Lust am Forschen. Zur Zerstreuung möchte er in der Bibliothèque Nationale, in der er forscht, ein Buch nur zum Vergnügen lesen, und stößt durch Zufall im Katalog auf ein Nachschlagewerk, das er wahllos aufschlägt und dort einen Hinweis auf die Lehre des Philosophen Gaspard Languenhaert vorfindet, von dem er zuvor noch nie gehört oder gelesen hatte, denn dieser „hatte keinerlei Einfluß auf seine Zeitgenossen, und ebensowenig auf die Nachwelt.“301 Die Überzeugung dieses Philosophen lautete:

\footnotetext{
Ob ich mich nun bis zum Himmel emporschwinge oder in die allerunterirdischsten Gegenden hinabsteige, so gehe ich doch nie aus mir selbst heraus, und nie nehme ich etwas anderes wahr als meinen eigenen Gedanken. Also existiert die Welt nicht an sich, sondern in mir. Also ist das Leben nur mein Traum. Also bin allein ich mir die ganze Wirklichkeit... ${ }^{302}$
}

Wie im Radikalen Konstruktivismus liefert nach Languenhaerts Überzeugung die Wahrnehmung kein Abbild der Realität, sondern ist vielmehr eine Konstruktion des Betrachters. Jegliche Wahrnehmung sei subjektiv und werde mit Eindrücken, Empfindungen und Erinnerungen kombiniert und assoziiert. So schaffe sich jeder seine eigene Welt, schlechthin, weil jeder Mensch die Welt auf seine Weise wahrnimmt. Daher sei Objektivität als Konsens der Wahrnehmungen mehrerer Individuen und einer für alle gleich aussehende Realität nicht möglich. Alle Menschen und Dinge seien Schöpfungen des Ichs, die Welt sei also die Summe der Wahrnehmungen von Einzelindividuen und daher nicht objektiv erfahrbar. Es existiere keine Materie, da die Welt nur im Geiste entsteht, ist sie eine Traum- und Scheinwelt. An Languenhaerts Credo „Ich bin mir und nur mir selbst die Welt, die gesamte Wirklichkeit und ihr Ursprung ${ }^{\text {‘303 }}$ scheitert letztlich die in der doppelten Fiktion von ihm gegründete „Schule der Egoisten“, denn jedes Mitglied beansprucht die Rolle des Schöpfers der Welt für sich.

Auf den Protagonisten wirkt das neue Interesse an Languenhaert belebend, das Geheimnis regt Fantasie und Tatendrang an. Der Fall des Philosophen, der in keinem Nachschlagewerk erwähnt wird und über den nur schwer Sekundärliteratur aufzutreiben ist, von den Primärwerken ganz zu schweigen, erscheint dem Erzähler mysteriös, aber auch fesselnd, da der Autor ihm im- 
mer wieder entschlüpft: „Languenhaert, der große Unbekannte, hatte mich bereits fest im Griff.“304 Der Protagonist fügt in beinahe kriminalistischer Kleinarbeit das Leben und die Lehre Languenhaerts wie ein Puzzle zusammen, wobei ihm Languenhaerts Reaktion auf Kritik an seiner Lehre als Vorbild für konstruktives Forschen dient: Man müsse Kritik berücksichtigen, Gegenargumente nicht ablehnen, sondern annehmen, durchdenken und diskutieren. Der Protagonist wirkt verbissen und beinahe manisch bei seinen extensiven Recherchen, er wird zum „Sklaven seiner Nachforschungen“305. Bei diesen Nachforschungen stößt er auf ein Netzwerk aus Titeln ${ }^{306}$, die auf den nächsten und einander verweisen: Das ist, wie Forschung funktioniert. Sie verläuft nicht geradlinig, sondern nimmt auch Umwege oder führt in Sackgassen.

Nicht nur Languenhaerts Philosophie geht von der Welt als traumhafter Scheinexistenz aus. Auch dem Protagonisten erscheint die Welt angesichts seiner sinnlos erscheinenden wissenschaftlichen Forschungen und der rätselhaften Existenz Languenhaerts, die sich in einem Nebel von Zeit und Geschichtsschreibung in den Katalogen der Bibliothek verliert, als Schein und im Geist geboren. Der Protagonist ist seiner Forschung überdrüssig und empfindet genauso wie es ihm Languenhaerts Lehre vorführt: „Ich träume ... ich lebe nicht mehr ... Ich bin gefangen in einer Scheinwelt. ${ }^{\text {“307 }}$ Hier klingt eine beinahe subversive Kritik an wissenschaftlicher Forschung und ihren Traditionen an. Die Welt wird ihm tatsächlich zur Fantasiewelt, wenn er den Gegenstand seiner Forschung verinnerlicht und sich fragt, ob er selbst zu Languenhaert und somit zum Objekt seiner Forschung geworden ist.

Für den Protagonisten beweist ein Porträt noch mehr als die Schriften Languenhaerts Existenz, er übersieht aber, dass ein Egoist, der nur in der eigenen Vorstellung existiert, körperlos ist, und nur eine geistige Existenz aufweisen kann, die sich auch im Geist des Betrachters und Mitdenkers manifestiert. Jemand, der nur „,in sich, durch sich und für sich“6308 existiert, kann der Nachwelt kein Bild von sich hinterlassen, da es ohne ihn die Welt gar nicht gibt. Die liturgische Anspielung weist darauf hin, dass sich Languenhaert als Weltenschöpfer und Gott gleich ansieht, seine „Metaphysik Gottes“ würde also in erster Linie wiederum ihn selbst beschreiben.

Genau wie Languenhaert der Welt keine Existenz zubilligte, hatte die Welt sämtliche Hinweise auf seine Existenz getilgt, was zu seiner Mystifikation beiträgt, oder ist er nur eine Erfindung? Hat es den Philosophen wirklich gegeben oder ist er nicht nur, wie es seiner Doktrin nach

304 Ebd., S. 17.

305 Hans-Heinrich Obuch: Rezension zu Die Schule der Egoisten, RadioBremen.de [http://www.radiobremen.de/ magazin/kultur/literatur/buchtipps/schule_der_egoisten.html], eingesehen am 21.07.2008, inzwischen nicht mehr abrufbar.

306 Vgl. Schmitt (2006), S. $166 f$.

307 Ebd., S. 7.

308 Ebd., S. 10. 
folgerichtig erscheint, ein Produkt der eigenen Imagination? Für den Protagonisten ist er mehr und mehr ein Produkt der Bücher, die ihn zufällig auf seine Spur gebracht haben. Er ist versessen darauf, alles über Languenhaert zu erfahren und dadurch dessen frühere Existenz zu beweisen, damit dieser nicht in der Scheinwelt der eigenen Philosophie versinkt. Es ist jedoch der Protagonist selbst, der sich in einer fantastisch anmutenden Scheinwelt verliert, wenn er in Betracht zieht, ob er selbst vielleicht Languenhaert ist. Auf diese Weise wird das Thema von dessen Philosophie auch zum Thema des vorliegenden Romans: Die Wahrnehmung wird über extensiver Forschung derart eingeschränkt subjektiv, egoistisch, dass sich der Forscher im Zentrum der Welt wähnt und diese als Konstrukt der eigenen Wahrnehmung bzw. Imagination ansieht.

\subsection{Vom Autor besessen}

Das Buch bildet in Die Schule der Egoisten und auch in Der Buchtrinker die Ausgangssituation für die Schilderung eines Autors, dessen Vorführung das Zentrum der Romanhandlung einnehmen oder aber gleichwertig neben der Geschichte des Protagonisten stehen kann. Die bibliophilen Protagonisten, ein Doktorand und ein Student, stoßen bei ihren Recherchen bzw. bei der Suche nach neuem Lesematerial auf Bücher, deren Autoren ihnen so spannend erscheinen, dass sie deren Lebensumständen nachspüren möchten. In ihrer wissenschaftlichen Position sind sie den Autoren ähnlich, da sie sowohl Rezipienten als auch Produzenten von Texten sind.

Der Buchtrinker schildert in parallel verlaufenden Handlungssträngen - die Kapitel berichten abwechselnd über den heute lebenden Protagonisten und über den historischen Magister Tinius -, wie sich der Student Falk Reinhold durch die Lektüre der real existenten Autobiographie des historischen Magister Tinius' dem Autor immer obsessiver annähert. Die fortschreitende Lektüre, aus der im Tinius-Teil Passagen wiedergegeben werden, und weitere Titel des Autors geben immer weitere Auskünfte über den Autor, der Reinhold so fesselnd erscheint. Als Büchernarr findet er sich in der Biographie des Bibliomanen wieder: „Falk Reinhold, ein heutiger Büchernarr, fantasiert sich derart in die zwanghafte Welt des Tinius hinein, so daß schließlich auch sein Leben aus den Fugen gerät. “309. Allerdings erschrickt Reinhold vor dem eigenen Schicksal, das ihm womöglich droht, wenn er Tinius gänzlich nacheifert, „so weit also konnte die Bücherwut führen, bis zum Mord“‘310.

Auf seiner Suche nach mehr Kenntnis über den Autor muss Reinhold immer mehr Bücher von und über Tinius besitzen und lesend mehr über den büchermanischen Pfarrer erfahren. Wie sein Vorbild Tinius liest Reinhold, als Büchernarr nicht selbstverständlich, seine Bücher tatsächlich und häuft sie nicht bloß an. So versucht sich Reinhold in Tinius hineinzufühlen. Tinius glaubte

309 Ulrich Karger: Rezension zu Der Buchtrinker. Büchernachlese: Rezensionen-Archiv, ohne Datum [http://

home.arcor.de/karger/buechernachlese-archiv/uk_huizing_klaas_buchtrinker.html], eingesehen am 29.11.2010. 310 Huizing (1996), S. 62. 
an die Vorsehung, also sieht sich Reinhold von der Vorsehung auserkoren, hinter des Magisters Geheimnis zu kommen. Nachdem er die Biographie ausgelesen, sie in der Metapher des Textes „leergetrunken““311, hatte, macht sich Reinhold auf die Suche nach weiteren Büchern zu Tinius. Reinholds Jagd nach diesen Büchern wird Tinius' Verbrechen, die dieser begeht, um an mehr Bücher zu gelangen, in ,Bildern' ${ }^{312}$ gegenübergestellt. Von den Büchern ist Reinhold wie Tinius besessen und muss sie besitzen, „koste es, was es wolle ${ }^{\text {‘313. }}$. Dabei ist offensichtlich nicht nur der pekuniäre Aspekt gemeint, sondern, dass er wie sein historisches Vorbild in Kauf nimmt, dass ein Mensch Schaden nimmt, wie Tinius wird er zum Dieb und schreckt auch vor Gewaltanwendung nicht zurück: Nach verlorener Auktion schlägt er den Meistbietenden nieder und eignet sich das begehrte Buch an, ebenso wie dessen sonstige Bücher über Tinius. Der Gewinner der Auktion soll G.A. Bolenk geheißen haben. Dieser Name erinnert an G.A. Bogeng (1881-1960), der das bis heute unübertroffene Werk Die großen Bibliophilen (1922) über berühmte Bibliophile und ihre Sammlungen, geordnet nach Nationalepochen, verfasst hat. Der fiktive Bolenk soll an einem Pandämonium-Projekt gearbeitet haben, was einen ironischen Kommentar zu den Bibliophilen liefert.

Der Einfluss von Tinius auf den Protagonisten gewinnt im Verlauf des Romans immer mehr an Gewicht und führt zu immer stärkeren Veränderungen in Reinhold Leben: Der Buchfund löst seine Besessenheit vom Autor Tinius aus, die zur Trennung von seiner Freundin führt, da Tinius immer mehr Raum in seinem Leben einnimmt. Schließlich setzt er sich mit Tinius gleich, als sich sein Selbst aufzulösen beginnt, verschwindet er in seinem PC. Im Laufe seiner Recherchen stellt Reinhold die Texte über sich und sein Leben: „Wichtiger als er selbst, aber auch wichtiger als der Autor Tinius war längst die Lust an den Texten geworden. “314 So ist der Buchtrinker nicht nur ein Roman über zwei Bibliomane, sondern vor allem eine Anleitung zum ,richtigen’ Lesen, denn auch der reale Leser soll sich mit der intensiven Art zu lesen identifizieren (vgl. Kap. III.8.2).

\subsection{Der Autor, der das Leben verändert}

Wie in Der Buchtrinker stehen in Nachtzug nach Lissabon die Geschichten des Protagonisten und die des fiktiven Autors gleichwertig nebeneinander. Raimund Gregorius, ein Berner Latein- und Griechischlehrer, begibt sich im Nachtzug nach Lissabon und, initiiert durch das Buch mit dessen Aufzeichnungen, auf die Spur des verehrten und gesuchten Autors. Das Buch besteht aus den philosophisch-tiefgründigen und sehr persönlichen Anschauungen des portugiesischen Arztes Amadeo Inácio de Almeida Prado. Auch Prados Lebensgeschichte schlägt sich in den Aufzeich-

\footnotetext{
311 Huizing (1996), S. 131.

312 Ebd., Kapitel „Der korrekte Mörder“ über Tinius, S. 123-130, und Kapitel „Er spielt Bilder nach und ersteigert beinahe ein Buch" über Reinhold, S. 131-137. 
nungen nieder und schildert neben seinem schwierigen Verhältnis zum Vater auch den Widerstand im Portugal unter Salazar. Im weiteren Verlauf des Romans ist nicht mehr die Rede vom „Buch“, sondern von den „Aufzeichnungen“315 und dem Autor, der damit zu Wort kommt.

Das Buch tritt in Gregorius' Leben und stellt es gründlich auf den Kopf. Er entschließt sich dazu, die routinierten Abläufe aufzugeben, die gewohnten Orte zu verlassen und Neues zu wagen, das Leben „,in die eigenen Hände zu nehmen““316, wo er bisher weitgehend bestimmt und geprägt durch die Erwartungen anderer an ihn war.

Der Augenblick, der alles verändert, ist geprägt durch das Unbekannte und die Erkenntnis des verlorenen Lebens: „Eine namenlose, gefühlsverwirrte Portugiesin. Vergilbte Aufzeichnungen eines Adligen Portugiesen. Ein Sprachkurs für Anfänger. Der Gedanke an die verrinnende Zeit.“317 Das Buch, dessen Maximen Gregorius klar machen, dass er mit seinen Lebensumständen in Wahrheit unzufrieden ist, ist also ein Punkt unter mehreren - neben Exotik und Schönheit, einer fremden, wohlklingenden Sprache und dem Gedanken an das womöglich verlorene Leben -, die den Ausschlag für den willentlichen Bruch mit seinem früheren Leben geben. Bevor er die Aufzeichnungen zur Kenntnis nahm, hatte er allerdings kein Gefühl des Mangels. Die Kraft der Worte und ihre Wirkung auf den Leser sind also nicht zu unterschätzen, hängen aber maßgeblich von dessen Verfassung und Lebensumständen ab. Als Motiv zieht sich das Buch in Form von Prados Aufzeichnungen als roter Faden durch den gesamten Roman, das Thema des Romans ist aber das Ausbrechen aus der alltäglichen, eingefahrenen Routine.

Die Aufzeichnungen geben den endgültigen Anstoß dafür, das alltägliche, eingefahrene Wirkungsfeld zu verlassen und auf den Spuren des verehrten Autors nach Lissabon zu reisen, denn „er war dabei, aus seinem bisherigen Leben wegzulaufen.“"318 Prados Worte scheinen Gregorius direkt anzusprechen und für ihn in seiner Situation geschrieben zu sein: „Und dann hörte er Sätze, die in ihm eine betäubende Wirkung entfalteten, denn sie klangen, als seien sie allein für ihn geschrieben worden, und nicht nur für ihn, sondern für ihn an diesem Vormittag, der alles

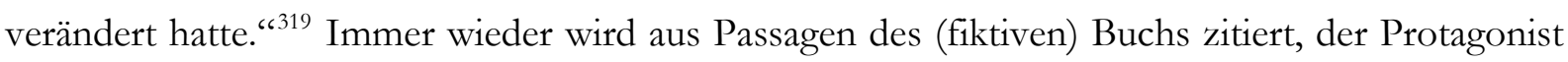
erfährt so immer mehr über den (fiktiven) Autor. Gregorius muss sich allerdings erst mühsam seinen Weg durch Prados Aufzeichnungen bahnen, denn die portugiesische Sprache muss er sich mithilfe von Wörterbüchern und Grammatiken erst erschließen. An die z. T. recht umfänglichen, zweifach fiktiven Zitatpassagen schließen sich in der Romanhandlung Treffen mit Weggefährten

315 Mercier (2006), u. a. S. 38, 96, 115 .

316 Ebd., S. 24.

317 Ebd., S. 41.

318 Ebd., S. 24.

319 Ebd., S. 28 
des Autors an, mit Geschwistern, Bekannten, Untergrundkämpfern. Von ihnen erhält Gregorius ergänzende Hinweise und auch weitere Texte, z. B. Briefe, die das Wesen des Autors enthüllen. Unglaubwürdig erscheint allerdings, dass diesen Weggefährten Gregorius’ Interesse nicht lästig oder suspekt vorkommt und sie ihn sämtlich mit offenen Armen empfangen, intimste Fragen zulassen und ihrerseits detaillierte Auskünfte über ihre Zeit mit Prado geben. Die Erzähler berichten dabei alle auf demselben sprachlichen Niveau, was Ausdrucksfähigkeit, Wortwahl und Emotionalität des Erzählten angeht, was nicht ganz wahrscheinlich wirkt.

Nicht nur Gregorius' äußeres Leben wird durch das Buch verändert, er verspürt während seiner Spurensuche in Lissabon auch eine allmähliche Veränderung in sich, die durch die Metapher des veränderten Sehens angedeutet wird. In Lissabon benötigt er eine neue Brille, wobei die Augenärztin eine andere Sehschärfe feststellt als sein Berner Augenarzt. Er hat sich ein neues Sehen, eine neue Sichtweise auf die Dinge angeeignet. Kurzsichtigkeit steht für das alte Leben, die Aufzeichnungen haben seine Sicht geschärft, er „sah besser als jemals zuvor“ ${ }^{\text {‘320 }}$.

\subsection{Das Leben des Autors nachleben}

Der Schatten des Windes ist das einzige Beispiel der Vierergruppe, in denen das ,Buch im Buch' ein Roman ist. Dennoch gibt es keine reine Fiktion wieder, sondern die fiktional geschilderte Lebensgeschichte des fiktiven Autors Carax mit dem Titel „Der Schatten des Windes“, eine „Geschichte von einsamen Menschen, von Abwesenheiten und Verlust ${ }^{\text {‘321 }}$. Verlust ist auch das Thema des vorliegenden Romans: Der Protagonist Daniel hat die Mutter verloren, Carax den Vater und die Geliebte.

Daniel entdeckt das Buch zu Beginn des Romans auf dem ,Friedhof der Vergessenen Bücher' und liest es gleich von Deckel zu Deckel durch. Der Roman, der die Lebensgeschichte des fiktiven Autors enthüllt, beeindruckt ihn dermaßen, dass er nun mehr über den faszinierenden rätselhaften, unbekannten Julián Carax erfahren möchte. Doch auch in gut unterrichteten Buchhändlerkreisen kennt ihn niemand oder weiß, ob er noch lebt. Carax hat noch mehr Romane verfasst, von denen keiner mehr verfügbar ist. Später stellt sich heraus, dass Carax selbst für das Verschwinden seiner Bücher verantwortlich ist. Er steckt die Lagerhalle seines Verlages in Brand, um sämtliche Exemplare seiner Bücher zu vernichten, nachdem er zuvor erfolglos versucht hatte, den Bestand komplett aufzukaufen. Sein Ziel ist es, sich selbst in den Flammen umzubringen, er überlebt aber schwerstverletzt. Die Buchvernichtung ist für ihn als erweiterter Selbstmord zu verstehen. Er möchte seine Lebensgeschichte, die er im Buch beschreibt, auslöschen, also müssen auch die Bücher vernichtet werden. Es wird impliziert, dass der Autor zwar sterben möge, seine Seele 
stecke doch in seinen Werken und lebe weiter. Alle seine Figuren sei der Autor selbst, will ihn jemand vernichten, so muss er sich auch aller Bücher entledigen, in die ein Teil seiner Seele eingegangen ist ${ }^{322}$. Je ein gedrucktes Exemplar von Carax' Romanen wurde von Nuria, einer Verlagsangestellten, Geliebten von Carax und Tochter des Friedhofwächters Isaac, auf dem ,Friedhof der Vergessenen Bücher' untergebracht, um sie vor der Vernichtung zu schützen.

Daniels Buchauswahl geht schnell vonstatten, denn ohne dass er es wusste, stand schon lange fest, dass dieses Buch für Daniel bestimmt war: „....jedenfalls hatte ich die Gewißheit, daß das Buch seit Jahren, wahrscheinlich seit der Zeit vor meiner Geburt, hier auf mich gewartet hatte.“323 Daniel scheint mit dem Lösen des Geheimnisses um den Autor die Mutter wiederfinden zu wollen, denn es wird die Geschichte von jemandem beschrieben, der Ähnliches erlebt hat.

Der Buchfund setzt in der Fiktion die Forschung nach dem Autor ebenso in Gang, wie die weiteren Ereignisse - das Aufdecken von Carax' Geschichte, seine Rehabilitierung als Büchervernichter, schließlich auch den Tod des Antagonisten -, da das Buch die Hintergründe über Carax' Geschichte liefert. Als Doppelgänger beobachten Daniel und Carax einander interessiert, da sie die Parallelen zwischen ihren Schicksalen entdecken. Im Obertext, der Daniels Suche nach dem Autor vorführt, treten die Analogien erst nach und nach zu Tage, ohne dass Daniel etwas dazutut. All diese Ereignisse führen Daniels Reifung und Initiation in das Erwachsenendasein herbei.

Die Nachforschungen werden durch Daniels Interesse an Carax über seinen Roman motiviert, dessen Schicksal sein Leben kreuzt, letztlich aber zudem angestoßen durch den rätselhaften, entstellten Fremden, der so viel über ihn zu wissen scheint und ihm nachspioniert. Daniel sucht wie Merciers Gregorius Weggefährten des verehrten, verschollenen Autors auf, um mehr und Persönliches über ihn zu erfahren, und erhält von ihnen mündliche Berichte oder sogar schriftliche Notizen. Der Text wird an einigen Stellen für mehrere Seiten lange Passagen durch die Geschichte von Carax unterbrochen, erzählt aus dem Blickwinkel eines auktorialen Erzählers. Daniel forscht Carax nach, der wiederum ihn beobachtet und genau studiert, da er Sympathie für einen wahren Leser empfindet, der sich für seine Romane ernsthaft interessiert und das letzte Exemplar seines Werkes um keinen Preis veräußern möchte. Carax bringt besonders solche Exemplare seiner Werke an sich, um sie zu vernichten, die in Händen von Menschen sind, die nichts für die Bücher empfinden und nur mit ihnen handeln oder sie als Kuriositäten betrachten. Hier wird eine Reverenz vor dem ,richtigen' Lesen und dem respektvollen Umgang mit Büchern deutlich, die sich in diesem Fall auch an den realen Leser richtet.

\footnotetext{
322 Vgl. an dieser Stelle die Horkruxe in Harry Potter, mit deren Hilfe der Antagonist Voldemort seine Seele in Teile aufgespalten aufbewahrt und so gleichsam unsterblich wird.

323 Ruiz Zafón (2003), S. 11f.
} 
Außerdem zeigt sich mehr und mehr ein Determinismus für Daniel, der es ihm unmöglich macht, seiner Bestimmung zu entrinnen. Die Geschichte wiederholt sich: Das fiktive „Buch im Buch' ist in Daniels Geburtsjahr zuerst erschienen, in Daniels Leben ereignen sich Dinge, wie sie auch im Buch passieren. Alle Figuren erscheinen wie Marionetten in einem Spiel, das Schicksal aller ist vorbestimmt und scheint miteinander verbunden.

Mit seiner Begeisterung für Carax und das Buch erobert Daniel das Herz von Bea, der Schwester seines besten Freundes, und verstrickt sie ebenfalls in die Nachforschungen. Als sie Interesse äußert, das Buch zu besitzen, nimmt Daniel sie mit zum Friedhof, wo sie sich Thomas Hardys Tess (1891) aussucht. Der Roman über eine junge Frau, deren illegitime Schwangerschaft sie in Bedrängnis bringt, nimmt ihr eigenes Schicksal vorweg. Bei der Auswahl des Buchs empfindet Bea das Buch als für sie bestimmt: Das Schicksal der Figuren wird durch die Bücher geprägt.

Die Ähnlichkeit zwischen Daniel und Carax wird von Nuria explizit festgestellt: „Es ist, als sprichst du von dir. ${ }^{\text {‘324 }}$ Daniel und Carax stammen beide aus bescheidenen Verhältnissen und sind verliebt in die Schwester des Freundes aus gutem Hause. Intellekt, Geist und Feinfühligkeit bestimmen das Leben von Daniel und seinem Vater, der einen Buchladen führt, wohingegen der Alltag im Hause Carax von Gewalt bestimmt wird. Ein verbindendes Element ist für beide wieder der Füller: Daniel betrachtet ihn im Schaufenster und träumt davon, damit Hugos Werke weiter zu schreiben. Er ahnt nicht, dass der Füller einst Carax gehörte, der damit Velazquez' ungemalte Bilder malen wollte. Daniel gibt sich schließlich einem Klassenkameraden von Carax gegenüber als dessen Sohn aus, um ihm Informationen zu entlocken. Später korrigiert er sich und nennt sich einen ,geistige[n] Sohn“(325 Carax schließlich bittet Daniel, „an seiner Stelle zu leben“326. Der Kreis schließt sich, als Daniel und Bea ihren Sohn nach Carax benennen, den Daniel zehnjährig auf den Friedhof führt. Dort sucht sich der Sohn ein eigenes Buch aus, das an die Stelle von „Der Schatten des Windes“ tritt und nun wiederum wichtig für den Sohn wird.

Hier wird das Leseverhalten von Kindern und Eltern fiktional umgesetzt: Der zuverlässigste Weg, Kinder für das Lesen zu begeistern ist, sie durch das eigene Vorbild an Bücher heranzuführen. So betreibt der Autor Ruiz Zafón an dieser Stelle eine ausdrückliche Werbung für Bücher und Lesen. Es wird in der Fiktion geschildert, dass alle Leser von Carax' Romanen eine wahre Begeisterung bei der Lektüre empfinden und sich fasziniert zu dem Autor hingezogen fühlen. Durch diese positive Darstellung begeisterter Leser soll der Funke auch auf den realen Leser überspringen, der, ist er dem Roman zugetan, den Roman im Bekanntenkreis empfehlen soll. 


\subsubsection{Figur, fiktiver Autor und realer Autor}

Der Schatten des Windes ist der einzige Roman in dieser Motivgruppe, in dem der fiktive Autor noch leben soll, obwohl dies erst spät aufdeckt wird. Der Autor gilt vielmehr als verschollen, denn er ist im Literaturbetrieb unbekannt. Als geheimnisvoller Fremder, der Daniel verfolgt, um ihm das letzte Exemplar von Carax’ Buch abzunehmen, ist die Figur Carax ein Spannungselement, da nicht klar ist, wem die Bedrohung aus welchem Grund gilt. Er kennt persönliche Details von Daniel, was unheimlich wirkt, er scheint ihm nachgeforscht zu haben. Zudem wird er als entstelltes Monster vorgeführt: Er riecht nach verbranntem Papier, da er alle Exemplare seiner Werke, derer er habhaft werden kann, vernichtet, ist durch Brandnarben entstellt. Bei der Suche nach seinen Büchern gibt er sich den Namen einer Figur aus seinem Roman, die dort der Teufel trägt, sie sei

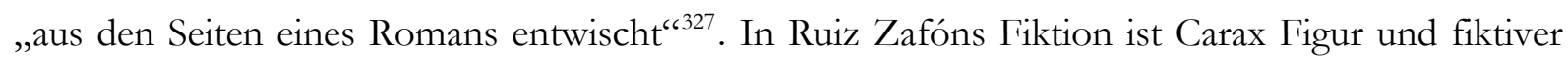
Autor, in der zweifachen Fiktion Figur. Der Schatten des Windes erhält auf diese Weise Elemente des Spannungsromans, wobei das Buch das mysteriöse Element des Doppelgängers betont.

Wie der Leser seine Spuren im Buch hinterlässt und nicht nur das Buch in ihm, reagiert auch der fiktive Autor auf den Protagonisten als Leser. Er beginnt wieder zu schreiben und zwar über Daniel, quasi sein alter ego, und knüpft so an seine vorige Autorentätigkeit an, denn in „Der Schatten des Windes“ hat er seine eigene Lebensgeschichte wiedergegeben.

Im Abschlusskapitel „Nachspiel 1966“ nähert sich der vorliegende Roman dem ,Buch im Buch' an, wenn berichtet wird, dass der fiktive Autor Carax am Ende seines Romans „Der Schatten des Windes“ einen Überblick über die Schicksale seiner Figuren in späteren Jahren gibt - genau wie es Ruiz Zafóns „Nachspiel“ eben auch tut.

Der Autor Ruiz Zafón untermauert seine eigene Glaubwürdigkeit durch Abgrenzung vom fiktiven Geschehen, wenn er seiner Figur in den Mund legt, Carax' Geschichte, die doch denselben Titel trägt wie sein Roman, sei wie ein „Schundroman““328. Carax fiktiver Verleger soll vor seiner Karriere im Verlagsgeschäft ebenfalls „Schundromane“(329 veröffentlicht haben. Vielleicht amüsiert sich Ruiz Zafón aber auch in ironischer Brechung über sich selbst.

\subsection{Identifikation des Protagonisten mit dem fiktiven Autor}

Daniel entdeckt in Der Schatten des Windes bereits zwischen ihm und dem Autor Carax bestehende Analogien, ohne dass er als Leser etwas dazutut. Der Inhalt des Buchs, das den fiktiven Autor fiktional und autobiographisch porträtiert, ist ihm bald nach Beginn des vorliegenden Romans

\footnotetext{
327 Ruiz Zafón (2003), S. 198. 
bekannt, wird aber nicht zitiert. Die Parallelen zwischen Daniel und Carax scheinen determiniert, als ob Daniel durch die Auswahl des Buchs auf dem ,Friedhof der Vergessenen Bücher' dazu bestimmt worden sei, Carax tragische Lebensgeschichte nicht in Vergessenheit geraten zu lassen. An ihm selbst wiederholt sich die Geschichte der hindernisreichen, in Carax' Fall tragischen, Liebe zur Schwester des wohlhabenden Freundes.

Bei Schmitt, Huizing und Mercier nähert sich der fiktive Leser dem Autor, über den er forscht, mehr und mehr an, übernimmt seine Gewohnheiten und Ansichten, die Schicksale werden sogar derart verschränkt, dass der Protagonist nicht mehr zwischen den Identitäten unterscheiden kann.

Der Protagonist in Die Schule der Egoisten sieht sich schließlich als Doppelgänger des Autors, dessen Lehre ihn dermaßen aufgewühlt hat. Er hat sich so tief mit Languenhaerts Person und Ideen auseinandergesetzt, dass er seine Nachfolge antreten kann. Wie in der romantischen Selbstvermittlung bei Novalis oder Schlegel erscheint hier eine unendliche Steigerung und Doppelung, der Leser wird durch die Übernahme von Ideen zum Doppelgänger des Autors. Auch der Rezensent Altenburg sieht bei Schmitt ein „Konstrukt aus romantischen Versatzstücken“3330. Die Person verschmilzt mit der Idee, so dass der Protagonist im Schlusssatz fragen kann: „War am Ende ich Gaspard Languenhaert?، ${ }^{331}$ Als Doppelgänger Languenhaerts wird der Protagonist selbst vom Leser zum Autor und kann dessen Text fortführen: „Ich war überzeugt, zum Kern dieser Worte vorgedrungen, ja, ihr eigentlicher Kern zu sein. Ich hätte sie weiterschreiben können... “332 Angesichts der immer stärkeren unbewussten Identifikation mit Languenhaerts Ideen wird er zum „Mitwisser des Geheimnisses“3333. Hier klingt eine religiöse Anspielung an, denn die Gläubigen feiern in der Liturgie das, Geheimnis des Glaubens'.

Languenhaert scheint sich alle 50 Jahre mit neuen Publikationen über sich selbst zu zeigen. In Intervallen von 50 Jahren werden immer neue Bereiche seines Lebens, seiner Persönlichkeit und Gedankenwelt aufgedeckt und veröffentlicht, über seine Biographie, Liebschaften, Philosophie, die Etablierung seiner „Schule der Egoisten“, seine Gedanken über Religion. Der Abschnitt über sein Sterben, den der Protagonist auf der Grundlage seiner Recherchen verfasst hat, bildet nun den Abschluss der literarischen Biographie Languenhaerts. Ungeklärt bleibt jedoch, ob sich alle 50 Jahre Forscher mit Languenhaert auseinander setzen, oder ob es der unsterbliche Languenhaert selbst ist: „Steht nicht ein und dieselbe Person hinter all diesen Schriften? Wer beweist uns,

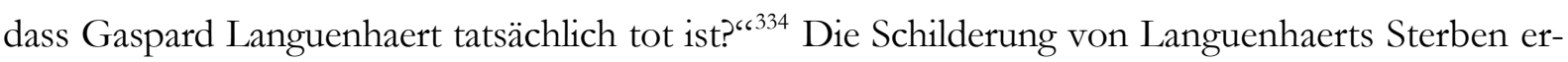


scheint allerdings paradox, da gleichzeitig suggeriert wird, dass er als Schöpfer der Welt in der Person des Protagonisten noch existiert. Seiner Lehre zufolge hätten alle Werke jedoch mit ihrem Schöpfer untergehen müssen. Der Philosoph existiert nur geistig und vergeht daher nicht wie der Mensch und die Dinge. Es entspräche sogar seiner Doktrin, dass er als Urheber aller Dinge auch selbst alle Schriften über sich besorgt hat. Der Protagonist hat sich das Werk so intensiv angeeignet, dass er dazu in der Lage ist, es fortzuführen. Es bleibt offen, ob hier eine ideale Rezeption von Literatur geschildert wird, die als Modell für den (realen) Leser dienen soll.

In Der Buchtrinker eignet sich Reinhold im Akt des Lesens den Text von Tinius' Autobiographie an, bis die Essenz seiner Persönlichkeit abzunehmen beginnt und mit den Eindrücken aus dem Text überschrieben wird. Das Verständnis von Tinius' Leben ist nur möglich, wenn er ihm völlig „eingeschrieben“335 ist und dieses Leben wiederholt, dabei aber sein eigenes Ich aufgibt. Im Romantext heißt es, der Autor werde entblättert, je mehr ein Leser über ihn aufnehme, desto voller werde er mit den Texten.

Gregorius, der Protagonist in Nachtzug nach Lissabon, bemerkt nach seinen Recherchen eine Veränderung in seinem Wesen: Er beginnt, zuerst an sich selbst zu denken, und hat nun einen veränderten Umgang mit Texten, neu für ihn ist es z. B. in der Natur zu lesen. Auch in anderen vermag er Veränderungen zu bewirken, was ihn dem verehrten Autor Prado, dem seine Zeitgenossen mit Ehrfurcht begegneten, ähnlich macht. Das ,Buch', also Prados Gedanken und Überlegungen, haben einen Wandel in Gregorius Wesen und Lebensumständen herbeigeführt, so dass ihm seine Heimatstadt Bern bei seiner Rückkehr fremd geworden ist. Gregorius bezieht Gelesenes direkt auf sich und sein Leben und beginnt umzudenken. Ebenso bewirkt er eine Veränderung im Leben von Prados Schwester. Er möchte sich und andere „aus der erstarrten Vergangenheit befreien und in ein gegenwärtiges, fließendes Leben zurückholen “‘336. Gregorius hilft ihr, den Tod des geliebten Bruders nach Jahrzehnten zu akzeptieren, die Trauer abzulegen und den Stillstand der Zeit zu überwinden. Als eher schlichtes Symbol dient dabei, dass er die angehaltene Standuhr wieder in Gang bringt. Er wird zu Prado, da er bei seinen Recherchen unterschiedliche Standpunkte zu und Sichtweisen auf ihn aufgenommen und ihn nun in Gänze vor sich hat. Alle Facetten und Gedanken, die fragmentarisch bei den Wegbegleitern aufbewahrt wurden, haben ein vollständiges Puzzle ergeben. Sein Forschen und sein Interesse haben ihn Prado identisch gemacht: „Und [Gregorius] war auch dieser Bruder selbst, der in der Erzählung wieder lebendig

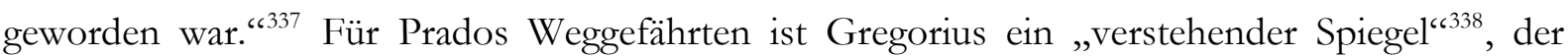


ihnen beim Erzählenlassen und Zuhören die Vergangenheit mit Prado wieder lebendig macht. Er gibt ihnen Trost und Kraft, weil er sich als Fremder mit dem Leben und den Aufzeichnungen von Prado beschäftigt. Prado hat nicht nur Gregorius, sondern alle seine Wegbegleiter geprägt. Gregorius reiht sich ein, als habe er Prado ebenso persönlich gekannt.

\subsection{Schlussfolgerung}

In allen vier hier untersuchten Titeln wird das Buch als elementarer Bestandteil des Romans vom Leser erwartet, da in der Einführung eine Umgebung eröffnet wird, die Bücher etabliert. Die Protagonisten werden als Wissenschaftler, Studienrat oder Buchhändler dargestellt, zu deren Handwerkszeug Bücher zweifellos gehören. Der namenlose Doktorand wird gleich im ersten Satz, einem establishing shot gleich, bei seinen Recherchen in der Bibliothèque Nationale gezeigt ${ }^{339}$, Falk Reinhold wird als Student und Büchernarr eingeführt ${ }^{340}$, Daniel Sempere, der aus einer Buchhändlerfamilie stammt, berichtet im ersten Satz vom Tag auf dem ,Friedhof der Vergessenen Bücher ${ }^{341}$, auch die Überschrift dieses Prologs vermittelt dem Leser die richtige Atmosphäre. So überrascht nicht, dass diese drei Protagonisten besondere Bücher finden, die ihr Leben verändern. Einzig für Gregorius ist das Buch zwar Anstoß zu etwas Neuem und elementar wichtig, doch noch wichtiger ist die Veränderung ${ }^{342}$.

Die Schule der Egoisten kann zum einen als Roman über das wissenschaftliche Forschen angesehen werden, zum anderen als belletristische Darstellung einer philosophischen Richtung, des Solipsismus, der an den Konstruktivismus grenzt. Hier folgt der Roman einer Tradition, für die Jostein Gaarder mit Titeln wie Sofies Welt (1994) Maßstäbe gesetzt hat. Zwar wird das Buch als Motiv, mindestens als Ausstattung, im Roman erwartet, doch hauptsächlich als Mittel zur Aufdeckung des Geheimnisses. Matthias Altenburg stellt sich in seinem Verriss von Schmitts Roman dennoch die Frage: „Wer liest so etwas? ${ }^{6343}$ Er vermutet, dass die Leser, die zu diesem Titel greifen, für tiefsinnig gehalten werden möchten und die Atmosphäre des Geistigen schätzen, dabei aber „Denkfaulheit für Herzensklugheit ${ }^{\text {‘344 }}$ halten. Deutlich wird mit dieser Einschätzung, dass die professionelle Bewertung die Thematisierung der Philosophie im Zentrum des Romans sieht,

\footnotetext{
339 „Es war an einem Dezemberabend in der Bibliothèque Nationale.“, Schmitt (2006), S. 7.

340 „Falk Reinhold packte seine Bibliothek aus.“, Huizing (1996), S. 21.

341 „Ich erinnere mich noch genau an den Morgen, an dem mich mein Vater zum ersten Mal zum Friedhof der Vergessenen Bücher mitnahm.“, Ruiz Zafón (2003), S. 7.

342 „Der Tag, nach dem im Leben von Raimund Gregorius nichts mehr sein sollte wie zuvor, begann wie zahllose andere Tage.“, Mercier (2006), S. 13.

343 Altenburg (2004).

344 Ebd.
} 
nicht die Beschäftigung mit Büchern. Die Leserschaft ist laut Leserrezensionen bei Amazon.de ${ }^{345}$ gespalten: Eine Gruppe lobt den Roman für seine philosophischen Tiefgründigkeit, die andere lehnt den Roman als langweilig ab. Die Leser sind größtenteils enttäuscht, da sie den Roman mit weiteren Titeln des Autors vergleichen, aber auf eine unterschiedliche Herangehensweise stoßen. Über das Buch-Motiv reflektiert keiner der Laienrezensenten.

Ausgelöst durch die Schilderung der Büchernarren-Figur Tinius ist das Buch in Der Bucbtrinker unabdingbar. Wer die Geschichte des Magisters Tinius kennt, weiß bereits, dass Bücher eine große Rolle spielen werden. Der Roman ist gleichzeitig eine mit ironischen (Unter-)Brechungen und Kommentaren versehene Version der bekannten Geschichte von Tinius und zeigt in der Parallelhandlung außerdem, dass es heute genauso wie zu Tinius' Zeit Büchernarren gibt. Diese Titel sind an gebildete Leser gerichtet, die Freude an Bücher-,Krimis ${ }^{346}$ haben, in denen das Buch mysteriöse Umstände aufklärt und auf die Spur geheimnisvoller Autoren führt. Neben der Beschäftigung mit dem Buch stehen hier rätselhafte Ereignisse im Vordergrund, wie z. B. die Identifikation des Protagonisten mit dem Autoren, allerdings werden auch die Rolle des Buchs und der richtige Umgang mit Büchern reflektiert.

Der Schatten des Windes ist eher als „Schmöker“6347 für ein breiteres Publikum anzusehen. Der Buchbezug wurde von Ruiz Zafón vermutlich gewählt, um den fiktiven Autor einzuführen und ihn dem Protagonisten als Doppelgänger gegenüber zu stellen, wodurch wiederum eine geheimnisvolle und rätselhafte Atmosphäre geschaffen wird. Die verschiedenen Erzählwelten und -möglichkeiten durch den zweifach fiktiven Text von Carax’ Roman und dem vorliegenden Roman, der Daniels Geschichte folgt, bieten hier Raum für ein Spiel mit Identitäten, allerdings wird keine nähere Auseinandersetzung mit erzähltheoretischen Fragen angestellt. Mit der Schilderung begeisterter Leser und der Einführung des ,Friedhofs der Vergessenen Bücher', wo Bücher neue Besitzer erwarten, macht Ruiz Zafón eindrucksvoll Werbung für Lesen und Bücher. Allerdings verpufft die Werbewirkung größtenteils, da vermutlich eher Leser zu diesem Roman greifen, die Bücher ohnehin wertschätzen und durch den Namen des Autors angelockt werden, und somit weniger neue Leserkreise erschlossen werden.

\footnotetext{
345 Vgl. Leserrezensionen zu Nachtzug nach Lissabon bei Amazon.de [http://www.amazon.de/product-reviews/ $325060061 \mathrm{X} /$ ref=cm_cr_pr_link_prev_1 ?ie=UTF8\&showViewpoints=0\&sortBy=bySubmissionDate Descending], eingesehen am 14.07.2010.

346 Die Schule der Egoisten ist dem Klappentext der Tb-Ausgabe zufolge ein „,philosophischer Krimi“, Schmitt (2006); Die Zeit bezeichnet Nachtzug nach Lissabon als „Bewußtseinskrimi“, Umschlaginformation der Tb-Ausgabe, Mercier (2006), und Reinhold Falk begibt sich laut Klappentext der Tb-Ausgabe auf die Spuren eines „geheimnisvollen Falles“, Huizing (1996).

347 Elke Heidenreich über den Roman, Umschlaginformation der gebundenen Ausgabe, Ruiz Zafón (2006).
} 


\section{5 „Es gibt nichts Gefährlicheres als ein Buch"6348 - Das gefährliche Buch}

Das Buch ist für den Leser nicht nur Freund, Tröster und Erzieher, sondern kann auch gefährlich, bedrohlich oder schädlich sein. Bücher vermögen nicht nur Existenzen zu verändern und Leben zu retten, sie können auch töten. So galten Bücher in der Historie immer wieder als Bedrohung für den, der sie schrieb, besaß und las. Bibliotheken machen Wissen verfügbar, okkulte Büchersammlungen verbergen es auch, „eine Bibliothek ist, wie jedes Waffenarsenal, auch immer ein Hort der Macht. ${ }^{\text {(349 }}$ Der Topos des gefährlichen Buchs wird auch in der Literatur thematisiert und kommt als Motiv in den untersuchten Romanen vor.

In literarischen Darstellungen können Bücher auf zwei Arten bedrohlich sein, zum einen ganz explizit: Die Bücher können töten, wie bei Živković oder auch Perutz, Anonymous und Eco anklingt, pro-aktiv, indem sie einen Mörder auf den Plan rufen oder zum Selbstmord verleiten. Zum anderen können Bücher auch aufgrund ihres Inhalts zur Gefahr für den Besitzer und Leser dieser Inhalte werden. Wieder wird eine Unterscheidung zwischen dem gegenständlichen Buch und dem Inhalt deutlich: Der Gegenstand tötet aktiv und selbständig, der Inhalt subtil und vermittelt.

\subsection{Gefährliche Bücher und gefährliches Lesen}

Seit dem Mittelalter galten häretische oder klandestine Schriften - pornographische oder politisch brisante; solche, die sich gegen Personen, die Regierung, die Moral oder Religion richteten Schriften, die also eine gewisse politische oder gesellschaftliche Brisanz bargen, als gefährlich für Autor und Leser, noch mehr aber für die Autoritäten wie Staat und Kirche. Bücher können Ideen von Freiheit, Selbstbewusstsein und Ideologien vermitteln. Vorgeblich sollte der Leser vor diesen verderblichen Schriften geschützt werden, doch war und ist es vielmehr so, dass die Autoritäten durch den aufklärerischen Einfluss gewisser Schriften auf den Leser ein Aufbegehren fürchten und ihre Macht in Gefahr sehen. Aus diesen Gründen wurden diese Schriften von den Machthabern unterdrückt, um eine fortschreitende Aufklärung des Volkes zu unterbinden. Das Potential von Büchern zu Revolution und Umsturz kommt auch im Nachstehenden zum Ausdruck:

\footnotetext{
Das abergläubische Volk beginnt bereits, die Erfindungen in Europa als Werkzeuge des Satans zu sehen. Stellt Euch nur vor, wie die Leute reagieren würden, wenn sie herausfänden, was Ihr der Welt bringen könnt. Bücher, die entgegen aller Grenzen, aller Wahrheiten, behaupten: Da ist noch mehr. ${ }^{350}$
}

Suspekt war den Autoritäten die eigenständige Denkweise, die für den Einzelnen beim einsamen Lesen, das sich weitgehend der Kontrolle durch Dritte entzog, hervorgehen würde. Der Leser 
kommt in Berührung mit einem libertären Inhalt, der von Autoritäten unerwünscht ist und als gefährlich angesehen wird. Eine allgemeine Lesefähigkeit war unerwünscht aufgrund einer entstehenden Mündigkeit des Lesers. Ein Buch ist ,geheimnisvoll', weil es verborgenes oder sogar verbotenes Wissen in sich birgt, also Wissen, das zwar überliefert werden soll, aber nur an bestimmte und auserwählte Kreise, nicht an die Öffentlichkeit. Dies ist einer der Gründe, weshalb die Obrigkeiten im 18. Jahrhundert eine allgemeine Lesekompetenz ablehnten.

Die Bedrohung durch das Bücherlesen, die in den untersuchten Romanen zum Ausdruck kommt, schließt letztendlich an die Lesesucht-Debatte der 1770er Jahre an. Seit dem ausgehenden 18. Jahrhundert, der Zeit der sucht- und epidemieartigen Verbreitung des Lesens von Romanen besonders unter Bürgern, wird das Lesen zur reinen Unterhaltung als Gefahr für das Seelenheil und die sinnvolle Teilnahme des Individuums an der Gesellschaft betrachtet (vgl. Kap. II.1.2). Jens Schreiber folgert, dass die Lesesucht-Kritik des 18. Jahrhunderts das Lesen nicht nur als Folge der zunehmenden Alphabetisierung und damit Aufklärung als Laster brandmarkte, sondern auch aus Lustfeindlichkeit: „Eine neue Leidenschaft wird signalisiert, der Exzeß einer neuen Erotik und eines kranken Genießens: das Lesen [...] Das Lesen ist die Krankheit des Genießens.“351 Auch Paul Goetsch stellt fest, dass das Lesen als bloßer Genuss und die Lust am Text „verurteilt und [...] eingeschränkt werden [muss], wenn es nicht krank oder süchtig machen soll.““352

Allerdings sind die Vorwürfe an die Vielleserei, wie die Sinnlosigkeit des massenhaften Lesens oder die Annahme, dass der Vielleser körperlich und geistig krank werde, denkbar konventionell. Vielleserei wurde in den Anfängen der Expansion des Buchmarkts als intellektuelle Faulheit angesehen, da die Bücher nur unverdaut verschlungen würden, man sich aber nicht die Mühe machte, das Gelesene ganz aufzunehmen, gar auswendig zu lernen, wie es zuvor üblich war, und gründlich durchzuarbeiten ${ }^{353}$. Auch heute ist die überblickhafte Lektüre die am meisten verbreitete, obwohl im größten Teil der Gesellschaft weniger gelesen wird als früher (vgl. Kap. IV.3.2.2).

Die Konzepte des Open Access, des kostenlosen, schrankenlosen Zugangs zu (wissenschaftlicher) Literatur für jedermann, und anderer OpenSource-Bewegungen beweisen die heutige Auffassung, dass Wissen niemandem gehört, sondern allen offen stehen sollte. Durch die allgemeine Lesefähigkeit und den breiten Zugang zu einer stattlichen Anzahl an wissenschaftlichen und anderen Bibliotheken in den meisten Bevölkerungszentren stehen Bücher ohnehin schon allen offen. Open Access bietet hier eine an die veränderten Rahmenbedingungen und den verstärkten Einsatz und Gebrauch von elektronischen Medien angepasste zeitgemäße Lösung. Aber auch hier stehen sich die einzelnen Parteien und unterschiedliche wirtschaftliche Interessen selbst im Weg. 
Heute sind die Zugangsmöglichkeiten zu Wissen und Information größer denn je. Daher sind Bücher über verbotenes Wissen und geheimnisvolle, zurückgehaltene Bücher meist in historischer Vorzeit angesiedelt. Zugleich können die Romane über geheimnisvolle Bücher als eine Reaktion auf die Umbrüche in der Informationsgesellschaft angesehen werden: Angesichts der immensen Konkurrenz durch andere Medien bedeutet das Lesen heute einen exklusiven Status für seine Leser, Lesen wird nicht mehr zurückgehalten, sondern gilt als fördernswert.

\subsection{Unerwünschte Bücher in politischen Kontexten}

Bücher sind implizit aufgrund ihres Inhalts gefährlich, wenn dieser unerwünscht oder indiziert ist und der Besitz Sanktionen nach sich zieht. Den Obrigkeiten missliebige und auch gefährlich erscheinende Bücher wurden verboten oder vernichtet, zumeist verbrannt, wobei zu allererst an die Bücherverbrennungen durch die Nationalsozialisten zu denken ist, die aber bei weitem nicht die erste in der Geschichte war. Das Buch kann sich im politischen Kontext als Gefahr für seine Besitzer erweisen - so etwa in instabilen, repressiven politischen Verhältnissen, besonders in Diktaturen, in denen viele Leser zwischen ihrem Leben und den Büchern wählen müssen und ihre potentiell gefährlichen Bücher verbrennen oder verstecken. „Bücher verändern das Schicksal der Menschen. “354 - sie lenken das Leben der Leser in bestimmte Bahnen, aber „,[d]ie Menschen ver-

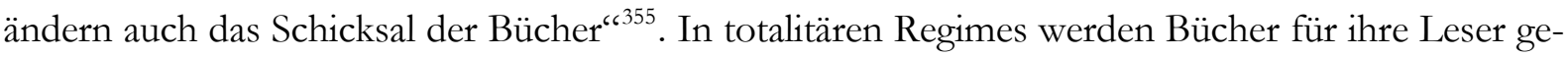
fährlich, und so werden die Menschen den Büchern gefährlich (vgl. Kap. III.3.1.4.2). Als Reaktion auf die Repression vernichten die Leser ihre Bücher, ehe es die Handlanger der Regierung tun. Werden dennoch unerwünschte, da potentiell aufrührerische Bücher gefunden, können sie für ihre Besitzer oder Autoren gefährlich, sogar tödlich werden.

Die Machthaber schwingen sich zu Richtern über Bücher auf, darüber, was gut und richtig oder aber falsch ist. Dabei sind doch die Bücher Produkt eines Schreibprozesses und nicht selbst verwerflich, sondern Ausdruck der Gedanken und Meinungen ihrer Autoren. Ein aktuelles Beispiel für ein von Autoritäten für gefährlich gehaltenes Buch und die Konsequenzen für den Autor ist der Fall von Salman Rushdie und seinem Roman The satanic verses (1988). Die darin dargestellten Begebenheiten und Figuren wurden für eine Verunglimpfung des muslimischen Glaubens und eines seiner höchsten Vertreter, des Glaubensführers Khomeini, gehalten, weshalb Rushdie mit einem Mordaufruf, einer Fatwa belegt wurde.

Autoren können beim Marketing ihres Buchs und ihrer Person auch ,politisch' motiviert sein. Manche streben mit allen Mitteln Bekanntheit und Ruhm an, während z. B. Stefan George um 
die Wende zum 20. Jahrhunderts seine Bücher exklusiv sehen wollte und nur einer bestimmten elitären Käufer- und Leserschicht vorbehielt. In Das Papierhaus heißt es in Bezug auf die Situation der Schriftsteller im heutigen Buenos Aires, Jahrzehnte nach der letzten Militärdiktatur:

Ihre literarischen Bestrebungen waren politisch und mithin militärisch kalkuliert, so viel lag ihnen daran, die Mauern ihrer Anonymität als unüberwindliches, von nur wenigen Privilegierten genommenes Hindernis, zu durchbrechen. [...] In Buenos Aires waren die Bücher zum Gegenstand eines spannenden Krieges um Strategien, um die Gabe der Allgegenwärtigkeit und um die Macht geworden. ${ }^{356}$

In Fahrenheit 451 (1953) gelten Leser, die Bücher besitzen, als Staatsfeinde. Die reale Welt auf den Kopf stellend, wird ausgerechnet die Feuerwehr zur Vernichtung von Büchern mit Feuer eingesetzt. Bücher repräsentieren Geist und Menschlichkeit. Die Unterdrückung des Geistes, also der Bücher, kommt durch kulturelle und gesellschaftliche Nivellierung zustande. Niemand soll durch Geist oder Bildung aus der Masse hervorstechen. Politische Korrektheit führt zu einem Akt der Selbstzensur, in der alle anstößigen Passagen gestrichen werden, bis Bücher schließlich ganz verboten werden, weil sie ideologisch gefährlich sein können. Die allgegenwärtige passive Berieselung durch TV in diesem Roman passt zur herrschenden Ideologie, in der Denken unerwünscht ist.

Drei Titel des Korpus befassen sich mit Büchern, Lesern und Autoren vor repressiven politischen Hintergründen. Das Papierhaus schildert in Ausschnitten die Situation von Autoren während der letzten argentinischen Militärdiktatur in den Jahren 1976-1983, in Nachtæug nach Lissabon wird das persönliche Schicksal eines Widerstandskämpfers vor dem Hintergrund der Diktatur Salazars in Portugal vorgeführt. Dies dient der Illustration und Motivation der Taten des vom Protagonisten verehrten Autors. Als angesehener Arzt zunächst nicht involviert, rettet er ein ranghohes Mitglied der Führungselite, wird geächtet und tritt dann aus Frustration über die ihm entgegengebrachte Ablehnung durch das Volk aktiv dem Widerstand bei. In Der Schatten des Windes dienen Bürgerkrieg und Franco-Regime jedoch eher als Kulisse, um Drohgestalten zu plausibilisieren. Während Domínguez und Mercier reflektiert die Rolle von Lesern und Autoren in diktatorischen Staatsformen thematisieren, findet bei Ruiz Zafón über die persönliche Geschichte hinaus keine Auseinandersetzung mit repressiven Umständen statt.

Ross King zeigt in Das Labyrinth der Welt ein Bild der Restoration nach Cromwell, in der politische Machtspiele, Intrigen und der Streit zwischen England und Spanien um die Vorherrschaft in Europa das öffentliche Leben bestimmen. Es geht außerdem um die Gefährlichkeit und die politische Sprengkraft von Büchern, die nicht umsonst verboten werden, da sie verschwörerische, ketzerische, blasphemische und staatsgefährdende Tendenzen zeigen. Der Buchhändler Inchbold wird damit beauftragt, ein angeblich verschollenes Manuskript, das „Labyrinth der Welt“, wieder zu beschaffen. Seine Auftraggeberin geht nicht selbst auf die Suche, denn „[h]ier hält man jede Frau, 
die des Lesens mächtig ist, für eine Hexe.“3577 Das Manuskript selbst ist gefährlich, doch „,[w]ie

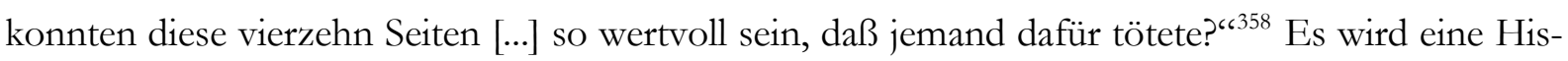
torie über das Manuskript eröffnet, die seine politische, religiöse und moralische Brisanz legitimiert und erklärt, warum es nicht in die falschen Hände geraten darf. Es soll ein gestohlenes Werk aus Konstantinopel und über die Bibliothek Rudolfs. II. und seinen ,Einkäufer' nach England geraten sein. Als apokryphes Manuskript soll es zum Corpus hermeticum gehören. Das Manuskript musste in der Fiktion immer wieder vor religiös motivierten Kriegen und Bränden in Sicherheit gebracht werden, da es politische Sprengkraft bot. Das Corpus hermeticum beschreibe ein Universum eines wunderbaren Zusammenhangs und verleihe seinem Besitzer alchimistische Fähigkeiten und Macht, die Geschicke des Himmels zu seinen Gunsten zu beeinflussen. Damit habe es magische und politische Macht, so dass Vatikan und Monarchen es in Besitz bringen und unterdrücken wollen, denn es ist sowohl blasphemisch als auch staatsgefährdend. Reformatoren und Ketzer interessieren sich für das Manuskript, um den Hermetiszismus als Ersatz für das Christentum einzusetzen, denn dann würde die Lehre des Hermes Trismegistos Religionskriege überflüssig machen und das Corpus hermeticum als Autorität einer universellen Reformation dienen. Der Text bedrohe also die orthodoxe Lehre, so dass Rom sich veranlasst sieht, diese Ketzerei zu unterdrücken.

Das Thema des Romans ist es darzustellen, wie sich Wissen über Bücher und ihre Leser ausbreitet. Eine Büchersammlung zeigt die Weltanschauung ihrer Besitzer. Mit dem Winterkönig Friedrich von Böhmen, einem Protestanten auf einem katholischen Thron, war für die Protestanten in ganz Europa die Bibliothek zugänglich, die der Habsburger Rudolf II eingerichtet hatte, und die häretische und indizierte Schriften enthielt. Der Vatikan war also außer Stande zu kontrollieren, wer die verbotenen Bücher las. Es entstand Furcht vor der Verbreitung von Wissen, das Staat und Kirche angreifbar machte und neue Sekten und Revolutionäre hervorbringen würde. Die Bibliothek erschien nun als geöffnete Büchse der Pandora, deren unliebsame Inhalte vernichtet werden müssen, um sie falschen Kreisen vorzuenthalten, denn „[e]s gibt nichts Gefährlicheres für einen König oder Kaiser [...] als ein Buch.“359 Ein Bibliothekar erinnert daran, dass nicht nur die Kirche, sondern auch alle Eroberer zunächst die Bibliotheken vernichten: „Schon erstaunlich, wie versessen Könige und Kaiser von jeher darauf waren, Bücher zu vernichten. Aber schließlich fußt die gesamte Zivilisation auf derlei Entweihungen, oder nicht?‘6360 


\subsection{Tödliche Bücher}

Bücher können töten: Zum einen im figurativen, zum anderen im Wortsinn durch einen direkten Angriff, sie können zu einem Unfall führen oder (Selbst-)Mord herbeiführen. Hier sind die Bücher als Objekte tödlich, oder zumindest schädlich.

In Das Papierhaus kommt Bluma um, weil sie lesend nicht auf den Straßenverkehr achtet. Außerdem werden triviale Beispiele für den Tod durch Bücher genannt, wie der Leser, der von der Leiter fiel, als er ein Buch aus dem Regal nahm. Die Großmutter des Ich-Erzählers warnt den Protagonisten als Jungen vor Büchern: „Weißt du denn nicht, wie gefährlich Bücher sind?،361 Sie wird als Deutsche eingeführt, womit auf die figurative und tatsächliche Gefährlichkeit und Gefährdung der Bücher in der Zeit des Nationalsozialismus verwiesen wird.

Lebendige Bücher, die den Leser angreifen, kommen aufgrund ihrer Natur ausschließlich in fantastischer Literatur vor, so in Die Stadt der träumenden Bücher. Von Bücherjägern mit tödlichen Fallen ausgestattet, greifen die Bücher den Leser an. In dieser Welt gibt es außerdem, ebenso wie an anderen Handlungsorten der Weltliteratur, giftige Bücher, die durch Berührung mit dem angereicherten Kontaktgift tödlich sind. Ein solches vergiftetes Buch kommt auch in Der Name der Rose vor. Das gefährliche Buch ist hier der verschollene, wohl fiktive 2. Band der Poetik des Aristoteles über die Komödie, ein Buch, das unterdrückt werden soll, da es einem unerwünschten Genre Raum bietet. Jeder Leser soll durch das Gift auf den Buchseiten sterben, damit der ketzerische Inhalt nicht popularisiert werde. Der Foliant ist an den Seitenrändern mit Gift versehen, beim Befeuchten der Finger zum Umblättern kommt der Leser mit dem Gift in Berührung und bringt es zum Mund. William von Baskerville blättert im Beisein von Jorge von Burgos den Folianten durch. Die Seiten kleben aneinander, so dass William die Finger mit Speichel benetzen müsste, um sie voneinander zu lösen. Doch er trägt Handschuhe, wie er dem blinden Mönch mitteilt:

\footnotetext{
Mit den so bewehrten Fingern kann ich die Seiten nicht voneinander ablösen. Ich müßte mit bloßen Händen weitermachen, ich würde mir dabei die Finger an der Zunge benetzen, [...] und ich würde so lange weiterblättern, bis mir genügend Gift in den Mund gelangt wäre. ${ }^{362}$
}

Der Topos des vergifteten Buchs wurde vermutlich aus den Erzählungen der 1001 Nacht übernommen. In einer davon wird eine ganz ähnliche Situation geschildert:

Der König wollte [das Buch] öffnen, fand aber, daß die Blätter aneinanderhafteten. Also steckte er seinen Finger in den Mund, befeuchtete ihn mit seinem Speichel und blätterte die erste Seite auf. Genauso verfuhr er mit den restlichen Blättern, die sich alle nur mühsam aufschlagen ließen. Schließlich hatte er sieben Blätter geöffnet. Er schaute hinein, konnte aber keine Schrift finden. [...] | Der König blätterte so lange, bis ihn das Gift völlig durchdrungen hatte, denn das Buch war vergiftet. ${ }^{363}$

361 Domínguez (2006), S. 8.

362 Eco (1982), S. 596.

363 Tausendundeine Nacht. Nach der ältesten arabischen Handschrift in der Ausgabe von Muhsin Mahdi erstmals ins Deutsche übertragen v. Claudia Ott. 4. A. München: C.H. Beck, 2004, S. 71f. Das Zitat stammt aus der Geschichte „König Yunan und der Arzt Duban“ der 16. Nacht. In älteren Übersetzungen ist dies „Die Geschichte Mahmuds“. 
Über ein Buch, das die Leser durch das Beispiel der Autorin zum Selbstmord verleitet, berichtet der Debütroman Juja (2010) von Nino Haratischwili. Darin wird von einer fiktiven Autorin berichtet, die sich das Leben genommen haben soll. Indem sie sich mit dem Text identifizieren, beschließen in der Fiktion die Leserinnen der feministischen Autorin ebenfalls zu sterben. Der Roman von Haratischwili wurde inspiriert von einer wahren Begebenheit. Als Vorbild diente die Geschichte einer jungen französischen Schriftstellerin, die Suizid begangen haben soll. Es heißt, viele Leserinnen ihrer Texte haben sich nach der Lektüre ebenfalls getötet. Allerdings stellte sich heraus, dass der Herausgeber der eigentliche Verfasser des Buchs war ${ }^{364}$.

Die Parallele zu Leo Perutz’ Der Meister des jüngsten Tages (1923) ist unübersehbar. Bei Perutz begehen die Leser Selbstmord nach der Lektüre eines Folianten und dem gleichzeitigen Genuss eines Räucherwerks, das Wahnvorstellungen und Schreckensvisionen hervorruft. Wo Perutz den Selbstmord der Leser im Anschluss an die Lektüre schildert, gibt es auch Beispiele, in denen die Leser aufgrund der Lektüre und letztendlich aufgrund des Wissens aus dem Buch getötet werden. Der Roman Das Buch obne Namen (2006/2007) von einem anonymen Autor schildert die Ermordung der Leser nach der Lektüre, während Zoran Živković’ Das letəț Buch (2008) (vgl. Kap. III.9.3) eine erzähltheoretische Lösung für die toten Leser anbietet.

\subsection{Schlussfolgerung}

Der Topos des ,gefährlichen Lesens' knüpft an klassische Vorwürfe gegen das Lesen an, die davor warnen, dass Leser durch Bücher ein zu großes Selbstbewusstsein und Wissen erlangen, und so die Autoritäten in Frage stellen könnten. Darüber hinaus leisten die Autoren der Bücher um gefährliche Bücher einen gesellschaftspolitischen Beitrag, indem sie auf die Repression von Büchern und Lesern in diktatorischen Staatsentwürfen aufmerksam machen.

Das Buch ist in der Gesellschaft ganz konkret gefährlich, da es sich negativ auf den Konsum auswirkt. Zwar ist das Buch ein Konsumgut, doch ist die Ausgabe für das Buch erst einmal getätigt, bedeutet Lesen keinen Verbrauch und keinen anderweitigen Konsum, da man sich lange mit einem Buch beschäftigen, das bereits gelesene Buch noch einmal lesen und sogar an Dritte weitergeben kann. Diese Eigenschaft teilt das Buch mit anderen Trägermedien wie DVDs oder Musik-CDs. Es verbraucht sich nicht und nutzt sich nicht ab, aber nur das Buch gewinnt sogar, wenn es von mehr als einem Leser gelesen wird, da es durch Randnotizen oder Anmerkungen des vorigen Lesers und seine Kommentare aufgewertet wird - diese Eigenschaft unterscheidet das Buch von anderen Medien und wertet es auf.

364 Vgl. Rita Nikolow: „Tödliche Lektüre“. Rezension zu Nino Haratischwili: Juja (2010). In: SpiegelOnline, 26.07.2010 [http://www.spiegel.de/kultur/literatur/0,1518,708125,00.html], eingesehen am 27.07.2010. 


\section{6 „Leser durch und durch ${ }^{6365}$, von einer „fast krankhaften Sucht nach Bücherbesitz ${ }^{\text {(366 }}$ Befallene und „Mörder aus Bücherwut ${ }^{\text {(6367 }}$ - Büchernarren}

Wenn ein besonderes, auratisches Buch als Motiv in einem Roman vorkommt, ist im Text mit der Liebe der Figuren zu Büchern zu rechnen. Die Liebe zu Büchern wird in den Romanen häufig durch einen extremen Bücherfreund oder Bibliophilen vorgeführt, der Bücher sammelt sowie gern und viel liest - der Leser, der zu diesem Roman über Bücherfreunde gegriffen hat, kann sich in der bibliophilen Figur wiedererkennen. In diesem Kapitel werden Büchernarren-Figuren vorgestellt, die ein ganz besonderes Verhältnis zu Büchern zeigen, das Büchersammeln aber auch bis hin zu krankhaftem Wahn übersteigern. Diese Büchernarren oder Bibliomanen sind nach dem Vorbild real existenter Bibliophiler gestaltet, so dass die literarische Darstellung dieses Typus auch die Sichtweise auf Vielleser in der Realität beeinflussen kann (vgl. Kap. III.11.7) Doch bietet die Porträtierung der oft manisch an ihren Büchern hängenden Figuren dem Leser ein negatives Beispiel für den Umgang mit Büchern.

Literarische Buchleser- und Bibliomanen-Darstellungen gab es schon in der Spätantike, wohl inspiriert durch die Gelehrtenkultur in Alexandria und der dortigen Universalbibliothek. Die fiktionale Schilderung dieser Figuren kulminiert aber in der Literatur des 18. und 19. Jahrhunderts, als die Buchproduktion vor allem für ein bürgerliches Publikum massiv zu expandieren begann, wo der Buchmarkt doch zuvor ein Markt überwiegend für den gelehrten Leser war. Reste dieser Marktumwälzungen sind noch in der heutigen Romanliteratur in der Figur des gelehrten Lesers und Büchersammlers zu finden.

Büchernarren werden in literarischen Darstellungen durchgehend als männlich dargestellt, was auch der Fall bei den Protagonisten beinahe sämtlicher Korpustitel ist (vgl. Kap. III.11). Der fiktive Büchernarr kann in den Korpustiteln der Protagonist selbst sein, der in den vorgestellten Titeln zumindest bibliophil ist, um das Buch in den Romanen überhaupt zu legitimieren, oder auch eine andere Figur. Die Liebe zu Büchern kann in der Romanhandlung aber auch durch das fiktionsinterne Porträt eines Büchernarren, wie Magister Tinius in Der Buchtrinker, vorgeführt werden. In seiner extremen Form ist ein Bücherfreund ein Büchernarr oder Bibliomane, jemand der eher ,närrisch' nach Büchern ist als nach dem Lesen. In der Benennung steckt schon der Hinweis, dass das Objekt und nicht die Tätigkeit im Vordergrund steht, denn dieser Typus Leser wird als „Büchernarr' bezeichnet, nicht aber als ,Lesenarr'. Er häuft Bücher an, hauptsächlich, um sie zu 
besitzen, die Inhalte zählen weniger. Der Begriff ,Bibliomanie’ wurde vom Wort „Büchersucht’ übernommen. Die Encyclopédie von Diderot und d'Alembert definiert Bibliomanie als „»fureur d'avoir de livres, et d'en ramassere“"368. In dieser Definition wird deutlich, dass Bücher in Besitz gebracht und angesammelt werden, während die Praxis des Lesens außer Acht gelassen wird.

Der Normalleser lässt sich über das Buch definieren, der gelehrte Leser über eine Büchersammlung. Der gelehrte Leser gilt als „Zwangleser“ ${ }^{\star 369}$, der gegenüber dem Normalleser ein professionelles, verpflichtendes Verhältnis zum Buch unterhält, um seine Forschungen voranzutreiben. Ihn quält die Furcht, einen wichtigen Text zu übersehen, da er sich möglichst umfassend informieren und bilden möchte. Unter Umständen spielt auch ein pathologischer Zwang eine Rolle, der sich in eine Bücherwut steigert und mit dem Empfinden verknüpft ist, immer noch zu wenig Bücher zur Hand zu haben.

An dieser Stelle muss allerdings eine Abgrenzung dieser Arbeit zur Wissenschaftler- und Gelehrtendarstellung getroffen werden, wie sie in jüngster Zeit Alexander Košenina mit Der gelehrte Narr. Gelebrtensatire seit der Aufklärung (2003) vorgelegt hat. Darin wird der Typus des Büchernarren zur Abrundung des Gelehrtenbildes geschildert und bietet interessante Beispiele von Büchernarren in der fiktionalen Literatur. Die vorliegende Untersuchung betrachtet das Buch und den Büchernarren, aber nicht, um ihn zu karikieren, sondern um seine Begeisterung für Bücher verstehen zu können. Statt einer Zusammenschau von Gelehrtenfiguren in der Literatur soll gezeigt werden, warum Büchernarren in der aktuellen Literatur thematisiert werden. Zwar sind die Protagonisten aller Korpustitel Büchern zugetan, doch dass die Romanhandlung einen Bücherverrückten ins Zentrum stellt, kommt nur in einigen Fällen vor. Besonders wichtig ist hier das klassische Beispiel des Büchernarren Tinius, dessen Fall schon zu Lebzeiten ein reges Interesse entgegen geschlagen ist und der bis heute von mehreren Autoren u. a. fiktional bearbeitet wurde.

\subsection{Bibliophilie oder Bibliomanie?}

Die Bücherliebe und das Büchersammeln scheinen Voraussetzung für den qualifizierten Umgang mit Büchern zu sein. Die Konvention zeigt, dass jeder Gelehrte ein Büchernarr ist, aber nicht jeder Büchernarr ist auch ein Gelehrter. Doch ist die Zuneigung zu Büchern unterschiedlich stark ausgeprägt. Wo man das Lesen wie ein Handwerk erlernen muss, ist der Bibliophile ein Meister seines Fachs. Aus der Gewohnheit wird ein Bedürfnis, und so kann aus dem Bücherfreund ein Büchernarr werden, bis er als Bibliomane seine Bücher nicht mehr liest, sondern nur noch, weit über den Rahmen der realistisch zu bewältigenden Menge an Büchern hinaus, wahllos anhäuft. 
Der Bibliomane tritt also in zweifacher Ausprägung auf: Als ,gelehrter Narr', der Bücher zu dem Zweck ansammelt, sie auch zu lesen, und der ungelehrte, der Bücher nur besitzen will.

Die Grenzen zwischen dem Bibliophilen und dem Bibliomanen verschwimmen jedoch, immer wieder kommt es zu Überschneidungen und Verschiebungen. G.A. Bogeng definiert in seinem Überblick über historische Bibliophile:

\begin{abstract}
Bibliomanie ist die Kehrseite der Bibliophilie. In den allmählichen Abstufungen einer Bibliofolie wird der Bibliomane aus dem Bibliophilen. Wer will entscheiden, wo der gute Bücherfreund aufhört, sich in den schlechten verwandelnd. Das ist eine Frage der Moral. Und wer will die Grenzen ziehen zwischen dem dummen und dem klugen Sammler; zwischen Wahnwitz und Weisheit; zwischen der Büchertollheit ungestümer Sammler und der Bücherwut krankhafter Veranlagung; zwischen Leidenschaft und Liebe. ${ }^{370}$
\end{abstract}

Der Bibliophile ist ein Bücherliebhaber, der fast immer auch Sammler besonders ausgestatteter, seltener und wertvoller Bücher ist, die er aus Liebe zu den Büchern sein eigen nennt. Die Sammlung ist meist auf ein bestimmtes Gebiet spezialisiert, wie z. B. Handschriften oder Wiegendrucke. Bücherliebe artet schnell in einen Bücherwahn aus, in eine „krankhaft überspitzte Bücherliebe، ${ }^{\text {(371 }}$, in deren Namen Gesetze von Vernunft und Moral gebrochen werden. Der Büchernarr ist kein Sammler von Spezialitäten, sondern bringt alles an sich, dessen er habhaft werden kann. Dabei missachtet er die Moral, indem er für den Besitz der Bücher Verbrechen begeht, sich Bücher kriminell aneignet oder sogar tötet, und die Vernunft durch das wahl- und ziellose Anhäufen von Büchern und die Vernachlässigung seiner Pflichten. Die Bücher bestimmen sein Leben und seinen Alltag, so dass er bald keiner geregelten Tätigkeit mehr nachgeht, dennoch benötigt er finanzielle Mittel für weitere Bücher, was zu seinem Dilemma wird. In der Person eines Büchernarren bündeln sich so die Argumente der Lesesuchtkritik. In moralischem Sinne gelten Magister Tinius und Don Vincente (vgl. Kap. II.4) als schlechte Beispiele, da sie bereit waren, für Bücher zu morden.

Seine Kenntnisse nutzt der Bibliophile zur Buchpflege und Erhaltung kostbarer Bände. Unter dem Vorwand, unersetzliche „Schätze der Wissenschaft ${ }^{\text {‘372 }}$ bewahren zu wollen, versuchte auch Don Vincente seine Taten als hehr und harmlos hinzustellen, blieb aber doch ein Bibliomane. Bibliomanie gilt als „übermäßige Ausschweifung in der Historie der Gelehrsamkeit ${ }^{\star 373}$, doch der Bücherbesitz allein macht noch keinen Gelehrten, worauf der Topos des ,ungelehrten Büchernarren ${ }^{374}$ hinweist, welcher Bücher als reine Sammelobjekte anhäuft, ohne sie zu lesen oder sich

\footnotetext{
370 Bogeng (1922), Bd. 1, S. 499, Anm. 10.

371 Helmut Hiller \& Stephan Füssel: Wörterbuch des Buchs. 7., grundl. überarb. A. Frankfurt/Main: Klostermann, 2006, S. 48.

372 Bogeng (1922), Bd. 1, S. 511.

373 Johann Andreas Fabricius: Abriß einer allgemeinen Historie der Gelehrsamkeit, 1752, nicht eingesehen, zitiert nach Košenina (2003), S. 141.

374 Vgl. ebd., S. 134.
} 
für den Inhalt zu interessieren. Die folgende Übersicht stellt die Charakteristika der Bibliophilie und der Bibliomanie einander gegenüber ${ }^{375}$.

\section{Bibliophilie}

- Büchertollheit

- Unschuldige Liebe

- Liebender Sammler

- Schätzt den Inhalt der Bücher, liest viel

- Verständige Auswahl, achtet auf hohe Qualität

- Wertung des Buchs nach Inhalt und Äußerem, Seltenheit, Ausstattung etc.

- „der Allgemeinheit nützende Buchpflege ${ }^{\text {‘3777 }}$

- Büchersammlung/Bibliothek zu Dekorations- und Repräsentationszwecken, als Beweis für die Gelehrsamkeit des Besitzers
Bibliomanie

- Bücherwut, krankhaft, Kehrseite der Bibliophilie: in Wahnsinn ausartend

- Verderbliche Leidenschaft

- Gieriger Raffer

- Schätzt das Äußere der Bücher, liest nicht alle oder keines seiner Bücher

- Wahl-, sinn-, ziellose, ungeordnete Anhäufung, Quantität, ,bookhunter, der Sammelsport betreibt ${ }^{\text {‘376 }}$

- Wägung und Vermessung, Äußeres und Formales

- Schreckt nicht vor Buchbeschädigung, Diebstahl und Verbrechen zurück, um zur persönlichen Bereicherung in den Besitz der Bücher zu gelangen

- Ungebildeter und Ungelehrter empfindet „Achtung, Angst, Bewunderung ${ }^{6378}$ vor einer großen Büchersammlung. Der Bibliomane kompensiert seine mögliche Unwissenheit durch das Sammeln von Büchern, das im Selbstzweck auf die abenteuerliche Jagd reduziert wird.

Tab. 2: Bibliophilie vs. Bibliomanie

\subsubsection{Umfang der Bibliothek}

Sowohl Bibliomanen als auch Bibliophilen ist an einer möglichst umfangreichen Bibliothek gelegen. Die Bibliomanen häufen an und horten, Bibliophile möchten viele Bücher zur Lektüre und ihrer Exklusivität wegen besitzen. Der Umfang der Bibliothek soll zudem Besucher in Staunen

\footnotetext{
375 Die Darstellung basiert auf Bogeng (1922) Bd. 1, Kap. IX „Bibliomanen“, S. 499-512 sowie Hiller \& Füssel (2006), S. 48f. 
versetzen, denn sie dient auch der Repräsentation von Belesenheit, Geschmack und finanzieller Mittel: „Tatsache ist, dass letztlich der Umfang einer Bibliothek zählt. Wie ein riesiges Gehirn wird diese nämlich unter fadenscheinigen Entschuldigungen und falscher Bescheidenheit zur Schau gestellt. “379 So tragen Büchernarren, zumindest in der Fiktion, leicht Bibliotheken mit einer Bücheranzahl im fünfstelligen Bereich zusammen. Allerdings macht eine große Bibliothek noch keinen Gelehrten, die Bücher wollen auch gelesen sein, so dass sich der Leser auch mit „geistige[n] Erwerbungen “380 schmücken kann. Aus diesem Grund beweist der Bibliomane, der nicht liest, einen falschen Umgang mit Büchern.

\subsubsection{Bibliomanie als krankhafter Umgang mit Büchern}

Košenina erwähnt, dass schon Christoph Martin Wieland die Bibliomanie in einer Lucian-Übersetzung als „eine der unschuldigsten Thorheiten“381 verharmloste. Auch Nicholas A. Basbanes zeigt in seiner Sammlung von Büchernarren und -freunden die Bibliomanie als ,gentle madness" und nach Benjamin Franklin als ,the gentlest of infirmities ${ }^{\text {“382 }}$. Mit ihren verschiedenen Ausprägungen wird die Bibliomanie als Bücher,verrücktheit' jedoch zur krankhaften Veranlagung und Suchterkrankung. Der Typ des Büchernarren wurde, eng verknüpft mit der Lesesuchtkritik, schon immer skeptisch betrachtet und sogar verspottet. Die gängigen Vorurteile gegen den Gelehrten werden auch dem Bibliomanen zugeschrieben, da die Büchersucht besonders häufig unter Gelehrten anzutreffen ist: Über seinen Studien gelinge es ihm nicht, eine Partnerin an sich zu binden, oder er zeigt daran überhaupt kein Interesse, da er die Bücher vorzieht. Zum anderen werden Gelehrter und Bibliomane häufig kränklich dargestellt, was auch in eine geistige Krankheit ausarten kann. Man nahm an, dass die übermäßige Lektüre wegen der Überanstrengung der Augen sowie der mangelnden Bewegung und der krummen Körperhaltung für den ,geneigten' Leser schädlich sei und Erkrankungen fördere. Zudem verzichten Bibliomanen häufig auf Nahrungsaufnahme und Schlaf, um ihrer Manie mehr Raum zu geben. Die Beschäftigung mit Büchern führe, im Übermaß durchgeführt, zu Hirnschäden und darüber zu körperlichen Beschädigungen, der Bücherwurm sei „meistentheils an Seele und Körper verkrüppelt ${ }^{\text {‘383 }}$. Unter Bibliomanen herrsche eine geistige Krankheit vor, die in den meisten Fällen unheilbar ist. Darunter leide er selbst, sei aber unfähig, seine Manie zu überwinden. Zum Bild des Büchernarren gehört auch die Verwahrlosung im Alltag, was sein Äußeres und mangelnde Hygiene ebenso betrifft wie den Mangel an sozialen Beziehungen und in einigen Fällen die Aufgabe von Beruf und Besitz, um ganz für die Bücher leben zu können.

\footnotetext{
379 Domínguez (2006), S. 18.

380 Ebd., S. 17.

381 Vgl. Košenina (2003), S. 134.

382 Nicholas A. Basbanes: A Gentle Madness. Bibliophiles, Bibliomanes, and the Eternal Passion for Books. New York: Henry Holt \& Co., 1995, S. 3.

383 Johann Christian Reil: Nervenkrankheiten, ${ }^{21805}$, nicht eingesehen, zitiert nach Košenina (2003), S. 138.
} 
Das schwerwiegendste Symptom der Bibliomanen ist die Fixierung auf den Besitz bestimmter Bücher, wobei der Büchernarr unterschiedliche Ausprägungen und Spezialisierungen ${ }^{384}$ zeigt. Ein Bibliotaph versteckt seine Bücher als Schätze, die er ganz für sich haben möchte und lediglich hortet. Dadurch, dass er sie wie Wertgegenstände im Tresor wegschließt, entzieht er sie dem lebendigen Gebrauch, für den sie eigentlich vorgesehen sind. So führt er eine „Totenhalle“6385 für Bücher, die nicht gelesen und der Öffentlichkeit vorenthalten werden. Der Biblioklast sammelt Spezialitäten und schreckt nicht vor der Beschädigung von Büchern zurück, wenn er z. B. einen bestimmten Aufsatz oder einen wertvollen Druck benötigt, schneidet er ihn aus dem Buchblock aus. Möglich ist auch eine Zerstörung von Büchern zu Sammlerzwecken, mit Hilfe derer der Biblioklast die Seltenheit seiner eigenen Bücher steigert und sie so aufwertet. Der Bibliokleptomane stiehlt triebhaft, misst den Büchern aber keinerlei Wert bei. Nicht außer Acht gelassen werden sollte, dass es neben dem Büchersüchtigen auch den Bibliophoben gibt, der eine krankhafte Abneigung gegen Bücher zeigt.

Als Psychotherapeut stellt Volker Faust ${ }^{386}$ die große Bedeutung des Buchs für Sozialisation und Persönlichkeitsausbildung eines Menschen fest und bewertet die zwanghafte und einseitige Fixierung auf das Buch als Suchterkrankung. Faust sieht jedoch nicht nur den schädlichen, sondern auch den durchaus heilsamen Effekt der Lektüre, der in Form einer Bibliotherapie genutzt werden kann.

Mit dem speziellen Fall von Magister Tinius befassen sich Frewer und Stockhorst ${ }^{387}$ und belegen die Bibliomanie anhand pathologischer und literarischer Untersuchungen von Tinius' Fall als kulturelles Phänomen. Die Bibliomanie sei nach Philippe Pinel eine auf eine einzelne Idee konzentrierte sog. Monomanie, die psychosomatische Ursachen habe und nach der gründlichen Analyse des Geistes durchaus heilbar sei ${ }^{388}$.

\footnotetext{
384 Vgl. Hiller \& Füssel (2006), S. 48f sowie Volker Faust: „Über den krankhaften und heilsamen Umgang mit Büchern", Homepage Psychosoziale Gesundheit von Angst bis Zwang, ohne Datum, [http://www.psychosozialegesundheit.net/psychohygiene/buecher.html], eingesehen am 18.11.2010.

385 Schweiggert (1989), S. 103.

386 Faust (o. J.).

387 Vgl. Andreas Frewer \& Stefanie Stockhorst: „Bibliomanie als Krankheit und Kulturphänomen. Pathographische Fallstudien zur Rezeption von Magister Johann Georg Tinius (1768-1846)“. In: KulturPoetik. Zs. f. kulturgeschichtliche Literaturwissenschaft 3 (2003), S. 246-262.

388 Ebd., S. 260.
} 


\subsection{Büchernarren in den untersuchten Romanen}

\subsubsection{Klaas Huizing: Der Buchtrinker}

\subsubsection{Magister Tinius}

Eine „Zentralfigur der literarischen Bibliomanie ${ }^{\text {‘389 }}$ ist die Person des historischen Pfarrers Magister Johann Georg Tinius (1764-1846). Um seine Büchersammlung zu mehren und seinem Bücherwahn nachzugeben, hat Tinius zwar keine Bücher entwendet, doch unter Missachtung von Moral und Vernunft Verbrechen begangen. Er hat Urkunden gefälscht und Kirchengelder veruntreut, um an die nötigen finanziellen Mittel für weitere Buchkäufe zu gelangen, und schreckte nicht davor zurück, Menschen zu berauben oder sogar zu töten. Seine Leidenschaft Bücher zu sammeln und seine kriminellen Taten fanden und finden in der Literatur große Beachtung, auch über seine Autobiographie und zeitgenössische Pitavale ist man heute bestens über sein Leben und seine Taten informiert. Der Fall Tinius wurde bis heute auch fiktional häufig behandelt ${ }^{390}$ : In dramatischer Form ${ }^{391}$, den Kriminalfall aufrollend ${ }^{392}$, im Roman, eben in Der Buchtrinker und zuletzt in Detlef Opitz’ Der Büchermörder (2005). Wie Huizing setzt Opitz einen heutigen Helden, den Erzähler, auf die Spur des Büchernarren und reflektiert damit die eigene Neuerforschung des historischen Kriminalfalls. Magister Tinius tritt als einzige Büchernarren-Figur in einem Korpustitel auf, die tatsächlich existiert hat.

Tinius' Fall ist wohl deshalb so bekannt geworden, da man einem Geistlichen eine solche kriminelle Energie nicht zutraut und weil er bis zum Äußersten ging und seiner Bücherleidenschaft Menschenleben opferte. Zur Legende wurde er seinen Zeitgenossen, da er raffinierte Betäubungsmittel (Schnupftabak, Blumensträuße) und Verkleidungen einsetzte, so dass bald abenteuerliche Geschichten über ihn kursierten und er zu einer Schreckensfigur nicht nur für Kinder wurde. Die anhaltende Rezeption zeigt, dass Tinius auch als literarische Figur bis heute reizvoll ist, da sie die Faszination für das Abgründige befriedigt. Seine Geschichte gehört beinahe in den Bereich der Schauerliteratur, hat aber einen realen Hintergrund. In den mit fiktiven Anteilen angereicherten fiktionalen Porträtierungen des Büchernarren wird dargestellt, was in der Realität tabuisiert ist: Ohne Rücksicht auf Verluste jedweder Art Unmengen an Büchern zusammentragen und sogar für

\footnotetext{
389 Frewer \& Stockhorst (2003), S. 248.

390 Weitere Titel über Tinius erwähnt Georg Ruppelt: Buchmenschen in Büchern. Wiesbaden: Harrassowitz, 1997, Anm. 20 zu Kap. V, S. 150.

391 Vgl. Paul Gurk: Magister Tinius. Ein Drama des Gewissens. Bremen: Schlüssel-Verlag, 1946.

392 Vgl. Ernst Arnold: Der Pfarrer und Magister Tinius. Leipzig: Reclam, 1936.
} 
sie töten. So bietet die Geschichte ein Identifikationsangebot für Bücherliebhaber, die tatsächlich nicht alles für Bücher tun würden, aber Tinius' Buch-Leidenschaft nachvollziehen können ${ }^{393}$.

Tinius, das „Bibliomanenungeheuer“ ${ }^{\text {394 }}$, wird in der Literatur ${ }^{395}$ immer wieder mit einem anderen mordenden Büchersammler, mit Don Vincente, dem „Ungeheuer von Barcelona“, in Verbindung gebracht (vgl. Kap. II.4). Beide waren Bibliomanen, die aufgrund der Zwangsvorstellung, bestimmte Bücher besitzen zu müssen, mordeten und somit die Bücher über die Menschen stellten; „Menschen brauchen nicht zu leben; aber Bücher müssen sein. “396 Košenina bescheinigt Tinius eine „pathologisch[e] Besessenheit“ ${ }^{\star 397}$, Bogeng die „Büchersucht ${ }^{\star 398}$. Bogeng ${ }^{399}$ zeigt allerdings den Unterschied auf, dass Tinius die Bücher zwar in großem Stil ansammelte, doch mitnichten der Bücher wegen mordete, und somit nicht als Bibliomane bezeichnet werden könne: „Tinius [...], den einen Bibliomanen zu nennen in jedem Falle seiner Schuld oder Unschuld kein Anlaß vorliegt. Denn er beging seine Verbrechen nicht der Bücher, sondern des Geldes wegen, um sich aus seinen Zahlungsschwierigkeiten zu befreien.“400 Don Vincente als echter Bibliomane dagegen mordete, um in den Besitz von Büchern zu gelangen, was als verwerflicher zu bewerten sei. Tinius unterscheidet von dem ausschließlich für den Erwerb seltener oder kostbarer Bücher mordenden Bibliomanen, dass er die Überfälle beging, um mit dem erraubten Geld seine Schulden abzutragen, die er wegen des Erwerbs von Büchern, ungeachtet seiner finanziellen Möglichkeiten, angehäuft hatte. Dennoch nahm Tinius den Tod seiner Opfer billigend in Kauf.

Don Vincente und Tinius sind echte Prototypen eines Büchernarren, der eine ein ungelehrter, der andere ein gelehrter Büchernarr. Don Vincente will nur besitzen, liest aber nicht. Die Objekte seiner Begierde sind austauschbar und willkürlich gewählt. Tinius hingegen hungert nach den Inhalten, weshalb er auch die Bücher besitzen will. Hunger ist ein Bedürfnis, das zur Lebenserhaltung befriedigt werden muss, und so betrachtet er auch die Bücher als lebensnotwendig. Arno Schmidt schildert in Das steinerne Heræ (1956) eine ähnliche Sicht auf den Büchernarren, der aus der Not heraus zum Mörder werde. Als mildernder Umstand gelte bei ihm die Sucht: „Ich dachte

\footnotetext{
393 Vgl. dazu Frewer \& Stockhorst (2003), S. 262, die Wolfgang Isers anthropologisches Konzept von Literaturrezeption aus Das Fiktive und das Imaginäre (1991) reflektieren.

394 Bogeng (1922), S. 507.

395 U. a. ebd., S. 510; Ruppelt (1997), S. 107; Košenina (2003), S. 138; Opitz (2005), S. 269.

396 Gurk (1946), S. 42.

397 Košenina (2003), S. 139.

398 Bogeng (1922), S. 509.

399 Vgl. ebd., S. 507-10 zu Tinius. Eine Bibliographie zu Tinius findet sich in Bd. 3, S. 248.

400 Ebd., S. 510. - Diesen Verweis stellt auch Rainer Schmitz her, vgl. Rainer Schmitz: Art. „Tinius, Johann Georg"'. In: Ders.: W as geschah mit Schillers Schädel? Alles, was Sie über Literatur nicht wissen. Frankfurt/Main: Eichborn, 2006, S. 1442f., hier S. 1443.
} 
lange an den Magister Tinius, den Bücherverfallenen, der mit seinem Hammer durch die öden Heiden des Fläming schlich: wenn Andere das Geld haben, und er braucht doch die Bücher?!، ‘01

Tinius” „Bücherei des Verbrechens““402 zählte etwa 17.000 Bände, in Gurks Drama liest man allerdings die weit höhere, exakte Zahl von $31.473^{403}$, Schmitz schätzt den Umfang auf „,zwischen dreißig- und sechzigtausend Bücher" ${ }^{\text {“404. }}$. Für die Bücher mietete er mehrere Lagerräume an, die noch zusätzliche Mietkosten verschlangen. Nach seiner Verurteilung wurde die ganze Bibliothek versteigert, auch Goethe soll einige Bände erstanden haben. Tinius soll seine Bücher alle bis zur „Inbesitznahme “405 auswendig gekannt haben, so dass ihm als fleißiger Leser, der er war, auch in Haft der Inhalt seiner Bibliothek geblieben ist. Dort verfasste er seine Auslegung der JohannesOffenbarung - ein theologisches Trend-Thema der Zeit - und Schriften zum Jüngsten Tag 406 ohne Hilfsmittel aus dem Gedächtnis.

Die Literatur zu Tinius, auch die fiktionalen Werke, greifen auf dieselben Quellen zurück und orientieren sich stark aneinander, bieten aber auch Einblicke in unterschiedliche kulturelle Diskurse, wenn die krankhafte Bibliomanie u. a. kriminalanthropologisch, soziologisch oder als teufelsbündlerisch erklärt wird ${ }^{407}$. Zeitgenössische Beiträge aus der Gartenlaube ${ }^{408}$ sind beinahe Wort für Wort in Arnolds Porträt des historischen Rechtfalles zu finden, der wiederum in Gurks Drama einfließt und zitiert in Der Buchtrinker zu finden ist. Bei Arnold in Der Pfarrer und Magister Tinius (1936) steht die Tatsache im Vordergrund, dass Tinius als Geistlicher zum Räuber und Mörder wurde. Sein Bücherwahn ist zweitrangig und wird als Erklärungsversuch für seine Taten vernachlässigt, denn „[s]eine Lieblingsneigung schien, an sich betrachtet, unschuldig zu sein.““409 Die Neigung zu Büchern an sich ist tolerabel, lobenswert sogar, als verwerflich wird aber beurteilt, dass sich Tinius als Pfarrer von einer einzigen Neigung beherrschen und diese sogar in Leidenschaft auswachsen ließ. Der Kontrollverlust, der mit seiner Leidenschaft einherging und vor dem Verstand, Bildung und Priesteramt bewahren sollten, führte ihn zu verbrecherischen Taten. Lesen und Bücherliebe sind eigentlich positiv konnotiert, und es erschien den Zeitgenossen unerklärlich, wie ein kultivierter Bücherfreund zu diesen Verbrechen fähig war. Wo Arno Schmidt zu erklären, zu

\footnotetext{
401 Arno Schmidt: Das steinerne Her:. Historischer Roman aus dem Jabre 1954. [Zuerst 1956] Frankfurt/Main: Fischer, 1991, S. 158.

402 Bogeng (1922), S. 509.

403 Gurk (1946), S. $20 f$.

404 Schmitz (2006), S. 1442.

405 Karger (o. D.)

406 Eine vollständige Tinius-Bibliographie findet sich bei Huizing (1996), S. $191 \mathrm{f}$.

407 Vgl. Frewer \& Stockhorst (2003), S. 259.

408 E. Fließ: „Das Ende des Magisters Tinius“. In: Die Gartenlaube. Illustrirtes Familienblatt H. 21 (1893), S. 346ff. \& Eduard Schulte: „Ein Verbrecher aus Bücherwut“. In: Die Gartenlaube. Illustrirtes Familienblatt H. 5 (1893), S. 76ff \& H. 6 (1893), S. 88-92.

409 Huizing (1996), S. 144 \& Arnold (1936), S. 23.
} 
verstehen und beinahe zu beschönigen versucht, wird Tinius in älteren Bearbeitungen als durch und durch schlecht hingestellt und die Frage nach seiner Motivation außer Acht gelassen.

Das Drama Magister Tinius, Ein Drama des Gewissens (1946) von Paul Gurk, das bereits in den 1930er Jahren erfolgreich aufgeführt wurde, spielt 1839 und fiktionalisiert Tinius nicht als Geistlichen, sondern zunächst als gnadenlosen Raubmörder. Diese Darstellung kippt in den folgenden Akten, wo er als „faustischer Charakter“410 gezeigt wird, dessen Teufelsbund ihn ins Verderben zog. Seine Bücherlust und Gewissenlosigkeit werden mit dem Streben nach Wissen erklärt. Die Sache des Buchs und somit des Geistes rechtfertigen seine Taten, die er in seiner Eigenschaft als bücherliebender Schöngeist begangen hat. Als Gelehrter, der zu schier unglaublichen Gedächtnisleistungen fähig war, wird er nun bewundert und als Märtyrer des Buchs gesehen. Im Drama werden Tinius Bonmots in den Mund gelegt, die den Stellenwert der Bücher für ihn als Freunde und Vertraute, Erzieher, Trost, Fürsorge, Heimat und Refugium verdeutlichen. Bücher seien Teil der Schöpfung, aber mehr wert als Menschen. Im Sinne der Aufklärung begründet er dies mit der Erschaffung der Bücher aus des Menschen Verstand. Košenina ${ }^{411}$ stellt sich die Frage, wie die zeitgenössischen Zuschauer und Leser in den 1930ern wohl auf die Tatsache reagiert haben, dass Tinius seine Taten aus einer falschen, aber für wahr gehaltenen Ideologie heraus begründet.

In Der Buchtrinker schildert Huizing die Geschichte eines „Mörders aus Bücherwut ${ }^{\star 412}$ und macht damit als einzige fiktionale Tinius-Darstellung die Bücherwut ganz explizit zum Thema. Wo in der übrigen Literatur eher von dessen „Büchersucht“ zu lesen ist, ist der moderne Terminus „Kaufsucht ${ }^{\text {“413 }}$ bei Huizing singulär. Das Buch als Objekt der Begierde wird so allerdings relativiert. Zwar gehören zu Tinius' Geschichte auch die Verbrechen, Huizing erzählt aber primär die Geschichte von Tinius' Bücherliebe, kommentiert sie und stellt sie in Zusammenhang mit der Geschichte eines fiktiven heutigen Büchernarren mit dem Ziel, das richtige Lesen und den falschen Umgang mit Büchern vorzuführen und vor einem Überhandnehmen digitaler Medien zu warnen.

Nicht durch das Lesen wird Tinius zum Autor, vielmehr verfolgt er zwei Karrieren: Als Geistlicher verfasst er seine theologischen Schriften, Leser ist er im Privaten. Schon als Kind zeigte er Begeisterung für das Buch „Sittensprüche des Buchs Jesus Sirach für Kinder und junge Leute aus

\footnotetext{
410 Košenina (2003), S. 140.

411 Ebd.

412 Huizing (1996), S. 13. - Die Umschlagabbildung von Der Buchtrinker zeigt eine Verfremdung von Johann Friedrich Schellenbergs Kupferstich Freund Heins Erscheinungen in Holbeins Manier (1785), der bei Košenina (2003), S. 159, im Original abgebildet wird. Darauf sieht man, wie der Tod in Gestalt eines Skeletts ein Bücherregal umstürzt, so dass die Bücher auf einen lesenden, am Tisch sitzenden Büchernarren herabfallen. Der Umschlag von Der Buchtrinker zeigt anstelle des Büchernarren einen Geistlichen. 
allen Ständen mit Bildern welche die vornehmsten Wörter ausdrücken““414. Die Hausbibliothek der Eltern war pietistisch ausgerichtet und überschaubar, denn ein Buch im Haushalt zu haben bedeutete etwas Wertvolles, Kostbares, Besonderes. Dabei ist das intensive Lesen im Buch für den jungen Tinius eine Alltagsflucht, bei der er sich in einen anderen verwandelt. Das Klischee des Eskapismus beim Lesen wird hier ganz deutlich: Er flieht vor den ungeliebten Geschwistern und dem kalten Elternhaus in eine Welt, die ganz ihm gehört. Fern der Familie im Studium übernehmen Bücher „als Pflegeeltern“415 seine Erziehung. Seine Bücherliebe beschert ihm das Wohlwollen von Pfarrer und Lehrer, durch seine Bildung wird er „,vornehm“416, während seine Geschwister „bücherscheu“ “417 bleiben, ein Neologismus in Analogie zu ,wasserscheu’ sein: etwas ablehnen, weil man es fürchtet. Als Geistlicher macht Tinius rückblickend die Vorsehung für seine Veranlagung und seine Taten verantwortlich. Bei Huizing wird Tinius' Prädestination für Gelddiebstahl und Buchkaufsucht ironisierend aus dem Familiennamen abgeleitet (lat. tinnire: mit Geld klimpern, zahlen). Tinius hob sich durch seine Bücherliebe zeitlebens von seiner Umgebung ab und wurde durch sie zwar zum Mörder, seine Mitmenschen zeigten aber auch Ehrfurcht und Respekt vor seiner Gelehrsamkeit. Er zeigte eine richtige Art zu Lesen, da er völlig in den Büchern versank und intensiv und genau las, jedoch einen denkbar falschen Umgang mit Büchern.

\subsubsection{Falk Reinhold}

„Reinhold, der Büchernarr“4418, der zweite Protagonist in Der Buchtrinker, definiert sich als büchersüchtiger, moderner Konterpart zu Tinius, bis er völlig im neuen Medium PC aufgeht. Zu seiner Charakterisierung dienen zwei Episoden besonders: Aufgrund des begrenzten Platzes in seiner Studentenbude muss sich Reinhold auf 20 Bücher für sein Bücherbord beschränken. Die Beschreibung der Auswahl und Behandlung seiner Bücher führt einen zwanghaften, beinahe pathologischen Büchernarren vor, der einen übertrieben sorgsamen Umgang mit den Büchern an den Tag legt. Reinhold wird darüber hinaus als Karikatur eines Bücherfreundes gezeigt, die auf Carl Spitzwegs Gemälde Der Bücherwurm (1850) anspielt: „Das ausgesichtete Buch unter den linken Arm geklemmt, schaute er die Spitze des Bücherberges durch, hielt ein Buch mit den Knien fest und blätterte versonnen in einem dritten.“ ${ }^{419}$.

Eine weitere Episode im Antiquariat führt vollends seinen Bücherwahn vor. Sowohl bei Tinius als auch Reinhold übersteigen die Ausgaben für Bücher die finanziellen Möglichkeiten, sie

\footnotetext{
414 Bilder ersetzen darin die Substantive, wie noch heute in einigen Buchreihen für Leseanfänger, z. B. in der Reihe „Bildermaus" bei Loewe.

415 Huizing (1996), S. 57.

416 Ebd., S. 58.

417 Ebd.

418 Ebd., S. 24.

419 Ebd., S. 43.
} 
lesen über ihre Verhältnisse. Um im Antiquariat angesichts seines begrenzten Budgets für Bücher eine Auswahl treffen zu können, muss Reinhold als „Bücherbergkumpel“420 die „Geologie des Bücherberges“421 abtragen. Hier zeigt sich eine Anspielung auf psychologisierende Erzählungen der Romantik wie z. B. Ludwig Tiecks Runenberg (1804): Das Eindringen in den Berg wird gleichgesetzt mit dem Eindringen in die Psyche. Gleichzeitig wird im Text aber auch ein Seitenhieb auf die Psychologie unternommen, der man nicht trauen könne.

Es bleibt offen, warum „der früh gereifte Büchernarr“ ${ }^{\text {‘ } 22}$ aus vier vorausgewählten Werken seine Wahl für Tinius' Autobiographie trifft. Die Situation der Auswahl und die endgültige Entscheidung für das Buch bestimmen die Ausweitung seines Bücherwahns und somit den Fortgang der Erzählung: „Psychologische Untersuchungen zum Bücherwahnsinn sprechen hier von einem Initialerlebnis, dessen innere Struktur den Verlauf des Wahns bestimme.“423 Der Erzähler geht also fest davon aus, dass Reinholds Büchersucht pathologisch sein müsse. Aber was genau war dieses Initialerlebnis? Bücher gekauft hatte er ja auch schon zuvor. Ist es die knappe Auswahl unter vier gleichwertig geschätzten? Dass Tinius der einzige ihm unbekannte Autor und das Buch das preiswerteste der Auswahl war, hat vielleicht die Entscheidung für das Buch gegeben, das die Begeisterung für den historischen Büchernarren und die Suche nach weiteren Tinius-Titeln initiiert. Seinem historischen Vorbild wird er dabei immer ähnlicher, zum einen, wenn er ebenfalls beim Lesen die Texte auswendig lernt, zum anderen, wenn er für das Erlangen eines Buchs Gewalt anwendet.

In Der Buchtrinker kommen auch die Bücher selbst zu Wort. Reinhold findet im Antiquariat ein Buch, das er dem Ex-Libris nach der Tinius-Bibliothek zuordnen kann, und an dessen Einband ein anderes Buch anhaftet. Beide Bücher berichten von ihren Schicksalen. Diese Vermenschlichung von Büchern soll vermutlich die Sympathie der Leser wecken und sie zu einem besseren Umgang mit Büchern führen. Das Tinius-Buch erzählt von der Geschichte, die Bücher haben, und die an ihre Besitzer und ihre Aufenthaltsorte gebunden ist. Der Besitzer und seine Bibliothek, aber auch der literarische Gehalt der Texte kennzeichnen den sozialen Status der Bücher, der bei Büchern aus Tinius’ Bibliothek getrübt ist: „Wissen Sie, was es heißt, das Buch eines bigotten Mörders zu sein?“424 An dieser Stelle könnte man auch „Angehöriger“ des Mörders lesen, denn die vermenschlichten Bücher betrachten den Käufer als Vater und freunden sich untereinander an. Das unbenannte antiquarische Buch ist ein Ladenhüter, der schließlich als Remittende 
auf dem Wühltisch landet. Diese degradierten Bücher tragen das „Kainsmal“425 der Makulatur und werden so zu büchernen Mauerblümchen, für die niemand Interesse aufbringt. Ihr ramponiertes Äußeres verhindert die Bindung an, sprich, den Erwerb durch einen interessierten Leser, was in der Fiktion noch einmal die Existenz verschiedener Klassen von Büchern unterstreicht.

\subsubsection{Carlos María Domínguez: Das Papierhaus}

Jede einzelne Persönlichkeit in Das Papierhaus steht im Bann der Bücher und hat sie zum Mittelpunkt des Lebens gemacht: Bluma hat dem Lesen ihr Leben geopfert, als sie durch die Lektüre abgelenkt von einem Auto überfahren wurde, der Ich-Erzähler sammelt, aber nicht exzessiv, der elegante Bibliophile Delgado vereint seine Bücher stilvoll in Vitrinenschränken, liest aber auch viel, wenn auch im geordneten Rahmen eines Stundenplans, der Bibliomane Brauer schließlich ist ein fanatischer Büchernarr, dessen Sammlung und damit sein Leben nur noch Sinn über die Ordnung seiner Bibliothek erhält.

Nachdem zwar nicht die Bücher selbst, doch der Katalog zu seiner kostbaren Privatbibliothek in Flammen aufgegangen und er so eines zuverlässigen Ordnungssystems beraubt ist, gerät Brauer in Verzweiflung, da er nicht mehr imstande ist, einen Überblick über seine Bibliothek zu finden. Als Bibliomane, aber auch exzessiver Leser, geht ihm die Ordnung seiner unzähligen Bücher über alles. In der Konsequenz gibt er seine Bibliothek auf und baut sich auf einer Düne in einer Lagune vor Montevideos Strand ein Papierhaus: Ein Haus, statt aus Ziegeln errichtet aus seinen Büchern. Mit dem Bau des Papierhauses sind alle bisherigen Ordnungsprinzipien für Bücher außer Kraft gesetzt. Keine exzentrischen Kriterien wie Dichterfeindschaften für die Anordnung der Bücher zählen mehr, für den Bau eines möglichst stabilen Hauses sind nur noch Äußerlichkeiten wie Größe oder Umfang der Bücher entscheidend. Der passive Leser wird vom theoretisch-analytisch Ordnenden zum praktisch vorgehenden Handwerker, indem er seine Bücher für das Papierhaus einer rein äußerlichen, praktischen Bestimmung zuführt.

Für Brauer haben die Bücher nun keinen geistigen Wert mehr und werden zu profanen Gegenständen, zu Bausteinen seines Hauses umfunktioniert. Inhalt und ideeller Wert der Bücher werden völlig ignoriert, was nun noch zählt, sind ihre äußeren Eigenschaften. Dies ist eine Sichtweise, die jedem Bücherfreund, der häufig nicht einmal ein Eselsohr in seinem Buch duldet, widerstreben muss. Auch der Ich-Erzähler wird auf das ,Buch im Buch’, dass die Geschichte erst voranbringt, nur dank seines Äußeren aufmerksam, da er es mit Zement verkrustet im Nachlass seiner Kollegin Bluma findet und seinem Besitzer zurückgeben möchte. Bücher werden aus ihrem ästhetischen Kontext gelöst und als Gegenstand nutzbar gemacht. Als der Erzähler an besag- 
tem Strand eintrifft, ist Brauer fort und das Haus von den Wellen zerstört. Mit dem Auffinden des Papierhauses ist die Suche beendet, der Kreis hat sich geschlossen.

Die Geschichte des Bibliomanen Brauer ist ein Abgesang auf den Büchersammler des alten Typs, wie er heute beinahe ausschließlich noch in der Fiktion vorkommt, und die ,alte' Art, Bücher zu sammeln und mit ihnen umzugehen. Bücher werden in der Fiktion zu Objekten degradiert und zweckentfremdet, doch diesen neuen Zweck, Obdach zu bieten, können sie nicht erfüllen, da das Papierhaus von den Wellen aufgeweicht und zerstört wird. Gelöst von der Fiktion bedeutet dies, dass die Privatbibliothek weitgehend an Bedeutung verliert, denn Inhalte können auch auf andere Weise, nämlich digital, verbreitet und konsumiert werden.

\subsubsection{1 „Sammler“ und „Leser durch und durch“}

In Das Papierhaus werden Bücherfreunde in zwei Gruppen eingeteilt. Es ist in der Fiktion von „zwei Sorten von Menschen““426 die Rede, als gelte diese Charakterisierung für alle Menschen, dabei sind doch nicht alle Leser.

Sammler betrachteten Bücher als kostbare Stücke, die sie in großem Stil ansammeln, wobei sie nach seltenen Publikationen und erlesenen Ausstattungen suchen. Auch der Wert spielt eine Rolle. Delgado, der Ästhet und „Sybarit des Buches““427, legt bei der Auswahl der Bücher Wert auf Exklusivität und besten Erhaltungszustand. Er lebt nicht wie Brauer inmitten seiner Bücher, sondern hortet die Bücher in einer Wohnung, die er eigens für die Bibliothek angemietet hat, in der er sich zu festen Zeiten aufhält und nach einem Stundenplan liest. Familie und Bücher sieht er als gesonderte Territorien, die unterschiedliche Bereiche seines Lebens ausmachen und hält sie daher strikt getrennt, da das Familienleben die Bücher sonst „beschmutzen würde“ ${ }^{\text {‘428 }}$ - die Bücher ersetzen ihm nicht die Familie, er schätzt sie aber höher. Die Bibliothek ist seine „Höhle ${ }^{\text {‘429 }}$, in die er sich zurückzieht und die ihm Abschottung und Schutz bietet.

„Leser durch und durch "430 ist Brauer, der beinahe zwanghaft liest, studiert, verstehen will und sich die Texte durch ausgiebige Notizen erarbeitet. Lesen betrachtet er nicht nur als Genuss, sondern auch als Arbeit, denn er strebt zum tief liegenden Sinn der Bücher. Auf der anderen Seite ist er ein gieriger Raffer, der unkontrolliert sammelt und so eine beachtliche Bibliothek zusammenträgt, ohne auf den finanziellen Aufwand zu achten. So wird er zum „Eroberer“431, der Verantwortung für die erworbenen Bücher übernimmt und sie verwaltet. Er zeigt eine Manie für die 
Katalogisierung und lässt seinen Büchern eine „Ordnung der Emotionen“ “432 angedeihen, bis ihm die Kontrolle entgleitet, so dass nun die Bücher die Kontrolle über sein Leben übernehmen. Für ihn ist nicht der Erhalt des Bestehenden wichtig, sondern die Anhäufung von Neuem.

Beide Büchernarren verbinden mit dem Lesen eine übersteigerte Ästhetik als Lustgewinn. Bei der Lektüre sollen möglichst alle Sinne angesprochen werden, und so werden die Romane des 19. Jahrhunderts bei Kerzenschein genossen, wird als Ergänzung der genussvollen Lektüre eine zeitgenössische Oper gehört und ein zweites Glas Wein für den Protagonisten bereitgestellt. Dieses Szenario wirkt übertrieben und überspannt, der Büchernarr lebt nicht mehr in der Realität, sondern ausschließlich in der Lebenswelt seiner Romane.

Wo Bücher derart in den Mittelpunkt des Lebens rücken, geraten sie zum Fetisch, der nichts anderes mehr zählen lässt, der Fanatismus ist zum Greifen nahe. Letztlich führt die übergroße Liebe zu den Büchern zu Realitätsverlust, schlimmstenfalls zur Zerstörung eines Menschen, sobald er sich in ihren Bann begibt und sich verschlingen lässt. Dafür steht auch die letztliche Zerstörung des Papierhauses: Eine Warnung an die Büchernarren, sein Herz nicht nur an das Objekt zu hängen, sondern sich mehr am Inhalt zu erfreuen.

\subsubsection{Das ,Buch im Buch' - Die Schattenlinie}

Das ,Buch im Buch’ in Das Papierbaus stellt der Roman Die Schattenlinie. Eine Beichte (1917) von Joseph Conrad dar. Dies ist einer der seltenen Fälle, in dem ein real existenter Roman in einem Buch-Roman des Korpus erwähnt wird. Das Buch gehört Brauer, der es an Bluma verschenkt, ihr Kollege, der Ich-Erzähler, findet es wiederum in deren Nachlass und bringt es nach Argentinien zurück. Dort erzählt ein bibliophiler Freund Brauers über dessen Erlebnisse. Das Buch löst die Handlung aus, da sich der Ich-Erzähler nach dem Fund auf den Weg nach Südamerika macht, wo er der Geschichte des Bibliomanen begegnet. Das Buch hat auch auf den Ich-Erzähler selbst Einfluss, da er mit dem Geschehen um Brauer konfrontiert wird, von dem ihm allerdings nur berichtet wird, dabei bleibt er ausschließlich Beobachter und Protokollant. Mit dem Erzähler der Schattenlinie teilt er die Erzählstimme und die Namenlosigkeit.

Der Inhalt der Schattenlinie wird fiktionsintern nicht erwähnt oder reflektiert, in manchen Passagen scheint er aber als Subtext durch. Die Überschreitung einer Schattenlinie bedeutet die Übertretung einer ideellen Grenze, die ein Mensch um sich gezogen hat, aber ständig neu definiert. Ist diese Grenze überschritten, ändert sich alles. Das Leben wird dann mitunter als sinnfrei und unbedeutend empfunden. Daraus resultieren unbedachte Entschlüsse, bevor eine Wende eintritt, die Tatkraft mit sich bringt, ähnlich wie die Initiation ins Erwachsenendasein, Wachstum und Reife. 
Die Figuren in Das Papierhaus sind mit einer Überschreitung ihrer Schattenlinie konfrontiert. Der Ich-Erzähler überquert nicht nur den Äquator, es findet auch ein Wechsel von seinem beschaulichen Leben in Cambridge nach Südamerika statt, wo er in das Leben eines völlig Fremden eintaucht. Blumas Schattenlinie wird von Brauer übertreten „mit seiner Brutalität, mit seiner Ver-

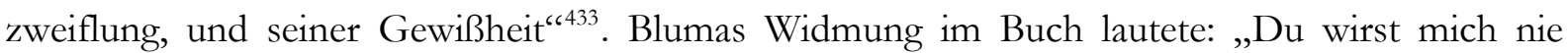
überraschen können“434 - war dies Anlass für ihn, Neues zu wagen? Ihre Gewissheit, dass er immer der Alte bleiben würde, wurde Lügen gestraft: Es hätte sie wohl überrascht, dass er seine Einstellung zu seinen Büchern völlig ändert. Brauers eigene Schattenlinie ist überschritten, als der Katalog und damit die Ordnung seiner Büchersammlung zerstört wird, und die Bücher aufgrund ihrer Menge zur unkontrollierbaren Last werden. Ein Leben wie bisher ist nun unmöglich, vom Träumer wird er zum Handelnden, vom Leser zum Tatkräftigen. Er muss, wie die Schiffsmannschaft im zugrunde liegenden Roman, den ,Fluch’ der Schattenlinie brechen, indem er das Haus baut und seine Bücher einer Bestimmung zuführt.

Auch ein Buch selbst besitzt mit seinen zwei Seiten eine Schattenlinie: Auf der einen Seite sein ideeller Inhalt, auf der anderen sein Wesen als Objekt und seine Eigenschaft als Medium. Die Schattenlinie des Buchs ist „eine unbekannte Dimension, die Inhalt und Medium des gedruckten Wortes in einem merkwürdigen Spiel vereint.“435

\subsubsection{Alfons Schweiggert: Das Buch}

Der Protagonist Bibli, ein „unverbesserlicher Büchernarr“" und „Sonderling،“436, ist stolz darauf, ein Bibliophiler und kein Bibliomane zu sein, „der nur auf den Besitz des Außergewöhnlichen aus

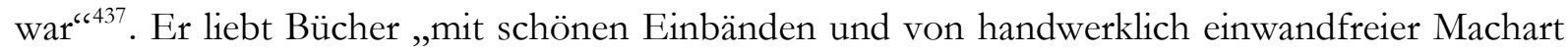
[...]. Im Gegensatz zum Bibliomanen, der nie das Innenleben seiner Schätze kennenlernen will, las er jedes seiner Sammelstücke. ${ }^{“ 438}$ Ermordet wird von Bibli in Buchgestalt daher der Bibliotaph, der Bücher nur als kostbare Wertgegenstände schätzt, sie nicht liest und sich nicht mit ihnen auseinandersetzt. Der Erzähler stellt aber durchaus „Bibliomanie“ ${ }^{\text {‘39 }}$ bei Bibli fest, denn er kauft verschwenderisch, entscheidend ist das Erscheinungsbild der Bücher, wobei er äußerliche, ästhetische, künstlerische, aber durchaus auch inhaltliche Auswahlkriterien ansetzt. Als Biblio-

\footnotetext{
433 Domínguez (2006), S. 96.

434 Ebd., S. 12.

435 Ebd., S. 74.

436 Schweiggert (1989), S. 50.

437 Ebd., S. 19.

438 Ebd.

439 Ebd., S. 48.
} 
mane kann sich Bibli durchaus vorstellen zu morden, um in den Besitz eines Buchs zu gelangen, wie Don Vincente, der von einer „fast krankhaften Sucht nach Bücherbesitz““440 befallen war.

\subsubsection{Arturo Pérez-Reverte: Der Club Dumas}

Der Büchernarr in Der Club Dumas ist nicht der Protagonist, der ein äußerst prosaisches Verhältnis zu Büchern pflegt und sie hauptsächlich als lukrative Einnahmequelle betrachtet, sondern ein Büchersammler, bei dem er ein echtes Exemplar des Buchs der neun Pforten erwartet. Victor Fargas ${ }^{441}$ sagt von sich, „ich bin kein Bibliophiler, ich bin ein Bibliomane “442. Die Selbsteinschätzung der Figur deckt sich mit der Definition beider Bücherfreunde. Es wird geschildert, dass er verarmt ist, aber nach wie vor das heruntergekommene Familienanwesen unterhält, um die große, kostbare Bibliothek zu erhalten. Um sich vor dem Ruin zu bewahren, könnte er diese veräußern, daran hindert ihn aber seine übergroße Bücherliebe: „Aber wenn ich das alles verkaufen würde, hätte mein Leben keinen Sinn mehr, und wozu bräuchte ich dann noch Geld?‘ ${ }^{443}$ Für seinen Lebensunterhalt verkauft er nur drei bis vier Exemplare im Jahr, Situationen, die er mit Abrahams Opfer vergleicht. In Hinblick auf Bücher gebe es keine „Moral im herkömmlichen Sinne“ ${ }^{\text {(444 }}$, und Fargas verweist wiederum auf Don Vincente: „Bei Ihnen in Spanien erzählt man sich doch die Legende von dem mörderischen Buchhändler aus Barcelona - nun, ich wäre wie er in der Lage, für ein

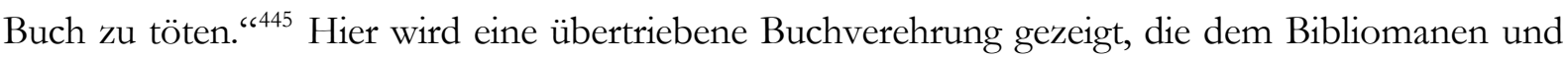
seinen Lebensumständen selbst zum Nachteil gereicht.

\subsection{Richtiger und falscher Umgang mit Büchern}

Die genannten Beispiele der Bücherschändung (vgl. Kap. III.3.1.4.2) sind im Verhältnis gesehen nur Beschädigungen kleinen Stils. Bücherverbrennungen als Zerstörung des Geistes, der die Bücher hervorgebracht hat, sind bereits an anderer Stelle ${ }^{446}$ ausgiebig behandelt worden und sollen hier nicht von Belang sein. Auch die ,brennende Bibliothek' ist ein in dieser Arbeit nicht diskutierter Topos, der immer wieder in der Literatur anzutreffen ist, so auch bei Canetti, Eco u. v. a., wohl zurückgreifend auf den Brand der antiken Universalbibliothek von Alexandria.

\footnotetext{
440 Ebd., S. 47.

441 Pérez-Reverte (1997), S. 174-189.

442 Ebd., S. 178.

443 Ebd., S. 182.

444 Ebd., S. 183.

445 Ebd.

446 U. a. in Jürgen Serke: Die verbrannten Dichter. Lebensgeschichten und Dokumente. Weinheim etc.: Beltz u. Gelberg, zuerst 1977.
} 
Bibliophile und Bibliomanen in Fiktion und Realität sind sich nicht einig darüber, wie der richtige Umgang mit Büchern aussieht ${ }^{447}$. Für den Bibliophilen ist natürlich besonders wichtig, dass seine Bücher in einem guten Erhaltungszustand sind, dass sie pfleglich behandelt werden. Dem Bibliomanen ist der Zustand nicht wichtig, solange die Bücher selten, kostbar, besonders sind und er sie in großer Zahl ansammeln kann. Schweiggerts Protagonist in Das Buch geht auf die Schändung von Büchern ein: „,[Bibli] dachte an Voltaires Barbarei, aus Büchern die ihm zusagenden Seiten oder Seitenhälften herauszureisßen und zu neuen Büchern zusammenzukleben. “448 Für Bibli ist dies eine Vorstellung Frankensteinschen Ausmaßes. An anderer Stelle wird allerdings betont, dass nur diejenigen Leser Bücher wirklich lieben, die sie benutzen und Notizen und Anstreichungen vornehmen. Der Ästhet Delgado in Das Papierhaus legt ebenfalls Wert auf makellose Bücher, während sein bibliomanes Gegenstück Brauer die Bücher mit Notizen versieht und so seine wertvollen Ausgaben verunstaltet, aber auch mit praktischem Wert auflädt.

Auch Georg Ruppelt lehnt handschriftliche Anmerkungen in Büchern ab. In seiner Sammlung über Buchmenschen in Büchern ${ }^{449}$ versammelt er alle Punkte, die ästhetischen Bücherfreunden am Umgang mit dem Buch missfallen, so Beschmutzungen an Buchumschlag und -seiten, ausgerissene Seiten, Einleger in Büchern, die das Buch beschädigen können, Bücher, die aufgeschlagen liegen gelassen werden. Zur Illustrierung führt er historische und literarische Belegstellen zu „Buchschändern“"450 an z. B. aus dem Philobiblon ${ }^{451}$ von Richard de Burys aus dem 14. Jahrhundert, das eine mittelalterlich-christliche Bibliotheksidee vermittelt. Darin wird erstmals schriftlich festgehalten, was später zum ungeschriebenen Gesetz im äußeren Umgang mit Büchern wurde.

Daniel Pennac revidiert in Wie ein Roman (1992) mit seinen bekannt gewordenen ,unantastbaren Rechten des Lesers“ z. T. die strengen Vorgaben, was die Art zu lesen angeht. Diese zehn Regeln sollen dem Leser mehr Freiheiten geben und ihm die Lust am Lesen erhalten, z. B. wird dem Leser das Recht gegeben, irgendetwas zu lesen, auf das er gerade Lust hat, das Recht, Buchseiten zu überspringen oder einen Text erneut zu lesen, es soll aber auch einfach das Recht zugestanden werden, nicht zu lesen. Der Leser wird so von jeglichem Zwang das Lesen betreffend befreit, er muss sich nicht mehr mit Bestsellern quälen, die ihm die Lese(r)gemeinschaft als (Pflicht-) Lektüre vorgibt, oder zum Lesen gezwungen werden, denn „das Verb ,lesen’ duldet keinen Imperativ ${ }{ }^{452}$. Quintessenz ist, dass der Leser lesen darf und soll, was und wie er es für richtig hält, und somit seine Art zu lesen und seine bevorzugte Lektüre selbst finden soll, entscheidend ist, dass er

\footnotetext{
447 Vgl. auch Löffler (2005), S. 16.

448 Schweiggert (1989), S. 75.

449 Ruppelt (1997), Kap. V „Von Bücherschändern und Bücherdieben“, S. 83-117.

450 Ebd., S. 84

451 Über das Philobiblon vgl. auch Rieger (2002), S. 66-70.

452 Daniel Pennac: Wie ein Roman. Köln: Kiepenheuer \& Witsch, 1994, S. 13
} 
überhaupt liest. Dieser Maxime entspricht, dass heute vorwiegend Bücher nach dem Lesergeschmack produziert werden (vgl. Kap. IV.3.2.1) Die liberalen Vorschläge, die Lesern die Möglichkeit geben, sich nach eigenem Gutdünken und Geschmack mit einem Buch auseinanderzusetzen, nimmt Pennac durch neue, aber doch ganz alte, beinahe dogmatische Richtlinien für den korrekten, respektvollen Umgang mit dem Buch wieder zurück. Die angeführten Tabus im Umgang mit dem Buch decken sich mit den bei Ruppelt genannten.

Laut Sigrid Löfflers Einschätzung aus dem Jahr 2005 florieren „Benimmbücher über das Lesen“ sowie „Ratgeber mit Tipps, was und wie man lesen soll“453. Dabei vermischt sie allerdings Leseanleitungen oder -anregungen mit Anleitungen zur Kunst des Umgangs mit dem Buch, die offensichtlich notwendig sind, da der Normalleser nicht mehr korrekt mit dem Buch umzugehen weiß, ausgelesene Buchseiten einfach ausreißt und sich sonst vermeintlich ungehörig verhält. Die Autoren dieser Anleitungen sorgen sich laut Löffler um die Lesekultur: „Manche Verhaltensmaßregeln lesen sich wie Idiotenführer - als gelte es, Wilde mit einem fremden Kulturgut bekannt zu machen. “454 $\mathrm{Ob}$ dies tatsächlich der Fall ist und ob es wirklich fatal ist, ausgelesene Bücher zu entsorgen oder weiterzuverkaufen, um sie anderen nutzbar zu machen, und damit als „Verbrauchsgüter، ${ }^{\text {455 }}$ zu behandeln, sei dahingestellt.

\subsection{Schlussfolgerung}

Der ,ewige Büchernarr' ist eine tragische, manchmal allerdings auch komische Figur, die als Typ immer wieder in Zusammenhang mit der fiktional geschilderten Liebe zu Büchern auftaucht. Unverbesserlich ver,narrt', lässt er sich nicht helfen und zeigt auf, wohin eine extreme Bücherleidenschaft führen kann.

Die Darstellung des Bibliomanen heute erinnert an eine, gute, alte Zeit', in der noch viel mehr Menschen maßlos Bücher gesammelt haben, aus diesem Grund sind die Fiktionen auch so häufig in historischen Kontexten angesiedelt. Für den heutigen Leser dient die Porträtierung des Büchernarren zweierlei Zwecken. Der Leser wird es als angenehm empfinden, über einen leidenschaftlichen Leser als Spiegelung seiner selbst zu lesen, der ganz für seine Bücher lebt, so wie er selbst es vielleicht auch gern täte. In der Figur kann er sich als Bücherfreund selbst erkennen, sich mit ihr identifizieren und zu einer eingeschworenen Gemeinschaft von Lesern zugehörig fühlen. Andererseits ist es auch möglich, dass sich der Leser durch die extreme Darstellung erschreckt fühlt, was aus ihm selbst werden könnte, und fortan einen moderateren Umgang mit Büchern wählt. 
Verbunden mit der Schilderung des Büchernarren ist immer die Einladung zum und sogar Forderung nach dem ,richtigen' Lesen und dem ,richtigen' Umgang mit dem Buch, wo der Büchernarr doch so vieles falsch macht. In jedem Fall ist die Verwendung der Figur des Büchernarren in fiktionaler Literatur eine Art Werbung für das Lesen.

Wo öffentliche Bibliotheken als Wissensspeicher „Macht, Gewissheit und Zeitresistenz “456 ausstrahlen, dienen Privatbibliotheken der persönlichen Repräsentation. Bücherfreunde interessieren sich für die Sammlungen von Bekannten, im harmlosesten Fall, um Leseanregungen zu erhalten, aber auch oft, um sich selbst daran zu messen. Anhand der Bücher ist es möglich, den Besitzer besser einschätzen zu können, denn die Bibliothek, ihr Umfang und die enthaltenen Bücher sagen etwas über ihren Besitzer aus. Die Bibliothek beschreibt die Intelligenz, den Geschmack, die finanziellen Mittel des Besitzers, die er für Bücher einsetzt. Doch der Besitz allein macht noch keinen Gelehrten, die Lektüre der Bücher und die Aufnahme ihrer Inhalte sind entscheidend.

Ist der Umfang einer privaten Bibliothek noch ein gültiger Beweis für Intellekt, Geist und Intelligenz, wenn Inhalte auch elektronisch, d. h. körperlos verfügbar sind? Bei digitalen Veröffentlichungen kann ein solches Zur-Schau-Stellen des Gelesenen und des Besitzes nicht stattfinden, es sei denn, die Daten sind auf Speichermedien konserviert. Zählen Bücher in der Öffentlichkeit noch so viel, dass ihr Besitzer sich mit ihrer Aura schmücken und sich ihretwegen Respekt und Anerkennung verdienen kann? Ob heute noch viele Privatbibliotheken in der Größenordnung der in der Fiktion vorgeführten existieren, bleibt zweifelhaft. Zwar wird laut einer Leserund Käuferstudie aus dem Jahr 2008 viel gelesen, doch hat auch der Anteil der „Ausleihenden Leseratten“ gegenüber der Vorgängerstudie von 2005 zugenommen, die sich nicht jedes Buch, das sie lesen, selbst anschaffen, sondern auch viele Bücher ausleihen, z. B. bei Bekannten oder in der örtlichen Bibliothek ${ }^{457}$. Nicholas A. Basbanes versucht in seiner Zusammenstellung von Anekdoten und kurzen Erzähltexten über Büchersammlungen und -sammler das Phänomen Büchersammeln zu verstehen. Er zitiert Lawrence C. Wroth: „As long as people collect and as long as there are books there will be book collectors. “458 Die nahe Zukunft wird zeigen, ob dieser Ausspruch zutrifft und tatsächlich weiterhin umfangreiche Privatsammlungen existieren werden. Eine Erhebung zur Anzahl der Bücher pro deutschem Haushalt ${ }^{459}$ durch den Börsenverein des Deutschen

456 Manfred Schneider (2004), S. 76.

457 Vgl. die Verbraucherstudie Buchkäufer und Leser 2008 - Profile, Motive, Wünsche II. Hg. v. Börsenverein des Dt. Buchhandels, in Zs.arbeit mit GfK und Sinus. Nov. 2008. Band I ist im Jahr 2005 erschienen. Kurzfassungen beider Studien sind online erhältlich unter [http://www.boersenverein.de/de/158446/Studien/158287].

458 Basbanes (1995), S. 5f.

459 Vgl. die Erhebung „Wie viele Bücher haben Sie im Regal?“, veröffentlicht in: Die Zeit, 15.10.2009, S. 40, [http://de.statista.com/statistik/daten/studie/71160/umfrage/anzahl-der-buecher-pro-haushalt-im-jahr2008/], eingesehen am 20.04.2011. - Statista ist laut Selbstdarstellung „das führende deutsche Statistikunternehmen im Internet“ und bündelt professionell statistische Daten verschiedener Institute und Quellen. Es werden Statistiken zu über 60.000 Themen aus mehr als 1.000 verschiedenen Quellen zugänglich gemacht. 
Buchhandels, die Frankfurter Buchmesse und die Stiftung Lesen ergab für das Jahr 2008 Folgendes: Etwas mehr als die Hälfte der Befragten (57\%) gab an, dass sie unter 50 Bücher im Haushalt haben, während lediglich 6\% der Befragten über 250 Bücher besitzen. Die Zeit der überbordenden Privatbibliothek scheint sich also ihrem Ende zu nähern.

Der heutige Umgang der meisten Leser mit Büchern ist gelassener geworden, und tatsächlich behandeln viele ihre Bücher als Gebrauchsgegenstände, in denen sie gern Notizen machen und die sie auch mitunter im Umfang verkleinern, um sie angenehmer lesen zu können. Andere legen Wert auf pflegliche Behandlung und dulden keinen Knick, kein Eselsohr. Dennoch sehen sich beide Gruppen als Bücherfreunde. Das Credo der fachkundigen Sachbuch-Anleitungen zum Umgang mit Büchern lautet jedoch, dass das Buch zwar gründlich gelesen werden, aber immer noch verlagsfrisch aussehen soll, kurz, es darf überhaupt keine Spuren des Gelesenseins enthalten. Doch ist es gerade das Lebendige an Büchern, dass der Leser persönliche Spuren darin hinterlassen kann. Gibt er dieses Buch weiter, geht etwas von ihm über das Buch auf den nächsten Leser über, was gerade den Mehrwert des Buchs gegenüber den Bildschirmmedien ausmacht. Ein Buchexemplar wächst und gewinnt, je mehr Leser es hatte.

Das Bücherlesen vermittelt immer noch, vielleicht heute mehr denn je, ein gewisses Prestige und grenzt den Leser von Nichtlesenden ab, und das mit einem „sozialen Distinktionsgewinn“4460. Bücher stehen für ein altes bildungsbürgerliches Ideal und sind schichtenübergreifend ein Ausdruck von Intelligenz und Intellekt, aber auch sozialem Status und Abgrenzung von anderen Milieus. In einer Zeit, in der andere Medien dem Lesen massive Konkurrenz machen, stellt das Lesen von Büchern etwas Außergewöhnliches dar, erst recht das Viellesen, das zwar zum einen als Nicht-Mainstream-Freizeitbeschäftigung gegenüber Fernsehen, Internet etc. als eigenartig und besonders betrachtet wird, das aber auch mit gesellschaftlichen Ansehen und Anspruch verbunden ist (vgl. Kap. IV.3.1).

\section{Von Buchlingen und LiteraturAgenten - Fantastische Buchwelten}

Wo Fabrenheit 451 ein fiktives totalitäres System der Zukunft beschreibt, in dem nicht gelesen werden darf, eröffnen Walter Moers in Die Stadt der träumenden Bücher (2004) und Jasper Fforde mit Der Fall Jane Eyre (2004) ${ }^{461}$ utopisch-fantastische Welten, in denen Bücher eine ungemein größere Bedeutung einnehmen als in unserer Realität. Es soll im Folgenden gezeigt werden, wie Bücher in beiden Romanen durch ausgiebige Reflexion der Auswirkungen von Literatur und Bü- 
chern mit besonderem Wert versehen und glorifiziert werden. Dies gelingt durch die Darstellung fantastischer, das Buch überhöhender Welten, die der realen Welt von Buchkäufern und Lesern den Spiegel vorhält und so für den Leser Übertragungen auf seine eigene Beziehung zum Buch möglich sind. Die Protagonisten beider Romane sind Helden von Buchreihen, deren weitere Titel um den fiktiven Kontinent Zamonien bzw. die Figur Thursday Next hier jedoch keine Berücksichtigung finden.

Die fantastischen Buchutopien von Moers und Fforde bieten stringent konstruierte Bücherwelten, in denen alles, auch Unvorstellbares, möglich ist. Ihre Kernstücke sind Bücher, Bücherfreunde und eigens geschaffene utopische Buchuniversen, in denen Bücher in den Alttag integriert werden und diesen bestimmen. Beide Romane sind geprägt durch postmoderne Einflüsse, was man an ihrer immensen Intertextualität sowie der oftmals ironischen Reflexion von Schreiben und Lesen erkennt. Während Moers zudem die unterschiedlichsten literarischen Traditionen in seinem Roman durchexerziert, bietet Jasper Fforde eine Mischung aus Thriller, Science Fiction und komischem Roman. Bei Moers spielen sich die Geschehnisse in einer Bücherstadt ab, die durch den Literaturbetrieb bestimmt wird, Ffordes Version einer Bücherwelt schildert Bücher und Autoren beinahe als Heiligtum, in jedem Fall aber als nationalen Schatz. Literarische Figuren sind dazu in der Lage, ihre Bücher zu verlassen, LiteraryAgents werden u. a. eingesetzt, um Fälscher und Schmuggler illegaler Buchkopien aufzuspüren ${ }^{462}$.

$\mathrm{Zu}$ beiden Romanen existiert kaum wissenschaftliche Sekundärliteratur, möglicherweise, da sie hauptsächlich als Unterhaltungsliteratur angesehen werden. Daher wurden bei den Recherchen Feuilleton-Rezensionen sowie die ausführlichen und kenntnisreichen Wikipedia-Artikel ${ }^{463}$, allerdings nicht uneingeschränkt, herangezogen.

\subsection{Walter Moers: Die Stadt der träumenden Bücher}

In Die Stadt der träumenden Bücher begleitet der Leser den Protagonisten, den Lindwurm Hildegunst von Mythenmetz, durch die sagenhafte Bücherstadt Buchhaim. Bei den Bewohnern der Lindwurmfeste, zu denen Hildegunst gehört, ist es Tradition, Schriftsteller zu werden. Das ganze Leben ist auf Lesen und Bücher ausgerichtet, deshalb hat jeder Lindwurm einen Dichtpaten zur

\footnotetext{
462 Ffordes Bücherwelt weist eine Parallele zu dem Sydney-Pollack-Film Die drei Tage des Condor (1975) auf. Darin ist es die Aufgabe der getarnten CIA-Dienststelle ,American Literary Historical Society', Bücher zu lesen und darin Strategien und Hinweise zu finden, die für die Arbeit des Geheimdienstes verwertbar sind.

463 Vgl. die Wikipedia-Artikel über die Thursday-Next-Reihe, [http://de.wikipedia.org/wiki/Thursday-Next-Reihe], eingesehen am 16.10.2010, sowie über Die Stadt der träumenden Bücher, [http://de.wikipedia.org/wiki/ Die_Stadt_der_Tr\%C3\%A4umenden_B\%C3\%BCcher] und [http://de.wikipedia.org/wiki/Zamonien], eingesehen am 19.05.2010.
} 
Seite, der für seine schriftstellerische Erziehung verantwortlich ist, ihn in die Literatur einführt, in der Wahl geeigneten Lesestoffes unterweist und ihm das Dichten beibringt.

Das ,Orm’ gilt in dieser Utopie als inspirativer literarischer Geist, als „eine Art mysteriöse

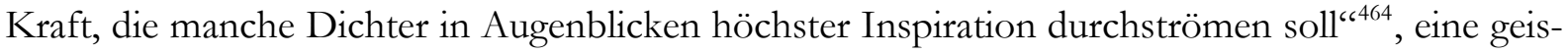
tige Fähigkeit, die „dichterische Inspiration“465, ,,jene seltene Befähigung zum Schreiben“4466 und „dichterische Grundkraft“4467 einschließt. Aus einer Anspielung auf Goethes Faust I („Dann geht des Ormes Kraft Dir auf..." $\left.{ }^{468}\right)$ geht hervor, das mit dem Orm ein Konzept gemeint ist, das in Fausts Monolog als „Seelenkraft“ (Faust I, Nacht) bezeichnet wird. Dieses Konzept der dichterischen Befähigung wird in der Fiktion allerdings von der aufgeklärten jungen Generation belächelt und als Mythos abgetan.

Von seinem Dichtpaten erbt Hildegunst ein geniales, beeindruckendes Manuskript von höchster literarischer Qualität, das das Orm fassbar macht. Derart fasziniert vom Können des unbekannten Autors, macht er sich auf nach Buchhaim, die Stadt der träumenden Bücher, um dort den Autor zu treffen und bei ihm in die Lehre zu gehen.

\subsubsection{Buchhaim als Buchstadt}

In Buchhaim lebt die Literatur, und das Leben besteht einzig aus Literatur, „[h]ier schienen Leben und Literatur identisch zu sein, alles kreiste um das gedruckte Wort.“4699 Im Roman wird mit einer Reihe kurioser Einfälle eine Stadt vorgeführt, die beinahe ausschließlich aus Antiquariaten, Buchhandlungen und Cafés mit Dichterlesungen besteht. Die detailreich und fantasievoll ausgestaltete Buchwelt, die in der Fiktion alle Sinne anspricht, ist als Gegenentwurf zur realen hochmodernen, aber künstlich-kalten EDV-Welt gemeint. Die Buchwelt dagegen wirkt altertümlich, aber gemütlich, was exemplarisch an der Beschreibung von Buchhaim ${ }^{470}$ als pseudo-mittelalterlichem Städtchen ausgemacht werden kann.

Buchhaim ist eine Stadt, in der nicht nur eifrige Buchkäufer und Leser leben und die BuchTouristen anzieht, sie ist auch eine Stadt voller Menschen, die mit Literatur und Büchern ihr Geld machen. Die Kehrseite zeigt, dass manche Akteure des Literaturbetriebs dies nicht immer auf lau-

\footnotetext{
464 Moers (2006), S. 20.

465 Sebastian Domsch: „Träumende Bücher“, tazmag, Wochenendmagazin der taæ, 16./17.10.2004, S. VI. Online [http://www.taz.de/1/archiv/archiv/?dig=2004/10/16/a0301], eingesehen am 28.10.2010.

466 Andreas Platthaus: „Zum Dichter geboren, zum Leser bestellt. Ein sensibler Lindwurm: Walter Moers verzaubert mit seinem neuen Roman aus Zamonien“. In: Frankfurter Allgemeine Zeitung, 11.09.2004, S. 44. Online [http://www.faz.net/s/Rub79A33397BE834406A5D2BFA87FD13913/Doc E264B06ACC92A49 C89A60123304649396 ATpl Ecommon Scontent.html], eingesehen am 28.10.2010.

467 Mario Fesler: Die Zamonien-Romane von Walter Moers als zeitgenössische Vertreter der Gattung Fantasy. Magisterarbeit. München: Grin Verlag, 2007, S. 34.

468 Moers (2006), S. 299.

469 Ebd., S. 41.

470 Vgl. ebd., S. 30-41.
} 
teren oder legalen Wegen tun. Buchhaim kann als Karikatur des gegenwärtigen deutschen Literaturbetriebs betrachtet werden. Den Seufzer des Großantiquars Smeik, „Wenn ich mir dagegen unseren modernen Literaturbetrieb ansehe...“ “471, kann der Leser auch auf seine reale Gegenwart beziehen. Viele Akteure des wirklichen Literaturbetriebs werden vorgestellt und persifliert, z. B. Literaturkritiker, die in der Giftigen Gasse zur Vernichtung von Existenzen gedungen werden wie Auftragsmörder, oder der Literaturagent Claudio Harfenstock, der ein gutes nicht von einem schlechten Manuskript unterschieden kann und zugibt, dass ihn nur der Schriftsteller interessiert, an dem er verdienen kann. Das Mittelmaß beherrscht den Markt, die hochwertige, vom Orm durchströmte Literatur wird zurückgehalten, damit sie diesen Markt nicht verdirbt, da jeder Leser dann nur noch diese geniale Literatur und keine durchschnittlichen Romane mehr kaufen würde - nur durch die Masse aber verdient der verbreitende Handel.

Unterhalb des Stadtlabyrinths gibt es ein zweites, das der Katakomben von Buchhaim. Dieses unterirdische Labyrinth kann man als Spielart der Bibliothek von Babel sehen, es ist ein geschlossenes, selbstbezügliches System mit unendlich vielen Büchern. Dort gibt es literarische Gattungen und literarische Wesen, wie die Buchlinge, die auch in Buchhaim noch nie ein Mensch erblickt hat.

\title{
7.1.2 Ausgestaltung der Buchwelt
}

Die detailreiche Ausgestaltung der Handlungsorte als Bücherwelt weist darauf hin, welche überragende und alles beherrschende Rolle die Literatur in der Fiktion einnimmt. Die Stadt der träumenden Bücher verdankt ihren Namen den „träumenden Büchern“, die darauf warten, dass Leser sie erwecken und ihnen Leben einhauchen, wie die Bücher, die vom ,Friedhof der Vergessenen Bücher' gerettet werden:

\begin{abstract}
So nannte man in dieser Stadt die antiquarischen Bestände, weil sie aus der Sicht der Händler nicht mehr richtig lebendig und noch nicht richtig tot waren, sondern sich in einem Zwischenzustand befanden, der dem Schlafen ähnelte. Ihre eigentliche Existenz hatten sie hinter sich, den Zerfall vor sich, und so dämmerten sie vor sich hin, zu Millionen und Abermillionen in all den Regalen und Kisten, in den Kellern und Katakomben von Buchhaim. Nur wenn ein Buch von suchender Hand ergriffen und aufgeschlagen, wenn es erworben und davongetragen wurde, dann konnte es zu neuem Leben erwachen. Und das war es, wovon all diese Bücher träumten. ${ }^{472}$
\end{abstract}

Des Weiteren rückt der Roman das Buch und Literatur durch eine Fülle von Einfällen bei der Ausgestaltung der Buchwelt durch Personen, Orte oder Eigenschaften in den Mittelpunkt und überträgt dabei heutige Phänomene der Popkultur auf das Buch. Die Fankultur der Buchtouristen z. B., die nach Buchhaim kommen und beim Anblick ihrer Lieblingslyriker ohnmächtig werden, erinnert an die heutige Verehrung von Stars aus Musik und Film. Außerdem bereiten kurios-wit- 
zige Buchtitel und Autorennamen dem Leser Vergnügen. In vielen Figurennamen, z. B. Ojahnn Golgo van Fontheweg, lassen sich in der Form von Anagrammen bekannte Autoren erkennen.

Die Figur des Schattenkönigs, der sich in den Katakomben von Buchhaim verbirgt, stellt lebendig gewordene Literatur in jedem Sinne dar. Er besteht als Opfer ,buchimistischer' Experimente aus Papier und trägt die Literatur in sich. Der Schattenkönig stellt sich als jener geniale Autor heraus, den Hildegunst sucht. Hildegunsts Bitte, ihn in die Kunst des Lesens und der Literatur einzuweihen und zur vollendeten Dichtkunst zu führen, erfüllt er, indem er ihm die Bibliothek des Orms erschließt. Darin sind ausschließlich Werke von Schriftstellern versammelt, die das Orm erlangt haben und somit zu den fähigsten und großartigsten Dichtern Zamoniens gehören. Hildegunst kennt kein einziges dieser Bücher, ist aber bereits nach kurzer Zeit so fasziniert, dass er vor lauter Lesen versäumt zu essen und zu schlafen. Deutlich wird darin der Appell an den Leser, auch Titeln abseits der Bestsellerlisten, die man vielleicht nicht auf den ersten Blick für die Lektüre in Betracht ziehen würde, eine Chance zu geben. Jeder Leser sollte auch Titel über seinem eigentlichen Niveau lesen, er wird in den meisten Fällen dafür belohnt.

Eine besondere Art von Buchgestalten, denen Hildegunst in den Katakomben begegnet, sind die Buchlinge. In den Katakomben von Buchhaim suchen sie als Bibliophile Bücher aus Liebe, um sie zu horten, nicht wie die Bücherjäger aus Gier. Sie ,sind’ Bücher, lebendig gewordene Dichtung, denn sie stellen jeweils eine(n) verehrte(n) Dichter(in) dar. Die Buchlinge haben es sich zum Anliegen gemacht, das dichterische Gesamtwerk dieses Dichters auswendig zu lernen und so zum lebenden Werk zu werden. Dieses Vorgehen erinnert wiederum an Fabrenheit 451, geht aber darüber hinaus, denn so wird nicht nur ein einzelner Text bewahrt. Ihre Namen entsprechen anagrammatisch denen der Dichter, deren Werke sie repräsentieren, und der Leser kann erraten, wer gemeint ist. Mit solchen Anagrammen arbeitete bereits Christoffel Grimmelshausen in seinem Simplicissismus („German von Schleiffheim“, vgl. Kap II.1.3.1). Beim sog. ,Ormen’, einem literarischen Ratespiel, das die Buchlinge mit Hildegunst durchführen, werden bekannte Gedichte ihren Dichtern zugeordnet und auf diese Weise Anagramme entschlüsselt, so u. a. Gofid Letterkerl als Gottfried Keller entlarvt. Darüber hinaus ernähren sich die Buchlinge von Büchern und werden vom Lesen satt, wobei Bücher je nach literarischer Qualität unterschiedlich nahrhaft sind: „Ein Buch verschlingen - wir können’s wirklich.““773 - Eine Fähigkeit, die ,Bücherfresser’ sicher auch gern hätten.

\subsubsection{Die fantastische Buchwelt und Buch-Motive}

In Die Stadt der träumenden Bücher sind viele schon besprochene Buch-Motive vereint. So wird der umfassende Charakter der porträtierten Buchwelt unterstrichen. Hier geht es zwar nicht um die 
Suche nach dem Buch, aber um die Suche nach dem verschollenen Autor des wunderbaren Manuskripts. Bei dem talentierten, ja genialen Autor, dessen Manuskript ihn so bewegt hat, möchte Hildegunst das Dichten neu erlernen, um seine Dichtkunst zu perfektionieren. Die Suche nach dem Autor als Buch-Motiv wurde bereits diskutiert (vgl. Kap. III.4). Der Autor des genialen Manuskripts hatte es an Hildegunsts Dichtpaten mit der Bitte um seine Einschätzung geschickt, auf dessen Totenbett hat Hildegunst es erhalten. Dieses Manuskript trägt Hildegunst nun bei sich und gerät deshalb in Buchhaim in Bedrängnis. Der Autor stellt sich als der Schattenkönig heraus, der sich in den Katakomben von Buchhaim versteckt. Wie bei den übrigen Titeln, die eine Suche schildern, wird der Weg zum Ziel: Die Erlebnisse und Ereignisse während der Suche formen den Protagonisten und führen ihn zur Erkenntnis.

Trotz der Fülle an Büchern ist auch in der fantastischen Buchwelt ein besonderes Buch wichtig für den Protagonisten, das die Handlung in Gang bringt und strukturiert. Das vollkommene Manuskript in diesem Roman ist das Pendant zum wertgeschätzten Buch in weiteren Korpustiteln. Es ist der ,großartigste Text der gesamten zamonischen Literatur ${ }^{\text {‘ } 474}$ und löst beim Lesen starke emotionale Reaktionen aus. Im makellosen Text erzählt der Autor von seiner eigenen Schreibblockade und wie er sie überwunden hat. Es geht also um ein wohlbekanntes, beinahe banales Thema, dass der geniale Dichter künstlerisch aber derart gekonnt variiert, dass der Text jeden Leser in seinen Bann zu ziehen vermag. Nicht zwingend zeugt, der Variationsästhetik folgend, nur ein neuer Inhalt von literarischer Virtuosität des Autors und hoher ästhetischer Qualität des Textes. Entscheidend ist die Variation des Bekannten, die kunstvoll-virtuos sein muss: „Aber dieser Text ging mit der verbrauchten Idee so brillant, so geistreich, so tiefschürfend und gleichzeitig derart erheiternd um, daß er mich binnen weniger Absätze in einen Zustand fiebriger Ausgelassenheit versetzte.“475

Für den Dichter ist der Text zum einen gefährlich, zum anderen hoch inspirierend. Mit der Perfektion des Textes ist das Erkennen der eigenen Unzulänglichkeit verbunden, so dass er Gefahr läuft, das Dichten aufzugeben oder Selbstmord zu begehen. Die Wirkung des makellosen Textes kann aber auch wie bei Hildegunst in Inspiration umschlagen, in den Wunsch, es dem genialen Verfasser gleichzutun und mit ihm in Wettbewerb treten zu wollen.

Gefährlich sind auch die ,Gefährlichen Bücher', die wortwörtlich töten können. Von Bücherjägern mit tödlichen Fallen ausgestattet, greifen sie den Leser an, der schließlich im Buch verschwindet. Auch die Bibliothek des Orms ist in gewisser Weise risikobehaftet, da sie süchtig nach Lesen macht und alles andere vergessen lässt. Lebende Bücher bewegen sich, pflanzen sich fort, 
rotten sich zu einer Bibliothek zusammen oder bauen sich zu einer Mauer auf. So wurde auch die Behausung des Schattenkönigs, Schloss Schattenhall, aus versteinerten Büchern errichtet und ist wie „Das Papierhaus“ scheinbar ohne Mörtel zusammengefügt. Die Mauern von Schattenhall bewegen sich durch einen „titanische[n] Mechanismus“4776, der an das sich ständig verändernde mechanische Schloss aus Salamander erinnert.

In Der Club Dumas wird der Antiquariats-Zulieferer Corso als ,Bücherjäger' tituliert. Die Bücherjäger sind in Die Stadt der träumenden Bücher ebenfalls Büchersucher und -diebe, die in den Katakomben von Buchhaim nach seltenen und kostbaren Werken forschen, um sie meistbietend zu verkaufen. Dabei kennen sie weder Skrupel noch Moral, sind gefährlich und tödlich. Die Bücherjäger sind keine Literaturkenner, oft Analphabeten, was betont, dass sie nur am Profit interessiert sind, den wertvolle Bücher der ,Goldenen Liste’ einbringen können. Der ,Held’ der Bücherjäger, Colophonius Regenschein, hingegen verfolgt andere Ziele. Er strebt nicht danach, die Bücher zu besitzen oder gewinnbringend zu verkaufen, sondern danach, die Buchschätze zu bergen und der Allgemeinheit zugänglich machen. Dieses Anliegen wird also positiv konnotiert und höher bewertet und als der reine Besitz von Büchern.

In mehreren Korpustiteln ist es der Fall, dass sich Wirklichkeit und Fiktion gegenseitig durchbrechen, z. B. in Agnes oder Der Bestseller-Mord. Das Ziel des Literaturtycoons Phistomefel Smeik, dem die meisten Antiquariate in Buchhaim gehören, ist schließlich die Durchsetzung der Wirklichkeit, so dass er alle Kunst, alle Fiktion abzuschaffen sucht.

Diese Einbindung diverser bereits definierter Motive, die häufig mit dem fiktionalisierten Buch kombiniert werden, zeigt, wie strukturiert und mit welcher großen literaturwissenschaftlichen Kenntnis das Buchuniversum in Die Stadt der träumenden Bücher ausgestaltet wurde.

\subsubsection{Die Stadt der träumenden Bücher als Fantasyroman}

Der Roman gehört zweifellos zum Genre Fantasy. Fantasy-Literatur zeigt eine zweifach imaginäre Welt: Es handelt sich um fiktionale Literatur, der Fantasie des Autors entsprungen, zum anderen wird eine ,Anderswelt' dargestellt, die von der erlebbaren Realität des Lesers abweicht. ${ }^{477}$ Bei Moers stellt diese ,Anderswelt' der fiktive Kontinent Zamonien dar, auf dem mit Buchhaim und der Lindwurmfeste die Schauplätze von Die Stadt der träumenden Bücher verortet sind. Zwar ist die Welt der Fantasy erfunden und nicht realitätsgetreu, jedoch an die wirkliche Welt angelehnt und legt aus diesem Grund Wert auf „Logik, Konsistenz und innere Geschlossenheit“ ${ }^{\text {(478 }}$. Bekanntes ist erkennbar, wird aber doch anders ausgestaltet, um einen reizvollen, z. T. ironischen Kontrast und 
Kommentar zur Realität herzustellen. Durch die Gegenüberstellung werden die Eigenheiten der Realität hervorgehoben, gleichzeitig wird so das Fantastische glaubwürdiger gestaltet. Daher kann sich der Leser in dieser Welt zurechtfinden und lässt sich darauf ein, dem Helden in diese Welt zu folgen. Fantasy-Welten sind häufig historisierend angelegt, oft vorindustriell oder mittelalterlich. Es sind Märchenwelten, die dem Leser bekannt vorkommen, da grundlegende Charakteristika menschlichen Lebens bestehen bleiben, aber doch so verfremdet werden, dass sie weit entfernt scheinen.

Die Stadt der träumenden Bücher spielt mit üblichen Klischees des Unterhaltungs- und besonders des fantastischen Romans, worauf schon der ,Lindwurm' als Protagonist hinweist. Der Leser ist sofort auf Fantasy-Literatur eingestimmt und rechnet fest mit dem dort üblichen Motiv der Suche, das zudem auf den Abenteuerroman verweist (vgl. Kap. III.2.1.2). Diese Lesererwartung wird auch erfüllt. Der Roman folgt vor allem dem in der Fantasy gängigen Modell der Queste ${ }^{479}$, das auch in The Lord of the Rings (1954/55) Verwendung findet. Die gesamte Handlung weist deutliche Parallelen zu diesem Klassiker und grundlegenden Werk der gesamten Fantasy-Literatur auf: Es findet eine Reise durch ein unbekanntes, von unserem Mittelalter geprägten Fantasiereich mit einem bestimmten Ziel vor Augen statt, aus der der Protagonist innerlich gestärkt hervorgeht, ein geliebter Verwandter hinterlässt dem Protagonisten ein Buch, der dunkle Herrscher des Fantasiereichs ist bei Moers in der Figur des Schattenkönigs vorhanden.

Bücherfreunde, die gern und viel lesen und einen Sinn für das Fantastische und KomischGroteskes haben, werden sich hier angesprochen fühlen. Bedeutend wichtiger und spannender als die eigentliche Handlung - Hildegunst sucht den Autor, um sich von ihm in der Dichtkunst unterweisen zu lassen - sind in diesem Roman Hildegunsts Erlebnisse und Bekanntschaften in der Bücherwelt, die anekdotisch und episodenhaft in Nebensträngen geschildert werden. So wird eine Bücherwelt entworfen, in der die reale Welt auf den Kopf gestellt wird, da hier der Literatur und Büchern eine viel größere Stellung zukommt als in unserer Realität.

\subsubsection{Anknüpfung an literarische Traditionen}

\subsubsection{Mittelalterliche Traditionen}

Moers bezieht sich auf eine Art der Texteinleitung, die im Mittelalter üblich war. Mit dem durchaus banal oder naiv wirkenden Einleitungssatz „Hier fängt die Geschichte an. “480 knüpft er an das Incipit (lat. „Es beginnt ${ }^{\star}$ ) an, eine formelhafte Wendung, die in mittelalterlichen Kodizes und 
noch in Inkunabeln den Beginn des Textes markierte und den ganzen Einleitungssatz meint. ${ }^{481}$ Das Incipit ist der mittelalterlichen Textgestaltung geschuldet und dient der optimalen Ausnutzung von Papierressourcen: Vor der Einführung eines Titelblatts und der Normierung von Autor- oder Sachtitel war das Incipit als „Initium“ grundlegend für die Identifizierung des Textbeginns auf einer Pergamentseite, die durchaus mehrere Texte, auch auf den Seitenrändern, beinhalten konnte. In heutigen Büchern wird die Texteröffnung von Titel, Überschrift, Inhaltsverzeichnis übernommen. Im Textabschluss geht Moers über die Tradition hinaus und rundet die Texteröffnung ab: „Und mehr gibt es nicht zu erzählen. Denn hier hört die Geschichte auf.“482

\subsubsection{Captatio benevolentiae}

Anstelle einer captatio benevolentiae (lat: „Erheischen von Wohlwollen“) warnt Moers vor der weiteren Lektüre des Romans. Mit einer solchen Devotionsformel wendet sich der Autor mit der Bitte um wohlwollende Aufnahme des Textes oder des Stückes mittels des Erzählers bzw. eines Redners an das Publikum ${ }^{483}$. Moers dagegen stellt gleich zu Beginn klar, dass sein Text nur für abenteuerlustige Leser geeignet sei, denn dieser warte mit einigen Schrecknissen auf. Moers bestätigt damit die Tradition der Horror- und Schauerliteratur, in der der Roman laut eigener Einordnung stehen soll. Mit der Warnung hoffe der Erzähler, den Leserkreis auf geeignete Leser dezimiert zu haben. Im Verlauf des Romans tritt der Erzähler daran anschließend immer wieder in Dialog mit dem Leser, der Leser nimmt direkt an den Erlebnissen des autodiegetischen Erzählers teil, folgt ihm bei seinen Abenteuern und weiß zu keinem Zeitpunkt mehr als er.

\subsubsection{18./19. Jahrhundert}

Eine Herausgeberfiktion wie in der Literatur des 18. und 19. Jahrhunderts, z. B. in Robinson Crusoe oder den Novellen E.T.A. Hoffmanns, wendet auch Moers an. Mario Fesler macht als Vorbild für Die Stadt der träumenden Bücher William Goldmans persiflierenden Fantasy-Roman Die Brautprinzessin (1973) aus ${ }^{484}$. Darin gibt der Erzähler vor, nicht selbst Verfasser des Romans zu sein, sondern eine ihm vorliegende Erzählung bearbeitet zu haben. Im Laufe der Handlung bringt der Erzähler immer wieder Hinweise ein, welche Passagen aus der angeblichen Vorlage er aus welchen Gründen gestrichen oder gekürzt habe. Eine ähnliche Herausgeberfiktion benutzt auch Moers. Im „Nachwort der Übersetzers“ behauptet er, nur einen Text des fiktiven Schriftstellers Hilde-

481 Vgl. zu diesem Abschnitt Hiller \& Füssel (2006), S. 165 sowie Ursula Rautenberg: Reclams Sachlexikon des Buches. Stuttgart: Reclam, 2003, S. 271 u. 277.

482 Moers (2006), S. 476.

483 Metzler Literatur-Lexikon. Begriffe und Definitionen. Hg. v. Günther und Irmgard Schweikle. 2., überarb. A. Stuttgart: Metzler, 1990, S. 75.

484 Fesler (2007), S. 26 u. 86ff, legt seiner Annahme ein Interview zwischen Walter Moers und dem Falter zugrunde, in dem Moers William Goldman als Schriftsteller nennt, der ihn inspiriert habe.

Vgl. Klaus Nüchtern: „,Mein Zielpublikum bin ich““. Interview mit Walter Moers. In: Falter 17 (2003).

Online [http://www.falter.at/print/F2003_17_2.php], eingesehen am 28.10.2010. 
gunst von Mythenmetz, der in Die Stadt der träumenden Bücher als autodiegetischer Erzähler auftritt, aus dem Zamonischen zu übersetzen und mit der Veröffentlichung diesen Text einem neuen $\mathrm{Pu}$ blikum zu erschließen. Der Roman, vermittelt von Moers, bestehe aus den ersten zwei Kapiteln der „Reiseerinnerungen eines sentimentalen Dinosauriers“. Moers erschafft dieser Konstruktion gemäß also den Roman nicht selbst, sondern überträgt lediglich ein Original-Manuskript aus Zamonien. Außerdem bezieht sich Moers mit dem Titel dieses zamonischen Manuskripts offenbar auf A Sentimental Journey Through France and Italy (1768), den bei Zeitgenossen sehr populären episodenhaften Roman von Laurence Sterne, der eine ganze Gattung von empfindsamen Reisebeschreibungen, geprägt von persönlichen Erfahrungen und Eindrücken, begründete.

\subsubsection{Bildungsroman}

Hildegunst von Mythenmetz erfährt aufgrund seiner Reise durch Buchhaim und die Katakomben Initation und Reifung, die mit einem Wissensgewinn und Erkenntnis verbunden sind. Daher kann der Roman auch als Spielart des Bildungsromans betrachtet werden. Bei Moers geschieht die Initiation, hier jene in die Perfektion der Dichtkunst, nachdem Hildegunsts Suche nach dem Autor des genialen Manuskripts, dem Schattenkönig, erfolgreich war. In der labyrinthischen Unterwelt Buchhaims gewinnt Hildegunst den Schattenkönig, ein Kunstwesen aus Papier und Literatur, als Lehrmeister und lernt von ihm alles Nötige, um ein begnadeter Dichter zu werden, so wie seine Herkunft von der Lindwurmfeste es verlangt. Ein Teil seiner vollzogenen Reifung wird gezeigt, indem er sich in der Konfrontation mit den Gefährlichen Büchern als unerschrocken erweist. Der Wissens- und Erkenntnisgewinn durch seine Lehrzeit beim Schattenkönig wird durch das Erlangen des Orm bestätigt.

\subsubsection{Metafiktion}

Im Roman wird auch mit Elementen der Metafiktionalität gespielt. Auf dem Sterbebett berichtet der Dichtpate von dem vollkommenen Manuskript und lässt es sich nicht nehmen, Hildegunst auf seine Art, ihm dies mitzuteilen, und die Situation, in der dies geschieht, aufmerksam zu machen: „Die letzten Worte eines Sterbenden - und er will dir etwas Sensationelles mitteilen! Merk dir diesen Kunstgriff! Da kann keiner aufhören zu lesen! Keiner!“485 Diesen Kniff soll Hildegunst als Vorbild für sein eigenes Schreiben verwenden, doch er bewertet dieses Stilmittel als „trivialen Trick für Jahrmarktschriftsteller ${ }^{\text {4 } 486}$. An anderer Stelle vergleicht Hildegunst seine Erlebnisse in Schloss Schattenhall mit denen eines Helden der zamonischen Literatur. Der zamonische Leser auf der fiktiven Ebene fiebere mit, was dem Helden in der (doppelten) Fiktion Abenteuerliches widerfährt, so wie der reale Leser gerade mit Hildegunst mitfiebert. In seiner Eigenschaft als 
Erzähler der vorliegenden Geschichte möchte Hildegunst dieses Muster jedoch durchbrechen und sich als Figur gar nicht erst in Gefahr begeben: „[] $[$ ch war kein stupider Held, der zur Befriedigung niedriger Unterhaltungsbedürfnisse sein Leben riskierte!“487

\subsubsection{Der Roman und seine Leser}

Das Phänomen der Stadt der träumenden Bücher konnten die Rezensenten der einschlägigen (Tages-) Zeitungen kaum fassen. Trotz sicher bestehender Vorurteile gegen Moers, der als Comiczeichner bekannt wurde, ist es ein Titel, der sowohl die seriöse Kritik als auch das Publikum überzeugt hat, wie der Verkaufserfolg von HardCover, Taschenbuch und Hörbuch sowie begeisterte Leserrezensionen ${ }^{488}$ und Fanwebseiten zeigen. Einer der ausschlaggebenden Gründe für den doppelten Erfolg ist sicher, dass es Moers gelingt, mit seinem Roman die Verbindung von Hoch- und Populärliteratur herzustellen.

Mario Fesler sieht heute eine Neuentdeckung des Genres Fantasy ${ }^{489}$, damit einhergehend eine Aufwertung des Genres, die sich auch in Rezensionen in Feuilletons und anderen seriösen Medien niederschlage. Die Aufwertung des Genres ist auch der Hinwendung zu postmodernen Methoden geschuldet, wie der Entdeckung der Lesbarkeit von Texten auf mehrfachen Ebenen, die auch bei Moers illustriert wird. Die Stadt der träumenden Bücher ist gattungsgerechte Fantasy-Literatur, birgt aber auch einen literarischen Anspruch durch Zitate der Hochkultur, besonders der Literatur. Diese Anspielungen auf klassische literarische Texte sowie Verballhornungen bekannter deutscher Lyrik und Autorennamen durch Bildung von Anagrammen richten sich spielerisch an ein gebildetes Publikum und werden vielleicht nicht von jedem Leser in Gänze durchschaut.

Moers nutzt die fantastische Literatur zur Parodie, zum einen des Literaturbetriebs, zum anderen des Genres selbst, wertet so das Genre auf und enthebt es dem Vorwurf, bloße und womöglich schlichte Unterhaltungsliteratur zu sein. Konventionen der Fantasy werden bei Moers z. T. übernommen, z. T. aber auch verfremdet oder ganz ausgelassen, zumal er selbst seinen Roman („das nächste Buch“) in der Tradition in der Horror- und Schauerliteratur verortet:

Bei der Arbeit am ersten Roman kam mir die fixe Idee für eine Buchreihe, bei der eigentlich nicht die Protagonisten, sondern der Ort, an dem die Handlung spielt, der eigentliche Held sein soll. Auf dieser Folie sollen unterschiedliche Genres und Literaturformen ausprobiert werden: Der erste war ein barocker fantastischer Roman, der zweite eine Märchenparodie, Rumo ist ein Abenteuerroman, das

\footnotetext{
487 Ebd., S. 324.

488 83\% der Leserrezensionen auf Amazon.de vergeben die Höchstwertung 5 Sterne, [http://www.amazon.de/ $\operatorname{tr} \% \mathrm{C} 3 \%$ A4umenden-B\%C3\%BCcher-Zamonien-Hildegunst-Mythenmetz $/$ dp $/ 3492045499 /$ ref=sr_1_1?ie= UTF8\&s=books\&qid=1288273727\&sr=8-1], eingesehen am 28.10.2010.

489 Fesler spricht zu Recht von einer derzeitigen „,Fantasy-Schwemme“ ausgehend von dem Phänomen Harry Potter und den Herr-der-Ringe-Verfilmungen durch Peter Jackson zu Beginn der 2000er Jahre, vgl. Fesler (2007), S. 5.
} 
nächste Buch wird die Horror- und Schauerliteratur zur Grundlage haben, das übernächste die Science-Fiction, wenn ich so weit komme. ${ }^{490}$

Spannend ist, dass der Ort, der auch Titelgeber ist, der eigentliche Held der Geschichte sein soll. Dies unterstützt die These, dass der Fokus nicht auf der Handlung, sondern auf der Ausgestaltung der Bücherwelt, den Figuren und der dargestellten Wertigkeit des Buchs liegen.

Die Rezensenten sehen im Roman, der weniger durch seine für einen Fantasy-Roman konventionelle Handlung als durch die konsequente Thematisierung von Literatur und Büchern besticht, daher durchweg eine ,Liebeserklärung’, „an das Lesen und die Literatur“491 oder „,an die Fantasie und das Geschichtenerzählen““492. Die Welt macht deutlich, wie multiadressiert der Roman ist und ebenso etwas für junge, Popliteratur liebende Leser zu bieten hat wie für „Bildungsbürger’ oder Intellektuelle, die sich an Borges' unendliche Bibliothek erinnert fühlen können. In erster Linie gehe es laut taz um „die Literatur und ihre physische Manifestation, das Buch“4933, daher empfiehlt diese Rezension den Roman Buchmenschen und anderen passionierten Lesern, also Lesern mit jeglichem Grad an literarischer Vorbildung.

\subsection{Jasper Fforde: Der Fall Jane Eyre}

Der Fall Jane Eyre ist der erste Teil eines Romanzyklus von Jasper Fforde um die Heldin Thursday Next. Der Titel spielt auf den viktorianischen Klassiker Jane Eyre (1847) von Charlotte Brontë an, der in der Handlung eine entscheidende Rolle einnimmt.

Fforde wird immer wieder mit Douglas Adams (Per Anbalter durch die Galaxis (1979) und Nachfolger) und Terry Pratchett (Scheibenwelt-Romane) verglichen ${ }^{494}$. Diese Autoren führen in Science-Fiction- bzw. Fantasy-Welten Phänomene unserer Welt vor und zeigen dabei unsere Wirklichkeit fantastisch überspitzt und ins Groteske gewendet, die Romane wirken so satirisch. Die witzigen, oft skurrilen Einfälle bescherten den Autoren eine große Fangemeinschaft, und auch Ffordes detailverliebten, skurrilen Romanen wird schon ein Kultstatus bescheinigt ${ }^{495}$.

\footnotetext{
490 Nüchtern (2003).

491 Holger Kreitling: „Wanderer, kommst du nach Buchhaim... dann nimm dich bloß in Acht vor Haifischmaden. Walter Moers schreibt ein Loblied auf die Literatur: Die Stadt der träumenden Bücher“. In: Die Welt - Literarische Welt, 25.09.2004, S. 5. Online [http://www.welt.de/print-welt/article342502/Wanderer_kommst_du_ nach_Buchhaim.html], eingesehen am 28.10.2010.

492 Domsch (2004).

493 Ebd.

494 Vgl dazu u. a. Peter E. Müller: „Rettet Jane Eyre! Krimiabenteuer à la Monty Python: In Jasper Ffordes Paralleluniversum sind Romanfiguren ihres Lebens nicht mehr sicher"،. In: Die Welt-Literarische Welt, 19.06.2004, S. 6. Online [http://www.welt.de/print-welt/article321422/Rettet_Jane_Eyre.html], eingesehen am 10.11.2010 sowie Tobias Gohlis: „Thursday im Leseland“. In: Die Zeit, 05.02.2004, S. 48. Online [http://www.zeit.de/2004/07/KA-Krimi07], eingesehen am 10.11.2010. - Auch Leserrezensionen bei Amazon.de verweisen auf die genannten Vorbilder.

495 Vgl dazu Müller (2004) und Marion Löhndorf: „Matrix, redigiert. Wenn Literatur herrschte: Jasper Fforde tritt durch das Prosa-Portal“. In: Frankefurter Allgemeine Zeitung, 07.06.2004, S. 38. Online
} 


\subsubsection{Science Fiction, Fantasy und Steampunk}

Wo Adams und Pratchett die Handlung in selbst geschaffene Welten verlegen, um die satirische Darstellung zu rechtfertigen, zeigt Fforde unsere Welt, wie sie hätte sein können, eine alternative Realität. Mit Elementen der Science Fiction, der Fantasy und des Steampunk zeigt er eine detailverliebte, mitunter absurd wirkende Utopie, die auf der Wirklichkeit der 1980er Jahre aufbaut und sie variiert. Bei Fforde dauert z. B. der Krimkrieg zwischen Großbritannien und dem zaristischen Russland noch immer an, die Gentechnik ist weit entwickelt, das Vereinigte Königreich existiert nicht, denn Wales hat seine Unabhängigkeit erklärt und sich zur Volksrepublik Wales ernannt.

Fforde führt eine fantastische Welt vor, in der Figuren mittels technischer Hilfsmittel die Erzählebenen wechseln können und in der Zeitreisen möglich sind. Agenten der ChronoGarde können die Zeit stoppen und Zeitreisen unternehmen, ihre Hauptaufgabe ist aber die Sicherstellung stabiler Zeitabläufe. Mitunter verändern die Agenten auch historische Ereignisse, so dass die Zeit nicht immer in der bekannten Art und Weise abläuft. Geschichtsrevisionisten lenken die Ereignisse in die von ihnen gewünschten Bahnen.

In den Thursday-Next-Romanen dienen Zeppeline, also ,Luftschiffe', der Fortbewegung, denn in der alternativen, fiktiven Realität war 1972 die Bereitstellung öffentlicher Gelder für die Entwicklung eines Düsenantriebs abgelehnt worden. Die technische Entwicklung, wie wir sie kennen, hat nur in bedingtem Maße stattgefunden, vielmehr hat in Ffordes Welt die Dampfkraft eine bedeutende Stellung erlangt, was eine Voraussetzung für das Genre Steampunk ${ }^{496}$ darstellt. In der Welt des Steampunk, die sich nicht nur auf Romane beschränkt, sondern auch Film, Comic, Computerspiel, Rollenspiel etc. einschließt, ist der technische Fortschritt bei der Dampfkraft stehen geblieben, so dass Eisenbahn, Luftfahrzeuge und auch Computer damit angetrieben werden. Allerdings sind ,echte' Steampunk-Romane meist in einer alternativen Realität angesiedelt, die auf der Viktorianischen Zeit und den Gothic Novels der Zeit basiert, sie übernehmen Gebräuche und Wertvorstellungen, auch Requisiten des ausgehenden 19. Jahrhunderts. Es findet außerdem eine Verquickung mit Magie und Geisterwesen statt, vermutlich basierend auf dem viktorianischen Interesse an Übernatürlichem, aber auch in Ffordes Romanen existieren Vampire und Werwölfe.

[http://www.faz.net/s/Rub79A33397BE834406A5D2BFA87FD13913/Doc E4C802D867F91452

CBBAA0C885CAB79C5 ATpl Ecommon Scontent.html], eingesehen am 10.11.2010.

496 Vgl. als Einführung in das Genre den Artikel „Steampunk“ in der englischsprachigen Wikipedia,

[http://en.wikipedia.org/wiki/Steampunk], eingesehen am 10.11.2010, sowie Jonathan Strickland: “How

Steampunk Works“, How StuffWorks.com, 15.02.2008, [http://electronics.howstuffworks.com/gadgets/other-

gadgets/steampunk.htm], eingesehen am 10.11.2010. 


\subsubsection{Die Buchwelt}

Jasper Ffordes Romane der Thursday-Next-Reihe zeichnen vor allem eine große Intertextualität, Wortspiele und der skurrile Humor aus. Das Entscheidende und Bemerkenswerte an der Anderswelt, die in Der Fall Jane Eyre vorgeführt wird, ist jedoch, dass Literatur ein Massenphänomen darstellt, deren Bedeutung diejenige der Literatur in unserer Welt deutlich übersteigt. Schriftsteller und ihre Werke werden als nationaler Stolz und Schatz begriffen und genießen nicht nur Popularität, sondern höchste Verehrung. Originalausgaben und Handschriften von Dichtern ersten Rangs und nationaler Bedeutung werden verehrt wie literarische Reliquien und unterliegen strengsten Sicherheitsvorkehrungen. In den Nachfolgebänden wird die Buchwelt noch weiter ausgeschmückt, z. B. wird sie als eine Borges'sche Bibliothek mit unzähligen Stockwerken und Regalen dargestellt, literarische Genres sind darin aneinandergrenzende Länder.

In Thursday Nexts Welt ist das Special Operations Network eine Polizeiorganisation mit mehreren Spezialeinheiten. Besonders wichtig für die Romanhandlung ist die Sektion SO-27 Literatur Agenten (LitAgs), in der die Protagonistin Thursday Next als A1-Agentin tätig ist. Die LitAgs werden gebraucht, denn „,[s]eit 1980 drängten die großen Verbrecherbanden auf den lukrativen Literaturmarkt ${ }^{\star 497}$. In der porträtierten utopischen Welt nimmt die Literatur eine viel bedeutendere Rolle ein als in unserer Welt. So befassen sich die LitAgs mit Raubkopien und Fälschungen von Erstausgaben sowie Diebstählen und Hehlerei von Büchern, z. T. sogar Geiselnahmen mit dem Zweck der Erpressung, was in unserer Welt nicht denkbar wäre, da einzelnen Büchern kein derartiges öffentliches Interesse entgegenschlägt oder materieller und ideeller Wert zugesprochen wird.

Fforde parodiert nicht, sondern zeigt eine besondere Bücherwelt, vor der sich alles abspielt, und die der eigentliche Held ist, genau wie bei Moers die Stadt. Die Welt der Fiktion und des Buchs nutzt er, um die Überschreitung der Naturgesetze in der Anderswelt zu legitimieren, wenn z. B. Figuren ihre Bücher verlassen.

Den Inhalt des Romans kann man nur erfassen, wenn man die Ausgangsvoraussetzungen berücksichtigt, unter denen die Handlung stattfindet. Wie bei Moers ist nicht die Handlung erstrangig, sondern die Mittel, mit denen eine durch und durch auf Büchern und Literatur basierende Gesellschaft gezeigt wird. In Der Fall Jane Eyre wird keine Queste und Suche nach dem Buch geschildert, eher eine fantastische und actionreiche, dennoch humorvolle Kriminalhandlung. Die Buchwelt spielt eindeutig die Hauptrolle, doch steht, genau wie bei Moers, ein besonderes Buch im Vordergrund. Die Bedrohung geht von dem raffinierten, berüchtigten Meisterdieb Acheron 
Hades aus, der plant, bekannte und beliebte Werke der Weltliteratur in ihrer ursprünglichen Form zu manipulieren und aus dem kollektiven Gedächtnis zu löschen. Dazu stiehlt er das Originalmanuskript von Jane Eyre und entführt die Protagonistin aus ihrem Roman mit der Absicht sie zu töten. Auf diese Weise erpresst Hades das Land, denn in einer derart literaturverrückten Welt ist dieses Vorhaben eine Katastrophe nationalen Ausmaßes.

\subsubsection{Ausgestaltung der Buchwelt}

Um zu unterstreichen, welche herausragende Rolle Bücher in der Utopie spielen, finden sich viele Phänomene unserer Gesellschaft und unseres Alltags bei Fforde wieder, allerdings mit einem viel stärkeren Bezug zu Literatur. Zu Beginn jedes Kapitels werden Abschnitte aus fiktiven Büchern wiedergegeben, die Hintergründe über die Thursday-Next-Welt aufdecken und zusätzliche Informationen geben. Diese Werke vermitteln unterschiedliche Perspektiven, z. B. eine distanzierte, übergeordnete in „Eine kurze Geschichte des Special Operations Network“, die persönliche der Protagonistin aus Tagebuch und Autobiographie oder des Kollegen aus seinem Tagebuch. Fiktive Bücher kommen auch in Moers' Zamonien-Romanen vor, wie z. B. Prof. Dr. Abdul Nachtigallers „Lexikon der erklärungsbedürftigen Wunder, Daseinsformen und Phänomene Zamoniens und Umgebung“, auf das in allen Romanen der Reihe Bezug genommen wird.

Bis heute ungeklärte literaturgeschichtliche Rätsel werden in der Anderswelt als öffentliche Debatte heftig diskutiert, wie Shakespeares Identität und die Urheberschaft seiner Werke. Jedermann weiß darum und hat eine Meinung oder Theorie dazu, was in unserer Welt undenkbar wäre. Diese Positionierung der Figuren zu literarischen Fragen führt in vielen Fällen zu „literarische[m] Fundamentalismus“ ${ }^{\text {“98 }}$. Als Resultat der sehr ernst genommenen Verehrung von Literatur kommt es zu Schmähungen und Kämpfen zwischen Anhängern unterschiedlicher Strömungen. Diese Ausschreitungen verfeindeter Parteien wirken wie heutige politisch motivierte Demonstrationen, die gegenseitigen Beschuldigungen der Parteien resultieren aus mangelndem Verständnis und Ignoranz. In Thursday Nexts Welt ersetzt die Begeisterung für Literatur und ihre Implikationen politische Auffassungen und Weltanschauungen. Die übergroße Leidenschaft für Autoren befeuert eine Fan-Kultur, wie sie heute nur aus der Popkultur und der Begeisterung für Musik und Film, weniger aus dem Literaturbetrieb bekannt ist, ein junger „Raffaelit“ z. B. „trug ein Kostüm aus dem sechzehnten Jahrhundert und hatte sich eine originalgetreue Kopie der „Hand Gottes’ aus der Sixtinischen Kapelle ins Gesicht tätowieren lassen. ““499. 
Die Begeisterung für Literatur führt so weit, dass Literaturliebhaber die Namen ihrer Lieblingsdichter annehmen:

Die Miltons waren die mit Abstand glühendsten Dichter-Verehrer. Ein Blick ins Londoner Telefonbuch ergab gut viertausend John Miltons, zweitausend William Blakes, ein knappes Tausend Samuel Coleridges, fünfhundert Shelleys, dieselbe Anzahl von Wordsworths und Keats' sowie eine Handvoll Drydens. Diese Flut von Namensänderungen führte zwangsläufig zu Problemen bei der Strafverfolgung. ${ }^{500}$

Beliebte literarische Pilgerstätten sind Häuser bekannter Dichter wie Charles Dickens' Gad's Hill oder Haworth House der Brontë-Schwestern, die täglich von mehreren 1.000 Neugierigen besucht werden, während in unserer Welt literarische Museen und Dichterhäuser immer neue Strategien entwickeln müssen, um Besucher anzulocken.

Die „Will-Speak-Maschine“ („wird sprechen“, verweist als Verballhornung auch auf den Nationaldichter William Shakespeare) ist eine Rezitiermaschine, die auf die Buchautomaten verweist, die erstmals Anfang des letzten Jahrhunderts preiswerte Leseausgaben des Reclam-Verlags, in Großbritannien auch Titel des Penguin-Verlages, anbot. Hier ist das Angebot allerdings akustisch:

Die Rezitiermaschine - ein sogenannter Literatur-Verkaufsautomat - brachte Richard III. Sie bestand aus einem schmucklosen Kasten, dessen obere Hälfte durchsichtig war. Im Inneren sah man den Torso einer Puppe im jeweils passenden Kostüm. Für zehn Pence gab die Maschine eine kurze Shakespeare-Passage zum besten. Die Dinger wurden seit den dreißiger Jahren nicht mehr hergestellt und galten inzwischen als Rarität; die Zerstörungswut der Baconier [die Francis Bacon als wahren Urheber der Shakespeareschen Werke betrachten, B.B.-S.] sowie mangelnde Pflege und Wartung hatten ihren Untergang beschleunigt. 501

\subsubsection{Literarische Figuren, Fiktion und Realität in der Anderswelt}

Fforde nutzt die Möglichkeiten, die die Welt der literarischen Fiktion bieten, um daraus eine spannende Erzählung über ein besonderes Buch zu kreieren. Entscheidend ist dabei die Porträtierung der Buchwelt und die Art und Weise, wie Figuren von einer Erzählebene zur anderen wechseln können, quasi in ein Buch einsteigen bzw. aussteigen können. Die Figuren dringen in die Wirklichkeit des Textes ein, und die im Text vorkommenden Orte und Figuren werden dabei lebendig.

Die Protagonistin Thursday Next, und später auch ihre Antagonisten, ist dazu in der Lage, in ein literarisches Werk einzusteigen und muss sich in dieser Wirklichkeit versteckt halten, um nicht zu einem Teil der erzählten Handlung zu werden. Figuren können ebenso ,ihr’ Werk verlassen und in die ,Realität' gelangen, d. h. in die Erzählung auf der ersten Ebene, die wir als Leser vor uns haben. Hier wird auf neoromantische Konzepte angespielt, die ein Ausloten erzählerischer Möglichkeiten vorführen, wenn auf das Werk selbst Bezug genommen wird. Der Autor beweist an dieser Stelle seine erzähltheoretischen Kenntnisse, da die vorgeführten Konstrukte um Figuren und Erzählebenen deutlich über die Bedingungen reiner Unterhaltungsliteratur hinausgehen. Der Leser muss diese Kenntnisse jedoch nicht besitzen, um den Roman zu genießen. Einzig 
wichtig ist der Unterschied zwischen „im Buch“, fiktiv, und „außerhalb des Buchs“, Realität bzw. 1. Erzählebene. Martin Spieß sieht in seiner Besprechung eines weiteren Thursday-Next-Romans in der Vermischung unterschiedlicher Ebenen von Fiktion und dem Einsteigen in ein literarisches Werk den eigentlichen Grund zu lesen reflektiert, nämlich ganz in der Lektüre aufzugehen und sich auf die Fiktion einzulassen, so dass man die Welt um sich vergisst:

Lesen bedeutet für Jasper Fforde in die Bücher einzutauchen, sich der Handlung und ihren Figuren, sich den Wendungen ersterer und den Entwicklungen letzterer ohne Vorbehalt hinzugeben. Die Realität sieht anders aus? [...] Eben das bedeutet es, zu lesen. Sich für die Dauer der Lektüre einer anderen Realität anzuvertrauen. ${ }^{502}$

Fiktionsintern gibt der Erzähler eine Erklärung für die Vorfälle der Fiktionsüberschreitung und die extreme, sogar gegenständliche Vermischung von Fiktion und fiktiver Realität, aus der heraus er erzählt: „In den vergangenen hundert Jahren sind die Grenzen zwischen Fiktion und Wirklichkeit aus unbekannten Gründen zunehmend durchlässiger geworden. ${ }^{\text {“503 }}$ An anderer Stelle heißt es: „Die Wirklichkeit, soviel stand fest, geriet zusehends aus den Fugen.“504 Gemeint ist zwar die ,Wirklichkeit' des Romans auf der ersten Erzählebene, in der die Grenzen zur Fiktion durchlässiger geworden sind, doch kann man hier auch eine Anspielung auf reale, moderne Schreibweisen fiktionaler Literatur erkennen. Vielleicht spielt der Erzähler, und damit wohl auch der Autor, auf Schreibweisen an, die neue, metafiktionale Formen der Fiktion anwenden und immer komplexer werdende Erzählstrukturen und -verschachtelungen ausprobieren, wie es besonders Autoren der Postmoderne auf die Spitze treiben (vgl. Kap. II.9).

Dem Leser kann dies zugemutet werden, da ihm konventionelle, lineare Methoden zu erzählen vertraut sind und sie ihm mitunter vielleicht sogar schon konservativ und langweilig erscheinen. Leser haben lange Lesebiographien hinter sich und eine gewisse Routine und ,Fingerfertigkeit' im Umgang mit Fiktion entwickelt, sie sind anspruchsvoller geworden, so dass neue literarische Erzählweisen manche Leser vielleicht überfordern, andere aber auch begeistern können.

\subsubsection{Eintritt in den Roman: Eindringen von der 1. fiktiven Ebene in die 2.}

Als junges Mädchen war es Thursday bereits gelungen, in die Welt eines Romans einzusteigen. Bei einem Besuch in Haworth House, dem Wohnhaus der Brontë-Schwestern, in dem das Originalmanuskript von Jane Eyre aufbewahrt wird, versetzte sie die Japanerin Mrs. Nakajima, die dazu in der Lage ist, unmotiviert in die Welt eines Buchs zu ,springen', durch Vorlesen in den Roman:

,Soll ich es Dir vorlesen?' fragte eine freundliche Stimme dicht neben mir. Es war die japanische Touristin. [...] Sie vergewisserte sich, daß niemand in der Nähe war, setzte ihre Brille auf und fing an zu

\footnotetext{
502 Martin Spieß: „Die Realität sieht anders aus. Jasper Ffordes Liebeserklärung an die Literatur“ (zu Band 4: Es ist was faul). In: Literaturkritik.de, September 2007, [http://www.literaturkritik.de/public/rezension.php? rez_id $=11118$ \&ausgabe $=200709]$, eingesehen am 11.11.2010. 
lesen. [...]; die Worte perlten vom Papier und beflügelten mein Vorstellungsvermögen. [...] Ich schloß die Augen, und plötzlich erfüllte ein leichter Frost die Atmosphäre ringsum. Die Stimme der Touristin war mit einem Mal ganz klar, so als spräche sie im Freien, und als ich die Augen wieder aufschlug, war das Museum verschwunden, und ich stand auf einem Feldweg. ${ }^{505}$

Die Begabung, in einen Roman einzudringen, setzt Thursday auch bei weiteren Abenteuern ein. Der Eintritt in die fiktive Welt, hier in die doppelte Fiktion, geschieht entgegengesetzt zu den Ereignissen in Cornelia Funkes Tintenher: (2003). Dort werden die Figuren durch Vorlesen lebendig und treten in die ,Realität' ein, bei Fforde gelangt die Protagonistin durch das vermittelnde Vorlesen des Originalmanuskripts in die Handlung und kann in die zweifach gebrochen fiktive Welt des Romans Jane Eyre eintauchen. Beschworen wird hier die Macht der Literatur, die das Gelesene für den realen Leser anschaulich vorstellbar, quasi lebendig macht, wenn auch für ihn nur vor dem geistigen Auge.

Dass ein Protagonist in die fiktive Welt eines Romans auf einer 2. Erzählebene schlüpfen kann, ist besonders in Jugendbüchern wie in Die unendliche Geschicbte (1979) der Fall. Fforde geht aber noch einen Schritt weiter, denn die Ebenen sind zu beiden Seiten durchlässig und es gibt aberwitzige Möglichkeiten, die Literatur in die Realität zu integrieren und umgekehrt. Dazu gehört in einer literaturverrückten fiktiven Welt, die nahe an der Science Fiction angesiedelt ist, eben auch eine Maschine, die es ermöglicht, in den Roman einzusteigen.

Thursdays hochintelligenter Onkel Mycroft hat ein „ProsaPortal“ erfunden, das als technisches Hilfsmittel auch Nicht-Begabten das ,Einsteigen' in die Welt eines literarischen Werkes ermöglicht. Das ProsaPortal besitzt das Aussehen eines typischen, auratischen Buchs: Es ist ein großes, in Leder gebundenes, messingbeschlagenes Buch, mit einer Vertiefung in der Mitte zum Einlegen des Buchs, in dessen Inhalt man einsteigen möchte. Zur vollen Funktionalität ist das ProsaPortal mit modernster Technik kompatibel, die wie ein USB-Anschluss funktioniert und die Kompatibilität des traditionellen Mediums Buch und seiner Inhalte mit elektronischen Medien ausdrückt. Das ProsaPortal besitzt eine Buchse für ein Starkstromkabel sowie Knöpfe und Regler auf dem Deckel. Ist es angeschlossen, öffnet sich eine Pforte im Raum, durch die der Literaturreisende treten und in die Welt des Textes eindringen kann, „wie in eine[n] Spielfilm“506. Über die technischen Raffinessen hinaus handelt es sich bei dem ProsaPortal um einen „Biomechanis-

505 Ebd., S. 73.

506 Löhndorf (2004). - Zudem werden in Spielfilmen wie The Matrix (1999, Regie: L. \& A. Wachowski) oder Stargate (1994, Regie: Roland Emmerich) Möglichkeiten thematisiert, die den Eintritt in eine doppelt fiktive Welt ermöglichen. In Stargate funktioniert ein Portal als Übertritt in die andere Welt. Das Eindringen in ein digitales Medium wird im Spielfilm-Klassiker Tron (1982, Regie: Steven Lisberger) sowie seinem Sequel Tron - Legacy (2010, Regie: Joseph Kosinski) gezeigt. Dort betreten die Figuren über eine biologisch-digitale Schnittstelle ein Computerspiel. 
mus “507, so dass als Ergänzung genetisch veränderte und mit Wörtern und Grammatik gefütterte Bücherwürmer benötigt werden, um interpretatorische Details des Textes zu berücksichtigen:

Sie glitten über den Text, wobei ihr kollektives Unbewußtes jeden Satz, jedes Wort, jeden Vokal und jede Silbe in sich aufnahm. Sie gingen den historischen, biographischen und geographischen Anspielungen auf den Grund, erforschten die in Metrum und Rhythmus verborgenen Bedeutungen und jonglierten geschickt mit Subtext, Inhalt und Metaphern. Danach dichteten sie selbst einige Verse und übersetzten sie in Binärcode. ${ }^{508}$

Die Bücherwürmer nehmen eine strukturelle, grammatische und hermeneutische Untersuchung des Textes vor, bevor das Portal in Gang gesetzt werden kann. Der Text und die Denotationen, Assoziationen und Konnotationen dahinter, der Sinn des Textes als geistiges Gebilde, wird zusammen mit elektrischen Impulsen in Computersprache („Binärcode“) und damit in digitale Daten transformiert. Um die literarische Welt so echt und so nah am Text wie möglich lebendig zu machen, werden also sowohl technische Mittel als auch biologisch-kognitive Daten benötigt, die das Portal dann konvertiert.

Streng genommen ist das Portal aber auch ein Lyrik-Portal, da der erste Versuch die Testperson in das Gedicht The Daffodils von William Wordsworth schickt. Die Vernichtung des Papiers, auf dem das Gedicht abgedruckt ist, würde den Tod der Person bedeuten, die in den Text gereist ist. Im Gedicht trifft die Testperson Polly auf Wordsworth, da das Gedicht von einem lyrischen Ich erzählt wird. Als Verfasser des Gedichts bemerkt dieser aber, dass etwas nicht stimmt: „Ich kann mich nicht entsinnen, das geschrieben zu haben...“509 Als die Stromzufuhr unvermittelt beendet wird, muss Polly in der Fiktion des Gedichts verbleiben:

Polly schrie vor Schreck, als See und Himmel sich berührten. Die Narzissen, Bäume und Wolken kehrten an ihren Platz im Gedicht zurück, nichts als Wörter, Schnörkel auf Papier, ohne jegliche Bedeutung außer der, die unsere Vorstellungskraft ihnen verleiht. Ein letzter Schrei entrang sich Pollys Kehle, als alles in Finsternis versank und das Gedicht sich über ihr schloß. ${ }^{510}$

Die Umgebung, die Polly gerade noch als ,echt', dreidimensional und erfahrbar erlebt hat, die „Narzissen, Bäume und Wolken“, werden nach dem Schließen des Portals wieder zu „Schnörkel[n] auf Papier“. Hier greift die semantische Zeichenlehre: Ferdinand de Saussures Begriffe von Zeichen und Bedeutung - Wörter auf dem Papier, die der Leser mit einem Objekt oder einem Abstraktum, auf das es sich bezieht, verbinden kann - werden durch das ProsaPortal um eine dritte Dimension erweitert, nämlich die Vorstellung, die das Wort vermittelt, und die in der Welt der literarischen Fiktion tatsächlich die dreidimensionale Darstellung ermöglicht. Diese Konzeption bildet das Semantische Dreieck nach, das Saussures Begrifflichkeiten um die Ebene des Wort- 
inhalts erweitert, der Kommunikation über etwas erst ermöglicht. Durch solches Einbeziehen linguistischer Konzepte hebt sich Ffordes Roman deutlich von reiner Unterhaltungsliteratur ab.

\subsubsection{Austritt aus dem Roman: Eindringen von der 2. fiktiven Ebene in die 1.}

„Was wollen Sie damit andeuten? Daß Charaktere [d. s. Figuren, B.B.-S.] nach Lust und Laune aus ihren Romanen heraushüpfen können? ${ }^{\text {c511 }}$ - Die Figur Rochester aus dem Roman Jane Eyre ist dazu in der Lage, den Roman zu verlassen und in die ,Realität', also auf eine übergeordnete Erzählebene zu gelangen, und das nicht vermittelt durch einen Vorleser seiner Geschichte, sondern aus sich selbst heraus. Seiner eigenen Fiktivität ist er sich dabei bewusst: „Ich bin niemals echt gewesen. “512 Seit ihrem Eintritt in den Roman hat Thursday eine besondere Beziehung zu Rochester, „die Grenze zwischen Rochester und mir ist irgendwie durchlässig“6513. Er begegnet ihr im Traum, um sie auf die richtige Spur des Erpressers zu bringen, und, da er dazu in der Lage ist, seinen Roman zu verlassen, versorgt er sie nach einem Angriff durch den Antagonisten. „Jane Eyre“ rettet Thursday also in zweifacher Hinsicht das Leben: Zum einen die Buchausgabe des Romans, die in ihrer Hemdtasche steckt und die Kugel abfängt, zum anderen die Figur Rochester.

Fforde hat mit der Konzeption einer aus ihrer Erzählwelt aussteigenden Figur einen prominenten Vordenker. In einer Rezension beschreibt Goethe einen Roman seiner Zeit, in dem sich eine Figur über seine Figur Wilhelm Meister äußert. Er beurteilt dies kritisch, denn dies diene wohl vor allem der Charakterisierung der Figur, die ihre Meinung derart äußert. Der Roman werde von der Autorin dazu instrumentalisiert, um ihre eigene Ansicht über Goethes Figur kundzutun ${ }^{514}$. Wilhelm Meister hätte stattdessen besser als Figur in besprochenem Roman auftreten sollen:

Eine Neigung, welche sie gegen Wilhelm Meister gefasst, wollen wir derselben weniger verargen; doch wünschten wir, die Verfasserin hätte, anstatt des Buches zu erwähnen, gedachten Romanhelden selbst [...] auftreten lassen, da sich denn wohl Gelegenheit gefunden hätte, ihm etwas Liebes, Gutes oder Artiges zu erzeigen. ${ }^{515}$

\subsubsection{Wechsel zwischen den Erzählebenen}

In Der Fall Jane Eyre ist literarischen Figuren der Wechsel zwischen den Erzählebenen möglich. So wird in der Fiktion berichtet, dass eine Nebenfigur aus Der Widerspenstigen Zäbmung, die nur einen kurzen Auftritt im 1. Akt hat, angeblich aus dem Werk in die ,reale’ Welt (die der 1. Erzählebene) gelangt sei. Ein anderer Fall erwähnt einen Menschen (in der Fiktion), der aus Begeisterung in einen Dickens-Roman gelangt und dort geblieben sei.

\footnotetext{
511 Ebd., S. 274.

512 Ebd., S. 196.

513 Fforde (2004), S. 274

514 Wuthenow (1989), S. 154.

515 Johann Wolfgang v. Goethe: Rezension zu Eleutherie Holberg (d. i. Karoline Paulus): Wilhelm Dumont. In: Jenaische Allgemeine Literaturzeitung, 16.07.1806, S. 240-243, hier S. 242f.
} 
Das ProsaPortal bietet die Möglichkeit, jede nur erdenkliche Fiktion wahr werden zu lassen oder unmögliche Gegenstände in die Realität zu holen. So stellt sich das Portal als „dreidimensionale[r] Fotokopierer“516 dar. Dinge können ,echt' und, werden sie in die Realität geholt, hergestellt statt nur betrachtet werden. Der monopolistische Megakonzern Goliath Corporation, der mit seinen Ablegern sämtliche Wirtschaftszweige und das öffentliche Leben von Thursday Nexts Welt kontrolliert, stellt unterschwellig eine nationale Bedrohung dar, da er staatliche Organisationen unterwandert und plant, die Herrschaftsgewalt an sich zu reißen. Ein Funktionär verfasst einen kruden Roman über neue Superwaffen, die er mittels des ProsaPortals in der Wirklichkeit zu holen plant.

Mithilfe des ProsaPortals gelingt die Kombination von Ein- und Aussteigen in einen literarischen Text. Eine Figur kann aus der fiktiven Welt des vorliegenden Romans in ein literarisches Werk einsteigen. Dort kann sie Figuren treffen und sogar den Inhalt verändern, z. B. eine Figur auf die 1. fiktive Ebene entführen und dort ermorden. Die Entfernung einer Figur aus ihrem Roman wird dabei als „Extraktion“ ${ }^{\text {“517 }}$ bezeichnet.

Anhand des Originalmanuskripts lässt sich größtmöglicher Schaden anrichten, da die Änderungen am Originaltext Auswirkungen auf sämtliche Druckexemplare überhaupt haben, denn alle Exemplare gehen auf den „ersten Schöpfungsakt ${ }^{\text {‘518 }}$ zurück. Die Auswirkungen der Entführung einer Hauptfigur, womöglich sogar des Ich-Erzählers, der intradiegetisch als Figur auftritt, wären fatal für das Fortbestehen des Textes: „Das Buch wäre nach einem halben Kapitel zu Ende. Können Sie sich einen Roman vorstellen, in dem die Charaktere tatenlos herumsitzen und auf das Eintreten der Hauptfigur warten. “6519

In Der Fall Jane Eyre hat der Antagonist Hades zunächst eine Nebenfigur aus dem CharlesDickens-Roman Martin Chu₹zlewit entführt und ermordet, was allerdings nur eifrigen Lesern aufgefallen ist. Nach dieser gelungenen Probe erpresst Hades das Land mit der Entführung einer Hauptfigur aus ihrem Roman, nämlich Jane Eyre. Die Auswirkungen sind für den Leser rasch nach dem Eingriff in den Text erkennbar. Der Roman schwindet, da die Hauptfigur daraus entführt wurde, der Text aber von einem homodiegetischen Erzähler wiedergegeben wird. „Zwanzig Sekunden nach Janes Entführung bemerkte die erste Leserin merkwürdige Vorgänge auf Seite 107 der ledergebundenen Luxusausgabe ihres Lieblingsromans. “520 Die Eingriffe finden Eingang in den Text, solange die Erzählsituation sie berücksichtigt. Als die Figur Jane entführt wird, wird der Text dahingehend verändert, da sie als Erzähler fungiert. 


\subsubsection{Figuren in ihrer fiktiven Wirklichkeit}

Die Figuren, denen Thursday nach dem Durchschreiten des ProsaPortals in deren literarischer, fiktiver Wirklichkeit des Romans Jane Eyre begegnet, allen voran Rochester, leben auch außerhalb der Erzählzeit und Fiktion des Romans. Wird gerade nicht über sie berichtet, führen sie ein Leben, von dem der Leser nichts erfährt. Allerdings sind die ihnen zugedachte Rolle und die im Roman fixierte Handlung für sie unausweichlich. Ereignisse finden statt, und sie sind determiniert, die beschriebenen Aktivitäten durchzuführen und ihre Dialoge unverändert zu sprechen, ohne dass sie Einfluss darauf nehmen oder die Handlungen verändern könnten, denn „[s]o steht es geschrieben. “521 Textänderungen von Seiten der Figuren wie ein Wechsel zu einer gewünschten Stelle des Romans oder ein erneutes Durchleben von Situationen „läßt der Roman leider nicht zu. ${ }^{\text {“522. }}$

Die fiktive Welt ist beschränkt auf die in der Erzählung vorkommenden Orte. Auch wenn ein Land namens „England“ als Handlungsort dient, sind nicht alle real existenten Orte vorhanden, sondern nur die für diese Welt erdachten, möglicherweise an der Realität orientierten: „[D]ie einzigen Städte in dieser Welt sind die Ortschaften, die Charlotte Brontë sich ausgedacht hat und die im Roman vorkommen. “523

Die Frage, ob Figuren eines belletristischen Werkes ein Leben auch außerhalb der Handlung, die über sie im Roman wiedergeben wird, besitzen, ob der Roman quasi nur einen Ausschnitt aus ihrem Leben schildert, wird hier nicht zum ersten Mal aufgeworfen. In der fantastischen Literatur wird diese Frage häufiger diskutiert, z. B auch in Das Letate Buch (vgl. Kap. III.9.3.4). Es wird angenommen, dass Figuren nicht nur während der Zeitspanne, während der der Roman gelesen wird, ,leben' sondern auch darüber hinaus. Jane rettet Rochester bei dem aus dem Klassiker bekannten Brand, eine Nebenfigur berichtet einem Eindringling: „Sie wird ihn retten, wie sie ihn schon tausendmal gerettet hat und noch weitere tausend Mal retten wird. So war es immer, und so wird es bleiben. “524 Geht man von einem eigenständigen Leben der Figuren aus, bleibt die Frage, wie es zu den Wiederholungen des Ereignisses kommt - Agieren die Figuren in ihrer Welt bei jeder Lektüre einer Buchausgabe des Romans oder in einem ewigen Kreislauf? In jedem Fall sind sie an die Ereignisse, die im Roman geschildert werden, gebunden wie an ein Drehbuch oder einen Dramentext, nach dem jede Figur agiert „wie es [ihre] Rolle verlangte“ ${ }^{\text {‘25. }}$.

Wenn Figuren nicht in einem Kapitel vorkommen - Jane erzählt die Geschichte, somit wird ausschließlich ihre Perspektive wiedergegeben -, tun sie zwar die vorbestimmten Dinge, können 
aber auch mit über das ProsaPortal Eingedrungenen interagieren. Diese Aktivitäten sind im Roman natürlich nicht vorgesehen und finden nur Eingang in den Text, wenn Jane daran beteiligt ist. Ist sie nicht vor Ort oder begegnet sie niemandem, sind die übrigen Figuren nicht in die Handlungen eingebunden und führen ein eigenes Leben, über das nicht erzählt wird, denn „Jane ist zu ihren Verwandten gefahren und hat die Handlung mitgenommen. “526 Auch Rochester kann nur ein Eigenleben führen, wenn er im Roman nicht vorkommt. Er tritt dann beiseite wie auf dem Theater und kann sogar den Roman verlassen. Jane bemerkt von all dem nichts, da sie auf ihre Perspektive konzentriert ist. Rochester heckt mit der in seinen Roman gereisten Thursday einen Plan aus, um die aus ihrem Roman entführte Jane Eyre zu retten:

Ich schlage vor, wir fangen ihn, wenn Jane abgereist ist [...] Wir werden dann ganz allein sein, weil sich mit Jane naturgemäß auch die Handlung nach Moor House zu diesen albernen Verwandten verlagert. Da ich im Buch dann nicht mehr vorkomme, können wir tun, was uns beliebt [...] [Sie dürfen] Jane auf keinen Fall beunruhigen oder gar verwirren; dieses Buch ist in der ersten Person geschrieben. Ich kann mich nur dann davonstehlen, um mit Ihnen zu sprechen, wenn ich in der Geschichte keine Rolle spiele. ${ }^{527}$

Mit dieser Konstruktion ist der Leser mit erzähltheoretischen Aspekten konfrontiert, die den Roman über das Gros der Unterhaltungsliteratur hinwegheben.

Ein literaturreisender Eindringling in den Roman ist nicht an die Handlungsstruktur gebunden und dazu in der Lage, sich mit Figuren auszutauschen, die gerade im Romantext und der -handlung keine Erwähnung finden. Da der Roman aus der Ich-Perspektive Jane Eyres verfasst ist, ist im Romantext z. B. nicht dokumentiert, wie die verrückte Bertha Rochester den Brand auf Thornfield Hall legt. Jane wird erst durch den Rauch darauf aufmerksam und berichtet denn auch erst über das Feuer, als sie es bemerkt. Der Eindringling kann also die Figuren, dabei beobachten, wie sie Dinge tun, die im Roman nur implizit geschildert werden. Die fiktive Welt des Romans wird hier als real mit in ihr lebenden Personen, den Figuren, geschildert, was die Fiktion gegenüber der Realität aufwertet.

Bei ihrem ersten Eindringen in den Roman mithilfe von Mrs. Nakajima ist Thursday angeblich am Kennenlernen von Jane und Rochester beteiligt. Thursday findet sich in einer Szene wieder, die einen Ausritt von Rochester in Begleitung seines Hundes Pilot schildert, der sie bemerkt: „Er schnüffelte seit 130 Jahren bei jeder Lektüre des Romans an dieser Hecke entlang, war dabei aber noch nie auf etwas gestoßen, das so, na ja ... echt roch.“528 Thursday ist es, die Rochesters Sturz vom Pferd verursacht und so Janes Eingreifen und damit beider Kennenlernen ermöglicht. Thursdays Eindringen habe laut Rochester die Handlung verbessert, sie ist nun geschildert, wie 
wir sie aus dem tatsächlichen Roman kennen. Rochester ist sich bewusst, dass sich die Handlung durch Eingriffe von außen verändern lässt:

Vorher bin ich meiner Jane lediglich zufällig begegnet und habe ein paar Worte mit ihr gewechselt. Wenn Sie das Buch vor ihrem Besuch gelesen hätten, würden Sie das sofort bemerkt haben. Daß das Pferd bei dem Versuch, Ihnen auszuweichen, ausrutschte und zu Fall kam, machte die Begegnung viel dramatischer, finden Sie nicht auch?529

Bei jeder Lektüre des Romans treten die Figuren in Aktion, sind aber durch die Romanhandlung an gewisse Handlungen gebunden, die sich ständig wiederholen:

\begin{abstract}
Heute, nach mehrfacher Lektüre des Romans, weiß ich, daß der Hund - er hieß Pilot - im Buch nie Stöckchen suchen durfte, weil er dazu viel zu selten auftrat, weshalb er sich diese Gelegenheit auf keinen Fall entgehen lassen wollte. Vermutlich hatte er instinktiv gespürt, daß das kleine Mädchen, das da plötzlich auf Seite 81 auftauchte, nicht an die strenge Erzählstruktur gebunden war. Er wußte, daß er die Grenzen der Geschichte hier und da ein klein wenig ausweiten und sich zum Beispiel aussuchen konnte, auf welcher Seite des Weges er schnüffeln wollte; wenn jedoch im Text stand, daß er bellen, umherrennen oder aufspringen sollte, mußte er sich wohl oder übel danach richten. Er war zu einem langen, sich endlos wiederholenden Dasein verurteilt, was die seltenen Auftritte von Menschen wie mir um so erfreulicher machte. ${ }^{530}$
\end{abstract}

Mit „Erzählstruktur“ ist die Abfolge von Ereignissen gemeint, die die Romanhandlung vorschreibt. Das Zitat gibt außerdem eine ironische Brechung wieder, wenn die in den Text eingedrungene Thursday „auf Seite 81“ auftaucht. Diese metafiktionale Brechung erinnert an die Romantische Ironie z. B. in Clemens Brentanos Godwi (1800/01). Dort zeigt der Protagonist Godwi dem IchErzähler und fiktiven Autor Maria einen Ort, der für ihn als Figur von Bedeutung ist: „Dies ist der Teich, in den ich Seite 266 im ersten Bande falle. ${ }^{\text {“531 }}$ Ein weiterer Beleg für diese Selbstreflexion des Kunstwerkes ist die Erwähnung, dass Rochester seine Jane „erst auf Seite einhunderteinundacht-

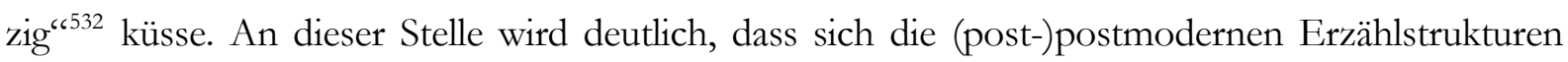
deutlich an neoromantischen Vorbildern orientieren, die bereits den Akt des Schreibens und Lesens und auch das Kunstwerk selbst im Werk reflektierten.

Thursdays Aufgabe und Grund für ihren Einstieg in Jane Eyre ist es, die Protagonistin wieder in ihren Roman zurückzuholen und die Textveränderungen, die sich aus Janes Entführung ergeben haben, rückgängig zu machen. Nach Janes Rückkehr setzt sich die Geschichte wie bekannt und vorbestimmt fort. Auf der 1. Erzählebene prüfen Thursdays LitAg-Kollegen den Text, „während der sich selber schrieb und die letzten zweihundert Seiten füllte, die tagelang leer gewesen

\footnotetext{
529 Ebd., S. 196.

530 Fforde (2004), S. 74.

531 Clemens Brentano: Sämtliche Werke und Briefe. Bd. 16. Prosa 1: Godwi oder Das steinerne Bild der Mutter. Ein verwilderter Roman von Maria. Hg. v. Werner Bellmann. Historisch-Kritische Ausgabe veranst. v. Freien Dt. Hochstift. Hg. v. J. Behrens et al. Stuttgart etc.: Kohlhammer, 1978, S. 379. 
waren“6533, denn Jane als Hauptfigur und Erzählerin war entführt gewesen und konnte die Geschichte nicht forterzählen.

Thursday dringt kurz nach dem Antagonisten in den Roman ein, „ein paar Zeilen über der Stelle ${ }^{\text {c534 }}$. Für einige Monate erzählte Zeit bleibt sie im Roman, während für ihre Kollegen auf der fiktiven Ebene, die mitlesen, wie sich die zur ursprünglichen Form zurückbildende Geschichte verfestigt, nur einige Stunden Lesezeit vergehen: „Die Geschichte entwickelte sich rasant; ganze Wochen schrumpften auf wenige Zeilen zusammen. “535 - „Für meine Kollegen von SpecOps war der nächste Tag angebrochen. Die Monate, die ich in dem berühmten Buch zugebracht hatte, waren für sie so rasch vergangen wie die Zeit, die man braucht, um davon zu lesen. ${ }^{\text {(536 }}$ Nur einige Buchseiten Erzählzeit vergehen beim Lesen dieser Passage für den realen Leser.

Letztlich dreht sich die Handlung des vorliegenden Romans darum, dass der Roman Jane Eyre inhaltlich verändert werden soll. Die völlige Auslöschung des Romans, wie sie der Antagonist plant, kann abgewendet werden, dennoch wird der Klassiker manipuliert, jedoch zum Wohle des Romans und der Leser. Jane Eyre hat in der utopischen Fiktion einen anderen Schluss, als wir ihn kennen, und mit dem kein Literaturliebhaber zufrieden ist, da Jane und Rochester nicht zu einander finden. Die Handlung von Der Fall Jane Eyre dient dazu, den unbefriedigenden Schluss behutsam anzupassen und harmonisch zu verbessern und so den uns bekannten Schluss des Klassikers - Happy End mit Heirat zwischen Rochester und Jane Eyre - herzustellen.

Hier tritt nicht bloß ein ,Buch im Buch’ als Motiv auf, vielmehr eröffnet Fforde eine ganze Buchwelt, die Bücher und Literatur thematisiert. Bücher reflektieren sich selbst, und der Leser nimmt quasi direkt am Entstehungsprozess des Romans teil, wenn dieser sich selbst nach der unzulässigen Änderung verfertigt. Ffordes Erzählweise ist sowohl von neoromantischen Traditionen als auch von der Postmoderne und Genres wie Science Fiction und Fantasy geprägt und lässt sich deshalb nicht eindeutig einem Genre zuordnen. Einem solchen Spiel mit seinen Erwartungen war der Leser bisher kaum ausgesetzt, die skurrile Ausgestaltung der Buchwelt geht über alles hinaus, was bis dato im Roman über Bücher zu lesen war. Ffordes Roman ist „ein Unikum, für das niemand bei seinem Erscheinen im englischen Original die richtige Schublade zu finden schien “537. So reagierten die Leser zumeist positiv bis überschwänglich auf die Romane der Reihe, einige jedoch auch irritiert, was im folgenden Kapitel erläutert wird. 


\subsubsection{Der Roman und seine Leser}

Die Zeit („schlaue[r], herrliche[r] Spaß“6538), die FAZ („Kultroman”“; „,intellektuelle[s] Kreuzworträtsel“ ${ }^{\text {(539) }}$ ) und die Welt („Kultstatus“ ${ }^{(540}$ ) loben den Roman und Ffordes gesamte Roman-Reihe aufgrund der intertextuellen Referenzen auf Klassiker ebenso wie auf populäre Genres und Autoren, die die literarische Versiertheit des Autors zeigen. Außerdem sehen sie, wie im Fall von Moers' Stadt der träumenden Bücher, eine „Liebeserklärung an die Literatur“541. Nicht die Handlung allein macht Charme und Cleverness des Romans aus, sondern die mit skurrilen Einfällen ausgestaltete Bücherwelt, die dem Leser Lust nicht nur auf diesen Roman, sondern auf das Lesen überhaupt macht.

Während die Feuilletons den Roman durchweg positiv besprechen und voll des Lobes sind, sind die (Normal-)Leser hin- und hergerissen, wie sich an Leserrezensionen ${ }^{542}$ zeigt. Ffordes literarisches Experiment ist ein Roman, der polarisiert. Die Leser sind entweder begeistert oder enttäuscht, denn der Beschreibung der Buchwelt wurde eine komplexe Figurencharakterisierung geopfert, und der Schreibstil ist betont salopp und umgangssprachlich gehalten. Die Verweise auf Terry Pratchett oder Douglas Adams werden von den Lesern zwar erkannt, aber unterschiedlich bewertet. Ffordes Schreibart zeigt Parallelen, ist aber doch ganz anders. Viele Leser sehen im Roman ein ,Kultpotential' aufgrund der anspruchsvollen Referenzen zu anderen Werken, andere sind durch die Absonderlichkeiten der Buchwelt und den sehr britischen, zum Teil albernen Humor irritiert. Fforde gelingt es dennoch wie Moers, Anspruch und humorvolle Unterhaltung zu verbinden, denn ein Leser lobt das Lesen „zur Entspannung“, ohne intellektuelle Anstrengung, das Fforde neben den kulturellen Anspielungen ermöglicht:

Literaturliebhaber die ausschließlich an hochklassiger Literatur Gefallen finden, sollten hievon die Finger lassen, denn sie werden das Buch hassen. Wenn Sie aber jemand sind, der ein witziges Buch zur Entspannung sucht so sollten Sie einfach überlegen ob das Thema des Romans etwas für Sie ist. Können Sie diese Frage auch mit ,ja' beantworten, so kann man nur eine uneingeschränkte Kaufempfehlung abgeben. (sic!) ${ }^{543}$

In seinen Thursday-Next-Romanen gelingt es Jasper Fforde, mit der Buchwelt und den fantastischen Möglichkeiten, in Romane einzusteigen und sie zu verlassen, Lust auf das Lesen zu machen und metaphorisch deutlich zu machen, was Lesen zur Unterhaltung überhaupt erst reizvoll macht: Völlig in einen Text einzutauchen und sich auf eine fiktive Welt einzulassen.

\footnotetext{
538 Gohlis (2004).

539 Löhndorf (2004).

540 Müller (2004).

541 Spieß (2004).

542 60\% der Leserrezensionen auf Amazon.de vergeben die Höchstwertung 5 Sterne, [http://www.amazon.de/FallJane-Eyre-Roman/dp/3423210141/ref=sr_1_1?ie=UTF8\&s=books\&qid=1289898310\&sr=8-1], eingesehen am 16.11.2010.

543 reini68.blogspot.com: „Ein Buch mit Kultpotential“, Leserrezension zu Jasper Fforde: Der Fall Jane Eyre, Amazon.de, 16.02.2004, [http://www.amazon.de/Fall-Jane-Eyre-Roman/dp/3423210141/ref=sr_1_1?ie $=\mathrm{UTF} \& \&$ s=books\&qid=1289898310\&sr=8-1], eingesehen am 16.11.2010.
} 


\subsection{Schlussfolgerung}

In den fantastischen Kunstwelten von Moers und Fforde wird eine Welt gezeigt, in der Bücher und Lesen eine übergeordnete Rolle einnehmen und somit einen Gegenentwurf zu unserer realen Gegenwart bilden. Für Literaturfreunde führen die Romane eine Idealwelt vor. Die Romane machen Lust aufs Lesen und stellen einen Appell an ihre Leser dar, sich mit Literatur zu befassen und zu lesen, wobei sie sich hier an eine Zielgruppe wenden, die Bücher ohnehin schon schätzt. Moers und Ffordes literaturdominierte Romane stellen, wie in diversen Rezensionen beschworen, eine Liebeserklärung an Lesen und Bücher dar.

Zwar kommt in beiden Romanen ein besonderes Buch vor, doch die Hauptrolle spielen Bücher im Allgemeinen, um die Bedeutung von Literatur zu veranschaulichen. Bei Moers ist der besondere Text das beeindruckende Manuskript eines genialen Dichters, dem nachgeeifert werden soll, indem der Protagonist bei ihm in die Lehre gehen möchte. Fforde schildert in einer absurden Welt den Diebstahl des Originalmanuskripts von Jane Eyre, die ,Extraktion' der Hauptfigur und die Erpressung des Landes durch diese ungeheuerliche Tat. Beide Romane bieten, losgelöst von der buchdominierten Umgebung, einen schlichten Plot, der für das Grundgenre der Romane, Fantasy bzw. Kriminalroman, sogar recht konventionell wirkt: Auf der einen Seite steht die hindernisreiche Suche in einer fantastischen Welt nach einer bedeutsamen Person, die schließlich gefunden wird, auf der anderen muss ein Verbrecher von einer Polizeiorganisation gefangen und dingfest gemacht werden. In beiden Romanen steht aber nicht der Inhalt, sondern eindeutig die Ausgestaltung der von Büchern und Literatur dominierten Welt im Vordergrund.

Obwohl scheinbar leichte Unterhaltung, wofür der leichte Ton, die umgangssprachlichen Wendungen und auch die flache Figurendarstellung sprechen, zeigen beide Romane einen zwar spielerischen, doch reflektierten Umgang mit Literatur, der die Romane aufwertet, sie für eine Besprechung im Feuilleton würdig macht und die literarische Versiertheit der Autoren untermauert. Darüber hinaus reflektieren die Romane nicht nur Weltliteratur, literaturhistorische Anekdoten oder den Literaturbetrieb, sie referenzieren auch auf ihre Gattung und das Werk selbst. So wertet Moers die Fantasy-Literatur auf und enthebt die Gattung und auch seine eigenen Werke vom Vorwurf der Trivialität. Fforde beweist seine literarischen Kenntnisse durch die spielerische Umsetzung literaturhistorischer Details bei der Ausgestaltung der Buchwelt und besonders Anspielungen auf Erzähltheorien, wenn Figuren ihre Erzählebene verlassen. Außerdem zeigen beide Autoren postmoderne Tendenzen und eine ,moderne' Schreibweise, wenn sie über das Schreiben und das Lesen schreiben und so auf ihr eigenes Werk verweisen.

Beide Autoren überschreiten die Grenze zwischen Hoch- und Unterhaltungsliteratur und richten sich an unterschiedliche Lesergruppen. Auf der einen Seite fühlen sich literarisch versierte 
Leser durch die Anspielungen auf z. B. Weltliteratur angesprochen, geübte Leser haben Freude am Spiel mit Realität und Fiktion, erst recht, wenn bekannte Werke der Literatur thematisiert werden, was ihnen ein Erkennen und ,Mitreden-Können’ ermöglichen. Auf der anderen Seite kommen Freunde skurrilen Humors sowie Science Fiction und Fantasy auf ihre Kosten.

Obwohl das materielle, haptisch erfahrbare Buch die Romane bestimmt, wird außerhalb der Fiktion extensiv das Internet genutzt. Im Falle von Jasper Fforde nutzt der deutsche Verlag dtv eine Homepage natürlich auch zu Marketing-Zwecken ${ }^{544}$. Auch der Autor pflegt umfangreiche, auf einander verweisende Webseiten ${ }^{545}$, zum einen um seine Bücher zu bewerben, zum anderen, um die fiktive Welt in die reale Welt zu integrieren und ihre Scheinexistenz aufrechtzuerhalten. Auf Ffordes Webseite wird u. a. ein Erratum als ein ,Upgrade' zu Ffordes Büchern angeboten, beschrieben wird die Anleitung zur Überarbeitung wie das Upgrade eines EDV-Programms. Damit sollen typographische und inhaltliche Fehler korrigiert werden, indem man seine Ausgabe des Romans an ein Wörterbuch anschließt, die Änderungen aber wie gewohnt mit einem Stift durchführt ${ }^{546}$. Metafiktiv werden also die Begebenheiten der Fiktion, die in der Realität unmöglich sind, wie die Kopplung eines Buchs an ein elektronisches Gerät, also in die Wirklichkeit übertragen.

Der medienscheue Walter Moers pflegt keine eigene Homepage, und auch der Verlag Piper bietet keine Webseite zu Die Stadt der träumenden Bücher oder anderen Zamonien-Romanen an. Die vom früheren Moers-Verlag Eichborn ins Leben gerufene und unterhaltene Webseite zu Zamonien entwickelte sich rasch zur Fan-Community. Eine weitere Webseite zu einem Moers-Titel zog nach dem Wechsel zu Piper nicht mit um und wird nun als Community ${ }^{547}$ von den Fans selbst unterhalten $^{548}$. Moers pflegt jedoch auch einen Bezug seines Romans zum Internet. Im fiktiven „Nachwort des Übersetzers" in Die Stadt der träumenden Bücher fordert Moers als Herausgeber der Schriften von Hildegunst von Mythenmetz dazu auf, ihm per E-Mail mitzuteilen, welches Kapitel aus dessen Autobiographie „Reiseerinnerungen eines sentimentalen Dinosauriers“ er als nächstes übersetzen soll. Die angegebene Adresse ist die von Mythenmetz beim Piper-Verlag, so dass weiterhin die Fiktion aufrechterhalten wird, dass Mythenmetz nicht nur eine Figur, sondern tatsächlich ein Autor ist.

Die Bücherwelten von Moers und Fforde zeigen utopische Welten, wie sie sich heutige Bücherfreunde angesichts des viel beschworenen Untergangs des Buchs und der Übermacht elektronischer Medien nur wünschen können. In einem Roman oder sogar einer Buchreihe heute eben das Buch in den Vordergrund zu stellen und eine von Literatur dominierte Welt darzustellen

\footnotetext{
544 Vgl. [http://www.jasperfforde.de/index.html].

545 Vgl. [http://www.jasperfforde.com] und [http://thursdaynext.com].

546 Vgl. die Webpage [http://www.jasperfforde.com/upgradegc.html], eingesehen am 10.11.2010.

547 Vgl. die Zamonien-Fanseite „Nachtschule“, [http://www.nachtschule.de/nachtschule.html].

548 Vgl. dazu den Wikipedia-Artikel „Zamonien“, [http://de.wikipedia.org/wiki/Zamonien], eingesehen am 10.11.2010
} 
bedeutet, gegen diesen Trend anzugehen und dem Buch eine besondere Stellung einzuräumen, die es in der Realität bereits eingebüßt hat. Um aber nicht die Augen vor der Realität der Medien zu verschließen, werden elektronische Medien extensiv in die Vermarktung und den Austausch der Leser über die Bücher einbezogen. So werden den Lesern Information und Austausch auf allen Kanälen geboten und auch neue Leserschichten erschlossen, die ohne das Internet vielleicht gar nicht erst auf die Romane aufmerksam geworden wären. Bücherfreunde, Viel- und Gernleser werden als Publikum direkt angesprochen und versammelt. Auf diese Weise ist dem Autor eine Leserschaft für Nachfolgebände gesichert.

\section{8 „Irgendwann im September 1991 ging die zivilisierte Welt unter. “549 - Buch und ,neue Medien’}

Die zunehmende Dominanz der ,neuen Medien' wird mehr und mehr als Bedrohung für das Buch betrachtet: Diese elektronischen und digitalen Medien wie TV, PC, Internet und WWW machen dem Buch in den Sektoren Information und besonders Unterhaltung massive Konkurrenz. Es werden sogar immer wieder Stimmen laut, die Sorge ausdrücken, dass das Buch durch diese Medien und Dienste abgeschafft werde, da es als Informations- und Unterhaltungsmedium überflüssig werden könnte.

In den untersuchten Romanen werden neben dem Buch und verwandten Motiven auch die ,neuen Medien’ reflektiert und kommentiert. In diesem Kapitel wird zunächst eine Erläuterung zur Definition des Begriffs ,neue Medien' gegeben, bevor die Medienkritik in den Romanen dargestellt wird. Huizing betrachtet in Der Buchtrinker digitale Medien skeptisch und lässt seinen Protagonisten einen Kommentar zum gegenwärtigen Leseverhalten geben. Der im Text verschwindende Protagonist deutet schon die Sorge um eine mögliche Abkehr vom Buch an. Stamm enthält sich in Agnes eines Vergleichs zwischen Buch und anderen Medientypen, zeigt die Textdatei aber als Ersatz für ein körperliches Schriftmedium: Seine Erzählung um eine in die Wirklichkeit überführte Fiktion hätte statt in den Computer getippt auch auf Papier geschrieben werden können.

\section{1 ,Neue Medien' heute}

Ein Medium ist ein Mittel, um Inhalte zu übertragen und Kommunikation zwischen Menschen zu ermöglichen. Im einfachsten Fall kann das Medium die menschliche Sprache und Schrift sein, doch werden seit den 1960er Jahren Medien als ,gesellschaftlich institutionalisierte Kommunikationsein- 
richtungen ${ }^{\text {“550 }}$ bezeichnet. Darin schwingt der soziale und kommunikative Ansatz von Medien mit, der auch Bücher als Medien zur Fixierung und Übertragung von Texten mittels Schrift einschließt.

Unter ,neuen Medien' versteht man solche, die in ihrer Zeit eine neue Technik einführen. Eine Definition aus dem Jahr 1982 bezeichnet die damals aktuellen, neuen Medien’ als

alle die Verfahren und Mittel (Medien), die mit Hilfe neuer oder erneuerter Technologien neuartige, also in dieser Art bisher nicht gebräuchliche Formen von Informationserfassung und Informationsbearbeitung, Informationsspeicherung, Informationsübermittlung und Informationsabruf ermöglichen. ${ }^{551}$

Die elektronischen und digitalen Medien, die hier erwähnt werden, sind heute zum Standard geworden. Neue Medientechniken waren z. B. in den 1930er Jahren Radio und Hörfunk, in den 1950ern das Fernsehen, dessen Siegeszug als ,Bildschirmmedium’ Marshall McLuhan im Klassiker der Medientheorie The Gutenberg Galaxy (1962) brandmarkt.

Heute gelten alle elektronischen, digitalen oder interaktiven Medien sowie solche, die Daten in digitaler Form verarbeiten und speichern (auf Datenträgern wie CD-ROM, DVD, Blu-ray Disc) und/oder über das World Wide Web übermitteln, als ,neue Medien, ${ }^{552}$. Manche Stimmen behaupten, alle Dienste, die über das Internet möglich sind, konstituieren die ,neuen Medien ${ }^{553}$, andere sind der Meinung, das Internet sei nur eine ihrer möglichen Ausprägungen ${ }^{554}$. Der vernetzte PC für den individuellen Privatgebrauch ist das heutige „Universalmedium für alle Lebensbereiche“, das „,neue Medium’ schlechthin“, dessen Einführung Ende des 20. Jahrhunderts als „Schock“6555 wahrgenommen wurde. Die Meinungen zu dieser Möglichkeit ,neuer Medien' sind immer noch geteilt, doch entwickelt sich an der Schwelle zum Medienwandel ein Medienpluralismus, der auch die etablierten Medien wieder verstärkt in den Fokus rückt, wie dies stets in Situationen der Konkurrenz durch aufkommende neue Medientypen auftritt: „Es ging [Ende des 20. Jahrhunderts] um das ,Neue Medium' als definitives Ende einer fünfhundertjährigen ,Gutenberg-Galaxis’, mit enthusiastischen und eschatologischen Perpektiven, aber auch um eine ,Wiederkehr des Buchs““556. Mit der These einer „Wiederkehr des Buchs“ verweisen die Autoren auf Helmut Schanze, der annimmt, dass die alten Medien immer auch in

\footnotetext{
550 Knut Hickethier: Einfübrung in die Medienwissenschaft. 2., akt. u. überarb. A. Stuttgart: Metzler, 2010, S. 20.

551 Dietrich Ratzke: Handbuch der neuen Medien. Information und Kommunikation, Fernsehen und Hörfunk, Presse und Audiovision beute und morgen. Stuttgart: DVA, 1982, S. 14.

552 Vgl. auch für das Folgende Wikipedia, Art. „Neue Medien“, [http://de.wikipedia.org/wiki/Neue_Medien], eingesehen am 22.10.2010.

553 Vgl. Sabine Heuser: Art. „Medien, neue“. In: Nünning (32004), S. 428f.

554 Vgl. „Definition Neue Medien“, [http://www.business-model-innovation.com/de/definitionen/ neuemedien.htm], eingesehen am 23.10.2010.

555 Gebhard Rusch, Helmut Schanze \& Gregor Schwering: Theorien der Neuen Medien. Kino - Radio - Fernsehen Computer. Paderborn: Fink, 2007, S. 21.

556 Ebd.
} 
den neuen enthalten sind. Das Digitalzeitalter stehe nicht zusammenhanglos, sondern in einer kulturellen Tradition, so dass Buch und Gedächtnis zu seinen Leitmetaphern werden ${ }^{557}$.

Die ,neuen Medien' werden weiterhin häufig mit dem Komplex ,Multimedia' gleichgesetzt, da alle denkbaren Kommunikationswege durch die zugrunde liegende Digitalisierung von Daten computergestützt ablaufen und interaktiv kombiniert werden können. So ist auch die Kombination von traditionellen und digitalen Medien durch Computer möglich: Textformate z. B. werden digital verfügbar gemacht und über das Www verbreitet, „das Schreiben verläßt die Buchform“‘558. Besonders unter dem Aspekt der Textpublikation wird befürchtet, dass Druckpublikationen wie Zeitung $^{559}$ und Buch durch elektronischen Medien und Dienste abgelöst werden könnten. Dabei stellen die elektronischen Medien bei der Verbreitung von Texten im medienpluralistischen Kontext wohl eher eine Ergänzung zu Druckmedien dar.

Im Kontext der elektronischen Textverarbeitung und der Online-Verfügbarkeit von Texten über den PC entsteht weiterhin eine neue Kommunikationssituation zwischen Autor, Text und Leser. Neben den Autor tritt der performative Leser, wie in der Rezeptionsästhetik skizziert ${ }^{560}$, der nicht nur passiv liest und aufnimmt, sondern selbst aktiv ist: Er ist dazu in der Lage, Texte fortzuführen und zu kommentieren und gelöst von der Textebene mit anderen darüber zu kommunizieren. Der Text ist digital nicht mehr nur als rein linearer Text verfügbar, sondern mit Querverweisen als Hyperlinks, die auf ein ganzes Netz von Texten verweisen.

Durch das enge Interagieren aller Medienbereiche in digitaler Form ist auch von einer heutigen ,Medienwelt' die Rede. Die seit Beginn der 1980er als ,neu'verstandenen Medien führten zudem im weiten Sinne zum Übergang zur Informationsgesellschaft, einer Gesellschaft, die auf Informations- und Kommunikationstechnologien basiert.

\subsection{Fiktionsinterne Kritik an den ,neuen Medien’ und die „Kunst zu lesen“}

Die Skepsis gegenüber ,neuen Medien’ ist in einigen Milieus, besonders unter Bücherfreunden, so groß, das Thema derart virulent, dass es auch in der fiktionalen Literatur als Ausdruck des Zeitgeistes und der Bedrohung für das Medium Buch im eigenen Medium, und hier vor allem im Roman, reflektiert wird. Medienkritik wird in die Romane eingeflochten und den Figuren in den Mund gelegt, auch werden in aktuellen Romanen ,neue Medien' den Büchern gegenübergestellt und mit dem Motiv ,Buch im Buch’ kombiniert.

\footnotetext{
557 Vgl. Helmut Schanze: „Die Wiederkehr des Buchs. Zur Metaphorik der Digitalmedien“. In: Osnabrücker Beiträge zur Sprachtheorie (OBST) 50 (1995), S. 53-60.

558 Heuser (2004), S. 428.

559 Vgl. u. a. Frank Patalong: „Die rote Liste der aussterbenden Presse“. In: Spiegel Online, 02.11.2010

[http://www.spiegel.de/netzwelt/web/0,1518,726676,00.html], eingesehen am 02.11.2010.

560 Vgl. Heuser (2004), S. 429.
} 
Der Autor Huizing lockt bibliophile Leser mit Der Buchtrinker, einem Roman über den bekannten historischen Büchernarren Tinius und nutzt diese Plattform und das so angeworbene Publikum für eine harsche Kritik an den ,neuen Medien'. Seine Sorge um den abnehmenden Einfluss der Bücher teilt er mit einem für das Thema vermutlich empfänglichen Lesepublikum. Er möchte Lust auf das Lesen machen und vermitteln, wie viel Vergnügen es bereitet, indem er zudem Zitate aus der Weltliteratur über Literatur und Lesen mit Reflexionen darüber verbindet.

In diesem Roman ,verschwindet' der büchernärrische Student Falk Reinhold am Ende in seinem Rechner. Zunächst wird er jedoch selbst zum Computer. Er besitze einen „geistigen Bildschirm“"561, doch seine Festplatte, sein Gehirn, scheint nicht ausreichend für die Flut an Informationen, deshalb kauft er sich einen PC mit großem Speicher. Reinhold scannt die Texte von Magister Tinius aus den alten Ausgaben und speichert die Dateien auf seinem PC. Auf diese Weise möchte er eine große Bibliothek anlegen. Hier wird im Roman auf die heute übliche Digitalisierung alter Monographien und Zeitschriften für einen breiten, kostenlosen Sofort-Zugang über PC und Internet hingewiesen. Das ,neue Medium’ PC wird für den Protagonisten wichtig, da es ihm neue Möglichkeiten bietet, mit dem Text umzugehen: „Erst wenn der Text auf dem Bildschirm erschien, konnte er sich wirklich in ihm spiegeln und mit der Maus in ihm herumfahren. Er würde sich einfach irgendwann in den Text verhuschen. “562 Er plant, mit dem Text eins zu werden und verschwindet in dem digitalisierten Text im PC, was bleibt ist nur der Cursor auf dem Bildschirm. Wurde er zum Opfer der neuen Zeit und der ,neuen Medien'? Hat er Selbstmord begangen aus Unfähigkeit und Unwilligkeit, in einer Welt zu leben, in der Bücher keine allumfassende Rolle spielen? So wie Tinius das Opfer seiner Bücher wurde, wird Reinhold zum Opfer der modernen Version des Textmediums im Computer, er probiert aber gleichzeitig die neue Art der Kommunikation zwischen Autor, Text, Leser über seinen PC aus.

„Irgendwann im September 1991 ging die zivilisierte Welt unter. Offensichtlich hat es niemand gemerkt. Nur Falk Reinhold. Immerhin. ${ }^{\text {“563 }}$ Im Schlusssatz des Romans spielt Huizing offensichtlich auf die Erfindung des World Wide Web und die beginnende Nutzung des Internet auch im Privatraum an, die die heute wichtigsten digitalen Medien darstellen (vgl. Kap. III.1.1.1.1). Am Freitag, dem 13. September 1991 zeigte Tim Berners-Lee von CERN einem Kollegen sein WwW. Gemeinsam testeten sie zum ersten Mal, wie es über das Internet funktioniert ${ }^{564}$. Mit dem Datum könnte auch die Entwicklung der Bibliothek libwnw gemeint sein, die alle Kernkomponenten der World-Wide-Web-Technologie besaß und anderen Programmierern die Entwicklung 
von entsprechenden Anwendungen erheblich erleichtern konnte ${ }^{565}$. Fiktionsintern habe nur der Protagonist die Vorboten des Weltuntergangs wahrgenommen, im Gegensatz zur allgemeinen Öffentlichkeit, die offensichtlich weniger bestürzt über die geringere Beachtung der Bücher ist, als der Erzähler es sich wünschte.

Das Thema Weltuntergang wird im Roman zweifach behandelt. Während Tinius in Haft eine Exegese der Johannes-Offenbarung schrieb, ist die Apokalypse bei Reinhold eine kulturelle und für ihn persönliche: Unter dem kulturpessimistischen Eindruck eines Weltendes verursacht durch die ,neuen Medien’ als medialer Konkurrenz für das Buch verschwindet er in seinem Computer, denn seine Büchersammlung, obwohl beachtlich, ist „,[n]icht einmal so groß, daß Falk darin hätte verschwinden können. “566 Außerdem fürchtet der Bücherfreund um den Einfluss der Bücher: „Und wenn Bücher eines Tages den Leser nicht mehr anschauen? Würde das den Untergang des Abendlandes einläuten? So ist es. “5677 Tinius’ Hauptwerk über den jüngsten Tag, Der jüngste Tag, wie und wann er kommen wird. In physischer, politischer und theologischer Hinsicht aus der Bibel erklärt, erschien 1836, dem Jahr, das der Theologe Bengel als Jahr des Weltuntergangs ermittelt hatte. Die Schlusszeilen der Abhandlung ergeben ein Akrostichon, das Reinhold für das Jahr 1991, seine Gegenwart, den Weltuntergang prophezeit. Die Vorboten des Weltendes meint er in den Nachrichten wahrzunehmen: Tod, Krieg, Verwüstung. Er sieht die Zivilisation als im Untergang begriffen und sich als letzten Zivilisierten ${ }^{568}$.

Kritik an den heutigen Medien wird anhand der Bewertung von Reinholds Büchersucht deutlich gemacht. Ein Büchernarr der Gegenwart wird nicht nur einem historischen gegenübergestellt, sondern auch dem Ende des Gutenberg-Zeitalters, das Büchern nach Einschätzung des Erzählers (und vermutlich auch des Autors) weniger Raum gibt und eine geringe Stellung beimisst. In der Fiktion gibt der Protagonist seine eigene Büchersucht zu und bewertet sie als Anachronismus, auch in Kommentaren anderer Figuren wird Kritik an der Situation der Medien zur Handlungszeit des Romans geübt. Reinhold nimmt sogar sein späteres Handeln, das Speichern der Texte im Computer, vorweg, wodurch wiederum ein Kommentar zum heutigen Umgang mit Digitalisaten, zudem auch zu elektronischen Unterhaltungsmedien gegeben wird:

Wie recht du hast, meine Bücherwut ist für die heutige Zeit nicht sehr gewöhnlich, aber freue dich doch, Mutter, dafür hocke ich nicht den ganzen Tag vor geistlosen Computerspielen, oder würdest du das etwa vorziehen, Mutter, alle Bücher verramschen und sich dafür einen kleinen Computer kaufen, der eine ganze Bibliothek speichern kann $[\ldots]^{569}$

\footnotetext{
565 Vgl. o. V.: „Das Phänomen World Wide Web“. Netplanet,

[http://www.netplanet.org/geschichte/worldwideweb.shtml], eingesehen am 02.11.2010.

566 Huizing (1996), S. 27.

567 Huizing (1996), S. 84

568 Vgl. ebd., S. 171.

569 Ebd., S. 61.
} 
Nach Reinholds Verschwinden äußert sich sein Buchhändler über ihn: „Mutmaßlich habe ich den letzten Büchernarren getroffen. Die Zukunft wird nur noch, da muß man kein Prophet sein, Computerfreaks kennen. (...) | Er ist zum letzten Buch geworden und liegt jetzt irgendwo in irgendeiner Bibliothek sicher verwahrt. ${ }^{\text {“570 }}$ Reinholds einziger Ausweg aus der Buchmisere ist es also, sich in ein Buch zu verwandeln, und zwar in das, letzte Buch', das als Idee mystifiziert wird, da uns die Vorstellung eines letzten Buchs unfassbar erscheint (vgl. Kap. III.2.2). An dieser Stelle wird davon ausgegangen, dass der unendliche Text mit der Seele gleichgesetzt werden kann, und somit ewig ist, während die Medien, wie der menschliche Körper, irgendwann vergehen und keinen dauerhaften Bestand haben.

Der Protagonist übt allerdings nicht nur Kritik an den Medien, sondern auch am Umgang mit Büchern und am heutigen Leseverhalten. Als geübter Leser liest Reinhold überaus genau, auch den Subtext zwischen den Zeilen. Querlesen und überfliegen verachtet er, obwohl das kursorische und schnelle Lesen zur reinen Information bereits im 18. Jahrhundert unter gelehrten Lesern, die unter dem Eindruck des wachsenden Buchmarkts und ihres Kompletionsanspruchs standen, gängig war, da sie andernfalls nicht alle Bücher hätten sichten können ${ }^{571}$. Heute ist die schnelle, dem Fernsehkonsum ähnliche die am weitesten verbreitete Methode der Lektüre (vgl. Kap. IV.3.3.2.6).

Es hat den Anschein, als lege der Erzähler dem Protagonisten diese Abrechnung mit dem ,falschen' Lesen und den ,falschen' Medien in den Mund, um einen Kommentar zur richtigen Handhabung von Büchern geben zu können. Das Ziel Reinholds ist es in der Fiktion, eine „Kulturgeschichte des Lesens“ zu veröffentlichen, die aus „Teppichen“ besteht. Die Bezeichnung folgt Clemens von Alexandrias (150-215 n. Chr.) Hauptwerk Stromateis. In der Fiktion schildern diese Zwischenkapitel Reinholds Gedanken zur Kunst des Lesens in neun Fragestellungen nach dem Wesen von Büchern und Lesen, wobei Zitate aus der klassischen und gegenwärtigen Philosophie und Literatur als Kommentare eingeflochten werden. Mittels der Bücher ist er „dem Rätsel des Lebens auf der Spur “572 - und das ist zweifellos das Thema und die Hauptaussage des gesamten Romans: Eine Anleitung dafür, wie man ,richtig' liest.

Um die Kunst zu lesen geht es auch im Roman. Das wird schon deutlich durch das Vorspiel „Höfliche Einladung, genauer zu lesen“6573. Durch das genaue Erforschen und Eindringen in Tinius' Konterfei offenbart sich der wahre Charakter der Person. Die Erforschung von Zeichen, um ihren Sinn zu erkennen funktioniert auch beim Lesen von Texten. Das ,richtige' Lesen ist bei Huizing eine intensive, schwelgerische „Wollust am Text. Wenn ich einmal richtig deutlich wer- 
den darf: Kopf runter und hinein ins Vergnügen der Texte“6574. Bei Fforde (vgl. Kap. III.7.2.4.1) wird dieses Eindringen ins Buch wörtlich genommen.

\subsection{1 „Das Buch Agnes“}

Eine ähnliche Reflexion der ,neuen Medien' zeigt sich in Peter Stamms Roman Agnes $(1998)^{575}$. Auf der Fiktionsebene wird der Text nicht einmal mehr in einem Buch abgedruckt, sondern in dessen moderne Variante, die Textdatei, eingeschrieben. Dieser Umstand hebt den Roman aus dem Korpus heraus, denn darin sollten nur physisch greifbare Bücher vereint sein. Aus diesem Grund wird Agnes ausschließlich unter dem Aspekt der Thematisierung der ,neuen Medien' im Roman herangezogen.

Agnes bittet ihren Partner, den namenlosen Ich-Erzähler, eine Geschichte über beide zu schreiben. Der Ich-Erzähler schreibt nun am Computer „das Buch Agnes“6576 über seine eigene Beziehung zu Agnes und ,erschreibt' auf diese Weise den weiteren Verlauf der Beziehung und auch der Romanhandlung. Hier liegt eine Doppelung von Schreiben, Erzählen und Lesen vor, denn wir Leser haben doch den Roman Agnes vor uns.

Es wird die Zukunft einer Lebens- und Liebesgeschichte erschrieben, ohne sie zu erleben. Ab dem Zeitpunkt der Schilderung, an dem die gemeinsame Gegenwart überholt wurde, ,müssen’ Agnes und ihr Freund tun, was dieser als Ich-Erzähler und fiktiver Autor, vorgeschrieben' hat und wie nach einem Drehbuch handeln. Auf Ungeplantes, wie Agnes' Schwangerschaft, reagiert der Erzähler deshalb überrascht und ungehalten - „nicht gerade, was ich mir vorgestellt habe [...] Agnes wird nicht schwanger “577 - , denn ein solches Ereignis ist schließlich nicht im ,Skript’ vorgesehen, nicht in seiner Imagination entstanden. Agnes aber spielt mit: Sie fühlt sich, genau wie ihr Partner und ,Drehbuchautor' es auch sieht, als sei sie „zu einer Person des Buches gewor-

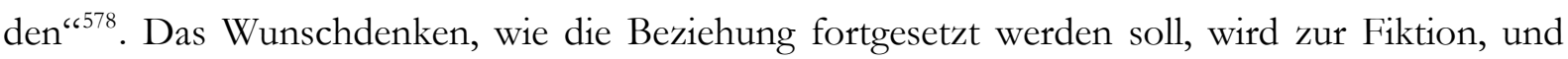
das Festhalten an der selbst geschaffenen Fiktion zur Manie, die den Erzähler den Bezug zur Realität, zum Leben mit seinen Zufällen verlieren lässt. So wie die ,neuen Medien’ das alltägliche Leben bestimmen, ist der Erzähler mit seiner Datei dazu in der Lage, das Leben seiner Freundin vorherzubestimmen und $\mathrm{zu}$ beeinflussen, bis sie schließlich in der Datei verschwindet wie Huizings Protagonist in seinem Computer. Agnes ist vornehmlich ein Beziehungsroman, aber es ist zweifellos interessant zu sehen, welche Rolle dem Schaffen von Fiktion beigemessen wird, und das nicht mehr festgehalten im Medium Buch, sondern in einem elektronischen Medium.

\footnotetext{
574 Ebd., S. 168.

575 Peter Stamm: Agnes. München: btb, 2004.

576 Stamm (2004), S. 140.

577 Ebd., S. 89f.

578 Ebd., S. 120.
} 


\subsection{Lese- und Medienkritik in der Fiktion}

In mehreren Romanen des Korpus wird den Figuren Kritik an Medien in den Mund gelegt, meist an jenen Medien, die im Begriff sind, die bisherigen abzulösen. In Der Club Dumas zieht die Freundin des Protagonisten, die als Fotografin wohl den visuellen Medien zugeneigt ist, Filme den Büchern vor:

Filme sind ein Gemeinschaftserlebnis. Wenn ich an Kino denke, denke ich an Kinder, die begeistert Beifall klatschen, weil das Siebte Kavallerie-Regiment auftaucht. Und Kino im Fernsehen ist sogar noch besser, weil man sich die Filme zu zweit anguckt und kommentieren kann. Deine Bücher dagegen sind etwas für Egoisten. Für Einzelgänger. Manche von ihnen kann man nicht einmal lesen, weil sie auseinanderfallen würden, sobald man sie aufschlägt. Wer sich nur für Bücher interessiert, braucht niemand anderen, und das macht mit angst. ${ }^{579}$

Hier wird ein klassisches Vorurteil gegen das Lesen bemüht: Der Vorwurf, dass Lesen eine einsame Beschäftigung sei, die einsam mache. Doch wie es im Zitat geschildert wird, lassen sich neben Filmen auch Bücher als kollektives Ereignis betrachten, denn man kann sie kommentieren und mit anderen besprechen, wozu es über die persönliche Begegnung hinaus auch im WwW diverse Austauschforen gibt.

Der in das Buch eingehende Leser, sei es durch eine Verwandlung, sei es durch ein ,Verschwinden' im Text, kommt immer wieder in Romanen vor. In Salamander verschwindet der Abbé im Geschichtenbrunnen, der die Quelle für alle Erzählungen darstellt. Der Roman spielt im Jahr 1741, und 300 Jahre nach Gutenbergs Erfindung „ertrinkt die Welt in Büchern“ ${ }^{\text {(580 }}$. In jeder Zeit, hier jedoch fiktional geschildert, gab es also den Eindruck, dass es zu viele Bücher gäbe, dass die Druckerpresse, lief sie erst einmal, durch menschliche Macht nicht mehr gestoppt werden könne. Die Massenproduktion bringt auch heute noch unendlich viele - vermutlich viel zu viele - Bücher hervor, aber in Salamander wird nur eines, dass alle in sich vereint, verlangt. Das absolute Buch der Romantik sowie der Mythos vom letzten und einzigen Buch sind damit eng verknüpft. Ein Argument für die Sintflut von Büchern ist es hier, die Menschen als Leser aufzuklären und nicht zu Fanatikern werden zu lassen: „Indem wir die Zahl der Bücher auf der Welt vervielfältigen, vervielfältigen wir die Zahl der Leser. Und mit jedem neuen Leser werden die Reihen der Bücherverbrenner ein wenig lichter.“581

In den Romanen werden gezielt Meinungen zum Lesen, besonders dem Lesen von Romanen geäußert. Diese Kommentare greifen die Argumente der Roman- und Lesesuchtkritik des ausgehenden 18. Jahrhunderts auf, zu dieser Zeit findet auch die Romanhandlung in Salamander statt. Hier heißt es, der Graf lese niemals erfundene Geschichten, er hält sogar eine Hetzrede gegen 
Romane, seiner Enkelin droht er Strafe an, werde sie noch einmal mit Romanen erwischt. Der Abbé ist Autor eines erfolgreichen Romans, den er aber Conte philosophique nennt, wie es auch im vorrevolutionären Frankreich üblich war. Die contes philosophiques, wie Thérèse Philosophe (1748) oder auch Schwester Monika (1815), ein Roman, der E.T.A. Hoffmann zugeschrieben wird, waren allerdings Romane, die sowohl mit philosophisch-libertären als auch durchaus pornographischen Passagen durchsetzt waren ${ }^{582}$.

In Der Schatten des Windes positionieren sich die Figuren ganz eindeutig gegenüber Büchern und anderen, neu aufkommenden Medien. Die einfache Formel lautet: Die positiv besetzten Figuren, so auch der Protagonist, schwärmen für Bücher, während die Antagonisten das Lesen kritisieren, sogar abfällig abtun und gespannt neue Medien betrachten. Im Jahr 1945 soll das Plädoyer eines begeisterten Lesers lauten:

\section{Bald befiel mich der Gedanke, hinter dem Einband jedes einzelnen dieser Bücher tue sich ein unend- liches, noch zu erforschendes Universum auf und jenseits dieser Mauern verschwendeten die Men- schen ihr Leben an Fußballnachmittage und Radioserien, zufrieden damit, kaum über ihren Nabel hinauszusehen. ${ }^{583}$}

Bücher gelten hier als Weltenöffner, obwohl doch gerade das Vorurteil ist, Bücherleser verbrächten ihre Zeit im ,stillen Kämmerlein'. Fermín, der Bücherdetektiv der Sempere-Buchhandlung, verteufelt in der Fiktion im Jahr 1955 die neue Erfindung Fernsehen als „Antichrist ${ }^{\text {“584 }}$, es mache die Menschen außerdem unselbständig. Aber auch vom Kino hält er nicht viel:

\footnotetext{
Meiner Meinung nach ist das nichts weiter als Nahrung zur Verdummung der verrohten Plebs, schlimmer als Fußball oder Stierkämpfe. Der Cinematograph ist entstanden als eine Erfindung zur Unterhaltung der analphabetischen Massen, und fünfzig Jahre später hat sich daran nichts geändert. ${ }^{585}$
}

Eine als unsympathisch vorgeführte Nebenfigur, erstaunlicherweise ein Buchverleger, lässt der Erzähler wettern: „Der Roman ist doch tot und begraben. [...] Die Amerikaner sind dabei, etwas zu erfinden, was Fernsehen heißt und wie Kino ist, aber zu Hause. Da wird es keine Bücher und keine Messe mehr | brauchen, rein gar nichts. “6586

Die Lesekritik des Antagonisten verweist auf die Lesesuchtdebatte. Er äußert: „Lesen ist für Leute, die viel Zeit und nichts zu tun haben. Wie die Frauen. Wer zu tun hat, hat keine Zeit für Märchen.“587 Lesen gilt als Zeitverschwendung, mit der Bezeichnung, Märchen’ wird der fiktionale Charakter der meistgelesenen Literatur - Romane - hervorgehoben und diese gleichzeitig als unwahr und Unterhaltung für naive Gemüter abgetan. Dieser Grundton wird noch einmal, quasi als

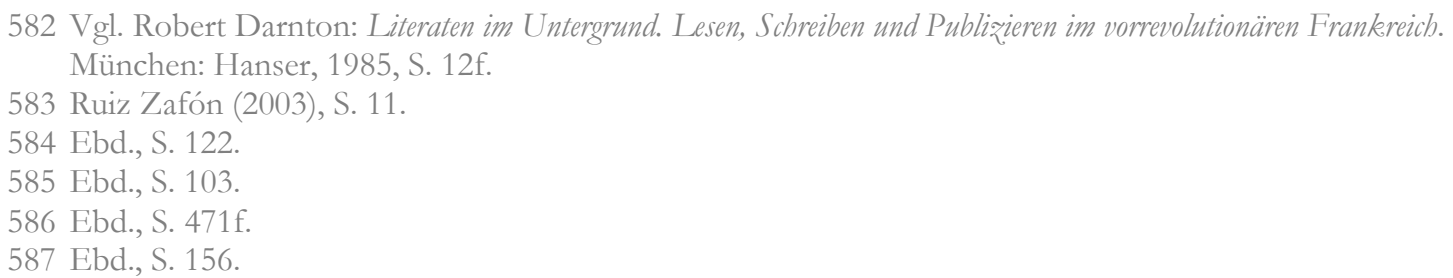


Allgemeinplatz, im Roman aufgegriffen: „Alle Welt wußte, daß Romane für Frauen und für Leute waren, die nichts zu tun hatten. ${ }^{\text {“588 }}$ Diese Kritik am Lesen entspricht beinahe wörtlich den Vorwürfen und Vorurteilen gegenüber der Lesewut des ausgehenden 18. Jahrhunderts (vgl. Kap. II.1.2).

\subsection{Schlussfolgerung}

Wie in den gesellschaftlichen Situationen, in denen sie entstehen, findet auch in der Fiktion eine Reflexion der Stellung des Buchs, also des eigenen Mediums, statt. Naturgemäß läuft diese (Selbst-) Reflexion auf ein Lob des Buchs hinaus und eine skeptische, z. T. ängstliche, z. T. überhebliche Kritik an den anderen, besonders den zu ihrer Zeit ,neuen Medien'. Die heutige Situation des Buchs und die Konkurrenz, die ihnen die elektronischen Kommunikationsmedien machen, werden in den untersuchten Romanen zur Sprache gebracht. Das fantastische Element des im Computer ,verschwindenden' Protagonisten und passionierten Lesers verdeutlicht, dass nach Ansicht des Autors die ,neuen Medien' für eine nachlassende Bedeutung des Buchs verantwortlich sind. Die Argumente dieser Medienkritik stehen in der Tradition der Lesesucht-Kritik des 18. Jahrhundert und wirken veraltet. Die Auseinandersetzung mit den ,neuen Medien' führt heute vielmehr zu einer größeren Beachtung des Buchs, was sich auch in einer verstärkten Thematisierung des Buchs in aktueller Romanliteratur niederschlägt. Darüber hinaus bedeuten die ,neuen Medien' heute vor allem eine Ergänzung zum Buch, das nicht so bald verschwinden wird (vgl. Kap. IV.3.4).

\section{9 „Unsere Wirklichkeit ist also nur die Fiktion eines Schriftstellers? ${ }^{6599}-$ Buch und Wirklichkeit}

Das Buch als literarisches Motiv ist einer langen Tradition geschuldet. In neuerer Zeit wird dieses Motiv verstärkt in Romanen verwendet, das ,Buch im Buch’ wird mit anderen Motiven neu- und rekombiniert, und somit in neue Zusammenhänge und Genres gebracht. Mit Rückgriff auf Merkmale der Postmoderne und die Mehrfachkodierung von Romanen wird, wie in Peter Stamms Roman Agnes (siehe Kap. III.8.2.1), ein Schreibprozess, der die Wirklichkeit herbeiführen kann, aber auch das Lesen selbst ebenso wie Erörterungen über Metafiktionalität ${ }^{590}$ und Selbstreferentialität reflektiert. Dies ist der Fall in den Titeln, die Gegenstand dieses Kapitels sind: Michael Collins’ Der Bestseller-Mord (2008) ${ }^{591}$, Arturo Pérez-Revertes Der Club Dumas (1997) und Zoran Živković' Das letzte Buch (2008). Diese Romane werden stärker in den Fokus genommen als die übrigen Korpustitel, die vor allem illustrierende Beispiele für besondere Implikationen waren, die das Motiv „Buch 
im Buch' in einen Roman einbringen kann. Im Folgenden werden die genannten Romane im einzelnen untersucht und erläutert, wie das Buch das Genre des Textes abwandeln kann, wie es mit Lesererwartungen reagiert und wie auf erzähltheoretische Konzepte angespielt wird, was die BuchRomane in die Nähe postmoderner Literatur rückt.

\subsection{Michael Collins: Der Bestseller-Mord (2008)}

\subsubsection{Inhalt des Romans}

Der Bestseller-Mord beginnt wie ein Campusroman: Die Hauptfigur E. Robert Pendleton ist ein gescheiterter Schriftsteller, der notgedrungen an die Universität fand. Als Dozent für Kreatives Schreiben am fiktiven Bannockburn College ist er erschöpft und verletzt über die Ungerechtigkeit der Welt, die, bei beinahe gleichen Lebensläufen, seinem Kommilitonen Horowitz ermöglichte, als Starautor zu reüssieren. Besessen von seiner „Langzeitnemesis“592 beobachtet er Horowitz’ Erfolgsgeschichte, die sein eigenes Scheitern noch deutlicher macht. Seine beständigen psychischen Probleme führen über einen Nervenzusammenbruch zu einem Versuch, sich das Leben zu nehmen, der Pendleton zunächst im Wachkoma ans Bett fesselt, bevor er verstirbt. Adi Wiltshire, Langzeitstudentin und Literaturliebhaberin, übernimmt seine Pflege. In seinem Testament vermacht Pendleton Adi seinen gesamten literarischen Nachlass, damit sie das Material für eine Dissertation nutzen kann. Neben der Nachwuchsförderung erhofft sich Pendleton posthumen Ruhm für seine Schriften, einige so gut wie unverkaufte Romane, die er im Selbstverlag herausgegeben hatte. Bekanntheit wird ihm zwar nicht durch die Aufarbeitung im Rahmen einer Dissertation, sondern durch den Skandal um seinen Roman „Schrei“ zuteil.

In Pendletons Haus findet Adi eine Kiste mit druckfrischen Exemplaren eines unbekannten, da nie verkauften Romans aus Pendletons Feder. Den literarischen Nachlass aufarbeitend, stößt sie auf den authentischen Mordfall an der 13-jährigen Amber Jewel, der in „Schrei“ geschildert zu sein scheint. Pendletons Roman wirft die Frage auf: „Ist der Autor der Mörder und das Buch seine Beichte? ${ }^{\text {‘593 }}$

\subsection{2,Buch im Buch' und Authentizität}

Der fiktive Roman „Schrei“ ist eine Reflexion über Pendletons Lebenskrise und schildert den grundlosen Mord an einem willkürlich gewählten Opfer, der kurz vor der fiktionsinternen Buchveröffentlichung tatsächlich genau so passiert ist. Anhand der Druckereirechnung lässt sich zweifelsfrei klären, dass der Roman vor dem Auffinden der Leiche fertig gestellt wurde, und somit 
Täterwissen offenbart. Der aus der Ich-Perspektive verfasste Roman scheint also das „autobiographische Geständnis eines Kindermörders ${ }^{\text {c594 }}$ zu sein. Die ab dem Zeitpunkt des Buchfundes auf der Fiktionsebene zugrunde liegende Frage ist die, ob Pendleton hier ein Verbrechen literarisch verarbeitet hat, das er selbst begangen hatte. Wie ernst ist der Erzähler zu nehmen, und ist er gleichzusetzen mit dem Autor?

Pendletons Konkurrent Horowitz finanziert die Neuveröffentlichung und sorgt mit überschwänglichem Rezensionslob dafür, dass der Roman für einen bedeutenden Buchpreis nominiert wird und in der Folge an die Spitze der Bestsellerlisten gelangt. Zusätzlicher Erfolg wird dem Roman zuteil durch den Skandal um die mögliche wahre Mordgeschichte und das persönliche Schicksal des Autors, der nicht mehr dazu in der Lage ist, sich selbst zu seinem Werk und dem Mordfall zu äußern. Wo er zuvor unbeachtet und verkannt war, wird sein literarisches Genie erst nach der Tragödie entdeckt.

Als der Fall ans Licht kommt, wird zunächst versucht, die Romanhandlung mit literarischen Mitteln zu deuten und nicht mit dem authentischen Mordfall in Verbindung zu bringen. Philosophische Deutungen werden ebenso angebracht wie die Möglichkeit des fiktional geschilderten Mordes als Topos zur Behandlung existentialistischer Fragestellungen. Bald darauf dominieren aber die Vermutungen über Pendletons Täterschaft, ,inzwischen wurde sein Roman als authentischer, bösartiger, kaltblütiger Bericht eines Mörder interpretiert, als offener Brief eines Psychopathen ${ }^{* 595}$. Außerdem taucht die Frage auf, ob ein auf offensichtlichen Tatsachen beruhender Roman noch als literarisches Werk gelten könne.

Während dem Protagonisten in der Fiktion unterstellt wird, seine eigenen Erlebnisse in einem Roman verarbeitet zu haben, kann eine Verschriftlichung auch auf zukünftiges Geschehen verweisen. Dies ist der Fall in dem Roman Die Schutzheilige des Taumels (1994) von Piero Meldini5 ${ }^{596}$. Darin entdeckt ein Heiligenforscher in einer apokalyptischen Prophezeiung, dass er als Leser jener Schrift einen Mord begehen wird. Sein drohendes Schicksal ist er aufgrund der Autorität der Schrift bereit für sich anzunehmen, denn er ist sicher, ,wenn es geschrieben steht, soll geschehen, was geschehen muss. “597

\subsubsection{Buch-Motiv und Genrewechsel}

Durch seine Konnotationen, die jeder Leser kennt, ist das Buch dazu in der Lage, das zugrunde liegende Genre des Buch-Romans zu variieren. Dies ist auch der Fall in den Romanen Das Labyrinth 
der Welt und Der Club Dumas. Hier werden die üblichen Genremuster des Detektivromans aufgebrochen, wenn die Suche der Protagonisten nach dem Buch ins Leere führt (vgl. Kap. III.2.1.1.2).

In Der Bestseller-Mord macht das Auffinden des Buchs überhaupt erst auf die Parallele zwischen dem authentischen Mordfall und der Romanhandlung aufmerksam. Nach dem Buchfund schlägt die Stimmung des vorliegenden Romans um. Auf der Fiktionsebene taucht ein Roman auf, der für die Schilderung eines, echten' Verbrechens gehalten wird: Das Erzähler-Ich dieses Romans wird mit dem Autor verwechselt. Gleichzeitig wechselt der Roman das Genre. Aus einem Campusroman und einer Satire auf akademisches Schreiben (Scheitern eines Schriftstellers; Schreiben und Publizieren im akademischen Kontext) wird ein Roman mit mindestens zweierlei Lesarten. Einerseits ist er lesbar als Satire auf die Genese von Bestsellern (lobende Besprechung durch bekannten Schriftsteller, der auch den Neudruck finanziert, Buchpreisnominierung, Bestsellerliste). Besonders das Wiederaufrollen des Mordfalls, der nur scheinbar in „Schrei“ geschildert wird, und die latente Annahme, der Autor Pendleton sei der Mörder, machen den Roman andererseits auch zum Krimi.

Das Auftreten des Buchs als Motiv in der Handlung zeigt an, dass etwas Neues passiert, denn es ist verknüpft mit gewissen Implikationen und Vorstellungen, die es im Leser weckt. Die Stimmung kippt, und der Roman wechselt in ein neues Genre, so dass von einem Genre-Mix die Rede sein kann: „Collins mixt akademische Satire, Philosophie und Tragödie“ ${ }^{\text {(598 }}$. Diese Hybridisierung von Genres, in der Literatur ebenso wie im Film, ist ein Merkmal postmoderner Kunst (vgl. Kap. II.9). Wo dem fiktiven Autor explizite Bezüge zwischen seiner Realität und Fiktion unterstellt werden, um sein Verbrechen öffentlich zu machen - hatte er sich „aus reiner Not der Postmoderne“ ${ }^{599}$ zugewandt? - bindet auch der Autor Collins postmoderne Charakteristika in seinen Roman. Sein Text, der nur vordergründig ein Krimi ist, bietet die Möglichkeit vielschichtiger Dechiffrierungen mehrfacher literarischer Codes.

Auf diese Weise wird mit den Lesererwartungen gespielt. Beginnend als Campusroman führt der Roman in die Welt der Universität ein, die im Weiteren eine Rolle spielen wird, und akademisches Personal - den unzufriedenen Dozenten, die Langzeitstudentin, den verkrachten Journalisten und Fotografen, der nun studiert - vor. An dieser Stelle besitzt der Roman entsprechende Motive. Die Atmosphäre wandelt sich, wenn das Motiv Buch, in Form des unbekannten Romans, hinzukommt. Schon in der etwas schlichten deutschen Übersetzung des Titels als „Der Bestseller-Mord“" werden Buch-Motiv und Krimigenre verbunden, denn ab dem Zeitpunkt des fiktionsinternen Buchfundes bereichern genretypische Merkmale eines Krimis die Romanhandlung: ein 
Mord als Dreh- und Angelpunkt, ein polizeilicher Ermittler, der diesen und weitere verwandte Fälle aufklären soll, die Entdeckung der Undurchsichtigkeit aller Beteiligten, ein weiterer Mord. Da der Roman über den weitaus größeren Teil als Krimi gesehen werden kann, wird er von seinem Verlag dieser Warengruppe zugeordnet und richtet sich dadurch an ein entsprechendes Publikum. Das Krimipublikum allerdings findet seine Erwartungen an einen Krimi nicht voll umfänglich erfüllt. Der Roman bietet keineswegs eine konventionelle Krimihandlung, sondern geht noch einen Schritt weiter, indem er Reflexionen über mögliche Subtexte des fiktiven Romans „Schrei“ über den Mordfall hinaus impliziert. Darüber hinaus ist Der Bestseller-Mord ein Roman über Literaturproduktion, -rezeption und -theorie, und das durch den unterschwelligen Bezug zur Theorie vom „Tod des Autors“, da Pendleton als Autor des fiktiven Romans im Roman für den Mörder im Kontext des ,authentischen' Verbrechens gehalten wird, das er literarisch verarbeite. Das Buch-Motiv in neuen Genreumwelten, wie hier im Krimi, bietet Möglichkeit und Anlass zur Selbstthematisierung von Literaturtheorie und Metafiktion.

\subsubsection{Intertextuelle Bezüge im Roman}

Neben dem Subtext des Mordfalls werden Pendletons Roman „Schrei“ die Wirkung des Existenzialismus, Bezüge zu Nietzsches Konzept des Übermenschen sowie zum Vorbild des authentischen Falls von Leopold und Loeb unterstellt. Die amerikanisch-jüdischen Studenten hatten 1924 Mord an einem willkürlich gewählten Opfer begangen. Realität und Fiktion vermischen sich hier, da auf der Fiktionsebene auf Kontexte angespielt wird, die real existieren und dem Leser bekannt sind.

In Pendletons Bibliothek wird ein Buch über Leopold und Loeb gefunden, weshalb vermutet wird, er habe ihre Idee eines ,perfekten Mordes ${ }^{900}$ nachahmen wollen, damit verbunden wird sogar ein literarischer Rückgriff auf Dostojewskis Schuld und Sübne / Verbrechen und Strafe (1866). Das Verbrechen der Studenten hatte philosophische Motive: Ihr Ziel war es, den Beweis der Existenz des Nietzsche'schen Übermenschen zu erbringen, die die Tötung eines niederen Wesens rechtfertigt. Auch Pendleton als mutmaßlicher Mörder soll sich in die Herausforderung Gottes hineingesteigert haben, die durch die Erhebung des Intellektuellen über die als ,Abschaum' betrachtete Unterschicht geschehen soll. Das Motiv des außergewöhnlichen Menschen, der Überlegenheitsgefühle entwickelt und den Mord an vermeintlich Unwürdigen als gerechtfertigt empfindet, ist auch in Schuld und Sübne anzutreffen.

Beinahe einen zweiten ,Buch-im-Buch'-Komplex stellen die Romane von Stephen King dar. Wright, Pendletons Student und wie sich herausstellt Erfinder des Urtextes, auf den sich dessen 
Roman bezieht, ist ein großer Anhänger des Horror-Schriftstellers, so dass dessen Werke an mehreren Stellen erwähnt und unter den Figuren diskutiert werden. King thematisiert in einigen Romanen die Nöte von Schriftstellern, das prominenteste Beispiel ist wohl Misery (1987). Pendletons Pflegerin trägt den Vornamen der Protagonistin, einer Krankenschwester, die einen Schriftsteller gefangen hält. Ein weiterer Bezug gilt The Shining (1977). Adi findet eine rückwärts geschriebene Schrift auf einem Spiegel, die an die berühmten rückwärts geschriebenen Buchstaben REDRUM aus der Kubrick-Verfilmung erinnert. In ihrem Seminar zu William Carlos Williams wird zudem gemutmaßt, ,[...] was war The Shining schon anderes als der flüchtige Einblick des Normalbürgers in das Schriftstellerleben, in den offensichtlichen Wahnsinn von Schreibblockade und mangelnder Inspiration? ${ }^{\text {6601 }}$ Auch Pendleton scheint dem Wahnsinn verfallen, und es wird die Frage gestellt, ob er im Wahn gemordet hat.

Die Thematisierung des Lyrikers Williams ist angesichts der postmodernen Bezüge im Roman nur folgerichtig. Williams evoziert mit seinen knappen Gedichten eher Bilder in seinen Lesern und weckt Emotionen statt auf Symbole hinzuweisen. Dies ist vielleicht in der Annahme begründet, der Leser empfinde eine Bedeutsamkeit in den Bildern, und zielt auf eine gemeinsame Vorstellungs- und Verständnisebene von Autor und Leser. Im realen Leser ruft ein Text die Erwartung von Versatzstücken von Genres oder Motiven hervor, die er aufgrund seiner literarischen Vorbildung besitzt und wie Bilder ,sehen' kann.

\subsubsection{Der Roman im Roman als „Beichte"? Roland Barthes' „Tod des Autors“"}

In Der Bestseller-Mord wird die Erzählsituation des Binnenbuchs auf der Fiktionsebene vom Großteil des Publikums missverstanden und der Autor des fiktiven Romans mit dem Erzähler-Ich gleichgesetzt. Dies geschieht aufgrund der Übereinstimmung der Details bei der fiktionalen Schilderung des Mordes und dem fiktionsintern authentischen Mordfall. Der Roman „Schrei“ trägt zwar autobiographische Züge, ist aber Fiktion (in der Fiktion). Die Annahme, Pendleton habe für literarischen Ruhm gemordet und der Roman sei der Beweis für seine Schuld, ist ein literarisches Missverständnis. Den naiven Blick auf die Situation gegenüber dem Verständnis eines in der Erzähltheorie bewanderten Schriftstellers schildert der folgende Dialog zwischen dem Autor Horowitz und dem Ermittler Ryder:

Schroff gab Ryder zurück: „Aber Pendleton hat Amber Jewel umgebracht.“

Horowitz schüttelte langsam den Kopf. „Detective, Sie verwechseln die beiden, den Schriftsteller und die Romanfigur. Ich nicht. Ich kann nur über das Buch reden, über Pendletons Hauptfigur.“

„Sie sind ein und dieselbe Person.“

„Okay, dann beweisen Sie es! Sie sind der Polizist.“602 
Der Autor Pendleton kann sich nicht mehr zu seinem Werk äußern, da er nach einiger Zeit im Wachkoma an den Folgen seines Selbstmordversuchs verstirbt. Aber ist es notwendig, dass sich ein ,Autor' zu seinem Werk äußert, kann man von diesen Aussagen gesicherte Erkenntnisse über ein Werk erlangen? Vielmehr ist es doch so, dass sich ein Autor gar nicht zu seinem Werk äußern sollte, da der Text für sich stehen soll ${ }^{603}$. Überdies kann er sicher nicht zweifelsfrei und voll umfänglich angeben, wie der Text zustande kam oder gar, ,was er bedeuten soll'. Der Text soll für sich selbst stehen und in Dialog mit dem Leser treten.

Der Text überlebt den Autor - gemeint ist hier die Theorie vom „Tod des Autors“, die Roland Barthes in den 1960ern aufgestellt hat, ein Konzept, das auch im Roman angesprochen und wörtlich genommen wird:

\footnotetext{
Mit seinem Selbstmordversuch hatte Pendleton sein Werk freigegeben, er hatte es ins Leben entlassen, denn nun gab es keinen eindeutigen Erzähler mehr und keinen Autor, bei dem man hätte nachfragen können. War das nicht eines der Kriterien großer Literatur - dass der Autor vor allem tot sein musste?604
}

Der Titel von Barthes’ Essay ist „nahezu sprichwörtlich geworden“, wobei sich Barthes dezidiert gegen die „naive Identifikation von Werkbedeutung und Autorbiographie ${ }^{\text {6605 }}$ richtet. Der auteur als Herr über den Text ist nicht mehr relevant, „[d]er Text wird von nun an so gemacht und gelesen, dass der Autor in jeder Hinsicht verschwindet.، ${ }^{606}$

Barthes meint, „linguistisch gesehen, ist der Autor immer nur derjenige, der schreibt ${ }^{6607}$, als Performativ nach der Sprechakttheorie. Damit schwindet der Autor als Schöpfer des Textes und als Subjekt. An seine Stelle tritt der „moderne Schreiber“6008, der scripteur, der den Text als immaterielle écriture nur zu Papier bringt und dabei aus bestehenden Diskursen kompiliert, denn der Text sei „ein Gewebe von Zitaten aus unzähligen Stätten der Kultur.“609 Jeder Autor bringe nicht mehr als eine Ansammlung von Gelesenem und Erfahrenem oder bestehenden Diskursen hervor, zwar in neuen Kontexten und neu verbunden, aber am Ende steht stets mehr als nur ein Text.

Barthes richtet sich gegen die Erschließung eines Textes über die Autorbiographie und nimmt so dem Autor die Autonomie über den Text, indem er ihn zum bloßen Kompilatoren im Spiel mit Intertextualität, Zitaten und Anspielungen macht. Der Autor soll also nicht mehr Bezugspunkt des

\footnotetext{
603 „Der Autor müßte das Zeitliche segnen, nachdem er geschrieben hat. Damit er die Eigenbewegung des Textes nicht stört.“, vgl. Umberto Eco: Nachschrift zum ,Namen der Rose’. München: dtv, 1986, S. 14.

604 Collins (2008), S. 77.

605 Fotis Jannidis: Einleitung zu: Roland Barthes: „Der Tod des Autors“ [zuerst 1967]. In: Texte zur Theorie der Autorschaft. Hg. u. komm. v. Fotis Jannidis et al. Stuttgart: Reclam, 2000, S. 181-184, hier S. 181.

606 Roland Barthes: „Der Tod des Autors“. In: Jannidis (2000), S. 185-193, hier S. 189.

607 Ebd., S. 188.

608 Ebd., S. 189.

609 Ebd., S. 190.
} 
Textes sein, denn der Text kann bei der Rezeption Implikationen entwickeln, die der Autor nicht geplant oder beabsichtigt hat.

In diesem Zusammenhang wird die Rezeption des Textes gegenüber der Produktion aufgewertet. Hinter dem Text steht nicht eine ,zutreffende' Bedeutung, ein endgültiger Sinn, vielmehr steht das Erkennen und Deuten von Verweisen auf Texte im Vordergrund. Über den Autor gehen lediglich jene Implikationen in den Text ein, die Umberto Eco das „Echo der Intertextualität ${ }^{\text {“610 }}$ nennt. Dies sind Diskurse und Texte, die den Autor beim Schreiben implizit oder explizit beeinflussen. Die Fäden der Verweise auf zitierte Schriften laufen im Knotenpunkt des Textes zusammen, wo sie der Leser durch mehr oder weniger Kenntnisreichtum mehr oder weniger erfolgreich entwirren kann. Der Leser unternimmt, abhängig von seiner literarischen und kulturellen Vorbildung, eine eigene Textinterpretation und liest wiederum unterschiedliche Texte und Lesarten aus dem Text heraus, vielleicht ganz andere, als der Autor eingeschrieben hat, und das auf unterschiedlichen Ebenen und Codes.

\begin{abstract}
Ein Text ist aus vielfältigen Schriften zusammengesetzt, die verschiedenen Kulturen entstammen und miteinander in Dialog treten, sich parodieren, einander in Frage stellen. Es gibt aber einen Ort, an dem diese Vielfalt zusammentrifft, und dieser Ort ist nicht der Autor (wie man bislang gesagt hat), sondern der Leser. Der Leser ist der Raum, in dem sich alle Zitate, aus denen sich Schrift zusammensetzt, einschreiben, ohne dass ein einziges verloren ginge. Die Einheit eines Textes liegt nicht in seinem Ursprung, sondern in seinem Zielpunkt $[\ldots]^{611}$
\end{abstract}

Diese Postulierungen weisen bereits auf Merkmale des postmodernen Romans hin (vgl. Kap. II.9). Nach Barthes erlangt das Werk erst durch die Rezeption Sinn, nicht durch die Produktion, durch den Leser, nicht den Autor. Barthes schlussfolgert: „Die Geburt des Lesers ist zu bezahlen mit dem Tod des Autors. ${ }^{\text {“612 }}$

In Collins' Roman wird der, Tod des Autors ${ }^{313}$ nun wörtlich genommen. Die englische Übersetzung von Barthes' Text erschien 1967 als The death of the author, während Collins' Roman im amerikanischen Original den Titel Death of a writer trägt. Die Ähnlichkeit ist sicher nicht unbeabsichtigt, wobei der feine Unterschied schon auf die Lösung hindeutet: Auf den Protagonisten Pendleton wird nicht als author, sondern richtig als „writer" verwiesen, was etwa dem Barthes'schen Begriff des scripteur entspricht. Ein fiktionsinterner Kenner von Barthes’ Konzept hätte die Figur also nie in Verdacht gehabt, einen selbst verübten Mord literarisch geschildert zu haben, da er

610 Eco (1986), S. 18.

611 Jannidis (2000), S. 191.

612 Barthes (2000), S. 193.

613 Bereits 1992 erschien Gilbert Adairs Novelle The death of the author (Der Tod des Autors. Edition epoca: Bern, 1997, Tb: Rowohlt, 2002). Darin schildert Adair den Mord an dem ,Theoriepapst' Sfax, hinter dessen die Literaturwissenschaft beherrschenden Theorie ganz eigennützige Zwecke stecken: Sfax möchte seine jugendliche Autorschaft nazifreundlicher Artikel ausradieren. In seiner Theorie sieht er eine Möglichkeit zur Ehrenrettung, indem er scheinbar nachweist, der Text sei autonom, schreibe sich selbst und konstruiere gleichsam seinen Autor, nicht umgekehrt. Der Mord am Autor Sfax beweist in der Fiktion, dass Texte mehr Autorität besitzen als (ihre) Autoren. 
werkimmanente Darstellungen nicht mit der Biographie des Urhebers des Textes in Verbindung gebracht hätte.

Pendletons Text ist ein Gewebe von Zitaten mit seinen diversen kulturellen Anspielungen, allerdings auch ein Plagiat. Es stellt sich heraus, dass Pendleton für seinen Roman „Schrei“ aus einem literarischen Versuch seines Studenten Wright abgeschrieben, als ungleich vermögenderer Schriftsteller das Manuskript aber zu einem Meisterwerk umgearbeitet hat. Wright kann also als ,geistiger Verfasser ${ }^{614}$ der wahren Mordgeschichte gelten, und tatsächlich stellt sich Wright als Mörder von Amber Jewel heraus. So wird für den ,naiven’ Leser das Konzept noch einmal ganz anschaulich gemacht: Pendleton, ,Autor', besser: scripteur, des Romans „Schrei“, hat auf bereits bestehende Texte zurückgegriffen, wobei sich die Subtexte von Nietzsche oder Leopold und Loeb als Finten zeigten. Wrights Manuskript aber ist der Schlüssel, der zum Mörder führt.

Zudem wird durch den Bezug zum literaturtheoretischen Konzept die Lösung, bzw. Lesart des Romans nahegelegt: Nicht der Autor dient als Deutungsinstanz des Textes. Vielmehr steht die Leserin, Adi, im Vordergrund, die Pendletons Werke auswertet. Der scripteur Pendleton ist tot - um mit Barthes zu sprechen, bedeutet dies, dass Pendleton den Freitod wählt, um die Entstehung der Leserin Adi zu ermöglichen. Wo er als Autor scheiterte, soll sie als Leserin und Forscherin über sein Werk reüssieren.

Ein Schriftsteller ist mitnichten alleiniger Schöpfer seines Werkes. Der Subtext seiner Kultur geht ebenso in sein Werk ein wie Einflüsse von Gelesenem bis hin zur Aneignung fremder Ideen und geistigem Diebstahl. Alle Bücher enthalten andere Bücher: Eine Begründung und Legitimation für das Motiv ,Buch im Buch’.

\subsubsection{Der Roman und seine Leser}

Das Urteil des auf dem Umschlag zitierten Rezensenten der W ashington Post, „Ein verteufelt spannender Krimi ${ }^{6615}$, teilen nicht alle Leser des Romans. Mit den Augen eines vor allem an Spannung interessierten Lesers erscheint der Roman zu langatmig, die z. T. langen, anspruchsvollen Dialoge um Literatur und Philosophie stören möglicherweise, und für einen Kriminalroman erscheint Der Bestseller-Mord zu ereignislos. Die Erwartungen eines Krimilesers an den Text werden nicht voll erfüllt, wie auch die folgenden Leserrezensionen deutlich machen: „Michael Collins verspielt eine an sich nicht gerade uninteressante Grundidee, indem er sich permanent in vollkommen unwesentliche Nebenhandlungen verirrt sowie ständig seine Protagonisten wirr und ab-

\footnotetext{
614 Darauf verweist auch schon sein Name. ,Wright’ steht im historischen Englisch für den Wortteil „-bauer“", ,-macher" oder „-verfertiger".

615 Collins (2008), Umschlaginformation.
} 
gehoben über Literatur und Philosophie diskutieren lässt.“616 - „Der Autor hat sich für meine Begriffe zu sehr an Details aufgehalten, die den Leser nicht sonderlich interessieren. “617

Die Erwartungen eines Krimilesers laufen an dieser Stelle in die Irre. Der Normalleser findet seine Genrevorstellungen nicht wieder, denn eine Lektüre auf der Ebene eines Krimis ist nicht ohne Weiteres möglich, da das Genre Krimi vermutlich hauptsächlich aus dem Grund gewählt wurde, um die Verrätselung der erzähltheoretischen Voraussetzungen fiktional umzusetzen. Das Konzept vom „Tod des Autors“ lädt geradezu zu solchen Gedankenspielen ein. So wurden die Leser vermutlich durch die Suggestion im Klappentext aufmerksam, es handele sich bei dem Roman um eine, sicher spannende, Mörderjagd. Ein vorgebildeter Leser, der die fiktionale Umsetzung der Theorie vom „Tod des Autors“ durchschaut, empfindet dagegen Vergnügen beim Erkennen der Anspielungen auf philosophische, gesellschaftliche und literaturtheoretische Konzepte.

\subsection{Arturo Pérez-Reverte: Der Club Dumas (1997)}

\subsubsection{Zum Roman}

Der Erzähler Boris Balkan schildert die Erlebnisse des Bücherjägers Lucas Corso, dessen Broterwerb es ist, seltene und wertvolle antiquarische Bücher für seine Auftraggeber zu beschaffen (vgl. Kap. III.2.1.1.2). Im Auftrag seines Freundes, des Antiquars Flavio La Ponte, soll er die Authentizität einer Handschrift angeblich von Alexandre Dumas père prüfen. Dabei handelt es sich um ein Kapitel aus dem Originalmanuskript zu Die drei Musketiere. Ein parallel zu erfüllender Auftrag durch den Antiquar Varo Borja führt Corso auf die Spur des geheimnisvollen (fiktiven) Teufelsbuchs Die neun Pforten ins Reich der Scbatten, von dem es nur noch drei Exemplare überhaupt gibt. Auch hier ist seine Aufgabe, die Echtheit des Buchs zu prüfen, was zu einer gelingenden Teufelsbeschwörung führen soll. Im Laufe seiner Recherchen begegnet er dem mysteriösen „Club Dumas“, der sich für Dumas’ Anerkennung als genialer Schriftsteller und die (Wieder-)Veröffentlichung und Verbreitung seiner Werke stark macht. Die Absichten des Clubs sind harmlos und rein schöngeistig, mit den Morden in Zusammenhang mit den Neun Pforten hat er nichts zu tun.

Leitmotive in Der Club Dumas stellen, neben den Büchern, der Autor Alexandre Dumas und sein Roman Die drei Musketiere sowie der Detektivroman als solches dar, auf dessen bekannte Vertreter wie Werke von Agatha Christie oder Arthur Conan Doyle immer wieder Bezug genommen wird. Diese Leitmotive bilden die Struktur der Handlung und verknüpfen einzelne Szenen.

\footnotetext{
616 Lesezeichen S. D.: „Langweilig, langatmig und vorhersehbar“, Leserrezension zu Michael Collins: Der BestsellerMord, Amazon.de, 04.04.2008, [http://www.amazon.de/Bestseller-Mord-Michael-Collins/dp/3442737184/ ref=sr_1_1 ?ie=UTF8\&qid=1297245357\&sr=8-1], eingesehen am 09.02.2011.

617 roseF, o. T.: Leserrezension zu Michael Collins: Der Bestseller-Mord, LovelyBooks.de, 17.04.2008, [http://www.lovelybooks.de/buch/17878230/michael_collins_der_bestseller_mord/uebersicht/], eingesehen am 09.02.2011.
} 
Strategien des Detektivromans werden schließlich auch bei der Auflösung eingesetzt (vgl. Kap. III.2.1.1.5.1).

Das Thema des Romans ist eine erzählerisch umgesetzte Interpretation des Konzepts der Metafiktion. In der Figur des Protagonisten Corso wird zudem eine falsche Art zu lesen vorgeführt, die von einer übergroßen Intensität bei der Anwendung intertextueller Bezüge und dem Grad der Identifikation mit den Figuren abhängt.

Die Verfilmung des Romans unter dem Titel Die neun Pforten (1999, Regie: Roman Polanski) mit Johnny Depp in der Rolle des Corso verschenkt den Clou des Romans und lässt den Erzählstrang um die Drei Musketiere völlig aus, während das dämonische Buch der Neun Pforten fokussiert wird. Die jeweiligen Handlungskerne sind schon aus den Titeln von Roman und Film ersichtlich. Aus diesem Grund ist der Club im Film eine Geheimgesellschaft von Teufelsanbetern, die nicht das Dumas-Manuskript, sondern alle Exemplare des Teufelsbuchs an sich bringen will. Das im Film betonte dämonische Element (Luzifer in Gestalt des Mädchens, dämonisches, von Luzifer illustriertes Buch) dient im Roman nur der Ablenkung und Verstrickung des Bücherjägers Corso in Kräfte, die seine Aufträge erschweren und ihn auf eine falsche Fährte locken und seine Überinterpretation anregen. Der dämonische Inhalt dient der Legitimierung, weshalb dieses Buch neben dem Dumas-Manuskript untersuchenswert ist. Eine Diplomarbeit untersucht Roman und Filmadaption und stellt fest, dass die verkürzte Verfilmung ,um alles bibliophile Beiwerk zu Dumas ${ }^{\text {‘618 }}$ gerafft worden sei. Diese Darstellung erscheint jedoch zu vereinfacht, denn gerade der bibliophile Club der Dumas-Verehrer und seine Hintergründe machen den Roman aus. Die intertextuellen Verweise, die mitnichten Beiwerk, sondern ganz essentiell für den Zugang sind, sind es gerade, die den Roman über das Niveau gewöhnlicher Spannungsliteratur heben.

Durch die Verwendung paranormaler Phänomene, die besonders mit der Figur des teuflischen Mädchens gekoppelt sind (beherrscht das Fliegen, hohe Bewegungsgeschwindigkeit, kennt Corsos Geheimnisse etc.), können Roman und vor allem Verfilmung auch dem Mystery-Genre ${ }^{619}$ zugerechnet werden. Dieses relativ neue, hybride Genre bildete sich aus der Kombination von Elementen unterschiedlicher bekannter Genres, wie denen des Krimis, des Horrors und der Fantasy. Die Mystery zeichnet sich darüber hinaus durch eine hohe Intermedialität, die Verfilmung beweist dies, einen postmodernen Schreibstil sowie den Kampf des Protagonisten gegen unheimliche, unbekannte Mächte, oft in Geheimbünden organisiert, aus, wobei das Lösen geheimnisvoller Rätsel durch den Protagonisten im Vordergrund steht. Das Mystery-Genre ist entstanden in einer Zeit, nämlich unserer Gegenwart, in der alles rational erklärbar scheint, und kaum ungelöste Geheimnisse existieren, 
ähnlich wie in der Zeit der Aufklärung eben auch Spukgeschichten en vogue waren: Das Rationale bringt an dieser Stelle sein Gegenteil hervor und führt zu einer Aufwertung des Übersinnlichen.

\subsubsection{Lesende Helden}

Nicht Corso als Hauptfigur ist ein ,lesender Held' (vgl. Kap. II.1.3). Vielmehr entdeckt er im vorliegenden Kontext durch die Bücher, die er im Auftrag Dritter untersucht, seine breite kulturelle Kenntnis und wendet eine falsche Art zu lesen an. Eine Heldin, die liest, ist Irene Adler. Durch ihre Lektüre der Drei Musketiere weiß sie die richtigen Stichworte für weitere Handlungen zu geben und kommt schließlich den Absichten des Clubs auf die Schliche.

Die eigentliche lesende Heldin wird jedoch erst im Finale als die im Hintergrund die Fäden Ziehende entlarvt: Es ist Liana Taillefer, Gründungsmitglied des Club Dumas, die in der Tradition von Emma Bovary Fiktion und Realität so weit durcheinander bringt, dass sie durch ihren Lieblingsroman Die drei Musketiere nicht nur in romantische Schwärmereien gerät und in ihrem Handeln beeinflusst ist (z. B. könnte sie sich darauf beschränken, Kleidung oder Ausdrucksweise der Hauptfiguren anzunehmen), sie besteht vielmehr sogar darauf, die Handlung nachzuspielen. Dabei dienen ihr ihre beträchtlichen finanziellen Mittel dazu, nicht nur diverse Handlanger als Nebenfiguren einzubeziehen. Corso bemerkt erst allmählich, dass er in ihrer Inszenierung die Rolle des D'Artagnan spielt, und dringt als Neuling in die etablierte Welt des Clubs wie in die Welt des Hofs von Ludwig XIII. ein, wo er sich nur schwer zurechtfindet. Ihre Vorliebe für die Figur der Milady begründet sie damit, dass sie sich als anspruchsvolle Leserin sieht, die sich „nicht mit stereotypen Gemeinplätzen“620 zufrieden gebe. Deshalb habe sie schon immer davon geträumt, „einmal ein richtig spannendes Abenteuer zu erleben - voll von Intrigen, Liebesaffären und Verfolgungsjagden, wie bei ihrem Vorbild Milady ${ }^{\text {“621 }}$, was sie mit Corso in der Hauptrolle in der fiktionsinternen Realität in die Tat umsetzt.

\subsubsection{Zwei Bücher - zwei Handlungsräume}

\subsubsection{Die drei Musketiere}

Der Roman Die drei Musketiere fungiert als Subtext für Der Club Dumas und liefert in dieser Rolle einen Kommentar zum Geschehen. Der Protagonist meint, in den Personen, auf die er im Rahmen seiner Recherchen trifft, Charakterzüge, Verhaltensweisen oder Personenkonstellationen zu begegnen, die auf Figuren aus Die drei Musketiere hindeuten. 
Während Corso selbst als D'Artagnan agiert, der als Protagonist im Mittelpunkt der Handlung steht, entspricht der Erzähler Boris Balkan der Literarisierung des Kardinals Richelieu ${ }^{622}$, als Eminenz im Hintergrund, die über mehr Wissen als andere verfügt. Mit diesem Überblick berichtet und kommentiert Balkan das Geschehen als Erzähler (vgl. Kap. III.2.1.1.5.1). In der Auflösung tritt er als ,Richelieu' in Erscheinung und klärt, allerdings in der Manier des Sherlock Holmes, den Protagonisten Corso darüber auf, welches die Hintergründe für seine Erlebnisse waren. Die Clubvorsitzende Liana Taillefer ist selbst ein Zitat. Die von ihr verehrte Milady de Winter wird in der klassischen Verfilmung (1948, Regie: George Sidney) von Lana Turner gespielt, wobei die Ähnlichkeit des Namens vermutlich vom Autor beabsichtigt ist. Auf diese Verfilmung verweist auch der Roman ganz konkret (vgl. Kap. III.9.2.4). Um ihrem Vorbild noch näher zu kommen, besitzt sie als Club-Mitglied das 37. Kapitel ,Miladys Geheimnis' sowie eine Tätowierung in Form einer Lilie. Der Handlanger des Clubs besitzt keinen Namen und wird nur Rochefort genannt. In einer TV-Verfilmung soll er diese Rolle bereits gespielt haben.

\subsubsection{Das Buch der neun Pforten ins Reich der Schatten}

Das fiktive Buch der neun Pforten ins Reich der Schatten soll 1666 in Venedig gedruckt worden sein. Es enthält neun Holzschnitte, die dem Delomelanicon entnommen worden sein sollen, das wiederum angeblich Luzifer selbst verfasst habe. Mit dem Buch der neun Pforten soll es demjenigen, der es zu interpretieren vermag, möglich sein, den Teufel zu beschwören. In Der Club Dumas eignet sich jedoch keines der drei noch existenten Exemplare für dämonische Zwecke, da die darin enthaltenen Holzschnitte eine Fälschung aufweisen. Corsos Auftrag führt also ins Leere. Das Auftreten dieses Teufelsbuchs rückt den Roman außerdem in die Nähe des Schauerromans.

\subsubsection{Zwei unverbundene Aufträge}

Der Roman Der Club Dumas verfolgt ein der Suche nach einem Buch entgegengesetztes Muster: Der Protagonist Corso ist bereits im Besitz der Bücher und muss nun versuchen, sich diese nicht abnehmen zu lassen. Corso, der seine Aufträge erfüllt und zugleich nach der geheimen Verbindung zwischen beiden Werken sucht, wird seinerseits gejagt, was dem Roman Elemente eines Thrillers hinzufügt. Darüber hinaus gibt besonders der Fund des Toten gleich zu Beginn das Genre Detektivroman vor. Doch wird im weiteren Romanverlauf nicht der Mörder gesucht, vielmehr stehen die geheimnisvollen Bücher im Vordergrund. Das Genre wird konsequent bis zum Ende durchgehalten, wobei fiktionsintern immer wieder explizite Bezüge auf das eigene Genre unternommen werden. Ein besonderes Beispiel dafür ist die Figur Irene Adler, die auf die Sherlock-Holmes-Erzählungen hindeutet (vgl. Kap. III.2.1.1.4). Angereichert wird der Roman 
nicht nur durch das Motiv ,Buch im Buch', sondern auch durch die vielen Bezüge zur Buchwelt und Anspielungen auf Werke der Weltliteratur, mit denen der Roman durchsetzt ist. Die Buchwelt wird besonders stark betont, nachdem Corso entdeckt zu haben meint, er sei einer Verbindung zwischen beiden Büchern auf der Spur, die zur Auflösung führe.

Allerdings sieht der Protagonist einen Zusammenhang, wo keiner existiert: "The original novel, El Club Dumas, is a complicated narrative that links two unrelated stories through the protagonist's (and the reader's) excessive intertextuality... “623. Die Verknüpfung stellt Corso aufgrund seiner Literaturkenntnis und vermeintlicher Querverweise her, die er zwischen beiden Büchern sieht. Die beiden gänzlich separaten Bücher und Aufträge werden jedoch nur in der Vorstellung des Protagonisten verbunden, der zeitgleich an den Aufträgen arbeitet, um Zeit und Geld zu sparen. Die einzige Verbindung ist, dass Corso beide Bücher in seiner Tasche bei sich trägt. Die unterstellten Bezüge sind ihm zwischenzeitlich so offensichtlich, dass sie „fast schon wieder unmöglich erschienen“624. Seine Fähigkeit zu intertextuellen Schlüssen ist ihm zwar nützlich, Zusammenhänge zu verstehen, verstrickt ihn jedoch auch immer weiter in unzutreffende Beziehungen, so dass er beinahe außerstande ist, Realität und Fiktion auseinanderzuhalten.

Die vermuteten Bezüge zwischen beiden Büchern vermischen sich soweit, dass Corso den Club Dumas für die aufgrund des dämonischen Buchs begangenen Morde verantwortlich macht. Während die Handlung übernatürlich und rätselhaft erscheint, sobald sie das Teufelsbuch in den Fokus nimmt, gibt es für die Aktivitäten des Clubs eine pragmatische Erklärung. Der Club hat zum Ziel, das verlorene Manuskript wiederzubeschaffen, um es an ein neues Mitglied weiterzugeben und inszeniert dabei die Handlung des Dumas-Romans mit Corso in der Hauptrolle.

Außerdem gibt es keine Intrige um Taillefers Tod, der nicht durch Mord, wie angenommen wird, herbeigeführt wurde, sondern durch Selbstmord. Er wählte den Freitod, da die Veröffentlichung seines eigenen historisierenden Fortsetzungsromans in Anlehnung an sein Idol Dumas („Die Hand des Toten oder Der Page Annas von Österreich“) vom Club-eigenen Verlag abgelehnt und er überdies als stümperhafter Schriftsteller und Plagiator entlarvt worden war. Aus Rache am Club wollte er sein Dumas-Kapitel über La Pontes Antiquariat in Umlauf bringen, um zu zeigen, dass Dumas auf seinen Ko-Autor Auguste Maquet angewiesen und längst kein Genie gewesen war, wie aus den Anmerkungen in der Handschrift hervorgeht. Liana Taillefer, Enriques Witwe und selbst ernanntes alter ego von Milady de Winter aus Die drei Musketiere, sucht nun das Manuskript für den Club wiederzugewinnen, damit das Dumas-Bild in der Öffentlichkeit nicht beschädigt werde. Bei genauem oder zweitem Lesen ist tatsächlich von Anfang an unzweifelhaft, 
dass Taillefers Tod Selbstmord war, da nichts anderes suggeriert wird. Dennoch ist der Leser versucht, dem Protagonisten in seinen Irrungen zu folgen, und wird zweifach an der Nase herumgeführt. Das Rätsel um den Selbstmord gibt dem realen Leser bereits zu Beginn einen Hinweis darauf, wie er den Roman zu lesen hat: nämlich genau.

Die Handlung, die sich über den größten Teil des Romans spannend und mysteriös darstellt, kippt mit der Auflösung. Diese wird komplett am Ende des Romans gegeben, wie es der Leser am Ende einer Detektivgeschichte erwartet. Die Auflösung bestätigt allerdings nicht wie angenommen und dem Muster von Detektivgeschichten folgend die vermutete Verbindung zwischen den beiden Büchern, sondern zeigt, dass beide völlig unverbunden nebeneinander stehen. In einem Dialog zwischen Balkan und Corso ${ }^{625}$, der an die abschließende Aufklärung eines Falles durch Sherlock Holmes im Beisein seines Assistenten Dr. Watson erinnert, werden die Hintergründe und Ziele des Clubs erläutert. Die bisherigen Geschehnisse dienten nur als Ablenkungsmanöver, zum einen für den Protagonisten, der sich in dämonische Mächte verstrickt sah, aber auch Realität und Fiktion nicht mehr unterscheiden konnte, zum anderen für den Leser, der die Handlung zunächst in den Genres Detektivroman oder Thriller verortete. Für den realen Leser wird nun gleichzeitig das ganze Ausmaß der Erzählstruktur entfaltet, und klar, welches das Thema des Romans ist: Buch und Erzählen, Leser und ihre Leidenschaft für Literatur, Fiktion über Fiktion.

\subsubsection{Der Protagonist als Leser}

Der Protagonist wird zweifach genarrt, zum einen vom Club, der ein Spiel mit ihm treibt und die Handlung der Drei Musketiere mit ihm nachstellt, zum anderen von sich selbst, da er zu viele literarische Kenntnisse bei der Lösung des Falls heranzieht und überinterpretierend die völlig zusammenhanglosen Aufträge und Bücher miteinander in Verbindung bringt.

Corso begibt sich in die Geschichte der Musketiere hinein - „Ich versuche nur den Fortsetzungsroman zu entschlüsseln, den hier irgend jemand auf meine Kosten schreibt... “626 -, doch mit ihm wird genauso ein Spiel getrieben wie mit dem Leser. Balkan erkennt Corso gegenüber an, wie sehr sich dieser auf die Geschichte eingelassen hat: „Sie nennen ihn Rochefort? Das ist spaßig... und sehr treffend. Ich sehe, daß Sie zu denjenigen gehören, die die Regeln anneh-

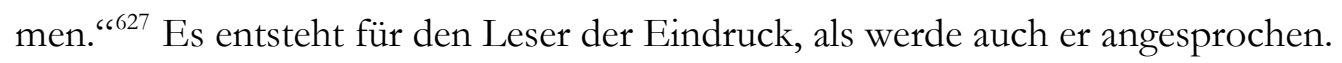

Mit der Entdeckung des Zusammenhangs zwischen beiden Büchern meint Corso den Schlüssel zu beiden Aufträgen und eine Ordnung gefunden zu haben, doch das Gegenteil ist der Fall. Wie später klar wird, setzt gerade an diesem Punkt die Konfusion ein. Corso versucht Bilder aus 
seinem Gedächtnis vor seinem inneren Auge wachzurufen und mit der Realität in Einklang zu bringen, um sich klar zu machen, warum er seinen Angreifer sofort mit der Figur Rochefort aus den Drei Musketieren in Verbindung gebracht hat:

Jetzt war die Szene komplett und in Farbe: Lana Turner in den Drei Musketieren hinter einem Kutschenfenster, und ein entsprechend grimmig wirkender Rochefort. [...] Verdammtes Hollywood. Aber von Filmen und Zelluloid einmal abgesehen, herrschte nun endlich ein wenig Ordnung in seinem Kopf. [...] Gesichter, Schauplätze und Gestalten zwischen dem Fiktiven und dem Realen waren auf seltsame und noch undurchsichtige Weise miteinander verknüpft: Dumas und ein Buch aus dem 17. Jahrhundert, der Teufel und die Drei Musketiere, Milady und die Scheiterhaufen der Inquisition - so absurd und romanhaft dies alles auch anmutete. ${ }^{628}$

Diese Schlüsselszene bildet den Ausgangspunkt für Corsos fatale Fehleinschätzung eines Zusammenhangs, jedoch beginnt er nun vage den Hintergrund des Spiels zu erkennen, das der Club mit ihm spielt. Darauf lässt er sich allerdings ebenso ein wie auf seine Rolle. Rochefort gehört für Corso „zum Hintergrundbild oder zur Bühnenausstattung“629 - angesichts dieses Vokabulars scheint er sich also im Klaren darüber zu sein, dass er sich in einer Inszenierung befindet.

Corso folgt einer Logik, die er aus der Literatur und vom Umgang mit Literatur her kennt und geht davon aus, dass die übrigen Figuren entsprechend handeln. Tun sie dies nicht, kann er keiner Ordnung mehr folgen und verstrickt sich in eine falsche Interpretation von Realität und Fiktion, as "he insisted on seeing intertextual links between two unconnected books"630. Der Erzähler und Drahtzieher Balkan wirft Corso vor: „Schuld ist nur Ihr übertriebener Hang zur Intertextualität, also dazu, aufgrund Ihrer persönlichen literarischen Vorbildung Querverbindungen herzustellen. “631 Somit ist er als Leser gescheitert: Er hat die Realität mit seiner eigenen Imagination vermischt bzw. mit subjektiven, persönlichen intertextuellen Referenzen. Als „anspruchsvoller Leser ${ }^{\text {632 }}$ hat er eine ihm vertraute Methode angewandt - intertextuelle Verweise erhöhen den Grad der Literarität und führen in seinem Beruf als Bücherjäger zu neuen Buchschätzen - und daraus die falschen Schlüsse gezogen.

Eine Überinterpretation durch ein falsches Lesen von Zeichen findet man auch in Das Labyrinth der Welt. Der Protagonist Inchbold fragt sich ebenfalls, ob die Zusammenhänge nur in seiner Fantasie entstanden sind und folgt aus einem bibliophil-kulturellen Verfolgungswahn heraus dem red herring, den er erst spät als solchen entlarvt: „Und mit einem Mal zweifelte ich daran, ob die Zusammenhänge, die ich überall sah [...] außerhalb meiner Fantasie überhaupt eine Bedeutung hatten. “633 Ebenso zweifelt der Protagonist in Der Name der Rose Zusammenhänge und Ordnun-

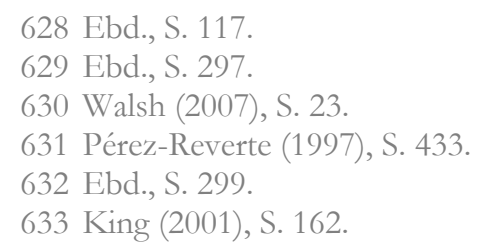


gen an: „Ich bin wie ein Besessener hinter einem Anschein von Ordnung hergelaufen, während ich doch hätte wissen müssen, daß es in der Welt keine Ordnung gibt. “634 Der „fehlende Zusammenhang" wird auch bei Borges angerissen, er meint damit die fehlende Verbindung zwischen Zeichen und Bedeutung, die „zuweilen mysteriös angemutet hat“ und den „Hauptgegenstand der Geschichte“635 darstellt. Hat sich Pérez-Reverte hier inspirieren lassen? Vermutlich unterliegt aber auch nur die Verfasserin selbst einer Überinterpretation...

Corso beginnt, seinen eigenen Realitätssinn in Frage zu stellen, ,weil er zu viel Romane gelesen hatte ${ }^{\text {6636 }}$, und fragt sich, wie Lesen heutzutage funktionieren kann und soll:

Bücher, Kino, Fernsehen, unterschiedliche Leseniveaus - was nützte das alles, wenn man noch immer nicht in der Lage war zu sagen, ob man es mit dem Original oder mit einer Kopie zu tun hatte, ob man im Spiegelkabinett vor dem echten Abbild stand oder vor seiner seitenverkehrten Version oder vor einer Summe aus beiden. ${ }^{637}$

Der Protagonist Corso ist ein exemplarischer Leser - wenn auch nicht im Buch, das seinen Auftrag nach sich zieht. Vielmehr liest er Zeichen in seiner Umgebung, als wäre die Welt, die ihn umgibt, ein großer Roman. Corso sieht sich selbst nicht als Detektiv (vgl. Kap. III.2.1.1.3), sondern hat die Rolle des Lesers verinnerlicht. Über seiner Lektüre weiß er Realität und Fiktion nicht mehr zu unterscheiden. Als Hilfsmittel dient ihm dennoch eine detektivische Kombinationsgabe, die in diesem Kontext Intertextualität bedeutet. Er ist belesen genug und hat ,genügend Filme gesehen“،638, um Bezüge herzustellen und geht das Problem an, wie er es als routinierter Leser gewöhnt ist: „Da es sich um Bücher drehte, mußte er das Problem wie ein kritischer Leser angehen - mit Verstand, und nicht wie ein Konsument billiger Schundliteratur, zu dem ihn hier offensichtlich irgend jemand machen wollte. ${ }^{\text {“639 }}$ Der Protagonist reflektiert also den Status der Handlung, deren Teil er ist, und kennt Methoden, Literatur mit Gewinn zu genießen. Gleichzeitig analysiert er, ob seine Erlebnisse dem Muster der konventionellen Handlung aus dem Detektivgenre entsprechen: „Da er sich an diesem Punkt bereits in einen sogenannten ,anspruchsvollen Leser’ verwandelt hatte, wäre er von einer allzu platten Klischeeszene enttäuscht gewesen." ${ }^{\star 640}$ Als Leser hat er das Detektivgenre betreffend gewisse Erwartungen und ist auf Klischees vorbereitet, schätzt seine Situation aber als komplexer ein und erwartet deshalb gerade nicht das Offensichtliche. Ebenso reflektiert er seine eigene Art zu lesen und kann sich selbst als gebildeten, ,anspruchsvollen', Leser einordnen. 
Darüber hinaus wird Corso ein „unfreiwilliger Autor“, seine Erlebnisse werden Text: „Prognosen, die sich später als falsch herausstellten, um letztendlich vom Text selbst bestätigt zu werden. Wie die Konstruktion eines komplizierten Romans, was es aber nicht war. Oder doch? r641 $^{61}$ Wie bei Živković (vgl. Kap. III.9.3.4) wird ein Protagonist mit Literaturkenntnis zum ,Autor' seiner eigenen Geschichte. Dabei entdeckt er seine eigene Fiktivität. Balkan, als Literaturkritiker und Übersetzer auch ein professioneller und kompetenter Leser, rechnet ebenfalls mit der Möglichkeit, die fiktionsinterne Realität sei nur Fiktion. Dabei wertet er den Status des Lesers außerhalb der Fiktion auf: „Wenn wir es hier nicht mit der Realität, sondern mit einer Fiktion zu tun hätten, dann wären Sie als Leser der Hauptverantwortliche.“642 - Der Club Dumas ist tatsächlich Fiktion, es ist also nicht nur der Leser Corso auf der fiktionalen Ebene gemeint, sondern auch der reale Leser.

\subsubsection{Der fiktionsexterne, reale Leser}

Die fiktionsinternen Reflexionen über Fiktivität und Überinterpretation durch zu intensive Anwendung intertextueller Verweise haben auch Konsequenzen für den realen Leser. Auch er fühlt sich am Ende des Romans übertölpelt, wenn er bemerkt, dass er es nicht mit einem dämonischen Thriller oder einem klassischen Detektivroman zu tun hatte, wie den ganzen Roman hindurch suggeriert wurde, sondern mit einem Roman über Literatur und Metafiktion. Außerdem fühlt er sich als ,Leser' angesprochen, da die Eigenschaft des Protagonisten als Leser, d. h. Entschlüsseler von Hinweisen, ausdrücklich Thema ist. Genau wie sich Corso als anspruchsvoller Leser sieht, kann ein vorgebildeter Leser den Roman vermutlich eher genießen, als jener, der einen Detektivroman erwartet.

Pérez-Reverte sagt über die Leser seines Romans: „The Dumas Club is not a book for innocent readers. “643 und meint damit vermutlich unerfahrene Leser, die sich mit naivem Blick auf den Roman einlassen. Seine Figur Balkan lässt der Autor dagegen sagen: „Es gibt keine unschuldigen Leser. [...] Ein Leser ist die Summe dessen, was er vorher gelesen und im Fernsehen und Kino gesehen hat.“644 Hier wird ein Leitmotiv postmodernen Erzählens von einer Figur angebracht, die vielleicht als Sprachrohr oder alter ego des Autors steht. Jeder Leser stellt einen Text (oder Film) in den Kontext seiner kulturellen Kenntnis und Erfahrungen, die er mit fiktionalen Inhalten gemacht hat. Daraus leitet er Interpretationsmuster für die weitere Lektüre (oder Kinobesuche) ab, die zu Erwartungen an diese neuen fiktionalen Inhalte führen. Der Club Dumas

\footnotetext{
641 Ebd., S. 447.

642 Ebd., S. 433.

643 Vgl. Walsh (2007), S. 31. - Die Autorin übersetzt aus einem Interview mit Pérez-Reverte: „Escribo por nostalgia de los libros que leí y amé“. In: Entrevistas: Arturo Pérez-Reverte, Vdlbooks, 1999, nicht eingesehen. 644 Pérez-Reverte (1997), S. 434.
} 
verlangt nach einem Leser, der dazu in der Lage ist, die Anspielungen auf erzähltheoretische Hintergründe zu verstehen und die Verblüffung, die die Nichterfüllung seiner Erwartung an einen Detektivroman mit sich bringt, zu schätzen weiß.

Leser bringen Erfahrungen beim Lesen mit ein und stellen Bezüge zwischen bereits Gelesenem und neuen Inhalten her. Im Roman wird aber auch gezeigt, dass ein Übermaß an Erwartungen durch Literaturkenntnis hinderlich sein kann, da man sich nicht auf die eigentliche Handlung einlässt, sondern unbedingt Verbindungen herstellen möchte, die vielleicht gar nicht existieren. Falsche Erwartungen an einen Text führen zu einem ungenauen Lesen, da der Leser meinen könnte, bereits zu wissen, worauf der Text hinsteuert und deshalb falsche Prognosen anstellt. Schlägt der Text eine unerwartete Richtung ein, ist der Leser mitunter enttäuscht oder kann der Handlung nicht mehr folgen. Auf der Fiktionsebene sieht Corso seine Erlebnisse als „romanhafte, unerklärliche und irreale Geschichte, in die er da hineingeraten war ${ }^{\text {c645 }}$ - mysteriös ist die Geschichte nur in der Fantasie des Lesers, der den Hinweisen Corsos, eines beinahe allzu vorgebildeten Lesers, folgt. Die Erlebnisse sind mitnichten unerklärlich, da es sich um zwei mehr oder minder gewöhnliche Aufträge für den Bücherjäger handelt.

Fiktionsextern ist es der Leser, der die Verbindung zwischen den Büchern herstellt. Durch häufige und extensive Lektüre ist er darauf konditioniert, intertextuelle Verweise zu bemerken und Schlüsse daraus zu ziehen, um seine Schläue und seine Fähigkeit zu durchschauen zu beweisen. Wie Corso liest und interpretiert er jedoch (zunächst) falsch. Corsos Überinterpretation übernimmt der kundige reale Leser, indem ihm die Geschichte zum größten Teil durch Corsos Augen erzählt wird. Walsh ${ }^{646}$ ist in ihrer Meinung zuzustimmen, ein Leser, der Die drei Musketiere kenne, freue sich darüber, dass er Corsos Anspielungen, Relationen und Schlüssen folgen könne, und sei geneigt, selbst solche Ableitungen herzustellen und sich daraus folgend auf die Illusion einzulassen. Ein Leser dagegen, der Dumas' Roman nicht gut kenne, werde sich nicht auf diese Schlüsse einlassen, ja nicht einmal wissen, wen Corso mit Rochefort meint, wenn er seinem Angreifer diesen Namen gibt. Dieser Leser lese den Roman vermutlich eher als einen spannenden Mystery-Thriller.

Wie in einem Gespräch zwischen Holmes und Watson klärt Balkan Corso am Ende des Romans über die Hintergründe auf. Wo es für den Detektivroman essentiell ist, dass in der abschließenden Auflösung die Zusammenhänge aufgezeigt werden, die bislang dem erzählenden Detektiv-Begleiter und auch dem Leser verborgen geblieben sind, ist es bei Pérez-Reverte gerade das Fehlen eines Zusammenhangs, das deutlich gemacht wird. Der bekannten Struktur des De- 
tektivromans folgend, begeht der Leser den Fehler, die Erkenntnisse, auf die er gemeinsam mit dem Detektiv stößt, anzunehmen, und sich von dem vermuteten Zusammenhang überzeugen zu lassen. Mit dem Protagonisten wird am Ende auch der Leser über die wahren Hintergründe aufgeklärt. Die überraschende Wende besteht darin, dass der Zusammenhang gerade fehlt und die Erkenntnisse nur vermeintliche waren, also sowohl Detektiv als auch Leser mit ihren Annahmen falsch lagen. In zweifacher Hinsicht hat hier eine falsche Lektüre stattgefunden, für den Detektiv eine falsche Lesart der Zeichen, für den Leser eine falsche Lektüre des Romans.

Die Fakten sprechen eine eindeutige Sprache, denn dem Leser werden von Anfang an Hinweise für das ,richtige' Lesen des Textes gegeben. Am Fundort des toten Taillefer finden die Ermittler eine Ausgabe von Der Graf von Bragelonne, des letzten Teils der Musketiere-Trilogie, so dass schon hier klar ist, dass dieser Roman der Schlüssel zum Geschehen ist, nicht das Teufelsbuch. Es wird außerdem schon früh im Roman vermutet, dass alle drei Exemplare davon gefälscht sind, Corsos Auftrag die Neun Pforten betreffend also nicht zu Ergebnissen führen kann. Das Einfache ist das Wahre, das Komplizierte entspringt nur Corsos Fantasie und der des Lesers, der ihm darin nacheifert, Bezüge außerhalb des Texts herzustellen. Balkan klärt Corso über falsche Arten zu lesen auf: „Das Wissen, das Bücher vermitteln, ist für gewöhnlich objektiv. Möglich, daß es von einem boshaften Autor auf eine Art und Weise aufbereitet wird, die den Leser irreführt, aber falsch ist es nie. Falsch ist Ihre Interpretation. “647 Die Frage stellt sich, ob Balkan hier wiederum für den Autor selbst spricht und ob der reale Leser sich angesprochen fühlen sollte. Wo der deutsche Text irreführend und ungenau übersetzt scheint, hilft das Original weiter: „La información (nicht,Wissen', B. B.-S.) que proporciona un libro suele ser objetiva. Quizá pueda estar planificada por un autor malvado para inducirle a errar, mas nunca es falsa. Es usted quien hace una lectura falsa. ${ }^{648}$ - „Hacer una lectura falsa“ - Es ist der Leser selbst, der eine falsche Art zu lesen unternimmt und falsche Schlüsse aus dem Text zieht. Der Leser ist aufgefordert, genau zu lesen, da der Autor ihn vielleicht spielerisch auf eine falsche Fährte locken möchte, wie dies in Detektiv- oder Kriminalromanen die Regel ist. Eine ,falsche Lektüre' ist jedoch nicht gleichzusetzen mit einer „falschen Interpretation“, die erst aus der Lektüre folgt. Aus der ,falschen’ Art zu lesen und der daran anschließenden falschen oder übertriebenen Interpretation ergibt sich Corsos Verwirrung und die falschen Schlüsse, die er in Hinblick auf die beiden unverbundenen Buch-Fälle zieht. Er rechnet nicht damit, dass sich die Drahtzieher, die Club-Mitglieder, einen Spaß mit ihm erlauben und versucht naiv zu ergründen: „Welche Absichten verfolgte der Verfasser? ${ }^{\text {‘649 }}$ Dabei kann er nur

\footnotetext{
647 Pérez-Reverte (1997), S. 434.

648 Walsh (2007), S. 29. - Die Autorin übersetzt aus der spanischen Originalausgabe, El Club Dumas, Madrid: Alfaguara, 1992, S. 457, nicht eingesehen.

649 Pérez-Reverte (1997), S. 299.
} 
scheitern, wie auch Walsh meint, "No wonder he is doomed to failure ${ }^{6650}$, da die Absichten des Verfassers keine Rolle bei der Interpretation eines Textes spielen, der Leser sich den Text vielmehr selbst aktiv erarbeiten sollte.

Dem Leser bleibt für ein richtiges Lesen nur, den Roman mindestens zweimal zu lesen, um die richtige Lesart zu finden. Auf eine erste, naive Sichtweise auf den Roman, die ihn zunächst als reinen Spannungsroman sieht, folgt eine genauere, interpretative Lektüre, die besonders Struktur, Erzählsituation und metafiktionale Hinweise auf die Lösung betrachtet - "On a second or subsequent reading these clues seem so obvious as to be an embarrassment." ${ }^{651}$ So ist im Grunde ein zweiter Roman im Roman enthalten. Das Einlassen auf den Text und seine Figuren, aber auch den Dialog mit einem Autor einzugehen, der dem Leser mitunter falsche Hinweise gibt, ist es, was Walsh als Pérez-Revertes "game of literature"652 bezeichnet.

\subsubsection{Der Protagonist und sein Status als Romanfigur}

Corso erkennt sich nicht nur in der Romanfigur D'Artagnan wieder, er entdeckt überhaupt seine Existenz als fiktive Romangestalt. Er hat den Eindruck, „als hätte [ich] diesen Roman schon mal gelesen“6533 - „Er hätte zu gern gewußt, ob das Ende dieser Geschichte schon irgendwo aufgeschrieben stand oder ob er selbst es war, der nach und nach ein Kapitel zum anderen fügte. “654 Wie in Das letzte Buch (vgl. Kap. III.9.3.4) reflektiert hier eine Romanfigur ihr Dasein als Figur in der Fiktion und nimmt den fiktiven Charakter der Erzählung, in der sie sich befindet, wahr. Dabei meint sie, was ihr passiert, stehe vorgeschrieben in einem Romanmanuskript oder einem Drehbuch.

Corso bemerkt, dass es einen Verantwortlichen für seine Erlebnisse, vielleicht den Autor eines Romans oder Films, geben muss und sieht sich selbst dabei folgerichtig als eine erdachte Figur, die nicht wirklich existiert: „Und er fragte sich, ob irgend jemand, ein versponnener Romanschriftsteller oder ein versoffener Drehbuchschreiberling, ihn sich in diesem Moment womöglich als ,irreale' Figur dachte, die sich in einer, irrealen’ Welt, irreal' vorkommt. “655 Ironischerweise hat er auf der fiktionalen - irrealen - Ebene recht: Bei ,Corso', dessen Abenteuer der reale Leser verfolgt, handelt es sich um eine fiktive Figur in einem fiktionalen literarischen Werk, dessen Abenteuer nur dann für den Leser fortgesetzt werden, wenn weitergelesen wird. Dieser Gedanke geht in der deutschen Übersetzung verloren. Dort heißt es, als der Protagonist darauf wartet, wie seine Erlebnisse wohl weitergehen mögen, er „,wartete darauf, daß jemand das Blatt wenden wür-

\footnotetext{
650 Walsh (2007), S. 29.

651 Ebd., S. 95

652 Ebd., S. 90.

653 Pérez-Reverte (1997), S. 137.

654 Ebd., S. 242.

655 Ebd., S. 337.
} 


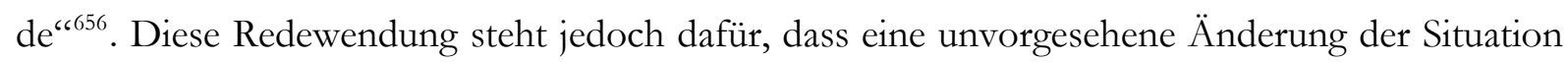
eintritt. Im spanischen Original und der englischen Übersetzung heißt es dagegen, er warte darauf, dass "alguien pasara la página" bzw. "someone turned the next page“657. Der Leser, der beim Lesen die Buchseite umblättert, sorgt dafür, dass die Handlung fortgesetzt wird. In Kontrast dazu steht allerdings die Annahme, dass die Figuren auch außerhalb der Fiktionsebene ein Eigenleben führen, an dem der Leser nicht teilnimmt, da er nichts darüber lesen kann. Balkan wechselt als Erzähler zwischen einer Nullfokalisierung, in der er mehr weiß als der Protagonist, einer internen Fokalisierung und einer homodiegetischen Perspektive, ist aber zugleich in der Lage, Corsos Gemütszustand wiederzugeben. Corso scheint Balkan außerhalb der Handlung, in Abwesenheit des Lesers, über die Ereignisse sowie seine Empfindungen und Überlegungen in Kenntnis gesetzt zu haben, sonst wäre der Wechsel in die personale Erzählhaltung nicht durchzuhalten. Wie Walsh feststellt, werden wir, die Leser, "forced to accept that Corso and Balkan meet outside the storyline."658 Ähnliche Konzeptionen werden auch in Das letzte Buch gewählt, wenn die Figuren ihren eigenen Status als fiktive Figuren reflektieren, und in Der Fall Jane Eyre, wenn der fiktive Rochester beiseite tritt, um die in die fiktive Welt des Texts eingestiegene LiteraturAgentin auf Thornfield Hall herumzuführen, da er im gerade sich abspielenden Kapitel nicht vorkommt. Führen die Figuren außerhalb der Erzählung ein Eigenleben? Wie Walsh meint, ist Der Club Dumas" a novel that leaves us in that strange position of agreeing with a character in a book who is aware of his own author."659

Interessant ist, dass eine kritische Analyse des Textes, auch diese Zeilen, über ,Corso' berichten kann, als sei er eine wirkliche Person. Wir gestehen der Figur aus einer Fiktion einen gewissen Grad an ,Echtheit' zu und identifizieren ihn als einen Menschen, über den wir sprechen können wie über einen Bekannten, während sich die Figur doch selbst als, irreal' und fiktiv erkennt.

\subsubsection{Fiktion über Fiktion}

Der Club Dumas ist ein Roman über Bücher und Bibliophile. Das ,Buch im Buch’ dient im Roman zum einen mit dem spektakulären Inhalt des Teufelsbuchs als Ablenkungsmanöver, zum anderen als mediales Wertobjekt (unersetzliche und unschätzbare Originalhandschrift) sowie als Objekt der Autorenverehrung. Während sich die Filmadaption Die neun Pforten ganz auf den Mystery und Schauer versprechenden Handlungsstrang um das Teufelsbuch verlässt, begibt sich der Roman in bibliophile Untiefen, die sich auf unzählige intertextuelle Referenzen erstrecken. Diese werden z. T. explizit als Zitate oder Erwähnungen literarischer Vorbilder vorgebracht. Eine erschöpfende zitiert aus der englischen Übersetzung, The Dumas Club, London: Harvill, 1996, S. 230, beide nicht eingesehen. 
Übersicht über real existente oder fiktive literarische Werke, auf die Bezug genommen wird, gibt der Artikel zum Roman in der englischsprachigen Wikipedia ${ }^{660}$.

Der Roman erzählt nicht nur eine Geschichte, er ist ein Roman über das Erzählen überhaupt. In dieser Hinsicht kann er als metafiktional bezeichnet werden, da auf der Fiktionsebene selbstreflexive Aussagen gemacht werden, die zu Reflexion über den Status des Textes und der Fiktion veranlassen, und das sowohl inner- als auch außerhalb der Fiktion. Dies ist auch in weiteren Romanen von Pérez-Reverte der Fall, denn "from being entertaining stories they move to become stories about storytelling itself, that is they become metafictions. ${ }^{6661}$

Die Grenzen der Fiktion werden überschritten, indem der Leser sich mit seinen eigenen Lektüreerfahrungen konfrontiert sieht, denn der Roman reflektiert das Buch, den Leser und das Lesen. Die Fiktion spiegelt die Realität nicht nur auf fiktiver Ebene, sondern auch in ihrem Effekt auf den Leser, der sich angesichts seiner Lektüre Gedanken über seine Art der Lektüre macht:

\footnotetext{
However, the significance here is that the reflection of life viewed in Revertian fiction is not allowed to remain separated from the reality of the reader's own life. Time and again, the narrative breaks the mirror and the escapist nature of fiction is destroyed, drawing our attention to the reasons why we read, and what we read, and how we read, without resolving or pinning down those reasons. ${ }^{662}$
}

Ob fiktionale Literatur immer eskapistischer Natur ist, sei dahingestellt. Doch die hier betonte aktive Rolle des Lesers ist signifikant. Der Leser ist in der Lage, das Gelesene zu vervollständigen und zu Ende zu führen, „The stories can only be completed by the reader, not their author ${ }^{4663}$ - eine Vorstellung, die bereits so unterschiedliche Konzepte wie die der Romantiker, das von Roland Barthes und das postmoderne Schreiben beeinflusst hat. Der vom Autor vorgelegte Text kann vom Leser durch seine Interpretation fortgeschrieben werden. Auf diese Weise interagiert der Leser mit Autor und Text, führt diesen in gewisser Weise fort (vgl. Novalis' Anspruch an ein fragmentarisches Manuskript, Kap. II.2.2) und erweckt den Text während des Leseprozesses quasi ,zum Leben’.

\subsubsection{Der Roman und seine Leser}

Die Filmadaption Die neun Pforten hat den Verkauf des Romans in Deutschland erst angekurbelt. Viele Leser scheinen jedoch durch die Verfilmung voreingenommen zu sein, die falsche Erwartungen an den Roman in den Lesern weckte. Wo der Film eine Mystery-Atmosphäre aufbaut, besticht der Roman durch die Hintergrundinformationen zur Buchwelt und die überraschende Wendung am Ende, die dem Leser die tatsächliche Struktur des Romans offenbart und ihn zu verblüffen weiß. Dennoch spielt auch das Thema Metafiktion in einigen Leserrezensionen eine Rolle, was

\footnotetext{
660 Vgl. den Artikel zum Roman in der englischsprachigen Wikipedia, [http://en.wikipedia.org/wiki/

The_Club_Dumas], eingesehen am 13.01.2011.

661 Walsh (2007), S. 9.

662 Walsh (2007), S. 10

663 Ebd.
} 
beweist, dass diese Leser die Überraschung zu schätzen wussten und der Text ihnen Anlass bot, ihre eigenen Erwartungen an den Text zu reflektieren: „Köstlich, wie der Autor mit den Erwartungen des Lesers spielt!‘6604

\subsection{Zoran Živković: Das letzte Buch (2007)}

\subsubsection{Zum Roman}

Der Autor Zoran Živković, ein studierter Literaturtheoretiker ${ }^{665}$, ist in Deutschland weitgehend unbekannt. dtv hat 2008 mit Das leţte Buch den zweiten Roman des Serben auf den deutschen Markt gebracht, der nur vordergründig einen Kriminalfall schildert.

In einer serbischen Buchhandlung wird eine Reihe von Toten aufgefunden, die keine äußeren Anzeichen einer Todesursache aufweisen. Unter den Opfern besteht scheinbar keine Verbindung. Ein Kommissar ermittelt und kommt dabei der Besitzerin der Buchhandlung näher. Es stellt sich heraus, dass die Toten alle in demselben Buch gelesen haben, das den Titel des vorliegenden Romans, „Das letzte Buch“, trägt. Damit wird Spekulationen über die Todesursache sowie metafiktionalen Aspekten Raum gegeben, die den Roman mit postmodernen Qualitäten ausstatten.

Der Kommissar gibt die Handlung als Erzähler-Ich wieder. Vor der Polizeikarriere soll der Protagonist, vielleicht ein alter ego des Autors, Literaturwissenschaften studiert haben, so dass er bei seinen Ermittlungen immer wieder auf sein literarisches Wissen zurückgreift ${ }^{666}$ und Einlassungen zur Literatur in den Text einbringt, z. B. zum Genre Detektivroman ${ }^{667}$ oder zur Massenund Bestsellerliteratur ${ }^{668}$.

\subsubsection{Buch-Motiv und Genrewechsel}

Die rätselhaften Todesfälle bieten einen Romanauftakt, der die Kriminalhandlung legitimiert und in Gang bringt sowie die Erwartungen des Lesers weckt. Im Weiteren erwartet er die Fortsetzung der typischen Motive eines Kriminalromans, nicht zwingend aber das Auftreten eines Buchs als zentrales Motiv. Dadurch werden Erwartungen an den Text in zwei Richtungen geschürt, die sich

\footnotetext{
664 kaminski27: „Intelligente Geschichte“, Leserrezension zu Arturo Pérez-Reverte: Der Club Dumas, Amazon.de, 08.07 2007, [http://www.amazon.de/product-reviews/3442721938/ref=cm_cr_dp_all_summary?ie=UTF8 \&showViewpoints=1\&sortBy=bySubmissionDateDescending], eingesehen am 09.02.2011.

665 Živković (2008), Umschlaginformation.

666 Diese Ausgangssituation erinnert an die Figur Cliff Janeway, eines Bücherliebhabers, Antiquars und Detektivs, die in den USA durch mehrere Romanfortsetzungen des Autors John Dunning Kultstatus erlangt hat. Auf dem deutschen Markt ist von Dunning bisher erschienen: Das Geheimnis des Buchbändlers. Rütten \& Loening: Berlin, 2007, Tb unter dem Titel Hunter, Aufbau: Berlin, 2009 (Amer. OA: The bookman's promise, 2004).

667 „Eine Buchhandlung ist der letzte Ort, wo man Tote erwarten könnte“, Živković (2008), S. 9. - Diese Aussage kann nur ironisch aufgefasst werden, denn die ,Tote in der Bibliothek' ist geradezu zu einem Topos der Detektivliteratur geworden (vgl. Kap. III.1.1.1.3.2).

668 „Literatur und Buchhandlung sind nicht gerade dasselbe.“, Živković (2008), S. 12. - Als vermeintliches Parodoxon wird hier wohl Kritik an gut verkäuflicher, nicht hochliterarischer Massenliteratur geübt.
} 
aber nicht grundlegend ausschließen, denn das Buch als Motiv wird auch in rätselhaften Kontexten eingesetzt. Der Leser reflektiert zudem seine eigene Wirklichkeit, besonders, da das fiktive todbringende Buch und das reale denselben Titel tragen. So wird ein Spannungseffekt genutzt, denn der reale Leser fragt sich, ob es ihm ebenso ergehen werde wie den fiktiven Lesern. Das wird auch im Klappentext suggeriert: „Warum ist Lesen so gefährlich?“669 Das gefährliche Lesen ist ein literarisches Topos (vgl. Kap. III.5), wird im Roman aber auch wörtlich genommen, da die Figuren durch das Buch umkommen.

Auch in diesem Roman wechselt das Genre, nachdem fiktionsintern klar geworden ist, dass das ,Buch im Buch’ eine besondere Rolle spielt. Der entscheidende Moment ist jener, indem der Kommissar erkennt, dass das, letzte Buch' für die Todesfälle verantwortlich ist, allerdings kann er noch nicht erkennen, ob eine metaphysische Erklärung vorliegt - das Buch selbst hat durch außergewöhnliche Kräfte den Tod der Opfer herbeigeführt - oder ob die Leser einem Mord oder Selbstmord bedingt durch das Buch zum Opfer gefallen sind. Diese Unsicherheit führt dazu, dass Elemente aus Mystery-Erzählungen - eine Geheimgesellschaft trifft sich an geheimnisvollem Ort zu einer Zeremonie zu Ehren des Buchs - eingebracht werden. Durch seine Träume kommt der Protagonist zu dem Wissen, dass er selbst in engem Zusammenhang mit dem Buch und dessen Autorschaft steht, wodurch die Stimmung noch einmal kippt und sich als wahrer Hintergrund des Geheimnisses Aspekte der Erzähltheorie entpuppen. Die Akzentverschiebung hin zu erzähltheoretischen Überlegungen in einem Krimi können nur durch den Protagonisten legitimiert werden, der einerseits als Kommissar zum typischen Krimipersonal gehört, andererseits literaturwissenschaftliche Kenntnis hat, einerseits Teil der erzählten Handlung ist, andererseits als narrative Instanz fungiert.

\subsubsection{Buch und Situation der Medien}

„Das letzte Buch“ umgibt nicht nur das Geheimnis der Todesfälle, eine Geheimgesellschaft erwartet außerdem die „Ankunft des letzten Buches“6700. Dieses religiöse Bild rückt die Gesellschaft in die Nähe einer Glaubensgemeinschaft. Die Mitglieder erwarten die ,Ankunft' des Buchs, die auch für das Erscheinen auf dem Buchmarkt stehen könnte. In der Fiktion fällt das Buch im Geheimen Urteile, und nur die Mitglieder der Geheimgesellschaft erwartet Rettung vor einer Apokalypse. So wird hier angedeutet, dass nur Leser, die zur Gruppe der „Buchgläubigen’ gehören, rechtschaffene Menschen seien, die es wert sind, gerettet zu werden. 
Eine weitere Reaktion auf die heutige Mediensituation stellt die fiktionsinterne Tatsache dar, dass das Buch nur tötet, wenn es geöffnet, also gelesen wird, „[a]ber wie viele Menschen öffnen in unserer Zeit schon ein Buch?“6711 Sarkastisch wird damit eine Darstellung der aktuellen Mediensituation gegeben, in der allgemein vermutet wird, dass nicht mehr viele Menschen zur Unterhaltung zum Buch greifen. Wie sich herausstellt, steht das ,letzte Buch' als pars pro toto für alle Bücher, damit gemeint ist, generell gesagt, die Literatur. So ist die Überlegung gerechtfertigt, ob der Roman einen Abgesang auf die Literatur darstelle und eine ,Bücherdämmerung’ verkünde. „Das letzte Buch“ steht also als Kommentar zur Mediensituation für das Ende der Literatur, womöglich für den Weltuntergang, vielleicht auch für einen drohenden Weltuntergang nach dem Fehlen der Literatur. All diese Spekulationen sind aber nur ein Ablenkungsmanöver für die erzähltheoretische Erklärung am Ende.

\subsubsection{Buch-Motiv und Erzähltheorie: „Wirklichkeit des Autors“ und „Wirklichkeit des Buches“}

Damit er über Erzähltheorie erzählen kann, benötigt der Roman das Genre Krimi, um eine zugrunde liegende Handlung zu schaffen und die Aufmerksamkeit des Lesers zu erlangen, der mit dem Genre, davon ist auszugehen, vertraut ist. Genre und Motiv verknüpfend, dient das ,Buch im Buch' als Erklärung für den Tod der Leser nach der Buchlektüre aus der Erzähltheorie heraus: „Aber sobald die Leute anfingen, es [das letzte Buch] zu lesen, über sich selbst zu lesen, haben sich die Wirklichkeiten hoffnungslos verflochten und sind ausgelöscht worden.“672 In dem ,letzten Buch' scheint also die Geschichte zu lesen zu sein, die wir im Roman Das letzte Buch vor uns haben, was auch durch den gleich lautenden Titel suggeriert wird.

Die geheimnisvollen Vorgänge treten ein, da sich die „Wirklichkeit als Autor“ und die „Wirklichkeit des Buches،673 überschnitten haben. Gemeint sind damit die Realität des impliziten Autors und die Fiktionsebene seines Romans: Die narrative Instanz vermischt sich mit dem fiktiven Bericht. Der implizite Autor ist nur ein Konstrukt und verfügt über keine eigene Erzählstimme. Um aber die Annahme aufrechterhalten zu können, dass sich die ,Wirklichkeiten' vermischt haben, wird erläutert, dass der Protagonist, zugleich das Erzähler-Ich, überdies der Autor des Textes sei. Seiner Freundin gegenüber versucht der Protagonist Dejan eine vereinfachte erzähltheoretische Erklärung seiner Vermutung über die Wirklichkeit der Figuren:

„Ich habe es geschrieben.“

„Du?"“

"Ja, ich. Aber nicht der Dejan, der dir jetzt gegenübersitzt.“

„Oh, gibt es noch einen anderen?“ 
„Ja. Den Autor des letzten Buches. Aus der anderen Wirklichkeit. Aber er heißt nicht so.“

„Und wie heißt er?“

„Ähnlich. Er hat aus mir die Hauptperson seines Werkes nach seinem eigenen Bild gemacht. Wir sind mehr als Zwillingsbrüder. Wir sind eins.“

„Ist er auch Kommissar?““

„Nein. Er ist nur Autor. Aber ich bin ebenfalls Autor." $" 674$

Isers Theorie des ,impliziten Lesers' folgend, bezeichnet sich der Protagonist als impliziter Autor des letzten Buchs und damit als Zwilling des realen Autors Živković. In der Fiktion habe der Protagonist das Buch geschrieben und in seinem Computer das 39. Kapitel des letzten Buchs gesehen. Im realen Roman passieren diese Dinge ebenfalls in jenem Kapitel. Nur in dieser Konstruktion war es für den Protagonisten möglich, das Buch gefahrlos zu lesen. Für die übrigen Leser haben sich, auf gefährliche, ja todbringende Weise, die Erzählebenen vermischt: Sie haben gelesen, was sie selbst tun und denken, was sie schließlich, ausgelöscht' hat.

Hier greift das Konzept der Metalepse, das die Möglichkeit zur Reflexion des Mediums Roman bietet und dabei auf neoromantische Traditionen zurückgreift, zugleich jedoch Ausdrucksmittel postmoderner Literatur ist. Es findet ein Wechsel zwischen den narrativen Ebenen statt, so dass die Figuren auf eine gesteigerte Erzählebene dringen, die Ebene des „Buchs im Buch’. Der Grund für die Auslöschung der Figuren ist also das Erkennen ihrer Fiktivität ${ }^{675}$, die innerhalb der erzählen Wirklichkeit, wahr' ist:

\footnotetext{
„Unsere Wirklichkeit ist also nur ... die Fiktion ... eines Schriftstellers?“

„Nein, Sie ist ebenso wirklich wie die seine. Aber seine hat die unsrige sieben Tage lang beeinflusst, solange das letate Buch gedauert hat. Nur noch ein paar Minuten, und der Einfluss wird verschwinden." ${ }^{676}$
}

Die Fiktion geht also davon aus, dass die Figuren auch über den erzählten Zeitraum hinaus, der im Roman vorgeführt wird, existieren (vgl. Kap. III.7.2.4.4). Die Beeinflussung der Figuren an „sieben Tagen“ meint die erzählte Zeit des Romans, „nur noch ein paar Minuten“ meint die Erzählzeit, die Zeit, die der reale Leser noch zum Lesen der verbleibenden etwa anderthalb Druckseiten des Romans benötigt.

Im Roman wird der literaturtheoretische Kniff im Gewand eines Krimis diskutiert, um mit dem Leser ein intellektuelles Spiel zu treiben. Das ,Buch im Buch’ ist hier Implikation der und ein Symbol für die Erzähltheorie: Es bietet Anlass zu Überlegungen erzähltheoretischer Art, denn die Figuren reflektieren u. a. ihren eigenen fiktiven Status und die fiktionsexterne Wirklichkeit. Diese Metafiktion, Metatextualität und Selbstreferenz sind eindeutige Indikatoren für den postmodernen Charakter des Romans, auf den auch schon die Anmerkung auf dem Buchdeckel hinweist:

\footnotetext{
674 Ebd., S. $220 f$.

675 Die Selbstthematisierung von Figuren in der Fiktion kann natürlich auch im Film vorkommen. Dies ist z. B. der Fall in The Truman Show (1988, Regie: Peter Weir) oder in Stranger than Fiction (2006, Regie: Marc Forster). 676 Živković (2008), S. 222.
} 
„Ein postmoderner Thriller von einem Meister des schwarzen Humors“6677. Um die geheimnisvolle Verrätselung des Geschehens fiktional aufzubereiten, passt am besten das Genre Krimi, um das rätselhafte Element zu betonen. Das ,Buch im Buch’ steht stellvertretend für alle Literatur und zeigt, dass Lesen ein intellektuelles Rätsel, anregend und auf hohem Niveau unterhaltsam sein kann. So stellt das Buch-Motiv im Grunde einen Beitrag zur ,Leseerziehung für Erwachsene’ dar. Allerdings spricht der Roman eher als Normalleser vorgebildete Leser an, die gewisse Vorkenntnisse im Umgang mit Literatur haben. Der Normalleser, der Krimis bevorzugt, wird sich in seinen Erwartungen an eine spannende Mörderjagd nicht vollkommen bestätigt und mitunter auch überfordert fühlen.

\subsubsection{Der Roman und seine Leser}

Durch die Information auf dem Buchumschlag („Ein postmoderner Thriller") ist der Leser bereits darauf eingestimmt, dass ihn hier ein intellektuelles Abenteuer erwartet und kein gewöhnlicher Krimi. Als Krimi ist Das letate Buch von nur durchschnittlicher Qualität: Der Roman strotzt nur so vor Klischees, die Dialoge sind hölzern, die Handlung plätschert ereignisarm dahin. Allerdings möchte der Roman auch nicht nur Krimi sein, sondern bringt mit dem Buch-Motiv den entscheidenden Aspekt ein. Für einen Normalleser, der eine spannende Krimihandlung erwartet, sind die erläuterten literaturtheoretischen Aspekte und die komplexen Gedankengänge dahinter nur schwer nachvollziehbar: „Fängt wie ein Krimi an, zieht sich lange hin, geht dann langatmig ins Mystische über. Nach der Buchbesprechung im WDR4 habe ich was anderes erwartet. “678

\subsection{Autor, Roman, Leser und Genrewechsel}

In allen drei in diesem Kapitel untersuchten Romanen steht ein besonderes ,Buch im Buch’ im Vordergrund. Sein Inhalt hat dabei entscheidende Auswirkungen auf den Protagonisten: Das Buch macht ihn als Autor zum mutmaßlichen Mörder, verstrickt ihn in überbordende intertextuelle und metafiktionale Überlegungen oder macht ihm seinen eigenen fiktionalen Status deutlich.

Das klassische Motiv „Buch’ erhält in diesen Romanen durch seine neue Umgebung in einem neuen Genre eine neue Funktion. In einem Kriminal- oder Detektivroman bietet das Buch-Motiv Anlass für die Selbstthematisierung von Literatur und Fiktionalität und führt so zu einem Genrewechsel (vgl. dazu auch Kap. IV.1.1): Der Campusroman wird zum Roman über Postmoderne und Erzähltheorie, der Detektivroman wird zum Roman über Intertextualität und das falsche

677 Ebd., Umschlaginformation.

678 Theo24: „Mehr erwartet“, Leserrezension zu Zoran Živković: Das letżte Buch, Amazon.de, 25.01.2009, [http://www.amazon.de/product-reviews/3423211032/ref=cm_cr_dp_synop?ie=UTF8\&show

Viewpoints=0\&sortBy=bySubmissionDateDescending\#R1R8LPIB8O0YX4], eingesehen am 09.02.2011. 
Lesen und der Kriminalroman wird zum metafiktionalen Roman. Durch diesen Genrewechsel erhält der Roman eine neue Qualität. Hybride Genres oder ein ,Genre-Mix', in den hier besprochenen Fällen eine Kombination von Genre und Motiv, sind typisch für postmoderne Literatur.

Zwar sind Der Bestseller-Mord, Der Club Dumas und Das letzte Buch mehrfach kodiert und von mehreren Leserkreisen lesbar und ,genießbar'. Doch zeigen die vielfältigen Anspielungen auf die Buchwelt, Erzähltheorie und Bezüge auf Gesellschaft, Philosophie etc., dass das vom Autor anvisierte Publikum eher eines ist, das mit diesen intertextuellen Verweisen umgehen kann. Wie aus den Lesermeinungen/-rezensionen hervorgeht, zeigen sich die auf einen genretypischen Roman eingestellten Leser enttäuscht angesichts der Implikationen, die das Buch-Motiv in den Roman einbringt und so das Genre variiert.

\section{Postmoderne und Multiadressiertheit}

Postmoderne Strukturen sind in vielen Buch-Büchern, auch in Titeln des Korpus', zu finden, da diese Romane u. a. durch metafiktionale und intertextuelle Schreibweisen geprägt sind. Zudem richten sich die Buch-Romane aufgrund ihrer Genreausrichtung sowohl an Normalleser, aber besonders an ein kompetentes, mit literaturwissenschaftlichen Methoden und Traditionen vertrautes Lesepublikum und sind somit multiadressiert. Dieses Kapitel geht den postmodernen Aspekten und Strukturen in den Romanen des Korpus nach.

\subsection{Postmoderne Aspekte in den untersuchten Romanen}

„Wie so viele postmoderne Schmonzetten beginnt [Schmitts] Schule der Egoisten mit einem alten Folianten. “679 In dieser Einschätzung steckt bereits die Aussage, dass die Reflexion von Schreiben und Lesen und auch das Buch-Motiv in Romanen mit postmodernem Unterbau eine große Rolle spielt. Umgekehrt zeigen viele Korpus-Titel postmoderne Tendenzen, wichtig ist für diese Romane besonders das postmoderne Konzept der Selbstreferen ${ }^{680}$ : In neueren Romanen, und auch in den Korpus-Titeln, wird besonders häufig autoreferentiell das Schreiben, der Text selbst oder das Lesen behandelt, d. h. der Autor reflektiert sein eigenes Schreiben. Beim Lesen als Selbstreferenz bzw. -reflexion findet oder erkennt sich der Leser auf einer gesteigerten Ebene im Gelesenen wieder. So liegt es nahe, dass ein Buch, über seinen Text ein Produkt künstlerischen Schaffens und Objekt der Lektüre, als literarisches Motiv zum Dreh- und Angelpunkt von Romanen wird. Die

679 Altenburg (2004), S. 53. - Auch das vorangestellte Motto in Der Name der Rose bezieht sich auf ein besonderes Textmedium und lautet „Natürlich, eine alte Handschrift“.

680 Zur Selbstreferenz als Merkmal postmodernen Schreibens vgl. Christoph Reinfandt: Art. „Selbstreferenz“.

In: Nünning ( $\left.{ }^{3} 2004\right)$, S. 601. 
postmodernen Qualitäten dreier Titel sowie die ihnen eigene Ansprache mehrerer Publikumsgruppen sind bereits in Kap. 9 behandelt worden.

Das Labyrinth der Welt weist postmoderne, dabei spielerische Strukturen auf, da der Roman auf unterschiedlichen Ebenen als spannender Detektivroman sowie als intellektuelles Rätsel zu lesen ist:

Umfangreiche literarische Anspielungen lösen bei manchen Romanlesern Unmut aus, weil sie sie als elitäre Ausgrenzungsmechanismen missverstehen. In Wirklichkeit erlauben Romane wie „Das Labyrinth der Welt", sie auf verschiedenen Ebenen zu goutieren, als Kriminal- und Abenteuerschmöker, als historischen und bibliophilen Roman oder als Netzwerk von Zeichen und Motiven. In dieses Netzwerk auch fremde Texte mit einzubeziehen eröffnet einfach eine weitere Lektüremöglichkeit, die erhellend sein, aber auch bewusst in die Irre locken kann. King ist ein ausgezeichneter Roman gelungen, der zeigt, dass die Stärke der anglo-amerikanischen Literatur keineswegs auf schlichtem Erzählen beruht, das neuerdings gewisse Verleger von deutschsprachigen Autoren fordern, sondern auf der Verbindung von spannender Handlung und intellektuellem Spiel. ${ }^{681}$

Was die Erzählweise betrifft, bietet Das Labyrinth der Welt zwei Handlungsstränge auf unterschiedlichen Zeitebenen, die zwar chronologisch geschildert werden, doch bietet die Erzählung auch Retardierungen im Handlungsfluss in Form von Rückblenden: Der Protagonist besucht abends einen Friedhof, auf dem er einen toten Briefkasten finden wird, diese Schilderung wird unterbrochen durch einen Einschub über seine Erlebnisse tagsüber. Die postmoderne Mehrdeutigkeit des Textes kann durch das Bild des Palimpsests verdeutlicht werden, das auch auf fiktionaler Ebene durch das Manuskript Verwendung findet: Ein Text überschreibt einen anderen, der aber durchscheint und auf diese Weise mitgelesen wird. Die unterschiedlichen Kodierungen des Textes sind zu vergleichen mit Geheimtinte, die durch bestimmte Substanzen zum Vorschein kommt, und die der Leser entweder anzuwenden vermag oder nicht. Darüber hinaus wird als Reverenz vor der autoreferentiellen Schreibweise des Romans die Wiedergabe des Textes als rahmende retrospektive Niederschrift durch einen autodiegetischen Erzähler stilisiert, der das Geschehen selbst erlebt hat. Außerdem werden fiktionsintern unterschiedliche Arten, Bücher zu schätzen, reflektiert. Als Protagonist ist Inchbold, wie Corso in Der Club Dumas, fremdbestimmt, da sein Auftraggeber ein verwirrendes Spiel mit ihm treibt. Dieses Spiel führt ihn mehrfach auf falsche Fährten, die nur in seiner Fantasie einen Sinn ergeben, so dass die Grenze zwischen Realität und Fiktion verwischt. In ihrer Selbstbestimmung und dem Erfahren ihres Ichs eingeschränkt sind auch diejenigen Protagonisten aus Korpus-Titeln, die sich bei der Verehrung und Identifizierung mit dem fiktiven Autor ihrer eigenen Identität unsicher werden.

Wie King kann auch Arturo Pérez-Reverte als postmoderner Autor gelten. In einer Rezension zu Der Schatten des Windes wird er als positives Gegenbeispiel zu Carlos Ruiz Zafón angeführt:

Es gibt einen spanischen Schriftsteller, der schreibt spannende Geschichten im Dutzend, in denen es [...] vor allem um zweierlei geht, nämlich um die Macht der Bücher und die der Liebe [...]. Der Autor versteht seinen Roman als Hommage an die Literatur, doch damit ihm die Leser in all den Zitaten und 
Querverweisen auch brav bei der Stange bleiben, erzählt er ihnen vordergründig eine Detektivgeschichte. Der Dichter heißt Arturo Pérez-Reverte ... ${ }^{62}$

Den Romanen aus Pérez-Revertes Feder wird hier ein weiteres Merkmal der postmodernen Literatur zugesprochen, nämlich die Adressierung verschiedener Lesergruppen bzw. die Möglichkeit, seine Romane auf verschiedenen Ebenen zu genießen, zum einen durch das Erkennen und Durchschauen der „Zitate und Querverweise“, zum anderen durch das Verfolgen der spannenden, ,vordergründigen“ Geschichte.

Walter Moers wird vermutlich nicht jedem Leser als Autor der Postmoderne, sondern als Autor einfach zugänglicher, humorvoller Fantasy- und Abenteuerromane präsent sein. Doch auch seine Romane um den fiktiven Kontinent Zamonien, besonders Die Stadt der träumenden Bücher, sind auf verschiedenen Ebenen lesbar, mehrfach kodiert und so an unterschiedliche Lesergruppen gerichtet. An der Oberfläche findet sich die unterhaltsame Geschichte, geht man tiefer, findet man in unzähligen Anspielungen und Zitaten, die zum Teil verfremdet und an die Welt Zamoniens angepasst werden, ausgiebige Reflexionen über die klassische Weltliteratur sowie Bezüge auf klassische und bildungsbürgerliche Inhalte ebenso wie auf aktuelle (Pop-)Kultur aus Literatur, Film, Musik, Malerei, Comics etc. Moers bringt sich überdies mit dem anagrammatischen Namen „Werma Tosler“ selbst als fiktiver Illustrator ein. Holger Kreitling sieht in Moers ebenfalls einen Autor, der verschiedene Leserkreise anspricht, er sei „ein unbedingt beachtenswertes Talent, das sich zwar einer breiten Leserschaft erfreut, doch auch dem nach geistigen Genüssen strebendem Publikum ernsthaft Freude bereiten wird.“683 Es fällt an dieser Stelle auf, dass dem ,breiten Publikum' Geschmack und Intellekt von vornherein abgesprochen werden. Die unterschiedlichen Codes eines Textes unterstreichen noch mehr als jene des anspruchsvollen Lesers, der sie zu entschlüsseln in der Lage ist, vor allem die Kenntnis des Autors, der die Verweise souverän einzusetzen vermag. So stellen wohl auch Kritiker bei der Beurteilung eines Werkes vor allem ihre eigene kulturelle Kenntnis und Belesenheit unter Beweis. Walter Moers selbst bleibt bei der Einschätzung seiner Klugheit in einem Interview mit der ZEIT über sein Buch Wilde Reise durch die Nacht (2001) bescheiden:

Die Zeit: Ihre Romane stecken voller Anspielungen, Sie verwursten Märchen, mittelalterliche Literatur und, und, und. Wie schlau muss man sein, um den vollen Spaß an Walter Moers zu haben?

Moers: Seitdem ich die 131/2 Leben des Käpt'n Blaubär geschrieben habe, unterstellt man mir eine Belesenheit und Popkulturkenntnis, die ich gerne hätte. Ich sollte diesen schmeichelhaften Mythos wohl besser schüren, aber viele der Bücher, deren Verwurstung man mir unterschieben will, habe ich 
gar nicht gelesen. Manchmal kenne ich nicht mal die Namen der Autoren. Die Kritiker haben einfach ihre Kenntnisse in den Blaubär rein- beziehungsweise aus ihm herausgelesen. ${ }^{684}$

\subsection{Postmodernes Schreiben und Lesen}

Alles in allem kann man das postmoderne Schreiben als Spiel mit dem kompetenten, ,wissenden' Leser bezeichnen, der die Verwirrung, die durch die Außerkraftsetzung gängiger literarischer Methoden entsteht, als literarische Qualität zu schätzen weiß. Seine Einbeziehung in den Text sieht er als intellektuelles Rätsel, bei dem er sein literarisches Wissen unter Beweis stellen kann. Dieser Kenntnis kann sich auch der Autor rühmen, der diese Rätsel erdacht hat. Hier findet mittels des Textes eine Kommunikation zwischen Autor und Leser statt, die Herausforderungen an den Leser stellt und ein aktives interpretierendes Lesen erfordert: "Postmodern fiction presents its readers with a challenge: instead of enjoying it passively, they have to work to understand it, to question their own responses, and to examine their views about what fiction is." 685

Es kann sich auch jener Leser an dem postmodernen Text oder dem Buch-Roman erfreuen, der ihn einfach zur Unterhaltung liest und die Hinweise auf andere Werke, vielleicht aus NichtWissen oder Nicht-Erkennen, außer Acht lässt. Verweise auf andere Werke sind allerdings in jedem Werk enthalten, ob dies nun explizit, durch Bezugnahmen oder Zitate, oder implizit, durch Anspielungen oder Nachahmungen, geschieht. Das intertextuelle Schneeballsystem, das von Buch zu Buch führt, funktioniert wie Hyperlinks in digitalen Texten: Verknüpft bzw. verlinkt mit anderen ergibt ein Text ein ganzes Netz von Texten.

Zu postmodernen Phänomenen gehört ebenso die Betonung des Lustvollen am Umgang mit Literatur, das Lesen als Erlebnis, das schließlich auch den Griff zum vorliegenden Buchs schmackhaft machen soll. Damit grenzt sich die Postmoderne gegenüber der Moderne ab, die eine kritisch-analytische Distanz zum Text propagiert ${ }^{686}$. Zwar wird der Intellekt des Lesers beim Entschlüsseln der Codes im Text gefordert, doch damit die Lektüre immer noch Vergnügen bereitet, wird das Spielerische unterstrichen, das den Roman als ,Denkrätsel' erscheinen lässt. Auch beim Krimi ist ein Mitdenken bei der Suche nach Täter und Motiv gefragt, so dass die Verbindung von intellektuellem Anspruch und unterhaltsamem Genre berechtigt ist und dazu beiträgt, den Vorwurf des Trivialen an Genres, wie z. B. den Detektivroman, zu entkräften. Aus diesem Grund ist das Motiv Buch oft in diesem Genre anzutreffen.

684 Christof Siemes: „Blaubärs Reise in die Nacht. Ein Gespräch mit dem Zeichner Walter Moers, der einen Roman zu den fantastischen Bildern des Illustrators Gustave Doré (1832-1883) geschrieben hat“. In: Die Zeit, 06.09.2001, S. 46. Online [http://www.zeit.de/2001/37/Blaubaers_Reise_in_die_Nacht], eingesehen am 28.11.2010. 
Der Autor reflektiert Lesen und Schreiben beim eigenen Lesen und im Entstehungsprozess seines Werkes. Im Verbund mit den ästhetischen Konzepten, die gerade aktuell und viel diskutiert sind, reagiert er beim Schreiben auf die virulenten postmodernen Erzählweisen. So liegt es nahe, dass er auch auf das Motiv Buch in seinem Roman zurückgreift.

\section{Die Protagonisten der Buch-Bücher - Lesertypologie}

Mindestens ebenso wichtig wie die Bücher in den Büchern sind die Protagonisten der Romane. Zwar besteht diese Arbeit nicht aus einer Lese- oder Leserstudie, doch braucht das Buch den Leser, um Gehalt zu erlangen. Ohne Leser ist das Buch nur ein unbelebtes Objekt und ein Gegenstand, kein Medium für einen Text, den es doch ,vermitteln' soll. Der Leser schließlich erfüllt diesen Text erst aktiv mit Leben, indem er seine Textperspektive einbringt. Dieser Ansatz ist einer Wirkungsästhetik, u. a. der Wolfgang Isers, geschuldet, die den Leser und seine Textrezeption verstärkt ins Zentrum rückt und so systematisch aufwertet. Der Autor tritt mittels des Textes mit dem Leser in Dialog, Lesen wird erst so zur Kommunikation. Ohne den Leser existiert der Text nur als Buchstaben auf dem Papier und ist aller Wirkung enthoben, da kein Adressat zur Verfügung steht. Die Textperspektive des Lesers wird so in den Text integriert, dass er in der Dreiheit Autor - Text - Leser quasi zu „eine[r] Art Ko-Autor ${ }^{\text {6687 }}$ wird.

Nicht immer sind es die Protagonisten, die als Leser des Buchs auftreten. Das erstaunt zunächst, doch nur in einigen Fällen wird der Leseprozess in der Fiktion geschildert und somit der Inhalt des ,Buchs im Buch’ direkt wiedergegeben (vgl. Kap. III.4). Die Protagonisten sind zwar im Bilde über den Inhalt, aber noch wichtiger als dieser ist das Buch selbst, das in jedem Romanbeispiel mit einer besonderen Bedeutung aufgeladen wird, sei es z. B. als Schatz oder als Mittel, einem Autor nahezukommen. Die Ausgestaltung des Erzähl- und Lesevorgangs auf der Erzählebene unterbleibt in den meisten literarischen Darstellungen, die das erlebende Ich in den Mittelpunkt stellen $^{688}$. Da die meisten der Korpustitel von einem autodiegetischen Erzähler berichtet werden, sind auch hier keine Leseschilderungen enthalten. Lesen als Aktivität kann in der Fiktion nur schwer wiedergegeben werden, zumeist geschieht dies durch das Einfügen einer Textpassage oder von Zitaten auf der Erzählebene. Bei fiktiven Büchern in Büchern ist dieses ,Zitieren’ noch schwieriger, da der Autor zwei oder mehr Fiktionen erfinden muss. Dagegen gibt es eine ganze Reihe von Möglichkeiten, die Auswirkungen der Lektüre auf die Lesergestalt zum Ausdruck zu bringen, z. B. durch literarische Anspielungen oder die Schilderung der Reaktion der Lesergestalt 
auf den Text. Die fiktionsinterne Diskussion der Lektüre dient dabei der Charakterisierung der Figuren $^{689}$. Zwar sind Inhalt und Buch als Medium eng miteinander verzahnt, doch zeigt sich in den untersuchten Titeln, dass eher der Gegenstand Buch, der aufgrund seiner Wertigkeit wichtig wird, für die Protagonisten von Belang ist.

Auffällig ist, dass die Protagonisten, die mit den Büchern zu tun haben, gänzlich stereotype Figuren sind. Sie tragen jene Merkmale und Eigenschaften, die der Leser bei einem literarisch porträtierten Buchmenschen erwartet, auch wenn diese Menschen in der Realität vielleicht ganz anders sind. Dabei ist der Leser geprägt durch die öffentliche Wahrnehmung und ein offensichtlich kollektives Wissen, das der Autor gezielt anwendet, um dem Leser eine gewisse Vorstellung und Atmosphäre der Handlung zu vermitteln und ihn in seinen Erwartungen abzuholen. Verallgemeinernd und grob gesagt sind die Protagonisten der Romane über Bücher gebildet, belesen, bibliophil, in Buchberufen tätig, aber dabei auch Sonderlinge. Sämtliche Protagonisten sind männlich und alleinstehend. Ausnahmen bilden die fantastischen Titel, deren Protagonisten ein Lindwurm und, als einzige Frau, eine LiteraturAgentin sind. Diese Romane gehen allerdings unter anderen Vorzeichen mit Büchern um, indem sie fantastische Welten eröffnen, in denen Bücher das Maß aller Dinge sind, so dass die Tatsache, dass diese Figuren nicht dem üblichen Muster unterliegen, unerheblich ist. Im Übrigen zeigen beide mit ihrer Bibliophilie, ihrer Belesenheit und der täglichen Beschäftigung mit Büchern die Grundvoraussetzungen einer Figur in Buch-Romanen. Erwähnenswert ist außerdem, dass sämtliche Korpustitel von männlichen Autoren verfasst worden sind.

Sigrid Löffler subsumiert die exzentrischen Leserprotagonisten in aktueller Romanliteratur unter der Bezeichnung „Bücher-Freaks ${ }^{{ }^{6690}}$. Ein Freak ist laut gängiger Definition ${ }^{691}$ jemand, der sich für etwas über ein durchschnittliches $\mathrm{Maß}$ hinaus begeistert, aber auch als unangepasster, eigenartiger Mensch gilt. In dieser Einschätzung stecken also Wissen und Bildung, die dem Bücherfreund zugeschrieben werden, zugleich jedoch ein nicht dem Üblichen entsprechendes, kauziges Verhalten, das in den literarischen Darstellungen von Buchliebhabern fast schon zum Standard gehört und weitläufig, auch satirisch, mit der Beschäftigung mit Büchern assoziiert wird. Der Begriff kann aber auch als eine Analogbildung zum ,Computerfreak' gesehen werden, der als gelehrter Typus der heutigen, auf die elektronischen Medien ausgerichteten Zeit in der öffentlichen Wahrnehmung präsent ist.

689 Vgl. dazu ebd. - Eine Charakterisierung der Figuren durch die Diskussion ihrer Leseeindrücke findet z. B. in der Rahmenerzählung in E.T.A. Hoffmanns Die Serapionsbrüder (1819/21) statt.

690 Löffler (2005), S. 10.

691 Vgl. z. B. Duden Fremdwörterbuch. 


\subsection{Figuren in Buchromanen - Äußeres}

In den Romanen des Korpus stehen ausschließlich männliche Protagonisten im Bann des Buchs. Eine Ausnahme bildet Thursday Next in Der Fall Jane Eyre. Während der Lesesucht-Debatte im ausgehenden 18. Jahrhundert war jedoch allgemein bekannt, dass besonders Frauen und junge Männer anfällig für das maßlose Lesen waren. Allerdings war bis zu diesem Zeitpunkt der gelehrte - männliche - Leser der vorherrschende Typus des Lesers. Die Protagonisten aller Romane sind, wie die Büchernarren in literarischen Darstellungen, männlich und alleinstehend, resultierend daraus, dass sie dem gelehrten Typ angehören, was schon aus ihren Berufen ersichtlich ist. Der Prototyp des gelehrten Lesers wurde bereits in der Literatur des 18. Jahrhundert etabliert und hat sich in der Fiktion bis heute zwar äußerlich der Zeit angepasst, aber in seiner Gelehrsamkeit und Leselust nur wenig verändert. Košenina klärt eindrucksvoll über die verschiedenen Typen, aber auch ihre Gemeinsamkeiten auf: Gelehrte und Büchernarren in der Fiktion sind eigenbrötlerisch, verbohrt, fixiert, häufig kränklich und etwas wunderlich. Über der intensiven Beschäftigung mit Büchern und deren Sammlung verwahrlosen sie sozial und persönlich, da sie keine Zeit mit Körperpflege und Ordnung des Haushalts verlieren möchten und über ihren Forschungen kaum soziale Kontakte unterhalten. Die Protagonisten zeigen körperliche Gebrechen, wie starke Kurzsichtigkeit, oder Auffälligkeiten. Etwas weltfremd, für ein Leben außerhalb der Welt ihrer Studien untauglich, ziehen sich einige von ihnen ganz in die innere Bücherwelt zurück.

\subsection{Figuren in Buchromanen - Beruf}

Die Protagonisten üben, ihrer Zuneigung zu Büchern entsprechend, sämtlich einen Buchberuf aus und gehören somit zum gelehrten Typus, sie sind Literatur- oder Sprachwissenschaftler, Lehrer und Studierende, Geistlicher, Buchhändler. Weiterhin zeichnet sie ihre intensive Beschäftigung mit Büchern als Büchersammler, außerdem Autoren und Leser aus. Uwe Japp weist darauf hin, dass Leserprotagonisten, die durch ihre Lektüre gekennzeichnet werden, „meist Intellektuelle, zumindest Gebildete ${ }^{\text {(6992 }}$ seien. In den Romanen trifft dies auch auf Protagonisten zu, die Bücher wertschätzen, ohne dass ihre Lektüreerlebnisse unmittelbar geschildert werden. Der Gelehrte lebt „,von Büchern für Bücher ${ }^{\text {‘693 }}$, genau wie Gelehrsamkeit und Bibliomanie zusammen gehören. Unter den Protagonisten ist die Bibliophilie unterschiedlich stark ausgeprägt. Allerdings haben sie alle ein besonderes Verhältnis zu Büchern und zum Lesen, das, wie für den Gelehrten, auch ein professionelles ist. 


\subsubsection{Das Klischee des Buchhändlers in der Fiktion}

Die literarische Darstellung von Buchhändlern ${ }^{694}$ ruft sofort bestimmte Assoziationen, Stimmungen und eine gewisse Atmosphäre im Leser wach, so dass er sich besonders gut in die fiktional geschilderte Situation hineinversetzen kann. Diese Vorstellungen sind häufig klischeebesetzt, was aber durchaus beabsichtigt zu sein scheint, und auch in den Romanen des Korpus kommt diese Darstellung der Protagonisten als Buchhändler zum Tragen. Interessant ist, dass ein Buchhändler in der Fiktion so gut wie immer ein Antiquar ist, während der Sortimentsbuchhändler nur in seltenen Fällen und nicht in den untersuchten Texten vorkommt. Wo der Bibliothekar als Buchkenner mit intellektuellem Ansinnen gilt, werden Antiquare in der Literatur häufig als weltfremde Büchernarren mit zahlreichen Eigentümlichkeiten gezeigt.

Das Klischee, das im Leser sofort nach dem Lesen der Berufsbezeichnung als Signalwort erwacht, wird in den Romanen und in literarischen Darstellungen tatsächlich befriedigt. Der Buchhändler wird so dargestellt, wie es der durchschnittliche bzw. die meisten Leser auch wirklich erwarten: Ein Buchhändler bzw. Antiquar wird stets in der vertrauten Umgebung seines Ladens gezeigt, den er als Inhaber selbst führt. Angestellte hat er nur wenige oder keine. Er ist männlich und alleinstehend, verbringt die meiste Zeit in seinem Laden, in den nur selten Kunden, dann aber Stammkunden kommen. Er ist ältlich, langsam und schwerfällig, kurzsichtig und genügsam, dabei stets freundlich, gütig und hilfsbereit und ebenso büchernärrisch wie die Besucher seines Ladens. Bücher sind der Mittelpunkt seines Daseins, und so ist er nicht nur belesen und in der Literatur zu Hause, sondern besitzt auch einen robusten gesunden Menschenverstand, so dass er dem Protagonisten, der als Kunde oder mit einem Anliegen an die Bildung und Erfahrung des Buchhändlers in den Laden kommt, ein offenes Ohr und Ratschläge zu bieten vermag. Trotz all dieser Tugenden wirkt der Buchhändler verschroben und exzentrisch.

Die Buchhändler in den Romanen des Korpus entsprechen diesem Klischee, besonders diejenigen, die als Statist auftreten und nicht in die Handlung eingebunden sind. Die BuchhändlerProtagonisten zeigen leichte Abweichungen, auch wenn sie dem Stereotyp in Grundzügen entsprechen, wie Inchbold in Das Labyrinth der Welt. Er ist etwas weltfremd, dabei kurzsichtig und asthmatisch durch das Leben inmitten von Büchern. Sein Kollege und Protagonist in Mein Leben als Buch legitimiert sich nur durch seinen Beruf und seine Buchleidenschaft für die Verwandlung in ein Buch, er ist ein Genussmensch mit Kenntnis von und Freude an Büchern. Sowohl Corso als auch sein Freund, der Antiquar Flavio, in Der Club Dumas fallen durch das gängige Raster, da sie beide zwar belesen sind, Bücher aber als reines Mittel zum Geldverdienen ansehen. Indem er seine Gelehrsamkeit stolz zur Schau stellt und ein dandyhaftes Gebaren an den Tag legt, passt der Buch- 
händler Barceló in Der Schatten des Windes ebenfalls nicht ganz in das Klischee. Selbstgerecht teilt er Besucher seiner Buchhandlung in „echte Büchernarren“ und „Sonntagsleser “695 ein, verschenkt aber Bücher an Menschen, die sich die begehrten Titel nicht leisten können.

Der Leser hat Erwartungen an die Fiktion und stellt sich den fiktiven Buchmenschen auf gewisse Weise vor, auch wenn diese Darstellung in der Wirklichkeit nicht greift. In den fiktionalen Darstellungen z. B. kommen ausschließlich männliche Buchhändler vor, während die heutige Buchbranche „mit (hochgerechneten) 83 Prozent weiblichen Beschäftigten eine von Frauen dominierte Branche ${ }^{6696}$ ist. Für Antiquarinnen trifft diese Tatsache allerdings kaum zu ${ }^{697}$. Das Antiquariat ist weiterhin männlich dominiert, so dass die stereotypen Darstellungen männlicher Antiquare berechtigt sind.

Aus einer Zeit, in der Buchhändler noch umfassend gelehrt sein mussten ${ }^{698}$, um ihren Beruf auszuüben, und sich Gelehrte noch als Buchhändler oder Bibliothekare (vgl. G. E. Lessing) betätigten, stammt das Klischee, dass der Buchhändler eine umfassende Bildung in beinahe allen Spezialgebieten besitze. Der Buchhändlerberuf wird nicht selten als „Ersatz- oder Ausweichberuf“699 ergriffen, wo die akademische Laufbahn versagt bleibt. In seiner Eigenschaft als Gelehrter und Gebildeter ist der Buchhändler in der Fiktion selbstverständlich männlich. In der Realität und literarischen Darstellungen besonders des 19. Jahrhunderts zeigt er sich im Spannungsfeld zwischen akademischem Gelehrtentum und Kaufmannsdasein. Dem feinsinnigen, hochgebildeten Buchhändler ist das kaufmännische Denken und die Welt des Handels von Grund auf fremd. Noch heute wird der Beruf des Buchhändlers als ,akademischster Ausbildungsberuf angesehen, in dem viele Studienabbrecher und künftige Studierende beschäftigt sind, da das Buch in der allgemeinen Wahrnehmung über seinen Status als materielles Handelsgut hinausgeht und als Kulturgut mehr mit seinem gelehrten oder wissenschaftlichen Inhalt identifiziert wird. Das Buch steht als Symbol für die Gelehrsamkeit, Wissen und Bildung seines Besitzers und Lesers. Dabei wird allerdings außer Acht gelassen, dass schon um 1800 und erst recht heute Romane und andere Unterhal-

695 Ruiz Zafón (2003), S. 18.

696 Aus der Studie „MehrWert. Arbeiten in der Buchbranche heute“, hg. v. Bücherfrauen e.V., 2010, nicht eingesehen, zitiert nach dem Blog Frankfurter-Buchmesse [http://www.buchmesse.de/blog/de/2010/11/03/ mehrwert-arbeiten-in-der-buchbranche-heute], eingesehen am 18.11.2010.

697 Doris Hermanns: „BücherFrauen - ein Netzwerk auch für Antiquarinnen“. In: Aus dem Antiquariat NF 7 (2009), Nr. 4, S. 266f. Online [http://www.buecherfrauen.de/pdfs/public/2009/09_artikel_\%20das_antiquariat.pdf], eingesehen am 18.11.2010.

698 Vgl. zum Bildungsanspruch unter Beschäftigten im Buchhandel und den Unterrichtsinhalten von Lehrlingen Friedrich Christoph Perthes: „Über den Beruf und Stand des deutschen Buchhändlers“. In: Ders.: Der deutsche Buchbandel als Bedingung des Daseins einer deutschen Literatur. Schriften. Hg. v. Gerd Schulz. Stuttgart: Reclam, 1967, S. 33-47.

699 Ruppelt (1997), S. 10. 
tungsliteratur die am meisten verkauften und gelesenen Gattungen stellen ${ }^{700}$. Allerdings beginnt diese Sichtweise auf das Buch durch einen härter gewordenen Handel, ein dem Massengeschmack angepasstes und verflachtes Überangebot sowie verschärfte Wettbewerbsbedingungen angesichts einer bröckelnden Preisbindung aufzuweichen.

\subsection{Figuren in Buchromanen - Privatleben}

„Der satirischen Literatur zufolge tun sich gelehrte Männer mit dem weiblichen Geschlecht außerordentlich schwer" ${ }^{\text {“701 }}$ und dies trifft nicht nur auf die satirische Literatur zu, sondern insbesondere auf den Büchernarren. So bestätigen auch die Protagonisten der untersuchten Texte diesen Gemeinplatz. In den untersuchten Texten haben die Protagonisten keine Partnerin an der Seite oder eine gescheiterte Beziehung hinter sich und sind ganz auf ihre Bücher fixiert. Sie sind Einzelgänger, denn bei einem Teil der Protagonisten spielen soziale und andere Beziehungen keine Rolle. Ihr Leben möchten sie eher den Büchern als einer Liebesbeziehung widmen, zu der sie vielleicht gar nicht dazu in der Lage wären, da den Büchern ihr uneingeschränktes Interesse gilt. Das „Liebesvermögen [von Bibliomanen] erschöpft sich [...] in der Wissenschaft, auf eine anregende Lektüre folgt gemeinhin keine Tat. Bucherotik dient vielmehr zur Kompensation unterdrückter oder beschädigter Sexualität. “' ${ }^{3702}$

Die Korpusromane führen dennoch auch Ausnahmen vor. Daniel verliebt sich in Der Schatten des Windes in die Schwester seines wohlhabenden Freundes. Dies dient in der Erzählstruktur allerdings vornehmlich dazu, die zum Autor parallel verlaufende Lebensgeschichte noch deutlicher zu machen sowie mit seinem Sohn die Buchauswahl auf dem ,Friedhof der Vergessenen Bücher' von neuem beginnen zu lassen und so als ewigen Kreislauf zu stilisieren. Zum anderen beginnt der Kommissar in Das letzte Buch ein Verhältnis, zwar nicht mit der Verdächtigen, doch im Rahmen seiner Ermittlungen mit der Buchhändlerin, in deren Laden die Toten aufgefunden werden, womit ein häufig verwendetes Klischee der Kriminalliteratur bedient wird.

700 Bis zum Jahr 1800 hatte sich der Anteil von Romanen auf dem deutschen Buchmarkt verdreifacht (vgl. Kap. II.1.1). - Laut den Wirtschaftszahlen des Börsenvereins des Deutschen Buchhandels für das Jahr 2009 ist das wichtigste Kaufsegment auf dem deutschen Buchmarkt nach wie vor die Belletristik. Im Jahr 2009 lag der Anteil belletristischer Titel bei 33,8 Prozent (2008: 32,3 Prozent) der gesamten Titelverkäufe. Innerhalb der Warengruppe sind Romane mit 47,2\% Anteil der wichtigste Umsatzträger, hinzu kommen Spannungsliteratur und SF/Fantasy mit zusammen fast 36\%, [http://www.boersenverein.de/de/portal/Belletristik/189810], eingesehen am 11.09.2010. 


\subsection{Der Buchfund - Anlass der Beschäftigung mit dem Buch}

Die Protagonisten als leidenschaftliche Leser oder Buchberufler sind ständig von Büchern umgeben, so dass die Begegnung mit dem besonderen Buch, die in den untersuchten Texten geschildert wird, keine ungewöhnliche Situation darstellt. Das Buch ist eines von vielen, mit denen sie zu tun haben, jedoch aus einem bestimmten Grund einzigartig und von großer Bedeutung für den Protagonisten.

Neben der Verwandlung in ein Buch, die in zwei der untersuchten Romanen geschildert wird, begegnen die Protagonisten dem Buch als Zufallsfund oder werden damit beauftragt, das als geheimnisvoll gekennzeichnete Buch zu beschaffen. Die Buchfunde geschehen zufällig, aber in Umgebungen, in denen Büchern zu erwarten sind, wie öffentliche oder Privatbibliotheken, Buchhandel oder Antiquariat, Nachlässe von Bibliophilen. Der Fund löst die Handlung aus und beginnt, einen beträchtlichen Einfluss auf den Protagonisten zu haben. Beauftragt, ein verschollenes Buch zu beschaffen oder die Echtheit und damit den Wert eines Buchs zu verifizieren, werden Protagonisten, die beruflich mit Büchern zu tun haben und so die nötige Expertise mitbringen. Bei ihrem Auftrag fungieren sie auch als Detektiv resp. dienstlicher Ermittler. Die DetektivProtagonisten Inchbold und Corso (vgl. Kap. III.2.1.1.3) sowie der Kommissar und gescheiterte Literaturwissenschaftler in Das Letate Buch begegnen bei ihrer Suche nach dem Buch, den Buchdieben und dem Mörder der Leser einigen Gefahren, die das Buch im mysteriösen Genre legitimieren und den jeweiligen Roman im Detektiv- bzw. Kriminalgenre verankern.

\subsection{Der Protagonist als Erzähler-Ich - Anlass des Schreibens}

In der Mehrzahl der untersuchten Romane ist es der Fall, dass der Protagonist den Text als autodiegetischer Erzähler wiedergibt. In einigen Texten erfolgt ein chronologischer Bericht, wobei die Ich-Perspektive hauptsächlich dadurch begründet ist, die Sichtweise des Protagonisten für den Leser zu intensivieren (Fforde, Jacobi, Ruiz Zafón), um die Illusion zu wecken, der Protagonist notiere alles, um die Begebenheiten selbst besser zu verstehen (Domínguez) oder um die Herausgeberfiktion (Moers) resp. die Erzählkonstruktion (Živković) zu untermauern. In Das Labyrinth der Welt notiert der Erzähler seine eigene Geschichte retrospektiv für die Nachwelt, während in Der Club Dumas eine Nebenfigur die Erlebnisse des Protagonisten aus wechselnden Perspektiven schildert.

Inchbold erzählt den Handlungsstrang, der seine Geschichte wiedergibt, als autodiegetischer Erzähler wie sie ihm in der Fiktion als erlebendes Ich widerfahren ist, wobei eine Begründung für sein Erzählen ausbleibt. Mit der rückblickenden Erzählung ähnelt er den Begleiter- und Erzählerfiguren Watson oder Adson von Melk, die die Handlung wiedergeben, aber nur als Nebenfigur an den Geschehnissen beteiligt waren und so im Grunde die Erlebnisse des geschätzten Detektiv- 
helden rekonstruieren (vgl. Kap. III.2.1.1.5). Inchbold dagegen hat alles selbst erlebt. Das Notieren der Ereignisse dient ihm als Erinnerungsstütze:

Ich $[\ldots]$ sollte fortan ahnungslos durch seine dunklen Arterien wandeln, durch geheime Korridore und verborgene Zimmer [des Hauses der Auftraggeberin], in denen ich mich [...] noch immer vergeblich nach einem Anhaltspunkt suchen sehe. [...] Also muß ich kehrtmachen und die Abzweigungen, die sich als Irrwege herausstellten, zurückverfolgen. Indem ich das Knäuel von Wörtern hinter mir abwickle, treffe ich noch einmal an jenem Ort ein, an dem für mich die Geschichte des Sir Ambrose Plessington ihren Anfang nahm. ${ }^{703}$

Die Erinnerung gleicht der Wanderung durch einen Irrgarten: Erlebnisse und Eindrücke verblassen oder verzerren sich in der Erinnerung, im Gedächtnis findet keine chronologische Abfolge statt. Durch die Verschriftlichung ist ein korrektes chronologisches Erinnern wie das Abwickeln und Verfolgen eines (Ariadne-)Fadens möglich.

Die Erlebnisse Corsos werden nicht vom Protagonisten selbst geschildert, und so schließt auch diese Erzählweise an die Erzählstimme der, Watson-Figur' an. In Anlehnung an diese Art des Erzählerberichts schildert die Nebenfigur Balkan, die nicht an den Geschehnissen beteiligt war, die Ereignisse, wie Corso sie erlebt und ihm mitgeteilt hat (vgl. Kap. III.2.1.1.5.1). Im Großteil des Romans geschieht dies in einem Modus, in dem der Erzähler mehr weiß als die Hauptfigur, einige Kapitel führen die interne Fokalisierung des Protagonisten vor, während Balkan drei Kapitel als homodiegetischer Erzähler wiedergibt. Balkan hat die Ereignisse in Gänze überschaut und verfolgt und nutzt die unterschiedlichen Erzählstimmen und -modi, um dem Leser Informationen anzubieten oder vorzuenthalten.

\subsection{Der reale Leser heute}

Über einen heutigen durchschnittlichen realen Leser lassen sich kaum allgemeine Aussagen machen wie über die Lesergestalten eines begrenzten fiktionalen Korpus, was Äußerlichkeiten, Beruf oder Privates angeht. Aus der Verbraucherstudie Buchkäufer und Leser - Profile, Motive, Wünsche lässt sich aber mehr erfahren über heutige Käufer- und Lesertypen. Die repräsentative Studie wurde von der Nürnberger Gesellschaft für Konsumforschung (GfK) in Zusammenarbeit mit dem Marktforschungsunternehmen Sinus Sociovision (Heidelberg) im Auftrag des Börsenvereins des Deutschen Buchhandels durchgeführt und 2008 nach 2005 zum zweiten Mal herausgegeben. Mit der Panelstudie wurde das Lese- und Kaufverhalten auf dem aktuellen Buchmarkt untersucht und Einstellungen der Käufer und Leser zu Buch und Lesen ermittelt. Zu diesem Zweck wurden 10.000 Probanden befragt und Kaufdaten von 8.000 Personen ausgewertet. Geplant ist, alle drei Jahre dieselben Personen zu befragen, um gezielt Veränderungen im Konsumverhalten verfolgen 
zu können. ${ }^{704}$ Bei der Auswertung wurde auf die gängigen Sinus-Milieus zurückgegriffen, die die Gesellschaft in ihrer Gesamtheit nach Lebensauffassung und Lebensweise sowie Wertorientierung in zehn Milieus einteilt.

Laut der Studie haben 90\% der Deutschen im Vorjahr der Studie mindestens ein Buch gelesen, wobei der Lesertyp „Wenigleser“ (bis zu neun Bücher im Jahr) darunter mit 43\% am höchsten ist $^{705}$. In der Zusammenschau von Lesern und Käufern wurden „Buchtypen“ definiert. Die größte der acht Gruppen bildet mit 33\% der Buchtyp „Gelegenheitsleser“, der zwar liest, aber nicht kauft. Häufig sind dies Personen mit angehender höherer Bildung, aber geringem Einkommen, also Schüler und Studierende. Aus der Studie geht allerdings nicht klar hervor, ob diese Personen tatsächlich ,Bücher' gelesen haben oder Texte, die online verfügbar sind, oder solche, die aus Büchern kopiert wurden.

Allgemein gesagt werden auf dem deutschen Buchmarkt von einer Mehrheit an Personen also durchaus Bücher gelesen, wenn auch nur wenige Exemplare im Jahr, und diese werden eher nicht erworben, sondern z. B. ausgeliehen. Entsprechend der Lese- und Kaufschwerpunkte, die mit den Buchtypen abgebildet werden, sind die Sinus-Milieus der Konservativen und Postmateriellen als Zielgruppe für den Buchhandel besonders relevant. Potential, eine mögliche Zielgruppe zu bilden, besitzen Etablierte, Moderne Performer, Bürgerliche Mitte und Experimentalisten. Diese Milieus stellen also Personen, die am ehesten ein Buch kaufen oder lesen, woraus aber noch keine Aussage über einen möglichen Durchschnittsleser abgeleitet werden kann. Die Buchtypen („Buchresistente“, „Gelegenheitsleser“, „Ausleihende Leseratten“, „Wenignutzer“, „Durchschnittsnutzer“, „Kauffreudige Leseratten“, „Regalsteller“, „Buchkaufende Nichtleser“) sind vielfältig und zeigen, dass Käufer und Leser nicht gleichgesetzt werden können, da je nach Gruppe mehr Bücher gekauft als gelesen, aber auch mehr Bücher gelesen als gekauft werden. Das Bild eines deutschen Durchschnittslesers ist also facettenreich und nur schwer eindeutig festzulegen.

Allerdings ist das Bild des Lesers in der öffentlichen Wahrnehmung, man könnte annehmen besonders unter „Buchresistenten“, ein nicht durchgehend Positives (vgl. Kap. IV.3.1.1). Ein heutiger realer Normalleser, vor allem ein Vielleser, muss sich in einer Umgebung verorten lassen, die dem Klischee des fiktional geschilderten Leserprotagonisten, Buchhändlers und Bibliomanen nahe kommt. Er muss sich den Vorwurf gefallen lassen, einem Hobby zu frönen, das langweilig, anstrengend und elitär erscheint, da es sich mit Wissen und Bildung befasst, und das im Verdacht steht, einsam zu machen. Diese Vorurteile lassen sich sämtlich kaum belegen, sind aber in der kollektiven Wahrnehmung des Buchliebhabers als Erben des Gelehrten und Bücher-

\footnotetext{
704 Vgl. einen Bericht des Börsenblatts über die Verbraucherstudie 2005, o. V.: „Dem Leser auf der Spur“,

Börsenblatt. Wochenmagazin für den deutschen Buchbandel 45 (2005), 10.11.2005, S. 12-17.

705 Vgl. auch für das Folgende Buchkäufer und Leser II (2008), S. 19-36.
} 
narren fest verankert. Seinen nichtlesenden Zeitgenossen ist der Buchliebhaber mitunter suspekt. Diese Belegung des Lesers als Exot fördert allerdings auch das Prestige des Bücherlesens und ermöglicht über die Empfindung, einer sozialen ,Gruppe’ anzugehören, eine Gruppenbildung unter Lesern, die sich in der Mitgliedschaft in Buchclubs oder der Teilnahme an Buchdiskussionsforen im Internet manifestiert (vgl. Kap. IV.3.1.2).

\subsection{Schlussfolgerung}

Wie hängen nun die fiktionalen Darstellungen von Bücherfreunden, wie jene der Protagonisten der untersuchten Titel, und die Einschätzung von Lesern in der Wirklichkeit zusammen? Es ist anzunehmen, dass die literarischen Protagonisten Züge echter Leser tragen, und die realen Leser nun in der öffentlichen Wahrnehmung mit den literarischen Bücherfreunden in Verbindung gebracht werden. Die literarischen Darstellungen fußen auf den echten Vorbildern bekannt gewordener realer Büchernarren und dem Typus des gelehrten Lesers, deren typische Eigenschaften wie Gelehrsamkeit, Belesenheit und Einzelgängerdasein in die Fiktion eingebracht werden. Dabei sind diese Schilderungen auch immer einer literarischen Tradition geschuldet, um den Text in einem Genre zu verankern, ihn in eine Reihe mit berühmten Vorbildern zu stellen oder um im Leser mit Hilfe dieser Stereotype einfach eine gewisse Stimmung und zu evozieren und einen Erkennungseffekt zu erzielen. Reale Leser werden in der öffentlichen Wahrnehmung nun mit dem Bild assoziiert, das die Literatur - und auch der Film - über Büchernarren und gelehrte Bücherfreunde vermittelt. Bilder und Ansichten, Klischees und Vorurteile, die literarische Darstellungen, die immer nur Ausschnitt aus einer Darstellung der Wirklichkeit sein können, vermitteln, werden nun auf den echten Leser appliziert. Wie die Eindrücke von Bücherfreundund Leserfiguren in der Fiktion müssen auch die Klischees, die die Öffentlichkeit Lesern gegenüber anwendet, natürlich nicht immer der Wahrheit entsprechen. In der Fiktion wird die reale Leserwelt ohnehin nicht ganz korrekt abgebildet: Während die lesenden Romanhelden nach wie vor überwiegend männlich sind, ist die Mehrzahl der Leser fiktionaler Literatur weiblich ${ }^{706}$.

\footnotetext{
706 Vgl. Stocker (2007), S. 67f. - Die PriceWaterhouseCoopers-Studie Haben Bücher eine Zukunft? Repräsentativstudie zum Leseverbalten der Deutschen stellte im Okt. 2007 fest, dass zwei Drittel der Vielleser Frauen seien (S. 3). Es handelt sich um einen Untersuchungsbericht über die Ergebnisse aus 1.224 Interviews anlässlich der Frankfurter Buchmesse 2007. Online [http://www.pwc.de/ fileserver/RepositoryItem/tmt_PwC\% 20Buchm_Studie_4.10.pdf?itemId=3113240], eingesehen am 10.07.2008, inzwischen nicht mehr abrufbar.
} 



\section{Auswertung und Ausblick}

\section{Das ,Buch im Buch' in den untersuchten Romanen}

Die unterschiedlichen Titel im für diese Arbeit zusammengestellten Korpus an aktuellen Romanen zeigen, wie vielfältig das ,Buch im Buch’ auf fiktionaler Ebene eingesetzt und kombiniert wird, und welche Variationsbreite es in der Romanliteratur einnimmt. Gleichzeitig zeigt die Untersuchung aber auch, dass immer ähnliche Konnotationen mit dem Buch in Verbindung gebracht werden und es mit Stereotypen verknüpft wird wie die Wertigkeit, Auratisierung und Mystifizierung des Buchs. Zudem wird es stets mit einer nostalgischen, aber auch gelehrten Ausstrahlungskraft umgeben und besitzt die Kraft, läuternd, erhellend und stärkend auf den Protagonisten einzuwirken, der mit dem Buch in enge Interaktion tritt.

Der Inhalt des ,Buchs im Buch’ ist nicht klar umrissen, denn fiktionale und nicht-fiktionale Inhalte halten sich ebenso die Waage wie real existente und fiktive Titel. Auf unterschiedliche Weise wird fiktionsintern auch die Lektüre des Buchs im Roman gehandhabt. Ein fiktional geschilderter Leseprozess kommt nur in Ausnahmefällen vor, jedoch ist der Inhalt des Binnenbuchs dem Protagonisten stets bekannt. Die im Anschluss vorgelegte Tabelle gibt einen Überblick über die Bücher, die in den Romanen des Korpus vorkommen. Sie können sowohl fiktiv sein als auch real existent und in diesen Fällen auf die Welt außerhalb der Fiktion verweisen. Außerdem wird ihr fiktionaler bzw. nicht-fiktionaler Charakter angegeben.

\section{Roman}

Michael Collins:

Der Bestseller-Mord

Carlos María

Domínguez:

Das Papierhaus

Jasper Fforde:

Der Fall Jane Eyre

Klaas Huizing:

Der Buchtrinker

Peter Jacobi:

Mein Leben als Buch

\section{Buch im Buch}

Existentialistischer Roman „Schrei““

Joseph Conrad:

Die Schattenlinie. Eine Beichte (1917)

Charlotte Brontë:

Jane Eyre (1847)

Johann Georg Tinius:

Merkwürdiges und lehrreiches Leben des $M$.

Johann Georg Tinius, Pfarrers zu Poserna in

der Inspektion Weißenfels. Von ibm selbst

entworfen (1813)

Prototypisches Buch, in das sich der

Protagonist verwandelt
Fiktional? Real existent?

ja nein

ja

ja

ja ja

nein

ja

$?$

nein 


\begin{tabular}{|c|c|c|c|}
\hline Roman & Buch im Buch & Fiktional? & Real existent? \\
\hline Ross King: & „Das Labyrinth der Welt": & nein & ja (?) \\
\hline Das Labyrinth der Welt & Manuskript aus dem Corpus Hermeticum & & \\
\hline $\begin{array}{l}\text { Pascal Mercier: } \\
\text { Nachtzug nach Lissabon }\end{array}$ & $\begin{array}{l}\text { „Aufzeichnungen“ eines portugiesi- } \\
\text { schen Arztes und Widerstandskämpfers }\end{array}$ & nein & nein \\
\hline $\begin{array}{l}\text { Walter Moers: } \\
\text { Die Stadt der träumenden } \\
\text { Bücher }\end{array}$ & $\begin{array}{l}\text { Geniales Manuskript, variiert virtuos } \\
\text { ein bekanntes Thema }\end{array}$ & ja & nein \\
\hline \multirow[t]{2}{*}{$\begin{array}{l}\text { Arturo Pérez-Reverte: } \\
\text { Der Club Dumas }\end{array}$} & $\begin{array}{l}\text { a) Das Buch der neun Pforten ins Reich der } \\
\text { Schatten }\end{array}$ & a) nein & a) nein \\
\hline & $\begin{array}{l}\text { b) Alexandre Dumas père: } \\
\text { Die drei Musketiere }(1843 / 44)\end{array}$ & b) ja & b) ja \\
\hline $\begin{array}{l}\text { Carlos Ruiz Zafón: } \\
\text { Der Schatten des Windes }\end{array}$ & $\begin{array}{l}\text { „Der Schatten des Windes“: } \\
\text { Fiktionale Autobiographie eines } \\
\text { fiktionsinternen Autors }\end{array}$ & ja & nein \\
\hline $\begin{array}{l}\text { Éric-Emmanuel } \\
\text { Schmitt: } \\
\text { Die Schule der Egoisten }\end{array}$ & $\begin{array}{l}\text { Primär- und Sekundärliteratur zu einem } \\
\text { Philosophen }\end{array}$ & $\begin{array}{c}\text { ein } \\
\text { fiktionaler } \\
\text { Bericht, } \\
\text { weitere } \\
\text { non- } \\
\text { fiktional }\end{array}$ & nein \\
\hline $\begin{array}{l}\text { Alfons Schweiggert: } \\
\text { Das Buch }\end{array}$ & $\begin{array}{l}\text { Prototypisches Buch, in das sich der } \\
\text { Protagonist verwandelt }\end{array}$ & ? & nein \\
\hline $\begin{array}{l}\text { Peter Stamm: } \\
\text { Agnes }\end{array}$ & $\begin{array}{l}\text { „Das Buch Agnes“: Geschichte der } \\
\text { Beziehung der Protagonisten }\end{array}$ & ja & nein \\
\hline $\begin{array}{l}\text { Thomas Wharton: } \\
\text { Salamander }\end{array}$ & $\begin{array}{l}\text { Imaginäres, abstraktes Buch ohne } \\
\text { Anfang und Ende }\end{array}$ & $?$ & nein \\
\hline $\begin{array}{l}\text { Zoran Živković: } \\
\text { Das letə̧te Buch }\end{array}$ & $\begin{array}{l}\text { „Das letzte Buch“: Metafiktive } \\
\text { Darstellung des Romangeschehens }\end{array}$ & ? & nein \\
\hline
\end{tabular}

Tab. 3: Die Bücher in den untersuchten Romanen

Dieses Kapitel bietet in dreigeteilter Form zunächst eine Zusammenfassung der im vorangegangenen Kapitel gewonnenen Ergebnisse der Motivuntersuchung zur Funktion und fiktionalen Ausgestaltung des Buch-Motivs. Eine Rolle spielen hier interne und externe Funktionen des Buchs. So wird die Grundlage gelegt für den zweiten Teil, die Erforschung möglicher Gründe für den literarischen Einsatz und die Rezeption des Buch-Motivs in gegenwärtigen Romanen. Hier 
werden die Perspektiven von Verlag, Buchmarkt und vor allem Autor und Leser berücksichtigt. Drittens lege ich eine Einschätzung zur Stellung von Buch und Lesen heute angesichts der Konkurrenz durch digitale Medien vor. Diese Situation gilt als Auslöser für die verstärkte Hinwendung zum Buch und zum Buch-Motiv, wobei auch andere, innerliterarische Gründe für seine Verwendung überhaupt eine Rolle spielen. Um Aussagen über den Stand von Buch und Lesen treffen zu können, beziehe ich aktuelle Studien zum Buchkäufer- und Leserverhalten ein. Außerdem gebe ich einen Überblick, wie verschiedene Akteure der literarischen Kommunikation neue digitale Methoden bereits nutzen. Im Anschluss wage ich einen Ausblick auf eine mögliche Zukunft des Buchs.

\section{1,Buch im Buch' und Genre des Buch-Romans}

Die Ausgestaltung des Buch-Motivs ist ein wichtiger semantischer und struktureller Baustein des Textes, durchaus mit dem Potential ausgestattet, bedeutsam auf den Text zu wirken, sie macht ihn dennoch nicht ganz aus. Der entscheidende Aspekt eines Romans sind zunächst Gattungsund Genrekonventionen, an die sich ein Autor, möchte er einen gelungenen und erfolgreichen Text verfassen, halten muss. Im Folgenden werden exemplarisch drei untersuchte Romane, jene von Fforde, Moers und Ruiz Zafón, auf ihre Genrezugehörigkeit geprüft. Außerdem wird gezeigt, dass das Buch-Motiv das zugrunde liegende Genre des Buch-Romans zum einen variieren, zum anderen im Handlungsverlauf kippen lassen kann, wie bereits in der Motivuntersuchung deutlich wurde.

Leser sind an Genres orientiert und greifen gezielt nach Romanen, die in einem für sie interessanten Genre angesiedelt sind. Noch eher als an Einzeltiteln sind Leser an dem zugrunde liegenden Genre interessiert, was auch eine Autorbindung erklärt. Manche Leser bezeichnen sich als Krimileser, andere lesen nur Fantasy oder Science Fiction, wieder andere sind auf historische Romane spezialisiert. Voraussetzung für die Buch-Romane ist, dass die hochliterarischen Anspielungen von den Lesern verstanden werden. Dazu wird ein stereotypes und anachronistisches Bild vom Buch eingesetzt, das zunächst jeder Normalleser nachvollziehen kann und daraus die richtigen Ableitungen herstellt. Kombinationen mit Schreibweise und Genre fügen dann hochliterarische Elemente hinzu, die womöglich nur vorgebildete Leser ganz verstehen können.

Innerhalb des Korpus gibt es große Genreunterschiede, ebenso in Bezug auf die Schreibweise und das anvisierte Publikum. Fforde schreibt völlig anders als z. B. Schweiggert, Domínguez oder Moers anders als Wharton, während wie bereits festgestellt, Ruiz Zafón Pérez-Reverte nacheifert, ihm aber nicht ganz gerecht werden kann. Und doch arbeiten alle diese Autoren mit der formelhaften Konnotation des Buchs, es ist besonders, beeindruckend, lebensverändernd, aber auch alt und weise und auf faszinierende Weise rätselhaft. 
Fforde steht in der fantastisch-skurrilen Tradition von Terry Pratchett und Douglas Adams, schreibt also Romane, die auch ein weniger gebildetes Publikum von Normallesern unterhalten sowie Leser, die an den Genres Fantasy oder Science Fiction interessiert sind. Zudem setzt er umgangssprachliche Wendungen und auch Elemente ein, die ebenso gut im Film hätten vorkommen können, z. B. die ironischen, umgangssprachlichen Dialoge. In diesem Kontext überrascht das Buch zunächst, da das Motiv mit einer altehrwürdigen, fast ehrfurchtgebietenden Ausstrahlungskraft versehen ist. Fforde setzt das Buch in einem grotesk-absurden Kontext ein, um gerade auf dessen Anpassungsfähigkeit hinzuweisen. Dennoch greift er auch auf die üblichen feststehenden Attribute des Buchs wie Nostalgie und Autorität des Buchs zurück, nicht umsonst stellt er den Klassiker Jane Eyre ins Zentrum. Dieser Roman ist im kulturellen Gedächtnis verankert, die skurrilen Details der utopischen Buchwelt schmücken also einen Teil gut bekannter Literatur und Kultur aus, um diese für heutige Leser interessant zu machen.

Ffordes Roman funktioniert jedoch nur unter der Voraussetzung, dass die hochliterarischen Anspielungen verstanden werden, und die Leser überhaupt wissen, wer „Jane Eyre“ ist. Schon allein die Tatsache, dass der im Roman geschilderte Schluss des Klassikers nicht der reale ist, sollte bekannt sein. Im angelsächsischen Raum sind die Helden der literarischen Klassiker allerdings allgemein geläufig, anders als bei uns. Dort kann man ohne Bedenken voraussetzen, dass Figuren wie Heathcliff, die Bennet-Schwestern oder eben Jane Eyre bekannt sind, während in Deutschland den Figuren klassischer Literatur kein derart breites Interesse entgegenschlägt.

In der Fiktion von Der Fall Jane Eyre gilt eine allgemeine Anerkennung und Wertschätzung von Literatur, so dass der fokussierte Roman dort eine ganz andere Stellung hat als in unserer Welt. Angesichts der utopischen Bücherwelt in Ffordes Roman fragt sich der Leser, wie es denn in seiner Welt um Bücher bestellt ist, ob eine ähnliche Wertschätzung heute und hier möglich wäre.

Ähnlich wie Fforde steht auch Moers in der modernen populären Tradition einer einfach zugänglichen, humorvollen Fantasy und schreibt dabei vorwiegend für ein junges Publikum, das ihn von seinen Comics her kennt. Moers selbst führt an, dass er mit dem Romanen seiner Zamonien-Reihe bekannte literarische Genres ausgestalten wollte (vgl. Kap. III.7.1.6). Die Stadt der träumenden Bücher wäre laut dieser Aussage also dem Horror- und Schauerroman zuzuordnen, dessen Elemente u. a. in der Gestalt des Schattenkönigs erkennbar sind. Außerdem bezieht sich Moers auf literarische Traditionen, vor allem aber sind Elemente aus Fantasy, Bildungsroman und der mittelalterlichen Aventiure als Vorläufer des Abenteuerromans tonangebend.

Diese Genres werden aufgenommen und mit modernen Mitteln kombiniert und verfremdet, so im Sinne des postmodernen Romans spielerisch variiert und dadurch einem breiten Publikum zugänglich gemacht. Gleichzeitig parodiert Moers die Klischees der Unterhaltungsliteratur und 
der Fantasy aber auch, z. B. durch metafiktionale Brüche. Moers bringt populäre Elemente in seine Romane ein, macht aber auch immer wieder Anleihen bei der Weltliteratur (besonders in Wilde Reise durch die Nacht (2001)). Damit legt er Zeugnis seines kulturellen Wissens ab. Essentiell für den Roman ist, wie in den Genres Fantasy oder Abenteuer üblich, die Suche. Dass die Suche in Die Stadt der träumenden Bücher dem Autor eines beeindruckenden Manuskripts dient, ist also nur folgerichtig. Das Buch-Motiv wird mit seinen konventionellen Konnotationen verwandt, um die zitierten literarischen Traditionen im Leser wachzurufen. Nostalgie, Autorität des Buchs und historisierende ,Gemütlichkeit' spielen ebenso eine Rolle, vor allem bei der Beschreibung der Stadt Buchhaim, der Bücher-Hauptstadt. Doch Die Stadt der träumenden Bücher ist auf verschiedenen Ebenen lesbar, mehrfach kodiert und an unterschiedliche Lesergruppen gerichtet, die einerseits das Genre Fantasy genießen möchten, andererseits die weltliterarischen Anspielungen durchschauen und sich daran erfreuen.

Ein Buch-Roman kann sich mehreren Genres zuordnen lassen wie Der Schatten des Windes, der Anleihen beim Melodram, Schauerroman, trivialen Roman des 19. Jahrhunderts u. v. m. macht, und schließlich zum spannenden, massentauglichen Schmöker wird, der sich nicht für ein Genre entscheiden muss. Seit dem Zusammenbruch des Franco-Regimes wird die spanische Literatur stärker beachtet, und so kommt es, dass Autoren wie Pérez-Reverte oder Ruiz Zafón in den letzten Jahren so erfolgreich werden konnten. Auf Ähnlichkeiten zwischen beiden Autoren wurde bereits hingewiesen. Pérez-Reverte macht Gebrauch von einem weltliterarischen Wissen und einer postmodernen Reflexion von Schreiben und Lesen und reflektiert dabei sogar die literarische Tradition des Detektivromans im eigenen Genre. Dem gegenüber fügt Ruiz Zafón fast eklektizistisch Elemente einzelner Genres zu einem unterhaltsamen, aber doch stellenweise kitschigen und klischeebeladenen Schmöker zusammen. Bürgerkrieg und Franco-Diktatur werden zur Kulisse, denn es findet weniger eine subtile Bedrohung des Protagonisten statt, sondern die Verfolgung durch recht plakative Schurken. Das Buch versinnbildlicht eine pathetische Feier des Lesens, die mit fiktionsinternen Motiven kombiniert wird wie dem ,Friedhof der vergessenen Bücher' oder der Buchhändler-Familie des Protagonisten. Außerdem wird das Buch zur Motivation der literarischen Strategie des Doppelgängers eingesetzt. Der Protagonist wird des Buchs wegen verfolgt, welches von einem Geheimnis umgeben ist: Der Protagonist liest darin die fiktionalisierte Lebensgeschichte des fiktiven Autors, die schon bald in sein eigenes Leben hineinragen wird. Mit dieser Dopplung werden wieder Anleihen bei (neo-)romantischen Konzepten deutlich, die aber für den Leser leicht nachvollziehbar sind. Der Leser braucht keine literaturtheoretischen Vorkenntnisse zu besitzen, denn aus anderen Zusammenhängen, literarischen Traditionen, die Hochund auch Unterhaltungsliteratur einschließen, sind Konzepte von Analogien oder das Doppelgänger-Motiv jedem Leser bekannt. Das Buch eignet sich hier bestens dazu, auf diese literarischen 
Traditionen anzuspielen und überhaupt das Wissen zu vermitteln, dass die Identifikation des Protagonisten mit dem Autor hervorruft. Mit der verschachtelten Erzählweise ahmt Ruiz Zafón das postmoderne Erzählen eher nach, als dass er es in Der Schatten des Windes verwenden würde.

Über die an diesen Einzelanalysen gezeigte Verknüpfung von Buch-Motiv und Genre hinaus ist das Buch-Motiv in den untersuchten Romanen auch dazu in der Lage, übliche Genremuster der Buch-Romane aufzubrechen oder das Genre sogar kippen zu lassen. Zunächst werden im Buch-Roman Elemente gängiger Genremuster eingesetzt, um das Genre zu etablieren, z. B. um dem Leser einen Detektivroman anzukündigen. Im Weiteren, wenn das Buch auftritt, wird dieses Schema abgewandelt, wenn das Buch als Ziel einer Suche eben nicht wie üblich aufgefunden wird und sich herausstellt, dass der Protagonist von seinen Auftraggebern vorgeführt wurde (vgl. Kap. III.2.1.1.2). Außerdem kann das Buch, wenn es auf erzähltheoretische Konzepte verweist oder Anlass zur Selbstthematisierung von Buch und Lesen gibt, das Genre des Romans kippen lassen. In genretypisch aufgebaute Kontexte kann es einen neuen Baustein hinzufügen und so einen Krimi z. B. ganz anders fortführen, indem nun das Hauptaugenmerk auf dem Buch liegt (vgl. Kap. III.9.1.3). Leser reagieren mit ihren Erwartungen an das Genre unterschiedlich auf die Buch-Implikationen in diesen Genreumwelten.

Das Buch kann das zugrunde liegende Genre eines Buch-Romans variieren, indem es einen faszinierenden, selbstbezüglichen Aspekt einbringt. Das Buch-Motiv fügt zwar einen nicht zu unterschätzenden Beitrag zum Text hinzu, dominant ist jedoch das vorherrschende Genre des Romans, das dann in Marketing und Werbung für den Roman eine Rolle spielt, da Leser sich bei der Auswahl ihrer Lektüre an Genres orientieren.

\subsection{Funktionen des Motivs, Buch im Buch'}

Literatur hat heute ihre „,vermeintliche gesellschaftliche Funktionslosigkeit ${ }^{\text {“707 }}$ überwunden. Laut Gymnich und Nünning mehren sich sogar Ansätze, die Bezüge zwischen Literatur und Gesellschaft untersuchen. Literatur formt die moderne Gesellschaft, indem sie die Lebenswelten unterschiedlicher Leserschichten ästhetisiert, dabei bleibt ihr Einfluss aber auf Gruppen von Lesern beschränkt. Traditionell wirkte das Buch z. B. in Form der Bibel als moralische Instanz und Autorität und diente dazu, auf soziale Missstände aufmerksam zu machen (z. B. Dickens’ Romane). Der Roman wurde zur zentralen Instanz der Verbürgerlichung (vgl. Kap. II.1.1). Dennoch darf nicht verschwiegen werden, dass das Buch heute für die meisten Lebensentwürfe eine abnehmende Rolle spielt. Schon 1985 stellte Ernst R. Piper fest, dass der Vielzahl der jährlich weltweit erscheinenden Bücher zum Trotz ihre Relevanz „für die Entstehung von Überzeugungen, Ent- 
scheidungen und Handlungen beträchtlich reduziert ${ }^{\text {“708 }}$ sei. Literatur kann die diversifizierte Gesellschaft kaum noch in Gänze abbilden und daher nicht mehr für alle verbindlich lenken.

Die gesamte Funktionalität von Literatur kann nur über literarische Strukturen verwirklicht werden $^{709}$. Im Fall dieser Untersuchung ist es das Buch-Motiv, das Autor und Leser mittels des Textes im Kontext der Gesellschaft in Kommunikation treten lässt, wobei die Funktion des BuchMotivs mit generellen Eigenschaften von Motiven (vgl. Kap. III.1.1.2.1.2) koinzidiert. Das BuchMotiv tritt nie allein, sondern stets in Verbindung mit anderen Motiven auf, was eine Strukturierung des Textes ermöglicht, aber auch seine gleichzeitige bipolare Verankerung in Tradition und Zeitgeist hervorruft. Die Funktion des Buch-Motivs wird hier definiert als seine Fähigkeit, Relationen innerhalb unter den einzelnen Textelementen herzustellen und Wirkungen auf den Leser hervorzurufen. Aussagen über die Funktion von Literatur und ihre gesellschaftliche Relevanz können allerdings nur Hypothesen bleiben, da eine tatsächliche Wirkung von Buch und Literatur oder überhaupt Auswirkungen von kultureller Relevanz auf Instanzen der Gesellschaften kaum empirisch nachzuweisen sind. Indizien in Richtung Plausibilität ergeben sich aus Leserrezensionen, die Meinungen von Lesern wiedergeben, sie müssen aber kritisch betrachtet werden. Hinter einer anonym verfassten, virtuell verbreiteten Rezension müssen nicht zwingend ein echter Leser und seine Meinung stecken. Marketingmaßnahmen von Autor und Verlag oder die Webredaktion selbst könnten ebenso für eine Buchbesprechung verantwortlich zeichnen wie ein Leser, der die Rezension nicht ganz ernst meint.

Harald Fricke unterscheidet zwischen internen und externen Funktionen von Textelemen$\operatorname{ten}^{710}$. Die interne Funktion zeigt die Relation von Textelementen untereinander auf der fiktionsinternen Ebene an, z. B. die Relation des Buch-Motivs zu anderen Motiven oder Figuren. Die externe Funktion verweist auf Relationen von Textelementen zu außertextuellen Aspekten, z. B. auf die Relation des Buch-Motivs zu Aspekten und Kontexten der Gesellschaft, auf Reflexionen aktueller Themen im Text.

\subsubsection{Interne Funktionen des Buch-Motivs: Fiktionsebene}

Das Buch-Motiv wirkt bei der textinternen Strukturierung nicht zufällig, es trägt vielmehr entscheidende inhaltlich-thematische Aspekte, die die Strukturierung und Inszenierung der Handlung tragen. Wir haben gesehen, dass das Buch-Motiv in den untersuchten Romanen immer formelhafte, konventionalisierte Merkmale und wiederkehrende Konnotationen besitzt. Stets betont wird die Autorität des Buchs, seine Ausschließlichkeit und Exklusivität - auch im Sinne des

\footnotetext{
708 Ernst R. Piper: Einleitung zu Bismarck, Gaus \& Sieger (Hg.): Industrialisierung des Bewusstseins. Eine kritische Auseinandersetzung mit den „,neuen“ Medien, 1985, nicht eingesehen, zitiert nach Stocker (1994), S. 83.

709 Vgl. Gymnich \& Nünning (2005), S. 4.

710 Vgl. ebd., S. 9f.
} 
Außergewöhnlichen. Die Romane des Korpus einen diverse fiktionsinterne Elemente, doch kristallisieren sich für das Motiv ,Buch im Buch’ differenzierte Funktionen heraus. Das „Buch im Buch' wurde für die Untersuchung zu Motivgruppen zusammengefasst, die fiktionalisiert die verschiedenen Bereiche von Leben und Literatur zeigen, in denen ein Buch wichtig werden kann. Die Motivgruppen sind jedoch keineswegs zwingend. Dass einige Korpustitel unter mehreren Motivgruppen besprochen werden, legt schon nahe, dass die Motivgruppen auch anders hätten erstellt oder geordnet werden können, z. B. könnte die Verwandlung in ein Buch auch mit der Suche oder eine Büchernarren-Figur auch mit einem tödlichen Buch fiktional verbunden werden und sich doch eine schlüssige Handlung ergeben.

Im Text ist das Buch allgegenwärtig. Es initiiert die Handlung und strukturiert sie durch sein Vorkommen an Wendepunkten. Dabei bedingen sich Buch und Protagonist durch ihre Interaktion gegenseitig. In den meisten Fällen wird das Buch zufällig aufgefunden oder der Protagonist wird mit der Suche danach oder sogar dessen Herstellung beauftragt. Der Zustand oder die Einzigartigkeit des Buchs ziehen die Aufmerksamkeit des Protagonisten auf sich, z. B. das zementbehaftete Exemplar, das über die Geschichte des Büchernarren Auskunft gibt, oder das Buch, von dem nur noch ein Exemplar existiert. Tritt handlungsabhängig ein Antagonist auf, muss das Buch stets vor ihm geschützt werden. Im Handlungsverlauf dient das ,Buch im Buch’ dann als Moment der Spannungserzeugung: Sobald das Buch auftritt, geschieht etwas Entscheidendes, das Buch koinzidiert mit Wendepunkten der Handlung. Dem „Buch im Buch’ wird in den vorliegenden Romanen eine Reihe von Funktionen zugeschrieben, es soll eine potentielle politische Gefahr bedeuten, selbst einen persönlichen Wert besitzen, jedoch zu einem weitaus größeren Schatz führen (Das Labyrinth der Welt), Macht verleihen, zum ideellen Besitz einer Lesergemeinschaft gehören (Der Club Dumas), vermeintlich tödlich wirken (Das letżte Buch) oder die gesuchten Ingredienzien sollen ein perfektes, noch nie da gewesenes Buch ermöglichen (Salamander). Die Vermutung liegt nahe, dass es der ideelle Wert, den ein fiktionaler Leser in ein Buch hineininterpretiert, ist, der die Besonderheit des Buchs im Buch ausmacht.

Durch seine feststehenden Konnotationen ist das Buch vielfältig rekombinierbar, auch mit unterschiedlichen Genres, doch gehen sie alle auf denselben Kern zurück: Sie vermitteln das Geheimnisumwobene und Rätselhafte, auch Unheimliche, Einzigartige, Besondere, Auratische, Schützens- und Erhaltenswerte, wie es als Ziel einer Suche in Detektiv- oder Abenteuergeschichten vorkommen kann. Als Motiv ist das Buch nie allein anzutreffen sondern immer in Kombination mit anderen Motiven, mit denen es zum Motivkomplex wird. Wird das Buch von Anfang an fokussiert, z. B. im Kontext eines Suchauftrags, wird es zwingend im weiteren Handlungsverlauf erwartet. Variationen des Buch-Motivs ergeben sich dann aus dem Zusammenspiel mit den unterschiedlichen Ausformungen der Genres. Tritt das Buch-Motiv jedoch in einem Genre auf, 
in dem es nicht zwingend erwartet wird, kann es durch seine inhärenten Konnotationen das zugrunde liegende Genre bereichern und sogar modifizieren.

Das Buch beeinflusst Denken und Handeln des Protagonisten, lässt ihn nach der Begegnung als einen anderen zurück und führt eine Veränderung in seinem Leben und Alltag herbei. Gleichzeitig projiziert der Protagonist auch etwas in das Buch, seine Wünsche, Sehnsüchte, Vorlieben. Das Buch wird mit Assoziationen, Emotionen und Wert aufgeladen, so sehr, dass es für Autoritäten zur Gefahr werden kann und Existenzen aufs Spiel gesetzt werden. Über das Buch gerät der Protagonist auch mit dem Autor in Kontakt, zu dem er eine große Nähe verspürt und sogar Parallelen zwischen ihm und sich entdeckt. In den Titeln, in denen das Buch selbst thematisiert wird, erkennt der Protagonist sein eigenes literarisches und literaturtheoretisches Wissen und kann es anwenden, was zur Lösung führen kann aber nicht muss, wobei ein Übermaß an Kenntnissen eher hinderlich ist.

Ein Buch kann in seinem Auftreten weitere nach sich ziehen, so dass es zum pars pro toto für Literatur und zu ihrem Symbol wird. Im Fall der Verwandlung in ein Buch legitimieren Thematisierung und Milieu außertextuelle Funktionen wie die direkte Immersion des Lesers, um eine Reflexion der eigenen Position als Leser und auch des Status des Buchs im realen Leser zu bewirken.

\subsubsection{Externe Funktionen des Buch-Motivs: Außertextuelle Ebene}

Das Buch ist, enthoben aller hochliterarischer Provenienz, allen Leserschichten verständlich und wird so innerhalb der Gesellschaft zu einer gemeinsamen kulturellen Wissensbasis, es gehört zum „Reservoir[ von Kollektivsymbolen“ “711 unserer Gesellschaft (vgl. Kap. III.1.1.2.2). Ein Buch besitzt gewisse feste Merkmale, die immer wieder auftreten: Es vermittelt z. B. eine besondere Atmosphäre sowie Assoziationen des Gemütlichen, Altmodischen, Altertümlichen, aber auch Gelehrten und Historischen. Durch den Einsatz von Kollektivsymbolen in einem literarischen Text ist eine Verbindung von künstlerischen mit gesellschaftlichen Diskursen möglich ${ }^{712}$. So dient das Buch als Anknüpfungspunkt an kollektive gesellschaftliche Diskurse, denn eine Verständigung über Buch und Buch-Motiv ist unter Teilen und Mitgliedern der Gesellschaft als Interdiskursivität möglich. Literatur geht mit der Gesellschaft, in der sie entsteht und gelesen wird, immer auch eine Wechselwirkung ein, denn „[f]iktionale Texte sind nach speziellen Mustern geordnete Weltmodelle.“713 Die gegenwärtige Phase des häufigen Auftretens des Kollektivsymbols Buch in Romanen wird ausgelöst durch den Diskurs um Buch und Medienwandel, wobei das Buch für diverse feststehende Konnotationen steht: Das Buch steht für

\footnotetext{
711 Stocker (1997), S. 108. 
Literatur, für seinen Status als Medium, für eine Tradition, mit der heute wie befürchtet wird, gebrochen wird, für das wertvolle Alte, das überdauern wird, wie man auch an der Situation am Markt erkennen kann.

Die Herstellung der eng mit den internen verzahnten externen Funktionen des Buch-Motivs gelingt durch Textinterpretation, unterliegt ihr aber auch: Jeder Leser interpretiert einen Text anders und bewertet ihn assoziativ individuell unterschiedlich. Die Wirkung von Textelementen, ihre Relation zu gesellschaftlichen und kulturellen Kontexten, hängt von der Vorbildung, auch den literarischen Vorkenntnissen des Lesers ab. Kompetente Leser können noch elaboriertere Zusammenhänge herstellen, zu literaturwissenschaftlichen Theorien, zu Gattungen, zu Epochen und literarischen Strömungen etc., die aber für das grundlegende Verständnis des Textes nicht unbedingt notwendig sind. Das Motiv, und damit auch der gesamte Text, besitzt damit nicht nur eine Bedeutung, sondern so viele, wie es Leser gibt. Diese Polyvalenz der Textelemente resultiert in der Existenz mehrerer Leseebenen eines Textes und seiner Adressiertheit an verschiedene Lesergruppen, ein Stilmittel, das besonders in der postmodernen Literatur genutzt wird.

In einer auratischen, buchbetonten Atmosphäre in der Fiktion findet auf einer Metaebene auch eine Reflexion über den Umgang mit dem Buch statt. Der Leser sieht sich mit der Frage konfrontiert, ob z. B. Büchernarren übertrieben handeln und wie der eigene Umgang mit Büchern aussieht, wie weit er selbst bei der Suche nach einem faszinierenden Buch oder Autor gehen würde. Darüber hinaus bietet das ,Buch im Buch’ Anlass und Anregung zur Reflexion des heutigen Status von Büchern.

Die Verwendung gleicher Motive in literarischen Werken kann zu einer Verbindung zwischen Epochen und gesellschaftlichen Situationen führen: Die heutigen neuen Bedingungen der Medienlandschaft und der literarischen Kommunikation ähneln mit der Veränderung von Lesestoffen und -modi denen der ,Leserevolution' um 1800, so dass aus der historischen Erfahrung Ableitungen für die heutige Situation von Literatur in der Gesellschaft gemacht werden können.

Der Autor benutzt das kulturtypische Buch-Motiv, um in Kommunikation mit dem Leser zu treten. Ein Autor verständigt sich mit dem Leser durch gemeinsames kulturelles Wissen, das auf den kleinsten gemeinsamen Nenner gebracht wird und mitunter auf eine grobe Vorstellung oder ein Attribut reduziert sein kann: Die literarische Figur Don Quijote (vgl. Kap. III.2.1.2.1) mag nur wenigen aus dem Roman vertraut sein, als ,Ritter von der traurigen Gestalt' aber ist er im kulturellen Gedächtnis verankert.

Die Legitimität der Frage nach der Wirkungsabsicht oder Intention des Autors zum Zweck der Bedeutungsfestlegung eines Textes wurde durch Barthes’ einflussreiches Konzept vom „Tod des Autors“ (vgl. Kap. III.9.1.5) so gut wie außer Kraft gesetzt. Man könnte kulturellen Produk- 
ten, wie Romanen, im Kontext einer, Wirkung' auf die Gesellschaft und ihrer Instanzen dennoch eine gewisse mögliche Dynamik unterstellen. Bei der Diskussion der Funktion von Literatur und ihrer gesellschaftlichen Relevanz in dieser Arbeit wird dem Autor jedoch nicht eine konkrete Wirkungsabsicht unterstellt, sondern vielmehr nach einem geeigneten Publikum für Buch-Bücher und dem „Wirkungspotential“ ${ }^{\text {“714 }}$ solcher Romane auf den Leser und seine Reaktion auf das Buch-Motiv gefragt.

Das Buch-Motiv als Textelement und winziges Teilelement des Konzepts ,Literatur' ist dazu in der Lage, ein ganz vielfältiges Spektrum an internen und externen Funktionen zu erfüllen. Doch auf der außertextuellen Ebene bleiben seine Funktionen spekulativ, können jedoch z. T. durch die Frage nach dem, Warum' legitimiert werden: Warum schreibt ein Autor einen Roman, in dem das Buch-Motiv vorkommt? Warum werden solche Romane gelesen? Warum sind diese Bücher auf dem deutschen Buchmark.t erbältlich?

\section{Symptomatizität des Buch-Motivs im Roman oder Warum ,Buch im Buch'?}

Die Verwendung des Motivs ,Buch im Buch’ findet zunächst aufgrund des Kulturwerts des Buchs statt, andernfalls könnte jeder beliebige (Alltags-)Gegenstand zum literarischen Motiv werden. Das Buch aber als Vermittlungsinstanz von Texten besitzt schon eine inhärente Verbindung zu Literatur, so dass es sich als Motiv in literarischer Fiktion aufdrängt. Betrachtet wird in dieser Arbeit nicht das Lesen wissenschaftlicher Texte oder das Lesen zur Weiter- und Fortbildung, sondern ausschließlich das Lesen zur Unterhaltung, und hier vor allem die Lektüre von Romanen.

Diese Arbeit versucht dem Buch-Motiv nachzugehen, das in den Buch-Romanen zwar auf Traditionen zurückgreift, aber nicht in ihnen gefangen ist. Zugleich reagieren die Buch-Romane auf Themen des Zeitgeistes sowie auf die Umbrüche in den Medien, ein verändertes Marktverhalten und Veränderungen in Produktions-, Publikations-, Distributions- und Rezeptionsprozessen von fiktionaler Literatur und reflektiert diese (vgl. Kap. IV.3). Das zunehmende Interesse an Buch und Lesen und ihrer fiktionalen Repräsentation heute kann als Krisenerscheinung angesehen werden, denn die Konkurrenz zum Buch durch die ,neuen Medien’ ist groß und allgegenwärtig. Dennoch ist der Medienwandel nicht die einzige Begründung für das Vorkommen des Buch-Motivs. Unter Berücksichtigung der aktuellen Situation auf dem deutschen Buchmarkt sowie Studien zum Lese- und Kaufverhalten in den letzten Jahren in Deutschland und Statistiken zur Wertung von Büchern und Lesen kann man aus den Befunden, die aus der Motivunter- 
suchung gewonnen werden konnten, die im Folgenden skizzierten Schlüsse für die Begründung des ,Buchs im Buch’ ziehen.

\subsection{Situation am Markt}

Das fiktionalisierte ,Buch im Buch' kann u. a. als Reaktion auf die starke Ausdifferenzierung und Massenproduktion des Literaturmarktes betrachtet werden. Der Autor kämpft mit unzähligen anderen auf einem übergroßem Romanmarkt um die Aufmerksamkeit des Lesers, hinzu kommt der hohe Novitätendruck. Die Laufzeiten einzelner Titel bis zur Zweitverwertung im Taschenbuch, immer häufiger auch im Hörbuch, und schließlich bis zur Verramschung werden immer kürzer, jedoch nehmen Buchkäufer beinahe nur Neuerscheinungen wahr. Jede Generation von Buchlesern scheint unter dem Eindruck eines „Literaturüberschusses“715 zu stehen, dem Eindruck, aus dem Überangebot nicht mehr wählen zu können, möchte man sich umfassend informieren und an der literarischen Kommunikation teilnehmen. Romane mit Buchbezug können hier möglicherweise gegensteuern: Das Buch als zeitloses Motiv mit langer Tradition ist ein klar konturiertes und bekanntes Thema, das Leser auffängt, die als Wegweiser durch die unübersichtliche Novitätenlandschaft das Vertraute suchen. Vor allem zielt es auf buchaffine Leser als gesicherte Lesergruppe. Neue Leser bzw. Nicht-Leser werden sich kaum von Buch-Büchern ansprechen lassen, da sie Büchern per se nicht wohlwollend gegenüberstehen. Bei aller Massenproduktion stellt das fiktionalisierte Buch als Unikat einen, von vielen Autoren und Lesern wohl gewünschten, Bruch mit der Realität der Massenproduktion dar.

\subsection{Verlag, Buchmarkt und, Buch im Buch'}

Ein Verlag wird benötigt, um die äußere Kommunikation zwischen Autor und Buchmarkt sowie Autor und Leser überhaupt erst herzustellen. Der Verlag sorgt für die Aufwertung des Textes durch Korrektur, Lektorat, Satz und Layout (Herstellung), für die Um- und Ausformung eines Textes zu einem haptisch fassbaren papiernen Medium in vielfacher Auflage (Druck), für die Anbindung an den Buchmarkt (Publikation), für Werbung und Marketing sowie für die Verfügbarkeit im Buchhandel (Vertrieb).

Aus welchem Grund nimmt ein Verlag nun Bücher, i. e. Romane, über Bücher ins Programm? Die Verlage, die über die Veröffentlichungsqualitäten der Manuskripte entscheiden und die BuchBücher schließlich vertreiben, sehen möglicherweise eine Dringlichkeit des Themas Buch und damit ein Potential, das sich im Absatz bemerkbar machen wird, obwohl eine Verlagsmitarbeiterin diese Annahme nicht bestätigen konnte (vgl. Kap. III.1.1.1.4). Wie mitgeteilt wurde, gebe es 
für das von mir beobachtete häufige Vorkommen von Büchern in Büchern im besagten Verlag (bisher) keinen besonderen Grund. Die Autoren von Büchern über Bücher sind vielleicht bereits mit anderen Titeln im Verlag erfolgreich, so dass ein weiterer Roman, egal, welches Thema er behandelt, erneuten (Verkaufs-)Erfolg verspricht.

Die Romane des Korpus sind Romane ganz unterschiedlicher Provenienz und Genres. Bemerkenswert ist jedoch, dass 40\% der Korpustitel als Erstausgabe oder Zweitverwertung bei btb erschienen sind. Dieser Verlag rühmte sich in einer früheren Version der Homepage für sein ausgewähltes Programm für „leidenschaftliche Leser und Bücherfreunde“ - offensichtlich wird den Buch-Büchern, vielleicht unterschwellig, doch ein Potential besonders bei einem anspruchsvollen, belesenen Publikum kompetenter Leser zugetraut. Heute heißt es ${ }^{716}$, der Verlag biete „Literarische Unterhaltung für ein breites Publikum“. In dieser überarbeiteten Einschätzung des Programms hat also eine Öffnung stattgefunden hin zum Normalleser, der auch dazu in der Lage ist, anspruchsvolle Unterhaltung zu goutieren bzw. zu einer Multiadressiertheit, die den BuchBüchern das Potential zugesteht, sich an verschiedene Publikumsgruppen zu richten.

Dennoch werden die Buch-Bücher nicht als solche vermarktet, da dieses Genre nicht existiert. Die Romane mit Buchbezug unterliegen ihrem vordergründigen Genre und werden als diesem zugehörig, z. B. als Krimi, auf den Markt gebracht. Dies findet auch in Umschlagabbildung und Klappentext, Reizauslöser und Primärinformationen für den Buchkäufer, seinen Niederschlag. Vermutlich soll so auch das am jeweiligen Genre orientierte Publikum abgeschöpft werden, denn das Genre spielt bei der Titelwahl und für die Kaufentscheidung eine beträchtliche Rolle. Außerdem entscheidend für Vermarktung und Verkaufserfolg ist, welcher Warengruppe der Roman zugeordnet ist, also welche systematische und thematische Zuordnung der Verlag vornimmt, und in welcher Rubrik das Buch daraus folgend im Buchhandel angeboten wird.

Es wäre möglich, dass durch das Motiv ,Buch im Buch’ ein neues (Sub-)Genre entsteht, das gezielt auf den Markt gebracht werden könnte. Ein Beispiel für ein gerade im Entstehen begriffenes neues Sub-Genre ${ }^{717}$ auf dem Romanmarkt sind die heute im Übermaß erhältlichen Titel um Vampire. Der Vampirismus kann als einer der wirkungsmächtigsten Mythen der Moderne angesehen werden, der in allen Kulturen anzutreffen ist, als literarisches Motiv ist der Vampir seit Bram Stoker sehr beliebt und verbreitet. Gerade erlebt das Motiv eine Mode, da es durch die enorm erfolgreiche Vampir-,Saga' von Stephenie Meyer (Twilight (2005), New Moon (2006), Eclipse (2007), Breaking Dawn (2008)) zu einem Teil der Medienwirklichkeit geworden ist. Ein Ende des

\footnotetext{
716 Homepage des btb-Verlags, „Über den Verlag“, [http://www.randomhouse.de/btb/verlag.jsp? men=81\&pub=2000], eingesehen am 13.04.2011.

717 Dieses neue Genre wird von Verlagen unterschiedlich benannt, z. B. „Romantic Mystery“ (Goldmann) oder „Romantic Fantasy“" (Egmont Lyx).
} 
Trends ist nicht in Sicht und wird durch die intermediale Verwertung wie Verfilmungen, Medienauftritte der Filmstars, Merchandising etc. weiter angefacht. Für die heutige Zeit umgedeutet und an sie angepasst ist das Vampir-Motiv in diesem Kontext multiadressiert und spricht mehrere Altersgruppen an. Die zugrunde liegenden Konnotationen des Motivs sind dabei immer dieselben: Es geht um die großen Fragen wie Leben und Tod, Unsterblichkeit, Ewigkeit, um Sexualität und Unvereinbarkeit von Liebe und Gefahr. Die äußerlichen Attribute des Vampirs (klassisch: schwarzer Umhang, spitze Zähne, kein Spiegelbild etc.) können sich durch die Zeit verändern und an ihre Gegebenheiten und Bedürfnisse anpassen, Meyers Vampire z. B. besitzen das äußere Erscheinungsbild normaler Teenager von heute. So ist das Motiv zeitlos und überlebt in unterschiedlichen Umgebungen und Zeitumständen. Das literarische Motiv ist allen Lesergruppen bekannt, somit massenkompatibel, denn jeder Leser sucht sich das Attribut aus, das ihn anspricht und mit dem er emotionale assoziative Verknüpfungen erstellt. Die an Meyers Tetralogie anknüpfenden Titel, die deren Erfolg nachzuahmen versuchen, führen durch ihre Masse und Variationsbreite zu einem eigenen Sub-Genre. Diese Titel sind von variierender literarischer Qualität und betonen unterschiedliche Aspekte des Vampir-Motivs, besonders aber Gefahr und Sexualität.

Wie gezeigt werden konnte, ist auch das Buch-Motiv seit allen Zeiten beliebt und verbreitet. Unabhängig von literarischen Moden erscheint es immer wieder in der Romanliteratur und ist heute besonders präsent, so dass bereits von einem Trend zu metafiktionalen Romanen gesprochen werden kann. Die Zeitlosigkeit und Multiadressiertheit, die schließlich für die Bildung des Vampir-Sub-Genres förderlich waren, treffen auch auf das ,Buch im Buch’ zu. Diese Aspekte wären ein Vorteil bei der Durchsetzung eines Genres „Bücher über Bücher“. Es besitzt das Potential sich auf dem Markt durchzusetzen, ist dem Publikum die Möglichkeit gegeben, gezielt nach diesen Titeln zu greifen. Mit neuen Genres kombiniert und in neuen Umfeldern untergebracht bietet das ,Buch im Buch’ eine reizvolle Mischung aus bekannten Genres und bekanntem Motiv, die gemeinsam etwas Neues ergeben.

\subsection{Autor und ,Buch im Buch'}

Warum schreibt ein Autor einen Roman, in dem er ein Buch, Bücher oder das Lesen ins Zentrum stellt? Im Folgenden soll dieser Frage unter dem Aspekt literarischer Traditionen, aktueller kulturkritischer Positionen sowie neuer Wege fiktionaler Literatur nachgegangen werden.

\subsubsection{Tradition des Buch-Motivs}

Der Autor unterliegt beim Verfassen fiktionaler Texte Gattungs- und Genrekonventionen, aber auch literarischen Traditionen, in denen einzelne Textelemente, so auch die Verwendung bestimmter Motive, stehen. Das Zurückgreifen auf bekannte Elemente hilft dabei, den eigenen Text 
in einem Genre zu verankern und in eine Reihe bedeutender Vorbilder zu stellen, und so vielleicht von deren Bekanntheit oder Prestige zu profitieren, in jedem Fall aber dem Leser durch den Hinweis auf Bekanntes Signale zu geben, wie er den vorliegenden Text zu lesen hat. Die vielfältige und reiche Tradition des Buch-Motivs wurde bereits in Kapitel II hinlänglich erläutert. Bei aller Traditionalität des Motivs gibt es aber doch auch einen Trend zum Einsatz des Buch-Motivs in Romanen, wie diese Arbeit zeigen konnte. Das Buch-Motiv ist aktuell und virulent, es taucht in ganz aktuellen Titeln auf wie in Juja (2010) von der Neuentdeckung Nino Haratischwili oder dem mit Spannung erwarteten letzten Roman 1 284 (2009) von Haruki Murakami.

Das Motiv ,Buch im Buch’ ist einer primär romantischen Tradition verpflichtet und schließt an den Mythos des absoluten und einzigen oder des magischen Buchs an. Aufgrund von dessen dezidiert romantischem Erbe sowie der Selbstbezüglichkeit von Schreiben und Lesen tritt das Motiv auch im postmodernen Roman häufig auf. Dies kann eine Begründung für die beobachtete heutige besonders häufige Verwendung des ,Buchs im Buch’ sein. Über die Anknüpfung an Traditionen hinaus ist das Motiv aber immer auch seiner Zeit verpflichtet. Durch Neukombination des Buch-Motivs mit anderen Motiven oder neuen Genres entsteht der besondere Aspekt der Buch-Romane, der auch auf aktuelle Zeitumstände ihrer Entstehung verweist. Die folgenden Ausführungen Elisabeth Frenzels gelten zwar der Umformung eines literarischen Stoffes, doch ihre Aussagen lassen sich auch auf das Motiv ,Buch im Buch’ anwenden:

Probleme, Hoffnungen und Ängste der Menschen einer Epoche führen notwendig zum Ausdruck in verwandten dichterischen Bildern und Gleichnissen, ob sie nun selbst geschaut oder der Vorratskammer der überlieferten Motive entnommen sind; sie erzeugen Fabeln mit ähnlichen Katastrophen und Lösungen, ob sie nun Erlebnisse der eigenen Zeit verdichten oder alte Plots aus Geschichte und Literatur erneuern. ${ }^{718}$

Für das ,Buch im Buch’ gilt beides: Das Motiv ist alt, der zitierten „Vorratskammer“ entnommen, denn es findet Verwendung nicht erst in aktueller Literatur, sondern steht in einer langen literarischen Tradition. Gleichermaßen ist es Ausdruck der eigenen Zeit, u. a. der Reflexion gerade neuer Wege des fiktionalen Schreibens.

\subsubsection{Reaktionen auf neue Schreibweisen}

Das ,Buch im Buch' als Selbstbezug und -reflexion: Das ,Buch im Buch' bedeutet ,Literatur in der Literatur' in Form von intertextuellen Bezügen und Elementen der Metafiktion. In allen Büchern sind andere Bücher enthalten, sei es implizit durch Anspielungen oder Subtexte oder explizit durch Verweise und Zitate. Dies kann eine Legitimation für das Buch-Motiv sein. In der Literatur kann das Buch-Motiv für einen Selbstbezug ${ }^{719}$ stehen, der in einer Selbstreferentialität mündet,

\footnotetext{
718 Elisabeth Frenzel: Stoff- und Motivgeschichte. 2., verb. A. Berlin: Erich Schmidt, 1974 [zuerst 1966], S. 44.

719 Vgl. Japp (1975), S. 653.
} 
nämlich die von Schreiben und Lesen, von Autor und Leser: Der Autor reflektiert seine eigene Rolle als Autor im Geschriebenen, zugleich aber auch seine Rolle als Leser, indem er über das Lesen schreibt, was wiederum von anderen gelesen wird. Der Leser hätte an dieser Stelle die Möglichkeit, das Gelesene fortzuschreiben: Eine unendliche Steigerung, die wieder zu Novalis führt.

Die literarische Selbstreferenz zeigt sich als typisches Phänomen der Postmoderne, was auch die Metatexte in der neueren Literatur mit ihren Schreibweisen belegen, die neben dem Schreiben und Lesen auch die ,Person' bzw. Figur des Lesers thematisieren. Das Buch erscheint seinem Wesen nach als ein ideales Medium, das Lesen zu reflektieren und zu thematisieren.

Das im Buch thematisierte Buch ist mit Japp als „hermetische Figur“ zu identifizieren (vgl. Kap. III.1.1.2) - das Buch kreist um sich selbst und steigert sich somit unendlich, in dem ,Buch im Buch' könnte schließlich wiederum ein Buch auftauchen und so fort. Gerade diese Selbstbezüglichkeit führt aber aus der Abgeschlossenheit des Um-sich-selbst-Kreisens hinaus und eröffnet Raum für Reflexionen und Assoziationen. Das ,Buch im Buch’ wird in diesem Zusammenhang zu „Steigerungsfigur“ und Handlungsmoment, das den Leser, auch den auf der realen Ebene, während des Lesens zu ständiger Reflexion treibt, ausgelöst durch die Identifikation mit dem Gelesenen. Letztlich führt diese Reflexion für den Leser im Akt des Lesens zu Einsicht und Selbst- und Welterkenntnis.

Durch Brüche in der Erzählform wird der Leser in das Geschehen einbezogen, eine Technik, die vor 200 Jahren noch ,Romantische Ironie' hieß. Im Roman der Romantik, besonders bei Novalis, erreichte die Selbstbezüglichkeit einen Höhepunkt. Die Agenten der Frühromantik erkannten, „Literatur [...] drängt danach, sich in sich selbst zu spiegeln “720. Um eine (Selbst-)Reflexion beim Lesen überhaupt zu ermöglichen, wird das gespeicherte Wissen um bereits Geschriebenes, bereits Gelesenes, also Intertextualität bedeutsam. Auf Seiten des Lesers bedeutet die Spiegelung der Literatur in sich selbst zum einen die Prägung der Persönlichkeit, von Meinungen und Einstellungen durch Bücher. Zum anderen meint sie das Leserepertoire, auf das der Leser zurückgreifen und somit intertextuelle Bezüge zwischen den gelesenen Büchern herstellen kann. Auf diese Weise verbessert er sein Verständnis der Lektüre. Auf Seiten des Autors, der außerhalb seines Werks schließlich auch ein (privater) Leser ist, sind es literarische Traditionen, an die er anknüpft. Andererseits unterliegt er möglicherweise einem postmodernen Zwang zu selbstbezüglichen Schreibweisen, um seine Fähigkeiten, aktuell und ,modern’ zu schreiben, unter Beweis zu stellen. 
Immer elaboriertere Wege zu schreiben: Heutige (Roman-)Leser haben lange Lesebiographien hinter sich, die sie bei der Lektüre eines neuen Textes in den Rezeptionsprozess einbringen. Der bildungsbürgerliche Anspruch zielt auf ein Wissen um die Klassiker ebenso wie auf ein Schritthalten mit den jeweils aktuellen Neuerscheinungen und ein Informiertsein über den literarischen und kulturellen Diskurs. Um Leser, ,die schon alles gelesen haben' und in fiktionalen Techniken geübt sind, für seine Werke einnehmen zu können, muss sich ein Autor immer wieder etwas Neues einfallen lassen. Diese neuen Wege, den anspruchsvollen Leser zu begeistern, können durch das Einbeziehen intelligenter Konzepte beschritten werden, die das Mitdenken des Lesers fordern und durch das ,Buch im Buch' und damit verbundene intertextuelle Aspekte ausgelöst werden.

Wirkungsästhetische Konæepte: Seit den 1960/70er Jahren stellen einige literaturtheoretische Positionen eher den Leser als den Autor ins Zentrum ihrer Betrachtungen. Man erkannte, dass der Text ohne Adressat statisch und unvermittelt bleibt, erst durch eine stärkere Involvierung des Lesers wird der Text zum Kommunikationsmedium zwischen Leser und Autor. Diese Fokussierung und Aufwertung des aktiven, performativen Lesers wird in der Romanliteratur in Form von selbstreferentiellen Konzepten fiktionalisiert. Der selbstreflexive Ansatz der Romane mit Buch-Motiv impliziert nun, den Leser in den Deutungsprozess des Romans einzubeziehen, um daraus ein für alle Instanzen gelungenes Werk zu machen. Der Leser wird neben dem Autor systematisch aufgewertet und durch seinen Rezeptionsprozess in der Trias Autor - Text - Leser zu einer Art KoAutor für seine individuelle Version des Textes mit all seinen Verständnisebenen, Deutungsmöglichkeiten und persönlichen Assoziationen und Relationen.

\subsubsection{Reaktion auf den Medienwandel}

Das Motiv ,Buch im Buch’ ist heute nicht nur virulent aufgrund einer literarischen Tradition, der der Autor verpflichtet ist, oder eines literarischen Trends, sondern auch als Reaktion auf den Medienwandel, der seit der Etablierung von Internet und www in den 1990ern aktiv ist. Die gesellschaftlichen und kulturellen Bedingungen der Produktion, Distribution und Rezeption von Literatur haben sich durch den Medienwandel hin zu digitalen Medien verändert und damit auch die Beziehungen zwischen Werk und Gesellschaft. Angefacht wurde die Diskussion um einen vermuteten Rückgang der Beschäftigung mit dem Buch heute erneut aufgrund einer veränderten Medienpraxis. Medien sind immer stärker untereinander vernetzt und kompatibel. Die Sorge richtet sich dabei auf eine fortschreitende Digitalisierung elektronischer Medien. Die Beschäftigung mit dem Buch rücke dadurch, so wird vermutet, einerseits in den Hintergrund, andererseits absorbieren digitale Medien z. T. Funktionen und Aufgaben des Mediums Buch. So gibt es vielfältige neue Produktions- und Vertriebswege für literarische Texte wie z. B. die elektronische Bereitstellung von Texten (vgl. Kap. IV.3.3.2). 
Die Diskussion um den Medienwandel ist virulent, so dass das Buch gerade verstärkt in den öffentlichen Fokus tritt. Als Reaktion auf die Konkurrenz durch elektronische, ,neue Medien' und Internet wird das Buch im eigenen Medium, dem Roman, wieder mehr thematisiert. Dadurch wird vielleicht versucht, die viel beschworene Entebhrlichkeit und Verdrängung von Büchern zu kompensieren. Rusch et al. sprechen in Anlehnung an Schanze von einer „Wiederkehr des Buches“, und auch Stocker führt an, dass Rager \& Werner der Meinung seien, das Internet habe zu einer „Renaissance des Lesens“ ${ }^{\text {“721 }}$ geführt. Die Thematisierung des Buchs in der Fiktion liegt auch darin begründet, dass ,neue Medien' nicht zusammenhanglos stehen, sondern immer auf den alten beruhen und ihre Praktiken fortführen. So wird eine Nutzung des WwW ohne die Tätigkeit des Lesens auch in Zukunft nicht möglich sein.

Seit es Medien als Kommunikationsmittel und zur Übermittlung von Informationen gibt, beobachten sie sich gegenseitig. Auf die Konkurrenz wird reagiert, indem das eigene Medium in seinen Inhalten selbst reflektiert wird. Die Beobachtung anderer Medien und die dadurch hervorgebrachte Reaktion auf die Konkurrenz hat an der Schwelle zum 19. Jahrhundert in einem Zeitalter der Gelehrten Zeitschriften schließlich zum Durchbruch des Buchs zum Leitmedium und zur Beliebtheit der Gattung Roman geführt. Die Zeitschrift als Schlüsselmedium der bürgerlichen Gesellschaft ${ }^{722}$ bildete ein identitätsstiftendes Element für das bürgerliche Individuum, den individuellen Bürger des ausgehenden 18. Jahrhunderts: Bürger wurde, wer in die Medienkultur integriert war, sowohl produktiv (Autoren, Verleger, Kritiker, Leser als Rezensenten), distributiv (Verlag und Buchhandel) als auch rezeptiv (Leser). In dem immer vielschichtiger werdenden medialen Netzwerk kam das neue bürgerliche Selbstbewusstsein zu freier Entfaltung und führte zur Durchsetzung des Buchs als hauptsächlich und extensiv genutztem Medium, wobei der Aspekt der Unterhaltung eine ganz neue Qualität des Lesens darstellte. Diese Entwicklung stieß nicht nur auf Zustimmung, und so wurde die, Vielleserei' ebenso kritisch gesehen wie heute die verbreitete Nutzung der ,neuen Medien’. Heute werden aber nicht nur die Inhalte der kritisierten neuen Medien in Frage gestellt, sondern auch das Äußere, Mediale: Kann das Buch angesichts der mit ibm konkurrierenden ,neuen Medien’ überleben?

Die Medien reagieren selbstreflexiv zum einen auf Veränderungen in der eigenen Kunstform. Das ist der Fall u. a. in der Musik (z. B. Zitate von Themen, Potpourris, Coverversionen), der Bildenden Kunst (Begründung auf Tradition, aber der Wille Neues zu schaffen, z. B. Neogotik), im Film (Übergang vom Stummfilm zum Tonfilm, Silent movies vs. ,Talkies', z. B. umgesetzt im Film-

721 Rager \& Werner: Entwicklung und Struktur der Lesegesellschaft, 2004, nicht eingesehen, zitiert nach Stocker (2007), S. 70, Anm. 102.

722 Vgl. Werner Faulstich: Mediengeschichte von 1700 bis ins 3. Jahrtausend. Göttingen: Vandenhoeck \& Ruprecht, 2006, S. 50-55. 
Musical Singin' in the Rain (Regie: Stanley Donen, 1952) und auch im Buch, wie das Kapitel II und die angeführten Beispiele der literarischen Darstellung des ,Buchs im Buch’ zeigen.

Fiktionale Kunstformen verweisen aber auch auf andere Medien, die in Konkurrenz zu ihnen selbst stehen und das Potential besitzen, sie zu verdrängen. Das Buch steht heute nicht zum ersten Mal in Konkurrenz zu einem anderen Medium, das eine neue Praxis und Technik nutzt, um Inhalte zu transportieren. An diversen Wendepunkten in der Medienlandschaft wurde angenommen, dass das Lesen durch den Konsum anderer, neuer Medien ersetzt werde. Im 20. Jahrhundert waren dies u. a. Film und Kino, Hörfunk und Radio, besonders das fiktionale Hörspiel, vor allem aber das Fernsehen. Die Konkurrenz durch das Fernsehen wurde durch die kulturpessimistischen Prognosen von Marshall McLuhan (The Gutenberg Galaxy, 1962) besonders deutlich gemacht. Er ging sogar von einem Wandel des vorherrschenden Weltbildes im Zuge des Medienwandels hin zum Fernsehen aus, denn seiner Meinung nach konstruiere sich das persönliche Weltbild aufgrund des Mediums, das man am häufigsten nutze ${ }^{723}$. Wo Schrift und Buch Inhalte linear vermitteln, setze das Fernsehen, und heute auch andere Medien- und Unterhaltungstechnologien, auf mehrere simultane Sinneseindrücke, die den Eindruck mehrerer gleichzeitig ablaufender Ereignisse vermitteln. Das Denken werde von einer Vorstellung in sprachlicher und schriftlicher Form auf die Rezeption von Bildern und ein, visuelles Denken' verlagert. Mit Blick auf McLuhans Thesen wurde zudem einige Zeit lang davon ausgegangen, dass das Lesen von Büchern durch den Konsum von TV verdrängt und schließlich abgelöst würde, was sich bis heute nur z. T. bewahrheitet hat. Für bildungsferne Schichten stellt das Fernsehen heute allerdings tatsächlich ein Ersatzmedium für das Buch dar ${ }^{724}$. Untersuchungen der jeweils aktuellen Romanliteratur in früheren Medienkonkurrenzsituationen auf selbstreflexive Aspekte würden lohnen, für sie ist in dieser Arbeit allerdings kein Raum.

Es konnte bereits gezeigt werden (vgl. Kap. III.8), dass in der aktuellen Romanliteratur die Kombination von Buch-Motiv und Reflexion der ,neuen Medien' auftritt und damit der aktuelle Medien- und auch Gesellschaftsdiskurs aufgegriffen wird. Die Diskussion um die ,neuen Medien' begann in den Sprach- und Literaturwissenschaften vergleichsweise früh, nämlich in den 1970er und 1980er Jahren, und zeigt die Sorge um einen potentiellen Verlust den eigenen Gegenstand betreffend $^{725}$. Heute sieht sich das Buch einer ganzen Fülle von elektronischen Medien gegenüber, wobei ein Wechsel hin zu digitalen Medien, d. h. zum Großteil digitalen Versionen der bekannten elektronischen Medien, gerade erst im Entstehen ist. Dies sind Internet und Www, neue Hardware wie E-Book-Reader, neue Unterhaltungselektronik, Computerspiele u. v. m. Die

\footnotetext{
723 Vgl. Stocker (1994), S. $77 \mathrm{f}$.

724 Vgl. Haben Bücher eine Zukunft? (2007), S. 20.

725 Rusch et al. (2007), S. 35.
} 
Auseinandersetzung mit den ,neuen Medien' in der Fiktion findet deshalb zumeist kritisch statt, vielleicht um dem Leser kontrastierend die Vorzüge von Buch und Buchlektüre vorzuführen. Seine Stellung als Leitmedium hat das Buch allerdings längst eingebüßt, die ,neuen Medien’ sind als Informationsvermittler und Unterhaltungsmedium verbreiteter und gängiger. Befürchtungen wachsen, dass in naher Zukunft vielleicht sogar ganz auf das gedruckte Buch verzichtet werden könne. Das Www bietet wie andere Medien auch selbstverständlich Content an: Inhalte, die über unterschiedliche Kanäle rezipiert werden, eben auch Texte, die gelesen werden. Das WwW dient dabei ebenso wie das Buch als Medium und besitzt das Potential, die Lektüre von Gedrucktem zu ergänzen und zu modulieren - Ein völliger Ersatz des Buchs durch die ,neuen Medien’, speziell durch PC, Internet und WWW, ist jedoch auch in Zukunft nicht wahrscheinlich.

Die Thematisierung des ,Buchs im Buch’ dient möglicherweise als Kompensation gegenüber einem (vermuteten) Niedergangs des Buchs zugunsten virtueller Medien. Diese Befürchtungen sind „nostalgischer Bestandteil der Klage über die von den neuen Medien hervorgerufenen Süchte oder Zeichen der Hoffnung auf eine Rehabilitierung des Lesens“ ${ }^{\text {“726. }}$. Allerdings werden heute so viele Bücher verkauft wie nie zuvor, und es darf nicht vergessen werden, dass nicht einfach eine Verschiebung von der Nutzung des einen hin zu einem anderen Medium stattfindet. Vielmehr sind wir heute von einem Medienpluralismus umgeben, d. h. die meisten Nutzer von Medien nutzen viele unterschiedliche und sind „Mehrmediennutzer“. Für Buchleser gilt das besonders: Sie sind nicht auf ein Medium zur Unterhaltung oder Information festgelegt und lehnen , neue Medien' nicht per se ab. Die Glorifizierung des Buchs mithilfe einer Kontrastierung zu anderen Medien ist also nur bedingt als Werbung für Buch und Lesen geeignet.

Befürchtet wird außerdem die Entwertung des Buchs durch Konkurrenzmedien. Aufgrund der zunehmenden Immaterialisierung von Texten durch digitalisierte Medien findet eine Entsinnlichung von Buch und Bibliothek statt ${ }^{727}$. Ein Gegenentwurf dazu ist das auratische fiktionalisierte Buch in den Buch-Büchern. Es wird mit Wert aufgeladen, zu etwas Besonderem erhoben, kurz: glorifiziert und mythisiert. Wo die elektronischen und digitalen Medien einen Text nur virtuell, nicht medien-, doch körperlos, anbieten, wird das Buch in seiner Funktion als Romanmotiv systematisch aufgewertet. Seine haptischen Vorzüge werden betont, das angenehme Gefühl, ein Buch, besonders ein typisches Buch, ein altes, in Leder gebundenes, mit besonderem Geruch, in Händen zu halten. Zu dem sinnlichen Vergnügen des Buchs gehören auch äußerliche Ergänzungen wie ein ansprechender Umschlag oder Abbildungen, ein Vorzug, den auch Vinylliebhaber gegenüber digitalen Musikversionen ins Feld führen. Das Buch wirkt altmodisch, aber klassisch 
und altehrwürdig und vermittelt dadurch Prestige und ein bildungsbürgerliches Ideal. Die Aura des ,Besonderen', die um das ,Buch im Buch’ aufgebaut wird, färbt auch auf den Leser ab, der sich zu einer Community von Lesern zugehörig fühlen kann.

\subsubsection{Mythologisierung des Buchs}

Mit Blick auf die Schriftkultur und ihre Krise im 20. Jahrhundert formuliert Stocker:

Immer dann, wenn im zwanzigsten Jahrhundert die Schriftkultur von neuen Codes und Medien in ihrer Dominanz in Frage gestellt wird, reagiert die Literatur mit einer Beschwörung der Bibliothek als deren zentraler Einrichtung. | Die Thematisierung der Bibliothek stellt eine Art Selbstvergewisserung der Schriftkultur dar. ${ }^{728}$

Stocker untersucht die Einflüsse des Medienwandels auf die Schriftkultur im Spiegel des Bibliothek-Motivs in der erzählenden Literatur. Aber auch Fiktionalisierungen des Buchs stellen die zitierte „Selbstvergewisserung“ mit der Absicht einer Stärkung des eigenen Mediums dar. Durch den weiteren Blick auf die Literatur des gesamten 20. Jahrhunderts gelingt Stocker eine größere Einordnung, während diese Arbeit die Aktualität des Motivs Buch, nicht das der Bibliothek, und sein häufiges Auftreten in den letzten 20 Jahren auf dem deutschen Romanmarkt untersucht. Durch die veränderten Kommunikationsverhältnisse wird das Buch relativiert, was auch Stocker für die Bibliothek feststellt. Stocker gelingen Befunde über die Darstellung der Bibliothek in fiktionaler Literatur, die beinahe sämtlich auch auf das Buch in dieser Situation des medialen Umbruchs zutreffen ${ }^{729}$.

Intertextualität: Im Kontext des Buch-Motivs in den untersuchten Romanen wird Intertextualität offensichtlich. Es wird auch in Bibliotheksromanen gezeigt, dass „Bücher aus anderen Büchern bestehen, von anderen Büchern abhängen und mit diesen korrespondieren““730.

Remythisierung: Während für die literarischen Darstellungen der Bibliothek komische Formen gefunden werden, Stocker nennt Ironie, Parodie und Groteske, zeigen alle untersuchten Romane eine fast ehrfürchtige Mythisierung des Buchs, selbst wenn per se humorvolle Formen wie die Fantasy angewandt werden. Auf das Buch trifft die folgende, nach Stockers Untersuchung zitierte Passage ebenso zu: „Die paradigmatische Institution der Schriftkultur, die durch den aktuellen Medienwandel in die Krise geraten ist, wird auffallend oft als Motiv verwendet und dabei häufig verklärt und stilisiert. Bücher und Bibliotheken werden [...] als aussterbende Art sakralisiert.“731 Genau wie das Buch wird auch die Bibliothek zum Ort gewordenen Rätsel, das eine Aura des Mysteriösen umgibt: „Die moderne Literatur inszeniert die Bibliothek als geheimnisvollen Raum 
verborgener Schriften und Rätsel.“732 Der Leser vermag dieses Rätsel durch Mitdenken und -rätseln auf den Spuren des Detektiv-Protagonisten zu lösen.

Buch als Zuflucht. Das Buch bietet im Geistigen wie die Bibliothek als Raum eine Rückzugsmöglichkeit vor dem Alltag und den Menschen. Sowohl das Buch, durch seine Möglichkeit der persönlichen Zwiesprache, als auch die Bibliothek, durch die ihr inhärente und durch sie vermittelte Ordnung, stellen ein zuverlässiges, unveränderliches Element in einer unbeständigen Welt dar und weisen den Weg durch eine unüberschaubare, chaotische, ausdifferenzierte Welt.

Weltfremdheit von Buchmenschen: Die Leserprotagonisten der untersuchten Romane leben von der Gesellschaft zurückgezogen (vgl. Kap. III.11), in Bibliotheksromanen kommt es nicht selten vor, dass sich der Protagonist in (s)einer Bibliothek verschließt. Für das aktive Leben in der Gemeinschaft sind diese fiktionalisierten Leser untauglich. Es ist anzunehmen, dass mithilfe der Fiktionen eine Kritik an der Isolation des Gelehrten stattfindet, am Umgang des Büchernarren mit Büchern, die ihnen die Menschen ersetzen.

Dominanz des Motivs ,Suche': In Verbindung mit dem Buch-Motiv gilt die Suche, oft im Erzählmuster der ,Queste', der Auflösung eines rätselhaften Geheimnisses. Beim BibliotheksMotiv findet eine Akzentverschiebung statt, denn es instrumentalisiert die Suche zur Erlangung eines generalisierten Wissens, wobei die Suche auf ein besonderes, exklusives Buch abzielt, „dem einen Text, der alles erklärt"“733.

Selbstreflexion der Schriftkultur: Sowohl Buch- als auch Bibliotheks-Motiv werden im Bewusstsein um die eigene literarische Tradition verwandt. Aufgrund des unmittelbaren Kontexts von Literatur werden direkte Rückbezüge auf die Motiv-Tradition ebenso eingebunden wie die Selbstreflexion von Schreiben, Lesen und Leserprotagonisten.

All dies zusammengenommen kann angenommen werden, dass die gehäufte Thematisierung von Büchern in Romanen Ausdruck eines derzeit bestehenden Diskurses um Bücher ist. Dieser Diskurs kommt allem Anschein nach zustande durch die enorme und rasche Eindrängung der neuen Medien in Bereiche, für die bisher allein das Buch und Akteure des Literaturbetriebs zuständig waren, besonders für die Verfügbarkeit, Vermittlung und Diskussion von Literatur. Eine mögliche Erklärung für die Thematisierung des Buch-Motivs in aktuellen Romanen kann auf Seiten eines Autors die Furcht vor der Verdrängung des Buchs durch die ,neuen’ Medien seine, der sie mit einer extensiven innerliterarischen Thematisierung entgegenzuwirken versuchen. Es findet so mutmaßlich eine Kompensation gegenüber den neuen Medien statt. Der Autor reagiert mit seinem Werk auf gesellschaftliche Befindlichkeiten, wie den Vormarsch der neuen Medien in 
fast allen Bereichen des gesellschaftlichen Lebens, was auch nicht vor dem literarischen Leben haltmacht, und bringt sie zur Sprache, um den Leser zur Reflexion und Diskussion anzuregen.

\subsubsection{Autor und Publikum - Für wen schreibt der Autor?}

In seiner Rolle als Leser ist ein Romanautor, ausgestattet mit einem hohen Maß an literarischem und theoretischem Wissen, selbst ein kompetenter Leser, ein expert reader. Wie der Leser gern über Bücher und Leser liest (vgl. Anm. 154), schreibt ein Autor vermutlich auch gern über dieses ihm vertraute Milieu. Man könnte annehmen, der Autor schreibe für seine peer group, also ausschließlich für den kompetenten Leser. Man könnte weiter vermuten, dass das „Buch im Buch’ aufgrund seiner Affinität zu Denkrätseln und literaturtheoretischen Konzepten eher in hochkultureller Literatur erwartet werde. Als kulturelles Erbe habe Literatur Anspruch auf einen hochkulturellen Inhalt und eine gewisse Wertschätzung. Wolpers verankert das Buch-Motiv denn auch in „Kunstliteratur“6734, da es literarisches Wissen und Gespür voraussetze und deshalb seinem Wesen nach in der „Volksliteratur nicht denkbar“ ${ }^{\text {‘735 }}$ sei. Stocker nimmt an, das Buch-Motiv sei nur Intellektuellen und eingeweihten Literaturkennern zugänglich ${ }^{736}$. Lesedarstellungen in der modernen Literatur greifen häufig eine vergangene Zeit auf, in der das Lesen eine ganz andere gesellschaftliche Stellung und Wichtigkeit innehatte als heute, und zeigen dadurch eine rückwärtsgewandte Auffassung des Mediums Buch. Die Gefahr dieser Selbstreflexion sieht Stocker darin, dass Literatur nur noch um sich kreise und dem Werk der Bezug zur Realität abhanden komme. Wer solle diese Buch-Bücher dann noch lesen?

An dieser Stelle sei noch einmal auf Japp verwiesen, der, wie oben erläutert, zeigt, dass das „Buch im Buch’ mitnichten völlig unzugänglich ist, sondern gerade durch Bezüge zu Gesellschaft und Realität sowie ständigen Anlass zur Reflexion aus der Abgeschlossenheit hinausführt. Stockers Befürchtungen werden auch dadurch entkräftet, dass das Buch-Motiv heute sehr wohl in massenkompatibler Unterhaltungsliteratur vorkommt ${ }^{737}$. Durch seine Fähigkeit, Assoziationen und Emotionen auszulösen, spricht es mehr als eine Lesergruppe und auch den interessierten Normalleser an. Zwar mögen die Buch-Bücher vorrangig an ein gebildetes Publikum gerichtet sein, das die intertextuellen Verweise voll umfänglich zu verstehen vermag (vgl. Kap. III.9.4), doch schreibt der Autor für beide Arten von Publikum, für den gebildeten expert reader und auch den Normalleser, möglicherweise mit der Absicht, bei allen Leserschichten Werbung für das Bücherlesen zu machen.

\footnotetext{
734 Wolpers (1986), S. 11.

735 Ebd., S. 12.

736 Vgl. Stocker (2007), S. 92.

737 Vgl. Bücherlisten von Lesern als ,Lieblingslisten’ bei Amazon.de, z. B. „Bücher, die über Bücher gehen (sic!)“, [http://www.amazon.de/Bücher-nbsp-die-nbsp-über-nbsp-Bücher-nbsp-gehen/lm/R4N9YRQOFQWJS/ ref=cm_srch_res_rpli_alt_6].
} 
Romane, in die das Buch-Motiv durch die Selbstthematisierung ein besonderes, intellektuelles Element einbringt, können nicht ausschließlich an kompetente Leser gerichtet sein. Wäre dies der Fall, möglicherweise damit sich der Autor auf dem Markt abgrenzt, würden seine Romane vom Verlag anders positioniert werden müssen, vielleicht in einer Reihe, die die Selbstbezüglichkeit deutlicher macht, z. B. „Genuss für Leser“ oder schlicht „Bücher über Bücher“. Ein solches Genre existiert (noch) nicht, so dass Leser nicht gezielt nach einem Roman über Bücher greifen können. Diese Titel gehören dem Genre an, das vordergründig für die Handlung dominant ist, wobei das volle Ausmaß der Implikationen, die das Buch-Motiv in den Roman einbringt - Bezüge zu Erzähltheorien, Intertextualität, Metafiktionalität - erst während der Lektüre ersichtlich wird. In der Folge greifen genreorientierte Leser, z. B. Krimileser, zu einem Buch, das sich beim Lesen als BuchRoman herausstellt. Der fortschreitende Leseprozess enthüllt quasi ein weiteres Buch im Buch.

Die bisher gewonnenen Hypothesen legen nahe, dass ein Autor mit der Verwendung des BuchMotivs vornehmlich das Ziel verfolgt, Werbung für Buch und Lesen zumachen. Im Buch-Roman finden sich Strategien zur Leseförderung (unter erwachsenen Lesern, hier ist keine Lesesozialisation gemeint) und zur „Image-Werbung، ${ }^{\text {‘738 }}$ für das Bücherlesen. Im Leserprotagonisten und seiner Beziehung zum Buch, aber auch in der Figur eines Bücherfreundes, der sein gesamtes Leben den Büchern untergeordnet hat, findet sich der reale Leser gespiegelt, was für ihn einen besonderen Reiz ausmacht ${ }^{739}$. Es liegt nahe, dass diese Strategien mit „,volkspädagogische[m] Motiv“740 angesichts eines befürchteten Niedergangs des Buchs und des gleichzeitigen hohen Ansehens von Buch und Lesen wegen angewandt werden. Darüber hinaus wird dem Leser das Versprechen einer Abgrenzung gegenüber anderen gesellschaftlichen Gruppierungen gemacht, so soll „auch der erwachsene Leser geködert werden - mit dem Versprechen sozialen Distinktionsgewinns durch Lektüre“7741 (vgl. Kap. IV.3.1). Allerdings richtet sich diese Werbung an ein Zielpublikum, das sich ohnehin schon für das Bücherlesen interessiert. Um das Phänomen ,Buch im Buch’ zu goutieren, muss man bereits Leser und Buchfreund $\operatorname{sein}^{742}$, so dass die tatsächliche Werbewirkung fraglich ist. Jemand, der sich nicht für Bücher interessiert, wird erst recht kein Buch über noch mehr Bücher zur Hand nehmen, neue Leserkreise werden durch das Buch-Motiv im Roman also kaum erschlossen. Wie zuvor gezeigt werden konnte, ist es allerdings schwierig, gezielt Romane mit Buchbezug äußeren Merkmalen nach zu erkennen. In vielen Titeln wird das ,Buch im Buch’ implizit eingebunden, so dass auch Leser, die nicht ausdrücklich nach dem Buchbezug gesucht haben, damit erfreut werden.

\footnotetext{
738 Löffler (2005), S. 15.

739 Vgl. Goetsch (1996), S. 405f.

740 Ebd.

741 Ebd.

742 Löffler (2005), S. 15.
} 
Nach der Fertigstellung durch den Autor unternimmt der Text eine Eigenbewegung, die der Autor nicht mehr steuern kann und soll, denn nun wird der Leser selbst aktiv und ,erschafft' gleichsam den Text, das bedeutet, er konstruiert aus dem vorliegenden Text, was er darunter versteht. Es existiert nicht nur ein Signifikat hinter dem Signifikanten, nicht mehr nur eine Bedeutung der Chiffre, so dass der Leser ausdrücklich zur eigenen Interpretation aufgefordert ist.

\subsection{Leser und ,Buch im Buch'}

Im Weiteren werden die Buch-Romane vor der Folie von Lesererwartungen an einen gelungenen Roman beurteilt. Je nach Vorkenntnissen, die der Leser bei der Lektüre mitbringt, ist ein Verständnis des Textes auf unterschiedlichen intellektuellen Ebenen möglich, was ein Aufweichen der Grenzen von ,Höhenkammliteratur' und Unterhaltungsliteratur bedingt. Mehrfachkodierungen, Mehrdeutigkeiten und unterschiedlichen Lesarten eines Textes können als postmoderne Phänomene aufgefasst werden. Ein Beispiel für multiadressierte Texte, die nicht unbedingt postmoderne Tendenzen beinhalten müssen, ist die ,All-Age-Literatur', die sich an Leser unterschiedlicher Altersstufen und somit an Leser mit unterschiedlicher literarischer Vorbildung und intellektueller Reife richtet (vgl. Kap. IV.3.3.2.7).

Aufgrund einer langen Tradition von Schreibweisen in den einzelnen Romangenres, eines Überangebots an Titeln und langer individueller Lesebiographien hat ein Leser sicher gewisse Erwartungen an einen Text, sobald er mit bestimmten Romanmotiven oder -genres konfrontiert wird. Der Autor versucht, den Leser zu unterhalten, indem er ihn mit neuen Ansätzen und Unerwartetem zu überraschen versucht. Diese Strategie, dass sich z. B. im Kriminalroman immer der oder die am wenigsten Verdächtige am Ende als Täter herausstellt ${ }^{743}$, ist aber schon derart oft angewandt worden, dass sie nun vom Leser geradezu erwartet wird. erwartet der Leser mittlerweile das Unerwartete. Mehr und mehr ist es nun literarische Mode, dass Autoren diese Erwartungshaltung umkehren und, für den Krimi gesprochen, nun gerade den Hauptverdächtigen als Täter einsetzen.

Das Buch-Motiv ist semantisch aufgeladen, dabei hoch assoziativ und emotional besetzt, und auf diese Weise von einer persönlichen Interpretation und Kontextualisierung durch den Leser abhängig. In diesem Rahmen ist auch Intertextualität erst möglich, da der Leser unter der Prämisse bereits erlangter Kenntnis von Texten Bezüge zu anderen Texten verstehen, nachvollziehen und bewerten kann. Die hier untersuchten Romane sind an mehrere Lesergruppen adressiert. Dies sind zum einen Leser, die einen Spannungsroman erwarten und allein an dem Genre interessiert sind.

743 Dieses Paradigma der Kriminalliteratur steht, „ganz in Übereinstimmung mit der Regel des Detection Clubs, dass er oder sie immer der am wenigsten Wahrscheinliche sein muß“, vgl. Gilbert Adair: Und dann gab's keinen mehr. Evadne Mounts dritter Fall. C.H. Beck: München, 2008, S. 121. - Der Detection Club ist eine tatsächlich existierende Vereinigung von Kriminalschriftstellern, die sog. „Regeln für einen fairen Kriminalroman“ herausgeben. 
Es ist zu anzunehmen, dass diese Leser den Kriminal-, Detektiv- oder Mystery-Roman als vergnügliches Abenteuer auch ohne die Implikationen des Buch-Motivs genießen und sich gut unterhalten fühlen können. Zum anderen sind Buch-Romane an Leser gerichtet, die das Buch-Motiv und die damit verbundene Selbstreferenz in der Fiktion schätzen und verstehen können. Die im Folgenden dargestellten Mutmaßungen über Leserreaktionen und -erwartungen sind zum einen als spekulativ zu verstehen, ergeben sich zum anderen aber aus den analysierten Leserrezensionen.

Unterschiedliche Leser(-gruppen) bringen beim Lesen unterschiedliche Erwartungen an den Text in die Lektüre ein. Der Leser erschließt sich auf einer metafiktionalen Ebene das Geschehen und wird so quasi aktiv am Entstehungsprozess , seiner' Version des Textes beteiligt. Das BuchMotiv bewirkt die fiktionsinterne Auseinandersetzung mit erzähltheoretischen Ansätzen, Interund Metatextualität, einem Spiel mit Fiktion und Realität im Buch-Roman, die man in einem typischen Krimi nicht unbedingt erwarten oder vermuten würde. Zugleich wird der reale Leser einbezogen, so dass die Verwirrung von Identitäten und die komplexen Denkrätsel dem Leser Vergnügen bereiten können. Die vorliegenden Texte erfüllen die Lesererwartungen an einen Roman des vordergründigen Genres bis zu einem gewissen Grad. Dann aber treten Abweichungen auf, die der Leser als ,untypisch' für das Genre ablehnt oder aber als interessante Steigerung empfindet.

Erfüllt der Text die Erwartungen des Lesers in vollem Umfang, kann dies bei der Rezeption als positiv bewertet werden: Den Leser erwartet das Gewohnte, Bekannte, er muss sich auf nichts Neues einstellen. Diese Erfüllung von Erwartungen kann für den Autor hilfreich beim Verfassen von Romanreihen sein, da so eine Leserschaft für weitere Bände garantiert ist. Werden Lesererwartungen voll erfüllt, kann sich jedoch auch der Eindruck des Konventionellen einstellen, des Ewig-gleichen und der Langeweile.

Werden die Erwartungen des Lesers an den Text nicht erfüllt, reagiert der Leser möglicherweise mit Befremden und Unverständnis ${ }^{744}$. Leser, die auf das vordergründige Genre eingestellt sind, werden möglicherweise enttäuscht, dass der spannende Krimi nun erzähltheoretische Erörterungen enthält, das Genre wird derart verfremdet oder angereichert, dass der Normalleser nicht viel damit anzufangen weiß. Mit den Implikationen des Buch-Motivs ist dieser Leser möglicherweise überfordert oder interessiert sich nicht dafür. Seinen Erwartungen wird nicht entsprochen, da er durch äußere Hinweise, die ihm das Buch vermittelt, auf die Genrekonvention eingestellt ist.

Der kompetente oder vorgebildete Leser dagegen wird zu schätzen wissen, dass die Selbstreflexion erzähltheoretische Fragestellungen, Metafiktionalität oder eine Autoreflexion des Protagonisten aufwirft. Er reagiert auf nicht erfüllte Erwartungen vermutlich positiv, da er die Anspie-

\footnotetext{
744 Die Leserrezensionen, die in der Motivuntersuchung in den vorigen Kapiteln herangezogen wurden, geben
} darüber beredt Auskunft. 
lungen, Zitate und intertextuellen Bezüge im intellektuellen Spiel nachvollziehen kann. Er weiß die Überraschung zu schätzen, die das im Genre-Kontext unerwartete Buch-Motiv mit sich bringt, anerkennt die schriftstellerische Leistung, die mit Intertextualität und Metafiktionalität virtuos umzugehen weiß, und erfreut sich am eigenen Durchschauen der ambitionierten fiktionalen Situation. Dieser Leser ist dazu bereit, zu unterschiedlichen Genres zu greifen und diese zu akzeptieren, aber auch dazu in der Lage, den Roman über die reine Spannung und Unterhaltung hinaus als anspruchsvolles Stück Literatur zu genießen. Durch die Buch-Bücher soll zwar der Intellekt bedient werden, es wird jedoch der spielerische Aspekt in abenteuerlichen Genres betont, damit der Leser nicht vorzeitig das Interesse verliert. Über Anspruch und intellektuelle Forderung hinaus soll der Roman doch Vergnügen durch eine spannende Handlung bereiten.

$\mathrm{Zu}$ Lesererwartungen und ihrer Unterwanderung durch den Autor bieten die Kriminalromane Gilbert Adairs ${ }^{75}$ eine interessante Perspektive. Diese Romane sind allesamt Pastiches auf den klassischen Kriminalroman, besonders den Agatha Christies, oder den Hitchcock-Film der 1940/50er. Adair lehnt sich deutlich an den postmodernen Roman an und treibt im dritten Teil der Reihe die Selbstreferentialität auf die Spitze. Der Ich-Erzähler trägt den Namen des Autors und berichtet aus dessen Blickwinkel, für die Unmöglichkeit des Mordes an seiner Hauptfigur und Detektivin Evadne Mount dienen postmoderne Konzepte sogar als Erklärung. Durch den Handlungsort, die Reichenbach-Fälle in der Schweiz, schließt der Autor an den Wunsch Conan Doyles an, seine bekannteste Figur Sherlock Holmes ,umzubringen' und so keine weiteren Detektiv-Erzählungen mehr schreiben zu müssen. Ein Rezensent ${ }^{746}$ wundert sich nun darüber, dass Adair in diesem Roman mit dem erfolgreichen Modell der beiden Vorgänger bricht, und fragt sich, warum er so seine Leser verprelle, die doch etwas anderes erwartet haben. Adair, Autor des Romans und zugleich stilisierter Ich-Erzähler, berichtet über die ,Begegnung’ mit der Protagonistin seiner Romane auf der Fiktionsebene und äußert sich zu Lesererwartungen:

\footnotetext{
Ich hatte meinen Spaß am Klischee und hoffte, der Leser würde ihn teilen. | Unter diesem Gesichtspunkt wäre es absolut verständlich, wenn der eben angesprochene Leser bei der Wiederbegegnung mit Evadne Mount in diesen Aufzeichnungen es als eine weitere postmoderne Spielerei, als erneutes Unterlaufen der Konventionen des Genres gelassen hinnehmen würde, dass die Frau offensichtlich inzwischen auf die hundertzwanzig Jahre zugehen müsste. ${ }^{747}$
}

Einerseits ist Adair verhaftet in seinem Genre, er möchte schließlich seine Verehrung für die großen Vorbilder zum Ausdruck bringen, andererseits durchbricht er die Konvention durch die Kombination mit einem neuen Motiv. Seine Detektivin lässt er ihrem „Dr. Watson in Gestalt

\footnotetext{
745 Die Titel der Trilogie mit der Hauptfigur und Detektivin Evadne Mount, The Act of Roger Murgatroyd (2006), A Mysterious Affair of Style (2007), And Then There Was No One (2009) spielen auf Agatha-Christie-Romane an. 746 Manuel Bauer: „,Postmoderne? Was für ein Quatsch! Was für eine Farce!' Gilbert Adairs Roman Und dann gab’s keinen mehr befremdet den Leser mit einem vergnüglichen Verwirrspiel“. In: Literaturkritik.de, Nr. 5, Mai 2009, [http://www.literaturkritik.de/public/rezension.php?rez_id=12961], eingesehen am 12.04.2011. 
eines Scotland-Yard-Inspektors“778 einen Heiratsantrag machen, „ein narrativer Kunstgriff, [...] weil es sich um eine Wendung handelte, die nicht wie die meisten Wendungen in den meisten Kriminalromanen schon in der Natur des Genres angelegt ist. ${ }^{\text {“749 }}$ Adair schafft so etwas Neues, wie es auch bei der Neu-Kombination von Buch-Motiv und Erzählgenre der Fall sein kann.

\section{Bücher und Lesen heute}

Nicht nur die Literatur selbst wird durch Zeitumstände und Medienwandel verändert, auch die Lesegewohnheiten des Publikums. Alle Instanzen des Literaturbetriebs sind von den Auswirkungen des Medienwandels betroffen und passen sich mehr und mehr den neuen Bedingungen des Buchmarkts an. Heute gilt es nicht mehr vorrangig Leser für Bücher zu suchen, sondern Bücher zu machen, die ein Publikum finden. An dieser Stelle wird allerdings keine Studie zur Lese(r)sozialisation oder sozialgeschichtliche Analyse durchgeführt. Die Frage im Mittelpunkt ist die nach den Veränderungen in der literarischen Kommunikation und des Leseverhaltens, auch bedingt durch die neuen Anforderungen, die die elektronischen und digitalen Medien mit sich bringen. Diese neuen medialen Bedingungen bestimmen den Diskurs um Bücher und führen auch zu einer verstärkten Reflexion des Buchs in literarischen Darstellungen. Wo in den Buch-Romanen kulturkritische und sogar -pessimistische Tendenzen deutlich werden, die dazu führen, dass das Buch spannungsgeladen auftritt und mythisiert präsentiert wird, zeigt sich auf dem Buchmarkt ein entspannteres Bild: Das Buch wird von anderen Medien nicht verdrängt, sondern ergänzt.

\section{1 „Prestige des Bücherlesens ${ }^{650}$ und Gruppenbildung}

In den Buch-Romanen wird eine überhöhte Auffassung des Buchs kultiviert: Es wird suggeriert, es besitze Autorität und Exklusivität. Lesen diene dem Wissensgewinn, dem unterhaltsamen Genuss, sei eine intellektuelle Beschäftigung und diene der Teilhabe an der Kultur. Das Buch hat nach wie vor ein „positives Image in der Gesellschaft ${ }^{\text {“751, }}$, sogar ein „elitäre[s] Image“6752. Mitunter empfinden Leser dadurch eine Zugehörigkeit zu einer als elitär empfundenen Historie der Gelehrsamkeit, wodurch Versprechen und Ahnung eines ,Prestiges' entstehen, das sich wiederum in einer Gruppenzugehörigkeit durch Abgrenzung ausdrückt. Diese Abgrenzung der Leser wird zum einen von Nichtlesern - von außen - zum anderen von den Lesern selbst - von innen - betrieben.

\footnotetext{
748 Adair (2008), S. 111.

749 Ebd., S. 117.

750 Löffler (2005), S. 15.

751 Haben Bücher eine Zukunft? (2007), S. 20.

752 Stocker (1994), S. 83.
} 
Zwar galt das Viellesen von Romanen bis in die Literatur des fin de siècle als schockierend, verrufen und gefährlich ${ }^{753}$, jedoch erscheint ,in der Gegenwart die Lesesucht akzeptabler als je zuvor ${ }^{6754}$. Im Gegensatz zum 18. und 19. Jahrhundert wird mangelndes Bücherlesen heute als ein Anzeichen für mangelnden Intellekt betrachtet, allerdings eher in konservativ-bildungsbürgerlichen Kreisen und gebildeten Eliten. Heute ist es weniger das Problem, dass die Menschen vom Lesen abgehalten oder sogar davor gewarnt werden müssen, als dass das Lesen vielmehr als etwas Sinn- und Wertvolles betrachtet wird, das zu unterstützen und fördern ist. Im Zuge dessen findet häufig eine Polarisierung statt: Auf der einen Seite steht, überspitzt ausgedrückt, das kulturell hochgeschätzte Buch, auf der anderen das kulturfeindliche Fernsehen und Internet. Es gibt heute zwar ,Mediensuchtdebatten' bezogen auf Computerspiele und Internet, aber nicht auf Bücher, da es nach wie vor als erstrebenwert gilt, viele Bücher zu lesen. Aus diesem Grund wird versucht, das Lesen gerade bei Kindern und Jugendlichen durch Leseförderungsmaßnahmen (z. B. durch die Stiftung Lesen) zu stimulieren. Erwachsene Leser sollen sich selbst für das Lesen als Freizeitbeschäftigung entscheiden. Um ihnen dies zu erleichtern, werden literarische Strategien angewandt, z. B. wenn Buch-Motive in die Fiktion eingeflochten werden und selbstreflexive Elemente den Leser dazu veranlassen, sich mit dem Protagonisten besonders zu identifizieren oder sich selbst zu erkennen. Übermäßiges Bücherlesen dagegen ist nicht mehr die Norm und bringt den Leser eher in den Ruf eines Sonderlings, als dass es ernsthaft schlecht beleumundet wäre.

\subsubsection{Abgrenzung von außen - Der Leser als Kuriosum}

Das Buch wird vielfach als Relikt vergangener Tage oder hochkulturelles Studienobjekt weltfremder Elfenbeinturmbewohner wahrgenommen. Die öffentliche Meinung sieht das Lesen z. T. als „nicht nur zeitraubend und asozial, sondern auch anstrengend ${ }^{\text {“755 }}$, Bücher lesen sei „introvertiert, nicht aktuell, langfristig verwertbar und schwer zugänglich“6756. Der Leser gilt als einsam, verkopft, weltfremd, zurückgezogen, bieder, rückwärtsgewandt (vgl. Kap. III.11.6), da er an einer Kulturtechnik festhält, die heute durch den Fortschritt als überwunden gilt. Es wird mitunter vermutet, der Leser gehöre zu einer „abseitige[n] und etwas verschrobene[n], manchmal auch verdächtige[n] Minderheit ${ }^{6757}$. Lesen diene weniger der Unterhaltung als der Vermittlung von Bildung, der Förderung des Intellekts, es vermittele aber nur eine unpraktische, nicht alltagstaugliche Bildung:

Zwischen den Büchern und der Wirklichkeit ist eine alte Feindschaft gesetzt. [...] Die Luft in Bibliotheken ist stickig, der Überdruß, in ihr zu atmen, ein Leben zu verbringen, ist unausbleiblich. Bücher

\footnotetext{
753 Stocker (2007), S. 89.

754 Goetsch (1996), S. 403.

755 Löffler (2005), S. 15.

756 Stocker (1994), S. 83.

757 Löffler (2005), S. 8.
} 
machen kurzsichtig und lahmärschig, ersetzen, was nicht ersetzbar ist. So entsteht aus Stickluft, Halbdunkel, Staub und Kurzsichtigkeit, aus der Unterwerfung unter die Surrogatfunktion, die Bücherwelt als Unnatur. ${ }^{758}$

Eine gängige Meinung nimmt an, dass Lesen zur Unterhaltung keinen großen allgemeinen Stellenwert mehr habe, sondern nur in Spezialgruppen gepflegt werde. Tatsächlich ist der Vielleser in Zeiten einer vermeintlich beobachteten rückläufigen Beschäftigung mit dem Buch und der vielfältigen Konkurrenz durch andere Informations- und Unterhaltungsmedien eher in bestimmten Gruppen anzutreffen. Lesen hat seine Rolle als Freizeitbeschäftigung für die Massen an andere Medien abgeben. Eine Medienanalyse bestätigte 2009, dass das Fernsehen von weit mehr Menschen zur Gestaltung ihrer Freizeit genutzt wird als das Lesen von Büchern. Zur Information über ihre Freizeitaktivitäten und Mediennutzung gaben 87,1\% der Befragten an, mehrmals pro Woche fernzusehen, während nur knapp 40\% mehrmals pro Woche Bücher lesen (Mehrfachnennung war möglich $)^{759}$. Für weite Teile der Gesellschaft ist der Vielleser ein Kuriosum, er wird belächelt aufgrund seiner anscheinend altmodischen, einsamen Beschäftigung mit Büchern.

\subsubsection{Abgrenzung von innen - Gruppenbildung}

In einer Zeit, in der das Lesen von Büchern öffentlich neutral oder sogar eher negativ wahrgenommen wird, wird der Leser zu etwas Außergewöhnlichem, das mit Status und Ansehen verbunden ist. Löffler bezieht sich auf eine Rangliste von Hobbys der Deutschen, in der Fernsehen den Spitzenplatz einnimmt ${ }^{760}$, Lesen dagegen stehe abgeschlagen. Das Buch wird von einem breiten Publikum weniger geschätzt, woraus sich wiederum der distinguierte Aspekt des Bücherlesens verdankt. Weniger selten als Belege für Vorurteile gegen das Lesen und den belächelnden Blick eines Teils der Öffentlichkeit auf Leser sind enthusiastische Darstellungen der Vorzüge des Lesens oder des Büchersammelns, wie sie in unzähligen Veröffentlichungen gepflegt werden, aber doch eher die Gruppe von Viellesern anspricht, die ohnehin schon liest.

Das Bücherlesen vermittelt einen Status, an dem nicht jeder partizipieren möchte. Wo das Buch selbst seinen Status als Leitmedium eingebüßt hat, gewinnt der Leser soziale Distinktion und Ansehen, er wird aber auch belächelt. Bücher werden nun hauptsächlich von einer eingeschworenen Gemeinschaft konsumiert, die Aussage „Ich lese“ ist zum Bekenntnis geworden. Die LeserCommunity steht gerade auch Normallesern offen. Wo es immer weniger Gern- und Vielleser gibt, suchen Buchleser den Zusammenschluss mit Gleichgesinnten, welcher über Buchclubs und Lesekreise (besonders in den USA) gelingen kann. Ein Gemeinschafts- oder Zugehörigkeitsgefühl kann

\footnotetext{
758 Blumenberg (1981), S. 17.

759 Vgl. die Medienanalyse „Medien und Freizeit Deutschland 2009“, veröffentlicht 31.08.2009, [http://de.statista.com/statistik/daten/studie/36838/umfrage/freizeitaktivitaeten\%3A-mediennutzung-indeutschland-im-jahr-2009], eingesehen am 09.05.2011.

760 Löffler (2005), S. 13.
} 
sich auch aus der individuellen Lektüre des gleichen Lesestoffs ergeben, wie in einem Lesezirkel oder schlicht das Lesen eines Bestsellers, den schon viele Menschen gekauft und wohl auch gelesen haben. Der Leser kann ,mitreden'. Der einzige Leser eines speziellen, vielleicht weithin unbekannten Buchs zu sein, vermittelt wiederum das Gefühl des Besonderen und Einzigartigen, verleiht mitunter etwas Erhebendes.

Leser vereinen sich zu einer eingeschworenen Gemeinschaft, Anhängern einer „,magische[n] Geheimpraxis für Auserwählte“6761, wie Löffler das Lesen nicht frei von Sarkasmus nennt. Diese Gemeinschaft ist einerseits Nichtlesern unzugänglich, andererseits erscheint sie elitär, man denke hier an den titelgebenden „Club Dumas“ bei Pérez-Reverte, zu dem nur Prominente und Geldadel zugelassen sind, oder die Geheimgesellschaft bei Živković. Gespiegelt wird dieser elitäreinzigartige Ansatz in der Fiktion durch den Mythos des einzigen Buchs, der in diversen BuchBüchern zum Tragen kommt und die Massenproduktion von Büchern konterkarikiert.

\subsection{Buchmarkt, Buchkäufer und Leser}

Um zu ermitteln, wie es um die Stellung des Buchs in der Medienlandschaft und in der Gunst eines Publikums, das Unterhaltung sucht, bestellt ist, wird im Folgenden ein kurzer Überblick über den aktuellen Romanmarkt gegeben sowie Studien zu Buchkauf und -lesen analysiert. Daraus ergibt sich ein konturiertes Bild der Stellung von Buch und Lesen heute. Außerdem kann ein mögliches Publikum für die Buch-Romane definiert werden, dass nicht auf Bücher festgelegt ist und mehrere Medien selbstverständlich nutzt.

\subsubsection{Buchmarkt}

Praktisch jeder verfügt in der heutigen Wissens- und Wohlstandsgesellschaft, der Gesellschaft des 20. Jahrhunderts, die bis heute andauert, über genügend (Frei-)Zeit, Geld und Bildung, um an der literarischen Kommunikation teilzunehmen ${ }^{762}$. Das Buch steht jedem zur Verfügung. Faulstich sieht allerdings in Bezug auf das Buch eine „Tendenz zum Elitemedium““763, da die Durchschnittspreise für ein Buch steigen und die Buchpreisbindung diese Preise festlegt. Diese Tatsache mag der Wahrheit entsprechen, doch wird hier zu kurz gedacht und einseitig argumentiert. Es ist vielmehr der Fall, dass die Möglichkeiten zum Buch zu kommen, noch nie so einfach und vielfältig waren wie heute. Die Laufzeit des gebundenen Buchs wird immer kürzer, so dass die Zweitverwertung im preisgünstigen Taschenbuch oder aber die Möglichkeit, das gewünschte Buch im Modernen Antiquariat zu erwerben, immer rascher nach Erscheinen der Erstausgabe gegeben ist. Außerdem gibt es eine Fülle von Angeboten, ein Buch in Second-hand-Buchläden oder auch online

\footnotetext{
761 Löffler (2005), S. 13.

762 Vgl. Jost Schneider (2004), S. 416.

763 Faulstich (2006), S. 139.
} 
gebraucht zu erwerben, z. B. über ebay ${ }^{764}$, Amazon Marketplace ${ }^{765}$, ZVAB (Zentrales Verzeichnis antiquarischer Bücher ${ }^{766}$, booklooker ${ }^{767}$ etc. sind auch aktuelle Romane, größtenteils gebraucht, für wenig Geld zu haben. Außerdem ist die Ausleihe von Büchern aus öffentlichen Bibliotheken möglich und üblich. Ein Buch verbraucht sich nicht, so dass es einerlei ist, ob ein Exemplar bereits gelesen wurde oder nicht, kommt es dem Leser vorrangig auf das Lesen des Textes, denn den Besitz eines eigenen, druckfrischen Exemplars an.

Der Buchmarkt lässt sich auf die Formel bringen, dass sich von einem gut gehenden Roman, einem Bestseller, tausende von Exemplaren verkaufen, während andere Titel quasi unberührt daneben liegen. Bestseller definieren sich dadurch, dass sie in kurzer Zeit, aber auch nur für eine begrenzte Zeitspanne, überdurchschnittlich hohe Verkaufszahlen in ihrem Segment und damit hohe Umsätze erzielen. Faulstich hält Bestseller für ein natürliches Phänomen des kapitalistischen Marktes $^{768}$. Verlagen garantieren Bestseller finanziellen Erfolg, mit dem sie umsatzschwächere Titel stützen können, während der Handel mit hohen Rabattierungen seitens der Verlage und hohen Verkaufszahlen rechnen kann. In der so gut wie unüberschaubaren Masse an Titeln bieten Bestseller und deren Verkaufsstatistiken in Bestsellerlisten eine Entscheidungshilfe und Orientierung für den Leser, was er lesen, soll', damit er mitreden kann und sich so zu einer Gruppe von Lesern zugehörig fühlt. Allerdings darf nicht vergessen werden, dass dem Leser so eine Selbstbestimmung über seinen Lesestoff abgesprochen wird. Nur weil ein Buch viel verkauft wird, muss es nicht literarisch ansprechend oder ein Lesevergnügen für jedermann sein. In Bezug auf das Leseverhalten bedeutet die Durchsetzung von Listen-Bestsellern auf dem Buchmarkt: „Wenige Leute lesen viele Bücher. Viele Leute lesen die gleichen Bücher. ${ }^{\text {(769 }}$ Die Feststellung wurde Mitte der 1990er geäußert, trifft aber auch heute noch zu.

Dem Bestseller-Boom zum Trotz war das Buchangebot noch nie so breit wie heute. Der Trend legt nahe, dass die Buchproduktion zwar leicht, aber doch immer weiter ansteige und eine immer größere Variationsbreite von Titeln und Genres entsteht. Genau wie die Gesellschaft diversifizieren sich Lese- und Lesergesellschaft, also die Leserinteressen, immer mehr aus. Dies ist auch ein Indiz für den medialen Umbruch, in dem wir uns befinden: Es werden Bücher für jeden Geschmack angeboten, wobei der Lesergeschmack in vielen Fällen vor der literarischen Qualität steht.

Die Verlage produzieren immer mehr Output, immer mehr Einzeltitel, aber pro Titel kleinere Auflagen aufgrund einer Ausdifferenzierung des Markts und einer zunehmenden Spezifizierung

\footnotetext{
764 Vgl. [http://www.ebay.de].

765 Vgl. [http://www.amazon.de/gp/help/customer/display.html?nodeId=886416].

766 Vgl. [http://www.zvab.com].

767 Vgl. [http://www.booklooker.de].

768 Faulstich (2006), S. 138.

769 Stocker (1994), S. 84.
} 
der Titel. Die zahlreichen, diversifizierten Romangenres binden dabei aber auch immer nur eine kleine Gruppe von Lesern, jeder Titel spricht ein spezifiziertes Publikum an. Die Reaktion darauf ist die Produktion von noch mehr Titeln, die hauptsächlich als Novitäten ihre Käufer finden. In Grundzügen ähnelt dieser Teufelskreis der Zeitschriftenkrise seit etwa der Mitte der 1990er, die das Prinzip des Open Access erforderlich gemacht hat: Sinkende Auflagen durch geringere Nachfrage führen zu steigenden Preisen, was die Verkäufe erneut verringert.

\subsubsection{Buchkäufer und Leser}

Untersuchungen zeigen, dass das Leseverhalten bis in die $1990 \mathrm{er}$ stabil blieb ${ }^{770}$. Dies ist ein erstaunliches Ergebnis, denn trotz Konkurrenz durch andere Medien hätte das Lesen zur Unterhaltung eigentlich zunehmen müssen, da der allgemeine Bildungsstand immer höher wird, außerdem immer mehr Zeit zur freien Verfügung steht und finanzielle Mittel für den Konsum vorhanden sind. Zeit und finanzielle Ausgaben werden heute jedoch auf mehrere Freizeitaktivitäten und, aufgrund eines vorherrschenden Medienpluralismus, auf mehrere Medien verteilt.

Eine Erhebung zur täglichen Nutzung von Medien ergab Anfang 2010 771 , dass die Deutschen täglich durchschnittlich 220 Minuten Fernsehen und 83 Minuten im Internet verbringen, aber nur 22 Minuten in Büchern lesen: „Alle gut gemeinte Animateur-Prosa zur Glorifizierung des Lesens kann nicht darüber hinwegtäuschen, dass das Bücherlesen in der Konkurrenz zu Fernsehen und DVD etwas blass aussieht.“772 Angesichts der hohen Zahl der „Wenigleser“ und der Existenz von Nichtlesern erscheint die für das Bücherlesen aufgewandte Zeitspanne im Querschnitt allerdings doch verblüffend hoch. Natürlich kann eine solche stichprobenhafte Erhebung nur einen Ausschnitt der tatsächlichen Mediennutzung wiedergeben, einen Eindruck vermittelt sie allemal.

Jost Schneider hat das Leseverhalten im Jahr 1992 untersucht. Er stellt fest, dass in diesem Jahr etwa ein Drittel der deutschen Bevölkerung - das aus Viel- und Intensivlesern sowie 2\% Berufslesern bestand - intensiv an einer schriftlichen literarischen Kultur partizipierte, und dies „trotz verschärfter Medienkonkurrenz ${ }^{\text {“773 }}$. Gegenüber früheren Jahrhunderten, in denen in den meisten Milieus Zugang, finanzielle Mittel, Zeit und schlechthin Bildung zu und für eine Beschäftigung mit schriftlich fixierten Texten fehlten, haben wir es hier mit einem Spitzenwert zu tun. Was die schriftliche literarische Kommunikation betrifft, findet heute jedoch eine Öffnung in Richtung der elektronischen Medien statt. Die Schriftkultur ist heute nicht mehr nur auf Texte, gedruckt auf Papier beschränkt, denn das Lesen hat sich auch auf die elektronischen Medien ver-

\footnotetext{
770 Vgl. Stocker (2007), S. 65.

771 Vgl. die Erhebung „Massenkommunikation 2010“, veröffentlicht durch ARD und ZDF bei einer Pressekonferenz am 09.09.2010, [http://de.statista.com/statistik/daten/studie/164504/umfrage/taegliche-nutzungsdauer-vonmedien-in-deutschland/], eingesehen am 20.04.2011.

772 Löffler (2005), S. 17.

773 Jost Schneider (2004), S. 435.
} 
lagert. Gerade Internet und WwW werden nicht nur genutzt, um nach bestimmter oder zufälliger Information und Unterhaltung zu ,surfen' oder PC-Spiele zu spielen, vielmehr stehen sie auch für die Konsumierung literarischer Texte zur Verfügung. Die Befürchtungen vor dem Ende der Lesekultur oder dem Rück- oder Niedergang des Buchs beziehen sich daher immer auf einen Rückgang der Printmedien, nicht auf das Lesen generell.

Die Wirtschaftszahlen des Börsenvereins des Deutschen Buchhandels zeigen für das Jahr $2009^{774}$, dass heute mehr Umsatz denn je mit Büchern gemacht wird. Leichte Preissteigerungen in allen Segmenten sind dafür sicher mitverantwortlich, es lässt sich aus diesem Ergebnis aber auch schließen, dass die Abverkaufszahlen insgesamt höher waren. Nach einem Umsatzeinbruch in den Jahren 2001 bis 2004 für den Buchverkauf ist seit 2005 keine rückläufige Tendenz erkennbar. Zwar wurde noch 2005 angenommen, der Buchverkauf stagniere ${ }^{775}$, doch gibt es seitdem ein stetiges Wachstum, gerade auf dem Belletristik-Markt.

Auf der Basis einer Studie der Stiftung Lesen von 2001 zum Leseverhalten in Deutschland im neuen Jahrtausend lässt sich feststellen: „Immer weniger Menschen lesen also immer mehr Bücher.“776 - ein vereinfachtes Fazit, das von den Studien Haben Bücher eine Zukunft? und Buchkëufer und Leser-Profile, Motive, Wünsche II (2008) sowie den Wirtschaftszahlen des Börsenvereins bestätigt wird. Es findet eine Gruppenbildung statt: Die lesende Bevölkerung konzentriert sich auf eine Gruppe von Viellesern, die immer mehr liest, während Personen, die bisher schon wenig lasen, heute noch weniger lesen.

Die beiden Studien zu Lese- und Kaufgewohnheiten kommen durchaus zu ähnlichen Ergebnissen, verfolgen aber unterschiedliche Ansätze, u. a. bedingt durch unterschiedliche Bezugsgrößen und Herangehensweisen. Die Repräsentativstudie Haben Bücher eine Zukunft? zum Leseverhalten der Deutschen basiert auf 1.224 Interviews und wurde 2007 von PriceWaterhouse Coopers anlässlich der Frankfurter Buchmesse durchgeführt. Dabei wurden in der Hauptstudie Leser ab 14 Jahren und in einer separaten Studie Kinder zwischen 10 und 13 Jahren befragt. PWC kommt zu dem Ergebnis, dass eine deutliche Polarisierung im Leseverhalten stattfindet: Die Schere zwischen Viel- und Weniglesern öffne sich immer weiter. Bei der Definition beider Typen verlässt sich PWC auf die subjektive Einschätzung der Befragten, die die Häufigkeit und Entwicklung ihres persönlichen ,gefühlten’ Bücherlesens angeben sollten ${ }^{777}$. Laut der Studie nehme die ,gefühlte’ Lesehäufigkeit ab: „Generell sagen mit 46 Prozent große Teile der Bevölkerung,

\footnotetext{
774 Vgl. Wirtschaftszahlen des Börsenvereins des Deutschen Buchhandels, [http://www.boersenverein.de/de/158446/Wirtschaftszahlen/158286], eingesehen am 11.09.2010.

775 Vgl. u. a. Löffler (2005), S. 13.

776 Stocker (2007), S. 66.

777 Vgl. Haben Bücher eine Zukunft? (2007), S. 5.
} 
dass sie heute weniger lesen als früher.“778 Als Gründe für den Rückgang des Lesens werden neben der Konkurrenz durch Fernsehen und andere Medien Schnelllebigkeit und berufliche Belastung angeführt, kurz: Es fehlen Zeit, Konzentration und Muße, sich in ein Buch zu versenken. Es fällt auf, dass diese Aspekte nicht hinderlich für die Nutzung des Internets sind. Bildung ist ein entscheidender Faktor für das Viellesen, außerdem, dass Frauen mehr lesen und Bücher kaufen als Männer. Das Leseverhalten hängt, wie die Studie zeigt, nicht nur mit Bildung und Geschlecht zusammen, es hängt sogar davon ab. Allerdings stellen sich gebildete Schichten in Befragungen insgesamt eher als belesen dar, da sie aufgrund des hohen Status von Büchern meinen, das werde von ihnen erwartet ${ }^{779}$. Zusammengefasst kommt die Erhebung zu den Aussagen, dass

- Vielleser noch mehr, Wenigleser noch weniger lesen,

- Vielleser meist eine höhere Bildung haben (,gebildet, informiert, internetaktiv“)

und ökonomisch besser situiert sind als Wenigleser,

- Frauen mehr lesen als Männer, besonders „Bücher zur Unterhaltung““,

- das Lesen zur Unterhaltung im Vordergrund steht.

Die Studie Buchkeäufer und Leser - Profile, Motive, Wünsche II (2008) (vgl. Kap. III.11.6) definiert Viel- und Wenigleser aufgrund der Anzahl der gelesenen Bücher in den vergangenen 12 Monaten und stellt einen Rückbezug zu der 2005 durchgeführten Befragung her. 90\% der Befragten gaben 2008 an, in den vergangenen 12 Monaten mindestens ein Buch gelesen zu haben. Folgt man der Statistik von PWC ${ }^{780}$, die die subjektive Einschätzung des Lesens unter den Befragten ermittelt, gaben nur 5\% an, überhaupt nicht zu lesen, was sogar einen Anteil von 95\% Lesern ergibt. Die Mehrheit der Bevölkerung liest also, wenn auch nur wenige Bücher im Jahr. Laut Buchkäufer und Leser II ist der Anteil der „Wenigleser“ mit bis zu neun Büchern im Jahr mit 43\% am höchsten und dabei leicht gewachsen (2005: 40\%). Der Anteil der „Vielleser“ mit mehr als 18 Büchern im Jahr ist dagegen um zwei Prozentpunkte auf 25\% gefallen. Die Ergebnisse der PWC-Studie werden hier quantitativ ergänzt: Der Anteil der Wenigleser erhöht sich, wobei diese noch weniger lesen als bisher, während die Gruppe der Vielleser kleiner wird, jedoch noch mehr liest als zuvor.

Auch der Buchkauf ist auf wenige Exemplare beschränkt. Die größte Gruppe unter den 57\% Buchkäufern (2005: 55\%) ist mit 38\% die der „Wenigkäufer“. Um an Lesestoff zu gelangen, wählen viele Leser den Weg der Ausleihe. Die beiden größten Gruppen von Buchtypen, die sich aus der Zusammenschau von Käufer- und Lesertypen ergeben, bilden schließlich „Gelegenheitsleser“ (33\%; lesen, kaufen aber nicht) und „Ausleihende Leseratten“ (24\%; lesen mehr als sie kaufen ${ }^{781}$.

\footnotetext{
778 Vgl. Haben Bücher eine Zukunft? (2007), S. 3.

779 Vgl. ebd., S. 13 f.

780 Vgl. ebd., S. 5.

781 Vgl. Buchkäufer und Leser II (2008), S. 23ff.
} 
Buchkäufer und Leser lassen sich also nicht gleichsetzen. Generell wird aber weit mehr gelesen als gekauft (90\% Leser vs. 57\% Buchkäufer, beide von unterschiedlicher Intensität) - das Marktpotential für den distributiven Handel ist noch nicht voll ausgeschöpft. Die Kernzielgruppen für den Buchhandel stellen anhand des Kauf- und Leseverhaltens die Sinus-Milieus der Postmateriellen und Konservativen, aber auch Etablierte, Moderne Performer, Bürgerliche Mitte und Experimentalisten besitzen ein mögliches Zielgruppenpotential ${ }^{782}$. Die Studie Buchkëufer und Leser II kommt im Überblick zu folgenden Ergebnissen:

- Die Zahl der Käufer ist gegenüber 2005 leicht auf 57\% der Befragten gestiegen.

„Vielkäufer“ haben einen Schwerpunkt bei den Postmateriellen und Konservativen.

- $90 \%$ der Deutschen haben 2008 mindestens ein Buch gelesen, wobei der Wert gegenüber der Vorgängerstudie nahezu unverändert blieb. „Vielleser“ haben einen Schwerpunkt bei den Postmateriellen, die auch viel kaufen, sowie bei den Modernen Performern, die allerdings nur durchschnittlich kaufen.

- Der Anteil der Vielleser ist im Vergleich zu 2005 leicht gesunken, während die Gruppe der Wenigleser größer geworden ist und weiterhin die größte Gruppe der Leser stellt.

- Die Hauptmotive Bücher zu lesen sind Unterhaltung und Entspannung.

\subsubsection{Vielleser und ,Buch im Buch’}

Die Gruppe der Vielleser stellt höchstwahrscheinlich die ideale Zielgruppe für Romane mit Buchbezug dar. Das Motiv ,Buch im Buch’ spricht trotz Mehrfachkodierungen vor allem anspruchsvolle, kompetente Leser an, so wie der Vielleser es ist. Diese Lesergruppe ist zwar kleiner geworden, liest aber noch mehr Bücher als bisher, ist also dem Buch mehr als der durchschnittliche Leser zugetan. Vielleser sind häufiger überdurchschnittlich gebildet und besitzen lange Lesebiographien und viel Leseerfahrung, so dass sie dazu in der Lage sind, intertextuelle Bezüge und weitere Implikationen, die das Buch-Motiv mit sich bringt, voll umfänglich zu durchschauen. Das ,intellektuelle Rätsel' der Buch-Bücher reizt sie. Postmaterielle und Moderne Performer machen die Vielleser zum größten Teil aus. Postmaterielle zeigen die größte Affinität und Liebe zu Büchern, und das in allen Genres, und fühlen sich vermutlich auch zu einer fiktionalen Thematisierung von Büchern hingezogen, während Moderne Performer einen pragmatischeren Bezug zu Büchern haben, aber dennoch viel und gern lesen, besonders Krimis. ${ }^{783}$

\subsubsection{Buchleser und Internet}

Eine der wichtigsten Erkenntnisse der Studie Haben Bücher eine Zukunft? ist, dass das Internet dem Bücherlesen insgesamt weniger Konkurrenz macht, als bisher vermutet. Wer häufig Bücher liest 
und kauft, lehnt das Internet nicht automatisch ab, genauso wenig wie jemand, der das Internet intensiv nutzt, Bücher zwingend ignoriert. Es gibt vielmehr einen engen Zusammenhang zwischen Viellesen und häufiger und intensiver Internetnutzung: „Wer viel im Netz surft, liest auch mehr Bücher und umgekehrt. “784 Unter Nichtlesern seien nach eigener Angabe 62\% nie oder äußerst selten im Internet, während jeder zweite Vielleser täglich oder fast täglich ins Internet gehe $^{785}$. Das Internet verdrängt das Bücherlesen nicht, sondern ergänzt es sinnvoll: „Es handelt sich also beim Internet eher um eine ergänzende parallele als eine verdrängende Nutzung, was sich letztlich über eine vermittelnde Variable erklärt, die das ganze überlagert und den Zusammenhang herstellt: Bildung. ${ }^{\text {“786 }}$ Laut der Studie sind Vielleser häufiger überdurchschnittlich gebildet als Wenigleser.

Grob gesagt, existieren heute zwei Gruppen von Mediennutzern: Eine Gruppe kompetenter Mehrmediennutzer, die neben der Nutzung elektronischer Medien auch häufig Bücher liest, und eine Gruppe von Einmediennutzern elektronischer Medien (z. B. Computerspiele, TV, Internet), die kaum Bücher oder gar nicht lesen: „Es steht also weniger der Buchleser dem Nichtbuchleser gegenüber als vielmehr der Vielmediennutzer dem Wenigmediennutzer.““787 Die Gruppe der Leser ist in den letzten Jahren also nicht unverhältnismäßig größer oder kleiner geworden, vielmehr bilden Leser in ihrer Eigenschaft als Mehrmediennutzer einen Gegenpol zu den „NurPC“- oder „Nur-TV“-Nutzern. Buchleser machen Gebrauch von diversen weiteren Medien und sind dabei auch neuen Medien aufgeschlossen, die breite Zugänge zu Kultur und Gesellschaft gewährleisten. Erst Internet und Www ermöglichen eine simultane Vernetzung, Kommunikation und Austausch, auch zwischen Lesern, man denke hier an Fanseiten für Lieblingsbücher und Besprechungs- und Austauschforen für Leser. An dieser Stelle ergänzen die neuen die alten Medien als „add-on media“ - auch diese Arbeit wäre ohne die Benutzung des Www kaum realisierbar gewesen.

\subsection{Literarische Kommunikation und Leseverhalten}

Neue digitale Methoden, PC und Internet zu nutzen, haben auch Auswirkungen auf Akteure der literarischen Kommunikation wie Verlage, Buchhandel, Literaturkritik, Autoren, Leser. Das Buch wird nicht in seiner Funktion als Unterhaltungsmedium nicht einfach nur ergänzt, vielmehr können digitale Methoden auch Aufgaben verschiedener Instanzen des Buchmarkts und Literaturbetriebs übernehmen. Im Weiteren wird gezeigt, in welcher Form diese Institutionen schon rea-

\footnotetext{
784 Vgl. Haben Bücher eine Zukunft? (2007), S. 3.

785 Vgl. ebd., S. 6.

786 Vgl. ebd., S. 14.

787 Saxer, Langenbucher \& Fritz: Kommunikationsverhalten und Medien. Lesen in der modernen Gesellschaft, 1989, nicht eingesehen, zitiert nach Stocker (2007), S. 66.
} 
giert und neue Wege zur Umsetzung des Medienwandels gefunden haben. Die derzeitige Situation von Buch und Medienlandschaft trägt mit der Änderung von Lesegewohnheiten, der Ausdifferenzierung von Gattungen und Genres und der Entstehung neuer mediale Bedingungen basierend auf zunehmender Digitalisierung und Vernetzung sogar Grundzüge einer Medien,revolution'.

\subsubsection{Medienrevolution! Medienrevolution?}

Das Bücherlesen zur Unterhaltung hat in weiten Teilen der Gesellschaft anderen Medien Platz eingeräumt, wird generell aber durch die ,neuen Medien’ eher ergänzt. Neue Medien verdrängen die alten in den meisten Fällen nicht, sondern ergänzen sie als add-on media. Folgt man den Befunden, die die heutigen medialen Umbrüche reflektiert in Gesellschaft und Kultur nach sich ziehen, sind wir mit einer Medienrevolution konfrontiert, wie man sie in den 1960er Jahren um das Fernsehen diskutierte.

Die Zählweise der ,Revolutionen' differiert je nach Ansatz und Medientheorie. Eine Medienrevolution, auf die sich alle Ansätze einigen können, ist die Erfindung des Buchdrucks mittels beweglicher Lettern durch Johannes Gutenberg. Eine weitere markiert für viele der von McLuhan beschriebene durch die Bildschirmmedien hervorgerufene Medienwandel in den 1960er Jahren. McLuhans Befürchtungen werden heute sogar noch verschärft, denn der mediale Wechsel betrifft nicht nur die Ablösung des Buchs als Leitmedium durch das Fernsehen, sondern bietet sogar elektronische Möglichkeiten, das gedruckte Buch abzuschaffen.

Für die Bewertung, ob es sich um 1780 tatsächlich um eine Lese,revolution' handelte, sind die konträren Erkenntnisse von Rolf Engelsing, Erich Schön und Robert Darnton ausschlaggebend $^{788}$. Während Engelsing und Schön von einer Medienrevolution gegen Ende des 18. Jahrhundert im deutschsprachigen Raum ausgehen (analog zur politischen in Frankreich und zur industriellen in England), lehnt Darnton eine solche Annahme ab. Er vermutet eher die Änderung der Lesegewohnheiten und des Lesestoffs (Säkularisierung der Leseinhalte, Lesen zum Vergnügen statt zur Erbauung, Aufstieg des Romans) sowie eine Auffächerung der literarischen Kommunikation (u. a. ein neues Verhältnis von Autor, Text, Leser und ihre identifikatorische Verknüpfung), die jedoch massive Auswirkungen auf das Lesen und Lesergruppen in Deutschland hatte. Eine Veränderung im Buchangebot und dabei eine stärkere Ausdifferenzierung einzelner Genres und damit Lesergruppen findet auch heute statt, es wird ,anders' und ,anderes' gelesen als noch zuvor, so dass zu Recht nach einer weiteren Lese- und Medienrevolution in Anlehnung an die Umwälzungen im bürgerlichen Zeitalter gefragt wird.

788 Vgl. Engelsing (1969), Schön (1987) sowie Robert Darnton: „First Steps Toward a History of Reading“" in: The Kiss of Lamourette. Reflections in Cultural History. New York: W.W. Norton, 1990, S. 154-187. 
Der Open-Access-Begründer und -verfechter Stevan Harnad und der Medientheoretiker Werner Faulstich sehen beide die heutige Gesellschaft in einer 4. Medienrevolution befindlich, wobei sie sich auf sehr unterschiedliche Herangehensweisen und Begründungen stützen. Sie sind sich dahingehend einig, dass sich der heutige Medienwandel den digitalen Technologien verdankt, die die elektronischen Medien weiterentwickeln, verfolgen aber unterschiedliche Erklärungen.

Harnad sieht die Menschheit in seinem Aufsatz Post-Gutenberg Galaxy: The Fourth Revolution in the Means of Production of Knowledge ${ }^{789}$ aus dem Jahr 1991 an der Schwelle zu einer "fourth cognitive revolution". Dabei spricht er nicht für Romane, sondern ausdrücklich für die wissenschaftliche Kommunikation, vor allem mittels wissenschaftlicher Zeitschriftenartikel, auf die das Konzept des Open Access abzielt. Von einem kognitiven Standpunkt aus untersucht Harnad drei frühere Medienrevolutionen, die die menschliche Art zu Denken, die Produktion von Wissen und die Weitergabe von Informationen grundlegend verändert und erweitert haben: 1) Die Entwicklung der Sprache als mündlicher Ausdruck von Gedanken und die Möglichkeit der Übermittlung von Informationen an andere Menschen; 2) Die Entwicklung der Schrift als Möglichkeit der Konservierung dieser Inhalte, unabhängig von Sprecher und Hörer. Schrift sei reflexiver und damit weniger spontan als Sprache und weniger auf soziale Interaktion ausgelegt; 3) Die Entwicklung des (Buch-)Drucks: Die Vervielfältigung von Texten ermögliche eine größere Reichweite im Publikum, eine höhere Geschwindigkeit in der Verbreitung von Texten und mit der Einführung wissenschaftlicher Journale auch raschere Reaktionen innerhalb der Fach-Community (z. B. Gelehrte Journale als Austauschforen innerhalb der gebildeten Elite, heute: schnellere Veröffentlichung von rasch veraltenden Forschungsergebnissen, gerade in den Naturwissenschaften, raschere Reaktionen von peers). Harnad schließt, dass viertens die Entwicklung des Internets, hier noch „electronic skymriting“" genannt, also die Darstellung und Übermittlung von Texten über das Internet, zu einer neuen Revolution führe.

Bei Faulstich ${ }^{790}$, dessen zweibändiges Werk zur Mediengeschichte aus dem Jahr 2006 stammt, hat die 4. Medienrevolution bereits begonnen. Er geht von drei Entwicklungsstufen der Massenund Volksmedien vor der jetzigen aus: 1) Entwicklung der Primärmedien (,Menschmedien', Sprache, Mimik, Gebärden, Theater); 2) Entwicklung von Druckmedien als Sekundärmedien (Erfindung des Buchdrucks); 3) Entwicklung der elektronischen Medien, die das 20. Jahrhundert prägen. Den Wechsel von den elektronischen zu den digitalen Medien seit etwa 1990 bezeichnet Faulstich als 4. Revolution.

\footnotetext{
789 Stevan Harnad: „Post-Gutenberg Galaxy: The Fourth Revolution in the Means of Production of Knowledge”. In: Public-Access Computer Systems Review 2 (1), S. 39-53. Online [http://cogprints.org/1580/1/harnad91. postgutenberg.html], eingesehen am 19.04.2011.

790 Werner Faulstich: Mediengeschichte von den Anfängen bis 1700 sowie Mediengeschichte von 1700 bis ins 3. Jahrtausend. Göttingen: Vandenhoeck \& Ruprecht, 2006.
} 
Heute, um das Jahr 2010, kann man zwei große, ja historische mediale Veränderungen für die Formgebung und Verbreitung von Texten feststellen ${ }^{791}$ : Digitalisierung: Neue, digitale Formate für Texte und neue digitale Methoden sowie Vernetzung: Das Internet als Voraussetzung für die Austauschbarkeit digitaler Daten und Dateien. Erst die Kombination aus beiden ermöglicht neue Wege der Textverarbeitung und -distribution, neue Möglichkeiten der Erschließung von Quellen und Werkzeugen für deren Bearbeitung, für Öffentlichkeit und weltweite Zugänglichkeit zu Inhalten. Die digitalen Technologien ersetzen das Buch nicht, stellen aber doch eine starke Ergänzung und damit auch eine Konkurrenz dar. Wir befinden uns mitten in einem Medienwandel, vielleicht sogar einer Medienrevolution.

Die Digitalisierung verbessert die (inzwischen) alten Medien Film und Fernsehen, aber auch das Buch? An dieser Stelle muss wiederum zwischen Content und Medium, also Text und Buch, unterschieden werden. Digitalisierung gewährleistet eine bessere Durchsuchbarkeit von Texten, die Vernetzung ihre leichtere und bequemere Auffindbarkeit, einen verbesserten Zugang auch zu größeren Korpora. Das Druckwerk Buch als Medium steht erst am Ende dieser Verwertung, wobei der Text, ist er erst online, digital und so gut wie kostenfrei für jedermann via Www erhältlich, beinahe gar nicht mehr gedruckt werden müsste. Die Buchherstellung profitiert von der Digitalisierung insofern, als bis auf Liebhaberausgaben so gut wie sämtliche Druckwerke im DesktopPublishing-Verfahren (DTP) hergestellt werden. Die Methode Books on Demand (Herstellung eines Buchs nach einer digitalen Vorlage nach Bedarf) verändert die Distribution von Monographien. Hier wird eine digitale Version des Textes auf Abruf bereitgehalten, dem Text wird also wenig Verkaufspotential zugetraut, so dass er nicht in gedruckter Form am Lager bereitgehalten wird.

Auch die Literaturwissenschaften nehmen diese neuen Möglichkeiten wahr und beginnen sie zu nutzen, so dass heute in Deutschland zunehmend Zentren für Digital Humanities oder e-Humanities aufgebaut und so internationale Forschungsinfrastrukturen für die Geisteswissenschaften geschaffen werden ${ }^{792}$.

Die gängige Meinung lautete bisher, dass „Papier geduldig“ sei, dass das, was man „schwarz auf weiß“, also dauerhaft und zuverlässig vor sich habe, „getrost nach Hause tragen könne“. In einem Roman des Korpus lautet das Motto einer Bibliothek „Littera scripta manet“: Das geschriebene Wort ist beständig, was als Versprechen und Drohung zugleich aufgefasst werden kann. In unserer heutigen, im schnellen Wandel begriffenen Zeit scheint nur noch das auf Papier Geschriebene und Erhaltbare dauerhaft verfügbar zu sein, während die neuen Technologien und Medien so

\footnotetext{
791 Vgl. Fotis Jannidis: „Digitale Editionen“. In: Literatur im Medienwechsel. Mitteilungen des Deutschen Germanistenverbandes, H. 3 (2008), S. 317-332, hier S. 317.

792 Vgl. ebd., S. 331.
} 
rasch veralten, dass ihnen kaum Beständigkeit und Nachhaltigkeit zugetraut werden ${ }^{793}$. Niemand kann heute mit Bestimmtheit sagen, ob in einigen Jahrzehnten Formate wie PDF überhaupt noch lesbar sein werden. Es ist jedoch anzunehmen, dass die Technik dann derart entwickelt sein wird, dass eine Konversion in ein zu diesem Zeitpunkt übliches Format oder die Rekonstruktion veralteter Formate keine Schwierigkeit darstellen dürfte. Das Gegenteil ist also der Fall: Digitalisierte Texte sind häufig länger erhältlich als gedruckte Bücher am Markt und als einzelne Titel bei ihren Verlagen digital archiviert werden. Dokumenten- und Publikationsserver garantieren die weltweite Verfügbarkeit von Volltexten und Metadaten und die langfristige Archivierung von Publikationen. Ihre Zitierfähigkeit ist durch dauerhafte, stabile www-Adressen über persistent identifiers garantiert. Die digitalen Dokumente werden mit Hilfe strukturierter Metadaten bibliographisch beschrieben und über nationale und internationale Bibliothekskataloge, Suchmaschinen und andere Nachweisinstrumente erschlossen.

Ausdruck der heutigen Ausdifferenzierung der literarischen Kommunikation im digital turn sind darüber hinaus Veränderungen im Leseverhalten, in Lesegewohnheiten und -interessen des Publikums, eine veränderte Wahrnehmung von Buch und Lesen sowie neue Anforderungen an alle Akteure des Literaturbetriebes.

\subsubsection{Auswirkungen des Medienwandels auf die Akteure der literarischen Kommunikation}

Im Umfeld der neuen Medien erhalten das Bücherlesen und die Auseinandersetzung mit seinen Inhalten neue Funktionen und Bedeutungen. Literatur ist heute allseits sichtbar. Jeder kann ohne Anstrengung an Literatur gelangen, sich über Literatur austauschen, an Literatur weiterschreiben, viele schreiben eigene Blogs, die Zugänge zur Veröffentlichung eigener Werke sind niedrigschwellig. Nicht nur das Schreiben, auch das Lesen verlässt die Buchform, denn gelesen wird nicht nur Literatur, und diese nicht nur in gedruckter Form, sondern auch Texte im WwW.

Die Akteure des Literaturbetriebs sind nicht mehr klar definiert und im Wandel begriffen, denn ihre Aufgaben vermischen sich: Der Leser wird zum Produzenten von Literatur oder zum Rezensenten. Autoren veröffentlichen ihre Texte selbst. Elektronische Medien übernehmen die Aufgaben, die traditionell Büchern zukamen. Elektronische Technologien machen dem stationären Handel Konkurrenz, Online-Portale betätigen sich in der Produktion digitaler Buchveröffentlichungen. Amazon.de ist zur vielleicht wichtigsten Plattform des deutschen Buchmarkts geworden. Neben einer internationalen, breiten Produktpalette im Bereich Buch bietet das Unternehmen Peerto-peer-Angebote wie Leserrezensionen, Leserforen, Lieblingslisten, die die Partizipation des Einzelnen ermöglichen, und sogar ein eigenes Publikationsportal. Buchdateien können über das 
Amazon-Kindle-Portal hochgeladen und direkt vermarktet werden („Kindle Direct Publishing ${ }^{\circ}$ ). Seit kurzem gibt es auf dem E-Book-Markt sogar eine Anleitung ${ }^{794}$ dafür, eigene E-Books zu erstellen.

Nicht nur die literarische Kommunikation, die gesamte Buchbranche steht vor neuen Herausforderungen. Ein stärkerer Fokus liegt in allen Bereichen auf dem Leser, schließlich ist er nicht nur performativer Teil des Entstehungsprozesses von Literatur und im Leseprozess ,Erwecker' der Bücher, sondern als Käufer lebenswichtig für deren Fortbestehen. Die neuen technologischen Entwicklungen spielen auch für die Konstruktion sozialer Netzwerke von Lesern eine nicht zu unterschätzende Rolle. Diese Praxis kann für Verlage und Buchhändler nicht uninteressant sein. Die folgenden Ausführungen bilden einen Überblick über die neuen Anforderungen, denen sich die Instanzen des Literaturbetriebes und der Buchbranche stellen müssen, und führen Maßnahmen an, die als Reaktion auf die aktuelle Mediensituation ergriffen werden.

\subsubsection{Verlage}

Obwohl Texte, die eine Bearbeitung und somit inhaltliche und formale Aufwertung durch einen Verlag erfahren haben, immer noch hoch angesehen sind, werden traditionell verlegerische Kompetenzen heute auch von anderen Instanzen wahrgenommen. E-Books werden zur Konkurrenz für verlegerische Geschäftsmodelle, wenn Autoren ihre Werke selbst veröffentlichen und direkt vermarkten können.

Verlage selbst nutzen die neuen digitalen Möglichkeiten vor allem im Bereich Marketing. Wo kleine Verlage aufgrund der Konzentration auf Spitzentitel im Handel kaum sichtbar sind, nutzen sie das Internet zum Direktvertrieb an den Kunden. Social networks dienen als Marketinginstrument für belletristische Titel, um so besonders junge, internetaffine Leser zu erreichen. Dafür legen Verlage z. B. Profile für beliebte Romanfiguren an, mit der sich die Leser virtuell befreunden können. Außerdem profitieren Verlage von Online-,Kunden-Reviews', so dass schon einige Verlage Rezensionsexemplare nicht nur an Feuilleton-Rezensenten, sondern auch an ,Top-Rezensenten' bei Amazon.de verschicken ${ }^{795}$. Darüber hinaus setzen Verlage mehr und mehr auf serielle Titel, um im Anschluss an einen gut verkauften Titel einen weiteren garantierten Verkaufserfolg zu erzielen. Veränderte Genreeinteilungen differenzieren die Zielgruppen ${ }^{796}$, woran sich auch der distributive Handel anpassen muss. Verlag und Buchhandel kommen mit den bisher üblichen Genreklassifizierungen, Kategorien bzw. Warengruppen kaum noch aus.

\footnotetext{
794 Vgl. [http://www.amazon.de/Amazon-Kindle--Books-erstellen-ebook/dp/B00507HJQG/ ref=zg_bs_530886031_30].

795 Privates Gespräch mit Amazon-Top-Rezensent Thorsten Wiedau, Januar 2007.

796 Vgl. Buchkäufer und Leser II (2008), S. 81.
} 


\subsubsection{Buchhandel}

Der Buchhandel muss sich neue Strategien einfallen lassen, um Kunden anzulocken, besonders, da der Kauf von Büchern im Internet zunimmt. Zwar ist der beliebteste Ort für den Bücherkauf nach wie vor der stationäre Sortimentsbuchhandel, doch der Online-Buchhandel holt auf. 2009 erreichte der Internet-Umsatz mit Büchern einen Umsatzanteil von 12,2\% am Buchmarkt, was einer Steigerung von 16\% gegenüber dem Vorjahr entspricht. Hier zeigt sich ein stetes Wachstum, denn schon 2008 stieg der Umsatz mit Büchern im Internet um 20\%. ${ }^{797}$ Hinzu kommen Buchkäufe bei ebay oder anderen, nicht auf Büchern spezialisierten Online-Händlern. Außerdem werden hier vor allem Umsätze mit gebrauchten Büchern gemacht, welche aber völlig an Verkaufs- und Wirtschaftszahlen vorbeigehen, da dort nur Neuware erfasst wird. Allerdings sind gebrauchte Bücher generell wenig gefragt, wie die PWC-Studie feststellt: Nur 4\% der Befragten kaufen oft gebrauchte Bücher online, und nur 3\% kaufen oft in Antiquariaten ${ }^{798}$.

\subsubsection{Autoren}

Autoren nutzen das Internet als neuen medialen Weg der direkten Vermarktung ihrer Titel ${ }^{799}$. Der Roman The book with no name (2006/2007) von dem Autoren Anonymous z. B. erschien zuerst im Selbstverlag und eroberte seine Leser über das Internet ${ }^{800}$. Fehlt der verlegerische Qualitätsfilter, wenn also jeder veröffentlichen kann, was er möchte, ist natürlich auch einer eher semiprofessionellen Literatur Tür und Tor geöffnet. Autoren nutzen das Internet nicht nur, um ihre Werke, die vielleicht keinen Verlag gefunden haben, zu veröffentlichen ${ }^{801}$, sondern auch schlechthin, um Kontakt zu ihren Lesern aufzubauen. Online veröffentlichen sie exklusive Texte, lassen ihre Werke von Lesern weiterschreiben, geben Privates preis:

Jahrzehntelang hat uns die Literaturwissenschaft eingebleut, dass der Autor tot ist, dass der Text für sich steht und der Leser gefälligst allein mit ihm klarkommen soll - ohne Handreichung des Schöpfers. Und nun das: Im Internet ist der Autor lebendiger denn je, diskutiert mit seinen Lesern, liefert Schlüssel zu seinem Werk, durchaus auch private. Ein Popstar. ${ }^{802}$

Überhaupt erhält die Person hinter dem Buch zunehmend ein Gesicht in der Öffentlichkeit und wird wichtig für den Leser. Lesereisen geraten zu eventhaften Autor-Tourneen, weniger zu Buchvorstellungen. Autoren werden zu Prominenten und umgekehrt werden immer mehr Prominente

\footnotetext{
797 Vgl. Wirtschaftszahlen des Börsenvereins des Deutschen Buchhandels, [http://www.boersenverein.de/de/Wirtschaftszahlen/158286], eingesehen am 11.09.2010.

798 Vgl. Haben Bücher eine Zukunft? (2007), S. 17.

799 Vgl. dazu Frank Patalong: „Wer braucht noch einen Verlag?““. In: Spiegel Online, 19.06.2011 [http://www.spiegel.de/netzwelt/netzpolitik/0,1518,766824,00.html], eingesehen am 20.06.2011.

800 Der Roman wurde 2006 zunächst online bei www.lulu.com veröffentlicht und ein Jahr darauf bei Michael O’Mara Books. In deutscher Sprache erschien der Roman als „Das Buch ohne Namen” erstmals 2009 bei Lübbe.

801 Vgl. dazu den Artikel über die E-Book-Bestseller der US-amerikanischen Jungautorin Amanda Hocking von Frank Patalong: „Verleg’ dich selbst - und mach’ Millionen!“. In: Spiegel Online, 03.03.2011 [http://www.spiegel.de/kultur/literatur/0,1518,748220,00.html], eingesehen am 03.05.2011. 
zu Autoren, wobei das Buch möglicherweise hauptsächlich als zusätzliches Vehikel für ihre Bekanntheit und als Einnahmequelle dient.

\subsubsection{Literaturkritik und Leseempfehlungen}

Die Literaturkritik spaltet sich zunehmend auf in eine seriöse, fachkundige Feuilletonkritik und subjektiv-emotionale Leseempfehlungen. Die Literatursendung Lesen! $!^{803}$, zwischen 2003 und 2008 vom ZDF ausgestrahlt und moderiert von der Schriftstellerin und Journalistin Elke Heidenreich, war beim Publikum beliebt und sorgte regelmäßig für hohe Abverkäufe der vorgestellten Titel. Von der seriösen Kritik jedoch wurde die Literatursendung nicht ernst genommen und mit durchaus pejorativer Konnotation als „Sendung für Frauen“" ${ }^{\text {804 }}$ bezeichnet, vermutlich in Hinblick auf ein überwiegend weibliches Lesepublikum von Belletristik. Heidenreichs überschwänglich-emotionale, beinahe durchweg positiven Urteile über die vorgestellten Bücher wurden weniger als Lese-, denn als reine Kaufempfehlungen verstanden - die Kritik werde hier durch den Buchtipp ersetzt ${ }^{805}$.

Neben der Fachkritik haben (Normal-)Leser dank des demokratischen, partizipatorischen Charakters des Internets die Möglichkeit, Leserrezensionen und ,Kunden-Reviews’ zu Büchern zu veröffentlichen. Innerhalb der Leser-Community kann ein Buch über Mund-zu-Mund-Propaganda bestens verbreitet werden. Im Zeitalter des Internets bieten Internetforen (wmm.lovelybooks.de, wmw.literaturcafe.de u. v. m.) oder Portale von Online-Buchhändlern, z. B. Amazon.de, Austauschmöglichkeiten an, in denen Bücher besprochen, bewertet und untereinander empfohlen werden. Über ein virtual bookshelf ${ }^{806}$ ist über manche Portale online einsehbar, was andere Buchliebhaber lesen, so dass sich jeder Leseanregungen geben lassen und mit anderen austauschen kann. Dies bestätigt, dass Leser keineswegs Einmediennutzer sind, sondern auch dem Internet gegenüber äußerst aufgeschlossen sind.

Meinungen zu Büchern werden wiederum kommentiert, was einen regen Austausch innerhalb der Community ermöglicht. An dieser Stelle unterscheiden sich moderne Buchbesprechungs- und -diskussionsräume nur wenig von Rezensionsorganen der deutschen (Spät-)Aufklärung wie der Allgemeinen Deutschen Bibliothek, in deren Ausgaben Lesern die Möglichkeit zur aktiven Partizipation an der literarischen, gesellschaftlichen oder auch theologischen Diskussion mittels Rezen-

\footnotetext{
803 Vgl. dazu den ausführlich belegten Wikipedia-Artikel „Lesen!“, [http://de.wikipedia.org/wiki/Lesen!], eingesehen am 03.05.2011.

804 Ebd.

805 Vgl. Gunther Nickel: „Krise der Literaturkritik. Historische Dimensionen eines aktuellen Themas“. In: Kaufen! statt Lesen! Literaturkeritik in der Krise? I. A. der Deutschen Literaturkonferenz hg. v. Gunther Nickel. Göttingen: Wallstein, 2006, S. 5-19, S. 15.

806 Vgl. Hermione Buckland-Hoby: „The rise of the virtual bookshelf”. In: The Guardian, 28.05.2008, [http:// www.guardian.co.uk/books/booksblog/2008/may/28/theriseofthevirtualbooksh], eingesehen am 09.05.2011.
} 
sionen, Repliken und Gegenrepliken offen stand, wobei die Redaktionen moderner Portale nicht wie die Journale moderierend in die Diskussion eingreifen ${ }^{807}$.

Obwohl sich die Gesellschaft mehr und mehr individualisiert, suchen Leser offensichtlich gerade bei der Empfehlung geeigneter Lektüre den Austausch mit peers. Persönliche Empfehlungen werden Hinweisen auf Bücher in Literaturkritik und Medien vorgezogen und ihnen gegenüber immer wichtiger. Die Studie Haben Bücher eine Zukunft? kommt zu der Aussage, dass sich beim Buchkauf 55\% der Befragten von Freunden, Bekannten und Kollegen beraten lassen, denn „,[s]elbst die Vielleser setzen weniger auf Bestsellerlisten, Buchrezensionen und Büchersendungen als auf persönliche Empfehlungen. “808 Hierzu zählt allerdings auch die Beratung durch Stammbuchhändler, wovon kleinere Buchhandlungen mit Stammkundschaft profitieren.

Die Studie Buchkäufer und Leser II bestätigt dies. Empfehlungen von Freunden, Bekannten, Kollegen haben für 76\% der Befragten einen hohen Stellenwert, nur noch übertroffen vom „Stöbern im Geschäft" und dem Klappentext (Mehrfachnennung war möglich). Während die Wertschätzung von Buchrezensionen in Zeitung, Zeitschrift, Radio und TV leicht rückläufig sei, nehme der Einfluss des Internets zu. 30\% der Befragten gaben an, dass Buchbesprechungen oder -empfehlungen im Internet einen hohen Stellenwert für sie haben - eine Steigerung von 7\% gegenüber 2005. Online-Besprechungen von peers für peers gleichen offensichtlich persönlichen Empfehlungen. Die Informationsquellen zu Büchern, die Verlage zur Verfügung stellen, wie Titelverzeichnisse und Homepages, liegen abgeschlagen auf dem letzten Platz der Informationsmöglichkeiten rund ums Buch und sind somit deutlich optimierungsfähig. ${ }^{809}$

\subsubsection{Lesepublikum und Genres}

Es wurde eine zeitlang angenommen, dass der Anklang bei einem breiten Publikum „ein Zeichen für Minderwertigkeit ${ }^{\star 810}$ von Literatur sei. Literatur kann jedoch über eine hohe Qualität verfügen und zugleich, z. B durch die Mischung mit Elementen der Populärkultur, ein großes und auch breites Publikum ansprechen. Umgekehrt können Titel für ein breites Publikum durchaus anspruchsvoll sein. Es gibt im Zuge dessen kaum noch eine Trennung zwischen elitärer Hoch- und Trivial- bzw. Massenkultur. Mehr und mehr Titel sind multiadressiert, u. a. im Zuge postmodernen Einflusses, und sprechen sowohl ein gebildetes als auch ein durchschnittliches Lesepublikum an. Kulturkritiker vermuten hier allerdings einen Verfall - Literatur könne nicht mehr bedeutsam für die Gesellschaft sein, wenn sie in kulturelle Niederungen absteige.

\footnotetext{
807 Vgl. Thomas Habel: Gelehrte Journale und Zeitungen der Aufklärung. Zur Entstehung, Entwicklung und Erschließung deutschsprachiger Rezensionszeitschriften des 18. Jahrbunderts. Bremen : Ed. Lumière, 2007, S. 283-295.

808 Vgl. Haben Bücher eine Zukunft? (2007), S. 3.

809 Vgl. zu diesem Abschnitt Buchkäufer und Leser II (2008), S. $142 \mathrm{f}$.

810 Eco (1986), S. 70.
} 
All-Age-Romane (vgl. Kap. IV.3.3.2.7) zielen auf unterschiedliche Lesergruppen, auch Altersgruppen ab. Auf der anderen Seite wächst die Titel- und Genrevielfalt. Genres differenzieren sich schneller aus, vermischen sich, um neue zu formen, wie die Bildung des Mystery-Genres zeigt (vgl. Kap. III.9.2.1; vgl. auch IV.2.2). Die neuen, sehr spezifizierten Genres sprechen kleinere, diversifizierte gesellschaftliche und auch Leser-Gruppen an. Hier zeigt sich der allgemeine Trend, dass der Leser nicht mehr für den Kauf bestimmter Titel umworben wird, vielmehr wird Literatur für den Geschmack des Lesers produziert. Der Expertenleser, der viel liest und mehreren Genres gegenüber offen ist, steht an dieser Stelle neben dem Vielleser von leichter Literatur oder dem Spezialisten, der ausschließlich in einem Genre liest, z. B. Fantasy-Leser ${ }^{811}$. Erst die Gesamtheit dessen, was in einer Gesellschaft gelesen wird, macht jedoch deren literarische Kultur aus.

\subsubsection{Wie gelesen wird - Umgang mit dem Text}

Die Annahmen aus der Zeit der Lesesucht gegenüber extensiver Lektüre und fiktionalem Lesestoff überhaupt sind heute größtenteils wahr geworden, u. a. stellen Romane die meist verlangte Buchgattung dar (vgl. Kap. III.11.2.1). Aufgrund des expandierenden Buchmarkts wird hauptsächlich Aktuelles und nach immer neuem Lesestoff verlangt. Die Zahl der verkauften Bücher sowie der Umsatz mit Büchern steigen stetig. Die ,neue' Lesesucht ist allerdings eher das Phänomen einer Gruppe von Lesern als ein Massenphänomen.

Vor der „Lesesucht’ des 18. Jahrhunderts galt ein „Lesen in“ (einigen ausgewählten Büchern), dann ein „Lesen von“ (vielen Büchern), das heute einem „Lesen über“ Platz gemacht hat. Um der Flut an neuen Büchern Herr zu werden, wird häufig nur eine kurze Orientierung über den Inhalt eines Werkes gesucht und Beurteilungen Dritter zum schnellen Überblick herangezogen (Rezensionen und ,Kunden-Reviews’, Wikipedia- oder Kindler-Artikel).

In der Informationsgesellschaft wird der Einzelne mit immer mehr Informationen in immer kürzerer Zeit versorgt, Information ist überall verfügbar. Das sinnliche Lesen hat der Stellenlektüre, dem An- und Querlesen Platz gemacht, der Leser liest häufig unverdaut und oberfläch$\operatorname{lich}^{812}$. Beim Bücherlesen nähert sich der Leser somit den Methoden der Konsumierung des Leitmediums Fernsehen $a^{813}$ :

\footnotetext{
Alle statistischen Untersuchungen zeigen uns, dass sich das Leseverhalten gewandelt hat - weg vom Durchleser, hin zum Überflieger, zum Häppchen-Leser, zum Bücher-Zapper. Immer mehr Menschen lesen so, wie sie fernsehen - sie zappen sich durch die Bücher wie durch die TV-Programme. Sie lesen mehrere Bücher parallel, blättern nach interessanten Stellen, legen sie kaum angelesen wieder weg. Wir haben es also immer öfter mit gehetzten, ungeduldigen und zerstreuten Gelegenheitslesern zu tun. ${ }^{814}$
}

\footnotetext{
811 Fesler (2007) spricht von einer ,ausgesprochen lesewütigen Fangemeinde“, S. 5, also genreorientierten Lesern. 812 Vgl. dazu Haben Bücher eine Zukunft? (2007), S. 20.

813 Vgl. dazu Stocker (1994), S. 85.

814 Sigrid Löffler: „Literaturen, Literaturkritik und Leser um 2000“. In: Evi Zemanek \& Susanne Krones (Hg.):

Literatur der Jahrtausendwende. Themen, Schreibverfabren und Buchmarkt um 2000. Bielefeld: transcript, 2008,

S. 435-446, hier S. 442; verkürzt auch in Löffler (2005), S. 13.
} 
Brecht stellte fest, dass Filmsehende anders lesen ${ }^{815}$, was heute genauso gilt: Durch den routinierten Umgang mit elektronischen Medien verändert sich das Lesen. Anspielungen, Zitate und Verweise in einem Text ähneln Hyperlinks in einem digitalen Text, was dazu führt, dass Texte häufig nicht mehr linear von Anfang bis Ende gelesen werden, sondern stellenweise oder mehrere Bücher parallel. Im partiellen und selektiven Lesen sieht Stocker aber keine Degeneration, vielmehr sei dies ein geübter, „souveräner Lesestil“‘816.

\subsubsection{Was gelesen wird - Das Beispiel All-Age-Literatur als Lesetrend}

Angesichts immer ambitionierterer Schreibweisen finden sich manche (Normal-)Leser auf dem Buchmarkt nicht mehr zurecht und überfordert. Immer mehr Leser greifen deshalb zu All-AgeLiteratur. Hier wird die Grenze zwischen Erwachsenen- und Jugendliteratur aufgeweicht, was aber kein primär postmodernes Phänomen darstellt. Auf unterschiedlichen Ebenen und je nach Erwartung an den Text empfindet der Leser Vergnügen an der Lektüre.

Bestes Beispiel hierfür ist die Harry-Potter-Reihe von J. K. Rowling, aber auch andere Titel des boomenden Jugendliteratur-Marktes, wie die Romane von Cornelia Funke oder Stephenie Meyer. Das generationenübergreifende Phänomen Harry Potter, originär an Kinder, in späteren Bänden an Jugendliche adressiert, wurde auch sehr viel von Erwachsenen gelesen, für die es eigene Ausgaben gab, mit altersgerechtem Umschlag und einer dem Erwachsenen-Segment entsprechenden Preisgestaltung. Besonders urbane, gebildete Internetintensivnutzer sind Harry-Potter-Leser. Generell hat die Reihe einen Trend zum Lesen ausgelöst: Nur jeder dritte erwachsene Harry-PotterLeser gibt an, weniger zu lesen als früher, von den Nichtlesern der Serie behauptet das hingegen fast jeder Zweite ${ }^{817}$.

Im All-Age-Bereich sind die üblichen Buchkategorien vor allem im vergangenen Jahrzehnt mehr und mehr verschwommen. Diese Titel zählen eigentlich genuin zur Jugendliteratur, sind also besonders geeignet für Leser ab 12 oder 14 Jahre, was man u. a. an ihren Verlagen, Warengruppen, Umschlaggestaltung und Vermarktung ablesen kann. Die Verkaufszahlen in diesem Segment sind allerdings so hoch, dass man nicht nur von jugendlichen Lesern ausgehen kann, sondern auch von erwachsenen. Die „Bestseller des Jahrzehnts“, die 2009 für den Spiegel durch das Fachmagazin Buchreport anhand von Abverkaufszahlen ermittelt wurden, bestätigen einen Trend zu dieser Art Literatur. Erhoben wurden die Daten ab Januar 2002. In den Top 20 der „Bestseller des Jahrzehnts“ findet man je drei Titel der Autorinnen Funke und Meyer und sogar sechs von 
Rowling, die auch die Top-3-Titel stellt ${ }^{818}$. Gemein ist diesen Titeln die originäre Adressierung an Jugendliche, das Genre Fantasy, eine spannende Handlung, ein leicht rezipierbarer Schreibstil sowie die Zugehörigkeit zu einer Buchreihe.

Erwachsene Leser greifen also verstärkt zu einer Literatur, die sich eigentlich an Jugendliche richtet, was nach einer möglichen Verkindlichung des erwachsenen Lesers fragen lässt ${ }^{819}$. All Age bedeutet immer die Ausrichtung zum einfachen, mitunter auch zu einem ,Unter-Niveau-Lesen'. Diese Art von Literatur vermittelt Übersichtlichkeit: Sie besitzt einen chronologischen Aufbau, eine klare Trennung in Gut und Böse, beschließt mit einem Happy End, so wie es charakteristisch für Märchen ist. Der Erfolg der All-Age-Romane bestätigt einen Trend zu einem Eskapismus in idealisierte Phantasiewelten, die besonders ein viellesendes, weibliches Publikum ansprechen. Man muss diesen Titel aber zugutehalten, dass sie innerhalb von Familien häufig eine Brückenfunktion einnehmen, denn über den gemeinsamen Lesestoff ist eine Verständigung über Generationen hinweg möglich. Andere Stimmen beklagen allerdings den Rückgang von dezidierter Kinderliteratur, die einer möglichst viele Altersgruppen ansprechenden Literatur weicht.

Für Verlage, Buchhandel und Autoren sind All-Age-Romane besonders interessant, da sie meist in Buchreihen erscheinen. Nach einem erfolgreichen Einführungsband sind diese Reihen dann Selbstläufer, so dass sich der herstellende und verbreitende Handel auf den Erfolg weiterer Bände, die Leser auf ein weiteres Lesevergnügen einstellen können.

\subsubsection{Intermedialität}

Bücher müssen konkurrenzfähig bleiben, daher wird eine Verschmelzung von Medientypen immer wichtiger, die Grenzen zwischen einzelnen Medien weichen auf. Das Buch wird zunehmend zum Sekundärmedium ${ }^{820}$, z. B. weil ein Vorabdruck in einer Zeitung die Leser neugierig gemacht hat oder sie quasi als Begleitmedium zum Film erscheinen. Obwohl es sich häufig um Verfilmungen literarischer Werke handelt, ist der Film eher in der öffentlichen Wahrnehmung präsent als das Buch. Literatur ist heute nicht mehr nur über das Buch sichtbar, sondern auch reflektiert in weiteren Medien, im Film, Hörbuch, sie wird diskutiert bei Fangruppen-Treffen. Literatur wird zum allumfassenden Event.

Schon seit Ende der 1990er und in zunehmendem Maße steht das Buch einem Konkurrenten aus einem originär anderen Medium gegenüber, nämlich dem Hörbuch. Der Umsatz mit Hörbüchern ist in den vergangen Jahren kontinuierlich gewachsen, 2009 betrug der Umsatzanteil am

\footnotetext{
818 Vgl. „Die Bestseller des Jahrzehnts“. In: Spiegel Online, Archiv, Der Spiegel 53 (2009), Online [http://www.spiegel.de/spiegel/print/d-68425711.html], eingesehen am 25.05.2011.

819 Vgl. Joachim Telgenbüscher: „Bisschen was für alle“. In: Spiegel Online, 29.12.2009

[http://www.spiegel.de/kultur/literatur/0,1518,668780,00.html], eingesehen am 20.04.2011.

820 Vgl. dazu Stocker (2007), S. 72.
} 
Buchverkauf 4,3\%. ${ }^{821}$ Das Hörbuch stellt somit eine ernstzunehmende Ergänzung und sicher auch Konkurrenz zum traditionellen Buch dar.

Das Buch als Medium scheint generell beinahe verzichtbar, denn „[i]n ihrer Eigenschaft als Graphemsequenzen sind literarische Werke nicht auf das Buch angewiesen, sondern können in einer Vielzahl von Speicher- und Transportmedien zu den Rezipienten gelangen. “822 Die Tätigkeit „lesen“ ist nicht nur auf Bücher und die darin abgedruckten Texte beschränkt, auch das Lesen eines Textes über andere Medien ist möglich. Inhalte sind virtuell am Bildschirm einsehbar, sie werden elektronisch auch z. B. über TV (Videotext) angeboten oder sind über den PC als Datei lesbar. Neu sind seit einigen Jahren elektronische Lesegeräte speziell für Texte wie E-Book-Reader und überhaupt elektronische ,Bücher'. ${ }^{823}$

Nicht nur die Vertriebswege für Bücher werden durch digitale Möglichkeiten modernisiert, sondern auch die Textformate: Das E-Book stellt ein neues Konkurrenzformat zum Buch dar, auch deshalb, weil der E-Book-Markt eine deutlich höhere Publikationsgeschwindigkeit hat als Buchverlage. Eine direkte Reaktion auf aktuelle Themen ist möglich. Aufgrund der Erweiterung digitaler Angebote im Buchbereich wurden große Veränderungen auf dem Buchmarkt prognostiziert, denn das elektronische Format E-Book ist zudem einzig über entsprechende OnlinePortale erhältlich und wirtschaftet am traditionellen Handel vorbei. Für den deutschen Buchmarkt wurde deshalb das E-Book-Portal libreka! (24 $^{24}$ eingerichtet, das E-Books zentral speichert, einseh- und durchsuchbar hält und zum Verkauf anbietet. Außerdem steht seit April 2011 der „Kindle-Shop“ über Amazon.de zur Verfügung, der Inhalte für den unternehmenseigenen EBook-Reader Kindle anbietet, und auch das Unternehmen Google plant den Verkauf von E-Books in Deutschland. Der E-Book-Markt ist keine Mitnahme- oder Stöbermarkt - dort wird gezielt gesucht, so dass namhafte Autoren oder solche, über die in den Medien berichtet wird, dort besondere Chancen haben. In der Ratgeberliteratur in Form von E-Books ist es außerdem der Fall, dass der Leser ganz unmittelbar einen entscheidenden Beitrag zum Text beisteuert: Es ist Praxis, dass neue Auflagen anhand von Leserfragen oder -kommentaren erweitert werden ${ }^{825}$.

821 Vgl. Wirtschaftszahlen Hörbuch des Börsenvereins des Deutschen Buchhandels, [http://www.boersenverein.de/de/portal/Hoerbuch/158293], eingesehen am 30.05.2011.

822 Jost Schneider (2004), S. 425.

823 Zu digitalen Herausforderungen für den Buchmarkt vgl. Joachim Güntner: „Der Buchmarkt im Strudel des Digitalen“. In: Zukunft des Buches. Aus Politik und Zeitgeschichte (APuZ) 42-43 (2009), 12.10.2009, Beilage der Wochenzeitung Das Parlament, S. 9-17. Online

[http://www.bpb.de/publikationen/GSYKBQ,0,0,Zukunft_des_Buches.html], eingesehen am 09.05.2011. 824 Vgl. [http://www.libreka.de]. 825 Vgl. dazu Patalong (19.06.2011). 
Bislang sind nennenswerte Umwälzungen in allen Bereichen jedoch ausgeblieben: Das Geschäft mit E-Books ist bislang ein eher marginales, ein Nischengeschäft ${ }^{826}$, besitzt aber das Potential, größere Bedeutung anzunehmen. 31\% der Befragten der Studie Buchkäufer und Leser II können mit dem Begriff „E-Book“ etwas anfangen, doch nur etwa ein Drittel davon findet das Format bisher sympathisch oder sehr sympathisch, hier besonders junge Leser. Aus der Sympathie folgt die Kaufwahrscheinlichkeit: 17\% der Befragten, die E-Books kennen, halten einen zukünftigen Kauf für wahrscheinlich oder sehr wahrscheinlich, doch nur $8 \%$ dieser Gruppe haben schon einmal ein E-Book gekauft. ${ }^{827}$

Es wurden bisher nicht nur ökonomische Umwälzungen auf dem Buchmarkt („,die Buchlese-

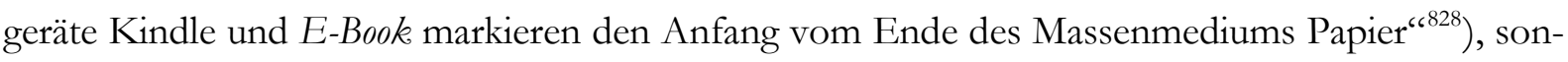
dern auch Veränderungen kognitiver Leseprozesse durch den Konsum digitaler Bücher für möglich gehalten. Es bleibt abzuwarten, ob sich diese Annahmen bestätigen. Das E-Book kann naturgemäß nicht wie das Buch auf eine lange Historie und Tradition zurückblicken, dem Leser fehlen Erfahrung, Vertrautheit und Gewohnheit im Umgang mit dem Medium. Die ,Geschlossenheit' des Buchs als Medium, das man von Deckel zu Deckel liest, fehlt, die Offenheit und Hypertextualität digitaler Texte sind allerdings auch ihre Stärke.

Das E-Book als körperloses ,Buch’ könnte beinahe einen Ersatz für das Buch aus Papier bieten und besticht durch bessere Durchsuchbarkeit und Platzersparnis: Auf elektronischen Lesegeräten, E-Book-Readern oder anderen tragbaren MultiMedia-Geräten (Smartphones, Tablets o. ä.), ist eine Vielzahl von Texten als Dateien bequem speicher- und ohne viel Gewicht transportierbar. So kann eine ganze Bibliothek auf einem Abspielgerät (wie Musikdateien auf einem mp3-Player) gespeichert werden. Ob Buchfreunde wirklich auf die haptischen und repräsentativen Qualitäten ihrer Bücher verzichten möchten, wird sich zeigen. Die Hersteller der Lesegeräte für digitale Texte wissen aber auch die Vorzüge des Buchs zu schätzen. Trotz des neuen Konzepts der Lesegeräte kopieren diese noch erkennbar die konventionellen Eigenschaften des Buchs, was Buchgröße und -format sowie das Leseformat wie das Umblättern von gegenüberliegenden Seiten anbelangt. Die Textdarstellung nähert sich mittels einer elektronischen Tinte dem Druckbild von Büchern immer mehr an, was ein angenehmeres Lesen am Bildschirm ermöglichen soll. In diesem Zusammenhang werden die Qualitäten des Buchs überhaupt wieder gelobt, wie seine haptischen Vorzüge, die einfache Handhabbarkeit, die Unabhängigkeit vom Stromnetz und anderer Hilfsmittel sowie die im Verhältnis zu elektronischen Lesegeräten deutlich geringeren Kosten. Generell nach Präferenz befragt, gaben neun von zehn Teilnehmern der Studie Buchkäufer und 
Leser II (91\%) an, einen Titel im Format Buch zu bevorzugen, 8\% bevorzugen ein Hörbuch und nur $1 \%$ ein $E-B o o k{ }^{829}$. Es wird sich in den nächsten Jahren zeigen, inwieweit das E-Book hierzulande an Publikum gewinnt und in welchem Maße es dem traditionellen Buch Konkurrenz machen wird. Die Geschäfts- und Vertriebsmodelle und besonders eine kundenfreundliche Bedienbarkeit sind allerdings noch verbesserungsfähig, z. B. kann dem Kunden kaum vermittelt werden, weshalb eine virtuelle Textdatei denselben Preis wie ein gebundenes Buch haben soll, wie es die Buchpreisbindung derzeit verlangt.

\subsection{Zukunft des Buchs}

Die Akteure des Literaturbetriebs sorgen sich heute um die Zukunft des Buchs. Das traditionelle und langlebige Medium und sein unveränderlicher, da gedruckter Inhalt stehen dem im raschen Wandel begriffenen digitalen Medium und seinem weltweit verfügbaren und austauschbaren Content gegenüber. Das Buch scheint bedroht von den neuen digitalen Medien, die das Buch zum einen als Leitmedium längst abgelöst haben und zum anderen nun dazu in der Lage sind, Aufgaben des Buchs zu übernehmen, nämlich Texte verfügbar zu machen. Insbesondere das neue Format E-Book. steht in Verdacht, das gedruckte Buch zu verdrängen und obsolet zu machen. Es wird befürchtet, dass sich das Buch - wie sich bereits bei anderen Printmedien wie der Zeitung abzeichnet ${ }^{830}$ - im Netz auflöse. Gerade angesichts der neuen medialen Kontexte, in die das Buch gesetzt wird, rückt es in der Öffentlichkeit und überhaupt im gesellschaftlichen Diskurs verstärkt in den Fokus, was sich auch in der fiktionalisierten Darstellung des Buchs in aktuellen Romanen niederschlägt.

\subsubsection{Die Zukunft des Buchs in den Korpustiteln}

Die Konkurrenzsituation des Buchs gegenüber den digitalen Medien ist nicht nur im fachspezifischen, sondern auch im gesellschaftlichen Diskurs virulent. Die „Wiederkehr des Buches“ in der Romanliteratur wird durch ein fiktionalisiertes Lob des Buchs und des Lesens ausgedrückt. In vielen Titeln des Korpus, die der aktuellen Romanliteratur zuzurechnen sind, wird das Buch in historischen Kontexten gezeigt, außerdem werden besonders wertvolle oder mit Wert aufgeladene Bücher vorgeführt, um die Auratisierung, ja Mythisierung des Buchs noch stärker zu betonen. Dasselbe trifft auch auf Bücher in dezidiert bibliophilen Umgebungen zu. Das Buch wird in der Fiktion überhöht in Zeiten und Kontexten vorgestellt, in denen es ausschließlich positiv besetzt ist und in denen die Konkurrenz für das Medium gering ist, es also in Zukunft nicht in Frage stehen wird. Die heutige Konkurrenz zum Buch durch andere Medien wird in der Fiktion ausgeblendet, wenn ein Bücherfreund im Zentrum steht, der nur für seine Bücher lebt. 
Nur in einigen wenigen Titeln des Korpus wird die derzeitige Medienkonkurrenz, in der sich das Buch befindet - gerade elektronische Medien werden von einem Großteil der Bevölkerung stärker genutzt als Bücher -, angesprochen und so eine mögliche Zukunft des Buchs explizit thematisiert. In Huizings Der Buchtrinker findet eine harsche Kritik an den neuen elektronischen Medien statt (vgl. Kap. III.8.2). Der Protagonist, ein büchernärrischer Student, seiner Zeit enthoben und sich mehr und mehr dem historischen Büchernarren Magister Tinius annähernd, sieht angesichts eines vermuteten Rückgangs des Lesens sogar den Weltuntergang gekommen. Die Furcht vor der Verdrängung des Buchs durch neue Medien und der skeptische Blick auf deren zunehmenden Einfluss wird exemplarisch am Verschwinden des büchernärrischen Protagonisten in seinem PC verdeutlicht: Wird auf diese Weise auch das Buch im Netz verschwinden? Pessimistisch und sehr explizit werden die neuen Medien für den Untergang der zivilisierten Welt verantwortlich gemacht, die wohl nur durch das Buch gegeben ist, die Zukunft des Buchs wird also eher negativ eingeschätzt.

Ruiz Zafón entwirft in Der Schatten der Windes eine plakative Parteinahme für das Buch im Spanien der 1930er und 1940er Jahre (vgl. Kap. III.8.2). Veraltet wirkt allerdings die überhebliche Kritik und Verteufelung von TV und Kino als neue Medien, die auf Vorurteile der Lesesuchtdebatte zurückgreifen, pathetisch dagegen die Verklärung des Buchs. Nur die Antagonisten betrachten die neuen Medien gespannt, denen sie ein großes, wenn auch die Bücher verdrängendes, Potential zutrauen.

Eine Leserstimme (,Kunden-Review') zu Mein Leben als Buch von Peter Jacobi befürchtet die zunehmende Ablösung von Büchern durch ein digitales Medienangebot (vgl. Kap. III.3.1.2.1). Für die fiktionale Ebene wird betont, dass die geschilderte Verwandlung in ein Buch ,in die Zeit“ passe. Es wird hier allerdings vernachlässigt, dass die digitalen Medien ergänzend wirken und letztlich eine Stärkung des Buchs sowie eine häufigere Fokussierung des Buchs als Motiv in Romanen hervorrufen. Der Verlag erwähnt die Sorge um das Buch im Medienkontext explizit im Klappentext. Vermutlich wird an dieser Stelle ein Konsens mit dem Leser erwartet, um ihn zum Kauf zu animieren. Es herrscht unbeirrte Sicherheit, das Buch werde bestehen - die ,Unsterblichkeit des Buchs' wird betont und deckt sich mit den meisten Prognosen zur Zukunft des Buchs.

\subsubsection{Prognosen zur Zukunft des Buchs}

Mit der Aussage, dass Bücher auch im Kontext neuer Medien „das wichtigste intellektuelle Informations- und Leitmedium bleiben“ ${ }^{\text {(831 }}$, hat sich Dietrich Ratzke 1982 leider geirrt. Man muss kein Medienwissenschaftler sein, um beurteilen zu können, dass Fernsehen und Internet in der breiten 
Öffentlichkeit heute eine einflussreichere Position einnehmen und als Informationskanäle und besonders als Mittel der Freizeitgestaltung eher verbreitet sind als das Bücherlesen. Die in den 1980ern revolutionären Neuerungen im Bereich Buch waren die moderne Buchherstellung am PC (DTP) sowie neue Vervielfältigungs- und Drucktechniken, die heute zum Standard gehören und noch deutlich erweitert wurden. Heute sieht sich das Buch in seiner Funktion der Vermittlung von Texten einer Konkurrenz durch digitale Medien gegenüber.

Regelrechte Kassandrarufe machen zunehmend auf einen Untergang der Buchkultur aufmerksam. Zeit-Autor Jürgen Neffe sieht ganz rational eine Ära zu Ende gehen: Für ihn ist eine „alte Entwicklungsstufe menschlicher Selbstvergewisserung abgeschlossen, der eine neue, andere folgt ${ }^{\star 832}$. Unter Umständen trifft dies sogar zu. Die Technologien der neuen Medien unterliegen ständig neuen Entwicklungen, die beinahe täglich perfektioniert werden, während das Buch lange kein ,Update' mehr erfahren hat, dieses aber nun in der Gestalt des E-Books vorliegt.

Andere Stimmen machen in einem Generalvorwurf „das Internet“ für einen vermuteten Niedergang der Buchs verantwortlich. Es ist jedoch problematisch, Internet und Buch zusammenhanglos im direkten Vergleich gegenüberzustellen, da das Internet viel mehr Aufgaben und diese anders erfüllt als das Buch. Das Internet dient z. B. über das WWw der raschen Information oder dem social networking, dem Verbinden von Einzelpersonen über eine virtuelle Schnittstelle. Bücher vermitteln Inhalte und werden heute hauptsächlich zur Entspannung und Unterhaltung gelesen (vgl. Kap. IV.3.2.2.). Wie bereits gezeigt wurde, dienen an dieser Stelle digitale Möglichkeiten und auch das Internet als Ergänzung zum Buch. Das Buch wird, zumindest in nächster Zukunft, neben digitalen Angeboten Bestand haben, und wenn es zunächst, angesichts einer verbreiteten Neugierde auf neue technische Möglichkeiten, aus Tradition und Gewöhnung ist.

Ruppelt gibt literarische Darstellungen von Buchmenschen und Büchern wieder ${ }^{833}$ und stellt fest, dass diese Darstellungen in der 2. Hälfte des 20. Jahrhunderts besonders häufig waren, dazu gehört auch Marie Luise Kaschnitz' bekannte Kurzgeschichte Das letrte Buch (1970). Es ist anzunehmen, dass die Sorge um die Zukunft des Buchs der Tatsache geschuldet war, dass die Konkurrenz zu anderen Medien, z. B. Radio und TV, bereits bestand, und geahnt wurde, dass noch weitere Medienentwicklungen folgen würden. Die „Chancen der herkömmlichen Printmedien in der Konkurrenz mit elektronischer Informationstechnik“"834 werden laut Ruppelt in diesen Fiktionalisierungen eher negativ eingeschätzt.

832 Vgl. u. a. Krüger (2009), S. 5.

833 Vgl. Ruppelt (1997), Kap. VI „Vom letzten Buchautor und von der Zukunft des Buches in der utopischen Literatur", S. 119-134.

834 Ebd., S. 119. 
Außerhalb der Fiktion werden jedoch kaum Zukunftsszenarien entworfen, in denen das Buch endgültig durch elektronische Medien abgelöst wird. Häufiger, und höchstwahrscheinlich zutreffender sind Aussagen, in denen das Buch speziellere Aufgaben erhält und von den dominierenden elektronischen Medien ergänzt wird. Die medienpluralistische Gesellschaft sorgt für eine gleichzeitige Nutzung beider Medienkomplexe. Der Verleger Klaus G. Saur nahm 1996 an, dass in naher Zukunft „Telefonbücher, Adreßbücher, zahlreiche Nachschlagewerke und sicherlich auch eine Reihe von speziellen Fachzeitschriften und Fachpublikationen “835 hauptsächlich elektronisch angeboten und genutzt werden, was sich heute in der Tat zum Trend ausbildet. Der Unternehmensberater Thomas Laukamm ist der Meinung, Papier, also Druckwerke, müsse erst gar nicht „künstlich verteidigt werden“836. Schon vor 15 Jahren - nachdem „Multimedia“ das Wort des Jahres 1995 gewesen war - gab Laukamm ein korrektes Bild der heute meist verbreiteten Art von Mediennutzung: „,Alles, was gelesen wird, bleibt auf Papier, alles, was nachgeschlagen wird, kommt in elektronischem Format' [...] Der richtige Ansatz lautet ,Sowohl als auch'. Zukünftig

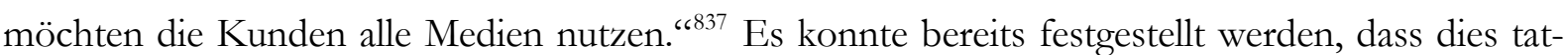
sächlich der Fall ist und gerade eifrige Leser allen Medienbereichen gegenüber aufgeschlossen sind.

Heute lässt uns die virtuelle digitale Vernetzung in viele, auch vergangene Kulturen eintauchen. Neben Digitalisierungsinitiativen wie der Europeana ${ }^{838}$, die im großen Stil das europäische Kulturerbe digital sichtbar machen und erhalten möchte, plant Google Books, das Digitalisierungsprojekt des Suchmaschinenbetreibers, auf Understatement verzichtend das Wissen der Welt zu organisieren. ${ }^{839}$ Für das Großvorhaben wurden Millionen von Büchern - ob legaler oder unerlaubter Weise ist noch nicht zweifelsfrei geklärt - aus Bibliotheken digitalisiert und online verfügbar gemacht. Gerade vergriffene Werke, die den Großteil der Bibliotheksbestände ausmachen, profitieren von der weltweiten digitalen Sichtbarmachung im Netz, doch offensichtlich möchte Google diese und andere Werke auch kommerziell erschließen, wogegen von unterschiedlicher Seite rechtliche Schritte eingeleitet wurden.

Die Studie Haben Bücher eine Zukunft? befindet „Bücher haben eine Zukunft ${ }^{\text {“840 }}$ und führt dies auf die Kauf- und Lesefreudigkeit gerade weiblicher Leser zurück. Generell wird zwar viel gelesen (90\% Leser innerhalb einer repräsentativen Gruppe, vgl. Kap. IV.3.2.2), doch muss man sich in Zukunft fragen, ob die Inhalte über das Medium Buch rezipiert werden oder ob sich Texte in

835 Ruppelt (1997), S. 133.

836 Thomas Laukamm: „Glänzende Zukunft für Papier“. In: Börsenblatt für den Deutschen Buchhandel 35 (1996), 30.04.1996, S. 40-44, hier S. 41. - Der Autor stellt in diesem Artikel elf Thesen zur Zukunft des Buchs zusammen, die auf seiner Studie „Multimedia \& Strategies“ aus demselben Jahr gründen.

837 Ebd., S. 41.

838 Vgl. [http://www.europeana.eu/portal/].

839 Vgl. ausführlich Jeanette Hofmann: „Zukunft der digitalen Bibliothek“. In: Zukunft des Buches (2009), S. 25-32.

840 Vgl. Haben Bücher eine Zukunft? (2007), S. 3. 
digitaler Form, als E-Book auf einem speziellen Lesegerät oder online verfügbar, durchsetzen werden. Ein Trend zeigt, dass der Umsatz mit Büchern leicht ansteigt, es wird sich zeigen, ob neben dem Buch auch andere Formate mehr Käufer finden. Es darf angenommen werden, dass besonders medienkompetente und -affine Vielleser auch neuen Formaten gegenüber aufgeschlossen sind. So wie sich literarische Genres immer mehr aufspalten und eigene, differenzierte Lesergruppen finden, so haben unterschiedliche Leser unterschiedliche Bedürfnisse an den Umgang mit dem Text, so dass Buch und digitales Angebot wenig gegenseitige Hindernisse darstellen. Praktiken und Gewohnheiten des Lesens werden zumindest für die nächste Zukunft nebeneinander bestehen. Für das Lesen längerer Texte, wie Romane, werden Monographien geeigneter bleiben, die detaillierte Hintergrundinformationen liefern. Für kürzere und besonders wissenschaftliche Texte eignet sich die Online-Bereitstellung (schnellere Veröffentlichung und Zugänglichmachung) und -Einsichtnahme (Durchsuchbarkeit, einfacheres Auffinden markanter Textstellen).

Das Buch wird bleiben, und das nicht nur aufgrund des schon jetzt abgenutzten Arguments, die Schriftkultur werde sich aufgrund ihrer einfacheren und schnelleren Verfügbarkeit und ihrer Langlebigkeit durchsetzen. In Zeiten der schnellen Veränderung und der Unübersichtlichkeit in allen Bereichen des Lebens wird Beständigkeit, auch die des gedruckten, bleibenden Wortes, wieder sehr hoch bewertet, auch wenn digitale Möglichkeiten der Langzeitarchivierung von Texten ständige Verbesserungen erfahren und so mit dem Gedruckten mithalten können. Die Tradition und historische Kontinuität des Buchs spielen ebenso eine Rolle wie Gewöhnung und Vertrautheit. Stocker reflektiert das vermeintliche „Ende der Literatur“ und stellt fest, „Medien mit so großer historischer Kontinuität werden nicht einfach von neuen verdrängt. “841 Vielmehr gibt es zunehmend und in Zukunft wohl noch verstärkt Differenzierungen und Funktionsverschiebungen von Literatur und Buch.

Wenn in Zukunft der Content mehr zählt als das Medium Buch, ist eine neue Definition von Literatur nötig, in deren Zuge auch Geschriebenes in anderen Medien wie von Lesern verfasste Texte und Blogs dazu gehören sollten. Schreiben beschränkt sich nicht mehr auf Bücher. Außerdem hat das Schreiben nicht abgenommen, im Gegenteil nimmt es immer mehr zu: „[W]enn es eines Tages keine Literatur mehr gibt, dann nicht, weil keiner mehr schreibt, sondern weil alle schreiben. “ ${ }^{842}$ Stocker bezieht sich auf Vilém Flusser, der 1990 angesichts neuer Medientechnologien einen „Untergang des Schreibens“ ${ }^{\text {(843 }}$ postulierte. Flusser prognostizierte, dass die Schrift durch digitale Codes abgelöst werde. Allerdings ist doch eher anzunehmen, dass das Schreiben durch seinen dialogischen Charakter überleben wird, genau wie das Lesen. Es gibt heute (noch) 
keine andere adäquate Möglichkeit, Sprache zu konservieren, Informationen festzuhalten, aufzubewahren und an dritte zu übermitteln, die über vernetzte Medien sinnvoll funktionieren würde. Eine Übermittlung von Sprachaufnahmen über auditive Medien wäre eine Möglichkeit. Doch dies ist (noch) zu aufwändig und immer an ein elektronisches Trägermedium gebunden, während Schrift bequem auf Papier oder über ein elektronisches Medium geschrieben und ausgedruckt werden kann und einfach und ohne weitere Utensilien zu handhaben ist.

Ratzkes Ausblicke auf die für ihn zukünftige Bedeutung neuer Medien im Bereich der Textherstellung und -verarbeitung sind beinahe schon prophetisch zu nennen. Er vermutete 1982 ein beträchtliches Wachstum in der Entwicklung neuer Techniken und von deren Nutzungsmöglichkeiten. Die traditionellen Medien werden nicht überkommen, sondern selbst durch die Entwicklung neuer Medien perfektioniert und durch diese ergänzt werden. Anfang der 1980er sah er

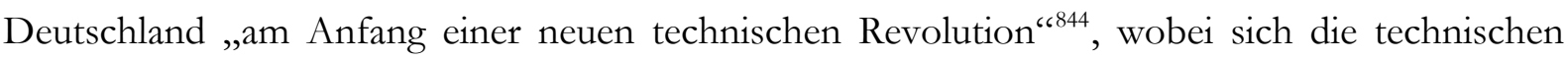
Möglichkeiten heute deutlich gegenüber den für Ratzke neuen Entwicklungstrends der technischen Kommunikations- und Medientechniken weiter entwickelt haben:

\begin{abstract}
Zudem wurden alteingeführte, bewährte Kommunikationssysteme durch die neuen Techniken nicht etwa abgelöst. Modifiziert und technisch verfeinert wachsen diesen elektronisch modernisierten, bewährten Kommunikations- und Informationsverfahren (zum Beispiel den gedruckten Medien) neue Aufgaben zu, die sie mit gesteigertem Zuverlässigkeitsgrad erfüllen können. Durch diese Vervollkommnung der konventionellen Medien wächst im Zusammenspiel mit den Neuen Medien der Anwendernutzen der Medien allgemein erheblich. ${ }^{845}$
\end{abstract}

Heute werden Buch und E-Book, traditioneller Buchdruck und elektronisches Publizieren tatsächlich als komplementäre Medien und Verfahren angesehen. Die technischen Möglichkeiten, die sich aus Digitalisierung und elektronischer Vernetzung von PCs und somit ihren Anwendern ergeben, bleiben zumindest in nächster Zukunft Ergänzungen zum Buch. Open Access Publishing beschränkt sich ohnehin auf wissenschaftliche Zeitschriftenartikel, denn das Konzept legitimiert sich aus dem Anspruch, aus öffentlicher Hand finanzierte Forschung in ihren Ergebnissen öffentlich kostenfrei sichtbar und zugänglich zu machen.

Gemeinsam mit dem Marktforschungsunternehmen Sinus Sociovision hat der Börsenverein des Deutschen Buchhandels in der Studie Buchmarkt 2020. Szenarien für die Zukunft (2008) drei mögliche Zukunftsszenarien für den Buchmarkt erarbeitet und untersucht, wie bereits heutige Faktoren und Entwicklungen wie Marktstrategien und Verbrauchertrends plausibel auf die Herausbildung dieser Szenarien hinführen. Die Szenarien basieren dabei auf gesellschaftlichen Kulturen, die durch die Sinus-Milieus definiert werden, und verweisen auf neue Geschäftsumfelder für die Branche, wobei die Buchbranche in den drei Szenarien völlig unterschiedliche Richtungen ein- 
schlägt. Allerdings stellen sie keine Prognosen für Buch und Buchmarkt dar, sondern geben mögliche Zukunftsgestaltungen wieder. Neben den Szenarien „Free is Fair" und „Shared Destiny" würde die „Metamorphosis“ die tiefgreifendsten Veränderungen für die „Welt der Bücher“ nach sich ziehen. Die „Metamorphosis“ ist gekennzeichnet durch einen Paradigmenwechsel nicht nur in der Gesellschaft, sondern auch für die „Welt der Bücher“ und deckt sich in beinahe allen Aussagen mit den in dieser Arbeit skizzierten Thesen.

In diesem Szenario ${ }^{846}$ sind die Menschen generell medienaktiv und gut informiert und nutzen verschiedene Medien und Informationskanäle selbstverständlich nebeneinander, maßgeblich ist ein „sowohl als auch“. Die Trennlinien zwischen Medien verschwimmen, und derselbe Content ist über unterschiedliche Medien, als Buch, E-Book, Hörbuch, Verfilmung, erhältlich - oder simpler auf den Punkt gebracht: „Der Content zählt, nicht das Medium.“ “847 Das Buch hat in der Medienlandschaft nach wie vor seinen Platz: Es steht für Sinnlichkeit, Beständigkeit und bietet „etwas Besonderes“. Das Interessenspektrum des Lesepublikums hat sich diversifiziert, für einzelne, spezifizierte Gruppen stehen besonders online Austauschforen zur Verfügung. Letztlich gilt es, eine Neudefinition von Buch und Buchmarkt zu finden und für die Mitglieder der Branche mit anderen Sektoren, wie Multimedia, zusammenzuarbeiten.

Trends und Tendenzen des Szenarios „Metamorphosis“ zeigen sich bereits heute ganz deutlich, und es ist anzunehmen, dass sie mit der Zeit wichtiger werden. Die Buchbranche muss sich also dringend mit diesen Phänomenen auseinandersetzen. Zwar wird das „digitale Medium“ als „Herausforderung“ für Kultur und die gesamte Branche betrachtet, weshalb verlangt wird, das neue Medium - sprich digitale Möglichkeiten, Texte verfügbar zu machen - an die Standards des Buchund Verlagswesens zu binden ${ }^{848}$. Doch muss die Buchbranche auch innovative Chancen und das kreative Potential der digitalen Vernetzung wahr- und annehmen. Sie wird belohnt werden durch neue Impulse der Markterschließung und der Interaktion mit Buchkäufern und Lesern.

Das Buch wird in naher Zukunft nicht verschwinden, vielmehr findet es in den elektronischen Medien und digitalen Bibliotheken eine wertvolle Ergänzung. Der Transfer des Buchs in neue Kontexte medialer, gesellschaftlicher und kultureller Art führt dazu, dass es in der Öffentlichkeit heute stärker präsent ist. Daraus resultiert auch eine stärkere Reflexion über das Buch in der Literatur. Das Buch wird als Motiv in seinem ureigenen Medium wieder mehr in den Fokus genommen, und so ist in aktueller Romanliteratur gehäuft das Motiv „Buch im Buch’ zu finden,

\footnotetext{
846 Vgl. Buchmarkt 2020. Sženarien für die Zukunft. I. A. des Börsenverein des Deutschen Buchhandels durchgeführt durch Sinus Sociovision Heidelberg, Januar 2008. Online [http://www.boersenverein.de/de/158446/ Studien/158287], eingesehen am 17.06.2008, S. 32ff und 44f, ab sofort nur noch für Mitglieder abrufbar.

847 Ebd., S. 32.

848 Vgl. Gottfried Honnefelder \& Claudia Paul: „Medienwechsel - Verlegen in digitalen Zeiten. Essay“.

In: Zukunft des Buches (2009), S. 6-8, hier S. 8.
} 
denn ein verstärktes Auftreten des Buch-Motivs in der jeweils aktuellen Literatur indiziert Veränderungen in der Medienkultur ${ }^{849}$. Die kulturellen Umwälzungen betreffen die gesamte literarische Kommunikation, so dass deren Akteure schon mit unterschiedlichen Maßnahmen auf die neuen Bedingungen reagiert haben. Die Leser der Buch-Romane, ohnehin „Vielleser“, fühlen sich in ihrer eigenen Buchaffinität und Wertschätzung des Buchs bestätigt und zur Gruppe der „Lesenden“ zugehörig. Diese Teilhabe an der Buchkultur und der „Welt der Bücher“ stärkt durch ein zunehmendes Lesen letztlich die Branche und das Buch. 


\section{Schlussbetrachtung}

In dieser Arbeit wurde untersucht, wie das Motiv „Buch im Buch' auf fiktionaler Ebene eingesetzt und kombiniert wird und aus welchen Gründen das Buch-Motiv so häufig wie beobachtet in der aktuellen internationalen Romanliteratur Verwendung findet. Es liegt nahe, den Medienwandel und die als Konkurrenz empfundene weit verbreitete Nutzung elektronischer und digitaler Medien und Methoden dafür verantwortlich zu machen. Der Medienwandel trägt zwar durch die Diskursivierung der Mediensituation dazu bei, das Buch als Motiv in aktueller Literatur zu verankern, doch ist dies nicht der einzige Grund für sein Vorkommen. Es konnte gezeigt werden, dass auch andere Gründe das Auftreten des Buch-Motivs bedingen wie literarische Traditionen, die Einübung immer elaborierterer Schreibweisen, die mit der Selbstbezüglichkeit von Schreiben und Lesen einhergehen, sowie ein damit verbundenes postmodernes Erbe. Zu welchen Anteilen ein Autor auf Traditionen zurückgreift, einem postmodernen Trend folgt oder seine Reaktion auf den Medienwandel fiktional aufbereitet, lässt sich jedoch nicht eindeutig feststellen.

Der Leser wird durch das Lesen über das ,Buch im Buch’ und die kulturkritischen Positionen, über die er liest, zu Wertungen von Literatur und des Buchmarkts sowie zu einer Reflexion des Kulturbetriebes und der Mediensituation angeregt. Die interne Funktion des Buch-Motivs ist also eine hoch spannungsvolle mit einem rätselhaften, geheimnisvollen Buch im Mittelpunkt, während die reale Situation des Buchs eine viel weniger gespannte ist. In der vorliegenden Arbeit konnte deutlich gemacht werden, dass die ,neuen Medien', besonders das Internet, in der Nutzung nicht die große Konkurrenz zu Büchern darstellen, die ihnen häufig unterstellt und von Buchmarkt und Literaturbetrieb sogar befürchtet wird. Es steht weniger der Buchleser dem Nicht-Buchleser gegenüber, als es vielmehr um den Umgang und die Nutzung aller Arten von Medien geht. Der Anteil der lesenden Bevölkerung ist, wie die herangezogenen Studien zum Buchkäufer- und Leserverhalten bestätigen, in den letzten Jahren nicht wesentlich größer oder kleiner geworden. Leser, und besonders Vielleser, zählen zu einer Gruppe kompetenter Mehrmediennutzer, die neben dem Buch auch andere Medien, vor allem das Internet, extensiv nutzen, da sie breite Zugänge zu Kultur und Gesellschaft gewährleisten. Wer viel liest, nutzt auch häufig das Internet und andere elektronische Medien. Den Gegenpol zu den viellesenden Mehrmediennutzern bildet eine Gruppe von Ein-Medien-Nutzern meist elektronischer Medien.

Das Buch als literarisches Motiv kann nicht allein vorkommen. Eine typologische Motivuntersuchung des ,Buchs im Buch’ auf der Grundlage ausgewählter internationaler Romane der letzten Jahre ergab Konnotationen des Buch-Motivs, die deutlich stereotyp verwendet werden, wie eine Historisierung des Buchs, eine Nostalgie, die der Leser mit ihm in Verbindung bringt, und eine überhöhende Wertschätzung als Mystifizierung des Buchs. Alles in allem wird in den 
Buch-Romanen also ein äußerst anachronistisches und sehr charismatisches Bild des „guten, alten“ Buchs gezeichnet. Außerdem wurden Motive ermittelt, die häufig mit dem ,Buch im Buch’ zu Motivkomplexen kombiniert werden, wie die Suche nach einem Buch, das Verhältnis von Leben, Lesen und Buch, die Gefahr, die von Büchern ausgehen kann etc. Alle diese Motivkombinationen weisen auf die Rätselhaftigkeit und ein Geheimnis des Buchs hin. Das Buch-Motiv kann in vielfältigen Kontexten eingesetzt werden, und doch wird nur ein kleiner Teil dieser Möglichkeiten immer wieder genutzt. Es ergibt sich zudem, dass das Buch-Motiv grundsätzlich in einer bestimmten Gruppe von Genres eingesetzt wird, die die aus seiner Anachronisierung resultierende Verrätselung unterstreichen, nämlich in Mystery-, Kriminal- und Detektivromanen.

Die Romane, die das Motiv ,Buch im Buch’ beinhalten, stärken das Buch, zumindest ideell, gegenüber den ,neuen Medien', indem sie es mit einer Aura des Besonderen und Geheimnisvollen umgeben. Trotz allem bedeutet dies nicht, dass Bücher weiterhin die Rolle in der Gesellschaft einnehmen, die ihnen vor dem Siegeszug der elektronischen und digitalen Medien sicher war. Vielmehr ist ihr Einfluss heute auf eine Gruppe von Lesern in der Gesellschaft beschränkt. Auf der Grundlage von Studien zum Buchkäufer- und Leseverhalten konnte eine Einschätzung gegeben werden, wie es heute um Buch und Lesen bestellt ist. Zwar liest der Großteil der Bevölkerung (90\% Leser innerhalb einer repräsentativen Gruppe), doch konzentrieren sich die besonders buchaffinen Vielleser in einer kleinen Gruppe. Die Studien zeigen, dass sich der Anteil der Wenigleser in den letzten Jahren erhöht hat, wobei diese noch weniger lesen als bisher, während die Gruppe der Vielleser kleiner geworden ist, jedoch noch mehr liest als zuvor.

Die Vielleser scheinen das ideale Publikum für die Buch-Romane zu sein, denn sie sind dem Buch nicht nur ausgesprochen zugetan, sondern auch gebildet und informiert. Diese Eigenschaften befähigen sie dazu, die Implikationen und Konnotationen zu erkennen und nachzuvollziehen, die das Buch mit sich bringt. Dies können Anspielungen auf erzähltheoretische Aspekte, intertextuelle Bezüge oder tiefergehende kulturelle Bemerkungen sein, die sogar dazu dienen können, das zugrunde liegende Genre des Buch-Romans zu modifizieren.

Nicht nur die fiktionale Literatur hat sich den neuen Bedingungen des Medienwandels angepasst. Auch die Akteure des Literaturbetriebes haben auf die Anforderungen unserer Zeit reagiert und begonnen, sich den Bedürfnissen einer ausdifferenzierten literarischen Kommunikationssituation anzupassen. Die originären Aufgaben einzelner Instanzen der Buchbranche können heute auch von anderen Akteuren übernommen werden. Bedingend wirken hier die elektronischen Medien und neue Methoden, die Autoren befähigen, ihre Werke selbst zu veröffentlichen, es Verlagen ermöglichen, neue Wege des Marketings zu beschreiten oder völlig neue Herstellungs- und Publikationsbedingungen schaffen. 
Insgesamt stellen elektronische und digitale Medien weniger eine Konkurrenz als eine Ergänzung zum Buch als add-on media dar. Es kann nicht die Rede davon sein, dass die ,neuen Medien’ zu einer Abkehr vom Buch führen, so dass sich in ihren Einschätzungen zu Zukunftsperspektiven für das Buch alle Instanzen darüber einig sind, dass das Buch, zumindest in naher Zukunft, nicht obsolet werde. Literatur ist in ausdifferenzierter, vielfältiger Form an unterschiedlichen Orten sichtbar, bestimmt aber als Medium nicht mehr Kultur oder Gesellschaft, denn nicht jeder ist für die Buchkultur empfänglich, nicht jeder sucht oder nimmt seinen Raum in der Literatur wahr, obwohl Lesen heute nach wie vor in gesellschaftlichen Leitmilieus überaus positiv konnotiert ist. Die heute zu beobachtende Mystifizierung des Buchs zielt allerdings nur auf die Gruppe kompetenter Leser, die die Buch-Bücher in vollem Umfang nachvollziehen und mit Genuss rezipieren können. So wird das Lesen in dieser Gruppe noch mehr verankert und das Buch gestärkt.

Neue Medien gründen auf den alten, sie stehen immer in Zusammenhang mit ihren Vorgängern und in ihrer kulturellen Tradition. So könnten auch Inhalte im WwW ohne die Kulturpraktik Lesen nicht rezipiert werden. Das Buch erfährt dank des Diskurses um mögliche Brüche mit Medientraditionen eine neue Hinwendung und Aufwertung, auch in der Literatur selbst. Nicht nur das Lesen wird seinen Platz behalten, auch Bücher werden bleiben, denn „die Antworten auf fast alle Fragen von heute stehen in alten Büchern. “850 



\section{Literatur}

\section{Buch-Bücher seit den 1990er Jahren - untersuchtes Korpus}

\subsection{Primärliteratur}

(Bei Nennung mehrerer deutschsprachiger Ausgaben wurde die benutzte unterstrichen.)

Collins, Michael: Der Bestseller-Mord. (Amer. OA: Death of a Writer, 2006): Dt. EA: München: btb, 2008 (btb 73718).

Domínguez, Carlos María: Das Papierhaus (Argent. OA: La casa de papel, 2004). Dt. EA: Frankfurt/Main: Eichborn, 2004. Tb: Diana, 2006 (diana 35116).

Fforde, Jasper: Der Fall Jane Eyre. (Engl. OA: The Eyre Affair, 2004). Dt. EA: München: dtv premium, 2004 (dtv 21014).

Huizing, Klaas: Der Buchtrinker. Dt. OA: München: Knaus, 1994. Tb: btb, 1996 (btb 72014).

Jacobi, Peter: Mein Leben als Buch. Dt. OA: Hamburg: Edition Nautilus, 1999.

King, Ross: Das Labyrinth der Welt. (Engl. OA: Ex-Libris, 1998). Dt. EA: München: Knaus, 1999. Tb: btb, 2001 (btb 72707).

Mercier, Pascal: Nacbtrng nach Lissabon. Dt. OA: München: Hanser, 2004. Tb: btb, 2006 (btb 73436).

Moers, Walter: Die Stadt der träumenden Bücher. Dt. OA: München: Piper, 2004. Tb: Piper, 2006 (serie piper 4688).

Pérez-Reverte, Arturo: Der Club Dumas. (Span. OA: El club Dumas, 1993). Dt. EA: Stuttgart: Weitbrecht, 1995. Tb: btb, 1997 (btb 72193).

Ruiz Zafón, Carlos: Der Schatten des Windes. (Span. OA: La sombra del viento, 2001). Dt. EA: Frankfurt/Main: Suhrkamp, 2003. Tb: Suhrkamp, 2005.

Schmitt, Éric-Emmanuel: Die Schule der Egoisten. (Frz. OA: La secte des Égoïstes, 1994). Dt. EA: Zürich: Ammann, 2004. Tb: Fischer, 2006 (fischer tb 16960).

Schweiggert, Alfons: Das Buch. Dt. OA: München: Ehrenwirth, 1989.

Stamm, Peter: Agnes. Dt. OA Zürich: Arche, 1998. Tb: btb, 2004 (btb 72550).

Wharton, Thomas: Salamander. (Kanad. OA.: Salamander, 2001). Dt. EA: München: dtv premium, 2003 (dtv 24350).

Živković, Zoran: Das letrte Buch. (Serbische OA: Poslednja knjiga, 2007). Dt. EA: München: dtv, 2008 (dtv 21103).

\subsection{Sekundärliteratur}

\subsubsection{Michael Collins: Der Bestseller-Mord}

Lesezeichen S. D.: „Langweilig, langatmig und vorhersehbar“, Leserrezension zu Michael Collins: Der Bestseller-Mord, Amazon.de, 04.10.2008, [http://www.amazon.de/Bestseller-Mord-MichaelCollins/dp/3442737184/ref=sr_1_1?ie=UTF8\&qid=1297245357\&sr=8-1], eingesehen am 09.02.2011.

roseF, o. T.: Leserrezension zu Michael Collins: Der Bestseller-Mord, LovelyBooks.de, 17.04.2008, [http://www.lovelybooks.de/autor/Michael-Collins/Der-Bestseller-Mord-145357320-w/], eingesehen am 09.02.2011. 


\subsubsection{Jasper Fforde: Der Fall Jane Eyre}

Div. Leserrezensionen zu Jasper Fforde: Der Fall Jane Eyre bei Amazon.de, [http://www.amazon.de/Fall-Jane-Eyre-Roman/dp/3423210141/ref=sr_1_1?ie=UTF8\&s=books\&qid $=1289898310 \& s r=8-1]$, eingesehen am 16.11.2010.

Gohlis, Tobias: „Thursday im Leseland“. In: Die Zeit, 05.02.2004, S. 48. Online [http://www.zeit.de/2004/07/KA-Krimi07], eingesehen am 10.11.2010.

Löhndorf, Marion: „Matrix, redigiert. Wenn Literatur herrschte: Jasper Fforde tritt durch das Prosa-Portal“. In: Frankfurter Allgemeine Zeitung, 07.06.2004, S. 38.

Online [http://www.faz.net/s/Rub79A33397BE834406A5D2BFA87FD13913/Doc E4C802D867F 91452CBBAA0C885CAB79C5 ATpl Ecommon Scontent.html], eingesehen am 10.11.2010.

Müller, Peter E.: „Rettet Jane Eyre! Krimiabenteuer à la Monty Python: In Jasper Ffordes Paralleluniversum sind Romanfiguren ihres Lebens nicht mehr sicher". In: Die Welt-Literarische Welt, 19.06.2004, S. 6. Online [http://www.welt.de/printwelt/article321422/Rettet_Jane_Eyre.html], eingesehen am 10.11.2010.

reini68.blogspot.com: „Ein Buch mit Kultpotential“, Leserrezension zu Jasper Fforde: Der Fall Jane Eyre, Amazon.de, 16.02.2004, [http://www.amazon.de/Fall-Jane-Eyre-Roman/dp/ 3423210141/ref=sr_1_1?ie=UTF8\&s=books\&qid=1289898310\&sr=8-1], eingesehen am 16.11.2010.

Spieß, Martin: „Die Realität sieht anders aus. Jasper Ffordes Liebeserklärung an die Literatur“ (zu Band 4: Es ist was faul). In: Literaturkeritik.de, Nr. 9, September 2007, [http://www.literatur kritik.de/public/rezension.php?rez_id=11118\&ausgabe=200709], eingesehen am 11.11.2010.

Webseite des dtv-Verlags zu Jasper Ffordes Romanen, [http://www.jasperfforde.de/index.html], eingesehen am 10.11.2010.

Webseiten von Jasper Fforde zu seinen Romanen, [http://www.jasperfforde.com] und [http://thursdaynext.com], eingesehen am 10.11.2010.

Wikipedia. Die freie Enzyklopädie: Art. „Thursday-Next-Reihe“, [http://de.wikipedia.org/wiki/Thursday-Next-Reihe], eingesehen am 16.10.2010.

\subsubsection{Klaas Huizing: Der Buchtrinker}

\subsubsection{Fiktionale und berichtende Literatur zu Magister Tinius}

Arnold, Ernst: Der Pfarrer und Magister Tinius. Leipzig: Reclam, 1936 (Berühmte Kriminalfälle. Nach dem Neuen Pitaval und anderen Quellen. Hg. v. Max Mendheim. Bd. 10).

Fließ, E.: „Das Ende des Magisters Tinius“. In: Die Gartenlaube. Illustrirtes Familienblatt H. 21 (1893), S. 346ff.

Frewer, Andreas \& Stefanie Stockhorst: „Bibliomanie als Krankheit und Kulturphänomen. Pathographische Fallstudien zur Rezeption von Magister Johann Georg Tinius (1768-1846)“. In: KulturPoetik. Zeitschrift f. kulturgeschichtliche Literaturwissenschaft 3 (2003), S. $246-262$.

Gurk, Paul: Magister Tinius. Ein Drama des Gewissens. Bremen: Bremer Schlüssel-Verlag, 1946.

Schmidt, Arno: Das steinerne Herw. Historischer Roman aus dem Jahre 1954. [zuerst 1956] Frankfurt/Main: Fischer, 1991.

Schmitz, Rainer: Art. „Tinius, Johann Georg“. In: Ders.: Was geschah mit Schillers Scbädel? Alles, was Sie über Literatur nicht wissen. Frankfurt/Main: Eichborn, 2006, S. 1442f.

Schulte, Eduard: „Ein Verbrecher aus Bücherwut“. In: Die Gartenlaube. Illustrirtes Familienblatt H. 5 (1893), S. $76 f f$ u. H. 6 (1893), S. 88-92. 


\subsubsection{Sekundärliteratur zum Roman}

Karger, Ulrich: Rezension zu Der Buchtrinker. Büchernachlese - Rezensionen-Archiv, ohne Datum, [http://home.arcor.de/karger/buechernachlese-archiv/uk_huizing_klaas_buchtrinker.html], eingesehen am 29.11.2010.

\subsubsection{Peter Jacobi: Mein Leben als Buch}

o. V.: „Gigantischer Lesespaß!“, Leserrezension zu Peter Jacobi: Mein Leben als Buch, Amazon.de, 10.04.2000, [http://www.amazon.de/Mein-Leben-Buch-Peter-Jacobi/dp/3894013443/ ref=sr_1_1?ie=UTF8\&s=books\&qid=1280413901\&sr=8-1], eingesehen am 12.07.2010.

\subsubsection{Ross King: Das Labyrinth der Welt}

Krützfeldt, Lutz: „Der Bücherwurm als Held. Ross Kings Roman Das Labyrinth der Welt‘. In: Neue Zürcher Zeitung, 28.10.1999, S. 35.

marielan: „Gefährliche Suche nach einem gefährlichen Buch“, Leserrezension zu Ross King: Das Labyrinth der Welt, Amazon.de, 06.08.2007, [http://www.amazon.de/productreviews $/ 3442727073 /$ ref $=$ cm_cr_dp_synop?ie $=U T F 8 \&$ showViewpoints $=0 \&$ sortBy=bySubmissionDateDes cending\#RRDWO7XLW6RTC], eingesehen am 11.07.2010.

\subsubsection{Pascal Mercier: Nachtzug nach Lissabon}

Div. Leserrezensionen zu Pascal Mercier: Nachtzug nach Lissabon bei Amazon.de [http://www.amazon.de/product-reviews/325060061X/ref=cm_cr_pr_link_prev_1?ie=UTF8\&showViewpoints $=0 \&$ sortBy $=$ bySubmissionDateDescending], eingesehen am 14.07.2010.

\subsubsection{Walter Moers: Die Stadt der träumenden Bücher}

Div. Leserrezensionen zu Walter Moers: Die Stadt der träumenden Bücher bei Amazon.de [http://www.amazon.de/tr\%C3\%A4umenden-B\%C3\%BCcher-Zamonien-HildegunstMythenmetz/dp/3492045499/ref=sr_1_1?ie=UTF8\&s=books\&qid=1288273727\&sr=8-1], eingesehen am 28.10.2010.

Domsch, Sebastian: „Träumende Bücher“, tazmag, Wochenendmagazin der taz, 16./17.10.2004, S. VI. Online [http://www.taz.de/1/archiv/archiv/?dig=2004/10/16/a0301], eingesehen am 28.10.2010.

Fesler, Mario: Die Zamonien-Romane von Walter Moers als zeitgenössische Vertreter der Gattung Fantasy. Magisterarbeit. München: Grin Verlag, 2007.

Kreitling, Holger: „,Wanderer, kommst du nach Buchhaim... dann nimm dich bloß in Acht vor Haifischmaden. Walter Moers schreibt ein Loblied auf die Literatur: Die Stadt der träumenden Bücher". In: Die Welt-Literarische Welt, 25.09.2004, S. 5.

Online [http://www.welt.de/print-welt/article342502/Wanderer_kommst_du_nach_Buchhaim.html], eingesehen am 28.10.2010.

Nüchtern, Klaus: „Mein Zielpublikum bin ich““. Interview mit Walter Moers. In: Falter 17 (2003). Online [http://www.falter.at/print/F2003_17_2.php], eingesehen am 28.10.2010.

Platthaus, Andreas: „Zum Dichter geboren, zum Leser bestellt. Ein sensibler Lindwurm: Walter Moers verzaubert mit seinem neuen Roman aus Zamonien“. In: Frankfurter Allgemeine Zeitung, 11.09.2004, S. 44. Online [http://www.faz.net/s/Rub79A33397BE834406A5D 2BFA87FD13913/Doc $\sim$ E264B06ACC92A49C89A60123304649396 ATpl Ecommon Scontent.html], eingesehen am 28.10.2010.

Siemes, Christof: „Blaubärs Reise in die Nacht. Ein Gespräch mit dem Zeichner Walter Moers, der einen Roman zu den fantastischen Bildern des Illustrators Gustave Doré (1832-1883) 
geschrieben hat“". In: Die Zeit, 06.09.2001, S. 46.

Online [http://www.zeit.de/2001/37/Blaubaers_Reise_in_die_Nacht], eingesehen am 28.11.2010.

Wikipedia. Die freie Enzyklopädie: Art. „Die Stadt der träumenden Bücher“, [http://de.wikipedia. org/wiki/Die_Stadt_der_Tr\%C3\%A4umenden_B\%C3\%BCcher], eingesehen am 19.05.2010.

-: Art. „Zamonien“, [http://de.wikipedia.org/wiki/Zamonien], eingesehen am 10.11.2010.

Zamonien-Fanseite „Nachtschule“, [http://www.nachtschule.de/nachtschule.html].

\subsubsection{Arturo Pérez-Reverte: Der Club Dumas}

kaminski27: „Intelligente Geschichte“, Leserrezension zu Arturo Pérez-Reverte: Der Club Dumas, Amaz̧on.de, 08.07 2007, [http://www.amazon.de/product-reviews/3442721938/ref=cm_cr_dp_ all_summary?ie=UTF8\&showViewpoints $=1 \&$ sortBy $=$ bySubmissionDateDescending], eingesehen am 09.02.2011.

Waldkirch, Nina: Der Trend zum Mystery-Genre in neuen Romanen und Filmadaptionen. Dan Brown, Arturo Pérez-Reverte und Wolfgang Hoblbein. Marburg: Tectum, 2007.

Walsh, Anne L.: Arturo Pérez-Reverte. Narrative tricks and narrative strategies. Woodbridge etc.: Tamesis, 2007.

Wikipedia. The Free Encyclopedia: Art. „The Club Dumas“, [http://en.wikipedia.org/wiki/The_Club_Dumas], eingesehen am 13.01.2011.

\subsubsection{Carlos Ruiz Zafón: Der Schatten des Windes}

Lovenberg, Felicitas von: „Labyrinth ohne Ausgang. Durch den Wind: Carlos Ruiz Zafóns Roman buhlt um Leserliebe“. In: Frankfurter Allgemeine Zeitung, 10.07.2003, S. 32. Online [http://www.faz.net/s/Rub1DA1FB848C1E44858CB87A0FE6AD1B68/Doc E02F6A269 F7984A87A90FE6584ACB5745 ATpl Ecommon Scontent.html], eingesehen am 07.09.2011.

\subsubsection{0 Éric-Emmanuel Schmitt: Die Schule der Egoisten}

Altenburg, Matthias: „Schmitts Galanteriewaren“. In: Die Zeit, 14.10.2004, S. 53.

Online [http://www.zeit.de/2004/43/Schmitts_Galanteriewaren], eingesehen am 13.11.2010.

Obuch, Hans-Heinrich: Rezension zu Die Schule der Egoisten, RadioBremen.de [http://www.radiobremen.de/magazin/kultur/literatur/buchtipps/schule_der_egoisten.html], eingesehen am 21.07.2008, inzwischen nicht mehr abrufbar.

\subsubsection{Zoran Živković: Das letzte Buch}

Theo24: „Mehr erwartet“, Leserrezension zu Zoran Živković: Das letəte Buch, Amazon.de, 25.01.2009, [http://www.amazon.de/product-reviews/3423211032/ref=cm_cr_dp_synop? ie $=$ UTF8\&showViewpoints=0\&sortBy=bySubmissionDateDescending\#R1R8LPIB8O0YX4], eingesehen am 09.02.2011.

\section{Buch im Buch, Buch und Bibliothek, Buch und Leser}

\subsection{Primärliteratur}

Borges, Jorge Luis: „Die Bibliothek von Babel“. In: Ders.: Die Bibliothek von Babel. Errä̈blungen. Stuttgart: Reclam, 1974 (rub 9497), S. 47-57.

Bradbury, Ray: Fabrenheit 451 [zuerst 1953]. Hg. v. Norbert Köhn. Stuttgart: Reclam, 1991 (rub 9270). 
Cervantes Saavedra, Miguel de: Der sinnreiche Junker Don Quijote von der Mancha. Aus d. Span. v. Ludwig Braunfels. 5. A. Düsseldorf: Artemis \& Winkler, 2008.

Eco, Umberto: Der Name der Rose. München: Hanser, 1982.

Novalis: „Heinrich von Ofterdingen. 1. Teil: Die Erwartung“. In: Werke, Tagebücher und Briefe.

Hg. v. Richard Samuel. Bd. 1: Das dichterische Werk, Tagebücher und Briefe. München \& Wien: Hanser, 1978.

\subsection{Sekundärliteratur}

Basbanes, Nicholas A.: A Gentle Madness. Bibliophiles, Bibliomanes, and the Eternal Passion for Books. New York: Henry Holt \& Co., 1995.

Bogeng, Gustav Adolf Erich: Die großen Bibliophilen. Geschichte der Büchersammler und ibrer Sammlungen. 3 Bd. Bd. 1: Die Geschichte \& Bd. 3: Die Anmerkungen. Leipzig: E.A. Seemann, 1922.

Dahms, Andrea Elisabeth: Erlesene Welten. Der fiktive Leser in der modernen Literatur. Karl Philipp Moritz, Gottfried Keller, Peter Handke. Frankfurt/Main etc.: Peter Lang, 2005.

Filstrup, Jane Merrill: „The Shattered Calm. Libraries in Detective Fiction”. In: Wilson Library Bulletin 1978, Vol. 53, Issue 4, S. 320-27; Issue 5, S. 392-98.

Goetsch, Paul: „Leserfiguren in der Erzählkunst“. In: Germanisch-Romanische Monatsschrift NF 33 (1983), S. 199-215.

-: „Von Bücherwürmern und Leseratten. Der Motivkomplex Lesen und Essen“. In: Literaturvissenschaftliches Jabrbuch 37 (1996), S. 381-406.

Hiller, Helmut \& Stephan Füssel: Wörterbuch des Buchs. 7., grundl. überarb. A. Frankfurt/Main: Klostermann, 2006.

Hölter, Achim: „Zum Motiv der Bibliothek in der Literatur“. In: Arcadia. Zeitschrift für Vergleichende Literaturwissenschaft 28 (1993), S. 65-72.

Japp, Uwe: „Das Buch im Buch. Eine Figur des literarischen Hermetismus“. In: Neue Rundschau 86 (1975), S. 651-670.

Košenina, Alexander: Der gelehrte Narr. Gelehrtensatire seit der Aufklärung. Göttingen: Wallstein, 2003.

Löffler, Sigrid: „Entspanne dich. Sammle dich. Nimm und lies!“ In: Literaturen. Das Journal für Bücher und Themen 10 (2005), S. 8-17.

Nelles, Jürgen: Bücher über Bücher. Das Medium Buch in Romanen des 18. und 19. Jabrhundert. Würzburg: Königshausen \& Neumann, 2002.

Rautenberg, Ursula: Reclams Sachlexikon des Buches. Stuttgart: Reclam, 2003.

Rieger, Dietmar: Imaginäre Bibliotheken. Bücherwelten in der Literatur. München: Fink, 2002.

Ruppelt, Georg: Buchmenschen in Büchern. Wiesbaden: Harrassowitz, 1997.

Sauder, Gerhard: „Geschichte[n] von Lesern und Büchern in Büchern [Sammelrez.]“. In: KulturPoetik. Zeitschrift für kulturgeschichtliche Literaturwissenschaft Bd. 4, H. 2 (2004), S. 255-266.

Schütz, Hans J.: „Seine Begierde, zu lesen, war unersättlich“. Sechsteilige Reihe im: Börsenblatt für den deutschen Buchhandel, 12 (1993) 12.2.1993, S. 14-23; 13 (1993) 16.2.1993, S. 18-23; 14 (1993) 19.2.1993, S. 30-34; 15 (1993) 23.3.1993, S. 24-28; 16 (1993) 26.2.1993, S. 22-26; 17 (1993) 2.3.1993, S. 16-20.

Siebeck, Anne: Das Buch im Buch. Ein Motiv der phantastischen Literatur. Marburg: Tectum, 2009. 
Stocker, Günther: Ein rebellisches Fossil. Die fiktionale Literatur im Zeitalter der modernen Kommunikationstechnologien. Aachen: Alano, 1994

-: Schrift, Wissen und Gedächtnis. Das Motiv der Bibliothek als Spiegel des Medienwandels im 20. Jabrbundert. Würzburg: Königshausen \& Neumann, 1997.

-: Vom Bücherlesen. Zur Darstellung des Lesens in der deutschsprachigen Literatur seit 1945. Heidelberg: Universitätsverlag Winter, 2007.

Winter, Ulrich: Der Roman im Zeichen seiner selbst. Typologie, Analyse und bistorische Studien zum Diskurs literarischer Selbstrepräsentation im spanischen Roman des 15. bis 20. Jabrbunderts. Tübingen: Narr, 1998.

Wuthenow, Ralph-Rainer: Im Buch die Bücher oder Der Held als Leser. Frankfurt/Main: Europäische Verlagsanstalt, 1980.

-: „Lesende Figuren: Die Bücher im Buch“. In: Neue Rundschau 2 (1989), S. 152-162.

\section{$3 \quad$ Allgemeines zum geistesgeschichtlichen Hintergrund}

Adair, Gilbert: Und dann gab's keinen mehr. Evadne Mounts dritter Fall. C.H. Beck: München, 2008.

Bauer, Manuel: „„Postmoderne? Was für ein Quatsch! Was für eine Farce!' Gilbert Adairs Roman Und dann gab's keinen mehr befremdet den Leser mit einem vergnüglichen Verwirrspiel“. In: Literaturkritik.de, Nr. 5, Mai 2009, [http://www.literaturkritik.de/public/rezension.php?rez_id=12961], eingesehen am 12.04.2011.

Benjamin, Walter: „Einbahnstraße, Nr. 13“. In: Gesammelte Scbriften. Hg. v. R. Tiedemann \& H. Schweppenhäuser. Bd. 4, Teil 1. Hg. v. T. Rexroth. Frankfurt/Main: Suhrkamp, 1972, S. 83-148.

Blumenberg, Hans: Die Lesbarkeit der Welt. Frankfurt/Main: Suhrkamp, 1981.

Brentano, Clemens: Sämtliche Werke und Briefe. Bd. 16. Prosa 1: Godwi oder Das steinerne Bild der Mutter. Ein verwilderter Roman von Maria. Hg. v. Werner Bellmann. Historisch-Kritische Ausgabe veranst. v. Freien Dt. Hochstift. Hg. v. J. Behrens et al. Stuttgart etc.: Kohlhammer, 1978.

Conan Doyle, Arthur: Werkausgabe in neun Einzelbänden. Nach den Erstausgaben neu und getreu übersetzt v. Gisbert Haefs. Erzählungen Bd. 1: Die Abenteuer des Sherlock Holmes. Zürich: Haffmans, 1984. Darin:

„Ein Skandal in Böhmen“, S. 7-36 und „Das gesprenkelte Band“, S. 203-235.

Goethe, Johann Wolfgang v.: Rezension zu Eleutherie Holberg (d. i. Karoline Paulus): Wilhelm Dumont. In: Jenaische Allgemeine Literaturzeitung, 16.07.1806, S. 240-243.

Hoffmeister, Gerhart: „Der romantische Roman. 1. Theorie“. In: Helmut Schanze (Hg.): Romantik-Handbuch. 2., durchges. u. akt. A. Stuttgart: Kröner, 2003, S. 208-212.

Kesting, Marianne: „Aspekte des absoluten Buches bei Novalis und Mallarmé“. In: Euphorion 68 (1974), S. 420-436.

Kremer, Detlef: Romantische Metamorphosen. E.T.A. Hoffmanns Eræäblungen. Stuttgart \& Weimar: Metzler, 1993.

Meldini, Piero: Die Schutz̧heilige des Taumels. Berlin: Berlin Verlag, 1999.

Pennac, Daniel: Wie ein Roman. Köln: Kiepenheuer \& Witsch, 1994. 
Perthes, Friedrich Christoph: „Über den Beruf und Stand des deutschen Buchhändlers“. In: Ders.: Der deutsche Buchbandel als Bedingung des Daseins einer deutschen Literatur. Schriften. Hg. v. Gerd Schulz. Stuttgart: Reclam, 1967 (rub 9000), S. 33-47.

Schnabel, Johann Gottfried: Die Insel Felsenburg, Frankfurt/Main: Insel, 1988 (it 953).

Schreiber, Jens: Das Symptom des Schreibens. Roman und absolutes Buch in der Frühromantike (Novalis/Schlegel). Frankfurt/Main \& Bern: Lang, 1983.

Schlegel, Friedrich: Kritische Friedrich-Schlegel-Ausgabe. Hg. v. Ernst Behler. Bd. 2: Charakteristiken und Kritiken I (1796-1801). Hg. u. eingel. v. Hans Eichner. Paderborn: Schöningh, 1967. Darin: „Athenäums-Fragmente“, S. 165-255.

„Ideen“, S. 265-272.

„Brief über den Roman“, S. 329-339.

Tausendundeine Nacbt. Nach der ältesten arabischen Handschrift in der Ausgabe von Muhsin Mahdi erstmals ins Deutsche übertragen v. Claudia Ott. 4. A. München: C.H. Beck, 2004.

Weischedel, Wilhelm: Art. „Fichte“. In: Ders.: Die philosophische Hintertreppe. München: dtv, 2001 (dtv 8563), S. 188-199.

\section{Theoretisches}

Barthes, Roland: „Der Tod des Autors“ [zuerst 1967]. In: Texte zur Theorie der Autorschaft. Hg. u. komm. v. Fotis Jannidis et al. Stuttgart: Reclam, 2000, S. 185-193 (rub 18058). Fotis Jannidis: Einleitung zum Text, S. 181-184.

Gymnich, Marion \& Ansgar Nünning: „Funktionsgeschichtliche Ansätze: Terminologische Grundlagen und Funktionsbestimmungen von Literatur“. In: Dies. (Hg.): Funktionen von Literatur. Theoretische Grundlagen und Modellinterpretationen. Trier: WVT Wissenschaftlicher Verlag Trier, 2005, S. 3-27.

Heydebrand, Renate v. \& Winko, Simone: Einfübrung in die Wertung von Literatur. Paderborn: Schöningh, 1996 (UTB 1953).

Iser, Wolfgang: Der implizite Leser. Kommunikationsformen des Romans von Bunyan bis Beckett. München: Fink, 1972 (UTB 163).

Link, Jürgen: Literaturwissenschaftliche Grundbegriffe. Eine programmatische Einführung auf strukturalistischer Basis. 3., unveränd. A. München: Wilhelm Fink, 1985 (utb 305).

-: „Literaturanalyse als Interdiskursanalyse. Am Beispiel des Ursprungs literarischer Symbolik in der Kollektivsymbolik“. In: Jürgen Fohrmann \& Harro Müller (Hg.): Diskurstheorien und Literaturwissenschaft. Frankfurt/Main: Suhrkamp, 1988 (st 2091), S. 284-307.

Martinez, Matias \& Michael Scheffel: Einführung in die Erzähltheorie. 2., durchges. A. München: C.H. Beck, 2000.

Metzler Lexikon literarischer Symbole. Hg. v. Günter Butzer u. Joachim Jacob. Stuttgart \& Weimar: Metzler, 2008.

Metzler Lexikon Literatur- und Kulturtheorie. Hg. v. Ansgar Nünning. 3., akt. u. erw. A. Stuttgart \& Weimar: Metzler, 2004. Darin:

Ansgar Nünning: Art. „Funktion“, S. 202ff.

Stephan Jaeger: Art. „Hermetik“, S. 257.

Werner Wolf: Art. „Metafiktion“, S. $447 \mathrm{f}$.

Beate Müller: Art. „Metalepse“, S. 449.

Christoph Reinfandt: Art. „Selbstreferenz“, S. 601. 
Metəler Literatur-Lexikon. Begriffe und Definitionen. Hg. v. Günther und Irmgard Schweikle.

2., überarb. A. Stuttgart: Metzler, 1990.

Nusser, Peter: Der Kriminalroman. 3., akt. u. erw. A. Stuttgart: Metzler, 2003 (sammlung metzler 191).

Stanzel, Franz Karl: Theorie des Eræählens. Göttingen: Vandenhoeck \& Ruprecht, 1979.

Wilpert, Gero von: Sachwörterbuch der Literatur. 8., verb. u. erw. A. Stuttgart: Kröner, 2001. Darin: Art. „Queste“, S. 656.

\section{$5 \quad$ Zu Motiv und Thema}

Daemmrich, Horst S. \& Ingrid Daemmrich: Wiederholte Spiegelungen. Themen und Motive in der Literatur. Bern: Francke, 1978.

-: Themen und Motive in der Literatur. Ein Handbuch. 2., überarb. u. erw. A. Tübingen \& Basel: Francke, 1995.

Frenzel, Elisabeth: Stoffe der Weltliteratur. Ein Lexikon dichtungsgeschichtlicher Längsschnitte.

9., überarb. u. erw. A. Stuttgart: Kröner, 1998 [zuerst 1962].

-: Stoff- und Motivgeschichte. 2., verb. A. Berlin: Erich Schmidt, 1974 [zuerst 1966].

-: Motive der Weltliteratur. 5. A. Stuttgart: Kröner, 1999 [zuerst 1976].

Reallexikon der deutschen Literaturwissenschaft. 3., neubearb. A. Berlin \& New York: de Gruyter.

Bd. 2 H-O. Hg. v. Harald Fricke, 2000. Darin: Rudolf Drux: Art. „Motiv“, S. 638-641.

Bd. 3 P-Z. Hg. v. Jan-Dirk Müller, 2003. Darin: Armin Schulz: Art. „Thema“, S. 634f.

Scarinzi, Alfonsina: Thematics - qu einer undisziplinierten Dis₹iplin. Aachen: Shaker, 2009.

Sollors, Werner: „Thematics today“. In: Max Louwerse \& Willie van Peer (Hg.): Thematics. Interdisciplinary Studies. Amsterdam \& Philadelphia: John Benjamins Publishing Company, 2002, S. 217-235.

Wolpers, Theodor: „Motif und Thema as Structural Content Units and ,Concrete Universals”“. In: Werner Sollers (Hg.): The Return of Thematic Criticism. Cambridge etc.: Harvard Univ. Press, 1993, S. 80-91.

- (Hg.): Gelebte Literatur in der Literatur: Studien zu Erscheinungsformen und Geschichte eines literarischen Motivs: Bericht über Kolloquien der Kommission für literaturwissenschaftliche Motiv-und Themenforschung 1983-1985. Abhandlungen der Akademie der Wissenschaften in Göttingen, Phil.-Hist. Klasse, III, 152. Göttingen: Vandenhoeck \& Ruprecht, 1986.

- (Hg.): Ergebnisse und Perspektiven der literaturwissenschaftlichen Motiv-und Themenforschung. Bericht über Kolloquien der Kommission für literaturwissenschaftlichen Motiv-und Themenforschung 1998-2000. Göttingen: Vandenhoeck \& Ruprecht, 2002.

\section{Zur Postmoderne}

Eco, Umberto: Nachschrift zum ,Namen der Rose’. München: dtv, 1986 (dtv 10552).

Huyssen, Andreas \& Klaus R. Scherpe: Postmoderne. Zeichen eines kulturellen Wandels. Reinbek: Rowohlt, 1986 (rowohlts enzyklopädie 427). Darin:

Andreas Huyssen: „Postmoderne - eine amerikanische Internationale?“, S. 13-44. Teresa de Lauretis: „Das Rätsel der Lösung - Umberto Ecos Der Name der Rose als postmoderner Roman“, S. 251-269. 
Metzler Lexikon Literatur- und Kulturtheorie. Hg. v. Ansgar Nünning. 3., akt. u. erw. A. Stuttgart \& Weimar: Metzler, 2004. Darin:

Ruth Mayer: Art. „Postmoderne, Postmodernismus“, S. 543f.

Möckel, Magret: Erläuterungen zu Peter Stamm: Agnes. Hollfeld: Bange, 2001 (Königs Erläuterungen und Materialien 405).

Nicol, Bran: The Cambridge Introduction to Postmodern Fiction. Cambridge: Cambridge University Press, 2009.

Reallexikon der deutschen Literaturwissenschaft. 3., neubearb. A. Berlin \& New York: de Gruyter.

Bd. 3 P-Z. Hg. v. Jan-Dirk Müller, 2003. Darin:

Hans Ulrich Gumbrecht: Art. „Postmoderne“, S. 136-140.

Wilpert, Gero von: Sachwörterbuch der Literatur. 8., verb. u. erw. A. Stuttgart: Kröner, 2001. Darin: Art. „Postmoderne, Postmodernismus“, S. 627f.

Zima, Peter V.: Moderne - Postmoderne. Gesellschaft, Pbilosophie, Literatur. 2. A. Tübingen \& Basel: 2001.

\section{$7 \quad$ Buch und Medien}

\subsection{Buch- und Mediengeschichte}

Darnton, Robert: Literaten im Untergrund. Lesen, Schreiben und Publizieren im vorrevolutionären Frankreich. München: Hanser, 1985.

-: „Leser reagieren auf Rousseau: Die Verfertigung der romantischen Empfindsamkeit“. In: Ders.: Das große Katzenmassaker. Streifzüge durch die französische Kultur vor der Revolution. München: Hanser, 1989, S. 245-285.

Erning, Günter: Das Lesen und die Lesewnt. Beiträge zu Fragen der Lesergeschichte, dargestellt am Beispiel der schwäbischen Provinz: Bad Heilbrunn: Klinkhardt, 1974.

Faulstich, Werner: Mediengeschichte von den Anfängen bis 1700. Göttingen: Vandenhoeck \& Ruprecht, 2006 (utb 2739).

-: Mediengeschichte von 1700 bis ins 3. Jahrtausend, Göttingen: Vandenhoeck \& Ruprecht, 2006 (utb 2740).

Ganz, Peter (Hg.): Das Buch als magisches und Repräsentationsobjekt. Wiesbaden: Harrassowitz, 1992. Darin: Michael Harbsmeier: „Buch, Magie und koloniale Situation. Zur Anthropologie von Buch und Schrift", S. 3-24.

Goldfriedrich, Johann: Geschichte des deutschen Buchbandels vom Beginn der klassischen Litteraturperiode bis zum Beginn der Fremdherrschaft (1740-1804). Leipzig: Verlag des Börsenvereins der Dt. Buchhändler, 1909.

Göpfert, Herbert (Hg.): Buch und Leser. Vorträge des ersten Jabrestreffens des Wolfenbütteler Arbeitskreises für Geschichte des Buchwesens, 13.-14. Mai 1976. Hamburg: Hauswedell, 1977. Darin:

Bernhard Fabian: „Der Gelehrte als Leser“, S. 48-88.

Dominik von König: „Lesesucht und Lesewut“, S. 89-124.

Habel, Thomas: Gelehrte Journale und Zeitungen der Aufklärung. Zur Entstehung, Entwicklung und Erschließung deutschsprachiger Rezensionszeitschriften des 18. Jahrbunderts. Bremen: Ed. Lumière, 2007.

Jannidis, Fotis: „Digitale Editionen“. In: Literatur im Medienwechsel. Mitteilungen des Deutschen Germanistenverbandes, H. 3 (2008), S. 317-332.

Schneider, Jost: Sorialgeschichte des Lesens. Zur historischen Entwicklung und sozialen Differenzierung der literarischen Kommunikation in Deutschland. Berlin \& New York: de Gruyter, 2004. 
Schön, Erich: Der Verlust der Sinnlichkeit oder Die Verwandlungen des Lesers. Mentalitätswandel um 1800. Stuttgart: Klett-Cotta, 1987.

Simons, Olaf: Marteaus Europa oder Der Roman, bevor er Literatur wurde. Eine Untersuchung des deutschen und englischen Buchangebots der Jahre 1710 bis 1720. Editions Rodopi: Amsterdam \& Atlanta, 2001.

Wittmann, Reinhard: Geschichte des deutschen Buchbandels. München: Beck, 1999.

\subsection{Buch und Literatur heute}

Laukamm, Thomas: „Glänzende Zukunft für Papier“. In: Börsenblatt für den Deutschen Buchbandel 35 (1996), 30.04.1996, S. 40-44.

Löffler, Sigrid: „Literaturen, Literaturkritik und Leser um 2000“. In: Evi Zemanek \& Susanne Krones (Hg.): Literatur der Jahrtausendwende. Themen, Schreibverfahren und Buchmarkt um 2000. Bielefeld: transcript, 2008, S. 435-446.

Nickel, Gunther: „Krise der Literaturkritik. Historische Dimensionen eines aktuellen Themas“. In: Kaufen! statt Lesen! Literaturkritik in der Krise? I. A. der Deutschen Literaturkonferenz hg. v. Gunther Nickel. Göttingen: Wallstein, 2006, S. 5-19.

Helmut Schanze: „Die Wiederkehr des Buchs. Zur Metaphorik der Digitalmedien“. In: Osnabrücker Beiträge zur Sprachtheorie (OBST) 50 (1995), S. 53-60.

Schneider, Manfred: „Von keinem Auge mehr belästigt . Wissensspeicher , Machtzentralen, Boten des Überholten: Das Schicksal der Bücher in der Dämmerung der Bibliotheken“" In: Literaturen. Das Journal für Bücher und Themen 3 (2004), S. 74-82.

o. V.: „Dem Leser auf der Spur“. In: Börsenblatt. Wochenmagazin für den deutschen Buchhandel 45 (2005), 10.11.2005, S. 12-17.

\section{3, Neue Medien'}

„Definition Neue Medien“, [http://www.business-model-innovation.com/de/definitionen/neuemedien.htm], eingesehen am 23.10.2010.

Hickethier, Knut: Einführung in die Medienwissenschaft. 2., akt. u. überarb. A. Stuttgart: Metzler, 2010.

Metzler Lexikon Literatur- und Kulturtheorie. Hg. v. Ansgar Nünning. 3., akt. u. erw. A. Stuttgart \& Weimar: Metzler, 2004. Darin:

Sabine Heuser: Art. „Medien, neue“, S. 428f.

Ratzke, Dietrich: Handbuch der neuen Medien. Information und Kommunikation, Fernsehen und Hörfunk, Presse und Audiovision beute und morgen. Stuttgart: DVA, 1982.

Rusch, Gebhard, Helmut Schanze \& Gregor Schwering: Theorien der Neuen Medien. Kino - Radio Fernsehen - Computer. Paderborn: Fink, 2007 (UTB 2840).

Wikipedia, Die freie Enzyklopädie: Art. „Neue Medien“, [http://de.wikipedia.org/wiki/Neue_Medien], eingesehen am 22.10.2010.

\section{$8 \quad$ Studien zu Buch und Lesen}

Langen, Claudia \& Ulrike Bentlage (Hg.): Das Lesebarometer - Lesen und Mediennutzung in Deutschland. Eine Bestandsaufnabme zum Leseverbalten 1999. Gütersloh: Verlag Bertelsmann Stiftung, 2000.

Buchkëufer und Leser 2005 - Profile, Motive, Wünsche. Grundlagenstudie zum Lese- und Kaufverbalten von Verbrauchern in Deutschland 2005. Hg. v. Börsenverein des Deutschen Buchhandels e. V., in Zusammenarbeit mit GfK und Sinus Sociovision Heidelberg. Nov. 2005 (Studienreihe 
Marktforschung). - Kurzfassung online [http://www.boersenverein.de/sixcms/ media.php/976/Verbraucherstudie_Presse\%20neu.pdf], eingesehen am 09.05.2011.

Buchkäufer und Leser 2008 - Profile, Motive, Wünsche II. Grundlagenstudie zum Lese- und Kaufverhalten von Verbrauchern in Deutschland 2008. Hg. v. Börsenverein des Deutschen Buchhandels e. V., in Zusammenarbeit mit GfK und Sinus Sociovision Heidelberg. Nov. 2008 (Studienreihe Marktforschung). - Kurzfassung online [http://www.boersenverein.de/sixcms/ media.php/976/Buchkaeufer_und_Leser_2008_kurz.pdf], eingesehen am 09.05.2011.

Buchmarkt 2020: Szenarien für die Zukunft. I. A. des Börsenverein des Deutschen Buchhandels durchgeführt durch Sinus Sociovision Heidelberg, Januar 2008. Online [http://www.boersenverein.de/de/158446/Studien/158287], eingesehen am 17.06.2008, ab sofort nur noch für Mitglieder abrufbar.

Haben Bücher eine Zukunft? Repräsentativstudie zum Leseverbalten der Deutschen. Untersuchungsbericht über die Ergebnisse aus 1.224 Interviews anlässlich der Frankfurter Buchmesse 2007. Durchgeführt durch PricewaterhouseCoopers. Online [http://www.pwc.de/fileserver/RepositoryItem/tmt_PwC\%20Buchm_Studie_4.10.pdfPitemId=3113240], eingesehen am 10.07.2008, inzwischen nicht mehr abrufbar.

Zukunft des Buchs. Aus Politik und Zeitgeschicbte (APuZ), 42-43 (2009), 12.10.2009, Beilage der Wochenzeitung Das Parlament. Online [http://www.bpb.de/publikationen/GSYKBQ,0,0, Zukunft_des_Buches.html], eingesehen am 09.05.2011. Darin:

Michael Krüger: „Die Zukunft des Buches. Essay“, S. 3-5.

Gottfried Honnefelder \& Claudia Paul: „Medienwechsel - Verlegen in digitalen Zeiten. Essay“, S. 6-8.

Joachim Güntner: „Der Buchmarkt im Strudel des Digitalen“, S. 9-17. Jeanette Hofmann: „Zukunft der digitalen Bibliothek“, S. 25-32.

\section{$9 \quad$ Onlinequellen}

\subsection{Wikipedia}

Wikipedia, Die freie Enzyklopädie: Art. „Lesen!“, [http://de.wikipedia.org/wiki/Lesen!], eingesehen am 03.05.2011.

Wikipedia, The Free Encyclopedia: Art. „Steampunk“, [http://en.wikipedia.org/wiki/Steampunk], eingesehen am 10.11.2010.

\subsection{Spiegel Online}

„Die Bestseller des Jahrzehnts“. In: Spiegel Online, Archiv, Der Spiegel 53 (2009). Online [http://www.spiegel.de/spiegel/print/d-68425711.html], eingesehen am 25.05.2011.

Becker, Tobias: „Autoren ans Netz“. In: Spiegel Online, 27.04.2009

[http://www.spiegel.de/kultur/literatur/0,1518,621749,00.html], eingesehen am 03.05.2011.

Dallach, Christoph: „Eheversprechen und Leichenschmaus“. Rezension zu Seth Grahame-Smith: Pride and Prejudice and Zombies (2010). In: Spiegel online, 05.07.2010

[http://www.spiegel.de/kultur/literatur/0,1518,704341,00.html], eingesehen am 06.07.2010.

Nikolow, Rita: „Tödliche Lektüre“, Rezension zu Nino Haratischwili: Juja (2010). In: Spiegel Online, 26.07.2010 [http://www.spiegel.de/kultur/literatur/0,1518,708125,00.html], eingesehen am 27.07.2010.

Patalong, Frank: „Die rote Liste der aussterbenden Presse“. In: Spiegel Online, 02.11.2010 [http://www.spiegel.de/netzwelt/web/0,1518,726676,00.html], eingesehen am 02.11.2010. 
-: „Verleg’ dich selbst - und mach’ Millionen!“. In: Spiegel Online, 03.03.2011

[http://www.spiegel.de/kultur/literatur/0,1518,748220,00.html], eingesehen am 03.05.2011.

-: „Wer braucht noch einen Verlag?“. In: Spiegel Online, 19.06.2011

[http://www.spiegel.de/netzwelt/netzpolitik/0,1518,766824,00.html], eingesehen am 20.06.2011.

Telgenbüscher, Joachim: „Bisschen was für alle“. In: Spiegel Online, 29.12.2009

[http://www.spiegel.de/kultur/literatur/0,1518,668780,00.html], eingesehen am 20.04.2011.

\subsection{Statistische Analysen bei „Statista“"}

„Wie viele Bücher haben Sie im Regal?“, veröffentlicht in: Die Zeit, 15.10.2009, S. 40, [http://de.statista.com/statistik/daten/studie/71160/umfrage/anzahl-der-buecher-pro-haushalt-im-jahr2008/], eingesehen am 20.04.2011.

„Medien und Freizeit Deutschland 2009“, veröffentlicht 31.08.2009, [http://de.statista.com/statistik/daten/studie/36838/umfrage/freizeitaktivitaeten\%3A-mediennutzung-indeutschland-im-jahr-2009], eingesehen am 09.05.2011.

„Massenkommunikation 2010“, veröffentlicht durch ARD und ZDF bei einer Pressekonferenz am 09.09.2010, [http://de.statista.com/statistik/daten/studie/164504/umfrage/taegliche-nutzungsdauer-vonmedien-in-deutschland/], eingesehen am 20.04.2011.

\subsection{Webseiten von Unternehmen und Organisationen}

Börsenverein des Deutschen Buchhandels e. V., Wirtschaftszahlen, [http://www.boersenverein.de/ de/portal/Wirtschaftszahlen/158286], eingesehen am 11.09.2010.

Webseite des btb-Verlags, [http://www.randomhouse.de/btb/], eingesehen am 31.03.2008.

Webseite des btb-Verlags, „Über den Verlag“, [http://www.randomhouse.de/btb/verlag.jsp? men=81\&pub=2000], eingesehen am 13.04.2011.

Internet-Timeline, [http://www.heise.de/ix/timeline/], eingesehen am 02.11.2010.

„How the Web began“, Webseite des CERN, [http://public.web.cern.ch/public/en/About/WebStoryen.html], eingesehen am 01.02.2010.

„Benjamin Franklin - In His Own Words”. Webseite der Library of Congress, [http://www.loc.gov/ exhibits/treasures/franklin-epitaph.html], eingesehen am 20.11.2009.

\subsection{Online-Artikel}

Blog Frankfurter-Buchmesse, [http://www.buchmesse.de/blog/de/2010/11/03/mehrwert-arbeiten-in-derbuchbranche-heute], eingesehen am 18.11.2010: Hinweis auf Studie MebrWert. Arbeiten in der Bucbbranche heute. Hg. v. Bücherfrauen e.V., Sulzbach: Ulrike Helmer Verlag, 2010.

Buckland-Hoby, Hermione: „The rise of the virtual bookshelf”, The Guardian, 28.05.2008, [http://www.guardian.co.uk/books/booksblog/2008/may/28/theriseofthevirtualbooksh], eingesehen am 09.05.2011.

Faust, Volker: „Über den krankhaften und heilsamen Umgang mit Büchern“, Webseite Psychosoziale Gesundheit von Angst bis Zwang, ohne Datum, [http://www.psychosozialegesundheit.net/psychohygiene/buecher.html], eingesehen am 18.11.2010.

Harnad, Stevan: „Post-Gutenberg Galaxy: The Fourth Revolution in the Means of Production of Knowledge". In: Public-Access Computer Systems Review 2 (1991), S. 39-53. Online [http://cogprints.org/1580/1/harnad91.postgutenberg.html], eingesehen am 19.04.2011. 
Hermanns, Doris: „BücherFrauen - ein Netzwerk auch für Antiquarinnen“. In: Aus dem Antiquariat NF 7 (2009), Nr. 4, S. 266f. Online [http://www.buecherfrauen.de/ pdfs/public/2009/09_artikel_\%20das_antiquariat.pdf], eingesehen am 18.11.2010.

o. V.: „Das Phänomen World Wide Web“. Netplanet, [http://www.netplanet.org/geschichte/worldwideweb.shtml], eingesehen am 02.11.2010.

o. V.: „Am 30. April 1993 ist das Internet gestartet“, Webseite der Internetagentur symweb GmbH, 30.04.2008, [http://www.symweb.de/news/world-wide-web-www-15-jahre_231.htm], eingesehen am 14.07.08.

Scheffer, Bernd: „Zur neuen Lesbarkeit der Welt: Es fängt jetzt überhaupt erst richtig an.“, Webseite der Uni München, Medienobservationen, 1999, [http://www.medienobservationen.unimuenchen.de/artikel/kunst/lesbarkeit.html], eingesehen am 14.05.2009.

Schiller, Maike: „Endstation Altpapierpresse. Makulatur: Nach dem Ramschtisch - was aus Büchern wird, die keiner mehr lesen will.“ In: Hamburger Abendblatt, 10.05.2005, [http://www.abendblatt.de/kultur-live/article325168/Endstation-Altpapierpresse.html], eingesehen am 14.11.2010.

Strickland, Jonathan: "How Steampunk Works", HowStuffWorks.com, 15.02.2008, [http://electronics.howstuffworks.com/gadgets/other-gadgets/steampunk.htm], eingesehen am 10.11.2010. 